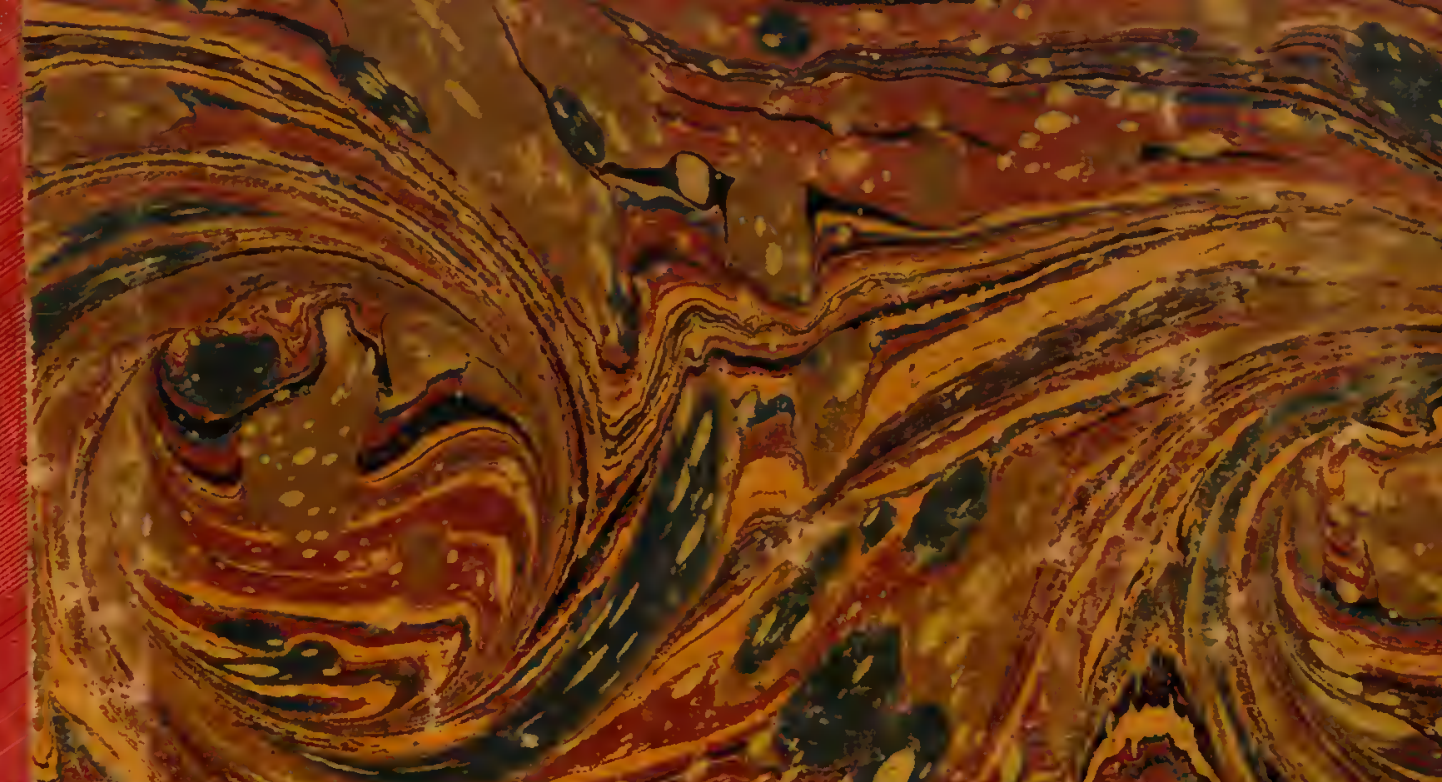
Jis

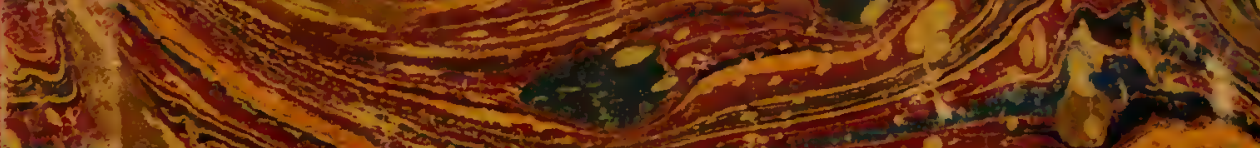

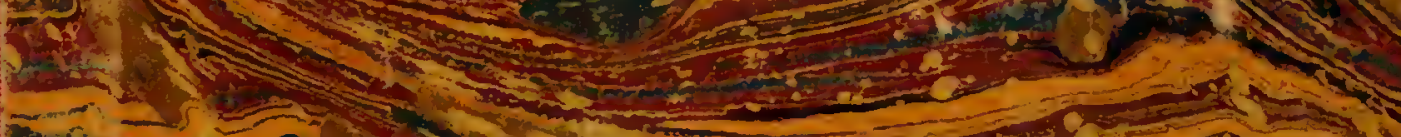

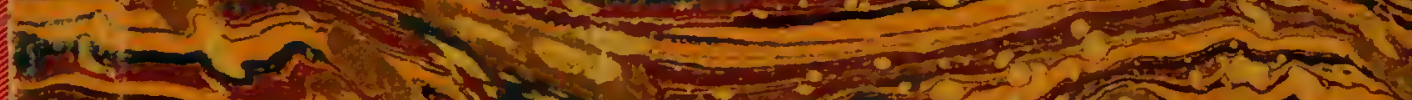

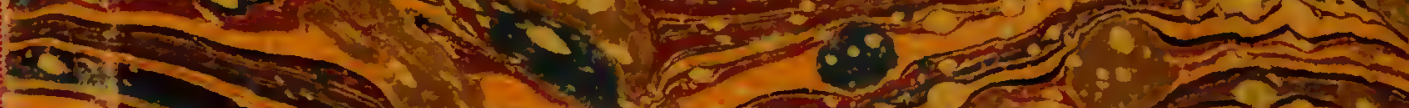

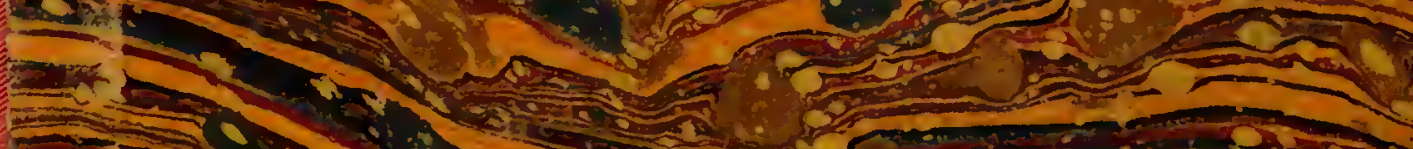

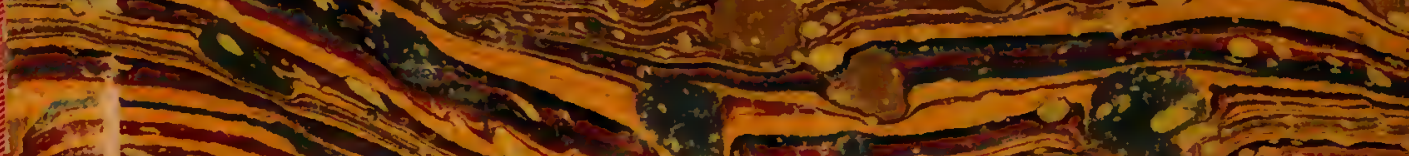

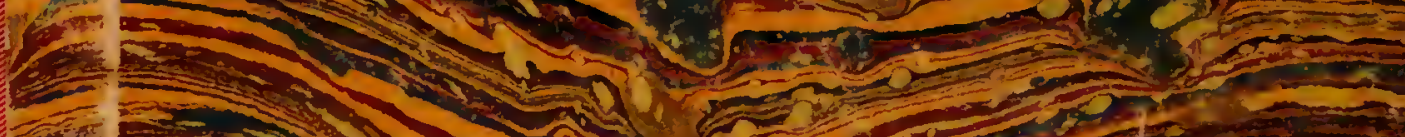

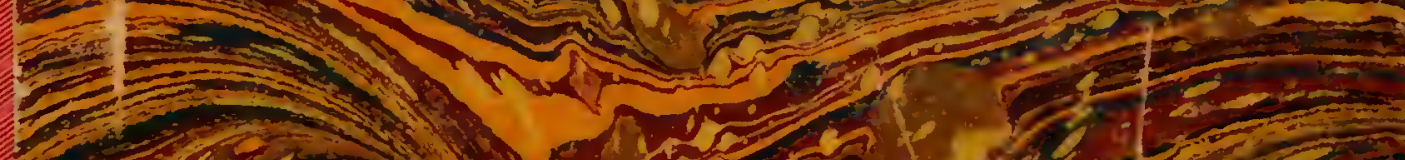

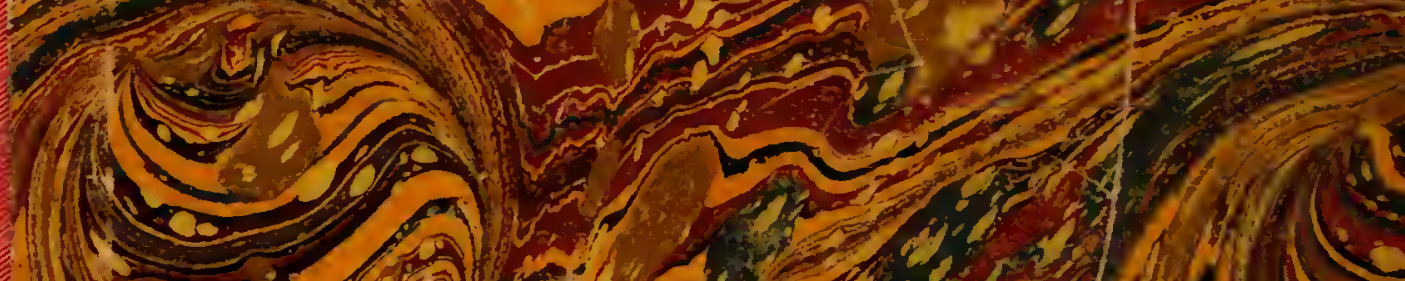

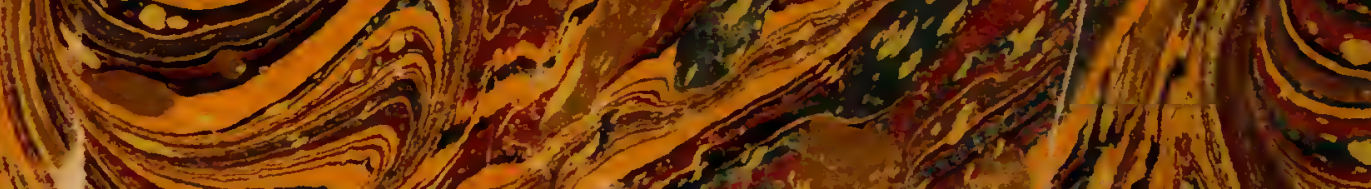

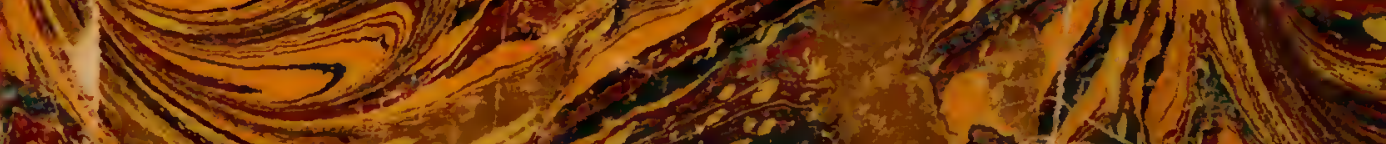
W 1 -

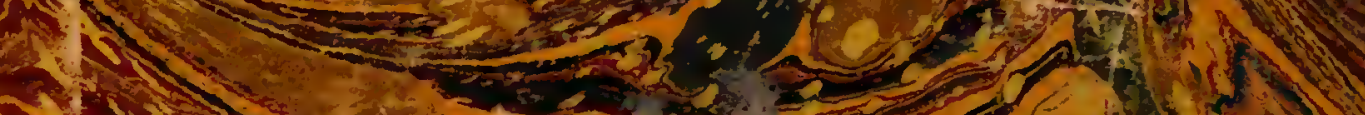

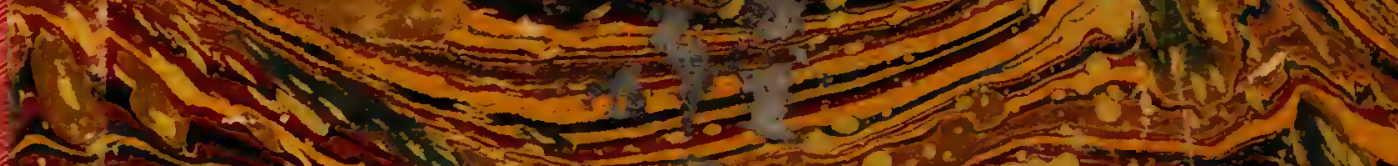

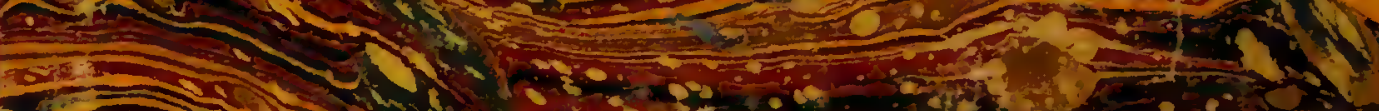

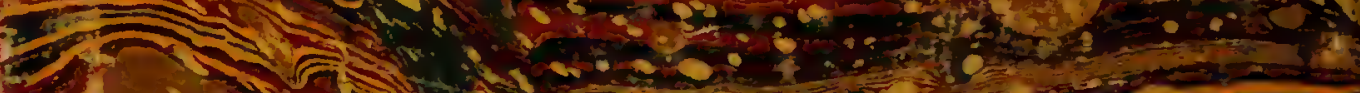

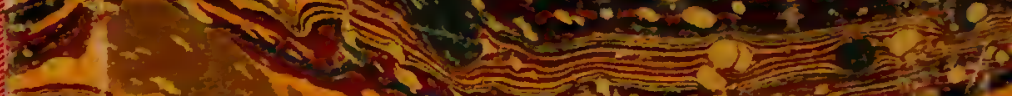

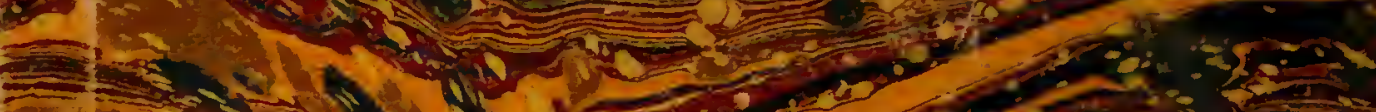

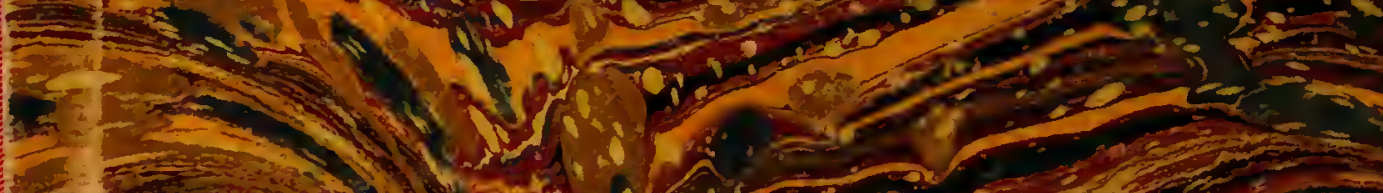

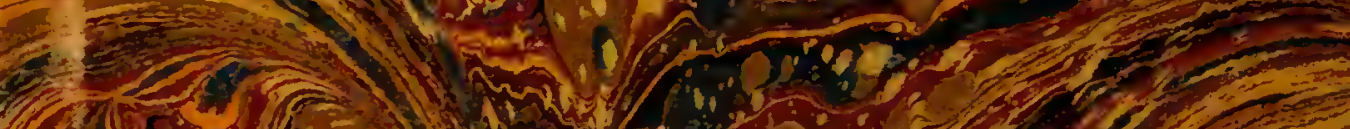

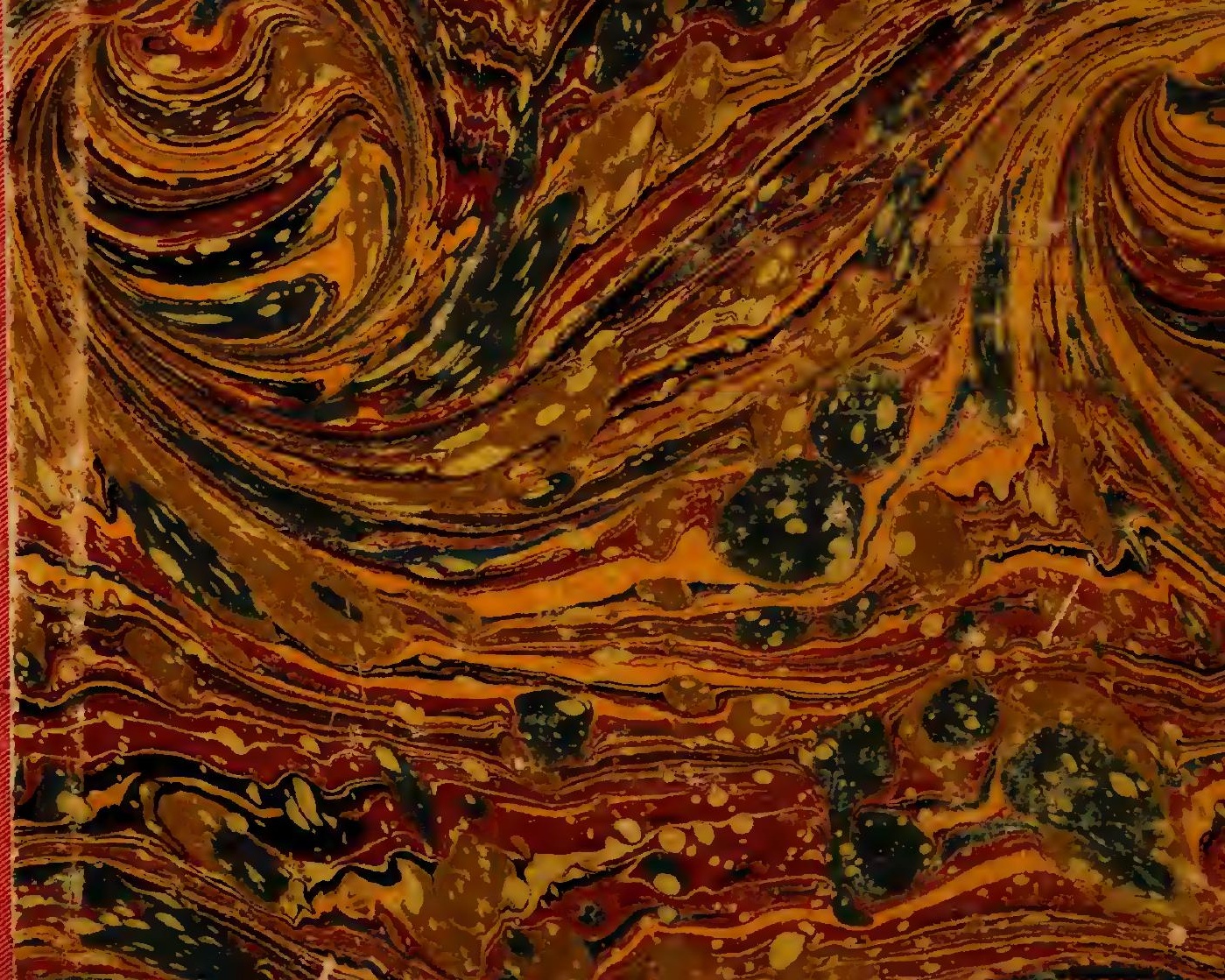




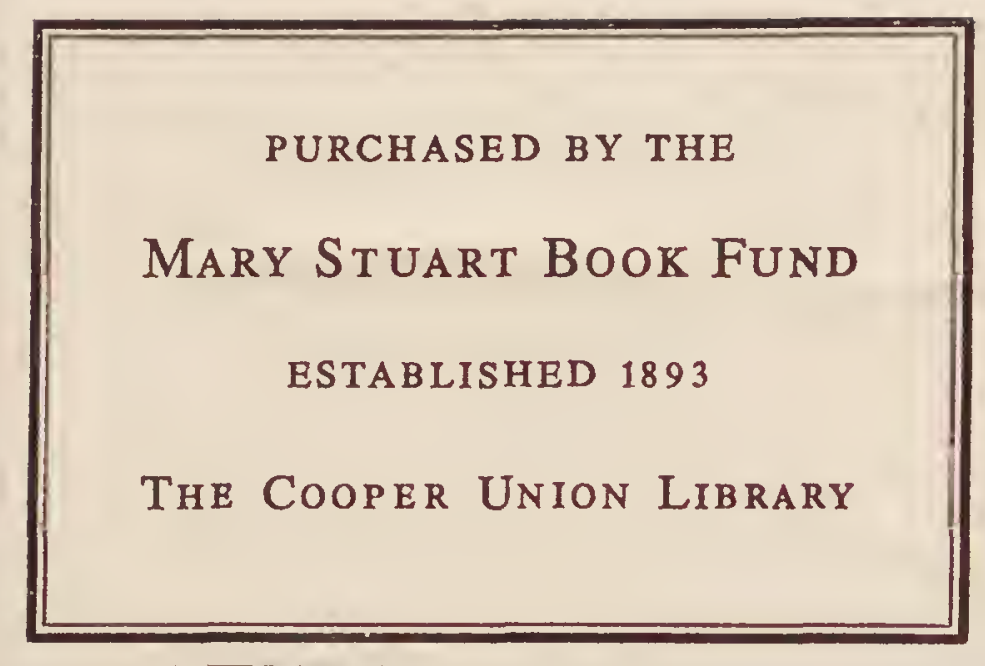


finge 

MINISTERE DU COMMERCE, DE L'INDUSTRIE

ET DES COLONIES

RXPOSITION UNIVERSELLE INTERTATIONALE IOE 1889

À PARIS

\section{RAPPORTS DU JURY INTERNATIONAL}

PUBLIES SOUS LA DIRECTION

DE

M. ALFRED PICARD

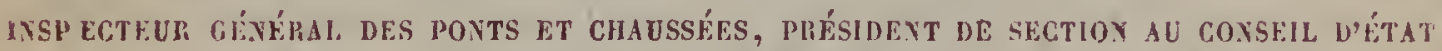
RAPPORTEUR GÉYÉRAL

$$
\text { Ciasse 24. - Orfèvrerie }
$$

RAPPORT DE M. L. FALIZE

ORFÈYRE-JOAILLILR

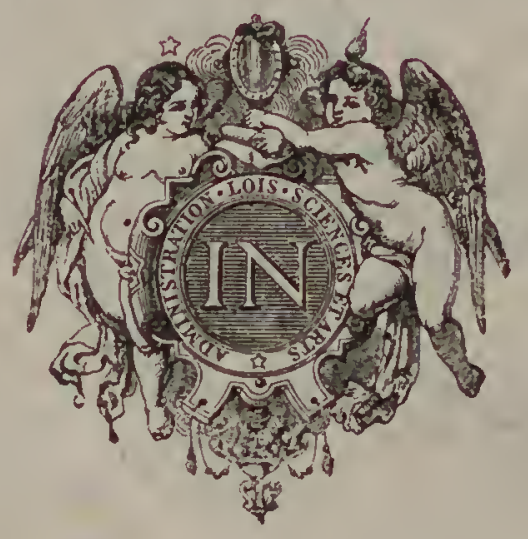

\section{PARIS}

\section{IMPRIMERIE NATIONALE}

M DGGG XGI 


$$
\begin{aligned}
& M \\
& 739.12 \\
& \text { P232R }
\end{aligned}
$$

320501

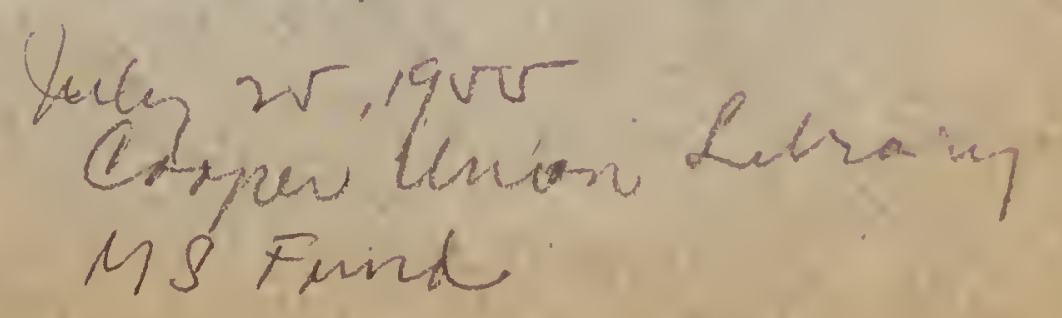





$$
\text { . }
$$


a Monsiur aef toarcel at enai sur lo métier J'afiune, de son bive affectucusunut devorié

EXPOSITION UNIVERSELLE

1889

ORFĖVRERIE

CLASSE 2/

RAPPORT DE M. L. FALIZE 




\section{PIAQUETE D'OR

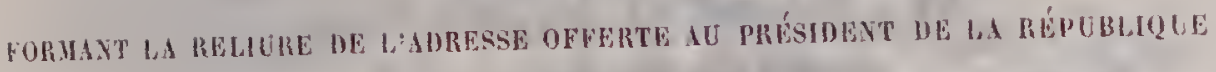 PAR LES JURLS FRIYCOAS

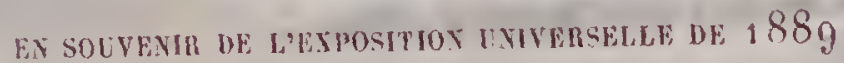 \\ Vodelie par Nerssover}

Pages 7 a 164

Bupst of Fahze orferren 
MINISTÈRE DU GOMUERCE, DE L'INDUSTRIE

ET DES GOLONIES

EXPOSITION UNIVERSELLE INTERNATIONALE IOE 1889

i PARIS

\title{
RAPPORTS DU JURY INTERNATIONAL
}

\author{
PUBLIES SOUS LA DIRECTION
}

$\mathrm{DE}$

M. ALFRED PICARD

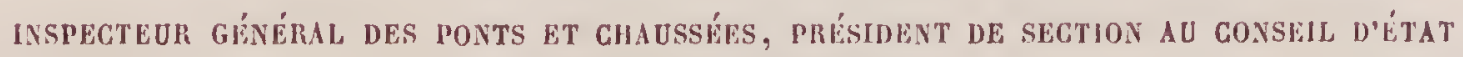
PapPORTEUR GÉTÉRAL

Cilasse 24. - Orfèvrerie

RAPPORT DE M. L. FALIZE

ORFE'VRE-JOAILLIER

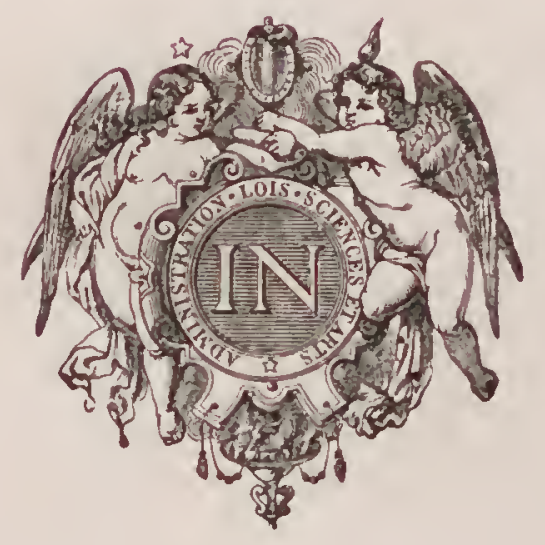

PARIS

IMPRIMERIE NATIONALE

M DGGG XGI 


$$
\begin{aligned}
& M \\
& 739.12 \\
& P_{232 R}
\end{aligned}
$$




\section{COMPOSITION DU JURY.}

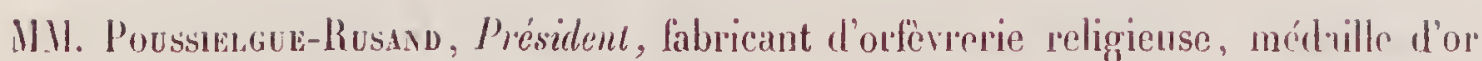
a l'Exposition de Paris en $1878 \ldots \ldots \ldots \ldots \ldots \ldots$ France.

Scnien (Jacques), Tice-Président................... États-Unis.

Fatze, Rapporteur, orfêrre-joaillier, grand prix à l'Exposition de Paris en

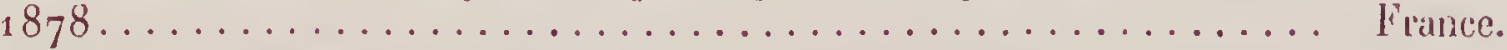

Cuenallitu, Secrétcive, ancien fabricant d'ortèvrerie, membre du jury des récompenses à l'Exposilion d'Anvers en $1885 \ldots \ldots \ldots \ldots \ldots \ldots$ Hance.

Kнос (A.), architecle....................... Danemark.

Saxboz (Guslave), joaillier......................... Égypte.

Ciroms, membre du Comité russe de Parris . . . . . . . . . . . . Russie.

Lanunièr: $\left(V_{0}\right) \ldots \ldots \ldots \ldots \ldots \ldots \ldots \ldots \ldots \ldots \ldots$ Suisse.

()рот, fabricant d'orfèvrerie, médaille d'or à l'Exposilion de Paris en $1878 \ldots$ France.

Flanar, suppléant, labricant d'orfèverie............... Fince. 


\section{ORFÈVRERIE.}

\section{L'ORFEVRERIE FRANCAISE AUX EXPOSITIONS DEPUIS L'AN VI.}

Mon but, en commencant ce rapport, n'est pas seulement de rendie un compte fidèle des opérations du jury de la classe 24 , je veux examiner l'orfèvrerie de plus près, en définir l'esprit, en analyser les ressources et faire un inventaire exact de sa force de production.

Pour cela, il faut étudier le goût du public, dégager la part de collaboration que l'artiste apporte au fabricant et chercher, avec les moyens mécaniques dont celui-ci dispose. quels éléments de décor il peut obtenir des métiers annexes. Il faut enfin peser les conditions commerciales de l'orfèvrerie, tant au dedans qu'au dehors, savoir à quels besoins elle répond et fixer son rôle dans nos mœurs et dalls notre état économinue.

Si je parviens à établir cette situation, et surtout, si je puis cimenter l'accord entre celui qui commande, celui qui compose et celui qui exécute, jaurai, je crois, rempli ma tiche.

J'écris pour tous ceux qui me voudront lire, mais je dédie plus particulièrement cette étude à mes confrères les orfèvres, avec l'espoir qu’ils l'accueilleront favorablement et la jugeront utile.

Je ne m’attarderai pas à de longues définitions, à des divisions techniques, encore moins it des digressions historiques.

Ils savent, et nous savons tous, que l'orfèvrerie a ses origines dans le passé le plus lointain, qu'elle tient à tous les temps, à tous les peuples, qu'elle se développe avec toutes les civilisations et que sa floraison la plus glorieuse est en France.

L'orferrerie frauçaise n’a rien à envier à l'art des autres pays, pas nueme à l'art italien; on a souvent répété que les meilleurs sculpteurs et les plus grands peintres de Florence et de Pise étaient sortis des ateliers d'orfèvres. En France, nos orfèvres ont été plus fiers; le mélier leur suffisait, ils le jugeaient un art assez complet pour ne rien cherclıer au delà.

Tous, depuis saint Éloi, ce patron français de tous les orfèvres chrétiens, sont restés fidèles au marteau. Ninistre de Dagobert, saint Éloi forgeait lui-même le trône du roi et gravait les monnaies; évêque de Noyon, il continuait à travailler pour l'éğlise, construisait la clâsse de saint Germain et ciselait les vases sacrés. Ainsi, dans une longue succession, ont fait après lui tous les maittres, jusqu'aux Ballin, aux Loir, aux Germain, 
aun Meissonnier. et celte tradition s'est suivie, clle al ôrandi comme un arbre géant qui, des racines ilu sommet, pousse sal sève d'un jet continu. C"est ce pui firit de l'orfèrerie française le premier, te plus beau, le plus parfait des métiers.

Art ou métier, il répond par ce double titre à l'esprit et au slyle de notre race; il tient à l'architecture, sallie à l'édifice, au mobilier, all costume; il ne s'inspire d'aucune importation átrangère; si quelque prince impose pour un temps la façon d'Italie ou la mode d'Espagne, le génie français l'absorbe, la transforme, la corrige. la fait sienne of lui donne la forme nonvelle qui simpose des lors aux autres peuples.

Qu'il s'agisse de l'art roman, du style ogival, de la renaissance même et surtout des xrue et xrm siècles, où trouver un type d'orfévrerie plus achevé. plus parfait que dans les œurres françaises?

C'est pourquoi nous ne célébrerons pas arec enthousiasme le double jubilé de 1789 . Cette date du centenaire, placée en tête de l'Exposition, résonne comme une joyeuse délivrance pour d'autres métiers, elle n’a pas pour le nòtre de si heureux souvenirs.

Turgot fit hien d'émanciper le travail en 1776 , et si l'édit fut rapporté six mois après, les corporations furent définitivement supprimées et leurs privitèges abolis par la loi du 17 mars 1791 . C'était la liberté pour tous, le droit au travail sans entraves, sans contrồle, sans hiérarchie, mais l'orfèrre n'en demandait pas tant; cette liberté lui fut ruineuse, elle apporta le désordre dans son art et le compromit à ce point, qu'après cent ans il se retrouvé à peine, et n'est pas revenu à l'état où la Révolution l'a surpris et frappé.

Oui, ce fut une révolution profonde el donloureuse: le mot s'applique à l'orfévrerio avec autant de justesse qu’i la chose publique. - Fil donnant à tous les orfères le droit de s'ŕtablir et de travailler, la Révolution chassait leur clientèle et détruisait leurs cuvres. - Vases sacrés, vaisselles opulentes, objets d’argenterie échappés aux édits royaux de 1688 et de $175 \mathrm{~g}$, tout fut fondu ou dispersé. Ce qui n'allait pas au creuset. de la Monnaie allait ì l'étranger; les émigrés emportaient en fuyant ce qu'ils avaient de plus précieur et le vendaient pour vire; l'Assemblée mit ì l'encan to mobilier des paliais et des riglises. On achetait à vil prix les meubles rares, et c'est ainsi que passèrent anr mains des Anglais et des Russes venus ì la curcéc les quelques pièces d'orfèvrerie françise ćchappées ì la fonte. - On sait ì quel prix on les paye aujourd'hui.

Les clients avaient fui,"roi, nobles. prêtres, tous ceux qui possédaient et qui ćtaient suspects avaient disparı; longue fut cette période de ruine; entre tous les métiers de luxe, celui de l'orfère est celui qui eut le plus ì sonffrir. La liberté qu'on lui avait promise, on la lui reprenait même en partic, car la toi du 19 brumaire an vi (9 noveinbre 1797) remettait l'orfévrerie en tutelle, lni imposait une règle plus ćtroite, une surveillance plus jalouse qu'autrefois. Ce n'était plus à ses experts-jurés qu'on confiait la surveillance des titres, la garde et l'apposition des poinçons : l'État se faisait te maitre et le gardien de la marque, frappait un impôt et solnmettait l'orferre ì une réglementation jalouse, it des risiles domiciliaires dont les formes vexaloires sont encore en vigueur. 
C'est quelques mois après la promulgation de cette loi que s'ouvrit la première exposition publique des produits de l'industrie francaise $\%$. Elle dura trois jours et se tint au Champ de llars, comme celle-ri; on y compta 110 exposants, mais il n'y vint qu'un orfère, encore n'ótait-re ni Auguste, ni la reuve Odiot, ni ancun des maitres parisiens dont les ateliers étaient déserts, re furent trois fabricants associés: Patoulet. Aubry et Lebeau, qui avaient ì Champlan, près de Longjumeau, une usine où l'on plarquait l'acier. Ils exposaient des rouverts plaqués d'or et d'argent.

Ce furent les premiers, les seuls qui figurèrent ì l'Exposition de l'an i. Il nous parait intéressant de conserver leurs noms en tête de ce livre où d'autres noms d'exposants vont suivre. François de Neufchâteau leur avait offert la première place, tout romme faisaient les rois quand ils methaient les orfères en tête des métiers, dans les processions et les cortèges. Nos fabricants de courerts ne paraissent pas rependant parmi les donze lauréats de l'Exposition, avec les Bréguet, les Isnoir, les Didot, les Comtí, les Dihl, etc., ils ne viennent que dans une deuvième série de ce treize noms que lo jury ne pent se dispenser de produire après les douze lauréats qu'il a cités d'abord".

C'est qüil ne restait plus rien de l'orfèverie française, qu’il n'y avait plus ni maitres, ni artistes, et que François de Neufchâtean ne parvenait pas encore à démontrer que ela liberté individuelle est préférable à l'ancien système de la maîlrise et des rorporations".

Nons n'avons pas dessein d'obscureir le lableau, mais puisqu'il y a une date écrite sur re livre et que nous faisons la récapitulation dı travail d'un siècle, nous voulons démontrer que, pour nous orfèvres, cette date n’est pas une renaissance, qu'elle n'est pas même un affranchissement, mais un recommencement total, une révolution complète et quil a fallu tout reconstituer pour parvenir où nous en sommes.

Je n'exagère rien; d'autres rapporteurs ${ }^{(1)}$ ont signalé avant moi des faits dont la brutale vérité s'étale dans les inventaires de vente et les procès-verbaux de la Monnaie.

Comme préface à l'Exposition moderne, nons pourrions conduire nos lecteurs à l'exposition rétrospective de l'art français qui occupait l'aile gauche du Trocadéro. Là, figurait ce qui reste de la vieille orfèvrerie nationale, en nos églises, en nos musées et dans quełques collections privées. Les évêques avaient consenti à prêter les ornements ronservés dans leurs trésors, les vases sacrés, les chàsses, les reliquaires, les crosses, les croir, les tableaux d'émail, re que l'art, la scince et la foi conservent arec une piété égale. On trouvera dans un autre de ces rapports la description de ces chefsd'œurre, et nous renvoyons an catalogue dressé par MM. Alfred Darcel et Molinier, pour la nomenclature des objets d'art de toutes les époques, depuis le reliquaire de l'abbaye de Conques jusqu'aux soupières, aux aignières, aux flambeaux et aux jolies pièces d'argenterie du xvu1 ${ }^{\complement}$ siècle. Cies dernières ont été cataloguées par II. Paul Eudel et par M. Ch. Mannheim.

(1) Voir les rapports de M. Wolowski en 1849 , du comte de Laborde et du duc de Luynes en 1851. 
Mais ce quil fallail faire pour celle exposition dur centenaire, e'est la collection des aurres d'orfevrerie produites, non pas avant la Rérolution, mais depuis. Ce que l'Administration des beaux-irts a fait pour la peinture et la sculpture, en remettant sous nos yeur les tableaux de David et de Prudhon, d'Ingres, de Delacroix, de Deseamps, de Millel; les statues de Hondon, de Chaudet, de David d'Angers, de Rude, de Barye, etc., pourquoi ne l'a-t-on pas fait pour les eurres exécutées en argent par Auguste, par Odiot, par Biennais, par Wagner, par Callier, par Fauconnier, par Froment-IIeurice le père, parr Wechte, par Feuchières, par Klagmann, par Duponchel et par louron?

C"est un regretlable oubli : la Minere de Simart et le Louis XIII de liude sont des arures d'orfèrerie, qui vont de pair arec les aures de marbbe et dont la place était maryuéc; le public ne les connait pas ot l'étude en aurait été profitable à nos ouvriers.

l. lemps nous manque pour en faire l'histoire, mais cette histoire est facile ì reconstituer. Cette tiche appartiendrait à la chambre syndicale des orfèves. De l'an ir à 1849 , il y a eu à Paris onze expositions nationales de l'industrie; de 1851 à 1889 , il $y$ a $\mathrm{eu}$, pour ne riter que les principales, sept expositions internationales universelles. Des ripports ont paru à la suite de charune et les catalogues conservent les noms des crposints. C'est un procès-verbal fidèle des efforts de chacun et des récompenses obtenues. Il suffirait de rééditer ces documents pour tirer des noms de l'oubli, pour enseigner ì ceux qui les ignorent les progrès qui datent d'hier; il y a des industriels qui ne connaissent pas même l'histoire de leur's prédécesseurs. Ciette réédition des rapports serait une ouvre utile dans tous les métiers, car tous y ont une part égale, mais je n'avais à m'occuper que du mien et jaai collationné tout ce qui a trait aur métaur précieux. J'ai lu tout ce qui est relalif à l'orférerie et anx bijoux.

Je ne puis, ici, qüindiquer sommairement les ouvrages à consulter; je fournirai des renseignements plus complets, si la Chambre syndicale des orfères reut donner i d'autres chambres l'esemple d'une réédition partielle des rapports qui intéressent ses
adhérents.

Ar vi. - Première exposition des produits de l'industrie française, ordonnée par Erançois de Teufchàteau et tenue au Champ de Vars. On n’y complail, arons-nous déjà lit, qu’un seul orfèvre et le rapport général. très court, est signé de Chaptal.

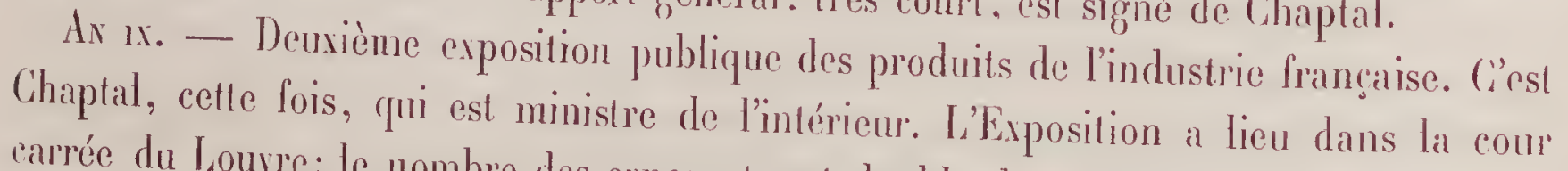
carrée du Lourre; le nombre des exposants est double de ce qu'il avait été précédemment, mais on ríy trouve aucun orfève, à moins que nous n'admettions comme tel le sieur Bouvier, fondeur, pour des ouvrages en filigrane. Costaz fait le rapport.

AN x. - Troisième exposition, dans la cour du Louvre. Elle compte 540 exposants, Cliaptal la dirige encore el Costaz en est le rapporteur, il fait au chapitre XIII (Beaux-
Arts) l'éloge d'Auguste el d'Odiol Ces derite Arts) l'éloge d'Auguste el d'Odiot. Ces deux orfèves sont récompensés chacun d'une
médaille d'or : c'est la première manifostation d'un médaille d'or : c'est la première manifestation d'un réveil de notre art. Ćemuntú. . 
1806. - Quatrième exposition publique des produits de l’industrie francaise. Elle est ouverle, à la fin de septembre, à l'hòtel impérial des Invalides. Napoléon règrne, II. de Champagny est ministre de l'intérienr' la pompe impériale a ramené le travail et lo luxe chez l'orfève. Les ateliers sont en pleine activité, et, sur 1,422 exposants, nous comptons 10 orferres; Auguste, Odiot, Biennais, sont les noms qui se dislinguent des antres; Costaz fait encore le rapport général.

1819. - Cinquième exposition. Le roi l'ouvre le 25 anônt dans la cour et dans les salles du Louvre; le nombre des exposants s'élève à 1,662 et nous relevons au catalogue 21 noms d'orfévres, parmi lesquels ceux d'Odiot, de Biennais, de Calier, de Thomyre, de Fauconnier, de Nention, etc.; Auguste a disparu. Le comte Decazes est ministre, mais Costaz reste le rapporteur général de la commission royale comme it l'avait été sous la République et sous l'Empire. ("'est à la suite de cette exposition qu'Odiot offrit au Gouvernement la collection complète de ses modèles. Elle est restée longtemps au musée du Luxembonrg, elle est maintenant dans les réserves du Louvre. Nous voudrions la voir sortir de l'ombre.

1823. - Sixième exposition des produits de l'industrie française. Le catalogue imprimé cliez Anthelme Bonclier contient 1,648 noms, mais la proportion des orfévres tomle ì 7 , et nous y remarquons, avec Odiot et Lebrun, Cahier qui fait pour la cathédrale de Reims les vases sacrés quion y voit encore. Aucoc et Gavet sont associés pour la fabrication des nécessaires et de la coutellerie; ils ont succédé ì Maire.

1827. - Septième exposition de l'industrie ouverte au Louvre te $1^{\text {er }}$ août. 1,795 exposants; les bronzes, l'orfèvrerie d'argent et le plaqué sont confondus dans une mème galerie, mais nous relevons 13 noms d'orfères. Odiot reste fidèle à tous ces concours. Thomyre expose un surtout de table ponr la ville de Paris; Balaine, Rouyer, Fabre, d'autres encore, propagent l'industrie du plaqué d'argent. Finconnier fait avec Tamisier et avec Barfye des ouvres admirables qui le ruinent, mais qui méritent que son nom soit conservé et reste lıonoré : on sait que les frères Fannière sont ses neveux el ses dignes continuateur's.

Jusqu'ici ces expositions n'ont donné lien qu’à des rapports d'ensemble; les deux derniers sont dus à Héricart de Thury et à Migneron. Nous allons commencer à trouver des rapports spéciaus sur chaque groupe.

1834. - La huitième exposition publique des produits de l'industrie francaise s'ourre le $1^{\text {er }}$ mai, non plus au Louvre, mais sur la place de lir Concorde, dans des Daraquements provisoires, mal construits et insuffisants. On y compte 13 orfèvres sur 2,447 exposants. Thiers est ministre et le baron Charles Dupin fait un rapport détaillé, le premier qui fournisse la statistique de chaque industrie et des considérations intéressantes sur les progrès réalisés dans les métiers et dans les arts. Cée mémoire est curieur à lire et nous y trouvons, avec les noms d’Odiot, de Fauconnier et de Lebrun, des noms nouveaux, qu'il faut saluer, conme celui de Veyrat, de 
Lefranc, et surtout le nom de Cils. Wagner qui s'associe avec Mention et qui va donner il l'orfèrrerie d'art une impulsion puissante.

1839. - La neuvième exposition des produits de lindustrie française occupe, anx Champs-Élysées, le carré Marigny ou Carré des fêtes, où s'élève à présent le palais de l'Industrie. Elle couvre 16,500 mètres carrés, réunit 3,38 1 exposants, dont 220 orfèvres. Aux noms que nous avons cités déjà et qui restent fidèles à ces concours périodiques, il faut ajouter des noms nouveaux tels que ceux de Morel, Froment-Meurice. Harrel frères et enfin Christofle, qui n'expose encore, avec des bjoux, que l'imitation en argent de tissus hrochés, mais non loin de qui parait la maison anglaise d'Elkington and $C_{i}$, gui a ouvert, au 34 de la rue du Temple, un atelier de dorure sans mercure. C'est la première apparition de la galvanoplastie qui va révolutionner l'orfevrerie.

1844. - Divième exposition des produits de l'industrie francaise, dite quinquennale. L'espace s'élargit, te nombre des exposants atteint presque 4,000, mais la proportion n'augmente pas pour les maisons d'orfèvrerie; si nous $y$ lisons toujours les mêmes noms, nous devons noter cependant que Rudolphi a succédé à Wagner et que Aucoe n'a plus d'associé.

Le rapport sur l'orfèvrerie est signé de Denière; le vicomte Héricart de Thury fail un compte rendu des travaux de ciselure, d'émail et de lapidairerie. Nous y relevons les noms de Feuchères, de Cavelier, de Wechte, de Théret; ceux de Léon Rouvenat et de Castellain, qui sont les collaborateurs dévoués de Ch. Christofle, dont le succès grandit et qui śtend ses affaires d'exportation.

1849. - Onzième et dernière exposition nationale des produits de l'industrie. Elle avait été décrétée par l'Assemblée nationale le s a novembre 1848 ; elle est ouverte le

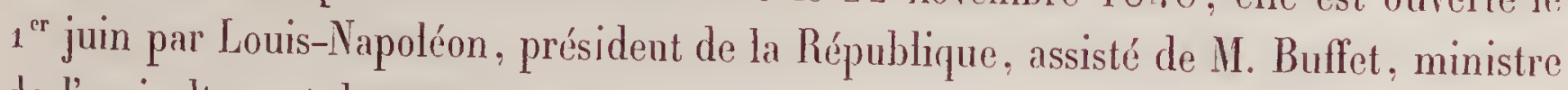
de l'agriculture et du commerce.

Sil est une industrie qui a subi le contre-coup de nos agitations potitiques, c'est bien celle qui façonne les métaux précieux.... par une répétition de ce qui s'est passé en d'autres temps, les nécessités de la vie, autant que des craintes excusables ont commandé à beaucoup de personnes de se défaire des objets travaittés dont l'or et l'argent forment la substance. Pendant plusieurs mois, l'hòtel de la Monnaie a été assiégé par tes citoyens qui demandaient à transformer en pièces d'or et d'argent les objels devenus pour eux une ressource précieuse aux jours de détresse.... . Le burean de garantie était vide et inoccupé; on fondait les articles d'orfèvrerie, on n'en créait pas.

Qui parle ainsi? ("est Wolowski, le rapporteur de la section d'orfèvrerie ${ }^{(1)}$.

Mais les orfèrres ont fait preuve de patriotisme et de dévouement; des médailles d'or sont décernées à Froment-Meurice, Rudolphi, Duponchel, Christofle, Odiot, Rouvenat, Lebrun; et des médailles d'argent à Mayer; Gueyton, Durand, Trioullier, Aucoc, Fray, Dafrique, Payen, Gringer et Veyrat.

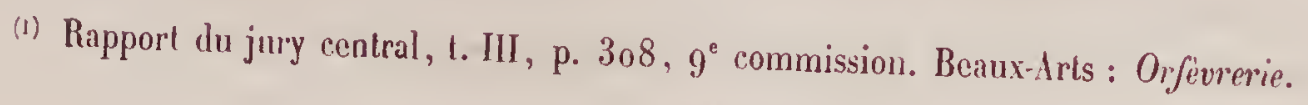


Il faudrait citer des plurases entières des rapports de Woloushi et du vicomte lléricart de Thury; mais il en est une que nous tenons à reproduire parce qu'olle est un hommage ì deux hommes dont la mémoire est chère ì notre art:

Beancoup de travaux commandés ì M. Froment-Menrice ou quili se proposait d'entreprendre ont étré paralysés depuis dix-huit mois; nianmoins, quelques hommes qui savent faire de leur fortune un graud et noble usage en l'employant à l'encouragenent des arts, et en tête desquels il est juste de riter M. te due de Luynes, dont plusieurs sections de cette exposition ont fail constater la large inlluence, ont permis i M. Froment-Mleurice de ue pas rester inactif(1).

Nous aurons prochainement à reparler de ce grand seignenr artiste. si doux anr ourriers; il connaissait les collaborateurs de l'orfevrerie, et c'est en 1849 que nous voyons enfin leurs noms révélés au public par une louable indiscrétion : Jean Fenrhères, le modeleur; Sollier, l'émailleur; Rouillard, Justin, Cavelier, sculpteır's; Bulnon, Wisset, Fremonteille et Croville, des orfèves; Mulerel, Dalbergue, Fannière, Poux. riseleurs; Liénard, dessinateur. Ceur-là sont présentés par Froment-Ileurice. Rudolphi nomme, comme lui, ses artistes: Pascal, Feuchères, Geoffroy de Chaumes, ses ouvriers: Verraur, Magnus, les Plouin, Cileff, Dolbergue et Douy; Duponchel ne présente que trois de ses collaborateur's : Simard, le statuaire; Aurillac, l'orfèvre, et Névillé, le dessinateur.

Ceux qui ont vu cette exposition de 184.9 , la dernière de nos expositions nationales, gardent le somvenir d'une solennité qui parul d'autant plus belle qu'elle suivait de priss une révolution et qu'elle rassurait l'opinion publique sur l'avenir et la prospérité de la France. 1.532 exposants avaient figuró dans les bâtiments ólevés au carré Narigny el qui couvraient a7,040 mètres carrés. C'est peu, comparé à ce qu'est une exposition aujourd'lun, mais on était déjà bien loin des 110 exposants de l'an vi. Liidée ingrénieuse de François de Neufchâteau avait mûri et c'est à un autre Français, ì Thouret $^{(2)}$, qu'est due la première pensće des expositions universelles. Ce projet nouveau avait été sérieusement présenté et débattu au lendemain des émeutes de 1848; le gronrernement de la République ne se crut pas assez fort pour oser faire cette grande révolution économique; il écouta aceur qui prétendaient que si l'Angleterre, la Belyirque ef la Suisse exposaient en France, cen était fait de notre industrie\%. Voilà comment une idée française, grande, généreuse et hardie, fut. comme tant d'autres, re rueillie, acceptée et mise en pratique par les Anglais.

1851. - Le $1^{\text {er }}$ mai, s'ourrit ì Londres la première exposition universelle el internationale. Nous n'arons pas à en faire te tableau, mais il nous appartient de dire que si les Angilais y montrèrent des machines alors sans rivales et l'oulillage industriel lo plus avancé, la France y remporta sur les autres nations une victoire complète dans toutes les industries somptuaires. L'orfèvrerie eut une part importante dans cet śclatant triomphe et il en revint quelque gloire ì Froment-Meurice le père. Morel

(1) Wolowski, rapport du jury contral, t. III, p. 313. - (2) Anthony Thouret, publiciste et représentanl du peuple, né a Tarragone en 1807 , de parents français. 
était allé sétablir à Londres ef essayait en vain d'y introduire notre influence commerciale.

Pour qui veut se rendre un compte exact de ce qu’était en 1851 l'orfévrerie, il faut lire en entier le rapport du duc de Luynes: c'est le meilleur et le plus complet qu'on ait jamais écrit à la suite d'une exposition. Le due arait été choisi pour présider to $2.3^{\mathrm{e}}$ jury, celui de l'Industrie des métıux précieux. It consentit ì faire le rapport que lui demandait la Commission française; aucun orfèvere n'aurait su parler de son métier en termes plus clairs et plus précis.

Le due de Luynes était le guide qui convenait aus ouvriers et aur artistes; de tels hommes ont une part considérable dans l'ouvre de leur temps; il pénétrait dans l'atelier, il était l'ami de Simart et de Rude, de Vorel et de Duponchel, de Vechte et de Feuchères. Il sarait, call ce n'est pas par désonvrement qu'il s'attachait à ces tritvaux, mais par une passion d'artiste et d'archéologue. Il avait conquis sa place à l'Trstitut par de savantes études, et, quand il était clez l'orfère, il ne craignait pas de prendre un marteau, de retrousser ses manches et de forger.

Il avait aequis le droit d'enseigner; son autorité et son indépendance en faisaient un maitre; sa grande fortune lui permettait de commander les travaux qu'il avait rêvé d’avoir; ce généreux Nécène était en même temps le critique le plus indulgent et le plus fin.

J'ignore si, au lendemain de l'Lxposition de Londres, les orfévres ont lu arec l'attenlion qu'elle méritait cette étude précise, sincère, attachante. ("est l'histoire de nos itleliers ef de notre art pendant la première moitié de ce siècle; éest le livre classique de l'orfèrrerie de notre temps. Je doute cependint qu'il soit connu de mes confrères d'aujourd'hui.

Il en est malheureusement ainsi de presque tous ces rapports; il en sera de même de celui que jécris : on les édite arec soin, mais quand ils parraissent l'occasion est manquée, l'altention est sollicitée par quelque antre sujet, et le volume entre dans la bibliothèque pour n'en pas sortir: on l'oublic, on n'en coupe mème pas les feuillets.

Le rapport du due de Luynes est aujourd'hui presque introuvable (a), ainsi que l'admirable étude que publiait en même temps le comte de liaborde sur l'Union des arts et de lindustrie ${ }^{(2)}$ et qui est devenue une rareté bibliographique.

Entre tous les rapports sur l'orfèverie, s’il en est un quil faille remettre au jour, imprimer ì nouveau, c'est celui du duc de Luynes; les orfères lui doivent cet hommage de reconnaissilnce et jai te ferme espoir que cela sera fait avant peu. Il conviendra de l'accompagner d'extraits nombreux du live de M. de Laborde, qui ont trait ì notre

(1) Exposition universelle de 1851 . Trataux de la Commission firancaise sur l'industrie des nations, pru.. hiés par ordre de l'Empereur; t. XXIII. Jury; rapporl du duc do Luynes; Paris, Imp̧rimerie impériale, 1853.
(2) Exposition universelle de 1851,1 XXX. Jury'; Application des arts à l'industrie; rapport de N. Le comte to Iaborde; Paris, Inprimerie impríriale, 1853. 
industrie, ì uos artistes, et dont les conseils sont aussi sages et aussi à propos fue sils dalaient d'hier.

1855. - On avait compté 1 $3,9^{3} 7$ exposants à Londres, il y en eut 16,000 à Parris. ("était la première fois que les orfèves étrangers venaient se mesurer avec nous, sur notre terrain, el, bien que les premières maisons de Londres et de Vienne fussent représentées, l'avantage resta entièrement à la France. La classe 17 réunissail tous tes métiers dérivés de l'orfèvrerie, mais il y eut trois rapporteurs qui se partagèrent le soin d'en rendre compte : Deveria, conservateur des estampes à la Bibliothèque impériale, lit te rapport sur les bronzes d'art; Fossin, l'ancien joaillier do la Couronne, écrivit le rapport sur la bijouterie et la joallerie; enfin, le rapport sur l'orfèrerie proprement dite fut confié à Ledagre, qui avait été président du tribunal de commerce et qui occupait un rang distingué parmi les marchands-orferres de Paris.

Le jury était présidé par le marquis d'Hertford; il représentait la Grande-Bretagne, mais on sait qu'il habitait i Paris plus souvent qu'i Londres et que ses merieilleuses collections d'objets d'art le désignaient comme un connaisseur émérite. Le comte de Laborde avait la vice-présidence.

Les Pays-Bas, la Turquie el la Prusse étaient représentés dans le jury, mais non pas la Russie, avec qui nous étions en gurrre.

Ledagre fit son rapport d'une facon plus sommaire que n'avait fait le duc de Luynes; il l'écrivit en négociant plus qu'en industriel ou qu'en artiste. Nous ne l'analysous pas, mais nous y relevons deux faits : Io dévoloppemenl de lindustrie de l'orfévre cuillériste et l'importance croissante de l'orfèverie religieuse.

Les perfectionnements mécaniques apportés à la fabrication des couverts s'étendent à l'orfèrerie d'argent autant qu'au métal blanc argenté de Christofle; c'est à Allard, graveur-estampeur, que revient le mérite de ce progrès : it fut récompensé d'une médaille d'lonneur.

Poussielgue-Rusand el Baclectet exposaient des autels de cuive doré, véritables wurres d'orférrerie, comparables à celles du moyen àge, et c'est pourquoi le rapporteur constate la résolulion des orféres à revendiquer un rôle quils avaient abandonné aus fiabricants de bronze : el'orférerie. dit-il, envahit ì son tour le domaine du bronze et labrique arec la supériorité d'ajusté, de montage et de maniement du martean qui lui est propre, des objels en cuivre couverts de dorure et d'irgenture, capables de lutter par l'effet aree les produits de sa rivale."

J'ai cité cette phrase, parce qu'olte me servira encore cette fois à revendiquer des ceurres qui sont ì nous et qu'on a mal classíes.

Enfin, parmi les ouvragres d'orfèvrerie qui furent particulièrement remarqués, indiquons le surtout de table exécuté par Christofle pour l'Eimpereur et qui fut détruit en ${ }_{1} 87$ 1, dans l'incendie des T'uileries; te service d'argent commandé à Marrel ainé par lo vice-roi d'Éggpte, el, enfin, le grand rase de jaspe, d'or et d'éminil, auquel Dorel travaillait depuis plusieurs années el que lui avait commandé II. Hope, le banquier anglais. 
Norel mourut bien pen de temps après l'avoir achevé. It faut eonserver son nom arec le respect qu'on doit aur grands ouvriers, aux passionnés de notre art.

Nous nous boruons, comme nous l'avous fait pour les expositions nationales, ì citer les noms des orfèrres qui figurèrent au Palais de l'Industrie en 1855; la liste en est longue cette fois; ce sont: Allard, graveur; Duponchel, qui venait d'achever la Minerve; Froment-Ileurice, qui exposait les deux groupes d'ivoire et d'argent qu'on a revus cette année dans l'Histoire du Travail: Gueyton, qui cherchait à introduire les reproductions galvaniques dans l'orfévrerie, pour remplacer la fonte et la ciselure; Morel, que nous avons nommé; Christofle, dont l'exposition occupait un espace considérable et que II. Becquerel citait dans un autre rapport, à propos de perfectionnements nouveaus apportés daus les procédés d'électrotypie; Aucoc ainé et Audot, fabricants de nécessaires; Balaine et fils; Cosson-Corby; Durand; Hemr-Hayet, un artiste qui excellait à composer et à modeler des sujets et des ornementations dans le goût du xrme siècte; Jarry ainć et Marrel ainé, d'excellents fiahricants; Lebrun, le doyen des orfèvres (Odiot ne figurait pas ì l'Exposition de 1855); Maurice-Mayer: Wiese, un homme de goût, un créateur ingénicux; Rossignneux, le savant architecte, le dessinateur à qui toutes les industries d'ant doirent une part de direction : il exposait une charmante coupe d'argenl; Rudolphi; Poussielguc-Rusand, Thierry, Trioullier, tous trois des spécialistes daus l'orfèvrerie religieuse; Thouret, Veyrat, Grichois, qui fabriquaient tous les trois aussi des arlicles de consommation plus courante; Dolin, l'orfèrre-émailleur' Granger, le netteur en wure des orfèreries de théatre; puis enfin Bachelet, Berthet, Cardaillac, Chardor, Debain, Fray, Girous, qui esposait les euvres des Fannière; Halphen, yui estampait les couverts; Lyonnais, qui produisait de grandes pièces en galvanoplastic; ele. J'en passe pour arriver à Hancock, à Garrard, à Hunt et Roskell, les trois grands orféves de Londres. qui déja montraient les progrè̀s réalisés depuis 1851. mais qui s’étaient adjoint des artistes francais et, entre antres, le regretté Wechte, qui demeura jusquàa sal mort attaché à la maison IIortimer, comme Morel-Ladeuil à la maison Elkington. Elkinglon, qui était alor's associé à Mason, avait obtenu une médaille d'honneur dans la classe y, où C'hristofle exposait aussi.

Wollgold, de Berlin, el l'Académie de Dusseldorf étaient classés en première ligne dans l'orlèverie.

1862. - Le baron Clartes Dupin, qui avait entrepris d'écrire te rapport gónéral sur l'Exposition universelle de 185 1, s'était attaché surtout à évaluer la force productive des nations. Cest une statistique curieuse à consulter pour les économistes, mais l'échelle en a été bien modifiée depuis.

Après l'Exposition de 1862 , M. Michel Chevalier fit ì son tour le rapport général. mais sur une autre base; il s'attacha, du moins dans une notable partie de son étude. à ela nécessité de répandre l'enseignement des beau-arts parmi la classe ourrière\%.

("était reprendre le thène qu'arait si bien développé en 185 l le comte de Laborde: mais il yavait un intérect réel à le faire. car les progrès réalisés en dis ans par les 
Anglais élaient pour nous étonner. Nos voisins avaient ouvert des musées, créé des écoles, appelé des artistes; ils avaient opéré dans tous les arts décoratifs de tels changoments que ce fut une surprise générale. Celte Rixposition de 1862 ne fut mème, dans l'esprit de la Commission supérieure qui l'organisa, qu'un moven lardi et très halbile de compléter pour l'industrie anglaise l'enseignement commencé en 185 ; l'essai devait s'arrêter là : les Anghlais n’ont pas renouvelé l'épreuve, et les expositions partielles tentées à Londeres depuis 186.2 n'ont pas ru le caractère des concours de 1851 et de 1862: ceux-là, pour modifier to goût do la nation, ont fait plus que cinquante ans d'ílude et de travail.

II. Michel Chevalier conslate cette évolution dans son rapport; il en attribue te principal mérite ì Sir Henry Cole, le créaleur et l'éminent directeur du South Kensington Huseum. C'est rendre justice à cel lıabile administrateur, qui fut avisé et plus clairvoyant, plus sagge (que d'autres ne le sont, yui se croient plus aptes el qui n'ont pas la patience ct li rolonté de Sir Henry. Nous qui l'avons connu et aimé pour sa bienveillance, nous Jui rendons hommage et nous saluons sa mémoire, comme il convient de faire eu parlant d'un des hommes illustres de l'Angleterre.

Ontre le rapport de M. Hichel Cihevalier, il faut lire encore, à propos de l'Exposition de 1862 , le chapitre consacré à l'art industriel par M. Mérimée ${ }^{(1)}$ et celui que te grénéral Morin a écrit sur l'enseignement industriel (2).

C'est ì II. Fossin qưóchut li tâche do rendre compte des industries de l'or ef de l'argent is l'Exposition de Londres en 1862 ; la joaillerie, la bijouterie el l'orfévreric ne formaient qu'une seule classe, la classe 33.

Ce rapport n'est pas très long; il entre moins que celui de Ledagre daus les considératious industrielles el commerciales. Il met au rang de cliefs-d'œurre : le baptistìre le Baclıelet; les dem reliquaires exposés par Poussielgue-Rusand; les ciselures de l'anniìre: Ie surtout de la Ville de Paris, dont Christolle présentait les premières pièces; les vases d'argent repoussés par Veclite el exposés par Hunt et Roskell; la coupe de Shahespeare, composée par l'Italien Monti el evécutée chez Hancock; enfur, les belles “iselures que Jorel-Ladenil avait faites pour Elkington. S’il arait à se prononcer entre (es aurres. "sa préférence pencherait vers l'œurre de Bachelet», écrit II. Fossin. Hìtons-nous de dire que les candélabres et le baptistère, evécutés par Bachelet Je père. araient été composés et dessinés par Viollet-le-Duc et que les dessins de l'admirable arliste, qu'on a vus après sa mort exposés à l'hôtel Cluny, ont démontré combien il entendail en ses moindres détails tout ce rui touche à l'orfèrrerie religieuse.

C'est à l'exposition anglaise que paraìt pour la première fois un orfèvre de Lyou, rncore un orfévre religienx, dont la réputation va grandir vite : M. Armand-Callial. Nous y trouvons, outre des fabricants de Berlin, les orfèvres russes de Saint-Pétersbourg et de Iloscou et enfin Castellani, le savant archéologrue-bijoulier ef orfére de

(1) Rapporls sur l'Exposition de $1862 ;$ t. WI, 1.367. - (2) Lbid., p. 186. 
Rome: il montre parmi ses merveilleux ourragres l'épée d'or que Napoléon III hui avait commandée après la guerre d'Italie.

III. Fannière, Bachelet, Poussielgue, Gueyton, Christofle, Odiot, Rouvenat, Duron, Rudolphi el lant d'autres, fabriq̣uent cux-mêmes et leurs talents se retrempent chaque jour au conlact d'une clientèle composér de tout ce que l'art, la science, la noblesse et l'élévation des idées possèdent de plus distingué. Voilà le secret de cette supćriorité, de ce goùt saus cesse rajeuni, dont tout l'argent du monde n’a pur encore nous dépouiller.

Ainsi s'exprime M. Fossin, et il termine son rapport par un tableau du commerce spécial de la France, relatif anx industries des métaux précieus.

1867. Exposition universelle internationale de Paris. - Ciette date est assez près de nous pour qu’il soit inutile de rappeler ce que fut cette fête de la pair que la gruerre devait suivre. Le succès de cette exposition fut si grand, la supériorité de la Frantee dans les arts et les industries de tous genres fut si manifeste, que cette victoire-là n'a pas été amoindrie par nos défaites el que Paris est resté, après comme avant, la grande cité pacifique, reine du travail et du progrès. C'est en 1867 que M. Le Play, adoptant un classement nouveau, a défmitivement disjoint l'orfèvrerie en reportant dans le groupe du vêtement la joaillerie et la bijouterie, tandis que l'orfèvrerie proprement dite restait comprise dans le groupe du mobilier. Nous dirons plus lard notre pensée sur cette classification qui a prévalu dans tontes les expositions suivanles.

IIV. Fossin et Baugrand furent chargés de faire le rapport sur les bijoux et les joyau, rangés dans la classe 36. C"est II. Paul Christofle qui acceptil de rendre compte de l'exposition de l'orfèvrerie, qui occupail lia classe 21 ; un autre rapport fut annexé au sien; il est dî à M. Philippe Delaroche et il est relatif aux émaux et ì la damasquine.

En 1851, nous avons vu le comte de Laborde étudier dans un livre devenu célèbre les rapports de l'art et de l'industrie; M. Mérimée avait, en 1862 , fait une étude analogue sur le rôle des arts industriels à Londres. Ce fut M. Guichard, président de "l'Union centrale des beaux-arts appliqués à l'industrie", qui fut en 1867 chargé de cet examen.

Nous détachons de son mémoire cinq propositions, qui restent des eritiques aussi justes à présént qu'elles l'étaient alors :

"Les ourrages exposés, dit-il, décèlent dans leur ensemble et sauf quelques exceptions :

$\pi 1^{\circ}$ Une habileté d'exécution poussée à l'extrême;

" $2^{\circ}$ Des industries d'art puisant tout aur sources anciennes avec peu de discernement et vivant sur le capital laissé par nos pères, sans y ajouter rien, ou à peu près;

- $3^{\circ}$ L'absence d'invention ou de style propre;

" $4^{\circ}$ Des cuvres concues en dehors des convenances de leur destination et des lois harmoniques des ensembles;

« $5^{\circ}$ L'art trop souvent négligé, non parr l'artiste, mais par la mode aveugle, par 
les gonts despotiques d'une clicutèle iggnorante, par la nécessité de iendre, ce qui, aux défauts déjà signalés, ajoute encore la banatité prétentieuse el le luxe de manvais aloi."

En relisant ce dernier paragraphe, n’est-on pas obligé de reconnaitre que ni les expositions, ni les criliqnes des rapporteurs ne corrigent les artisles, les industriels of les ouvriers, et surtout le public; ce que disait II. Guichard après 1867 , n'auronsnous pas à le dire nous-même, en termes presque identiques, après 1889 ?

Le rapport de M. Christofle est concis : c'est un orfère qui ćcrit; il ne s'étend pas cependant sur les travaux des orféves avec la même complaisance que l'avail fail le duc de Lujnes, mais tout est précis, exact et empreint d'une courtoise considération pour tous ceur qui ont soumis au jury l'ensemble de leurs travaur.

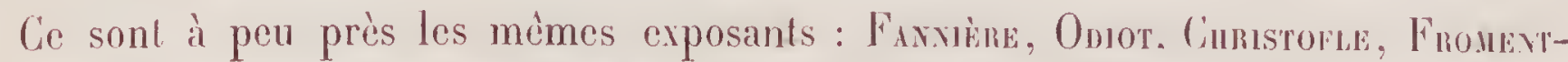

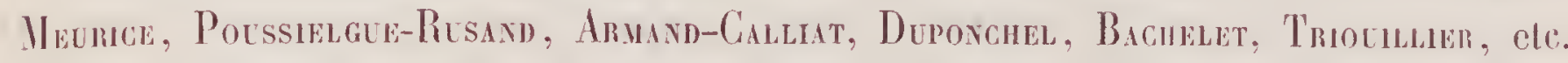

Cependant ì ces noms et à d'autres que nous avons écrits maintes fois déja, il en faut ajouter quelques-uns, qui n'araient jamais vu le plein jour des expositjons, fitbricants ol artistes qu'une trop grande modestie ou que des nécessités commerciales araient écartés des concours publies:

Lepec. l'artiste émailleur, emporte la première médaille d'or et aftirme à l'émail sa vraie place dans l'orfévrerie; nous la lui conserverons nous aussi dans uotre rapporl.

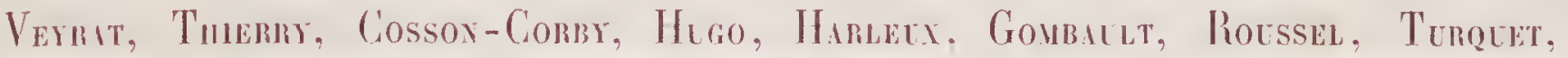
Fizuxe, Cambar et Birarib, elc., représentent l'atelier. la fabrique, le vérilable commerce de l'orfèrerie, inconnu jusqualors du public et du jury.

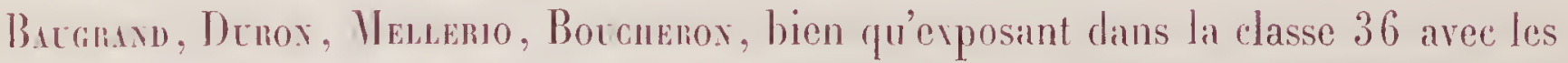
joailliers, ont droit, pour rnelqnes remarguables travaux d'orfèverie d'art, à être compris dans la liste des orfèvres.

Les élrangrers n’ont jamais été si nombreux; ce sont, parmi les orfèrres anglais:

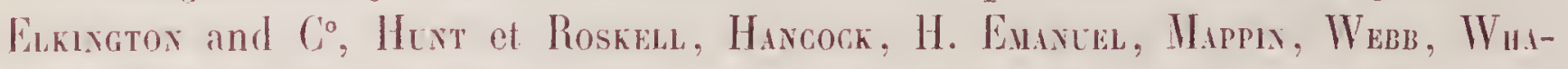
tuerson, Sumu el Fismer, ete.

Les Russes sont: Sistkofl, Ortscunvikofr et Friget.

La Prusse a Sr el Whaser, de Berlin; la Belgigue a la remarquable exposition de

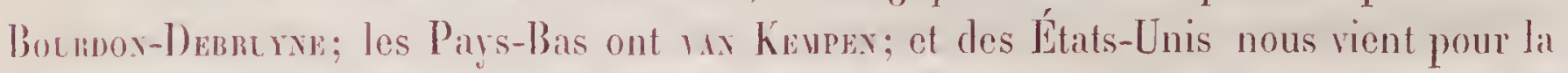
première fois Thasar.

On fail au collaborateurs me large place, on récompense Monel-Ladecil d'une médaille d'or' ciseleurs et seulpteurs sont cités: Gubbent, Micunu, Hoxoné, Dionìne: IVuss, et avec eux l'atelier, depuis les chefs jusqu'an brunisseuses.

La tendance est done manifeste de rechercher partout le productenr, d'exiger la sincérité, de faire tomber les étiqnettes menteuses qui favorisaient l’intermédiaire aur dépens du fadrieant el de l'ourrier. L'exposition marque une érolution dont les eftèts se freront progrressivement sentir' le public comprendra vite et, soncieur de ses intérèts, il

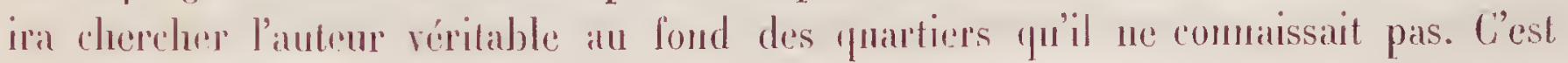


Inne rérolution économique et commerciale qui se prépare et dont les conséquences seront grandes.

1873. Exposition universelle de Vienne. - C'est à l'Autriche, après la guerre, que revient l'honneur d'aroir recommencé une lutte bien autrement profitable à la gloire et à la prospérité des peuples, et dans laquelle, se rencontrant sur le champ des expositions, ceux-ci font assaul non plus de barbarie, mais d'intelligence, de travail et de science.

Ce qui était pour nous le lendemain d'une guerre en était déja le surlendemain pour l'Autriche, mais ce füt un spectacle plein d'enseignement que celui de ces deux vaincus devant leur vainqueur. La France et l'Autriche-Hongrie étaient plus grandes, plus belles, plus robustes d'intelligence, de force productive el de travail confiant, que l'Limpire d'Allemagne, malgré sa force armée et sa puissance politique.

II. Dusommerard et M. Ozenne étaient les commissaires généraux de lia section française; MII. Rouvenat et Fontenay représentaient la France, dans le jury chargé de juger les objets d'or' et d'argent. Nous recommandons à nos confrères la lecture de leur rapport: la division en est originale. On y trouve les pays produisant l'orfévrerie et les bijoux séparés en trois groupes, suivant que ces pays obéissent à une tradition immuable, quils cherchent le progrès el se font créateurs ou que, purement manufacturiers et commercauts, ils se bornent ì copier les modèles des autres.

L'Italie, le Danemark, la Russie, la Norvège, l'Espagne, le Porlugal et les Indes orientales sont les nations «qui virent du passé et reproduisent éternellement les mèmes types empreints d'un caractère tout local ".

En Angleterre, en Belgique, en Suisse et surtout en Allemagne, orfèves et joaillier's "ne voient que le còté mercantile de leur industrie", et pour e renouveler leurs dessins et entretenir leurs affaires, ils trourent plus commode de se servir de modèles tout faits que d'en créer eux-mêmes".

"La France pour la joaillerie, l'orfèrerie et la bijouterie, et l'Autriche pour la joaillerie composent la série intermédiaire; là sont les artistes qui, travaillés par une ardeur de créer, poussent en avant et inventent en s'aidant avec bonheur de l'étude des styles."

Plus nous approchons, moins il est besoin de relever parmi les exposants des nours qu'on n'a pas eu le temps d'oublier; il est plus aisé, d'ailleur's, de retrouver ces listes que celles des anciennes expositions nationales que nous rappelions en commençant.

Peu nombreux avaient été les orfères français; si Christofle tenait à Vienne une place considérable, słil montrait à côté de ses vaisselles et de ses couverts argentés des énaux cloisonnés admirables, de curieuses incrustations métalliques et des meubles où le métal s'alliait au bois, les autres orfèvres n’avaient apporté que des essais isolés : c'était Philippe, qui essayait des restaurations égyptiennes; Mellerio, qui montrait des travaux intéressants; Boucheron, qui mêlait des ciselures d'argent à des diamants; c'était surlout Poussiegue-Rusand, qui cmporta en $18_{7} 3$ un grand et légitime succès; 
ses ouvrages d'orfèvrerie religieuse n'ont pas été jugés dans la classe 7, mais dans le groupe XXIII, dont U. Bœswilwald était le rapporteur.

Villeminot, le statuaire, el Désiré Attarge, le fin ciseleur, que la maison Barbedienne avait pris à l'atelier d'un orfèvre pour se l'attacher, obtimrent de très hautes récompenses.

Les Anglais et les Allemands étaient venus nombreux; on trouvera les noms de leurs orfèvres au catalogue ofliciel. Ce qu’il faut surtout retenir de l'exposition de Vienne, c'est que l'art oriental s'y révéla mieux qu'il ne l'avait firit encore. Les Indes, le Japon et la C'line même avaient envoyé des ceuvres admirables de inétal. Le goût qui portait les plus fins amateurs vers les choses de l'Extrême Orient s'augmenta et pénétra la masse du public.

Cette évolution du goût vers l'Orient se manifesta plus vivement encore en $187^{6}$, à l'Exposition de Pliladelphie; mais notre intention n'est pas de nous attarder aux expositions de Porto, de Munich, d'Amsterdam, de Bruxelles, d'Anvers, de Melbourne, de Nüremberg, de Barcelone, ni même de signaler les expositions plus spéciales qu'orgarnisiat à Paris l'Union centrale. Nous arons hàte de terminer cet avant-propos, en ne parlant plus que de l'Exposition universelle de 1878 .

1878. - Cette exposition fut merveilleuse. C'était une revanche déjà pour la France, et l'on peut aftirmer qu'elle reprit par les arts et le travail la plice qu'elle a toujours occupée parmi les nations et qu'elle avait failli perdre par la chance des armes. Mon regretté ami, II. Bachelet père, a rendu compte, en ce temps-là, des travaux du jury de la classe 24 , et je veux croire que son intéressante étude est entre les mains de tous nos confrères. Très court, ce rapport donne cependant la physionomie exacte de l'exposition; il passe en revue les principaux de nos orfèvres et décrit leurs travaux : c'est ce que nous ferons tout à l'heure à son exemple.

Notre ami Bachelet est mort, sont morts aussi deux autres de nos collegues du jury de 1878 : le professeur Archer, l'éminent directeur du Musée de science et d'art d'Édimbourg, et M. Veyrat père, notre sympathique vice-président. Nous leur gardons une grande estime et une reconnaissante affection. C'est ainsi que ces notes de rapport deviennent trop vite des notes d'histoire; la mort emporte les artistes sans leur permettre souvent d'achever leur's æeuvres, et ce sont des documents biographiques que nous laissons à ceux qui feront un jour des recherches sur l'art du xix siècle. Hs trouveront pour les aider denx magistrales études sur l'Exposition de 1878 : le Rupport général, de II. Jules Simon, et le Mémoire sur les arts décoratifs, de M. Éd. Didron.

On juge de l'importance des travaux publiés sur les expositions depuis l'an ir; ils forment un nombre de volumes considérables et pour s'en rendre compte il suffit de voir la place qu'ils tiennent dans la bibliothèque de la Chambre de commerce de Paris. Nos chambres syndicales ne peuvent pas reconstituer au complet ces collections, mais il serait aisé, pour chaque branche de nos arts et de nos métiers, de faire le classement particulier des pièces qui l'intéressent, et e'est pourquoi jinvite la Chambre syndicale 
des bijoutiers, joailliers et orfères à faire rémprimer tout ce qui a trait à l'industrie de l'or et de l'argent.

Elle trouverait à couvrir les frais d'une telle publication; il n'est pas un orfèvre, pas un ouvrier bijoutier ou joaillier qui ne souscrirait à l'historre de l'art dont il vit el qui ne voudrait s’instruire de ce qu'on $y$ a fait depuis l'abolition des maîtrises : ce serait une digne façon de célébrer le centenaire de $178 \mathrm{~g}$.

J'aurais pu résumer cette histoire et en faire la préface de mon rapport, mais, outre qu'il eût fallu répéter ce qu'a dit en 185 1 le due de Luynès et déflorer l'intérêt de la publication que je réclame, c'eût été tarder trop longtemps à aborder l'examen de l'Liposition de 1889 .

Nous nous bornons à résumer les caractères générau de ces cent ans de travail pour l'orfèvre.

Affranchi par la loi de 1791 , mais frappé dans la source de son travail de luxe par le départ de ses clients anciens, l'orfèvre reste longtemps désorienté, souffrant d'une révolution quili a appelée, qu'il admire et dont il supporte aree résignation les effets ruineux. Il espère et, en effet, le travail lui revient dès que la société française se reconstitue sur de nouvelles bases. L'atelier a perdu ses traditions, le gon̂t nouveau a bien quelques affinilés avec le style du xvin' siècle, mais, chez l'ouvrier, le dessinateur, le modeleur et le ciseleur, sont entrées des idées qui ont pris forme. Ce n'est plus le style aimable, souple et gracieux qui sous Louis XVI faisait retour aux simplicités antiques; c'est une imitation brutale, héroïque, mais un peu prétentieuse et barbare, des formes et des attributs grees et romains où reste le souvenir des ornementations françaises. Toutes les orfèvreries de la fin de la République et de l'Empire ont des raiideur's voulues que trahissent la grâce de l'outil et l'habitude de la main; on comprend que si les vieur maitres orfèrres n'existaient plus. leurs ouvriers n'avaient pas tous disparu. Mais on suivait le courant du goût, les événements commandaient à la mode, et la campagne d'Égypte venait mêler aux éléments d'architecture grecque et romaine des sphinx, des obélisques et des attributs nouveaux.

Tout grand artiste qu'il était, David ne fut pas un chef d'école à la façon de Lebrun: il n'eut pas sur l'industrie l'action profonde qu'avait esereće sur les ateliers des Gobelins le peintre de Louis XIV. Percier et Fontaine dessinèrent pour les orferres comme avaient fait Marot, Berain ef Lepautre, mais ceux à qui ils commandaient n'étaient pas disciplinés, ceux pour qui ils travaillaient ne leur laissaient pas le loisir de composer et d'apprendre; on avait hâte, il fallait faire vite, jouir d'une fortune inespérée, d'une gloire immense. L'empereur entrainait après lui une cour de parvenus illustres par les armes et le talent, mais dont l'esprit, les goûts et les mœurs n'avaient pas eu le temps de s'assouplir. Prudhon fut le maître le plus français de cette époque, et, sans rien emprunter aux formes délaissées, il commençait à trouver en lui-même les ressources d'un style, dont quelques orfèrreries ont gardé la marque, quand tout s'écroula de nouveau. 
Les Bourbons ne ramenèrent aucune des vicilles traditions de goût, d'art et do luxe; ils continuèrent, sans y changer autre chose que les abeilles et les aigles, le style quils prétendaient détruire. L'orfèvrerie de la Restauration ressemble à celle de la Révolution et de l'Empire; elle ne se modifie que lorsque la littérature vient changer, avee elle, l'architecture, le mobilier et le costume. Car nous sommes dans l'ère des perpétuels changements : un livre, une pièce de vers, un drame, un discours à la Chambre ont sur l'esprit public, sur la forme des chapeaux et le dessin des artistes, une influence prépondérante. Jamais la mode n’a été si inconstante, l'esprit si mobile. Une senle chose conserve à l'orfèvre une garantic de durée dans ses formes, c'est l'imitation anglaise. En vain quelques critiques s'attaquent-ils à ce travers, on a gardé un étrange engonement ponr les choses d'outre-mer, on copie la vaisselle anglaise dans ce qu'elle a de plus disgracieux, el nous verrons que ce travers s'est continué, que nos clients nous y roudraicnt pousser encore.

Lin ce temps, les fortunes ne sont pas en rapport avec le luxe qu'appelle l'orfévreric. L’industrie du plaqué se propage, car elle permet de garder ì peu de frais l'apparence des vaisselles somptueuses. L'Église, elle-même, est appauvric. Elle n'a, pour refaire ses trésors, ni assez de goît, ni assez de science, ni assez d'argent; le romantisme gagne l'atelier, il envahit la sacristic, la meuble de vases gothiques qui déparent l'autel.

La bourgeoisie qui grandit, qui s'enrichit, mais dont l'éducation n’est pas faite, devient pour l'orfèvre un appoint considérable; mais, inquiète, jalouse, prétentieuse, clle exagère tous les défauts du goût, impose ses exigences et gâte ce que quelques artistes essaient d'imventer.

C'est le temps où les Sauvageot et les Dusommerard s'occupent à chercher, à ramasser sans bruit, à sauver ce qui reste de nos vieur arts. Ce qu'ils collectionnent en leurs cabinets, nos peintres et nos littérateurs le devinent et le reconstituent ì peu près, par intuition, avec plus d'imagination que d'étude. En sorte qu'il se fait parallèlement un travail de classement par des documents et des épaves et un travail d’invention par des idées el des recherches artistiques. On refait te moyen âge et la Renaissance à la fois, les uns par des relirpnes et des débris, les autres par une fiction rimée on peinte, el c'est une renaissance pleine d'enthousiasme et de brio qui s'opère en nos arts et en nos métiers. Le nom de Wagner et celui de Froment-Meurice y sont attachés, avec ceux de Feuchères et de Vechte. Si Chenavard, avec sa facilité, sa fougue et sa verve, mène les arts industriels trop vite, d'autres travaillent avec moins de fracas et s'appliquent, comme Ducliesne l'aîné, à retrouver et à classer les modèles des maîtres anciens et à préparer aux orfèvres et aux bronziers des éléments d'étude.

C'est aussi le commencement d'une suite déplorable de pastiches ridicules et maladroits. Des documents mêlés, des gravures prises à tous les arts, à toutes les écoles, ì tous les temps, donnent aux fabricants la dimgereuse tentalion de tout essayer, de tout refaire; à mesure que celte éducation hattive se poursuit à l'atelier avec des estampes et des moulages, sans qu'aucune école apprenne à s'en servir, on voit appa- 
raitre des orfèvreries gothiques, renaissance, Louis XIII et Louis XIV, qui sont des adaptations, plus étranges en leur genre que ne sont les fantaisies littéraires que sauve du moins le génic du poète.

C'est à cette école pourtant que se sont formés nos onvriers et nos artistes. Cette récapitulation désordonnée de tout l'ancien bagage industriel a rénové le goût français, et c'est avec une surprise naïe et jalouse que les autres nations ont salué, au milieu du siècle, la résurrection d'un goût qu'ils croyaient à jamais perdu. N'est-il pas étonnant que ceux qui n'avaient pas aulant que nous subi la grande secousse: Anglais et Allemands, Italiens et Espagnols, n'aient pas conservé la tradition des arts et des ateliers industriels? Comment n'ont-ils pas été capables de prendie l'avance sur nous autres? Notre révolution, nos guerres et nos conquêtes les avaient donc si profondément ébranlés et révolutionnés cux-mêmes, qu'ils ont mis plus de temps ì se ressaisir? Il est certain que l'Exposition de 1851 ne fut faite, à Londres, que pour nous dérober ce secret génial, pour nous obliger à porter au dehors ce trésor d'invention, qui rendait enviables et charmantes nos créations, malgré leurs fautes. Ces étrangers qui étaient venus en foule acheter en 1792,1793 et 1794 , les restes de notre magnificence, et qui avaient eu à vil prix des chefs-d'œuvre de goût, ne les avaient pas compris; ils n'avaient pas su imiter les adorables merveilles du mobilier français : ils avaient des yeux pour ne pas voir.

Ce fut l'Exposition de 1851 qui inspira, aux Anglais d'abord, aux autres peuples ensuite, l'ardente émulation ver's le beau. Il semble que cette grande pensée de Colbert ait présidé aux concours internationaux : «Le goût est le premier des métiers"; mais, disons-le bien vite à notre avantage, en dépit des erreurs et des fautes que nous relevons dans nos essais successifs, l'orfèvrerie française est resté en ces concours supéricure à l'orfèvrerie des autres nations.

On aurait pu, sous le second empire, comprendre mieux le parti que l'industrie devait tirer de l'étude du dessin et de la culture du goût. Le rapport du comte de Laborde, déjà cité, que les étrangers ont lu plus attentivement que nous est ì ce sujet plein d'enseignements; le musée de Kensington et tous les musées-écoles de Vienne, de Munich et de Berlin, sont sortis de ce livre : c'est l'évangite des arts industriels en tous les pays.

L'orfèvreric a souffert de ces lenteurs, elle n'a pas même trouvé sous le gouvernement de Décembre la faveur qu'elle avait eue sous la royauté de Juillet. L'empereur avait une prédilection marquée pour les bijoux et les orfèvreries d'Angleterre, il contribua à retarder la rupture de l'esprit français avec la mode anglaise. La littérature n'eut plus d'action sur l'atelier. Froment-Meurice et le duc de Luynes moururent, et les orfèvres restèrent sans chef, chacun travaillait à sa guise; on recommença à s'essayer ì tout, la fantaisie s'attacha successivement à tous les styles. L'impératrice voulait ressusciter Trianon, tandis qu'au dehors on croyait, avec le genre néo-gree, avoir trouvé le style du second empire. On abusa des figures, des chimères, des feuillages, on dé- 
pensa beaucoup de talent, sans apporter un thème à la production. Tout cet effort s'est fait en pure perte. Avant d'écrire j’ai feuilleté les cartons de dix orfèrres, il y a là d'adorables dessins, mais on n'y voit pas de maîtresses pièces : Liénard, Peyre, Neviló, Klagmann, Fannière, Carrier-Belleuse, Justin, Lièvre, Rossigneux, Constant Sevin, Jullienne, Solon, Carlier, sont des inventeurs qui subissent l'influence de la clientèle qui les fait vivre. Il y a parmi eux de grands artistes, il n'y a pas un maìtre, pas plus qu'il n’a surgi en France un grand seigneur depnis le duc de Luynes. Il faut d'abord que quelqu'un sache vouloir et commander; toujours en France on trouvera un artiste pour comprendre et exécuter.

Mais dans cette société enrichie par d'heureuses spéculations, il n'y avait aucune éducation artistique; la collection de tableaux et de bibelots primait le goût des orfèvreries modernes. Le luxe de la table n'était pas encore de mode, on ignorait l'ordonnance d'une belle argenterie; les cuivres argentés, lourds et écrasants, qui composent le banal surtout des hôtelleries, suffisaient à des tables princières. Les femmes ne s'étaicnt pas encore reprises de goût pour les délicates et charmantes coquetteries, qui font de l'argent ciselé les jouets du salon et les ustensiles de la toilette. Il a fallu vingt ans d'usage de la fortune pour qu'en pleine république, la société française rapprît et enseignât au monde, aux millionnaires d'Amérique comme aux lords d'Angleterre, la beauté, le prix de ces raretés qu'on se dispute dans les ventes. Ce qui reste de l'orfèvrerie française d'autrefois se paye comme ruvres d'art, à des taux jusqu'alors inconnus, et c'est à imiter ces merveilleux ourrages que tendent nos orfèvres.

En sorte qu'il a fallu cent ans de recherches, de tâtonnements et d'essais pour revenir au point où étaient parvenus les maîtres du xvrile siècle, de même qu'orfèvres et bronziers n'ont pas trouvé mieux pour décorer l'autel que de refaire ce qu'avaient fait aux XII ${ }^{e}, \mathrm{XII}^{\mathrm{e}}$ et XIV $\mathrm{X}^{\mathrm{e}}$ siècles leurs grands ancêtres.

N'avais-je done pas raison de dire en commençant que la Révolution, si bienfaisante aux industries qu'elle délivrait, n’a pas été favorable à la nôtre ? Mais si elle a retardé chez nous la prospérité de l'orfèvrerie, si clle en a détruit les œuvres, elle a eu dans l'orfèvrerie étrangère un contre-coup plus néfaste encore. Nous aurons à examiner quelle est notre situation comparée à celle de nos voisins. 


\section{II}

\section{LOREEVRERIE À L'EXPOSITION DE 1889.}

Il est malaisé de trouver un système de classification qui satisfasse anx intérèts de tous les exposants. J'ai déjà dit quelques mots de celui de II. Le Play et jai laissé́ voir l'inconvénient quil a pour les orfères.

II a contribué dans une large mesure à séparer ceux-ci de leurs confrères. les joailliers et les bijoutiers; pourtant ces métiers sont des métiers jumeaux, employant les mèmes matières, usant des mèmes outils, ayant la même origine, Mais de ce que les bijoux et les pierres précienses servent à la parure, il s'en est suivi que la bijouterie et la joaillerie ont été ramgées dans le groupe IV, classe 37, avec les fils de coton, les tissus de lin, la soie, la laine, tout ce qui sert à vêtir l'homme et la femme, tandis que l'orfèvrerie demeurait classe 24 , dans le groupe III, avec les meubles de bois, les tentures, les cristaux et li céramique, qui forment les éléments dı mobilier.

Les réclamations n'ont pas manqué de se produire depuis $\mathbf{1 8 6 7}$, et celle fois encore, la Chambre sjndicale des joailliers, des bijjoutiers et des orfèvres, avinit demandé la réunion des classes 2 lı et 37 .

La direction générale ne pouvait pas modifier son programme, mais elle a donné une satisfaction très large anx intérêts des deux classes en les disposant sur un plan parallèle. Elle a réparé pour les yeux des visiteurs ce que, dims le catalogne, celte séparation des métiers avait d'amormal el, de plus, elle a fait aux joailliers et aux orfèvres une place d'honneur.

Aı centre du palais, aussitôt après qu'on avait passé sous le dòme. on tronvait, dans la grande nef, l'exposition des orfèvres à droite, et en face d'elle, à gauche, l'exposition des bijoutiers.

Ils étaient là placés en tête des autres métiers, occupant dans cette magnifique revue du travail le premier rang, comme antrefois, au temps des rois, dans les cérémonies publiques.

Et c'éfait bien leur place, car l'orférrerie répond à des besoins de luxr et de décor qui font la joie des yeux; elle marque, dans une société policée, le summum de la civilisation, elle est le point de contact de l'art et de l'industrie.

la commission supérieure offrait ainsi à l'admiration des visiteurs de magnifiques écrins, des étaliges éblouissants, tout un amoncellement de trésors qui, ì côté des manufactures de Sèvres et des Gobelins, faisaient, aux expositions industrietles, la plus attrayante préface.

Nous aurons souvent ì traverser celte nef pour aller dans la classe 37 , parmi les 
bijoux et les pierres, prendre quelque exemple de fine ciselure ou d'émail, mais c'est dans la gaterie de droite que nous reviendrons surtout ${ }^{(1)}$.

(1) Toici la description sommaire yue nous avons dentandée à II. Lorain, l'labile arclitecte de la classe s/s, pour consarver le souvenir de l'espace el de la disposition des lieux :

La classe 24 occupait ì droite de la rolerie de 30 mètres une surfice totale de 1,693 m. 45. Elle contenait 40 exposants, dont en salons, 18 ; en vitrine, so; en emplacements isolés, 2.

Ia salle n'était pas régulière, l'un des pieds dn dòme central formant enclave de 8 mètres $x$ 8 mètres près de l'entréc. Une partic de cet emplacement fut occupée par un salon à l'usage des membres dil comilé.

Par suite de cette disposition, la porte monumentale sur la galerie de 30 nètres devait être réduite nux deux tiers de la largeur de la salle. Elle ne possédait donc que deux travées, dont l'mne dans l'axe de la voie de 5 mètres, l'autre formant la fiçade de l'exposition de MMI. Poussielgue-Rusand et fils.

Le programme à réaliser pour l'installation était le suivant: $1^{\circ}$ Élablir pour les exposants une série de salons de formes el de dimensions variées, offrant le plus grand développement possible de façades, la salle ayant sur son plus grand côlé une longueur tolile de $66 \mathrm{~m} .66$;

$2^{\circ}$ Etublir également $1 \mathrm{n}$ grand dévelopjement de vitrines d'un morlèle mniforme, dont les unes à (puatre faces, d'autres à trois faces, deux fices et une fice, eclles-ci devant avoir trois parois intérieures. La sille a été divisée en deux parties de forme octogonale allongré, se reliant entre elles par un large espace dans l'axe de la porte de communication avec la classe de la céramique.

Nous avons pu arriver ainsi ì fournir aux exposants ell salons un développement de 150 mètres. Le décor des façades consistait en colonnettes ou mâts placés en tèle des doisons séparatives; ces mâts dépassant la lauteur des plafonds étaient lerminés, suivant leur cmplacement, par un fleuron on une palmelle peints el dorés; ils élaient garmis dans la hiateur du salon par de la peluche vieux bleu clair, interrompue par deux barues dorées. A hauleur d'appui, était un socle mouluré et bronzé. Des traverses portant en mème temps les chaissis des plafonds en monsseline de l'intérienr et les bailis recevant la grande draperie en peluche de lin vieux blen galonnéc d'or', portant en brorlerie le nom de l'exposant.
Sur la ligne d'axe de la salle, étaient disposées les vitrines de modèle uniforme, construiles en fer sur sombassement en hois noir. Elles formaient un dére. loppement lotal de 79 metres en sept ilots, dont. quatre vitrines isolćes ì quatre faces.

Porte d'entrée sur la galerie de 30 mètres. - La disposition d'ensemble de celte porte élait absolıment motivée par la partie de la construction en fer cu'il élait indispensable de dissimuler en façade ef en épajsseur, la lıauteır elle-nıème étant limitée par l'administralion.

La classe 24 comprenant non senlenent le liavail des mélaux précieux, mais encore les divers procédés de fabrication de l'orfèvrerie religicuse qui a donné à diverses époques en France, en Italic et en Orient, quelques beaux exemples de ciboria, d'autels el d'iconostases, il devait venir à l'esprit de s'en. parer de ce genre de monument et d'employer les ressources de cet art à la décoration de la porte de la classe de l'orfévrerie.

Quelques exposants pressentis à ce sujet n'ayant pu nous assurer leur concours, forl occupés qu'ils élaient par des commandes ì livrer à liref dólaj on par lenr exposition personnelle, et, d'autre part, la somme à dépenser élant fort restreinte, nous avons dù recouril à l'emploi de matériaux plus écousomiques : bois, staff, peinture ef dorure. Néanmoins, nous avons étudié cette porte comme si clle devait ètre exéculćc en matériaux plus précioux : marbres divers avec monlures et ornements en cuivre doré rejoussé au marteau; le loul relraussé de cabochons ou points de diamants en verre ou émanx.

Une partie importante cependant cnt été incxécutable: je veux parter des colonnes en lapis-lazuli. Nolre première pensée avait été de les supposer en métul avec émanx cloisonnés d'un décor un pen large, mais il eut été impossible d'obtenir, par la dorure, la netteté indispensable pour produrire l'effel voulu.

L'ensemble de l'édifice était composé de quatre grands pilastres montant à fond, d'un entablement complet avec frise porlant les iuscriptions relatives i la classe (oriévrerie, groupe III, classe 24).

Entre les pilastres, étaient deux arcades portées sur des colonnes bleues en lapis, baguées au tiers de. la lanuteur el ornées sur toule la surface du tiers iuférieur de spirales en branclue de myrte dorćes. Les chapiteaux ólajent formés d'une corbcille ì grands grodrons ćmaillés bleu turquoise, accompagnée de quatre cau- 
Il nous faudra voyager ensuite jusqu'ì l'esplanade des Invalides pour y chercher, dans les constructions pittoresques des colonies, nos confrères d'Algérie, de Tunisie et d'Indo-Chine. Quant aux orfèvres étrangers, nous n'aurons pas la satisfaction de les trouver aussi nombreux qu'il aurait été désirable, pour faire entre eux et nous une comparaison instructive.

Avant d'aborder la revue des expositions particulières, disons quelques mots des travaux du jury des récompenses.

On a vu, au commencement de ce rapport, comment était composé ce jury; son président, MI. Poussielgue-Rusand, est mort aux derniers jours de l'année $188 \mathrm{~g}$. Je lui rends ici un tribut de respect et de reconnaissance pour la manière courtoise et libérale dont il a dirigé nos délibérations.

Les procès-verbaux de nos séances témoignent de la façon dont, pendant plus d'un mois, M. Poussielgue et ses collègues examinèrent minutieusement les produits de l'orfèvrerie, convoquant les exposants, écoutant leurs observations, recevant leurs lettres, les questionnant sur leur production, les progrès de leur commerce, le perfectionnement de leurs moyens de travail, leurs besoins; visitant même quelques usines et réclamant les noms des collaborateurs pour les récompenser.

Après chaque visite, la commission se réunissait dans le salon qu'elle s'était ménagé et faisait la revision des choses vues, échangeant les observations, contrôlant les notes; c'est ainsi que, d'un bout à l'autre de leurs travaux, les jurés de la classe 24 sont restés dans un parfait accord et ce m'est une grande satisfaction de le constater aujourd'hui, parce que notre verdict a été bien accueilli, parce que c'est une justice due à la mémoire de notre président, parce qu'enfin ces délibérations forment la base du rapport que je commence.

On a voulu que ce rapport fût complet, sincère, sévère même, afin d'être utile; j’ai

licoles à jour. L'astragale des chapiteaux étnit surmonté d'une sorte de couronne crénelée enserrant un rang de huit feuilles dont quatre montaient sous les caulicoles. Les archivoltes étaient moulurées et ornées de palmes dorées interrompues par des claveaux saillants portant des pointes de diamant, ton bleu turquoise.

L'espace existant entre les deux pilastres du milieu était occupé par une baie rectangulaire dans laquelle élait le beau vase en bronze, dédié aux Arts, de la maison Christofle, ce vase se détachant sur une draperie vieux bleu et or. Au-dessus de l'architrave portée sur deux colonnes, semblables à celles qui portaient les archivoltes, était un grand cil-de-bœuf, dans lequel était un buste.

Sur les quatre grands pilastres, étaient appliqués quatre cartouches portant les armoiries des orfèvres de Paris, Lyon, Tours et Limoges. Au-dessus de l'ordonnance étail élevé un petit étage à nrcatures couronné par une corniche architravée avec grande cimaise ajourée.

Pendant l'étude du projet, il était permis de supposer que les grandes haies vitrées de la galerie de 30 mètres auraient leur appui plus bas, de façon à faire les arcatures à jour pour y introduire des vitraux; mais le mur en briques qu'on a élevé tardivement nous a obligé à aveugler les arcatures et à emplojer des fonds d'or, pour remédier en partie à l'effet de lourdeur provenant et de la suppression du jour, et de la limite de hauteur imposée tardivement par l'Administration. Sur les fonds d'or des arcatures se détachaient les noms de dix orfèrres ou dessinateurs français d'orfèvrerie, savoir: 'Thomire, P. Germain, Th. Germain, Briot, Saint-Éloi, Cl. Ballin, R.-1. Angusle, R. Toutain, F. Déjardin, Cl. Marcel.

(P. Lonain, arch.). 
cependant la conviction qu'il adoucira pour quelques-uns ce que l'arrêt du jury pouvait avoir de pénible.

Je me conformerai à la volonté expresse de mes collègues en rétablissant ici l'ordre dans lequel ont été votées les récompenses.

I a liste publiée au palmarès officiel a été, pour des raisons de classement général, modifiée suivant l'ordre alphabétique; mais il convient de revenir au classement primitif, le seul juste et rationnel parce quil explique et confirme le jugement que nous allons porter.

Quelques-uns y perdront une illusion, je le regrette; d'antres y trouveront une satisfaction qu'ils n'attendaient plus.

Le catalogue qui nous avait été remis contenait :

Maisons françaises......................... 43

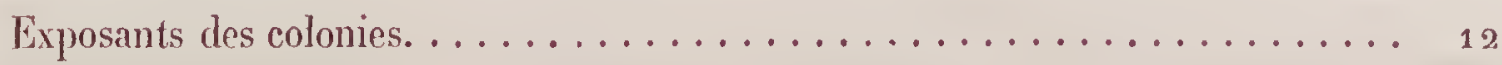

Exposants étrangers............................ 54

A ceux-lì sont venus s'en ajouter 22 autres qui ont été présentés régulièrement par leurs commissaires et par l'administration supéricure, ce qui porte à 131 le nombre des exposants.

Quatre étaient hors concours, comme membres du jury des récompenses, c'étaient MM. Poussielgue-Rusand et fils, Odiot, Bapst et Falize el G. Sandoz.

Il a été accordé :

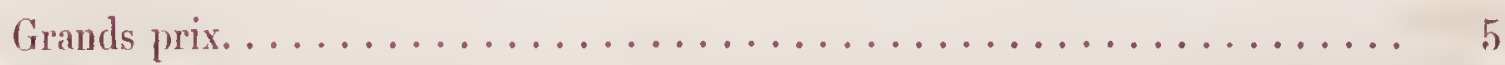

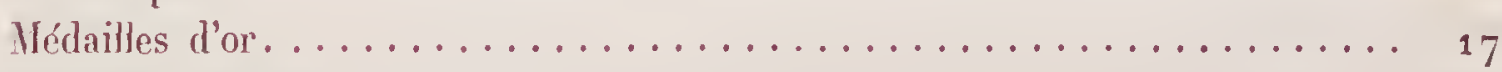

Médailles d'argent.............................. 21

Médailles de bronze. ........................... 29

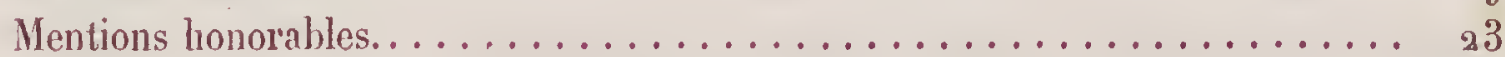

Total des Nominations............

Nous devons avouer que le vote du jury avait été plus restreint d'abord et que, voulant donner aux récompenses une grande valeur, il s'en était montré très avare. On a cédé ensuite à l'exemple des jurys voisins et les conclusions premières ont été modifiées.

Il est regrettable qu'un mode uniforme de comparaison ne puisse pas être trouvé pour donner aux jugements une égalité relative: le prestige des récompenses en serait augmenté.

Nous ne pourrons pas, dans l'examen que nous allons faire, suivre l'ordre absolu des récompenses. Nous sommes obligé, pour l'intelligence du rapport, d'adopter un classement par genre dont la portée apparaîtra à la lecture. Nous renvoyons à la fin du chapitre pour la liste des noms, telle qu'elle résulte du vote et telle que nous en conservons le texte original signé par tous nos collègues.

L'orfèvrerie civile a des origines qui la rattachent aux temps les plus lointains, aux 
peuples les plus divers. L’Orient, l’Égypte, la Grèce et Rome en ont fourni les types primitifs; mais l'orfèvrerie religieuse est plus française. C'est ici qu'elle a puisé ses formes consacrées et, si quelques-unes nous viennent de Byzance, elles ont été modifiées par l'usage.

\section{ORFÈVRERTE RELIGIEUSE.}

L'orfèvrerie religieuse tient an sol de la France comme la flore de pierre qui s'épauouit sur les murs de nos calhédrales; elle est une émanation directe de l'architecture qui, dès le xir siècle, fait de l'art français un modèle achevé de graice et de force.

Les ateliers d'orfèvres travaillaient à l'ombre des cloìtres; les mêmes artistes inspirés dessinaient el modelaient les détails de la châsse el les bas-reliefs de la chapelle; l'orfèvrerie a.suivi de près l'œurre de pierre, avec les variantes qu'erige l'emploi du métal, avec les vigueurs qu'amène la fonte, les délicatesses de la ciselure, l'éclat des gemmes, la coloration des émaux et la richesse des or's; des bords de la Mense aux montagnes du Limousin, les œuvres françaises se propageaient; it s'en faisait un grand commerce, et si l'Italie et l'Allemagne avaient des ateliers fameux, si elles possédaient des artiștes éminents, elles subissaient cependant la mode de France. Il n'en fut pas seulement aiusi pendant le moyen âge; l'église resta, plus longtemps que la cour, fidèle au style gothique; elte ne céda que tard à l'inflnence nouvelle et les orfèvreries religieuses de la Renaissance gardent une saveur nationale ${ }^{(1)}$. Lorsque la réaction se fit an xvil siècle et qu'on essaya d'autres inventions, ce sont nos orfevres parisiens qui en trouvèrent la formule.

Richelieu provoqua l'essai de cette orfèvreric nourelle et Ballin fit pour lui, avec les conseils de Sarrazin, son maître, des vases et des oruements d'église. Le goût français dn xvm siècle s’imposa ensuite jusqu’à parer l'antel des rocailles et des chricorées Lonis XV; les amours joufflus devinrent des chérubins ciselés au pied des calices ot les vases sacrés furent caressés du même outil délicat qui fouillait la vaisselle dn roi : le pape voulut avoir une chapelle à la facon de Paris, comme la reine de Porthgal voulait une toilette de Germain.

Aujourd'hui que nos édifices religieux ont repris, sous la surveillance de l'État et la savante direction de nos architectes diocésains, la tradition longtemps perdue, on refait à l'église un mobilier en rapport avec ses murs; on débarrasse ceux-ci des boiseries ijoutées et des plàtres moulés. On cherche à reconstituer l'orfèvrerie qui enrichissait les autels; mais il sera long, couteur et difficile, de remplacer tout ce que nos guerres de religion et nos révolutions politiques ont détruit.

Il $y$ aurait ì citer beaucoup de noms, si nous faisions ici l'histoire de cette reprise de possession de l'art chrétien : le P. Martin, Dusommerard, Didron, le R. P. Cahier,

(1) On a vu, à l'exposition du Trocadéro, le calice de l'église Saint-Jean-du-Doigt et le groupe de la Résurreclion, donné par Henri III à la callédrale de Reims. 
ont leur place marquée parmi les auteurs de cette renaissance, et anssi le frère de ce dernier, Léon Cahier, l'orfèvre, que nous avons déjà nommé en feuilletant les cataloggues de 1819 et 1823 . Il avait succédé à Biennais et avait exécuté, pour Charles $X$, les ornements et les vases du sacre, qui sont au trésor de Reims. C'est sur les conseils de son frère qu'il commença à revenir aux orfèvreries gothiques; mais il ne réussit pas à faire fortune, et quand cet homme de talent cessa d'être en nom parmi les orfèvres, ce fut pour entrer dans la maison, alors toute nouvelle, de Poussielgue-Rusand; il y apporta tous ses modèles; il mit au service de son jeune patron sa grande expérience, sa passion profonde de son art; il y amena les hauts prolecteurs, qui l'avaient pent-ètre poussé ì la rume en l'excitant vers un idéal trop impatiemment cherché, et c'est ainsi que la maison Poussielgue-liusand se ratlache aux premières années du siècle; Cahier el Biennais sont ses ancêtres industriels.

\section{HORS CONGOCRS.}

\section{Poussielgue-Rusind (Placide) el fils.}

M. Placide Poussiegue-Rusand avait 24 ans à peine quand, en 1848 , il ourrit un petit atelier sur le (quai des Orfêvres; il était fils du libraire qui éditait alors les Mélanges d'urchéologie , du R. P. Martin, et e'est de ce précicux recueil que l'orfêvre est sorti tout entier. II avait le sens comnercial développé au plus haut degré; doné d'un esprit fin, aimable, il était commu et apprécié de la elientè̀e ecclósiastiriue, qui frérquentait la maison de son père; n'ayant quä à frapper pour voir s'ouvrir les portes des évêchés de France, Poussielgue trourait le chemin bien tracé. Il lui fallut cependant toute la volonté et l'âpre persévérance dont il était doué, pour parvenir au résultat quiil a alteint. Si je dis ces closes, c'est que le souvenir me revient avec une netleté singulière de la conversation que j'avais avec lui bien peu de jours avant sa mort. .... . il était debout, bien portant, heureux, à la veille de prendre un repos bien gagoné; il allait transmettre à ses fils la maison qu'il avait faite et il s'abandonnait an plaisir de me raconter sa vie, ses luttes, de me parler des hommes quil avait connus. C'est en me demandant si je connaissais un bon chef d'atelier qu'il me racontait comment Cahier avait été son aide el son mâtre à la fois, et c'est en me disant les leçons qu'il arait reçues du P. Martin qu'il en vint à me montrer les dessins de Viollet-le-Duc et à me dire, ce que m'avait dit autrefois Bachelet père, la prodigieuse facilité du grand artiste à composer des modèles d'orfềrrerie.

Aussi ne pensé-je pas diminuer la valeur de l'orfève en affirmant qu'il fut un administrateur entendu, un commerçant avisé, Il sul se servir des éléments et des hommes; il groupa dans sa main tous les moyens de travail et comprit que pour entreprendre de refaire aux églises un mobilier en rapport avec l'édifice, il fallait ne pas se borner ì travailler l'argent, mais s'altaquer au bronze, au loois, au marbere, être prêt à toutes les besognes qu'on lui commanderait. Il devint done lentrepreneur à qui s'adressaient le plus volontiers nos architectes religicux et la liste est considérable des travaux qu'il a fails sous leur's ordres. A Paris, c'est le mobilier complet de Notre-Dame, dessiné entièrement par Viollet-le-Due; c'est, pour l'église de la Trinité, toute une série de bronzes, de meubles et d'orfêvrerie que Ballue a inventés et dirigés; c'est le maître-autel de Saint-MLédard; c'est à NotreDame-des-Victoires, à Saint-François-Xavier, à Saint-Ambroise, à Saint-Eustache, à Saint-Étiennedu-Mont, à Sainte-Cilotilde, au Panthéou, à Saint-Laurent, au Val-de-Gràce, tout ce quii relève du mobilier religicus. 
Le jour oủ nous l'avons conduit de son atelier à sa tombe, je songeais à ce pauvre el regretté Poussielguc, tandis qu’à Saint-Sulpice, les prectres et ses nombreux amis priaient pour lui et que l'orgue pleurait l'hymne des morts, et en voyant sur l'autel les ornements dorés, en contemplant les lourds candćlabres qui brillaient autour du catafalque, sous l'éclat tremblant des cierges, en considérant ce luxe qu’il avait créé, cette somptucuse orfèvrerie, ces bronzes puissants en harmonie avec l'architecture du temple, je pensais que c'étaient là de superbes funérailles pour un orfèvre et que.son ânc en devait être satisfaile.

On jugerait mal de l'importance de l'œurre de Poussielgue si on.pénétrait dans ses magasins de la rue Cassette; son exposition mồme n'en donnait qu'une idée insuffisante, car à côté de l'autel de Rocamadour s'étalaient les objets de bronze et d'émail, qui sont la menue monnaie de son commerce; mais si, aux églises de Paris que j’ai nommées plus laut, jajoutais la liste interminable des cathédrales de France, dont il a fourni les ornements ou dont il a construit les autels : Aniens, Bourges, Le Nlans, Toul, Metz, Angoulême, Sens, Quimper, Glıartres, Auch, Avigunon, SaintMalo, je n'aurais pas tout dit, car combien d'églises moins vastes où sont des auvres plus charnuantes, comme à Conches, à Honfleur, à Fougères, à Sainte-Inne-d'Auray . . . . .

Ce n'est pas en France seulement, c'est à l'étranger : c'est à l'église patriarcale de Jérusalent, c'est à Nalte, à Odessa, à Rome et à Canterbury; c'est à la cathédrale de New-York, à celle de Philadelphie, c'est ¿̀ Buenos-Ayres, c'est en Espagne, en Roumanie, en Grèce; en sorte qu'à se représenter l'œuvre immense de cel homme, la quantité prodigieuse d'ormements de bronze el d'argent, d'autels de marbre et d'or', de chandeliers, de vases, d'enccusoirs, de croix, d'ostensoirs, de reliquaires, de lampes, de chemins de croix, dont il a meublé les églises et les chapelles, on demeure étonné : il y a lì des curres de haute valeur auxquelles s'associent les nons de Viollet-le-Duc, de Ruprich-Robert, de Boeswilwald, de Corroyer, de Questel, de Duthoit, de Darcy, et de vingt autres de nos meilleurs architecles. N'avais-je pas raison de vanter son génie commercial et d'apprécier la laute situation qu’il avait su prendre dans son industrie?

Il convient maintenant d'examiner en détail la qualité de ces ouvrages. Qui n’a vu dans la grande nef de l'Exposition, en face du portique des orfèvres, l'autel de bronze doré qui est destiné à l'église Saint-Ouen, de Rouen? Il fallait que les proportions en fussent grandes el cependant harmonieuses, pour n’ètre pas diminuées, ni écrasées, par le cadre inmense et éclatant de la nef et j’imagine que, dans l'église calme et reposée, l'effet s'en trouve considérablement accru.

C'est d'après les dessins de M. Sauvageot, architecte du gouvernement, qu'a été exécuté le maitroautel de Saint-Ouen; le caractère est conforme à celui de l'ćdifice, il est inspiré du xıve siècle, comme la flèche de l'église.

Entièrcnent fait de bronze doré, l'autel mesure $5 \mathrm{~m}$. 6o de large el 11 mètres de haut; l'ordonnance en est belle, les lignes pures, la silhouette légère, hardie; sa plus grande beaulé réside daus le profil élégant des moulures, dans la franchisc parfaite de l'exécution; l'ornementation est sobre; les deux grands bas-reliefs formant retable, et représentant le sacre de saint Ouen et la translation des reliques de Darmetal à Rouen, sont dus à M. Charles Gauthier; le caractère des figures est excellent, ce n'est pas un pastiche d'une œuvre ancienne et cependant cette modelure se lie bien à l'architecture cl gardc un aspect religieux.

Lc jury des bronzes (classe 25 ) a examiné cet autel qu’il réclannait comme sien : MM. Poussielĝ̣cRusand appartiennent aux classes $24,25 \mathrm{ct} 42$.

Nous acceptons ce partage, mais en faisant cette remarque que l'art du bronze est sorti tout entier de l'atelier de l'orfêvre; fondeur et ciscleur, l'ouvrier du métal, dès qu'il se sert du feu, du marteau, du burin et du ciselet, est de la famille, et les barrières qu'on élève entre nous n'empêcheront pas que nous nous donnions la main.

Ce qui nous a engagé à retenir pour notre part le maître-autel de Saint-0uen, c'est l'aduniration 
que nous inspire sa parfaite exécution, la rectitude de ses grandes moulures tirées d'un seul morceau, l'ajusté de ses parties, la simplicité des montures. Quelque nom qu'on donne aux ouvriers qui ont fait ce chef-d'œuvre, qu'ils soient montenr's en bronze ou orfèvres, peu m'importe, ce sont d'admirables artistes, qui font honnenr à l'atelier. J'éprouve le besoin de nommer ceux des collahorateurs de Poussietgue, que nous avons récompensés, parce que ces noms s'associent dans te travail comnitu ; ce sont :

MM. BastiÉ, contremaitre, el Dardare, graveur, tous deux réeompensés d'une médaille d'or.

MM. GÉrard, dessinateur, el Colniot, ciseleur, médailles d'argent.

Mil. Lantoni, orfêvre, Labicue, tourneur, el Guenet, ciseleur, qui ont obtenu des médailles de bronze.

Et enfin MM. Adolphe et Charles Lecot, les deux frères, el Periliat, orfêvres. Fabvre, graveur, et IVatrieadx, émailleur, qui ont obtenu des mentions honorables.

Car il nous faudrait maintenant venir à tous les détails d'orfèvrerie où ces travaux de cisehure, de gravure el d'émail achèvent d'orner la forme.

Notre regretté président, dans son zèle à examiner les curres qu'il avait à juger, a omis de montrer à son jury sa propre exposition. Il est vrai qu'il était hors concours.

Nous devons à ses fils, ses dignes collaborateurs d'hier, ses continuateurs aujourd'lui, une louange sincère, pour le goût et la recherche dont témoignaient leurs ouvrages. Il faut citer jarmi les plus importants : l'ostensoir monumental de Brebières (Somme), dont M. Duthoit a fait le dessin et dont M. Delaplanche a modelé la figure : la Vierge enx brelis; c'est une pièce de grande dimension el d'un effet décoratif très marçué.

T'out autre est l'ostensoir dont M. Corroyer a composé la forme et dont les ligunes s'arrangent ingénieusement avec un profil très accusé. Il y a de bonnes copies des types classiques, conme le calice de Saint-Remy à Reims, le calice du trésor d'Oignies et le joli calice du $x v^{\mathrm{e}}$ siècele que garde le trésor d'lix-la-Chapelle.

Quelques pièces sont précieuses par la matière autant que par te travail : telle la mignonne chapelle d'or, enrichie de diamants, commandée par une dame piense. A louer aussi les plaquettes de bronze ciselé el les beaux émaux à la façon timousine qui rendent aux imagres saintes un caractère plus digne, d'art et de grandeur. Entre tous ces émaux, le plus remarquable était peint par II. Grandhomme, d'après un tableau de Crivelli. Nous aurons occasion d'y revenir en parlant des émaux peints de Grandhomme et de son ani Garnier.

L'émail et la ciselure, cependant, ne tiennent pas dans la fabrication de MM. Poussielgue-Rusand la place privitégicée à laquelle ils ont droit. Ceci n'est pas une critique, mais une simple remarque. Nous savons que les œuvres de ces orfêvres sont d'un grand effet décoratif; qu'clles ont besoin d'ètre ¿ l'échelle de la cathédrale; que placées sur l'autel, loin des fidèles, qui ne les voieut qu'ì travers la perspective du chour, elles exigent un gros effet comme les décors de théátre. Si la compraraison est irrévérencieuse, elle est assez juste pour la rendre excusabie.

Mais, tout en gardant ces effets puissants, je conseille à MIM. Poussielguc-Rusand d'étudier mieux les ressources de l'émail el de moins obéir aux sollicitations de l'architecte. Qu'ils se souviemment qu'ils sont orfêvres et fils d'orfêvre, et, remontant aux exemples anciens, pour les mieux pénétrer, qu'ils prennent à l'émail l'intensité de ses couleurs, pour s'en servir avec la puissance que le peintreverrier mettait en ses vitraux. Que la ciselure devienne non plus la traduction amollie d'une sculpture hanale, mais un accent personnel, souple, gras, vivant, accusant micux l'individualité de l'artiste et rendant au métal des qualités d'orfèvrerie lì où il n'a souvent que l'éclat dur et criard d'un cuivre doré. Les nielles sont un moyen simple et joli de produire avec les ors de grands effets.

Si l'imitation servile des modèles anciens ne doit pas être conseillée, il y a pour l'orfêrrerie religieuse une inspiration directe à tirer des reliques que nous gardent les trésors des églises et les musćes. 
MVI. Georges et Vaurice Poussiegue sont assez jeunes, assez ćpris du beau, pour s’adonner à l'álude. Pour peu cuilits fassent à l'exemple de leur père el qui'ils poussent droit devant eux, ils sont assurés d'aller loin et de voir grandir encore le nom respecté de l'liomme qu'ils pleurent et que nous reggretlons.

\section{GRAND PRIX.}

\section{Anuatio-Chabiat $(T h .-J o s e p h)$, ì Lyon.}

Celui-ci est grand artiste, un orfèvre épris de son arl, un passionnó qui n’a pas les aptitudes commerciales et adıninistratives du précédent : il a sacrifié souvent le prodnit d'une affaire à la joie de produire un chef-d'œuvre, mais il polit son ouvrage comme le poète cisèle sa rine. Il est orfèvre religrieux aussi, mais à sa gouise; il fnit, au lieu de la chercher, la collahoration de l'arehitecte. Pierre Bossan a été son maitre et son ami, mais depuis qu'il est mort, Armand-Calliat n’a pas voulu de collaboration nourelle. Il est jaloux de son œurre, il en reut être le maître. Orfèvre, oui, mais orfèrre inspiré, qui conte et écrit sa pensée dans le mélal, la grave et l'émaille. Il pourrail anssi meuhler une cathédrale, couler en bronze des châsses golhiques, ciseler des retables et pousser vers la voûte lís elochetons découpés d'un tabernacle. Il faudrait pour cela consentir à pasticher un art qu'il adninire, mais qu'il ne veut pas reprendre; il accepte l'archéologic comme une science, mais non pas comme une formule à copier. Il est indépendant, lihre, osé; il vit à Lyon, bien loin de l'École des beaux-irlts et de l'fustitut; il est dans sa honne ville le premier, le seul orlèvre, et déjì grand nombre d'évèques sc premnent ì aimer eet liomme nouveau qui fait prier l'argent et l'or autrement que les orfèrres de Paris.

J'arais commencé à le connaître et à l'aimer en 1878 ; il avait eu lì un beau succès près du public. mais il ne l'arait pas emporté aussi entier qu'il l'aurait fallu sur l'esprit du jury. Pourquoi ? Le temps u'étail pas renu; il en est des choses fabriquées comme des livres el des drames, on ne les acceplait pas hier, aujourd'lui, l'esprit s'ouvre, la lnmière so fail, on comprend ce qu'on n'entendait pas, on admire ce qu'on ne voulait pas voir. Le jury, cette fois, a voté d'enthousiasme, à l'unanimité, le gorand prix is II. Armand-Calliat.

Je scrais fort embarrassé pour rendre compte de l'exposition d'Armand-Calliat, s'il ne s'en était chargé lui-même. Je suppose que les orfèrres ont gardé la notice qu'il leur a offerte et dans lanquelle il a décrit ses curres.

11 avait fait ainsi déjì en 1878 , et dans l'entretemp̨s, il a publié le diseours de réception quil il avait prononcé le 19 juin 1888 , devant l'Aeadémie des sciences, des lettres et des arts de Lyon. Cie discours est un remarquable plaidoyer pro domo sua, une apologic de l'orfèrrerie, à laquelle nons pourrions emprunter des pages entières pour enrichir notre rapport.

11. Armant-Calliat est donc plus qu'un orfèvre, c'est un artiste délicat, un homme de lettres qui sait ce qu'il veut et qui fait de la bonne déecntralisation.

Ses ouvres sont absolument belles; ce n’est plus le décor fait pour les yeux d'une foule éloignnée et qui pique d'une note d'or la maje té de l'autel; ses vases, ses croix, ses ornements sont achevés pour le regard du prêtre qui les tient, les roit, y lit avec des yeux de inyope et n'y trouve pas une fante, pas une imperfection. Eilles sont dignes du trésor le plus exigeant, elles sont parfois trop parfaites.

Quel en est le style? Je ne sais. Pour qui a vu Lyon, l'œulve de Pierre Bossan, Notre-Dame-deFourvières, la filiation s'étahlit et l'ou sent que l'orfèvre procède de l'architecte, mais en le continuant, en l'expliquant, en pénétrant dems une minutie de détails, de conleur's, de modelés, (fne l'or, l'émail et lis ciselure rendent mienx que la pierre. Ciest d'un prítisne ralfiné, qui ne nanque pas de girandeur, 
qui a beaucoup de nohlesse, mais qui lasserait cependant si parfois Armand-Calliat n'était ranené aus formes consacrées.

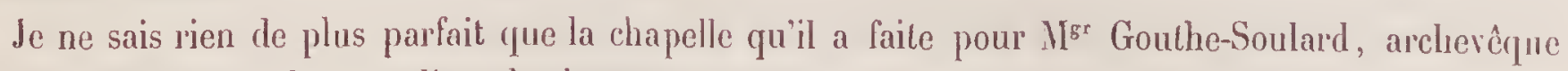
d'Aix; elle comprend : un calice, des burettes, lenr plateau, les saints-chrêmes, un plat, un bougeoir et la crosse; la croix et l'anneau complètent cel ensemble.

Comment, dans la crosse, l'artiste a su placer Notre-Dame-de-Fourvières, saint François-Xavier, saint Irénée et saint Vincent-de-Paul, les loger en des arceaux et faire jaillir du bâton pastoral une volıte puissante où s'accrochent des lions, des dauphins el qui s'épanonil comme une flenr pour présenter en son calice la délivrance de saint Pierre? Les orfèvres chrétiens d'autrefois excellaient à marir r sans confusion les ornements, les animaux symboliques, les figures saintes, mais jamais encore je u'avais vı un maitre moderne refaire ce quils avaient fait, le faire aussi bien, nuais le faire autrement. C'est la franchise du procédé qu'il faut louer. C'est avec des énaux de niellıre que l'orfèvre a dessinć son ornementation; il s'est souvenu du moine Hugo sans le copier el, sur une forme simple, il a peint en noir, en argent el en or, un adorable thème.

Je louerai fort le reliquaire de Saint-B rnard de Menthon, si ce n'était une restitution archéologique. M. Arınand-Calliat n'a dî se prèter à ce caprice que pour montrer combien le problème lui étail facile i résoudre; le revers de la plargue est charmant.

Ge que jaime moins, et encore dirai-je ainsi par le besoin naturel qu'on a de critiquer, ce que jaime le moins, c'est J'ostensoir de la Compagnie de Jésus, cette tige qui, à la manière d'un arbre de Jessé, sort de la grotte de Maurc̀ze el porte au-dessus te saint Ignace et de la Vierge les figures des martyrs du Brésil el du Japon; cette tige a des rondeur's lourles, son dessin s'accommode mal des sujets qu'elle soutient, elle a des pâleurs d'or et des fadeurs d'émail qui me déplaisent, et cependant je ne sais pas, si j’avais à composer une pièce aussi difficile, si je m’en tirerais autant à mon lionneur.

Nous sommes ainsi faits, nous voulons du nouveau, nous dentandoas de l'aulace, nous exigeons qu'on tronve el volontiers, à chaque essai, nous relournerions en arrière pour admirer les types consacrés d'autrefois. lls ont encore osé davantage, les deux amis, Armand-Galliat et Lameire, quand ensemble ils ont exécuté le ciborium qu'ils ont offert à Sa Sainteté Léon XIIl pour son jubilé en 1888.

L'orfêvre lyonnais avail gardé le souvenir du Catholicon dont le peintre avait exposé les cartons en ${ }_{1867}$, lesquels ont reparu depuis à l'Union centrale des arts décoratifs.

Dans la penséc du peintre, le ciboriun était immense : debout sur quatre colonnes de marbre, quatre anges aux ailes déployées, constellées d'énaux el de genmes, auraient tenu un voile qui, gonflé comme une coupole azurée, aurail abrité l'autel et le Saint des Saints.

Celle composition, grande, sobre et cejendant riche comme une orfèrerie de Byzance, comme une mosiïrue de Ravenne, cette composition a été ramenée par Armand-Callial aux proportions d'un tabernacle, ou d'une monstrance; il y a employé les matières les plus rares, il a joué de l'or et de l'argent, du jaspe et du cristal, de l'ivoire, du lapis, des émanx aux lons de turquoise. C'est une coloration fine dont la puissance démontre qu'on peut peindre avec la pierre et le métal comme avec le pinceau. Mais là encore, l'effort était trop vivant, le Saint-Père n’a peut-être pas compris la grande idée des artistes français, et il a fail don du ciborium ì la basilique de Montmartre. Tant mieux, je me réjouis de voir à Paris ce chef-d'œuvre d'un maître.

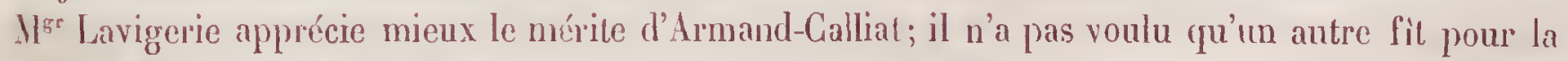
callıédrale de Garthage le reliquaire où repose le cour de saint Louis.

Quand le saint roi mourut sous les mur's de Tunis, son frère Charles d'Anjou rapporta ses restes en France, mais il obtint de garder son cour et ses entrailles et quand il rentra dans son royaume des Deux-Siciles, il confia ces précieuses reliques à l'abbaye de Monréal.

Elles y restèrent jusqu'en 1860 et François II, chassé de Naples, emporta ces restes précieux; il les offril depuis a Son liminence le cardinal Lavigerie. 
Le comte R. de Buisseret a pris l'initiative d'une souscription nationale pour reconstruire à Carthage le sancluaire de saimt Louis et sur celte lerre devenue française va reposer le cocur du roi franrais qui l'avait conquise il y a six cents ans el y était mort saintement.

11. Armand-Calliat a été bien inspiré, il a pris à la Sainte-Chapelle sa forme absolunent exacte; le reliquaire où reposera le cour du saint roi, c'est ce bijou d'orfèvrerie que fit Pierre de Montereau; il est d'or et d'émail, il s'élève vers le ciel comme une apparition; deux anges agenouillés te portent sur leur's bras tendus, ils sont beaux comme des femmes, nobles conme des preux, forts comme des hér'os, ces angoges aux grandes ailes qui portent l'armure des croisés, qui ont le sceptre et la couronne d'épines.

Le socle qui soutient ce groupe est lui-même une ocurre excellente, la gravure a déjà propagé la forme de ce reliquaire: la silhouette élégante en est restée dans les yeux des artistes.

Il y a bien d'autres pièces qu'il faudrait décrire : la couronne et l'ostensoir, et les ornements d'autel de la basilique du Sacré-Cœur de Berchem-les-Anvers, on l'influence des idées de M. Lameire est sensible; l'ostensoir de Saint-François de Sales, pour l'église de Lyon. C'est en exécution d'un legs de II"we Trinolet que ce magnifique ouvrage fut dessiné par Bossan et exécuté par trmand-Calliat; en même lemps, M Me Trimolet dépossédait le nusée de Lyon de la précieuse collection qu’elle lui avait destinée et en disposait pour le musée de Dijon.

I a cliapelle de M ${ }^{\text {gr }}$ Theurel, évêque de Monaco; le calice de Sainte-Clotilde, le calice de la Compagnie de Jésus; le relicquaire de Sainte-Roseline; la clâsse de Sainte-Madelẹine; les coffrets de l'Alliance catholique, etc., exigeraient des descriptions que nous ne pouvons faire ici.

Ce qui ressort de celte exposition, c’est une souplesse d'invention, une facilité à traduire la pensée chréticune, une ingéniosité à modifier les thèmes vieillis, une audace à tout oser comme forme et comine couleur.

II. Armand-Calliat est done un novateur en orfèvrerie, il approche plus qu'aucrun autre de ce style nouveau qu'on réclame et qu'on aurait hésité cependant à chercher dans l'église. Nous n'osons pas néanmoins proposer M. Armand-Calliat comme modèle anx autres orfèrres; là où il réussit d'autres échoueraient; ses ouvres sont trop personnelles, elles ne sauraient ètre innitées. Peut-être oserons-110us pour la seconde fois lui domner un conseil, celui d'user de l'émail avec plus de hardiesse; de moins cmployer les émaux opaques anx tons clairs; de se servir des couleurs transparentes et liches, des rouges rubis, des bleus saphirs, des verts d'émeraudes, des gris, des bruns et de loute la paletle qu'avaicnt les orfêrres émailleurs du $x i v^{e}$ et du $x y^{e}$ siècle, à Paris comme à Florence. C'est une harmonie nouvelle dont les effets l'ćlonneront d'abord, il s'y accoutumera vite et y trouvera des satisfactions promptes, des régals d'artiste. Je voudrais un jour tenter mon ani M. Armand-Calliat, l'arracher à ses rèves mystiques et lui proposer un poème tout paien, j’imagine qu'il ferait un chefd'œurre si, au lieu d'une légende chréticnue, il avait à broder, sur un vase de forme plus ample, quelgur falle païenne arec de belles nymphes, des figures plus libres d'allures; un débordement de verve et d'audace. Pourquoi pas? Les orfèvres d'autrefois ne se cantomaient pas dans le genre sacré. Certains mariaient même un peu librenent le Ciel et l'Olymple.

II. Srmand-Calliat a un fils qui est déjà son meilleur élève et dont l'ardeur' se tralit par les yeux. Ce que le père n'oserait pas, le fils le fera, j'espère; il a été nourri à celte belle école lyonnaise dont nous parlerons plus toin. Lavenir est plein de promesse. Le jury n'a pas pu citer tons les collaborateurs pour qui M. Armand-Galliat demandait des récompenses; il a donné une médaille d'or à M. VIxDry, sculpteur d'un grand goût; des médailles d'argent à deux ciseleurs, MM. Bovilner et Shax, ainsi qu'à M. Chanbsed, dessinateur; des médailles de bronze à II. Dufètre, son contremaitre

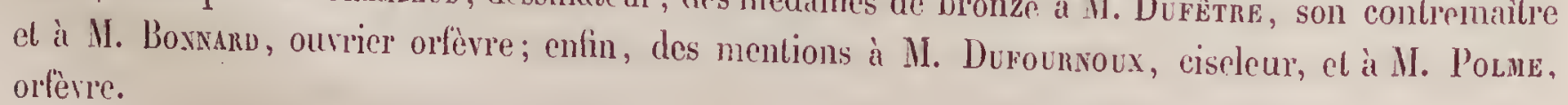




\section{MÉDAILLES D'ARGENT.}

MM. Troullien frères, ì Paris.

Le plein jour des expositions a pour l'industriel autant que pour l'artiste des surprises étranges; il amène des chances diverses et des mécomptes qu'on ne peut prévoir. Nos peintres se disputent la cimaise au Salon, nos seulpteurs savent de quelle inrportance est la lumière en tel point du jardin, car l'œuvre transportée à l'Exposition ne ressemble plus à l'œuvre vue à l'atclier. Ce sont là des vérités bim connues des artistes, ils les vérifient tous les ans; mais le terrain des Expositions universelles est moins fréquenté, il est plein d'embûches et quelques-uns y tombent : MM. Trioullier ont été victimes de ce jeu du hasard.

Une autre cause leur a nui considérablement, c'est le partage d'une exposition entre deux jurys d'examen. Nous avons eu l'occasion d'expliquer déjà, en parlant de MIY. Poussielgue-liusand, comment les grands travaux de bronze avaient été rangés dans la classe 25 et examinés par le jury de celte classe. Mais si MM. Ponssielgue étant hors concours ne pouvaient pas en souffrir, il n'en allait pas de même pour MM. Trioullier frères : eux aussi exposaient des autels de bronze doré et leur apport scindé entre deux jurys perdait immédiatement pour chacun de son importance. Cette division est très préjudiciable à l'exposiut, elle établit, quoi qu'on fasse, une inégalité dans le concours, et je dois en toute justice essayer de rétablir ici un équilibre nécessaire; non pas que je veuille infirmer le juggement du jury, mais je dois mettre en valeur tous les efforts de l'exposant.

Les Trioullier ont une des plus vieilles maisons d'orfêvrerie de France, ils ont succédé ì leur père et déjà nous avons cité leur nom en parlant des lixpositions de 1867 , de 1862 , de 1855 , de 1849 et de 1844; mais leur atclier porte une date plus ancionne; Bertrand, Parand, Parisey, Jacob, s'y sont succédé et l'origine en remonte à la fin du xvie siècle. lls sont cux-mèmes gens du métier, ils ont manié la lime et le martean, ils ont dessiné à l'école de M. Belloc : ce sont bien, dans l'acception la plus exacte du mot, des orfêrres parisiens.

Certainement, ils n'out pas encore l'nniversefle r'enomnée de l'oussiclgue-Rusand, ni la précieuse recherche d'Armand-Calliat; la lutte engagée l'an dernier entre ces deux champions de l'orfèvrerie religieuse détournait l'attention de concours plus modestes, ct, cependant, voyons ce qu'ont fint les Trioullier.

Tontes leur's œuvres ne sont pas là, on ne transporte pas un jubé comme un calice, et les vastes trâtaux de ces orfêvres tienuent à l'édifice, ils sont scellés à la picrre.

La jolie église de Saint-Pierre de Montrouge doit tout son nobilier de lronze à la maison Trioullier. 11. Vaudremer en a fait les dessins, en même temps qu'il achevait cerux de l'édifice.

Les appareils de lımière de Saint-Eustaclı sont aussi composés par le mème éminent architecte et exécutés par Trioullier, et c'est de leur collaboration qu'est sortie l'ornementation de métal de l'égylise Notre-I)ante d'Autenil.

$\mathrm{Si}$, de ces églises, on passait à des chapelles plus réduites où l'orfève se complait, où l'architecte se dépense en des travanx plus fins, on devrait citer l'autel et les pièces da la chappelle que le comte de Chambrun s'est fait construire en sa maison de la rue de Monsieur.

Peut-être conviendrait-il, pour juger un artiste, que le jury se transportât devant les œuvres qu'on ne peut pas lui apporter. - Nahomet se dérangeait bien pour aller ì la montagne qui ne pouvait venir à lui. - MII. Trioullier n'ont songé que tardivement à révéler au jury celte part considérable de leur travail; ils auraicut di ajonter qu'ils ne sont pat senlement les orfèvres de l'église, mais qu'ils ont fait à l'Hôtel de Ville de Paris des travaux importants et que, là où hésitaient de 
grands entrepreneurs, là où serruriers el bronziers ne savaient plus interpréter les dessins trop fins de l'architecte, ils sont venus, enx orfèvres, et s'en sont lirés à lat satisfaction des maîtres. MM. Ballı, Depertlies el Formigé en ont témoigné, el M. Sédille leur a demandé pour les magasins du Printemps les parties les plus délicates de son ornementation, comme a fail M. Lisch, pour l'hôtel Terminus.

Cependant, les Trioullier s'atlacient plus volontiers à l'orfêrrerie religiense et, s'il fallait compléter la liste de leurs ouvres, il conviendrait de citer d'abord le mailtre-autel en bronze doré el émaillé de la basilique de Saint-Quentin el le jubé de la même église, qui a 18 mètres de haut et porte, en son ormementation de métal, des stalues de grandes dimensions:

M. Boeswilwald, inspecteur des monuments historiques, a approuvé cel important ouvrage.

Les curicux d'orfevrerie et les confrères en art se souviennent certainement d'avoir vu, au Musée des arts décoratifs, l'iconostase, la porte et les pièces du mobilier que venaient de terminer MMI. Trioullier, pour la célèbre église de Curtea de Arges (Roumanic). Celte brillante décoration d'or et d'émail conçue dans un style oriental, voisin de l'arabe, faisait honneur à l'architecte, M. Leconte du Nouy, mais elle montrait la souplesse d'exécution de l'orfêvire.

A Lille, à Clermont-Ferrand, à Saint-Benoist-sur-Loire, nous pounrions indiqner d'autres œuvres. Mais nous en avions deux à l'Exposition, qui ont eu successivement la visite attentive des jurys de la classe 24 et de la classe 25 .

C'élait d'abord le grand autel destiné à la cathédrale de Rouen; Poussielgue avait fait celui de Saint-Ouen : tous les deux étaient dus au crayon fertile et savant du même architecte, M. Sanvageol.

Nous sommes trop loin maintenant, pour comparer ces œuvres entre eltes, nos notes sont un peu confuses et encore les lirions-nous mieux, que nous liésiterions à les traduire, car nous n'avons pas mission de juger les œuvres de l'archilecte. Mais nous pouvons rappeler que le maîlre-antel de Notre-Dame de Rouen n'est pas, comme celui de Saint-Onen, fait uniquement de bronze doré; le marbre blane s'y marie aux ors dans une proportion presque égale. L'aspect neuf, éclatant, de ces tons clairs et brillants, pouvait séduice quelques-uns; il n'était pas pour plaire à cenx qui ventent aux choses du culte une majesté plus calme. Placé an centre de la nef, au milieu des échantillons les plus liétéroclites de l'industrie, inondé de lumière, papillotant sous les raies du soleil, perdu, presque compromis dans une colue profane, le maittre-autel subissait un réel désavantage. Je m’altends à une impression loute autre, quand je le reverrai dans quelques années, dans la sombre cathédrale, arec ses ors ternis, son marbre jauni, baigné d'une ombre gorise el, cependant, découpant sa sillouette sous la voûte, s'enlevant sur les profondeurs de la chapelle de la Vierge.

II faut juger des choses en place, ainsi ont dù penser l'archilecte, l'évèque et l'orfèvre. On pardonnera au rapporteur de l'écrire el de revenir ainsi sur les impressions quavait pu avoir le juré.

J'en pourrai dire autant de l'autel de style roman, destiné à l'église de Merville (Nord). IIN. Trioultier l'ont composé avec l'architecte, M. Cordonnier, et leur collaboration se trahit par des qualités bien propleses à l'orfêrre. C'est bien une construction de métal, on ne ferait pas en pierre ces pilastres ajourés, ces chapiteaux aux ornements rapportés, cetle grille puissante, étrange, nourelle, dont les entrelacs de cuivre sont constellés de cabochons de verre. On y a trouvé des défauts et, moimêne, je regretle que certaines économies aient pu nuire ì quelques parties de l'œuvre, mais elle n'en est pas moins une tentative hardie qui est bien d'un orfêre et que de bons ouvrier's seuls poutvaient mener ì bien.

Plus mal placé encore que le maître-autel de Rouen, accolé contre un mur', écrasé entre deux rideaux de peluche, summonté d'une ferme de tôle, peinte en bleu, avec des boiseries d'un rouge vermillon et de grandes cordelières tombantes, cet autel a souffert de sa mauvaise exposition.

Près de là était la clâsse destinée à renfermer les reliques de saint Benoist et dont M. Lisch a dir'gé l'exécution. Les châsses étaient pour nos anciens orfèvres l'œuvre de prédilection; il n'y a pas de 
thème meilleur pour développer les ressources d'un art où conconrent la sculpture, la ciselure, la fonte, le repoussé, la gravure, les nielles, l'émail el la dormre.

Si la foi dans les reliqgues des saints se réveillait en France, nos ateliers d'orfèvres y tronveraient avantage, et c'est pourqnoi ils approuvent cerlainement l'église quand elle défend d'inciućrer les corps; que resterait-il des saints et des martyrs?

MII. Trinullier ont dans celte châsse fait œuvre d'orfères, mais c'est dans quelques pièces de moindre dimension qu'ils ont montré toute leur expérience dn mélier.

J'ai déjà autre part loné comme il fallait un bien joli calice d'or, dont la forme est copiée sur celu de Saint-Remy, mais dont l'ornementation de filigrnne, d'émail et de diamants en tables est empruntée à des läjoux.

Un autre calice d'or montre des délicatesses de ciselure qui ont fait l'admiration du jury; tandis qu'à côté, un calice d'argent, vigourensement repoussé en bosse, démontrail que les qualités d'énergio ne s'étaient pas perdues à l'atelier.

Il faudrail ciler encore l'ostensoir de la Délivrande, les conronues d'or, la Vierge à l'enfant, groupe d'argent coquillé, au marlean, d'après nne statue du xIV siècle qui a été retrouvée, dans l'église SaintGervais.

Je fais mes réserves sur ce dernier travail, quelle que soit l'habileté de l'ouvrier, mais il ne faut pas copier en métal les cuvres composées pour le marbre et la pierre.

J'aime mieux me rappeler la coupe élégante que $M^{\text {gr }}$ Thomas avait commandée aux Trioulliel' pour' le jubilé du Saint Père; elle étail destinée à contenir en un monceau d'or les offrandes du diocèse; on u'offre pas de façon plus galante, avec plus d'art, de gônt el d'esprit, un plus rnval présent. Le Saint Père a gardé la coupe, elle ne nous revient pas comme le cilorium d'Armand-Calliat, et nous n'avons vu à l'Exposition que la maquetle de l'œuvre. Mur. Trioullier ont la joie de savoir leur œuvre logéé au Vatican.

M. Gurenc, le jenne el intelligent dessinateur qui prête le concours de ses pinceaux à MV. Trioullier. n'a obtenu qu'me médaille de bronze; de mème N. Fauves, leur contremaitre; les collaborateurs partagent la bonne et la mauvaise fortune de leurs patrons. M. Kocsus, planeur habile, a reçu une mention honorable.

\section{Brunet (Paul), à Paris.}

L'fglise n'est pas riche, beaucoup de paroisses n'ont pour les frais dn culte qu'un budget insuffisant el l'autel ne peut avoir pour parure tout ce que l'imagination des fidèles rêve d'ornements, d'orfèvrerie el de luxe. De là, certaines nbligations commerciales qui s'imposent à l'orfèvre. A côté des somplueux autels que nous avons vus, des calices d'or et des ostensoirs constellés de pierres, il y a toute une fabrication courante qui alimente des ateliers nombreux.

Le duc de Luynes prétendait en 1851 que les orfêvres d'église étaient les plus habiles à la fabrication économique et courante.

M. Brunet était seul à représenter cette branche importante de l'orfèvrerie parisienne; il a eu la franchise d'exposer quelques-uns des types de son atelier, mais il a voulu aussi montrer quil élait capable de mieux faire.

C'est pourquoi, à ses risques et périls, sans commande, sans collaboration d'architecte, sans aide d'aucune sorte, il a composé, exécuté et exposé lui aussi un autcl. Ce n'est pas le maître-autel d'une cathédrale, c'est l'autel plus modeste d'une chapelle ou de quelque grand oratoire princier. Il est de style composite, d'une renaissance moderne, un peu fantaisiste, comme il convient pour la chapelle d'un château, chez des gens du monde qui veulent une religion aimable, accommodante, avec un luxe 
de bon aloi, ım prètre bien élevé et tolérant. Tout cela se voit dans la combinaison chaude, harmoniruse et coquelte des marhres, dans l'or des bronzes ciselés; la nappe d'autel, le costume de l'offlciant, les toilettes des femmes, tout cela ferait à ce joli antel sans style, mais d'un convenu très fin de siècle, un délicieux accompagrnement.

Ceci n'est pas une crilique, l'orfèvre est un homme d'esprit qui sait être de son temps et qui vit de l'autel an moins autant que le prêtre. 11 peut livrer ce joli morceau de marbre et de bronze pour 25,000 on 30,000 francs, $y$ compris les deux candélabres qui l'encadrent si élégamment, le tout rendu et posé.

Il trouvera, j'en suis persuadé, beancoup d'âmes pienses et de dévotes enrichies qui admireront son œuvre; quelçu'une l'achètera et s'cn fera mu marchepied pour monter an cicl, après avoir pendant de longues années récité son rosaire sur ses trois marches de marbre rose.

M. Brunet est un orfèvre labile, aucun ne ferait mieux les pièces de chapelle en argent doré qu'il a dessinées tui-même el qu'il nous a montrées avec une bien juste satisfaction. Là encore, pas de prétention au style, ancune recherche archéologique, pas de figures ni de difficile problème, mais une façon correcte, des formes pures, un ajusté impeccable, de jolis émaux, des inscriptions en lettres onciales courant sur des fonds de nielles et des lapis incrustés. Je u'ai que des louanges pour cette orfèvrerie sans prétentions, d'un goût demi-mondain, qui s'accomńode à l'esprit du temps et ne vise pas plus au ogrand art qrielle n'oblige à de grosses dépenses. Je ne crois pas utile de décrire les filigranes d'or mat qui font unc dentelle fine sur les fonds brunis des fausses coupes, ni les émaux peints comme des miniatures au côté des calices, ni les gravures descendues à l'eau-forte, ni les émanx opaques imitant les décors de Byzance et de Limoges.

C'est la fabrication régulière, continuelle de M. Brunet; on la retrouvera dans son magasin comme ¿ l'Exposition et, il fant bien le dire, ces vases ainsi décorés sont encore les plus commodes, les plus harmonieux d'effet dans les mains du prêtre.

M. Brunet a obtenu deux médailles de bronze pour ses collaborateur's : M. Marchand, dessinateur, et M. Bidault, contremaître.

Beaucoup d'autres orfèvres français travaillant pour l'église auraient pu figurer ì l'Exposition; s'il en est un dont nous regrettons l'absence, c'est M. Chertier qui $y$ aurait tenu un rang particulièrement honorable.

Nous avons examiné l'orfèvrerie religieuse, nous allons aborder l'orfèvrerie civile, mais, avant de continuer notre visite aux exposants français, nous croyons utile d'expliquer la méthode que nous allons suivre pour cet examen; le désordre pittoresque où s'étalaient tes produits de l'orfèvrerie avait un charme amusant pour les yeux, mais it aurait de graves inconvénients pour la clarté d'un rapport.

Nous séparerons l'orfévrerie d'argent de l'orfevererie d'imitation, les ustensiles de table et de toilette des objets d'art et de décoration. Nous croyons que ces divisions suffisent, elles sont très simples, mais elles nous obligent cependant à revenir plusieurs fois aux mèmes exposants. 


\section{ARGENTERIE.}

\section{ORFEVRERIE DE TABLE ET DF TOILETTE.}

Cie titre générique est bien français, le mot argenterie exprime mieux que les mots grosserie, petite grosserie, ce que nous voulons désigner. Nous y trouvons réuni tout ce qui touche au service de la table, ì la fabrication des couverts, à la vaisselle plate el ì la vaisselle montée, à la garniture, aux articles de bureau, aux nécessaires de voyage, pourvu que ces objets soient d'argent.

L'argenterie est un luxe et c'est une économie tout à la fois; elle constituait antrefois, avec l'orfèvrerie d'or et les joyaux, l'épargne et le trésor' il n'est pas besoin de remonter très loin pour en trouver des exemples et dans chaque famille l'argenterie représente encore une part de l'avoir, une réserve que n’atteint aucune crise; si l'homme riche fait consister cette réserve en nne vaisselle pesante, l'ouvrier la résume en quelques couverts d'argent; pour l'un et pour l'autre, c'est une suprême ressonrce qu'on peut monnayer s'il est besoin.

Cielte épargne a considérablement angmenté en France, elle s'accroît par une progression rapide. Or nous avons vu au début du siècle la France n'avoir plus un orfevve; elle n'apportait pas un couvert d'argent à l'Exposition de l'an vi; et maintenant l'Exposition du centenaire jette dans la balance 100,000 kilogrammes d'argent. Jamais encore, à Londres. à Philadelphie ou à Vienne, on n'avait vu déployer une telle abondance de vaisselle. La mode s'en est mêlée; la société s'est éprise du luxe de la table, il n'est pas une maison élégante où n'ait pénétré cette recherche; elle ne consiste plus seulement dans le choix des couverts, dans le poids des plats d'argent; elle s'attache au modèle des flambeaux, aux ciselures du surtout, au dessin de la corbeille à fleurs, à de menus objets qui amusent le regard et qui mettent un raflinement de coquetterie au repas. Tel le thé du ef five o'clock», telles aussi les sarantes dissertations sur l'orfèvrerie ancienne. Car la mode s'est compliquée d'une prétention à savoir distinguer la marque des vieux maîtres, et celui qui ne peut payer 20,000 francs un sancier de Germain prétend en commander une copie exacte à son orfère.

En sorte que, par un retour bizarre de la mode, cette Exposition de 1889 , qui marque pour nons, orfèvres, le centenaire d'une ruine complète, nous ramène au point où nous en étions quand éclata la Révolution et même en deçà, car le dernier mot du goût, en orfèvrerie, c'est le Louis XV. Nous en sommes revenus à la première moitié du xviri siècle, nous l'allons bien voir. 


\section{HORS COYCOURS.}

\section{Oniot (G.-Gustave-E.), ì Paris.}

Voilà bien te nom qu'il fant inscrire le premier, il a droit de présider à la fète; c'est son centenaire à lui qu'on célèbre. Ce nom tient glorieusement à l'histoire de l'orfèvrerie do xiš sièce, il apjarait à toules les expositions depuis l'an $x$, et toujours noblement porté, avec cette auríole de gentillonmmerie et d'héroïsme qui rayonne sur la corporation entière.

La maison de Mre veuve Odiot était comnue depmis longtemps déjà comme une des plus importantes de Paris. ponr le commerce de la hijouterie el de la joaillerie, lorsepue Claude Odiot, son fils, s'élablit orfère fabricant ${ }^{(1)}$. Il rivalisa bientôt avec Auguste, l'ancien orfèrre de Louis XVI ct quiand Augrnste fut obligé de quitter les affaires, il racheta ses modieles, en sorte que la maison Odiot tient par une double racine anx atcliers d'orfèvrerie et de joaillerie du siècle dernicr.

Coct Odiot-là, qui fit arec Thomire, sur les dessius de Prudlion, le berceau du roi de Rome, est le même cqui défendit Paris à côté du général Moncey, contre les alliés et qu'Horace Veruet a peint dans un tahlean célèbre. Il était te grand-père d'Ernest Odiot, qui est mort récenment, el de M. Guslave Odiot, son frère, notre collègue du jury; en sorte que colui-ci, denienre le senl survivant d'une dynastie d'argentiers. Ce mot d'rargentier ^ convient an chef de celte grande maison : il est de bon aloi, il pèse, il sonne, il est lıonnête, il peint la richesse, il est d'un bancquier, d'un surintendant, d'un lıomme chez qui la fortune a éln domicile; pas une grande famille de France qui n'ait en sa vaisselle marquée do poinçon des Odiot. Ce nom allait de pair avec celui des Bapst, joailliers de la couronne.

Quelques-uns pourront s'étonner de ne pas trourer daus cette maison tous les efforts d'invention qu'on remarque chez de moins riches et de plus jeunes. Elle s'altarde en son passé, elle s'atlache volonliers à ses traditions, clle aime ses vieux modèles el c'est précisément ces vieux modèles que sa clinntèle ainte aussi.

Je ne fais pas d'allusion, en parlant des vieux modèles, à celui que Mine Léopold Goldschnuidı a vouln qu'on rétablit pour elle : c'est là un caprice de goût rétrospectif qui nous ramène aux choses rlu premier empire et qui ne me déplaît pas: il était bien de vonloir qn'mon Odiot refit ce beau surtout qu'un Odiot avait exéculé quatre-vingts ans plus tôt sur les dessins de Percier et Fontaine et qu'arait ciselé Thomyre. Ce n'étail pas la moins belle pièce de celle exposition.

Les vieux modèles dont je parle constituent nu capital considérable, non senlement chez l'orfêvre, mais dans toutes les grandes fabriques, à quelque industrie qu'elles appartiennent, et, pour que ce capital ne soit pas improductif, il faut qu'on s'efforce d'utiliser ces types de la veille. Les anciennes maisons n'ont donc pas l'indépendance des nouvelles, elles gardent une majestueuse lenteur à se unouvoir et, si elles résistent aux impatientes ardeurs de la mode, il ne faut pas s'en plaindre, qne deviendrions-nous sans leur sagesse? Elles servent à modérer la marche progressive d'une industrie: si nous n’avions pas ces résistances-là, les hronzes, l'orfèvrerie, les tissus et les meubles snivraient bientôt la pente dangereuse où glissent chaque année les métiers de la couture et de la mode pour qui le perpétuel changement est une loi, loi folle et excessive qui fait ressembler la vie d'une société à une incessante métamorphose.

Ce n'est pas d'aillenrs ce reproche-là qu'on faisait aux Odiot. Les rapporteur's des expositions les ont accusés de s'être fait en France les introducteurs du gon̂t anglais.

(1) Rapport du duc de Luynes (1851). 
Dejàt en 1834, le baron Ch. Dupin, écrivait : „C'est avec un sentiment de regret que nous voyons nos artistes s'humilier jusqu'à suivre, à copier une morle éplrémère et bizarre, pour adopter des formes anglaises pesantes, prétentieuses et sans grâce... L'orfèvrerie anglaise n'est, selon nous, qu'une alliance maladroile de la prodigalité d'ornements qu'affectail la Renaissance avec les tortillements du genre Louis XV. Au lieu d'accepter cette combinaison monstrueuse, si l'on veut à toute force initer, pour(quoi ne pas remonter aux types primilifs ${ }^{(1)}$ ? $\pi$.

M. Wolowski revenait à la clıarge en 1849 et le duc de Luynes, plus morléré dans sa critique, se contentait d'écrire après 1851 :

«A l'Exposition universelle de Londres M. Odiot partut avec l'éclat labituel de ses æeuves dans le genre anglais... Quand il l'a voulı, M. Odiot fils a fait des weuvres remarquables, au point de vue de l'art, dans la direction qu'il a suivie. Le riche outillage de ses ateliers, la direction raisonn'e de son iudustrie, les appareils quil emploíe, lui permettent de produire avec une grande perfection le genve d'orfèvrerie qu'il affectionne, Les Anglais, chez lesquels il s'est inspiré dès l'origine, comprennent mieux que nous la qualité de ses auvres; on ne peut lui contester le litre de très halile orfève, et l'importance de ses affaires passées ou présentes, en France el surtout à l'étranger, n'est assurément pas le résultat d'une mo:le capricieuse, mais celui de sa bonne et riclıe fabricalion ${ }^{(2)} \cdot r$

Si j'ai fait ces demx citations, c'est pour m'autoriser de deux maîtres illustres et pouvoir comme cux critiguer; c'est surtout pour constater que crtte crilicune porte ses fruits, quand elle est faile avec autorité, quand elle est recue avec l'intelligence et la bonne volonté qu'on tronve cliez les gens d'esprit. On cherclerait en vain maintenant dans la maison Odiot ce que nos anciens rapporteurs nommaient le genre anglais et nous allons y découvrir des ceuvres qui sont le retour le plus franc vers les sources françaises.

D'ailleurs est-ce bien te goût anglais que suivait Odiot? Son fils, qui sait micux que nous l'histoire de sa maison, nous pourrait dire que son père a hien plus emprunté aux Anglais leur outillage que leur's modèles et qu'il a rendu à l'industrie entière d'immenses services en introduisant dans nos ateliers des procédés et des perfectionnements qui nous étaient alor's inconnus. Il n'y a plus aucune différence entre les machines-outils (qu'on emploie dans les deux pays, mais de 1830 à 1850 nos voisins avaient acquis une avance considérable, et c'est hien plus à ces moyens mécaniques qu'à leurs dessins et ì leur hon goût que les Anglais devaient leur succès; l'économie qui en résultait était notable. Odiot est le premier rui ait introduit dans son atelier ces outils-là, il a fait une rérolution dans l'industrie et, s'il est un peu tard pour l'en remercier, il est juste de rendre au fils le tribut de reconnaissance qu'on n'a pas su rendre au père. Doit-on s'étonner qu'avec les machines, les tours, les nuatrices et lous les outils d’invention anglaise le goût et la façon des modèles aient pénétré anssi. C'était inévilable et ce n'est pas seulement dans les articles d'orfèvrerie que cet engouement cxagréré pour les choses d'outre-mel' s'est prodnit, il règne encore entiel pour d'autres produits de la mode et de l'industrie, urais les clioses dites anglaises qu'on trouve à Paris ne ressemblent pas à celles fu'on voil ì lındres, elles sont revues et corrigées, faites à notre esprit, traduiles, adoucies, francisées déjà. 11 en est de celle imporlation comme de celle de certaines fleurs et de certains fruits exotiques qui ont pris racine cliez nous ot que la culture a rendus belles ou délicieux an goût. Si on les va voir dans leur pays d'origine, si on les veut goûter sur leur propre sol, on fait la grimace, on ne les reconuait pas. Il y a beaucoup de morles dites anglaises qui sont nées à Paris el qu’on a baptisées

(1) Rapport du jury central sur les produits de l'industrie française exposés en 1834, par le haron Ch. Dupin. Paris, 1836, 3 vol. (Voir t. III, chap. xxiı, section II.)
(2) Rapport du .'тII jury. - Métaux précieux. Exposition de Londres, 1851, p. 62 et 63, par le duc de Luynes. 
de ce nom pour les faire adopter de gens à système qui ne les auraient pas trouvées bonnes avec un nom français.

Toute maison d'affaire obéit d'ailleurs aux exigences de sa clientèle; celle-ci a le droit de commander paree qu'elle paye. C'est un axiome commercial sans réplique. Si la maison Odiot a été sollicitée jadis par les préférences de son chef et par celles de ses nombreux clients, clle a gardé un nom bien français, elle a porté sa réputation dans tous les pays et jamais ses marques accolées au poinçon de l'État n'ont été confondues avec les marques étrangères. Le caractère spécial à la maison Odiot ne tient donc pas à une imitation anglaise, mais bien à l'immense choix de modèles qu'elle possède. Si c'est une for'ce, c'est parfois un embarras. Elle a son per'sonnel d'ouvrier's, d'artistes ct de collaborateurs, auxquels elle est fidèle, vétérans de l'atelicr, habitués à la tradition de longues années et plus disposés à critiquer le courant noureau quä̀ le suivre. Ces orfèvres-là travaillent autrement que les jeunes, mieux, dirons-nous, mais leur manière a une date el cette date se trahit par le dessin, par le ciselet, comme se trahit la date d'un tableau, d'un livre ou d'une comédie. Je sais bien qu'il y a dans la maison des éléments jeunes, aussi y sent-on la lutte entre deux principes et le résultat en est bon, témoin les admirables candélabres à six lumières qu'Odiot a faits pour' M. Gunshourg. C'est le modèle connu de Meissomier', mais interprété, exécuté comme si le vieux maítre était là pour conseiller l'ouvrier, pour toucher la cire el conduire l'outil. Ces candélabres restent dans notre souvenir un des meilleurs morceaux de l'Exposition, et ils sont anssi beaux que les orfèvreries anciennes, qu'on paye à des prix insensés; ils devraient servic d'exemple aux tenlatives nouvrlles d'orfèvres plus jeunes.

Le duc de la Trémoille a fait exécuter par M. Odiot denx autres candélabres Lonis XVI, à têtes do bélier, dont les éléments décoratifs sont empruntés à de petits plateaux du temps. Ils étaient à l'Exposition, le duc les avait prêtés à l'orfèvre et ce sont deux modèles en leur genre.

J'aime moins le grand surtont à figures adossées, mais il faut signaler un joli thé d'argent doré, de style persan, dont la forme élégaute est un charme pour les yeux. La façon en est irréproclıal)le et le prix très abordable. Voilà de la réaction contre les imitations anglaises; nous n'avons pas vu dans les adaptations qu'on fait, à Londres, des dessins de l'Inde et de la Perse, une chose si bien appropriée à nos besoins.

Il en faudrait dire autant d'une cafetière composée dans le gount de la renaissance; un perı trop) richıe peut-être, mais si réjouissante à voir, pour un bon ouvrier, à cause des difficultés vaineues, des adresses dn marteau, de la netteté des soudures, de la pureté des moulures et des attaches.

Nous bornons la l'examen de cette importante exposition; il faudrait plusieurs pages pour en fairn l'inventaire, Nous nous y arrêterons encore pour parler des ciselures de M. Diovìme. Il est le collaboratenr fidèle de la maison Odiot, comme M. Ríaros, le sculpteur, dont les aeuvres ont contribué à enriclir la vieille maison. Le jury a décerné à chacun de ces deux artistes une mérlaille d'or' et à M. TaLif , contremaîtıe, une mérlaille d'argent.

\section{GRANDS PRIX.}

\section{Cunistofle et Cie, à Paris.}

C'est dans l'nrfèvrerie d'imitation qu'on a coutume de trouver le nom de Christofle, il est même devenu dans toutes les langurs un mot d'usage, qui signifie rorlèvrerie argentéen. Nous y revien- 
drons avec toute l'attention qu'il mérite, quand nous en serons là; mais MII. Christofle et Cie ont droit par quelques-mns de leur produits ì figurer parmi les orfèvres, les argentiers et les maitres qui ont poinçon à la Monnaie.

Ils ont, comme beaucoup de leurs eonfrères, l'origine ancienne du métier : II. Paul Christofle et I. Henri Bouilhet sont le fils et le neveu de Charles Christofle, le fondateur de la maison, et echui-ci, avant de développer en France l'industrie électro-elimique, avait été bijoutier et joaillier. Nous arons signalé son nom à l'Exposition nationale de 1839 .

Quand on entrait dans la galerie des orfèvres, on trouvait au centre la magnificque exposition de Chrristofle; elle y occupait la place la plus considérable et altirnit l'attention par un vaste étalage de vaisselle el d'oljets décoratifs. Au milieu, en avant des autres pièces, était un meuble à double [ablette supportant un service à thé en argent repoussé : voilì le service du five o’clock dont nous parlions tout à l'heure; voilà le guéridon de salon où le samovar fume à l'heure des visites, antour duquel on eanse en grignonotant des gâteaux, et, pour que le tout soit au dernier goût du jour, la table, enmme la théière, comme les tasses, tout est de style Louis XV.

Louis XV aussi, le grand service de table, l'œuvre d'argent la plus complète et la plus importante qu’ait exposée Christofle. On pent énumérer les pièces qui le composent: une grrande soupière ovale dont le couvercle est surmonté d'un trophée eiselé de léğumes, des girandoles à six lumières. des réchauds, de jolies casseroles d'eutremets, des plạts, des sauciers, des seaux à gylace, des earafes à vin, la corbeille à pain, le saladier, l'huilier, des bouts-de-table, le moutardier, des assiettes à dessert en vermeil, et, enfin, les eouverts assortis à cette vaisselle plate et inontée.

Ce service représente une somme d'argent considérable, et e’est démontrer la vérité de ee que nous disions de la fortune moderne que d'avoir osé le faire, ear ce service n’a pas été commandé, il s'offre et il trouvera preneur : il y a tant de millionnaires aujourd'luui. Ce service ne représente pas seulement beaneoup d'argent, il est le résultat d'un effort eonsidérable de travail, de recherehe et de goût. On l'a beaucoup eritiqué, beaucoup admiré, il a trouvé des partisans et des détracteurs, comme toutes les œuvres qui valeut qu'on les discute.

C'est M. Bouillıet qui l'a inventé. M. Bouilhet n'est pas seulement l'associé de M. Glıristofle, le chimiste et l'ingénieur de la gorande usine que nous verrons, c'est l'homme de goût, le eherelieur, dont l'esprit s'arrête aux moindres détails; il a done inventé ce service de table, il l'a voulu ainsi et c'est Joindy qui l'a modelé sous sa direction, Joindy, un nom d'artiste qu'il faut retenir, et qui reviendra souvent au cours de ce rapport.

Mais l'initiateur premier du modèle est un de nos vieux orfèvres, un Germain, un Roettiers, ou quelque dessinateur ineonnu, ear e'est d'un dessin sans signature, conservé à la Bibliollèque nationale et que n'ont goravé ni Meissonnier, ni Babel, qu'a été tiréc l'illée de toutes ces pièees; de jolies formes Louis XV, souples, mais point trop molles, où eourent en spires elégantes de larges cannelures, très légèrement coneaves, dont les arêtes se reneontrent pour faire jouer la lumière; des bouquets de légrumes et des fleurs potagères délieatement eiselés, voilà tout; mais ec qui achève de parer les pièces, ce qui leur donne un accent, un charme, une originalité vraiment nouvelle, c'est la bordure empruntée au céleri.

La moulure des assiettes et des vases est prise à cette côte si ferme, bien connue des artistes, et sur mes notes j'ai marqqué d'une croix ce très intéressant rapprochement de l'orfèvrerie avec la plante vivante, paree que e'est le thème auquel je reviens volontiers.

Avec eetle tendance au style Louis XV, il y a d'autres essais, ear la maison Christofle professe l'éclectisme en orfèvierie. C'est là qu'a flcuri d'abord le japonisme en France, mais le service à fleurs de chrysanthèmes modelées en bas-reliefs n'est pas absolument irréproehable: il a, selon moi, le défaut de n'avoir ni la fantaisic, ni la variété, qu'on trouve dans les choses du Japon.

Plus origginal est le service à café, qu'a modelé Chéret et qui, hien qu'emprunté au gônt 
Lonis XVI, garde une allure très moderne; la qualité de la ciselure est remarquable. De Chéret, encore un autre service en vermeil, inspiré de la Renaissance, et qui est nne des œuvres les plus exquises que je sache. Pourtant aucun amateur ne s'est présenté; l'acheteur est souvent avengle, il ne voit que ce qu'on l'oblige à remarquer. Je préfère cependant ces pièces ornées, bien pondérées, souples et qui jamais ne fatiguent le regard, au décor trop osé de Carrier-Belleuse, qui a posé des femmes sur des cafcières et sur des pots à crème, tourmentant lenrs corps nus pour les olyiger à servir d'anses ou de versoirs. II faut user avec moins de sans-facon de la figure lummaine, ou hien il faut l'ornemaniser, la fondre en des ornements plus donx, où elle se mểe par des combinaisons de lignes répétées el parallèles.

Ainsi a fait Levillain, copiant en cela les antiqunes : avec des athlètes et des léopards, il a composé tout un système de décoration, qui fait mne broderie originale et délicieuse aux pièces d'un service à thé; c'est comme une arahesque en doux relief qui s'estompe dans un or pâle. On y trouve un ressonvenir des orfèvreries romaines du $1 v^{e}$ siècle, mais non, c'est hien du Levillain, c'est son style, celui dont il a laissé l'écriture ferme dans plusieurs bronzes qu'a édités Barbedienne ot dont nous retrouvons la trace, cette annće, dans les lampes de Gagneau ct sur les menbles de Damon. Bientôt, nous reviendrons à MM. Christofle et pour rester longtemps avec enx.

\section{Froment-MEURICE (P.-H.-Émile), à Paris.}

Encore un orfêvre parisien à qui nous faisons une comrte visite pour lui revenir quand nous étndirrons plus particulièrement l'orfèvrerie d'art. Nous ne verrons de lui, maintenant, que J'argenterie de table.

Moins que ses confrères, beancoup moins, il a sacrifié au style Louis XV. Si les fils grardent quelque chose de ce qu'ils ont vu dans leur enfance, si Odiot se souvient des préférences paternelles pour les inventions anglaises, É. Froment-Meurice a été hercé, lni, dans t'amour de la Renaissance; mais voici longtemps qu'il est seul maitre dans la vieille maison sur laquelle la ville de Paris avait cloué son écusson. Et si le conseil municipal ne l'appelle pas, pour Jni continuer son brevet d'orfévre de la ville, il garde du moins la nef parisienne, il la garde à ce point qu'il en a fait l'emblème, l'oljet symbolique et charmant que les dames de France ont offert à Ja princesse Amélie quand elle a épousé le duc de Bragance en 1887.

Voilà trente-cing ans que Froment-Meurice est mort; son fils était bien jeune alors, mais il a en depuis à subir tant de caprices de la mode, tant d'assauts de cetle mâ̂tresse impérieuse qui, par cent voix, deinande de perpétuels changements, qu’il a pu oublier les préférences de sa jeunesse première. Aussi, avec son gônt fin, précieux, nous offre-t-il, comme type de ce qu'il aime, non pas une réminiscence de Percier et Fontaine, comme l'a fait Odiot, ni un agréable pasticlse de Germain, comme l'a fait Christofle, mais un surtout sobre ef élégant, quoique un peu froid, en sa simplicité. C'est Lechevalier-Chevignard qui l'a dessiné et c'est Moreau-Vauthier qui en a modelé les figures. Si je fais quelques réserves tonchant la grande corbeille centrale, je me déclare absolument ravi des deux coupes, qui sont parfaites, et je regarde le couronnement des candélabres comme un pur bijou.

11 faudrait peu de choses pour parfaire cet ensemble. Est-ce une ligne à changer, une couleur d'or à prononcer, sont-ce les plaques incrustées de lapis qui marquent d'une touche trop dure leur silhonette? Je n'ai phus sous les yeux les pièces et ne lis que mes notes, mais j'ai l'impression vivace d'm tout harmonieux, où la forme aurait à s'assouplir un peu; les figures y sont plus aimables que l'ornementation; celle-ci est sévère el n'a pas de la Renaissance française l'irrésistible séduction.

Les ouvres ciselées, modelées ou fondues sont le vivant portrait de ceux qui les ont conçues. 
MII. Froment-Meurice, Lechevallier-Ghevignard et Moreau-Vautlier se sont associés comme trois autenr's pour broder un scénario; la part de chacun reste absolument visible dans la piicce.

J'aime moins le service en vermeil de style Louis XVI; il est lì pour démontrer que l'orfèvre-artiste est anssi un marchand orfêvre et qu'il s'entend aux affaires comme il convient; nais je lone bien volontiers une déliciense toilette qui m'avait échappé à ma première visite et que j'ai revue plusieurs fois avec plaisir.

\section{Fanníne frères (Auguste et Joseph), à Paris.}

Nous reviendrons à cenx-ci comme à M. Froment-Neurice : c'est presque lenr faire irjure que de chercher en leur vilrine un plat, un saucier on quelque autre ustensile de vaiselle; tout ce rolils tonclient est œuvre d'art.

Les nevenx de Faucomnier ont gardé anx doights celte vertu des fées, qui ennoblit l'argent et lui donne la valeur de l'or. Si leur ciselet court sur' la panse d'une cafetière, comme celle que je vois, il y laisse un chairé délicat, comme l'épiderme d'un fruil, et adoncit ce métal, comme sous une caresse. On Ieur reproche d'être lents, de gुarder pendant des mois l'objet qu'on at tend avec impratience; ce ne sont pas des uarchands, des manufacturiers : leur oncle leur a léguć son talent, mais il ignorait l'art de faire fortune; il s'est borné à leur apprendre l'amour alssolu du beau. Ce sont les puns honnêtes gens du monde; tous leur's confrères les aiment, les respectent et les admirent, et leurs clients aussi : ils vont chez enx, dans leur atelier de la r'ne de Vaugirard, près du jardin silencieux où les oiseaux répondent an cli sec des ciselets comme ì un chant de sauterelles, et, venus pour exiger, its s'en vont patients, résignés, n'osant troubler cetle quiétude d'artistes à qui chaque jour complte sa tâche.

Il fallail, à ces modestes, un doux protecteur comme le duc de luynes : il est mort. ll leur restait son petit-fils, le duc de Chaulnes, bon comme son aïeul et, comme lui, sensible anx arts : il est mort. Il leur fallail une protectrice un peu originale, riche à millions, osant plus (qn'm liomme et jouant avec une bizarrerie singonlière son rôle de Mécène en jupons, $M^{\text {me }}$ Blanc : elle est morte. $1 \mathrm{H}$ lenr reste bien des clients fidèles, enthonsiastes même; cependant, on ne remplace pas ceux qu'ils ont perdus. J'en sais um, dont je puis dire le nom, car c'est nnn lomme de goût qui est mienx avisé que les chercheurs de bibelots anciens, qui vont courir les ventes : c'est M. Teyssier. Il s'est fait faire, pièce à pièce, un service de table siģné des Fannière, qui vant mienx qu'un service de roi. La corbeille centrale était exposée l'an dernier; elle n'est pas grande; nne figure de Flore, delout au milien des fleur's, se dresse en une jolie attitude; elle est souple par le modelé, donce sous l'outil, acherée prar le ciselet autant que par l'élbanclıoir. Et le style, dira-t-on, à quelie époque se rattaclıc-t-il? A la lienaissance certainement plus qu à toute autre éporgue; mais la marque y est si personnelle que, daus cent ans comme à présent, on dira sans hésiter de cela et de tout ce qu'ils ont fait : „C'est du Fannièren, comme on dit en musique : «C'est dn Mozartr.

J'ai remarqué des plats et des légumiers qui doivent dépendre du même service : c'est la démonstration de la sohriété dans la ligne et dans l'ornement. On s'étonne que la clıose soit si jolie, avec si peu de recherche.

Les salières appartiennent encore à l'argenterie de table; moins compliqurćes que la famense salière de Cellini, mais dérivées du même thème : pour l'une c'est Amplitıite et ponr l'antre Neptune. Denx cofuilles se crensent aux côtés dn dicu et de la déesse des mers, pour recevoir le sel.

Le Musée des arts décoratifs a choisi ce type parfait de décoration ćlégante et simple. 


\section{Bons-Tabunet, à Paris.}

Voici un jemne orfêvre. Sous nous arrètons volonliers à laire son portrait, car s'il n'a pas, comme ceux dont nous venons de parler, tout un passé qui le raltache à de vieilles traditions, l'aveuir lui sourit, le succès lui vient el tout le monde l'accueille.

Encore ai-je tort de dire qu'il n'y a point ici de tradition : je crois que tous ces orfèvres sont fils d'orfêres ou qu'ils ont du saug de joaillier dans les veines. II n'est pas un métier à Paris où les racines soient si tenaces. Boin est le neveu de M. Gaillot et de M. Peck, et, par les Caillot, il tient à trois générations de bijoutiers dont le nom est honorablement comnu dans l'industrie; son père et son grand-père furent les chefs d'une maison universellement conmue par son goût el qui a pour enseigne: L'Escalier de cristal. L'art de la verrerie el la céranique y ont eu leur réveil.

En $187^{3}$, il s'associe à II. Taluret, sou beau-père, el lui succède ensuite. M. Taburet étail un bijontier aussi, un bijoutier qu'ont bien conmu tous les amateurs de curiosités et de bibelots. C'est che\% lui qu'il fallait aller pour trouver les bijoux anciens, qu'il sauvait de la foute, les parures du xvı1 siècle surtont, mignomes inventions d'un goôt si fin, d'une invention si précieusement coquelte el jolie, que les femmes, qui ont linstinct de ce qui leur sied, en ont gardé à sa mémoire quelque reconmaissance.

M. Boin dessinait; il avait du goût déjà, et beancoup; les bijoux que collectionnait son beau-père le charmèrent. Il lui vint avec ces bijoux des pièces d'argognterie; il les copia, les imita, les compléta, comme il faisail des châtelaines, des bagues, des montres et des colliers, et insensiblement il se fit orfèvre sans y jenser, sans le vouloir, puisquill l'était déjà d'iustinct.

II. Boin a-l-il refait à lui senl celle mode el ce gount de l'orfèvrerie de Louis XV? Non, certes; elle arail commencé avant hui; il l'a plutôt subie, il y a cédé, puis il y a aidé.

Le milieu où il vivait était particulièrement favorable à l'étude et au développement de ce groût. Rieu ne le sollicitait dans une autre voie; il n'avait ni dessins ni modèles le rattachant aux modes de la veille; an coutraire, sa clientèle aimait les choses du xwn ${ }^{e}$ siècle; les sources d'où lui venaient les bujoux auciens lui fournissaient des ćléments, des dessins d'orfèvres de la même époque, qu'il comptéta, qu'il étudia : en peu d'années, il se trouva être l'homme de Paris le nicux outillé pour celte renaissance Louis XV.

Germain Bapst avait étudié l'orfêvreric aucienne arec te baron Pichon; il avait publić son livre sur les Germain. C'est à lui, à MI. Duhanel et à M. Boin que le colonel Laussedat demanda de reconstituer pour l'Exposition, dans la section de l'Histoire du travail, la boutique et l'atelier d'un orfèrre parisien.

Quand je vois cette boutique au décor si intime, avec sa forge, son établi, ses ontils épar's, ses al'moires à petits carreaux remphles de cafetières, d'hnilicrs, de flanbeaux et de limbales, cl que je regarde Boin, je l'associe tellenlent à celte reconstitution que, malgyré moi, je l'habille de soie, je te vois poudré à blanc et installé dans la boulique : il est Germain, Meissonnier, Roëllier's, Besnier ou je ne sais quel orfèrre; c'est un revenant, il cst maitre, et ses grands traits souriants et funs ront au costume de 1750 mieux quà la jaquette d’à présent.

Faul-il s'étonner ensuite de trouver le salon de M. Boin toul rempli d'œeuvres dul xville siècle? II n' ê pouvait pas faire d'autres.

La principalc est un grrand surtout franchement repris à l'œuvre de Meissonnier. Tout Paris l'a vu; tous ceux qui ont souci de ces jolies choses ont dit leur mot sur ce travail; des commissions se sont réunies pour savoir s'il fallait ou non l’acheter pour un muséc. Nous hésitous ì nous prononcer après tous ces docteurs en bibelots, et cependant il le faut.

Nous aimons ce surtout; il est d'un maitre. Nous en louons l'exécution; les deur sculpteurs qui en 
ont rétabli les modelures d'après les dessins de Meissonnier, MM. Bonat et Peynot, ont fait une savante reconslitution, et le ciseleur, M. Moisset, s'est associé à leur ouvre avec beaucoup d'intelligence; mais qui a fait la faute d'accumuler ainsi les détails, d'appuyer sur clıaque ligne, de ne rien sacrifier? Est-ce parce que la pièce est neuve? Les œuvres d'argent ont besoin de vicillir, antant que les édifices de pierre et les statues de marbre; il faut que les angles s'arrondissent, que les fonds s'estonpent, que les sécheresses disparaissent. Le cliarme de certimes pièces est dans l'usmre des surfaces et c'est une beauté qu'elles ont prise avec l'âge. Les ntruqueur's m le savent et ils ne se fout aucun scrupule d'user les ciselures el d'obtenir avec la ponce le travail des anuées. Sans aller si loin dans ce mode d'effacement, je crois qu'on rendrait plus parfaits encore les deux seaux à glace du surtout, qui en sont les morceaux les plus rénssis, si on caressait patiemnent, longtemps, avec la paume de la nain, les points saillants et les surfaces, el si on atténuait les ombres dont le ciseleur a marqué trop durement les fonds.

Un peu brutale d'effet est l'énorme soupière que M. Boin a faite en 1888, pour le Jockey-Clnl, nais elle est pleine de brio. C'est une pièce essentiellement décoralive qu'il a entièrement reconstituće avec son grand plateau, telle qu'elle est gravée dans l'ouvre de Germain (Pierre). Ce qui la reml particulièrement intéressante, c'est qu'elle est bien d'un orfèvve et non pas d'un lironzier, tout est fait au marteau, sauf les auses, le bouton et la bordure qui sont fondus; mais ce qui la rend critiquable, c'est encore la ciselure qui est dure, noire. Il faut bien avouer aussi que la somıne de 10,000 francs allouée à ces prix 'de course est très insuffisante et je soupçonne M. Boin d'en avoir dépensé davantage.

MM. Bonat et Peynot ont encore été là ses collaborateurs. La débauche de rocailles, de tiges enroulées, de chicorées, de coquillageses, s'accentuera tout à l'heure cliez certains orfêvres jusqu'en des enchevềtrements inextricahles et les choses qui déjà nous semblent ici compliquées nous paraitrout simples, conparées à d'autres.

Cependant, on peut signaler comme une audace les grands candélabres à sept lumières, dont les branches s'élancent du socle et, par' un tour hardi, comme feraient les tiges naturelles d'une plante, s'en vont lilhrement, si librement que les deux caudélabres ne sout pas pareils entre cux. Ce sont lì caprices de maîtres, qui jouent avec les difficultés el font, sans compter, des choses qui leur coûtent fort clier et ne doivent tenter que les gens de goùt.

C'est Prérost qui a ciselé ces pièces. Prévost est un artiste de beaucoup de mérite: nous le retrouverons chez M. Télard, qui l’a très justement proposé pour une médaille.

Il a ciselé avec Gaudin, le joli surtout rocaille, si savamınent modelé par Bonat, dans la manière des peintures de Rambouillet. Sur un platean de glace encadré d'une bordure d'argent, s'enlèrent en volutes des ormements capricicux et contoumés portant des fleurs ciselćes et des loras de bougogies; aux extrémités minatudent un singe et une gouenon, drơles en leurs atlitudes et sérieux en leurs bouffonneries, comme leur's frères de vieux Saxe.

Cette pièce a élé faite de verve, elle pétille d'esprit, rlle réjouit les yeux; ce sera sur' la table, au milicu des lumières et des fleur's, une audace de bon goût et je crois que c'est le rồle de l'orfèvrerie d'exciter aux gais propos el d'être le décor joyeux d'un bon repas.

Comme contraste, je signale le surtont de style Louis XVI, aux guirlandes de fleurs et aux têtes de béliers, dont l'ordonnance plus sage repose de ces audaces; la cisclure en est très poussée et cependant simple et moins sèche qu'en certaines pièces anciemues.

Da mème style est un joli thé de vermeil: la bouilloire a la forme d'un vase et le plateau est tout à fait charmant; je l'avais marqué dans mes notes de denx gुrands points d'admiration, tandis que le petit thé Lous XV m’avait absolument déplu; dire aujourd'hui pourquoi nne serait difficile.

Un llé́ Louis XIV m'avail séduit par son arrangement d'un goût simple, d'une construction noble. Je lis encore : $n$ Service de toilette à revoir ${ }^{2}$. Je ne l'ai pas suffisamment revu pour en faire la des- 
cription, et cependant je suis retourné souvent à cette jolie exposition de Nl. Boin-Taburet; je la régarde comme l'effort d'un artiste de grande valeur. Elle résume l'évolution de l'orlèvrerie en ces années dernìreses, elle marque le courant du goût, clte a la faveur du public, elle s'impose. Ses tendances vers le Louis $X V$ ne sont pas une copie banale, c'est, chez lui, une conviction bien arrêtéc que eetle forme convient micux à l'argenterie, qu'elle est la meilleure façon d'une vaisselle de table, la plus spirituelle expression du goût français.

D'ailleurs, c'est une opinion défendable, nous n'avons pas à y contredire, et ce qui prouve la bonne foi de M. Boin e'est qu'il a essayé d'une autre voie; il a eu recours à un artiste de grrande valeur, à M. Aubé, l'auteur de tant d'ouvres, les unes mignonnes el eliarmantes, les autres de grande allure. Ensemble ils ont composé un surtout très moderne où la poésie, la musique, la seutpture, la peinture sont représentées par des figures et des allégories qui se marient aux liggnes el complètent les profils des courbes.

Là, rien de Louis XV, on a proscril les rocailles et les chicorées, pas de fusée d'ornements s'enlevant comme une gerhe papillotante; c'est très sage et pourtant très graeienx, les figures sont aimables, et, cependant, M. Boin s'est eontenté d'exposer la maquette, il a nodestement apporté l'œurre d'Aubé mouléc en plâtre ; l'orfèvre n'y avait rien fait, il n'en a pas cncore, aujourd'hui, commencé l'exécution en argent. Pourquoi? Par un sentiment de crainte qui peint bien l'homme, il est gêné par les moulures d'arelitecture, il s'élonne de ne pas avoir des rondenr's, des bosses, de jolis thèmes à boutcroller au marteau. II regarde avec respect cette soupière qui lui semble en pierre, et je ne serais pas surpris qu'il la modifiât un beau matin d'une heureuse façon.

Tant il est vrai (que l'orfèvre est seul à savoir comment se manie le métal, il faut qu'il prête son expérience à l'artiste qui modèle; leur collaboration doit être si étroite qu'aucun ne puisse réclamer seul la paternité de l'œuvre qu'ensemble ils ont dû concevoir'.

Il semble que, parmi les sculpteurs qu'il emploie, celui avec qui M. Boin se plaise à composer soit surtout M. Boxat; c'est ensemble qu'ils ont mené à bien des ouvres difficiles, et e'est à lui que le jury a décerné une médaille d'or, tandis qu’il aceordait une médaille d'argent à M. Morsset pour ses helles eiselures. Il a décerné une médaille de bronze à M. MÉxaro, ehef d'atelicr de M. Boin-Taburet, et des mentions à deux ouvriers : MM. Dreux et Pierrat.

Les quatre noms qui vont suivre sont moins connus du public que ceux que nous arons vus déjà, mais ils ont une grande notoriété parmi les,orfévres; ce sont ceux de fabricants qui se tiennent ordinairement loin des expositions par des raisons de convenance commerciale; il en est de l'orfèverie comme d'autres industries où le consommateur n'a pas directement affaire au véritable producteur : des intermédiaires se placent entre eux, qui ont intérêt à empêcher un rapprochement.

C'est pour ménager la susceptibilité inquiète de ces intermédiaires que beaucoup de fabricants orfères s'abstiennent d'exposer. Ils représentent cependant la fraction la plus riche et la plus importante de l'orférrerie, par le nombre et la quantité des produits. Ils portent annuellement au bureau de garantie 80,0 o o kilogrammes d'argent, fournissent la presque totalité des chiffres d'exportation et suffisent à la consommation de la province, car, en dehors de Paris, on compte à peine huit orfèvres en France.

Cet isolement du fabricant est-il un bien ou un mal? Gagne-t-il en indépendance ce qu'il perd en direction à ne pas se trouver en contact immédiat avec le consommateur? Reçoit-il de l'intermédiaire, marchand ou commissionnaire, une orientation suffisante? 
Peut-il suive le gout du public? Lst-il, au contraire, en situation de te diriger? Nous allons essayer de répondre en étudiant l'exposition de M. Tétard.

\section{IÉDAILLES DOR.}

\section{T'́̀TaRd, à Paris.}

Ciest un noureatu venu parmi les orfèvres; il a succédé, en 1880, à M. Hugo, qui avait créć nal falmique en 1851 et y avait, pendant trente ans, fait d'inportmes affaires d'exportation. C'était l'alerlier au tràvail rapide où naissait l'orfèvjerie lógère anx blanchaurs d’argent mal, aux guillochés papillotaluts, aux ormements estampés el brunis, qui, par son incroyable bon marché, fournissait aux besoins courants du luxe.

Née arec Ie second Empire, celle maison avait longtrmps prodigué les iuventions faciles et banales aux conmissionnaires de la province el de l'étranger. Tout ce qui élail nouveau paraissail bien, on ne se piquait pas allor's de recherche artistique ou de science archéologique; briller el faire de l'effet étaient le seul but ì altrindre. Après l. guerre, il suffit de quelques modèles nouveanx pour donncr au stock de Hugo un regain de succès, el c'est une fallrique en pleine aclivité fu'il a transunise ì soa successenr. Mais, si l'érolution du goutt s'est produite dans la haute orfèvrerie, elle a en son contre('oup diuns l'orfevererie courante, et la commission n'a plus voulu des formes banales et vieillies dont rlle se contentait avaul. M. Tétald avait trouvé daus ses caves des milliers de kilogramunes de fonte représentant tout un matériel de poiucons ot de matrices dósormais sans emploi. Il fallait renouveler cr matériel, críer des modèles, se jeter daus te courant noureau. Un tel changement de front est une opération difficile, car il faut rompre avec toute la routiue d'une maison : les ourriers y sont re-

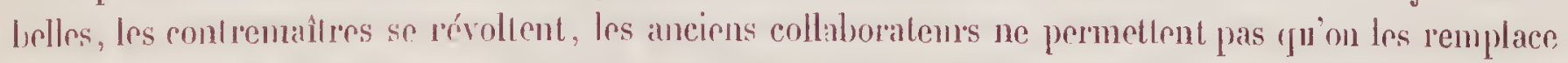
far de noureaux, Jes outils enx-mèmes onl pris des habitudes mécanirues, des mourements d'instinct

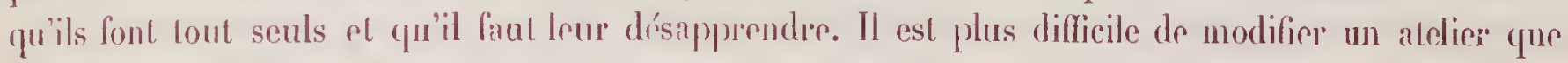
d'en créser un de toules piècess.

Mais celui qui souffrail surtoul de l'évolulion de M. Trítard c'élait son ami, son prédécesseur et son

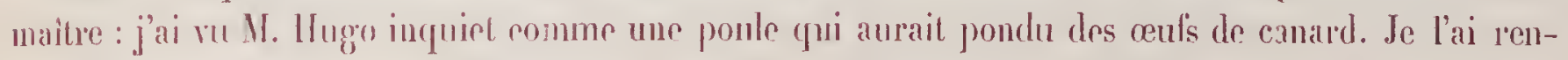
contré souvent au début de l'Eyposition; chaque essai nourean de sa vieille maison te jetait en des

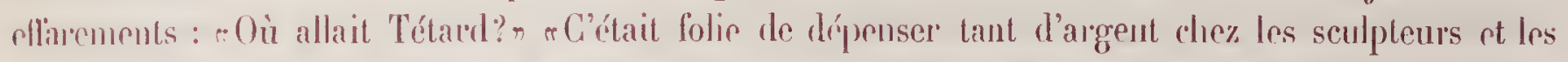
artistes! r El, en oflet, j’estime à plus de 100,000 franes la dépense de modètes qu'il a faite en 1889 .

Ce ruii dans sa tentalive est digne d'éloges, c'rst le bon sens quili a en, toul en relevant le nivean de sa faldrication, de ne pas romprer arre le courant d'affirires de sa maison. Il n'a pas essayé de lulter ave les Froment-Heurice et les Odiol, il s'est borné à se rapprocher du goùt public, à le devaner. mème, en conservant son mode de l'arail, mais en le perfectionnant. C'est un proggrès gónéral qui a surpris et charmé tous les membres du jury.

C'est au moyen de malrices d'iccier fondu, relouchées et cisplées par le graveur d'après less modèles mèmes du seulphenr, que s'oltient une grpande partie de celle argenterie d'usage.

II semble done rue le secret en orférererie, mème dans tous les articles de consommation courante, soil de sacrifier beaucoup it lit reclierclie, du modite en s'adressant aux premiers artistes, de perffetionuer tos moyens de reproduction el de vulgariser msuite, par la faltuication à bon marché, des types excellents. Bonne en principe, cetle opération est difficile daus l'application, parer que l'artistr pst rare, nial préparé à l'invention du modèle, ignorant des conditions de l'orlèvrerie, routinier s'il a

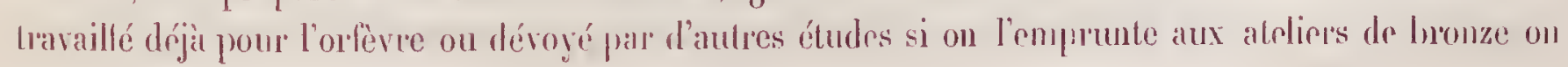


¿ l'écoir. Liaccord est donc très délicat à faire entre le sculptenr et le maitre orfèvre, d'autant plus que les conditions matérielles et mécaniques de l’outil ont des exigences dont il ne faut pas se déplarlir.

II. Boussard parail ètre, parui les artistes qu'a employés V. T'étard, celui qui a le mieux compris ces exigences et s'est le mienx identifié an métier de l'or'érre. Tous avons vu ses modeles cu plâtre

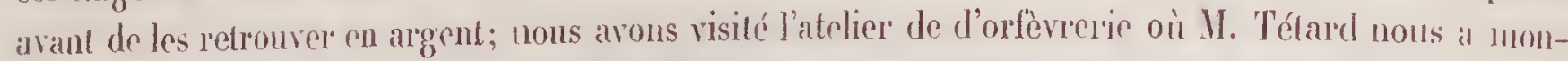
tré, arec beaucoup de bonne graice, ses piècess en comrs fallrication, ses malrices grarées, ses ápreuves d'essais. C'est merveille de voir estanper d’un seul coup un srand cadre de miroir arre ses I'ocuilles, ses feuillages et ses flents; on l'assemble, ou le sonde, quelques ornements fondus et relouclu's en cischre complètent l'effet, en accusant des reliefs et des points brillanls. Une calletière s'oblient de deux coquilles. Une écritoire sort arec ses bosselures ornées de l'eflort du balancier. Arece des feuilles minces d’argent laminé on produit une orfèverie aussi apparente que si clle cétait reponssée au marteau et ciselée à grands frais.

Bertiolle est l'habile gratreur qui exécule ces matrices d'acier.

Tout u'est pas fait ainsi : on emboutit et on retreint encore au matean, daus l'alelier de la lun Béranger; II. Tétard a voulu prouver quill restait orfèvre en nous présentant une calectièr à hosses', imitée des vases allemands du xve siècle. Elle est jolie el convient aux douceur's de l'argent que polit l'usage; à cóté de ectle pièce, il en arait mis d'autres aux formes variées, inachevées encore, pour démontre le mode du travail el prouver que le ciseleur avait relevé à la ressingue les ornenents repoussés sur les vases au col étroit. Une jolie corbeille Lonis XV retreinte par Florange montrait la cisclure d'Arvisenet et de Moisset presque achevéc.

La pièce capilale était un service de table conmmandé par le marquis de Linàès et dont les figurnes avaient été modelées par Peynot et Mathurin . Ioreau. C'était un consemble considéruble, u'aýant d'équivalent que dans J'exposition de Christolle; mais il était perdu dans l'ombre et si nal exposé quion l'a

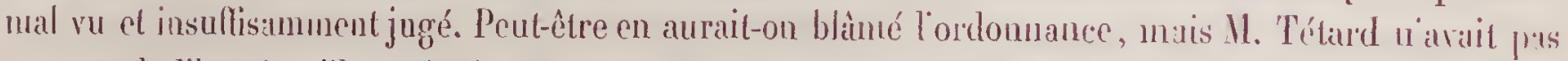
eu toute la liberté quill aurail ainé qu'on lui laissât pour inventer avec l'artiste sa corbeille de milieu, ses caudélabres et ses coupes.

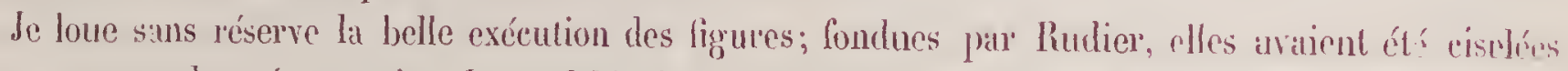
avec une grande préoceupation du modelé; c'est parce que je les ai vues el exaninérs, arant le monlagre, que j’en puis parler en orfévie et en artiste et que je les déclare sufrérieures ì beaucouj d'auvres analognes. Une patine grise, lerne ef top hâtivement faite, a mui à l'ensemble de celle œurre qui n'a été ni vue, ni jugée, ni comprise.

Très différent était un surtout Louis XV, dont on ne trouverait pas l'équivalent dans l'oenrre des' virux maitres. La corbeille à fleurs soulevée sur (quatre pieds sert de bercean à de grentils per'sontmages costmués el gl'oupés ì la faron de Watteau. C'est Quinton qui a modelé ces figurines, Prévost Irs "ciselées, el c'est un sujet aimable à nuellre sur la table, autant que le surtoul que jai loué daus l'exposition de M. Boill.

Hais ces compositions manquent de simplicité, cest aussi le défaut de la fontaine d'applique ol de son bassin; j̋̈ignore si la faute en est ì M. Canneré qui l'a dessinée on à M. Boussand qui l'a modelér, mais c'est trop meublé, trop rempli; il y a trop de détails, trop de cisehure, on fait nune désense d'invention el d'otnementation double de ce qu'il futrait; cela reste charmant, mais faligant par labus de la sculpiture.

J'aime mimx le service à thé Pompadour, ćest le non que lui donne l'orfèrre, nais le thème en est pris à la menniserie; jadmire volontiers les hoiseries de Berey ou de Rambouillel, mais elles ont été nventées pour la sculpture sur bois et non pas sur métal. C'est une faute de trausporter les imenions d'un art ù un art voisin. Celle réserve laite, je reconmais volontiers que ces pièces sonl belles de orme, réussies de fabrication et tout à fait soignnces de ciselure.

Je n'en dirai pas autant de l'écritoine ou l'artiste a copié la fontaine Médicis, du jardin du Luxem- 
bourg. Cette traduction libre de l'œuvre de Jacques de Brosse est une erreur encore el le groupe d'Acis et Galuthiée qui l'orne n'est pas pour' me plaire.

Tout er qui, dans l'exposition de N. Tétard, est d'ordée purement commercial doit être loué, ses montures de cristaux sont très lien faites; outre les carales, il y avait un service à bière d'une invention origituale el d'une fabrication parfaite. Nous ne pouvons pas nous arrèter plus longtemps aux essais de cel orfèvre, wais il convient de le signaler comme un de ceux pour rui l'lixposition de 1889 a ćlé l'occasion d'un effort considérable, d'un progrè̀s réel, el en faveur de qui le jury a disposé arec joie d'une récompense très méritée. Nl. Tétard a fait faire un grand pas ì l'orfèvrerie de consonmation courante; si dans tous les arts et ì tous les deggés nos exposants avaient mis l'ardeur, la voIonté et la persévérance que celui-ci a dépensées, le commerce et l'industrie de la France en auraieut brínéficié dans nue proportion magnifique.

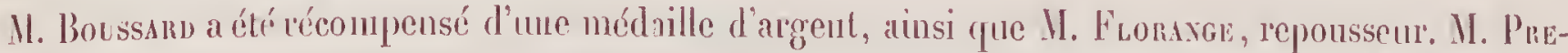
vost a obtenu une médaille de hronze pour ses belles ciselures. II n'a pas dépendu de M. T'étard de faire citer dans une plus lenge mesure ses collaborateurs.

\section{FrAY $(P h$.$) , i Paris.$}

M. Fray rst un fathricant comme II. Tétard el ce que nous arons dit de ce dernier pourrait aussi s'appliquer à lui; mais fils el gendre d'orfêvre, il a succédé en 1875 ì larteux, son beau-père. qui lui-mème en 1861 arail reçu de Fray le père la maison que ce dernier tenait de Dupré, dont il avait épousé la fille et qui avail commencé vers 1818 cette fabrique d'orfèrreric; nous retrourons touc dans une mème fantlle cette tradition ininterrompue de maitres offères.

1. Fiay fabrique pour la province et l'étranger', mais ses produits sont surtout de consommation partisicune, il fait en gुrand la vaisselle, plate, c'est-ì-dire: Ins plats, les léggumier's et les pièces d'argent ‘ui constituent le giturd luxe de la tab)]r; ses aleliers de la rue Pastourelle marchent à la vapeur et le Lour y est habilement employé; il a voulu faire un effort aussi et mettre à còté des pièces de sia fatlurication couraute des oljets d'un art plus raflué. Il s'est adressé pour cela à Joindy, le seulpteur,

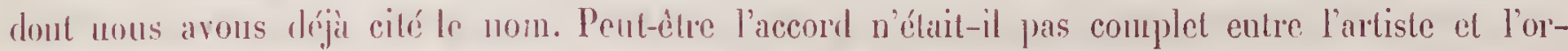
lève?

On seut une gène flans l'exéeution : éest peut-ètre une faute dans la cisclure, une erreur dans la facon de patiner l'argent; ce reproche que nous avons fait ì certaines pièces de M. Boin, nous le ferons surtout ici, parce rue celte orfêvrerie na plus l'air d’ètre en argent, elle al les sécheresses Ju bois. il aurait liallu peu de chose pour la rendre meilleure. Le gorand surtout Louis XV est cependant d'une invention origginale; il reste léger et, malgré ses vastes proportions, les oruentents s'emmanc!ent bien ot s'enlèvent en pyrantides ver's le centre, de faron ì porter tout un échafandage de fleur's maturelles, dont les couleurs graies se marient à l'argent el aux lumières. Il élail irutile d'insevir daus ces orneurnts des fignres d'enfants, ou bien il aurail fallu les micux faire.

Du mène sculptrur est une gorrande soupière de style rocaille où s'exagèrent encore les durelés d'oulit. Ce quilil y faut louer c'est le travail de l'orfève : parmi mes collègues du jury il y arait des gens experts et difficiles qui appréciaient comme il convient le mérite de l'ouvrier à modeler au marleau, sur' un plan ovale, les hossez el les courbes parallèles d'une pièce aussi grande et aussi difficile it manier. Il y a quelque rapport cutre la pièce qui nous occupe el le milieu de table que nous alvons trouvé chę Cluristofle; si je préfêre de beaucoup linvention de celui-ci, je dois reconnaitre dans l'exécution matérielle de l'œurre de II. Fray des qualités d'outil qui manquent à l'autre.

Un joli thé Lonis XVT mérite plus délogeses, an point de vue de la cisehure; un autre llué Louis XV 
est diuns une domnée solsre, roisine des bons modeles anciens; mais ce que je trouve alssolument parfail, c'est la séric des plats ronds el ovales, ì fenilles de liturier, d'un slyle el d'une exécution sans défants. Une antre série de plats Louis XV doit être également citíe.

I. Fray avail été mis hors concours en 1878 comme mentbre du jury de l'Exposition, il a donc pu se rendre compte alors des diflicultés qu'on éprouve à juger el comparer; mais il est commercant avant tout, el il n'a pas vouln morlifier le genre de sa maison pour courir les chances d'un concon's; il s'rst contenté de plaider pour ses collaborateu's et a obtenn : une médacille d'argent pour M. 1)esprez, son ciseleur; une métaille de bronze pour M. Dessrosse, son chef d'atelior, ef une mention pour Al. Batis, orlère.

\section{Debata (Alphonse-E.), à Paris.}

Encore un fils d'orfèvere, né et ćlevé dans l'atelier, ayant comme autrelois subi les épreuves du métiere el, par conséquent, en ćlal, hieu que très jeune, d'entrer en lutte avee les plus vieux mâtlexs.

Sm exposition était amoncée, elle n’a pas failli à ce qu'on attendait: une pièce senle aurait suffi ¿̀ lui valoir la métaille, éest une toilette en vermeil, concue dans le gouit des oeuvres de Germain, arringée ou pent-être un peu dérangée, mais restant, en dípit de quelques fiutes, une des pièces rapitales de l'Exposition.

Lo prérlouche du gitand broc s’attache mal, peut-être ćtait-il difficile de faire autıentent à cause du hesoin d'élever la pause du vase, el de la dégager du bassin. Les boìtes à toilette, iu contraire, sont si parfaites, que les amateurs d'orfèvreric auciemne sont tous venus les voir et que le Musée des arts décoratifs en a pris une, quil a mise en bone place dans ses vitrines.

Ferai-je le nême éloge d'une grande corbeille de table en argent oxydé, savamment modelée, mais dont les ornements neveux produiraient un meilleur effet en bronze qu'en argent : me lemme mue, sontevée par des flots. y symbolise ela Vagnen. Cette composition est imitée d'un lableau, et e'ust toujours une laute, nous l'avons dit, de traduire en argent ce qui n’a pas été conç pour l'orfèvraré.

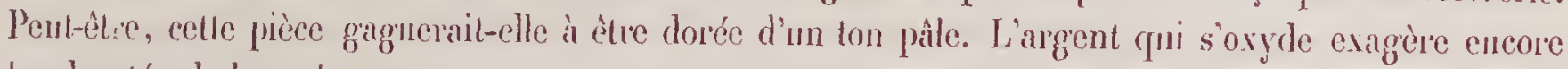
les durelés de la sculpture.

V. Debain, en cédant au courant, qui ramène les nffèvras an xvme siècle, ne s'est pas anssi volontiers que d'autres borné à l'imitation des choses anciemes; il a un serviee ì thé Reuaissance d'un oli dessin, et des essais nouveanx où la fantaisie tient plus de place que la réminiscence des styles. Tout cela est bien fait, on devine en ce chef de maison une volonté nette, une surreté déjả graunde, une surveillance attentive du travail de l'atelier. Ge qui manque encore, c'est la forme préeisé, ćest le gout, e'est l'art d'inventer, de dessiner, de modeler soi-même. Nais n'est-ce pas lì le défaut général, et, II. Debain, qui parmi les orlérres est le plus jeune, n'est-il pas excusable de montrer un peru d'iudécision? It participaul à une exposition pour la première fois, il aura trouvé là, dans l'examen de lui-nème el des antres, le moyen de s'orienter mieux.

Nous n’indiquons que pour mémoire les pièces de petite funtaisie, les couverts de talsle el tons les nenus objets que les boutiques de Paris empruntent à celte fabricque pour leur vente de chaque jour. Parmi ces bibclols de second ordre, on peut citer l'iugúniense pince it asperge, fuil est une uouveauté, cn nêtme temps qu'un instrunent commode; c'est avec ces articles d'orfévreric courante (r.te la maison Debain a doublé son chiffre d'affaires depuis cing ans.

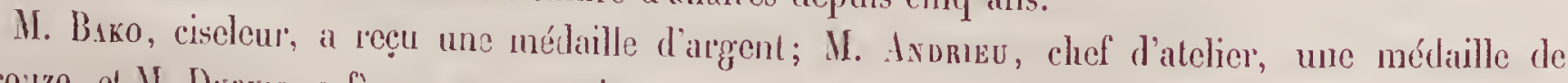
bro:ize, et II. Dupus, orfèvic, une inention. 


\section{Bachelet (Georges), ì Pimis.}

II. Bachelet est le fils de de mon ancien collègrue I. Bachelet qui a fait en 1878 , le rapport du jury des récompenses et qui est resté louģtemps l'orfère el le collahoraleur préfévé de Viollet-le-Due. Barlielel le père est mort laissant un nom très honoré dans son ant et sc; amis lni gardent un souvenir durable pour ses rualités exquises et sa grande bonté.

Son fils aurail pu continuer son ouvre et rester le rival de P'onssielgue-Rusand el d'ArmandCalliat; il a préféré, je ne sais pourruoi, abandonner l'orfèvrerie religiense, vendre la collection magnifique des dessins du grand archilecte que j'ai nommé el racheter avec le produit de celle vente le fouds et les modèles de Cosson-Corloy. De la sorle, il a marié deux vieilles maisons d'orfévrerie et il occupe maintenant, sur le terre-plein du Pont-Neuf, en face de la statue de Henri IV, une des plus ancienues maisons de Paris où ont vécu, avant lui, plısieurs goénćralions d'orfèvres.

Lat vitrine de M. Bachelet élait fort élroile, il s'est présenté très morlestement devaut le jurry ; mais l'exeellenee de sa fabrication lui a valu une des plus hautes réeompenses, el les experts ont jugé quili valait mieux qu'un orfèvire fìt $n$ service sans défaul que de s'essayer à des ouvres compliquées el prétentieuses. Lussi, n’lésité-je pas à dire : «que le meillenr service d'argenterie, le plus logique en sa forme, te plus pratique el cependant le plus approprié au goût du jour, puisgu'il est Ju plus pur style Ionis XV, se trouve chez M. Bachelet."

Cifle opinion a été confurmée par des gens qui, pour n’être pas des orfèvres el n'avoir pas fait parlie du jury, n’en sout pas moins des juges compétents: l'Union centrale a confirmé celte opinion en choisissant une des pièces de ce service pour la donner comme moldele.

I'n service à thé Louis XVI se recommande par l'exécution plutôt que par l'invention; le bon nuvrier l'emporte encore sur l'artiste. On trouve chor II. Bachelet les qualités d'oulits développées au plus haut poiut, el c'est diose trop rare pour que mous n'y insistions pas : celle nógligence de la facon se propage dans la fabrique; elle a fail perdre des points à beancoup d'orfèvres que la sévérité du jury pourra surprendre et nous soulailons que cet averlissement serve à quelques-uns pnur exiger p'us et mienx de leurs ouvirers. On nous a loué, en 1878 , d'avoir maintenu un jugement sévère à l'égard d'une puissante maison élrangère à cause de ses façons mauvaises; nous ne devons pas Atre aujourd'lui moins exigrant pour les orfèvres de Paris.

La pièce capitale de lexposition de NI. Bachelet ćtait une grande corbeille ì flenrs, entièrement repoussíe au unartean et dont les extrémitrés affectaient la forme l'une proue de navire, avec des rnfants et des gunillandes de lleurs cisclíes; je n'aimais pas ce modèle, et ce n'est pas cet objet-là quí. a valu à M. Baclielel sa módicille d'or.

Le seul collaboraleur qu’ait proposé M. Bachelet est M. Arvines t, ciscleur; nous ne uous expliquons pas que son unm ait étri nnis el uous rendons tardirement ici justice ì cet artiste de talent.

\section{Accoc (André), ì Parris.}

Yous avons thonvé le nom d'Ancoe en feuilletant les Comptes rendus de l'Exposition de 1823 et nous l'avons citś au premier chapilre de ce rapport, mais la maison ćlait plus ancienne encore, car si Casumir Aucoc, grant-pè̀e de celui que nous avons à juģer aujourd'lumi, s'était établi en 1821 , il ne renail alor's que succéder à Maire qui avait fondé sa maison en $179^{5}$; voilà done un orfèvre enerene pour qui l'Exposition esl presque un centenaire.

I.es Aucoe ont eu longitemps la spécialité des nécessaires de rovage et des pièces d'orfèvierie 
servant à la toilette; ce n’est que depuis une vingtaime d'annér qu'ils ont joint ì leur commeres la vente des bijoux arec la labrication de l'orfèrrerie de table. L'exposition présentée cette année contenail des échantillons de tous ces gronres: elle ćtait encadrée dans une façade originale dout le style xviti siècle servait d'enseigne ì ses produits. Est-ce à cela qu'il faut attribuer le charme et l'attraction qu'avait cetle exposition sur nous et sur beancoup de nos annis? Je ne sais, mais il est regretlahle que rurs, en détail, toutes les pièces qui la composaient n’aient pas montré les qualités d'exécution que nous avons signalées ehez II. Bachelet.

In point de vue décoratif, au contraire, les ouvres sont fort belles, et pour rendre à Germain, si souvent copié, un nouveau tribul, citons d’abord la buire et le bassin, exactement reconstitués, d'après la grravure qu'on trouve dans son œuvre; c'élait très beau quoigu'un peu dur; il faudra ciunquante ans d'àgoge à ces pièces-là pour les amener à point, elles seront alor's parfaites; mais le mérite en reviendra toujours à Germain plus qu’ H. Aucoc.

Nais c'est bien à Ml. Aucoc qu'appartient l'invention des candélabres ì trois lumières, qui cuveloppent de leurs branches des vases de cristal, en sorle que les fleurs qu'ou y met se peuvent marier ¿il l'éclat des hougies.

Plıs énergiques dans leur structure sont deux grands candélabres it ruatre branches, dont les tiges nervenses, puissantes, s'élancent de la base et, par une lorsion hardie, s'enroulent et vont jusqu'an sommet porter les lumières. Yous avous vu chez MI. Boin un essui analoğne, nous en trouverons un autre cléz le docleur Canus; nous n’hésitons pas ì dire que les candélabres de M. Ancoc semblent les mieux réussis; tout cela est de style Lonis XV.

Lonis XV encore la monture en vermeil de deux potiches vieux-Chine; cerlains amateurs s'étomnant qu'on ait fondu en argent des montures de porcetaine, qu'ils sont accoutuntés à voir en bronze. Ancoc répoud rqu'il est or ềvren et qu’un'acheteur lui a domné raison en choisissant ses vases.

Nous ne sortons' pas du Louis XV en citant un cadre en vermeil, fait entièrement au repoussé; non plus qu'une grande corbeille rétreiute au marteau, ciselée d'un outil énergigue et dont les anses et le pied seuls sont fondus; il est dommage que la façon d'orfêvrerie y soit un peu négligée, mais le prix en est très abordable.

Je prélère ì cette corbeille un plateau ì servir, en forme d'éventaire, dout le dessin libre, les contours souples, l'or'nementation grasse ont un style bien français; il me semble qu'en ses essais VI. Aucoe s'approche un peu plus que d'antres de l'esprit des choses du xvm siècle; il aurait peut-être réussi à satisfaire les plus exigeants, s'il avait mieux surveillé son atelier, mais il est, par sa position, en rapport plus intime avec le public, il subit le caprice de l'acheteur, il obéit ì lat mode; toute cette différence que uous siggralions tout à l'heure à propos des orfèvres apparait ici, entre M. Aucoc qui vit dans sa boulique, trop loin de l'atelier, et M. Tétard qui reste en son ateliec, iggnorant des besoins du client.

Je ne crois pas avoir' ì m'arrèter plus longtemps ì cette exposition, mais j’y veux noter cependant deux ourrages qui m’ont particulièrement séduit : c'est d'abord un petit tlé Louis XIV disposé avec gonit sur nne table basse pour le gontter du five o’clock. Les jolies formes à pans des pièces Louis XIV, simples, agrémentées de fines gravures ou reliaussées de goodrons, conviennent mienx à mon sens pour l'orfêvreric que les rocailles, les clicorées, les coquillages et les exagérations du rococo.

C'est paree que les modèles Louis XIV sont rares et parce fulils exigent plus de science et de reclierches que peu d'orfèvres s'y sont essayés; nous dirons plus loin ce qu'on devrait attendre des plus lıabiles.

Le dernicr oljet, rue je cite pour mémoire, est un petit ostensoir-bijou, presque un joujou d'auted, ramené aux dimensions de l'oratoire le plus mignon. Il appartient à II 'me Bouruet-Aubertot, c'est en quelque sorte une pièce de maitrise comme les orfèvres en faisaient au siècle dernier, pour aflirmer lenır habileté, mais celui-ci est une initation des pièces du xve siècle. 
La nom rue V. Ancoc s'est fait un plaisir de nous jroposer, comme étant celui du dessinateur émérite qui l'a aidé dans ses recherelies, est celni de M. Henri Canserú; nous le retrouverons allié an nom de Froment-IIenrice, mais nous pouvons déjà tui attribure la médaille d'or que In jury lui a décernée;

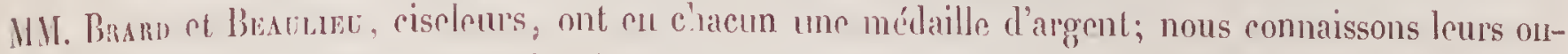
vrages at savons la part considríable de collaboration qu’ils ont dans l'orfèvrerie.

\section{MEDAILLES D'ARGEST.}

\section{Bovcinenor (Fr.), à Paris.}

Pour atter cherelıer M. Boucheron il faut traverser la grande galerie et pénétrer clınz les joailliers; là, parmi les diamants et les perles, à côté d'ouveres d'art que nous viendrons revoir, nous trouvons quelques essais d'argenterie que nous allons examiner paree que M. Boucheron nous les a présentés, cypligués et vantés tui-mêne et qu'il croit être mieux qu'aucun daus le droit clıemin; l'avenir et le public en décideront; nous n'avons, pour notre part, gu’à l'aduire l’impression du jury.

Le jury rui est composé d'orfèveres, d'artistes, de gens du monde, croit que M. Boucheron se tromper qu'en poussant aux plus minutieux détails ta copie des choses du xvme siècle, il dépasse les audaces de ses confrères les plus osés. Il ne tui sullit pas comme à II. Boin, comme à H. Lucoc ou il M. Debain, de copier Ies eeuvres de Meissonnirr, de Germain ou de Roëltier's; il en exagìre et en complirpue l'ornententation. puis. dans les fonds unis de l'argenterie. il grave en taille-douce des scènes enmplicpués. Done plus aucun repos, aucune blancheur d'argegnt; il prend à Marvye, à Conchiu et it Eisen leurs jolies gravures et, soit ru’il mmploie l'ean-forte, soit qu’il emploie le burin, it grave l'argent comme un graveur fait de sa planche, il l'incruste après d'encre noire comme s'il voulait on lirer des épreures; el son orferrerie devient une suite d'illustrations comme on en trouve sur les estampes anciennes. Celte mode prendra-t-elle? Yous verrons tout à l'lieure qu'elte a déjà trouvé dos imilateurs, et cela peut arriver, car avant de mettre des images sur t'argenterie comme le veut ll. Bouclicron, on les a peinles el imprimées déjà sur la vaisselle de fä̈ence, mais le goût public en a fait justice. Pour nous, nous n'ignorous pas que l'art de graver sur argent et d'y faire des nietles a en d'illustres maîteres en flalie ef rue le nom de Finiguerra reste attaché à l'invention de la gravure. Nous aimons les décors en taille-donce sur une tabatière d'or ou sur quelque boitr à mouche, mais nous ne voulons pas voir reproduire sur la panse d'une cafetière: Le sacre de Louis XV, ni tronver dans In fond d'un plat: Le feu d'artifice qu'on tira pour le mariage du. Dauplin.

A part ees criticpurs, it faut touer l'habileté du graveur et déplorer que Raut, l'artiste qui a gravé ces pièress, soil mort. Quant aux pièces d'orfèvrerie même, M. Bouclıcron y a cntassé tant de difficultés, lant d'ornements compliqués, que l'orfère s'est refusé à tes faire et que c'est un hijoutier. M. Menu, qui a consenti à entreprendre ces ceuvres difficiles. C'est une débauclie de rocailles beurtées, pointures, mílées, tronssailteuses, sans repos, et cependant, par un art infini, rien ne pique, ce qui fait peur aux yenx n'aceroche pas les doigts; on est surpris d'y porter la main sans se blesser. Comme plusicul's aulers, M. Boucheron abuse des oxydations, mais nous savons que tontes ces orfèvreries, les siennes commes les autres, sont destinées à passer par les mains de valets soigneux qui, à coups de trosse et ì grand renfort de blane, Ins nettoieront sans ŕgards. Peut-être ces innocents collaboratenr's donneront-ils ainsi, en les débarrassant de teur couche noire, un meilleur aspect anx oeuves de l'orfèvire.

La grande aignière imitée de Germain est belle, il y faudrait un peu plus de souplesse de modelé, mais la façon d'orfèrerie est exceltente. 
Pour mon goût ce que jaine sans réserve, ce que je trouve absolument nouveat, décoralif el bean, e'est la séric de plats Louis XIII dont les boeds sont enpichis d'ornements bouterollés qui accrochent la lumière de la manière la plus nenve el la plus ingénieuse : c'est très rénssi.

I. Hevrr, graveur, el M. Mexo, bijoulier-orfèvre, ont obtenu chacun tule médaille d'argent.

\section{Cardeililac (Ennest), à Parris.}

Encore une vieille maison, elle s'est transmise de père en fils depuis 1804 , mais c'est depuis dix ans senlement qu'on y fahrique tous les objels d'orfevreric que nous y lrowrons; on n'y faisail autrefois que la couldleric el Irs courerts. Celle question des converts, qui lient une si grande place dans l'orfèvrerie d'argent el dans le service de la lable, mérilerail de nous arrèter; cependanl nous noen dirons ce qu'il faut en dire qu'après avoir achevé la revue de tous les exposants. M. Cardeilhac a quelipues modèles à lıi et vend lous les modèles du conmerce; ses couverts ont un accent très persomnel, cmprunté, semble-t-il, à la ferronnerie, el ce mode de décor doit être particulier au chef de la maison ou à $\mathrm{M}$. Bonvalet, son dessimateur, car on le retrouve dans les plats de style renaissance donl les bordures sont ajourées el rui sont fort bien failes. Gela nous change de l'orfèvrerie I ouis XV; er n'est pas à dire qu'on n'en trouverail pas parni les pièces si élégantes présentées par M. Cardeillac, mais le dessin a plus d'accent, il en a mème quelquefois trop), en ce que les angles offensent les doights el que les pointes accrochent. Le contelier apparail, il travaille l'argent comme l'acier, el les riseleurs qu’il emploie, M. Desvignes el M. Viot, ont une énergie d'outil qu’il faudrait tempérer; je fais une exception ponr un sucrier de forme ovale. lout décoré de bossuages et qui est fait all maltean; je trouve aussi dans mes noles la mention diun joli plat long, décoré dans le slyle de la Régener. el que jarais marqué comme très réussi.

Outre Mil. Boxvalete, Desvigxe et Viot, que le jury a récompensés de deux médailles de fironze el d'me mention, M. Gardeilhac avail encore cité deux sculplenr's : MM. Mayer el M. Aigninier.

\section{Michaur (Eugène), ì Paris.}

M. Hichant est un ciseleur de talent, élève de Guérin el d'Hlonoré, qui a prêté sa collaboralion ì beancoup d'exposants. Il a en la discrétion de ne pas se vanter du travail qu’il avail fait pour les autres, nous l'initerons el ne le trahissant pas, mais nous ne voulons pas paraitre igunorep tont le néérite quil a; nous le comnaissons de longue date, il travaillait pour nous en 1878 , arant d'acquérir la vieille maison d'orfèvrerie de M. Turquet; il a apporté dans cette maison les idées qu il avait puiscées lui-mème auprès de ses maîtres : il a gardé d'Honoré e goủt français assez voisin des composilions de Iiénard, qui déjà porle une date, conme le style du milieu de ce siècle. En reprenant la maison d'un orfèvre, M. Michant y trouvait des morlèles anciens qui correspondent an goùt du mème Iemps. en sorte que, tout naturellement, il les a réédités el décorés de ciselures à sa manière. Voilà pourquoi son exposition est comme une fenêtre ouverle sur les choses d'hier; on y relrouve les échantillons: cišlés el soignensement finis dìn art qu'ont aimé nos an̂nés et qui plaîl encole à quelques-uus, puisquil trouve des acheteurs; mais il faut que Nichaut travaille moins par lui-même, quiil sol'le de l'atelier, quil se dégage de la besogne personnelle afin de voir de plus lauut, d'éludier en que font les antres el de rajeunir ses modèles; il a formé ses filles à manier le riselel comme lui-mềme, clles peuvent lui apporter des idées jeunes.

Le jury a donné une médaille de bronze à M. Petror, son clief d'atelier. 


\section{Leroy (Louis) et Cic à Paris.}

IV. Jeroy est le sucessem de M. Jules Pianlt, et M. Jules. Pianlt étail, on s'en souvient, un des grands fabricants de controllerie de Paris; il y a beaucoup d'analogie par conséquent entre cetle ntaison et la maison Cardeillac, et, dans celte dernière, l'orfèvrerie s'est implantée plus lòt, tandis qu'ctle est nonvelle-venue cliez M. Leroy. Douó des qualitós essentielles du commercant, M. Teroy scmble devoil être un ardent propaggateur de l'orfévererie française; M. Piault, dont on connait la comprétence en matière commerciale, nous a donné sur son successeur des détails iutríressants el les chiffres quil nous a prósentés démontrent les progrès qu'a fails à l'exportation celte importante. maison. Lille a choisi pour collahorateurs denx lommes de valeur : MM. Récipon et Diomède, l'un le sculptcur attilré, l'autre le ciseleur préférí des Orliot, et, assurće avec de lels maîtres de ne pas faire d'école, elle a étalli deux services complets d'argenterie, l'un Louis XV, l'autre Louis XV1. Ce dernier est très important, il vant je crois 60,000 ì 70,000 francs et si je n'aime pas beancoup l'ornement en forme de draperies, qui se répèle sur toutes les pièces, je dois dire que l'exécution en est très soignér el que, pour un jeune atelier, l'atelier rle M. Leroy rendrait des points à d'antres plus anciens. Or y a introduit des éenomies de falricilion, dont le consommatenr profitera; je cile pour exemple: Im saucier estanpré en rlenx coquilles, qui est fait avec tout te soin que peut exiger le meilleur contremaîlre; les plats ont des bordures venues au laminoir, d'antres à l'estanıage, mais très nettes et lrès proplement soridíes.

Parmi les converts, il y a toute une série de formes qu'on a haplisée de nons divers; le modèle que je préfère est de slyle Louis XVI; simple, doux ì la main. coquet, charmant jusqu à la coutel-

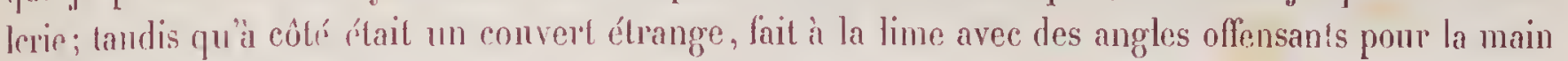

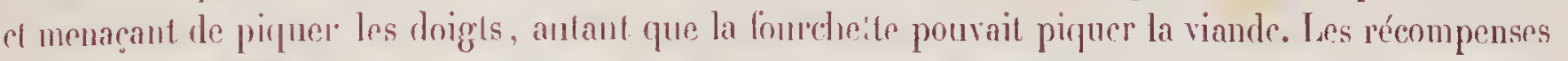

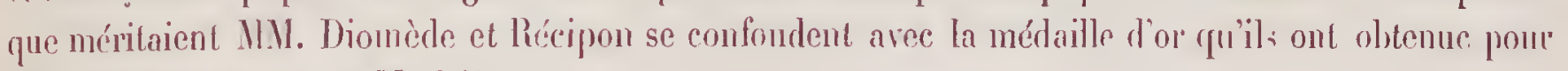
leur collaboration, clıe M. Orliot.

\section{Thalors et Miyence, ì Paris.}

Ils oul suecédŕ à M. F. Nicourl, dans l'aucienne milison Lavallée, et le jury leur a garlé le rang qu’ils occupaient ì l'Fxposilion de 1878 ; ce n'est pas quil y ail en progrès; la falorication nous a semblus stationnaire. HW. Tallois a Mayenee produisent principalement des couverts d'argent, ils exploitent leurss modètes et ne los font ni mienx, ni moins bien qu'avant. Pour intéresser les visileurs ils ont exposé le couvert d'argent à ses différents ćtals; il est inutile d'expliquer pour nos lectenr's les phases d'me industrie qu'ils connaissent.

Quant ì l'orfèveréc proprement dite, nons n avons rien à en dire non plus : les formes sont lourdes; les modèles dérivés dı style japonais n’ont ancun caraclère d'originalité; il serait à soulaiter quiuno réaclion se fit en ceile maison, que sa répulation ohlige.

Quedques pières gravées avec soin ont valu à H. Royer une médaille d'argent, ainsi qu à̀ M. Le:culexe qui partage aree N. Bako les travanx de ciselure de MM. Tallois at Mayence.

Cest anssi loceasion de parler ici de M. Gautruche, le doreur; le jury de la classe 24 u’a pu lui décerner de médaille parce qu’il exposait avec les brouziers dans la classe 25 ; mais il est te collaboraleur de tous les orfèves, it s'est appliqué à tronver tous les tons d'or, d'argent, de cuivre, à imiter les patines, à composer une paletle métallique si variée de nuances quil peint avec les dépôts galvaniques comme avec l'émail. Il n’en est pas arrivé encore à la perfection désespérante des Japonais, ses teintes n'ont pas toule la solidité désirable, mais si nous nous reportons en arrière il faut reconnâtre qu'on ignorait absolument avant lui cet art de muancer l'or et l'ergenent. 
Ceux qui ont visité attentivement l'exposition de 1878 se sonviendront des produits de MM. van Kempen el fils, les orfères patentés du roi des Pays-Bas; on s'élonnail alors des matis el des fonds grenus qu'obtenaient les Hollandais sur les surfaces d'argent. Le procédé n’a plus rien aujourd'hui qui surprenue l'orfèvre : on produit les sablés au moyen d'un ventilateur puissant qui précipile du grès, du sahle ou de la limaille d'acier sur les parties qu'on veut matir. M. Gautruche produit ì facon ces effets-là, sur l'argoent ou sur la dorure; il avait exposé les éclantillons les plus variés de ces sallés el la vitrine de MM. Tallois el Mayence en contenait des applications très intéressantes.

\section{Mírite (Charles), à Paris.}

Nons avons dit combien la mode cxagérait déjà les décors Louis XV et que certains procédés qui étaient des qualités cliez les uns produisaient par l’abus de graves défauts clę d'autres. Nous en trouvons ici la preuve et nous voulons croùe que c'est moins par la faute de l'orfèvre que par celle des clients auxquels il obéil.

Ce qui nous porte à le croire, c'est que M. Mérite a fail sur commande un surloul d'argent qui est lirectrment imité d'une fontaine de stỵe italien. Or, an xvm siècle, les Italiens et les Allemand. avaient travesti de pitoyable façon le style Lonis XV qu’ils n'avaient pas su comprendie. Si déja nous allons rẹnendre à Gênes ou à Sans-Sonci des modèles où s'entassent les rocailles, les grotesques et Ies ornements r rococon, la fatigue viendra vite de ces choses sans goùt el une réaction se fera vers des formes plus simples, comme la réaclion qui jadis amena le style Louis XVI.

- Nous n’insistons pas sur la composition bizarre qu'exposait M. Mérite, puisqu'clle ini étail en quelque sorte imposée par ses clients; mais pourquoi a-t-il répété les mêmes faules dans un second surtout qu'il aurait pu composer à son gré (j'enteuds celui que décorent des darplluus)? C'est dommage, car la corbeille du centre présentait de rares qualités d'exécution.

M. Nérite sait son métier autant qu'orfèvre te peut savoir et nous n’avons pas la prétention in hii en lemontrer; s'il fait des modèles rrococon, c'est qüil les aime; s̈il les oxyde au point de leur faire porter le deuil, cest que cela lui paraît mieux; sil ahuse des gravures à l'eau-forte el des décor's au burin, c'est qu'il partage le goût de M. Boucheron pour ces décors compliqués. Nous n'essaierons pas mème de lui démontrer qu'il a tort; si la mode de ces clioses se propage el cela peut arriver, il nous prourerait par. là (quili arail raison et ce serait ì nous de faire amende lonorable.

\section{KeLLen frères, à Paris.}

Voila des fabricants qui nons intéressent, ils introduisent. il est vrai, clez nous le gon̂t anghais, mais ils sappliquent i produire mieux et à meilleur comple celte petite orfevverie d'usagre, simple, confortable ot spéciale dont nos voisius avaient le monopole el qu'ils avaient importée ici avec un grand succès. lls y ont réussi, leur's produits surpassent en honne facon les produits anglais : les prièces gue nous avons examinées sont des petits chefs-d'œuvre d'ajusté, de nelteté, de joliesse étrange.

N'ayant plus à payer aux commissionnaires les droits qu'exigeaient ces intermédiaires, MM. Keller livrent à meilleur marché que les maisons anglaises. C'est un avantage pour eux, c'en est un pour le consommateur el c'est de la boune concurrence.

Rien n'est mieux fail que ces garnitures de nécessaire; boîtes et flacons s'ourrent ou se bouchent frassement, exactement, c'est un retour à celle excellente fabrication francaise qui primail jadis les meillenres mareques anglaises. Tous les articles de bureau, les eristaux montés, les tasses de méta! à hords d'ivoice pour garder les lères d'une brûlure, et les amusantes fantaisies de la morle, lout est 
lien sui porte te poincon des Keller. Nous n'avons pas trouvé là de modiles Louis IV, mais nous ne verrons rien chez les orfèvres anglais (fui soil comparable ì ceci.

M. Lagrencox méritait certainement la mention gue lui a donnée le jury pour la facon des pièces ruil dirige dans l'atelier de MII. Koller'.

\section{MÉDAILLES DE BRONZE.}

\section{Borvin (Victor), ì Paris.}

M. Boivin expose de l'orfèverie de table, rles comverts el de la coutellerie; c'est une falurication conrante qui révide un effort dinvention chez louvries, mais il n'y fant pas chercher autre chose. qu'un gout très relatif et, si nous examinions le grand service de toilette qu'expose II. Boivin, nous aurions à critiquer l'exubérance des ornements qui accrocìnt. Cée qui pour nous rst un défaut constitue pour Ir commerer d'exportation des qualités; la simplicilé ne convient pas aux pays oì se consomme celle orfèvrerie tapageuse et légère; les cristaux adroitement montés dans des ormements découpés nous étonnent par l'extrême hon marché des façons.

M. Leconder, contremaitre de M. Boivin, a oltenu me mention.

\section{Givard (Pierre), i Paris.}

Nous devons seconder les efforts des ouvriers qui travaillent eux-mêmes et fout avec quelrues apprentis des ouvrages dont l'ingéniosité et to bon marchŕ surpremnent les chefs d'industrie.

11. Gavard a Iongtemps travaillé chez M. Tonnellier où il tournait spécialement les timbales; futali à son compte il a étendu à d'antres articles la fabrication dont il avait vécu jusque-là. Sans doute la déeoration dont il couvre ses articles de toilette lajsse bien à désirer, mais cette orfevvrerie d'argent coûte moins clier que l'orfèvrerie de cuivre argenté, que nous examinerons plus loin.

\section{M"me Guerciet (reuve Gustave), à Paris.}

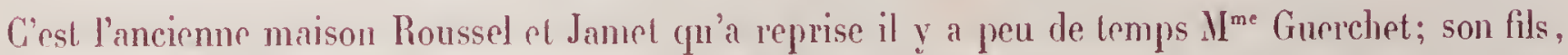
tout jeune lomme, travaille avec elle el, comme il dessine avec goût, on peut prédire à cette maison des progrès certains et rapides; its se sont adonnés pont commencer à la mode Louis XV que nous relromvons partout et dont les exagérations s'accusent ici plus qu'ailleurs; cependant il faut signaler comme très supérienre au reste une soupière ovale, qui n'est en réalité que la copie en argent d'une do res soupières de porcelaine el de faïnnce que les céramistes du siècle dernier empruntaient aux modèles d’orfèvrerie et quiu nous en ont conservé la forme, de la facour la plus exacte.

\section{MENTION HONORABLE.}

\section{Lambert (Léon), à Paris.}

Cort exposant mérite d'être encouragé, il est le collahorateur de tous les orfèvéz cuilleristes et fait au marlean et à la lime tont en que les matriers gravées ne peuvent pas produire : les pelles à 
crème, à tarte, les services ì poisson, les couverts à salade et tous les articles de facon rinsse, déenrés de nielles, de gravures à l'ean-forte et d'émail.

II est factisux qu'arec son halditeté d'ontil MI. Lambert n'apporte pas un peu plus de gonit dans l'invention du dícor.

\section{ORFEVRERTE ARGENTEE.}

Autrefois te plaqué tenail une place imporlante daus la fabrication parisienne et figurail dans les expositions nationales; il y avail une légristalion spéciale il ce sujet arec un contrôle d'État indiquant l'ćpaisseur proportionnelle de l'argent.

L'orfèrerie argentée par les procédés dectro-chimiques s'est substiluée an plaqué d'argent d'une facon à peu près complète, el cette industrie, quin'a pas encore un demisiècle d'existence, envahit le marché au point qu’elle a menacé l'orfévrerie d'argent elle-même. En effet, en même temps que par son bon marché elle pouvail salisfaire aux besoins les plus morlestes et à la consommation du plus grand nombre, ofle s'emparait des articles de grand luxe et e'est ainsi que sous l'Empire nous avons vu la lable de Tuileries et celle de l'Hôtel de Ville décorées de surtouts argentés. II n’y a pas plus d'une dizaine d'années que la vaisselle d'argent véritable reprend la vogute en France ef qu'elle s'impose dans toules les familles riches; celte réaction tienl sans doute au progrès de la fortune et au besoin du bien-être, mais elle est surtout une conséquence de l'abondance de l'argent.

L'orfèvrerie d'imitation n’en est pas diminuće, car, parallètement au progrès de la vaisselle plate, elle se répand aussi dans des milienx moins riches et trouve, dans le luve ì effet des hòtels, des paquebols et de tous les établissements publies, des éléments d'affarres considérables. Nous ne pouvons pas comparer la falbrication anglaise à la nôtre : la maison Elkinglon, de Londres, s'étant abstenue. e’est en Améripue que nous irous chercher un terme de comparaison. pour l'opposer ì notre champion francais : Christofle.

\section{GRAND PRIX.}

\section{Cinnistofle et $C^{i e}$, à Paris.}

Nous arons indiqué les détuts de celle maison, nous avons vu Charles Christofle figurant parmi .es bijontiers à l'Exposition de 1844, puis, achetant d'Elkington el de Ruolz les lorevets d'argenture et de dorure galvaniques, et devinant par un trait de génie que celte invention allait révolutionner l'industrie du métal : il est inntile de recommencer un récit qui a été lait à la suite de charue rxposition. L'histoire de la maison Cluristofle est intimement liée au progrès de la galvanophastie, et c'est un chapitre que l'on peut trouver dans les manuels.

Anjourd'huii, l'usine de Saint-Denis receit directement de la Nouvelle-Calédonie le minerai de nicked, elle en fait le trailement par des moyens nouveaux, le transforme en lingots el te live directement au laminoir, an découpoir, aux machines à emboutir et à tous les merveitleux ontils qu’a inventés la mécanique moderne et qui remplacent la main de l'ouvrier. 
C'est dans l'usine de Saint-Denis que soat fabriquíes les 120,000 douzaines de couverts que produil aunurllement la maison Ciluristofle; c'rst là aussi que sont préparés les vases, les graurles pièces de forme, que la machine donne à l'orfèvre qui les finit. Cétle usine que nous avons visilér el que nous aurions plaisir à décrire en détail, si cela nous était permis, a été pour nous tous une surprise : elle

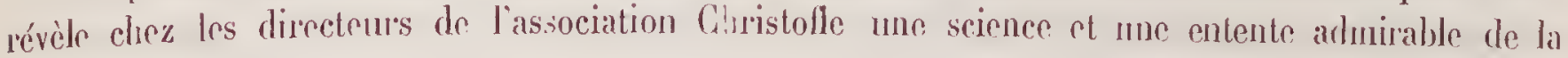
grande industrie.

Tout s'y accomplit avec un ordre et nne précision renarequables, mais la place et l'espace rendent facila ce qui devient plus malaisé dans la labriofue de la rue de Bondy; celle-ci est une fournuilière qui, des civves aux goreniers, présnte une activité, un travail, une méthode toul à fait extraordinaires. liesserrée entre les maisons voisines, l'usine d'orfèvrerie et de galıanoplastie a trouvé cependant, en creusant le sol, cul superposant ses ateliers, en accroctrant des graleries vitrées au-dessus des cours, le moyen de faire vivre et travailler tonte une armée de dessinateurs, de modeleurs, d'ouvrier's, de fenmes et d'enfants, el de produire les ceurres d'art les phins parfaites en même temps que les objets de consommation les plus ordinaires. D'immenses cuves contiennent en suspens, le métal que l'élretricitć transporte sur des surfaces ou dans les moules qu'on y plonge; ce n'est pas seulement l'argenture et la dor'ure qu'on fait ainsi, c'est une opération comparable à la fonte elle-mème, puisque les

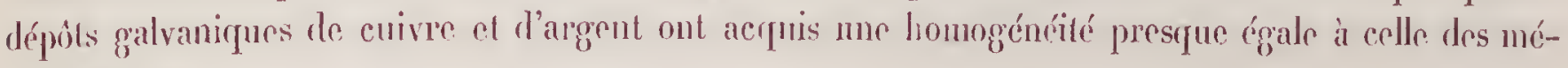
taux fondens.

Lal galvanoplastie est une découverte dont l'orfèrre commence à peine ì compiendre toute l'utilité, et ses applicatious ont eu dans les autres arts des résultats surprenants : la typographie et lia gravure sont en cela tributaires de l'orfèvrerie.

Par un chiffie qui a bien son éloquence, nous voulons cependant domner une idée des progrès de l'orlèvereric argentée : nous dirons que depuis son origine la maison Cinistofle senle a déposé chimiquement 275 nillions de grammes d'argent, ce qui représente plus de 50 millions de francs; cela représente anssi te confortahle, In bien-être et l'aisance qui pénètrent dans des milieux où juscqu'alors ils étaient inconnus; cela représente enfin une somme de travail considérable, donnée par l'ouvrier frauçais el produisant au commeree d'exportutiou des chiffres qu'on ne soupçonnait pas jadis.

Cependant notre adıniration ue ra pas sans rulelque crilique, car le défaut de ces vastess fabriques gî̀t dans l'eneombrement el la multiplicité des modèles; il faudrail un héroüsme rare chez un manuficlurier pour sacrifier certains modèles qui, pendant vingt ans, out fail lia fortune de sa maison, of les phus clairvoyants sa laissent aller volontiers à la routine, en ne renouvelant pas assez leurs lormes et leurs patrons. Ceci n’aurait pas les mèmes inconvénicuts chę nos voisins les Angglais, parce quïls sont moins changeants de gooit que nous-mèmes; mais pour une maison franẹaise, qni exporte en tous pays, il faul produire constamment des types nouveaux pour lutter contre les fabriques de même gonsure qui se créent partont st qui, d'Allemagne on d'Amérique, essaycut déjà d'introduire leurs produits sirr notre mirchié.

Nous n’arons pas cru nécessaire, à propos de l'argenterie, de faire un inventaire détaillé de toutes les piècess que produit la main de l'orfèvrer, nous n'allons pas essayer non plus de les nommer it propos de lorlêvrerie argentée. Tout ce qui se lait en argent se fait en cuivie ot ell mútll blane,

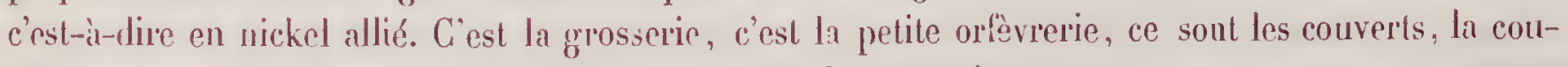
tellerire, ce sont les pièces de toilette, les girunitures de nécessaires, etc.

Liesposilion de MIM. Ciluristofle et Cie présentait tous les spécimens d'orfèvrerie, depuis les menus objets jusfu’aux grandes pièces décoratives; nous sommes entrés cliez eux déjil pour y voir quelques pièces d'argent, nons y entrons encore poill admirer des surtouts de table dont les mòdèles sont dus is des artistes tels que : MII. Mallet, Lafrance, Mat'murin-Moreau, Carrier-Belleuse, Delaplanche,

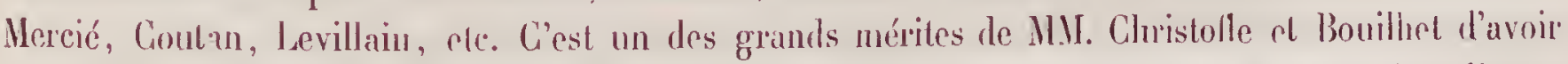

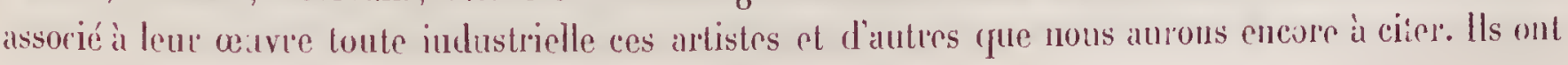


plus généreusentent el plus intelligemment offer' leur collaboration aux sculpleurs que ne l'ont fait les autres orfèvies, et l’ous se souvient du luxe el du gonit déployés par celte maison dans les exposilions de 1855 , de 1867 et de 1878 .

dussi s'attendait-on cette fois à un plus gros effort artistique; il n'a pas dépendu tout ì fait de MII. Christofle et Bouilhet yu'on vit dans la salle de l'orfèvrerie le plus grand surtout de table ‘u’aurait encore produit notre métier. Ces Jessienr's avaient proposé au Conscil munieipal de Paris d'eséculer, pour la grrande salle des Fêtes, une pièee d'art qui an'ail perpétué le souvenir du Centenaire. Les modèles ont été faits, nous en avons vo les maquettes en plâtre à gr'andeur d'exécution, présentées à l'Hòtel de Ville ì la place mène qu'aurait occupée l'oenvre de mélai si elle avait élé faite. Et pour donner une jdée assez exacte ale l'ordonnance du projet, nous dirons qu'il avait quelque analogie aree le fontaine monmmentale qui s’élère an centre mềne de l'Eyposition. II. Goutan, l'auteur de cette fontaine, avait modelé auparavant, sur les indieations de $\mathrm{H}$. Bonilhet, le surtout the la ville de Paris, et il n'est pas surprenant qu'il ait traduit en des proportions colossales l'œuvie d'ortèvie quill arait commencée.

Pour tenter le Conseil municipal, la majson Christofle avait fait des eonditions si avantageuses quil est surprenant qu’elles n’aient pas óté acceptées; nous ne savous pas ce qu'il faut loner le plus de la générosité de l'orlèrra ou du désintéressement de nos éliles. Eux qui cependant consacrent ì la décoration iutéricure de lHôtel de Ville des sommes considérables; eux qui donnent aux peintres, aux sculpteurs, aux ćbémistes, aux tapissier's, aux bronzicr's, des travaux si importants, oublient-ils yue les orfevres ont des droits égaux ì leur munificence? Nos ouvrier's se plaindront un jour d'avoir. cité nẹ́̂gligés.

Gelte grande pièce a done fait faute ì MIVI. Christofle, ils l'ont renplacée par quelques surtouts de moindre importance, dont plusieurs étaient conuus déjà; le plus récent, composé dans le style Louis XV, comprend une jardinière, deux eaudélabres, des coupes el des compoliers. Les norceaux les plus jolis de ce surioul sont les candélalbres à figures d'atlulètes qu'a modelées Matlun'in-Noreau.

Yous n'avons pas à parler maintenant des pièces d'al', auxquelles nous revicndrons par la suite, mais seulenent de l'orfèrrerie argentée; si nous n’entrons pas dans le détail des thés, des eafetières, des plats, des léguniers et mème des 52 modèles de couverts quil serait bien long d'examiner, nous pouvons dire eepentant qu'aucuu type absolument nouveau et spécial à cette importante fabrication ue se dégage de l'exposition actuelle; elle hésite entre le com'ant Louis XV et le goúl japonais Iont M. Bonilhet fut longtemps pénétré, elle obéit à des sollicitations si diverses : clients de province el clients de Paris, gens du monde élégant, cliefs de grrandes eompagnies, restanrateurs el maitres d'liôtels, qu'elle a quelque peine à trourer la formule qui pourrait satisfaire à tous ces besoills.

Et cependant, il fact uoter ure idée charmante, fraiche en son iuvention, surprenante el presufue incroyable ẹı sa simplicité de fabrieation : c'est l'impression directe des plantes les plus téuues et les plus fragiles dans le métal le plus dur et le plus résistant. De même qu'Aloüs Sénéfelder trouva le moyeu de dessiner sur la pierre nue fleur qui y était Lombée par hasard, de mème II. Bonilhnt a eu la pensée d'estamper sur' une plaque de cuivre les ıervu'es d'une fenille séchée; il a réussi el, d'essai cu essai, il est parvenu à incruster dans te métal les plus fines graminées, à imprimer les feuilles el les fleurs, à écrire enfin toutes les formes de la plante et à les conserver en intailles comme on les conserverait dans les pagees d'un herbier. Ce résultat obtenu, il n'y avait plus (pu'a peindre par épargne avec des dor'ures, des argentures ou des patines de bronze, les couleurs de ees plantes.

Cette décoration nouvello n'est plus un emprunt fait au Japon, c'est un retour à la nature, la frrande inspiratrice; clle se moule aux surfaces métalliques comme elle se mirail daus les plaques de Daguerre, et nous signalous ce procédé curieux comme la découverte la plus nouvelle et la plus extraordinaire de l'orlèvrerie en celte Exposition; je crois qu'on en peut tirer un grand parti. 
Du reste, la persévérance culalpporte M. Bouilhet ì diercher des procédés pour décorer l'orfèvrerie est counne de tous : il y a vingot ans qu’il s’applique à orner le métal; il a été l'uu des premiers à suivre le courant japonais, il a osé cloisonner el émailler les vases, alor's que ce procédé ćtait encore igyoré de ses confrères, il a grravé par des moyens nonveaux, c'est-it-dire fuilil a permis ì l'artiste de peindre directement au pinceau, sur la pièce elle-mème, des orruements el des fleur's, il réservail cusuite on crensail it l'eau-forte; puis, daus les fouds descendus, il incrinstail l'or ou l'argent par' les procédés galvaniçues.

Hullin, celte année, il est parvenu ì appliquer a l'orfèrerie le mode de gravure qu'emploient les graveur's en médailles; il fait modeler en gr'and l'orneuent de bas-relief' qui sera réduit ì une proportion déterminée; le modèle sculpté est ensuite fondu el placé sous la machine qui fonctionne automaliquement el qui répète, an moyen de fraises, la griasure plus rédıite avec une fidélité el ume minulie merveilleuses.

NI. Jauvier, le collaborateur de VINI. Roty, Nphrée Dubois el Chaplaiu, a prêté son aide ì MII. Christotle et $\mathrm{i}^{\text {cie }}$ pour l'exécution du service à thé dont N. Levillain avait fait les modètes.

Si nous comparons ces décor's au martelage dont les Américains araient introduit la mode en 1878 , si nous rappelons la fantaisic banale, imitation des peaux de crocodiles el de serpents, nous nianrous pas gremeld peine ì démontrer l'énorme supériorité artistique de la maison française sur ses rivales d'Hllemaģne et d'Amérique. Nous persistous à regreller que l'orfèvierie d'argent u’ait pas à nous offrir des tentatives aussi intéressanles.

La liste des collaborateurs de la maison Cluristofle et Cie serail longue s'il fallail nommer tous ceux qui ont une part dans le travail et daus l'iuvention. Le jury a dù horner le nombre des récompenses. mais il a cru ue pouvoir laire moins que d'accorder une médaille d'or à II. Brokchx, chele des ateliers

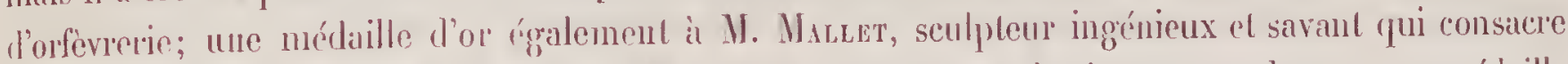
tout soul latent ì la maison Christofle; M. Gonn, anchitecte el dessinateur, à obtenu une médaille d'aryeul, ainsi que N. Trotrtŕ, chef de la ciselure, el MI. Latour, ehef de l'atelier de planage, qui fail

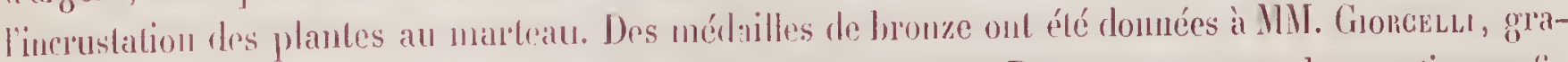

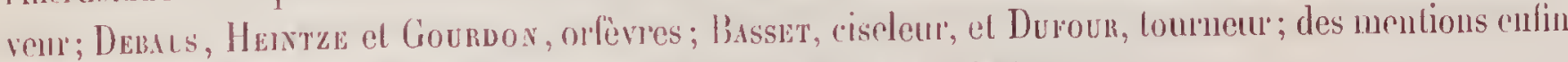

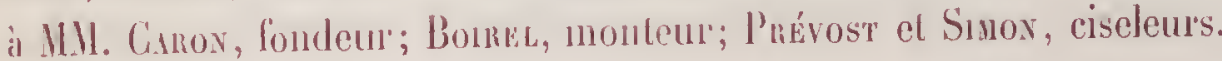

\section{MÉDAILLES DARGENT.}

\section{MH. Boulevger el Cie (A.), it Paris.}

If y arait autrefois une importante maison d'orfèvrerie qui fabriquail spécialement le couvert et créait à la maison Christofle une sérieuse concurrence; celle maison a récemment liquilé, mais il y a d'antres fabriques d'orfèvrerie argentée qui propagent en France ol dans les pays les plus bintains les ustensiles de lable el des objets d'un luxe relatif : l'une de ces fabriques est dirigée par M. Boullenger; elle s'est considrírablement augueutée depuis 1883 , éporue à laquelle efle s'est transportée i) Créteil. Il ny a pas ì tenter la moindre comparaison entre l'usine de Créteil et l'usine de SaintDenis, el, cependaul, des deux maisons, celle de II. Boulenger est la plus ancimne, car elle existait léji en 1810 , sous le nom de N. Hautin, grand-oncle de son clef acturl; ce n'est quiaprès que les brevels de Ruolz sont tombés daus le domaiue public que la maison a pu tenter d'entrer en lutle avec MIIJ. Chluristofle ol Cie.

C'est dans les articles de consommation conrante surtout que s'exerce l'industrie de M. Boulenger;

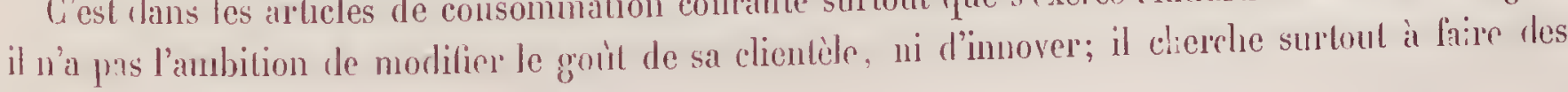


affaires el ses représentants voyagent dins le monde entier'; s'il n’a pas de dépôts dans toutes les villes de France, comme MII. Gluristofle, il tulte avantagensement cepentant contre les maisons angrlaises, allemandes el italiennes sur leur propre marché el nous avous eu des documents confidentiels qui démontrent les progrès ohtenus dans les affaires d'exportalion.

La fabrication du convert est la base de toute celle orfèrrerie, mais M. Bonlenger avail exposé

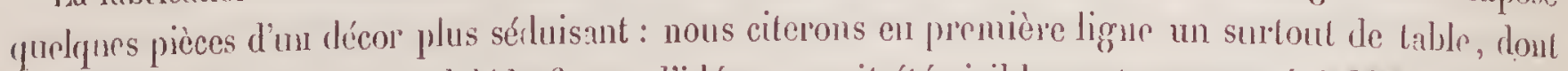
II. duguste Moreau avait modelé la figure; l'idée en avail été visiblement empruntée à MMl. Fannière et rappelait la Flore que nous avons décrite et qui appartient ì Il. Teyssier. Il secail superllu d'ajouter que ce n'étail là qu'une imitation très lointaine ef que, ni par la ciselure, ni piur la monture, la copic n'approcliait do morlèle.

Nous avions vu, Inrs du concours ouvert au Ministère de l'agriculture, la série de maquettes proposérs par M. Bonlenger et nous rel'ouvons à l'Exposition la statuette de M. Truffaul qui avait été choisie: c'est un semeuc, aux mouvemenls très justes, une réminiscenec agróable du beau dessin de Millet. Une grande buire d'argent doré el une loilelle, composée d'une cuvelle et d'un broc, démontrent que M. Boudnger s'essaye quelquefois ì des travaux d'argent vérilable; mais ces pièces sont lailes au tour cl non pas rétreintes au marlcau.

Un grand surtout aux formes tapageuses montre le décor qu'il faut ì certaines lables, c'est mu besoin en effet que ce luxe dont s'offenseraient les yeux des gens de gont; mais l'orfèvrerie a ses erigences, comme l'iudustric des meubles el des tissus, il faut pour les pays loiutains comme pour certains lıôtels de province des compositions voyantes, des surfaces polies et papillotantes el c'est à cela peut-être, que M. Bonlenger doil son succès commercial.

Le jury a décerné une médaille de bronze à ll. Dragras, direcleur de l'usine, el une menlion à II. Pountrait, cliel de l'atelier des orfères.

\section{Callatr $(N$.$) , B.y.rind el Cie, ì Paris.$}

Ge que nous venons de dire de M. Bonlenger', nous pourrions le répéter preśfure not ì mot en parlant de crtle maison qui a été fondér en 18 18.

II. Noël Cailar élail un négociant en métaux qui rachela le fonds connu sous la l'aison sociale de : Association des ouvriers cuilleristes. M. Bayard, orfèvre habile, qui avait dirigé la maison Thournt, vint prôter son expérience à M. Cailar; l'usine est à Paris, dans la rne Grange-aux-Belles, elle marche il la vapenr el emploie 200 ouvriers, lommes, femmes et enfauts; on y fait des couverts argentés ì base de nickel, dont l'alliage n'est pas alosolument le mème que celui des couverts Cluristofle.

La France consomme une part de ces produits, mais ils vont surtont à l'étranger ot notamment daus la République Argontine, en Espagne, en Égypte el en Turquie; c'est dire quils sont spécialement appropriés au gout de ces pays auxquels ne conviendraient pas les choses que nous ainlons ici.

Nous nous lappelons l'exposilion de MMI. Cailar et Bayard en 1878, el nous trouvous cette fois un sensible progrès; quelques pièces sont d'un goùt relativement sobre ol de formes correctes; le vase des boissons francrises n'est pas cependant pour nous plaire : c’est une composition prétentiens`, où le viu, le cidre el la bière sont représentés par des fiģures nédiocres. Beaucoup meilleur était le grrand surtout indien, anquel la présence à Paris de Buff:Jo-Bills domait un regain d'achatlité, car je ne suppose pas que MII. Cuilar, Bayard et Cie aient exprosé ces pièces comme une cemre nourelle.

Iis déclaren! faloriquer cinquante douzaines de courerts par jont, ce gui porterait a plus de 
180,000 couverts leur production annuelle; il est vai quà l'Lspagne et à l'Italie ils liveast ces produits bruts avant l'argenture.

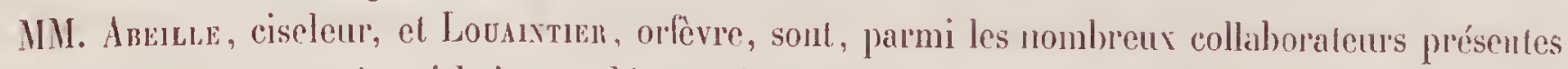
par leurs patrons, ceux à qui le jury a décerné des mentions.

\section{MÉD IILLES DE BRONZL.}

\section{Merle (Churles), ì Paris.}

Celui-ci n'est pas un orfèvie à la façon de ceux que nons avons vus, c'est plututôt un vannier, mais an lien de se servir de jones ou de fibres, M. Nerle ct ses fils font avec des fils de métal des corbeilles ì pain, des jardinières et toutes sortes de paniers d'un dessin charmant, quïls tressent aree beancoup d'adresse et les caprices d'une invention charmante. C'ette industrie n'est pas alsolument nouvelle, on la pratique en France depuis longues anmées el il nous est venu du Japon des travaus de vannerie métallique tout à fiit remarquables; nous croyons que M. Merle n’a pas ćpuisé les ressources de son métier et nous en vonlons pour preuve l'application nouvelle qu'il nous a montrée : dauns l'enveloppe enlacée qu'il prépare, il fait soufler par le verrier des bouteilles de cristal b'ane ou coloré; il fabrique ainsi des verres montés qui s"incrustent dans les mailles de la vanierie et forment des cabochons du plus brillaut effet. C'est à peu près le procédé que les verrier's autrichiens emploient avec leur filigrane; mais c'est d'un aspect plus décoratif.

MII. Henri et Félix Mente, collaboratenr's de leur père, ont obtenu des mentions.

\section{FRÉNIIS (Armand), à Paris.}

Sa fahricution trouve un débouché dans les hôtels et les restaurauts, elle consiste surtout dans la production des couverts de table; mais, en outre, II. Frénais nous présente un grand service de bronze argenté; il a suivi à tort la tendance qu'ont certains orfèveres à oxyder ent noir leur's objets d'argent véritable. Nous ne savons pas pourquoi celte vilaine mode a envali l'arrenterie, elle fait une tache désagréable sur la blancheur du linge. Dans la vitriue de M. Frénais il y avait un service à thé fort bien arrangé et d'un bon marché surprenant.

Gette fabrique occupe 120 ourricrs.

\section{Testeveide (Viclor), à Paris.}

C'rst l'ancienne maison Pauul Morin, dont il a ćté souvent question ì propos de l'iluminium et du lrronze d'aluminium. On espérait beaucoup de ce métal, il n'a pas encore domé tout ce füil promeltail; est-ce la faute de I'orfèrre? La légèrelé de poids de l'ahmminium, qui daus les arts a trouvé quelques applications, cause une surprise ì la main et n'a encore satisfait qu'à peu de besoins en orfèvrerie; il faut encourager et soutenir M. Testevuide c'll ses essais persévérants, sans quoi l'aluminimu n'aurait plus d'atelier en France.

II. Chavvicocrt a oblenu une mention. 


\section{MENTIONS IIONORABLES.}

\section{ILI. Laforge (Paul) el Cie, ì Paris.}

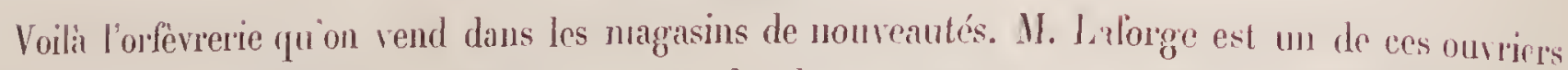
ingénicux, qui, s'aidant des apprèts qu'on troure chez les estanıpeurs, se servant des modèles découpés du commerce, fait toutes sortes de choses nouvelles et sinon jolies, du moins assez plaisantes pour satishaire in llhumeur changeante du pullic.

La qualité mailresse de celte orfèvreric est dans son incomparable hon marciné: un sucrier en eristal bleu cnveloppé de filigranes argentés coite chez. II. Laforge 3 fr. 60.

Quand le directeur d'un grand magasin choisit un de ces modèles, il te commande par donzaines ot même par grosses à l'ourticer, il l'oblige à des sacrifices nouveaux, et ce qui est surprenant, c'rst que l'orfèrre parvient ì y trource son compte; ce qui en souffre, c’est le bon goût, mais e'ost encore, prour les petits ateliers parisiens perehés an fond des cours et sons les toits, une victoire sur les grlandes usines d'allemagne ct d'Autriche qui menacent de nous envahir.

\section{H. Henny (A.-H.), ì Paris.}

Encore un ourricr faconnier travaillant seul chez hui. Il s'est fail une spécialité de la timbàe et du coulant et montre une certaine adresse ì souder les appliques sur des londs unis; c'est pour'puoi lui aussi emploie volonticrs les apprèts découpés el estanjpés, nous n'avons pas à vanter son gouti, mis plutôt son ingéniosité, sa persérérance; c'est bien lì l'ouvrier parisien indĺpendant, brichcur', qui pour garder sa liberté travaille deux fois plus quili ne le ferail à l'atclier el n'y gagne pas loujour's autant. Si

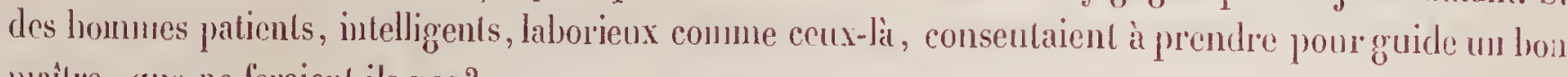
mailre, que ne feraicnt-ils pas?

\section{U. SAglen (E.-Victor), ì Paris.}

Il a longrtemps représenté à Paris limprortation anglaise, vendant surlout les services ì thé de cuivru

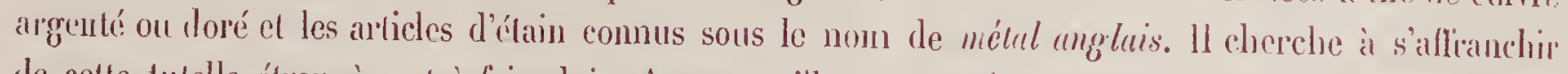

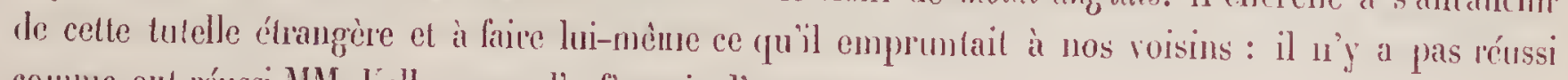
comme out réussi MII. Keller, pour l'orfèrrerie d'argónt.

\section{ORFEVRERIE D'OR ET D'ARGENT.}

\section{PILGES D'ART.}

C'est parr un sentiment de préférence, nous l'avouons, que nous avons réscrvé la fin de ce chapitre ì l'orfèverie d'art. Elle résume pour nous l'orférerie en ce qu'elle a toutes les libertés, toutes les ressources, toutes les richesses.

Expliquons-nous. L'orfère qui travaille pour l'église a deu maitres : Je prêtre et 
l'architecte, il obéil ì des lois ecclésiastiques qu’il ne peut changer' il est domimé par l'édifice, et si parfois on exige de lui des efforts superbes, on lui défend aussi d'oser.

l’orfevre qui fait la raisselle de table exerce un métice plus souvent qu'un art; son outillage est perfectionné, ses ouvriers sont habiles, il a des dessinateurs pleins de gont et des ciseleurs de tatent, mais il se meut daus la routiue des clioses, il est l'esclare de certains usages. Sa clientèle ne permettrait pas quöil clangeât rien ì li forme des ustensiles dont elle se sert et la mode qu’il subil, hien phus qu’il ne la crée, le ramène parfois en arriere ì des types qu’il essaye en vain de changer. Il n'a qu'uu métal ì employer : l'argent, il n'ose pas en modifier l'apparence, car presulue tous les moyens de décor hui sont refusés, il rra pas même ì cet égard autant de liberté que l'orfère d'église.

Et cependant, par une anomalie singulière, par une fausse interprétation de la valeur des mols, c'est lui qui a cnvalii le métier el qui s'y prétend mailre. Il croit aroir seul droit à ce nom d'orfevre el renverrait volontiers aux bronzes et aux bijous ses confrères, l'un parce que faire des flambeaux, des parements d'autel et des portes de cuive ne constitue pas, dit-il, un travail d'orferrerie; l'aulre, paree que fondre en or une figure, la marier ì des cristaux de roche, la ciseler, l'émailler, y sertir des pierres, demande l'aide de plusieurs ouvriers et confine anx travaux de bijouterie.

Ce n'est lì qu'une querelle de mots sans importance, mais elle tient à l'extréme division dı travail, à celte spécialisation des ateliers dont l'abus est un danger et que la classification des expositions derrait combattre an lien de l'exagérer.

Il faut une ingéniosité, une souplesse de moyens, une audace d'exécution très grandes à l'orfèvre qui s'adonne aux travaux d'art; il faut, suivant l'expression qu'employail ì son égard Théophite Gauticr, quil soit un hahile chef d'orchestre, pour savoir accorder les instruments les plus divers; il a sous sa direction le dessinateur, sil ne dessine pas lui-même, le sculpteur qui prépare ses marjuettes, le fondeur, le ciseleur, les orféres de l'atelier', le graveur, l'émailleur', le damasquineur, le lapidaire, le doreur el quautités d'autres.

Je n'indique qu'un petit nombre des métiers d'art qui gravitent autour de l'orfère et qui vivent de lui; mais chacun d'eux se subdivise, car charque ouvrier a sa facon spéchale; deux ciseleurs ne font pas de même el il faut à chacun d'eus, comme à tel ou tel graveur, donner la besogrne qui convient.

Il serail hors de propos ici d'énumérer toutes les capacités qu'on derait exiger d'un orférre, car nous n'écrivons pas un manucl; il serait plus intéressant d'expliquer de combien d'éléments dispose le maitre, depuis les métaux : l'or, l'argent et le cuive qu'il allie ef combine pour en changer les nuances, jusqu'anx gemmes les plus rares qu’il fait tailler chez le tapidaire. Nous allons, pour donner idée des ressources de cet art, faire ici l'analyse de quelques-unes des pièces exposées.

Ce n'est pas saus uir peu d'appréhensiou que nous abordons cette partic du rapport car il y faut parler de nous-mène: nous trésitions à le faire et un moyen s'ofliail qu'on 
a souvent employé, c'étail de passer la plume à un rapporteur adjoint qui nous aurait juggé dans un chapitre supplémentaire.

On sait ce que valent ces sortes d'arrangements, re sont de courloises complaisinces dont le lecteur n'est pas dupe.

Nos collegrues ont voulu que nous parlions en toute franchise, ils ont assez confiance en notre honnèteté d'orfère el notre bonne foi d'artiste pour croire que nous ne serions pas pour nous plus complaisint que pour d'autres. Certains ont prétendu même quril y avail là matière à une curieuse profession de foi et que le rapporteur de la classe 2h pouvait, en expliquant ses propres travaux, y trouver occasion de donner sa méthode mieus qu'en analysant ceus des autres.

J'ignore comment je vais me tirer de ee pas difficile. Je m'y risque néanmoins, et notre maison étant en dehors du concours, c'est par elle que je commence pour conserver l'ordre suivi précédemment.

\section{HORS CONCOURS.}

MM. Bapst et FaLIZE (ancienne maison Bapst), il Parris.

Comme plusienrs maisons déja citées, celle-ci a une origgine ancienne : (ieorges-Michel Bạıs, né en 1718 et mort en $177^{0}$, avail élé nommé orfèvre-joaillier privilégié du roi, en remplacement de Strass, son beau-père, le $1^{\text {er }}$ décembre 1752 ; depuis, s'est continutée en ligne directe el non inlerrompuc la gónéalogie des Bapst, jnsqu’à Germain Bapst, l’auteur de curieuses recherches el de savants travaux sur l'orfévrerie ${ }^{(1)}$. Les Bapst étaient joailliers de la couronne: its montaient les joyaux et en araient la goarde, mais arant de snecéder dans la farenrr rovale aux fameux Bohmer et Bossange, ils avaient été réellement orfèrres et ils le sont devenus de nonvean en 1880 , par leur association avec l'aucienne maison Falizc. Celle-ci n’a pas un si lointain passé; clle date de 1838 et a été crééc par Alexis Falize, mon père; il a joué dans son métier un röle important, y laissant la réputation du plus halhile drssinateur; en outre, il a contribué, sous l'anonyuat du fabricant, ì la fortune el à la réputitlion de plusieurs de ses confrères marehands ${ }^{(2)}$.

On récompensait plus souvent alors l'éditeur que l'auleur véritable, et les expositions ont considérablemenl gagné en sincérité : si quelques marchands accrochent encore leurs enseignes au Chanp de Mars, lit plupart restent dans leurs boutignes el n'osent plus prétendre à des récompenses qu'ils n’ont rien fail pour mériler.

Notre atclier n'est pas ì rrai dire un alelier d'orfêrre, on y fait de tout : des bijonx, des émaux, des

(1) Voici quelques-uns de ces ourrages :

Le Musée rétronspectif du métal.

Inventaive de Marie-Josèple de Saxe.

Testament du roi Jean le Bon et inventaire de ses joyaux à Isondies.

lítudes sur les métunx de l'antiquité et du moyen agge. (Ourrage récompensé par l'Académie des inscriptions et belles-lettres.)

Eitudes sur les coupes phéniciennes.

litudes sur l'orfèrerie firmçaise au sm siècle. -
Les Germain; orfevres sculpteurs du roi. (Onvrage couronné par l'Académie française.)

Les fouilles de Sicerskina (Caucase).

Histoire hes joynux de la couronne. (Ouvrage couromé par l'Académie frauçaise, prix Thérouanne.)

(2) A. Falize a pris part en effet à toutes les Exposilions de 1851 à 1873 , mais jamais sous son nom; ce n'est qu'en 1878 que la naison Falize a paru en titre dans une Exposition; elle a été récompensée d'un yrand prix. 


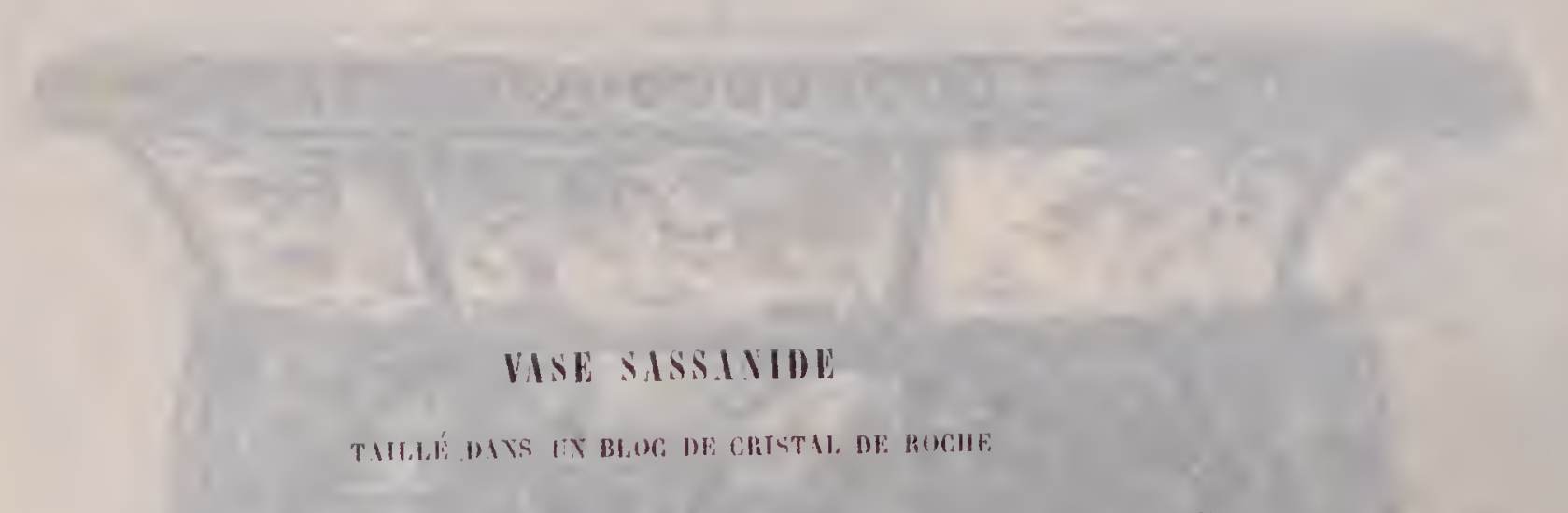

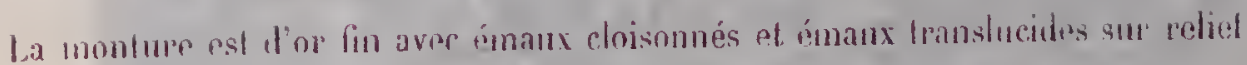

$$
\text { (1 } 3 \text { d'exiention) }
$$

Ippartient is V. Mf. Morrssot 


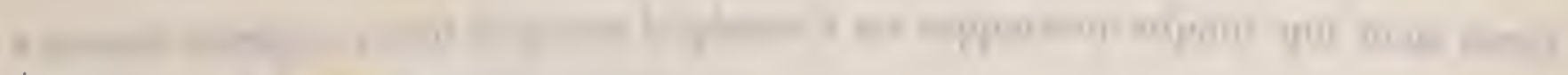
4.

!

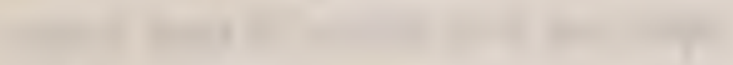

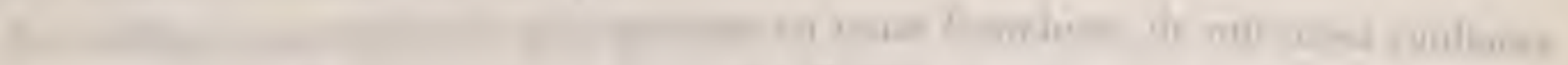
$n n^{\prime}$ In

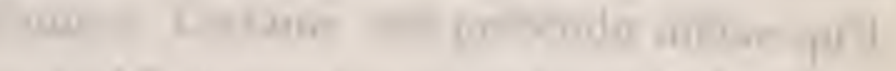

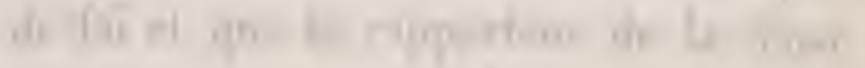

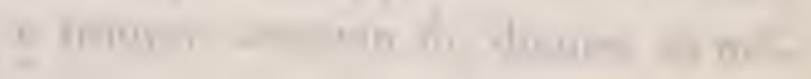

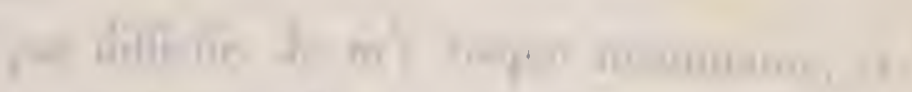

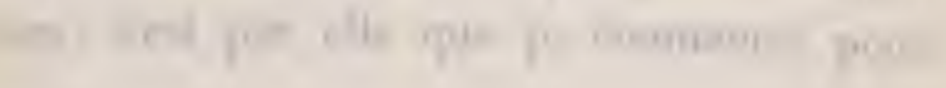

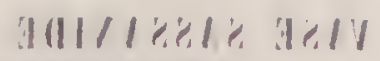

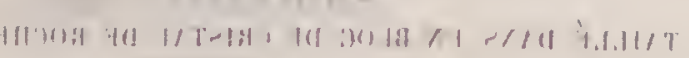

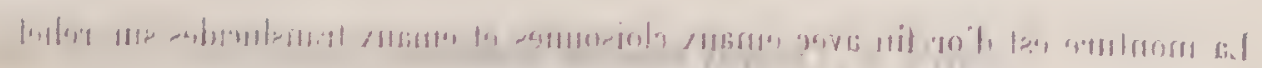

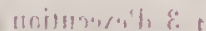

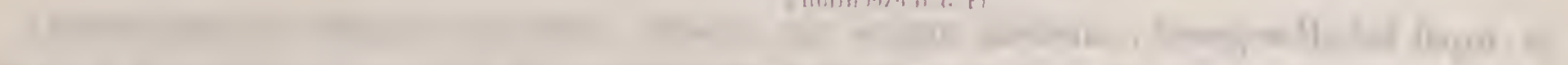

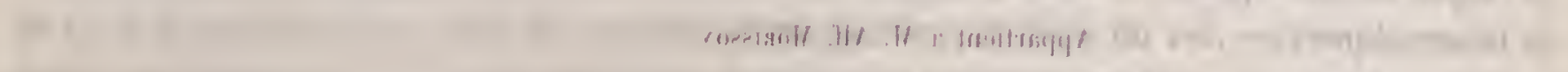

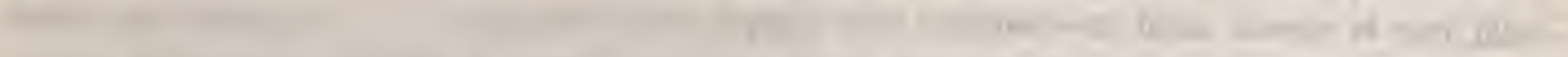

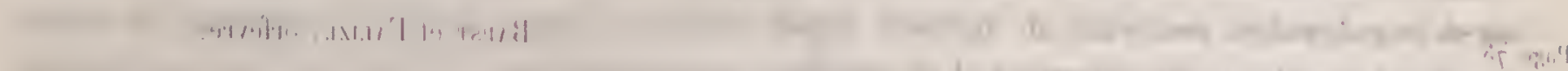

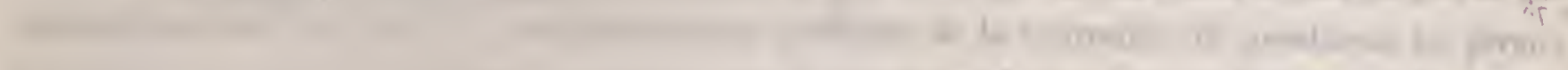

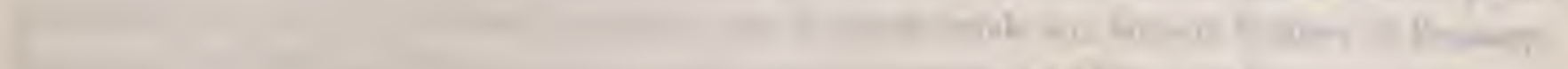

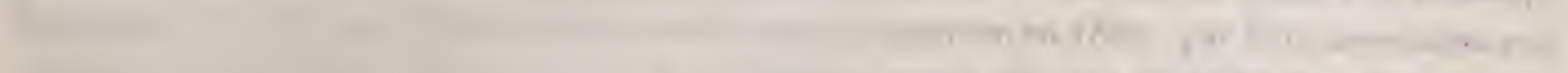

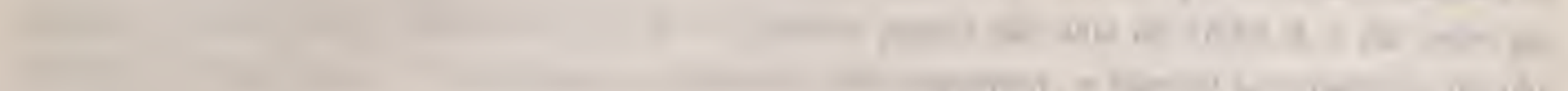

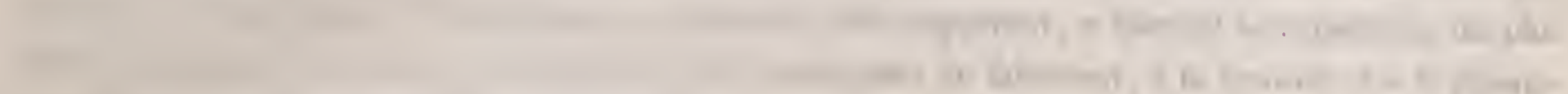

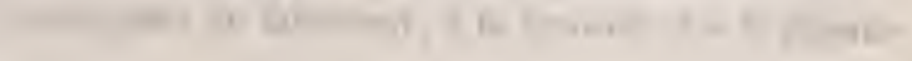

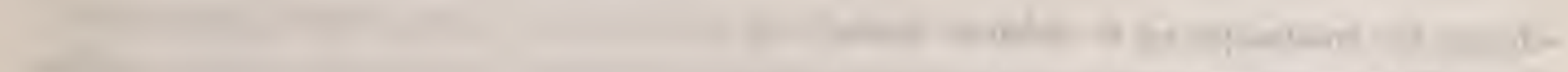

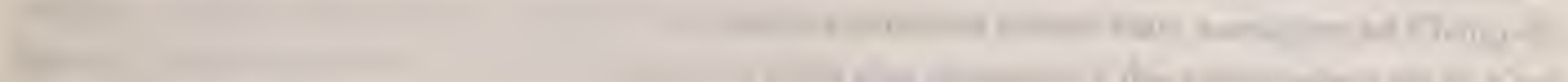

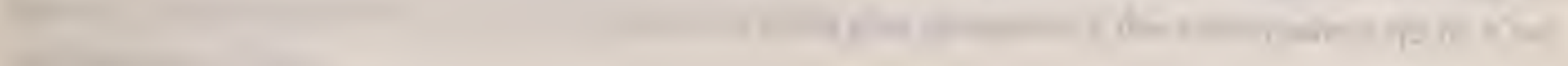

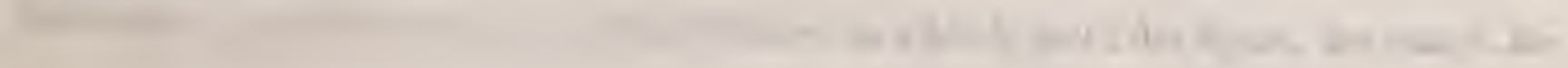

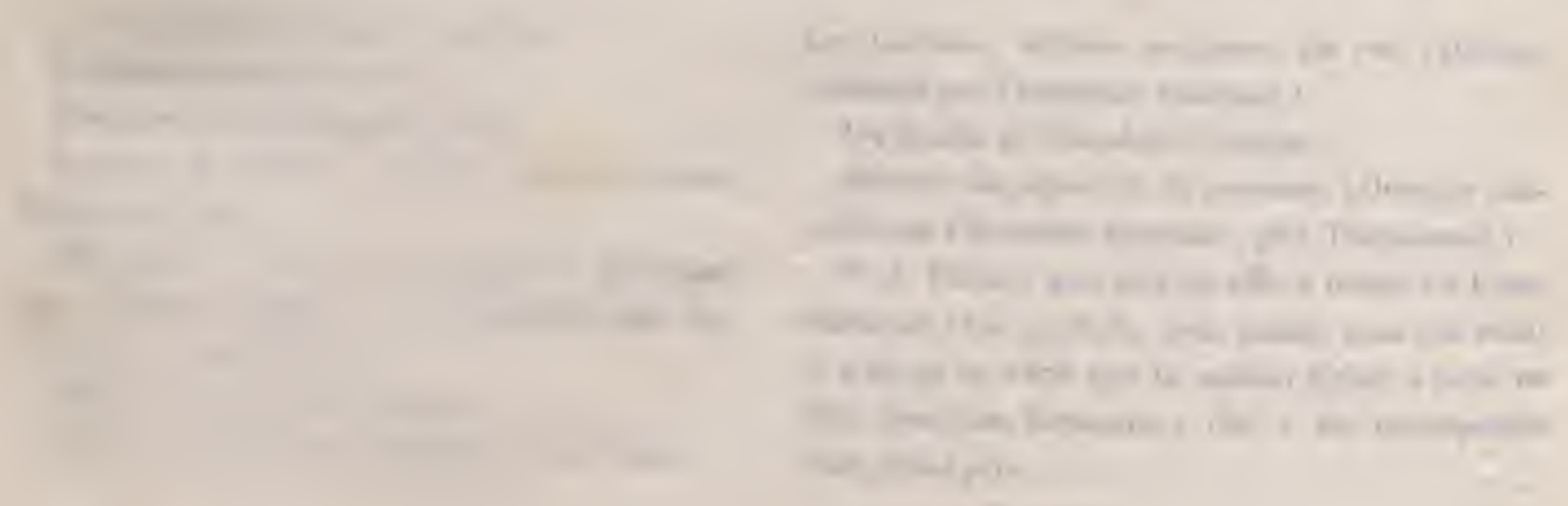




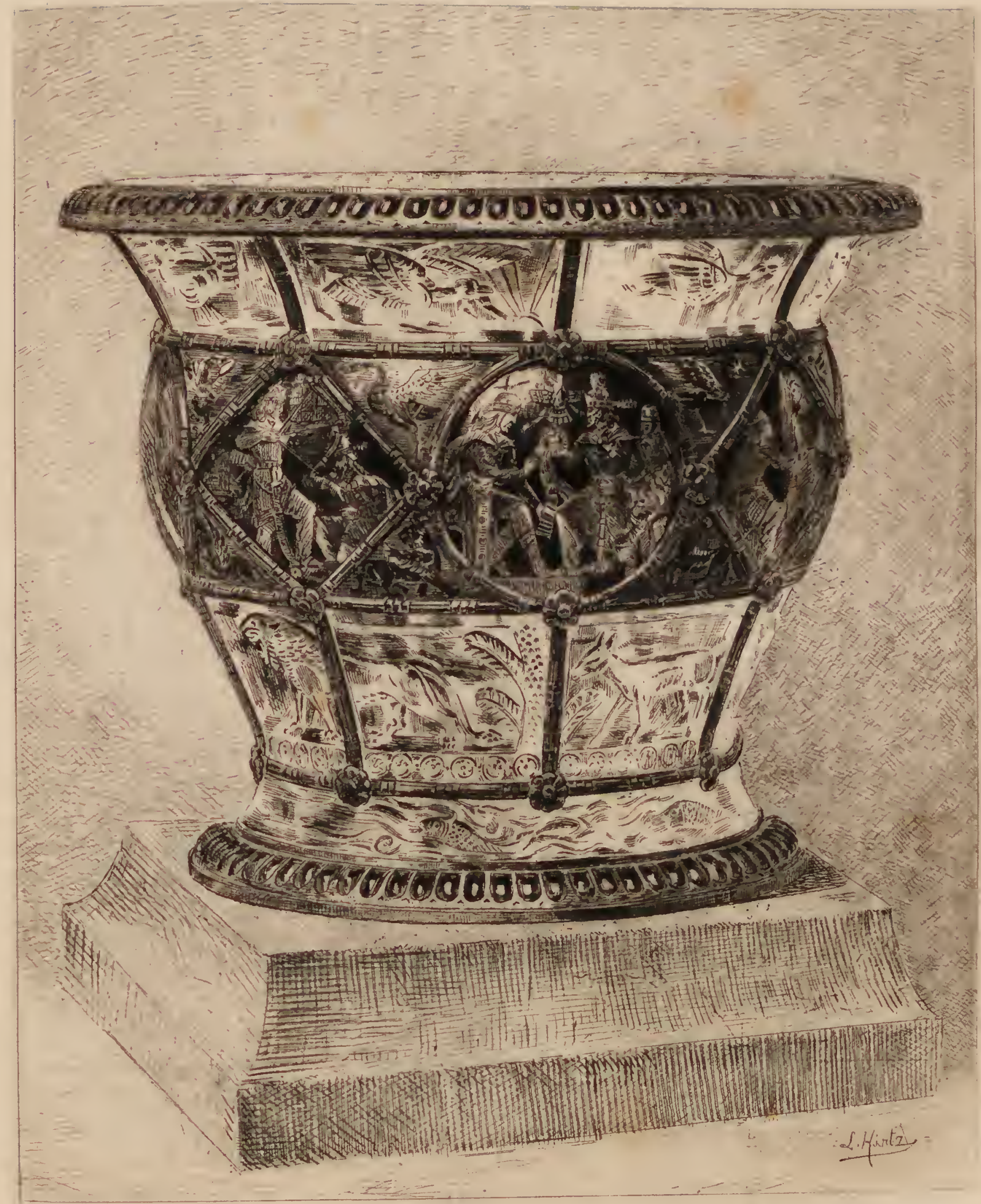



pièces d'art et des joyaux; ce qu'on y fait le moins, c'est la vaisselle: el nons alvons rirours, pour les ouvrages de four et de martean ì d'habites faegonniers qui travaillent au dehor's comme nos cisclenrs. C'est ponrquoi nous n'avons rien dit de fuelques services ì thé, de cafetières arabes el de certains modedes qu'on aurail pu citer. Nous n'indiqfuons que pour mémoire la riche garniture de toilette en vermeil que nous avons fitite en 1888 pour le mariage de S. I. I. la princesse Leotitia, et que les dames de Frunce réunies ì la ducliesse de Mouchy offraient à la princesse; nous mettrions quelque complaisance à décrire le grand plat d'argent qu'a acquis le Musée des arts décoratifs, si un critique antorisé n'en avait fait dójà un éloge trop flatteur.

Nous nous arrêterons plus volonticrs ì quelques pièces de surtout, qui ont un earactère bien déw terminé. La table oftre à l'orfèvre un cliarmant prétexte à déployer toutes les ressources de son art. C'est une ancienne tradition en France et les plus beaux onvrages d'or, d'argent ct d'émail, s'ils ornvient les dressoir's, occupaient ì l'heure du repas le centre de la table. L'usage n'en est pas encore revenu, on oblige l'orfèvre à s'en tenir à l'argenterie blanche ou dorée; l'ćmaillerie, les gemmes et les pierres n'ont pas le dioit de figurer sur la lahle comme aux $\mathrm{xIV}^{e}, \mathrm{xv}^{e}$ et $\mathrm{XvI}^{\mathrm{e}}$ siècles. Mais da moins les modèles de ces surtouts peuvent être l'œuvre d'artistes et nos seulpteur's ont loujour's eu plaisir ì nous prêter leur aide; ces mignonnes compositions les reposent du rude lábeur du marlıre et de la pierve; ils décourrent dans l'orlèvererie des surprises charmantes, ils y trouvent la réalisation de rêves caressés. Quand je me suis adressé à Barrias, à Millet, à Delaplanclıe, à Cordonnier, à Levasseur, la collaboration a été facile : j’ai tronvé en eux des amis preèts à m'éconter autant que je l'étais ì leur faire toutes les concessions. Nous nous sommes entr'aidés, n'ayant qu'um sonci, celui de fuir les banalités.

Il fant éviter pour la table les lourdes el solemelles architectures où des figures s'étagent en des équilibres prévus ou font d'inquiétantes pyramidns. il faut clıercher le piltoresque : si la figure lumaine se nềle aux fleurs, aux fruits, aux cristaux, aux lumières, ce doit ềre prar mue fantaisie spirituelle el vivante, comme si des génies familiers prenaient corps pour descendre an milien des manseries dı repas et animer la fête.

Ainsi avons-nous essayé de faire pour la corbeille de fleurs que nous avait conmandée M. Gustare Pereire. C'est une vasque ovale ornée de ciselures el de bas-reliefs dans le goît florentin. Sur le bord du bassin, une svelte figurine de fennne est assise, c'est Flore; elle semble aspirer le parfum des plantes, tandis que, grlissant d'un vol léger, Zéphyr vient vers clle, la caressant d'un souffle.

Cherdeville avait poétiquement rendu lis scène qu'Ovide a écrite; c'est la première tentative que nous ayons faite en ce goenre de décor; le talent souple el fin du sculpteur s'y prètait el nous regretelterons toujours ce c'tarmant artiste que la mort a pris si jeune.

C"est un thème plus sérieux que uous avons douné à N. F. Barrias, quand nous est venue la conmande d'un surtout de table pour un maître de forges; son usine produit les roves de locomotives et lis rones de wagons. Nous avons enlacé des loranches de eliêne el d'olivier autour de la vasque d'argent, et mons avons assis sur les bords uu forgeron de la Loire, Irapu, robuste, sortr de Cyelope moderne, ayaut à ses pieds la rouc qui court sur les rails de fer.

A l'autre côté la l'ortune, nue, graciense, prête à reprendre sa course et que des enfants rétiennent raptive, qu'ils enlacent el caressent, tandis qu'un antre enfaut lui dérobe la roue sur laquelle pose son pied fin; de la corne d’aboudance s'échappent la richesse el la prospérité. Birrias a rendu avec autant d'esprit que de talent cette allégorie, mais il n'est pas an poutoir de l'artiste de domner il ses œurves la vertu d'un talisman.

Plus récemment on nous a demandé de chercher un nonveau motif pour le service de la lable ct nous arous proposé plusicurs idées. Nous avions gardé le souvenir des adurirables figgneses couchées qui, à Versailles, entourent les bassins de la grande terrasse; il nous a tonjonrs semblé que c’étail le mollèle grandi l'un surtont magnifique. Et e'est pourquoi s"inspirant des famenc bronzes de Coyswox 
II. Levassenr a modelé pour nous deux figures de femmes, l'Automne et le Printemps, ou mieux: Jes fruits et les fleurs.

Des grroupes d'enfants s'ajouteront au surtout; ils porterout les lumières et ces figures dorées d'un ton psili émergeront des fleur's qui courriront la table comme Je parterre d'un jardin. On ne pouvait pas, dans la vitriue où elles étaient placées, expliquer l'emploi de ces statuettes. C'est dans l'imnense salle pour laquelle elles sont faites, sur la table el sous l'éclat des longgies, qu'il en fandra jugrer.

Mais les fignres d'argent ne sont pas toujours faites pour la nappe d'un festin. Barrias nons a inodelé une Psyché, qui a été donncée en prix par le Jockey-Club en $\mathbf{1 8 8 6}$, et Deloye a fait la jolie unaguetle du Pare qu’a gagné deux aus avant le cheval de M. Manrice Eiphrussi.

Ponr nn architecte de nos amis, nous arons exécuté en argent, en or, en jaspe el en lapis, le testimo:tial dont Ainé Millet avait sculpté Je modèle. Une fenme suspend à l'autel de Minerve l'équerre et te compas. Celte figure est une des plus jolies qu'alit conçues l'auleur de l'Ariune et du T'ercingétorix.

'Thutes ces orfêvreries sont achevées, minutieusement caressées par le ciselet de Mariotlon, de Jlulert, de Bralean, de Brard; comme la Vierge à l'cufunt, de Delaplanche, qui primitivement était destinée au couronnement du Czar, comme le saint Michel, de Millet, dont le modèle grandi couronnera probablement un jour la - Verveille-du-Miontr.

Vlais unus avons essayé de nous dispenser de toute ciselure et d'aucunes retouches et par deux fois nous arons coulé le mútal dans le monle où nous avions fondu la cire. Bingen, le très hahile fondeur, nous a prèté son expérience et Cordonnier a motelé ces deux statuettes qui resteront les types rares et précieux de ces prenuiers essais.

l'une est un moine, un bénédictin assis, il est de bronze, à la patine superbe el plus de cent amateur's se sont présentés, (pui voulaient acheter cette épreuve unique; elle appartient à M. Engogl Gros, de Bâle. L'autre, est nne élégante figurine, debout sur un chapiteau corinthien ì demi enfoni, elle tient le pic d'une main. une lampe de l'autre et fouille Ja terre pour y chercher les vestiges du passé. C'est l'archéologie, gracieusement symbolisée par une figurine qui rappelle les terres de Tanagra hien plus que les modernes peintures de Hamon. Coulée en argent, elle a couservé dans la peau du mótal les teintes nuancées de la fonrnaise; le moule a gardé l'empreinte du doigt de l'artiste, ancmne reloucle de eiselure n’a altér.' la pensée du maitre. C'élait la première fois qu'on faisait en argent une fonte à cire perdue, mais le procédé, s’il ne couvient pas à l'orfèrrerie courante, satisfait ì des désirs l'artiste, car Rodin a profité déjà de notre expérience.

Malheureusement ou a trop pen d'occasions en France d'utiliser pour l'orfèrrerie la bonne volonté des artistes: la générosité des ciloyens ne s'exerce pas ici, comme en Angleterre, pour décerner à des savauts, à des voyageurs, à des chefs d'industrie ou à des chefs d'armée, des témoignages de gralitude at d'admiration, Ces etestimonials $\pi$, ainsi que les nomment nos voisins, ont fourui anx orfertes de Lourleses, comme ils fournissent à cenx d'Amérique et d'Allemagne, des occasions de travail et des moyens de progrès. L'usage est différent en France, on attend la mort de celui qu'on honore ct e'est plus ou moins longlemps après qu'il a disparn, qu'on lui érige une statue de bronze snr son tombeau ou surr quelque place publique. La coutune en est touahle et la sculpture n'y perd pas ses droits, mais celui rg'on vent honorer ne jouit pas virant de cet homneur public; it arrive qn'un parti polilique déhoulonne le monument et remet à la fonte la statue de l'idole de la veille. Nos r'ues se peuplent eependant de honshommes de marbre, de pierre et de bronze, et je sais des senlptenu's qui trouveraient nne variante aimable à leurs compositions dans la recherche de fiğnres moins colossales, mieux proportionnées souvent aux mérites intimes et discrets des personnages auxquels elles seraient destinées.

Les seuls thèmes qu'on propose à l'orfèvre sont des prix de courses et de régates. Quelques soriétés de sport offrent charque année en prime aux gagnants des oljets d'art dont la valeur attrint un maximum extrême de 10,000 francs et le Ministre de l'aggricnlture décerne aux lauréats des conconr's 
régrionaux des vases et des grompes fo:rdus en argent. Il devient assez difficile de rinouveler ces modèles, loutes les apologies hippiquans, nautiques el agricoles ont élé trouvées. Nous avons pour notre part essayé de symboliser par la sculjtnre et l'émail peint la Pluie el le Beau temps, dans un larnmìtre d'argent qu'a offert aux régates de Nice la société du Yachı-Club; Grandhomme a peint à la faco: limousine les plaques de cel émail. Pour la Société des steeple-chases, nous avons composé un grand cartel d'argent de style Louis XIV dont Quinton a modelé les sujets: le Jour et la Nuit. Nous n'avions pu achever pour l'Exposition la grande jardinière que nous avaient commandée le baron Schickler et le baron Guslave de Rothschild pour le Jockey-Club. C'est à Barrias encore que nous devons les deux belles figures yni la drécorent. Nous avous vonlu qu'il y représentât la Seine et l'Oise. Elles s'enlèvent en liant relief sur les fonds, oì sont sculptés en arrière-plan les paysages de Longcliamps el de Cliantilly. Il uous a semblé ì propos de symboliser les champs de conrses favoris des sportmen français : la sillıonette de l'abbaye de Longehamps, telle qu'elle étail au temps de Louis XIV et la fière arehitcelure du châtean de Chantilly donneat ì la cischne des molifs aggréalbles; les deux rivières figurées par des femmes coucliées portent, l'une les emblèmes de la navigation, l'aulre le médaillon du grand Condé et des trophées de victoire.

La gravure en médailles s'est rue longtemps réduite aux commandes officielles et à la fabrication des nıonnairs. Elle jouit à jrésent d'un grand suceès, quel fues artistes inspirés lui font une renaissance splendide et après Ponscarme, Alphée Dubois, Tasset. Soldi, Dupuis, Heller, des maîtres comme Legros, Levillain, Cltaplain et Roty ont fail ì cet art excuis une jemnesse nouvelle où l'orfèvrerie puisera de runoi se transformer anssi. Ainsi ì Pise et ì Florence une école d'artistes se formait il $y$ a rquatre cents ans qui devait changer toutes les formules.

Nous anrons ì dire ce qu'on attend de ces maìtres, el nous reviendrons à eux; mais en notre vitrine, uous n'avons à siğnaler đu'un sẹul essai, c'est une plaquette d’argent modelée par Delaplanche et qui explique celte pensée d'un économiste ${ }^{(1)}$ : "Toutes les institulions sociales doirent avoir pour but lamétioration du sort moral, intellectuel et physique de la classe la plus nombreuse el la plus pauvre. n Elle a été offerte aux lauréats d'un concours onvert par les héritiers d'Isaac Pereire en 1885 el donnée aux membres du jury qui examina les mémoires des concurrents.

lin ce moment, Meissonnier exécule en cire le modèle d'une plaquelte que nons allons reprorluire. eı or repoussé, pour lormer la reliure de l'adresse que les jurés français offriront à M. Carnot, et qui perpétuera le souvenir de l'Exposition de $188 \mathrm{~g}$. Il est curieux de voir le peintre modeler ec fin hasrenlief, il le fait avec une délicatesse de détails, une amplenr de liģnes que j’armire et je l'écoute, m’enseiģnant un métier que je sais et qu'il ignore, mais qu'il devine avec son profond instinct de tout $\mathrm{ce}$ qui est beau, en sorte que j'anrais jlaisir', si ce n'était loors du sujet, à raconter ici un Messonnier' orferite.

Déjà, après l'Lxposition de 1878 , j'avais fait la relinre en orfèvrerie du livre qu'araient offert les exposants à M. Teisserenc de Bort, alors Ministre. J'y avais trouvé la collahoration de M. Chaplaiu, Ie graveur en médailles, et de P. Baudry, le peintre. J'avais rêvé cette année un projet superhe anquel jaurais associé Galland, le maître qui sait le mienx le secret de l'art décoratif. Des difficultés ont surgi, qui ont cimpêché de faire ce grand travail.

Combien d'œuvres retardées on indéfiniment ajournées! C'est ainsi que nous n'arous achevé ni la restitution en or de la monstrance de Raphaël que nous avions entreprise d'après la fresque du Vatican, la Dispute du Saint-Sacrement, ni la reconstitution de la Victoire de Samothrace, que nous faisons en bronze d'après le marbre du Louvie. Ces aurres importantes sont arrivées trop lard et ce n'est qu’à la fun de l'Exposition que nous avous apporlé un relable en ébène, en argoent, en lapis et en jaspe, que nous avions construit pour y loger un groupe de la Flagellation. Les trois figneres

(1) Isaac Pereire. 
qui composent ce groupe sont de Jean de Bologne ou de son école et ont fait partie jadis du sCabinet du Royn.

Nous nous essayons donc, oa le voil, à des compositions analogues à celles qui meublent la galerie d'Apollon, nous persistons ì les croire du domane de l'orlèv'e el nous sommes surpris d'être presspue les seuls à nous y risquer, surtoul à présent cin'une élite se prend de goût pour ces admirables choses.

Nous devons à la vérité de dire que cette élite n'ose pas encore aimer les choses moderues on aroure cel anour, nous sommes plus aidés par queliques grands amateurs élrangers que par nos nationanx. C'est pour Londres que nous avions composé les deux horloges que nous exposions. L'une est un bijou où la cisclure joue le principal rôle; Joindy et Delnye en avaient modelé les ornements et les figurnes; elle appartient à Lady Scotl.

L'antre est à M. Alfred Morrison; c'est ume œuvre plus complète, où l'horlogerie tient sa place par un savant mécanisme. Nous avons fail au mouvement compliqué qui donne toutes les divisions du temps une cage d'nr, d'argent et d'émail dont Chartes Blanc a dit quetque lien dans le deruier livre. qu’il a écrit(1). Ce pelit édifice, construil dans le styłe de la Renaissance française, porte les emblèmes des rnis Louis XII el Henri VIII et du pape Jules II. Les faces en sont occupées par des émaux de basse-taille, représentant les vertns chrétiennes el les vertus plitosophiques; le double cadran est d'émail cloisonné sur or et de cristal taillé, des statues d'or' sont assises aux quatre angles el la Vérité surmonte le petit édifice que constellent des cabochons d'amétliystes et de topazes.

C'est d'un effet très chaud, très coloré, l'harmonic de l'ŕmail, des pierres, de l'or et de l'argent, a séduit non seulement des arlistes mais des orfèrres, puisque celle pièce a été imilée en ruelquesunes de ses parlies.

Avant cela déjà nous avions fail deux autres borloges : la pelite pendule carrée, où dans un bloc dlivoire nous avions, à l'exemple des imagiers d'autrefois, sculpté les donze mois de l'année, la Salutation angrélique el la parabole des vierges sages et des vierges folles; des montures d'or encadraicut l'ivoire.

L'ivoire encore nous avail été d'un grand secours pour animer la pendude. Uranie. Carrier-Bellense arait scnlpté pour nous dans la belle matière la déesse qui observe les astres et les enfauts qui lui présentent le compas el le sextant. La sphère céleste était d'un pur cristal de roche, encerclé d'armilles d'or; les dieux y évoluaient marquaut les jours et les mois, et la base où reposaient les figures élait en lapis de Perse, monté daus loor fin, avec des émaux comparables a ceux de la belle éporque. Nons arons dépensé dans cel ouvrage tout ce que nous savons de notre mélier, nous y avous été aidé par Grachant, le plus habile orfèvre que nous sachions; à d'autres comme à nous, ect liomme de Lalent a prêté son concours, mais aucun n'ayant proposé son nom au jury, nous nous solumes fait un devoir de le patronner el de lui attribuer la part de mérite qu'il a dans l'exécution de la pendule Uranie. Le jury lui a accordé une mérlaille d'or de collaborateur; je m’en réjouis, bien que depuis l'achèvement de celte pièce, nous n'ayons plus fail aucun travail eusemble.

C'est dans notre aletier que s'est faile entièrement l'exécution de la Gullia el notre principal collaborateur ici, c’est l'artiste qui a modelé la fignre el a taillé l'ivoire avec tant de boulheur, M. Morean-Vauthicr. Ce bloc d'ivoire phénoménal était précieux déjà par sa rareté, avant de devenir l'admirable morecau de sculpture qui nous avait séduit el que nous avons voulu habiller d'or. Nous avons obéi à un sentiment loul personnel, en faisant de cette gurerière un peu triste et dédaignense, mais fière, résolue, indomptable, une Gallia. Nous l'avous voulue telle qu'elle est, avec le casque et la cuirasse, avec les nuances assourdics de l'or, les damasquines du fer, les cuivres rougis, les mailles d'argent de l'armure et le pullic nous al donné raison. Ge buste d'orfêvierie a produit une impression

(1) Grammaire des arts décoratifs, par Ch. Blanc. 
très profonde sur cenx qui l'ont vil; c’étuit l'curre la plus osée, le morceau d'orfèvrerie le plus décoratif et nous avons senti vibrer si réellement l'âme de la foule, que nous avons refusé l'offre d'un átranger: nous étions prêt à céder à l'État la Gallin républicaine, on la voulait an Louvre ou à l’Élysér; française, on la voulait ì Cihantilly. Elle est rentrée dans notre atelier, n'ayant pas voulu changer de nom pour symboliser une autre nation que la france. Ce busle marque un retour à la seulpture chryseléphantine, an mélange de l'ivoire el des métaux précieux comme lé pratiquaient les Grees, comme Simart l'avait essayé pour le duc de Luynes avec Duponchel, et nous allons tout à l'lieure trouver chez nos confrères de fréfuents échantillons do cet art charmant. Go n'est pas seulement Yivoire (qui s'allie au métal, e'est la pierre dure, er sont les gemmes, et le lapidaire est un de nos plus utiles ouvriers. Norel avait ressuscité celte branche importante de l'orfèvrerie vers 1840 , el après lui Duron s'était passionné pour ees ouvrages combinés de lapis et d'argent, de jaspe et d'or', d'agathe et d'émail.

On trouvail en notre vitrine une buire de jaspe ornée de figures énaillées que Garnier a modelées et eiselées ave toute la fougue de son talent et une minuticuse adresse. Mais le principal ouvrager, celui pour lequel nous avous une préférence marquée, e'est le vase sassanide. Je ne veux pas essayer de le décrire ici dans ses détails, mais je déclare que pendant trois ans il m’a occupé et a tenu en haleine trois de mes meilleurs ouvriers. Il s'aģissait de faire en or, en eristal et en émajl, un vase ì peu près tel qu'ent pu le composer un artiste du vi siècle vivant à la cour des Perses. J'ai supposé que Chosroès le Grand avail donné l'ordre à son orlèvre de monter en or un vase de cristal appartrnant an trésor royal el conservé depuis la prise de Babylone : quil y avail fait inserire l'histoire de son père Cahadès. J'ai donc reconstitué d'ahord ce vase tel qự̛l aurait pu être fait par les Assyriens. C'était la partie la plus séricuse de la composition et l'une des plus difficiles; le modèle trouvé, j’ai dù le faire tailler dans un énorme bloc de cristal; Varangoz m'a prêté son expérience et il a fait, dans son atelier de Saint-Siméon, un chef-l'œuvre unique en son genre; mais sur ce bloc il restait ì graver les figures d'animaux sacrés qui symbolisent la terre, le ciel et la mer; j’avais préparé les modèles; j’avais avec Joindy étudié les admirahles senlptures de Nimroud et de Koyoundjik, qui sont conservées au British Museum. C'est Cour'puin qui, patiemment pendant quinze mois consécutifs, a gravé it la soue ces bas-reliefs dans la masse pesante, conservant le caractère puissant de ces beaux modèles. A l'atelier, Bouchon et Lancosme ont entrepris la monture de la gemme; ils ont égalé Glachant comme. habileté et l'ont surpassé peut-être, car il fallait, outre les moyens de l'orfèvre, la légèreté de main dı lijoutier. Cetle ouvre est absolument sans défuut. Je l'ai décorée ensuite d'émail, y racontant par la couleur que rien n'efface, non pas seulement l'histoire du roi, ses chasses et ses guerres, mais y démontrant ce qui est plus intéressant pour les orfêvres, tous les procédés d'émail : l’émail cloisonné, l'émail champlevé, l'émail à taille d'épargnon, l'émail translucide sur relief et l'émail à jour' Hirt\% ol Pye ont ćté en cela mes précieux collaborateurs, et j’ai employé comme émailleurs Tourrelte et surtout le vienx Routhier, dont ce fut le dernier grand travail; il mourut peu de temps après l'avois" aclievé.

Des grrenats incrustés complètent la décoration de ce vase qui appartient à M. Alfre.l Míorrison, de Londres. Je me plais à dire que c’est à lui, à son grand goủt, à la confiance qưil m’a donnée ainsi qu'aux conseils si intelligents de II $^{\text {me }}$ Norrison, dont la compétence est grande en ces matières, que. je dois d'avoir pu commencer et mener à bien un ouvrage dont je tire quelque vanité.

C'était ume application de l'émail, dis-je, mais depuis quinze ans je m'essayais à refaire les émaux translucides sur reliefs. J'avais en 1878 montré mes premières tentatives sur or et sur argent. Cotte, fois-ci, je pouvais enfin exposer les grandes plaques d'or reproduites d'après les tapisseries de Scris et l'émail commandé pas le Musée de Saint-Pétersbourg.

J'ai pris au Lonvre mes premières leçons sons la direction de M. Barbet de Jouy; jai vu les émaux de Londres, ceux d'Aix-lat-Chapelle, ceux d'Orvieto, ceux de Florence, ceux de Munich, les pières 
admirables de sir Richard Wallace, de V. Spitzer, du baron 1. de Rothschild, et enfin la famense coupe du baron Pichon. C'est par l'étude comparée de tous ces émaux célèbres que je crois avoir rendu a l'art de l'orfèvrerie franģaise un procédé d'émail perdu depuis trois cents ans et qui avait fait sa gloire la plus incontestíe. (Voir Cellini.)

J'espère qu'on me saura goré d'avoir' mené à bien une lâclie patiente et difficile; j’y ai ćlé considérablement aidé par un admirable ouvrinr, el par ce mot ouvrier jo désigue avec intention l'homme fo travail qui aime son ontil, et mène aree autant de goût que d'lıabileté la leseggne difficile cu'on lui doune: M. Pye a été mon plus précienx et plus indispensable collaborateur en ce travail; j'eslime mos éman supéricurs pare quil les a faits et le jury, émerveillé de son talent, lui a décerné nne médaille d'or. Honillon, Tourrettr, Routhier, m’ont aidé comme ésnailleurss, mais le rôle principal appartient à celui qui tient l'ćchope, et Pye a la plus grande part du mérite dans l'achèvement de ers ćmaur.

L'émail de hasse-taille était dans les ateliers d'orfèvres le moyen de décoration le plus estimé; on l'a pratiqué en Allonaģue, en Italie, en Espagne, en Flandres, en Anghleterre, mais surtout en France; nos inventaires font sonvent mention de ces tableaux d'ćmail qui ont précédé les émaux peints; cenx-ci ne sont en réalité que la vulgarisation et la copie d'abord rudimentaire et imparfaile des admurables las-reliefs émaillés qqui avaient fait la réputation des maît’es.

Les Penicaurl. les Léonard, les Courtryss, sont venus après; ils ont changé l'émail des orfèvres ot cu out fait un art de peinture. Yons aimous certainement aussi ce mode d'émail, mais il n'est pas nôtre autant que celui où le métal joue sous l'émail, sans l'artifice de coulenrs ajoutées à la spatnle et morlelées dauts la pấle.

Cependiunt nous empruntous encore à nos peintres leur aille, et nons aimons à citer les noms de Ca. Popelin, de Grand'homme, d'Ilfred Nayer, de Garuier, de Courey, comme cenx de peiutres ámailleurs habiles qui u'out pas de rivaux, et qui gardent à la France la répulation qu'elle avait enr autrefois dans l'art de l'émailleric.

Nous avions exposé plusieurs plaques d'émail peint qui démontraient cette supériorité: des portraits d'enfunts, des plaques sur or, car l'émail peiut jone différemmeut suivant quıe la plarque de mútal est d'or', d'argent ou de cuivere, et l'or fin lui donne une chalcur', une intensité que rien n’égale. Nous avions de Graurl'homme une plarque représentant les grè̀res de Hont-Saint-Miclıel, avec une. jollie figure de frmme assise parmi les vagues et les blanches mourttes. Mais le plus bel émail de l'Exposition étail exposé dans la classe de la céramique chez MIM. Grand'homme et Garnier; ils l'ont copić d'aprè̀s me arpuarelle rle Gustave Morean et c'est assurément le maître qui sait le mirnx composer pour l'émail. Cette helle plaque appartient an Mnsée des arts décoratifs.

Qurlques coupes émaillées présestaieut une applicalion rajeunie de l'émaillerie, ce sont des sortes de draggenirs, des tclıckas russes. Nous eur avous fait aussi en argent qui sont un joli prétexte à ciselure.

Au cours de cel examen, nous arous nomné plusicurs de nos collahoraleurs, nous vondrions dire Ins noms de lous ceux que nous comnaissons el dont nous apprécions le talent. Trente ans de pratique nous ont mis rn rapport avec nos ouvriers et nos artistes; nous savons les nuances qui spécialisent ir talent de chacun et le secret de l'harmonie d'one œenre est souvent dans l'emploi raisonné des mains qui y participent. Combien de dessins et de modèles sont compromis par l'ouvrier! Que de projets clarmants ont été mal cxécntés! Il faut donc une surveillance incessante, un soin du détail, une direction ininterrompue; l'orfève doit inventer et conduire, il ne doit pas s'absenter, il faut cu'il garde. entière la responsabilité de son travail, surtout s'il s'agit des ouvies d'art dont nous parlons; un nubli, une négligence peuvent tout perdre. Quclque excellent que soit le contremaître, un patron vraiment soncieux de sa réputation et aimant son métier n'alıdique jamais; il doit vive entre son atolier el sa bontique, dessinant, étudiant le goût de sa clientèle, et suivant à l'atelier lez plases progressives de son travail. 
Ciest ainsi que mon père mia appris à faire el cést ainsi que font tous ceux de mes confrères qui méritent d’êtro loués.

\section{Saynoz (Gustuve), ì Paris.}

II. Gustave Sandoz fait aussi partie du jury ol à en titre ne peut coneonrir, lien cfu’il expose à la fois dans les classes a 6 et 37 , e'est-it-dire avec les joaillier's ot aver les horfogeres. C'est surtout un liorloger habile et son nom est intimement altaché à la science de l'horlogerié; il appartient à une ancienne famille suisse qui a illustré celle industrie. Ia compétener de VI. Sandoz en matière d’exposition et ses qualités d'administrateur le désignaient an ćsoix de ta Commission; les services rqüil a rendus dans une cireonstance récente ne pouvaient être oubliés el, colte fois encore, il s'est prêté aux désirs dn Ministre on acceptant de représenter les intérêts de l'ḱgypte et en suppléant un juré cmprêché. It a sacrifié ainsi le bénéfice quil aurait pu relirer d'mne exposition où il temait une Inege place ct oì il potwait prétendre ì me double récompense.

Nous n’avons pas à appréeier celles de ses ouvres qui seront jugées dans les classes 26 ot 37 , mais nous avons a dire grand hien d'un miroir concu daus le style des ouvrages italiens du xvis siècle; la cisclure, les ors et la lapidairerie s'y combinent en des tonalités harmonieuses, el cela rappelle certaines pièess de la galerie d'Apollon eontemporaines de Marie de Médicis. Nous croyons savoir rue M. Philippi a collaboré dans une large mesure à ce travail, e'est une oeuvre faite en commun par les deux confrères; elle est supérieure à ce que M. Philippi avait exposé sous son nom seul.

\section{GRINDS PRIX.}

\section{Christofle et $C^{i e}$, ì Paris.}

On a pur apprécier l’importance de la maison Christofle el juger de son opulente argenterie en mêne temps que de sa fabrication courante de vaisselle et de couverts argentés; il nous reste à dire le rôle qu'clle joue dans l'orfèvrerie d'arl. Dejà nous avons raconté la proposition tentante qu'elle avait faite an Conseil mmicipal de Paris : cétait là un thème altrayant pour nos sculpteurs. Si l'exécution de celte cuvre grandiose r'a pas été poursuivie, MV. Ghristofle et Bonillıct n'en ont pas moins exposé des ouvies fort belles, que nous allons essayer de décrire.

C'ŕtail d'abord l'Amphitrite; Mercié l'avait modelée en 1878 poir le grand surtout du duc de Santonia el clle était alor's fondue en argent et ciscléc. Elle est l’ivoire celle fois-ci, el c'est Scailliet, un des lons élèves de Morcan-Vanthier, qui l'a sculptée. Une draperie d'or fin envolée ajonte sa note clraule à l'ivoire pâle; la déesse lient à la main une branclıe de corail rose, elle a des perles ì ses pieds. Ces nuatières précienses ont me harmonie très délicate. Il avait été question d'offrir l'Amphitrite à l'un des plus laauts patrons de l'Exposition de $188 \mathrm{~g}$. C'est dire qu'elle était jugée l'nn des phus jolis oljets parmi ceux qui ont figmé an Clianp de Mars.

Déjà après 1878 , c'est à MM. Cluristofle et Cie qu'avait été confiée l'exécution du testimonial qui fut offert à M. Dietz-Monnin, nous l'avons revu près de l'Amphitrite. C'est une Minerve, non plus la déesse arnúe, mais la Minerve laborieuse : elle a quitté son égide pour prendre le lahlier de cuir, elle lient un marteau et s'appuie sur l'enclume, clle n'a gardé de ses attributs anciens que le ramean d'olivier qu'clle offre comme un gage de paix. M. Delaplanche avait été hien inspiré cn composant cettr figne, qu’il a baptisée Pax rt Labor; deux enfants s'appuient au socle el tienuent ouvert le plan 
de lEvensition de 1878 . Ce beau groupe foudu en argent avait été offert par les jurés français an directeur de la section française.

C'est égralentent ì M. Dietz-Ilonmin cue fut offert le testimonial de l'exposition d'Ansterdam en 1883 : c'était un grand vase dédié aux arts; la forme en est helle, nous le revoyons arce intérèt; les colorations d'or, d'argent et de cuive, rappeltent un pen les essais faits en ce genre pour le grand vase d'Anacrénn.

Chaque année, avons-nous dit, le Jockey-Cilub domne en prix, anx courses de printemps et d'antomne, deux oljets d'art. Il s'était adressé en 1879 el en 1886 ì Ciluristofle. L'une des compositions est du regretté Carrier-Bellense, elle symbolise la Victoire et appartient aut baron de Rotlischild; l'antre prix a été gagné par l'écurie du haron Sclickler: c'est une délicieuse figure de la Jcunesse, et c’est Vercié qui en est l'auteur. Ces pièces sont uniques, ce sont des œuvres originales dont les plattres ont été brisés après la fonte: ì leur mérite artistique s’ajoute done une valeur de curiosité que n’ont pas les bronzes répétés par un éditeur, füt-il soigneux de sa réputation comme Barbedieme, et comme hui jaloux de bien faire.

ll rien est pas de mème des choses qui vont suivre, elles sont répétées charque année en noubre plus ou unoins considérable : ce sont les objets d'art donnés en primes d'tionnenr dans les concours régionanx, par le Ministre de l'agriculture. C'étaient jadis des vases, des coupes, des groupes d'mue allure assez ordinaire, où la valeur do métal l'entportait de beaucoup sur le modèle et la façon; on a eu la pensée d'ourrir des concour's entre les orfêvres et les artistes, et nul n'a fait un effort comparable à celui de MN. Christofle et Bouilhet; au lieu de prendre ì la fable ses mythes et ses dienx symboliques: Cérès et Bacchus, Vertumure et Pomone, ils ont voulu faire raconter le poène de la terre par ses acteurs réeds, par uos paysans. Hs ont dit aux sculptenrs: "Faites cornme les peintres, innitez Troyon et Millet, prenez le laboureur, le vigneron; ils ont des altitudes aussi belles et plus justes que vos modèles d'atelier, et du moins vos outures seront comprises par ceux pour qui vous les faites r.

Y a-t-il au monde une école qui soit comparable à notre école de sculpture? Les artistes à qui II. Bouilhet sétait adressé acceptèrent lidée avec enthousiasme et je me sonviens de l'impression de surprise et d'adniration qu'on éprouva, quand s'onvrit rue de Varenne l'exposition des maruettes: le public parisien ne sait pas tout ce qui se dépense de talent et ne voit pas toutes ces manifestations d'art et de goût; (quelques privilégiés allèrent seuls examiner ce concours et le jury, s'il eit osé, anrait attribué eu bloc tous les prix et toutes les commandes à la maison Chiristofle. Elle en a en la phus graurle part et cétait justice; nous avons retrouvé à l'Exposition ces jolies compositions fondues en argent, acłevées: quelques-unes cependant ont perdu l'accent qu'a vait l'esquisse.

Déjà le regretté Lafrance avait autrefois, ì l'exemple de Millet, modelé pour Clnristofle un Semeur au geste large et superhe, mais il l'avait fait nu: il avait eu peur de l'hobiller de la blouse. Mathurin Horean a fait le Funcheur el lu Glaneuse, tels qu'ils sont; Gautherin a traduit comme l'eùt fait Bastien-Lepage le Retour des champs, et Coutan la franeuse. Pour le prix de larboricultnre, Longepien a imaginé une jolie statuette, le Greffeur, et pour celui d'horticulture une autre, l'Arrosuyre : c'est uu jardinier tel que nous le voyons les soirs d'été : coiffé du chapeau de paille, les pieds chlaussés de saloots et les lourds arrosoirs en mains, il donne ì la terre altérée l'ean qu'elle hoit avec ivresse. Fadguière a fait le Conducteur du t murean et Jac(puemart l Attelage des beenfs : ces petits groupes sont lieaux comme de grands morceanx de senppture el quand je voyais dans la section belge le grand hronze de Mignon, je n’éprouvais pas płus de plaisir qu'ì voir ces délicienses ródnelions. Gantherin a représenté la T'onte des moutons, de façon pittoresque : e'est joli à l'avir. Matlet et Tuevillain ont fait pour la sériciculture et la viticulture des vases décoratifs oì la Vendange et l'Élevage des vers à soie sont racontés avec antant de clarme, d'esprit et d'art que dans un las-relief antique. Hiolle al b́é poc̀te et a hien symbolisé dans la Source le prix de l'urrigation. It n’est pas jusru ä l'animal immonde 
et délicieux (qu'a si gariement chanté Ilonselet que n’aient illustré nos artistes: Ronillard a fait lu Porcherie et Nathurin-Moreau a pris sur le vif le Conducteur qui mène les porcs an merché.

Tout a l'henre, je disais qu’il appartient anx graveurs en médailles de rénover l'orf'rverie et jai déjà dit cueleques mots des modèles créés par Levillain pour Mill. Christofle, mais c'est l'œunre de Roty quili faut voir. Cet artiste a composé pour deux des prix d'agriculture des bas-reliefs très remarrfuahles. Si dans les gronpes que uous venons de nommer le sculpleur avait rendu le geste, le caractìre, la vérité du personnage, il n’avail pas eu, comme le peintre, le cadre qui est si nécessaire an sujet, le paysage, le ciel, qui sont les décor's oì se ment le paysan.

Roty garde celte ressonree, il peint avec l'éhauchoir; fuand il modèle la cire, il y met lillusion des lorizons, des prairies, des arhores; sa Bergère, dehoul, tricotant au hord du chemin pendant que le troupeau broute, remplit le tahleau el il y a de l'air autour d'elle; la Vachère assise, accablée sous la chaleur lourde, fait songer ì l'nrage qui pèse sur le paysage. Cies denx arlorabies plarquettes occupent le fond de deux plateaux carrés, dont les bords sont ornés de plantes anx donx reliefs et dont les anses sont faites de tètes de bélier's et de mufles de vaclies.

lialliste et l'orlêvire se sont souvenus des morlèles retrouvés à Hildeshein, ils n'ont rien copié des orfêvreries gréco-romaines, mais ils ont égalé dans ces deux ceuvres exruises les types parfaits de l'art antirque.

Il fant done féliciter hautement MM. Christofle et Cie d'avoir osé s'affranchir de la routine où on trainait depuis si longhtemps; par l'orfevierie officielle du Ministère, ils répandent dans nos départeunents et nos campagnes des modèles dont la puissance élonne, nais dont le charmie séduit; malheureusenent la somme d'argent allouée à ces primes ne permet pas torjours (ne la ciselure en soit achrvée autaut qu'on le sonhaiterait. Les ministres et après eux tes sociétés d'encouragenent deuraient proportionner la valeur des prix à la tualité des ourres rüils exigent.

1 la précédente Exposition, on avail pu constaler encore le penchant que montrait M. Bonilliet pour l'émail : il semble se désintéresser aujourd' hui de ce mode de décoration, car, dans les chnisonnés quili expose, nous retronvons des prièces rue nous avons vues déjà; ancume n’á été faite pour le présent concours.

Ce rést certainement par le groît personnel de l'orfèvre qui s'est modifié, c'est parce pue sa clitentète ne le suivait pas dans ses préférences, (pril a abandonné l'émail et nous sommes surpris rfu'il en soil aiusi chez Christofle, quand d'autres orfèves en France, et à l'étranger surtout, commencent précisément à employer l'émail. Quel rue soit l'avenir de l'orfêrrerie, en ce mode de décor, it ne faudra pas nublier que c'est à MII. Christofle et Bouillot ru'appartiement les premiers essais de coloration par l'ámail, par l'inerustation galvanicpue et par les patines nétalliques; ils datent de 1867. Ciest immédiatement après qui ils ont, eux, les premiers parmi les orfêres, osé adopter lia formule japonaise. Si d'autres l'ont copiée, bien ou unal, ce n’est qu’ensuite.

Cin gramul gonit, un souci constant d’imover, une recherche des besoins modernes, un accord du mótier et de l'art, telles sont les préocenpations et les rualités de MII. Christofle et Bouilliet; ils ont lait pour lenr industric heancoup plus que d'antres de qui l'on pourait tout attendre et qui ont trompé l'impalience du pullic : on est surpris de trouver lant d'art dans nne usine.

\section{Fronevt-Meurice, à Paris.}

Lui aussi a marié l'ivoire ave le métal, et c'est encore à Delaplauclie, ce sculptenr aimé des orferres, qui il a demandé un modèle : la figure de Flore est mi-partie en iroire, mi-partie en vermeil; dehoat sur un char, elle court en jetaut des fleurs; mais elle na a pas la steltesse de l'Amphitrite de 
Nereié, ni la màle beauté de la Gallin de Noreau-Vauthier; elle a la jemesse, un grand c'łarure, l'opulence du déeor et ces belles qualités ont sérluit l'acheteur. Celte jolie statuetle est derenue la proprićé d'un riche Américain; le nom de V. Froment-Menrice est, depuis un demi-siècle, connu et porté aux quatre coins du monde.

Uue œuvre de grrande dimension et d'une audace peu commune, c'est le vase d'argent qui a été exécuté d'après Jes dessins de M. Sédille; c’est un caprice royal qui rappelle les fastes de Versailles. Quel est donc le Louis XIV 'fni peut encore menbler son palais de caisses it oranger (1) foudues en alrgent? Ou ne songera pas à mettre des lleurs dans ce vase, il n'a plas besoin de ce décor supplémentaire et se suflit à lui-mème; la construction en est robuste et rappelle les beaux vases de la Remaissance italienne; peut-être le piédouche en est-il un peu grèle, mais la panse se modèle puissilnmment en ciselures fouillées et oxylées d'un ton naturel; aux anses s'enronlent des serpents dont les nouds rompent heireusement la ligue architecturale du vase; un ôr'and camré vigoureusement seulpté s"inscrit dans les ornements el sá conleur est mieux assortie aux douceur's de l'argent que celle des cahochons de lajpis qui sont sertis aux pieds. Cette pièce est très audaciense; si elle n'est pats tout ì fait irréprochable, elle est cependant sans pareille dans l'orfèrrerie liançaise et rien ne saurait lui être comparé che\% les orlèvres étrangers.

Tont fin, tout mignon, tout corfuet, semble, auprès de ce rase colossal, le petit vase de cristal londu el gravé par Gallé, que II. Froment-Meurice a monté en vermeil; c’est un verre rose. exquis de forme ef de conleur; l'arliste l'a enzlyassé dans un linceau de stvle Louis XV, si juste de proportions, si simple d'ornements que c'est peut-ètre l'oure la plus par'laite que nous ayons vue, parmi toutes les réminiscences du xrme siècle; le succès d'ailleurs en a ćté tel, que ce vase eủt été vendu vingt fois, sil avait ćté ì vendre; l'orfêrre arait travaillé pour Jui-mème, et c'est pour un caprice intime el tout familial que M. Froment-Meurice arait monté en argent le vase du verrier de Nancy.

Il y a daus l'exposition de la maison Froment-Meurice beaucoup d'ourres charmantes et délieates, quill ne uous est pas permis de décrire, pareo qu'elles appartiennent aux lijoux et à la joaillerie; nous aimous ì croire, que notre confrère de la classe 37 ne les oubliera pas; pour nous, qui avons déja signalé les surtonts de table et les services de toilette de M. Froment-Meurice, nous croyons devour revenir ì certaines pièces qui, bien qu'appartenant à l'nrfèrrerie redigiense, n'en sont pas moins de l'art le plus acheré; j’aine surtont un calice, inspiré des plus purs types du unyen âge el qu'il faut donner en exemple ì MH Poussielgue-Rusand, Armand-Galliat el Trionllier.

11. Fronnut-Meurice a fait un essai d'émail translucide sur relief, dans un de ces vases sacrés; c'ést croyons-nous le premier retour à l'orlèvrerie religiense, de ce mode d'énail que nous arons décril phus hetut. Il y aurail à critiquer l'exécution matérielle de cet émail, il n’est pass alssolument parlait, mais la tentative est les phus intéressantes.

'Très original, très osé, très riche est $11 n$ grand ciboire, tout émaillé de rouge et de bleu, qu'enveloppe un réseau de filigrane d'or; le dessin en est de M. Lameire, mais le collaborateur préféré de M. Fromeut-1leurice, c'est MI. Henri Cameré; nous arons déjà dịt son nom, mais éest ici ru'il convient de le noter particulièrement.

Si depuis quel(pues années M. Froment-Meurice hui a rendu une demi-liberté, dont il use all profit d'itutres orfêrres, il ne faut pas oublier que, depuis vingl-cing ans, il consacre tont son

(1) Perrault, dans ses Ilommes illustres, rapporte gu'il $y$ avait ì Versailles des grands vases d'argent, pour mellre des orangers et des brancards pour les porter. 11 est dit autre part qu'Alexis Loir el Duteil exéculcerent pour le Roi, de 1667 ì 168 a, des bassins de loules formes, de grands chandeliers, des balustrades de lit, des bordures de tableaux, des caisses d'orangers et une loule d'autres pieces d'orfévrerie d'une valcur de plus de 200,000 livres. 
Lalent, toute sa fantaisie à créer des modèles pour la maison à larpuetle il appartenail spécialentent d'albord; phrsieurs des services d'orlèvrerie que nous avons décrits ont été dessinés par lui, ausi que la plupart des bijoux qu'il ne nous appartient pas de juger: cependant ne pouvons-nous pais réclamer comme ourre d'orféve l'épée du colonel Négrier et l'épée de l'amiral Gourbel? C'est un homneur pour un artiste d'avoir à composer de lelles ámes, el c'est un bonlıerr' nour l'orfềrre d'atLacher son nom à ces insignes du courage el dı génie militaire.

Au-dessus de la vilrine de M. Froment-Meurice, la ilonimant, la protégeant, était une grande lyre d'argent traversée par une palme : elle avait été offerte à Viclor Hugo el les armiralemrs dı poète avaient été bien inspirés en s'adressant au fils de celui que Hugo avail immortalisé́ dans ses vers: on sait d'ailleur's que Paul Meurice, l'ani fidèle du gorand poète, était le lière de Franconis

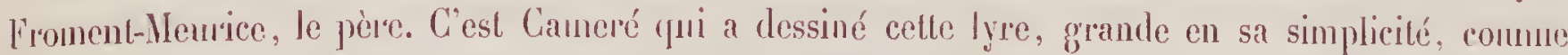
il arait dessiné el modelé la nef que les danes de France offrirent à la princesse Imélie, lorsqu'elle

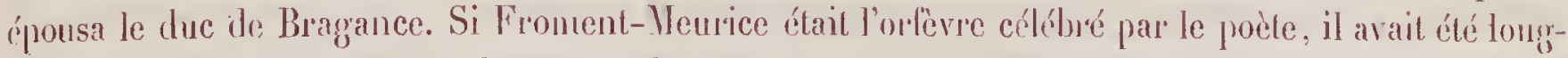
temps aussi lorlève patenté de la ville de l'aris et nul n'avait te droil, sinon hui, de ciseler la nof parisienne, que des sujets fidèles offraient à la fille du comte de Paris.

C'est Cameré encore qui a comprosé la tiare que recut le pape lors de son jubilé el qui lui lü portće par le curé de la Madeleine. Nous ne croyons pas utile après ces grands noms el ces grands souvenir's de décrire par le menu toutes Jes jolies inventions du dessinateur et les travaux acherés de l'orfér'e. It serait suporflu de nous étendre sur les qualités de goüt de M. Fronent-Meurice; la clientèle la phus arislocratique lui est restée firlèle, il a su garder el agraurdir encore la répulalion de. son père, il a réalisé ce difficile prohlène d’être labile dans un art où son prère arait été des phus habiles; et son jeune fils s'essaye à des travaux d'orfevrerie dójà : en sorte qu'on rema trois générations de firontent-Meurice, comme on a vu trois générations de Germain.

\section{MIM. Finniére frères, à Paris.}

Ce que nous avons dit des liannière en prarlant de forferrecie de table pourait nous dispenser d'en parder encore à propos des objels d'art, car quelque cliose qu ils fassent celle cliose appartient à l'ard et derient précieuse; mais si nous nous y arrêtons rolontiers, c'est pour parter de la ciselure, (püils représentent d’une facon plus spréciale encore que lorférrerie méme : ils sont seulpteurs ot orfères assuróment, nais ils sont ciscleurs avant tout, ces deux lrères Fannière. Leur oncle Fauconnicu les avait élerés tous deur dans l'amour de cel art clarmant el le ciselet est resté tonjours leur oulil de prédilection. Qüil s'agisse de la belle pendule de Mime Blanc, du groupe de Bellérophon comballant lu Chimére, ou du bouclier qui apprartenail au due de Chaulnes, la ciseInre reste ta qualité mailtresse de ces ourres et rien ne saurait lui èlre compraró dans les pièces cxposéres ailleurs. Peut-ître ntême les sculpteurs ne roudraient-ils pas voir tradnire arec une perfection anssi minutieuse leuss aumes, sils les confiaient aux Fannière : cette perfection de loutil amollit la fermeté des formes ef c’est en quoi la lonte à cire perdue, qui ne souffe ni relouche, ni finissage. convient mieux à cerlains tempóranents robustes; nous amons à roir d'autres ciseleurs, mais comme nous ne rencontprons plus de lechte, de Morel-Ladeuil, de Désiré Iltarge nous n’aurons pas de rivaux ì opposer aux Fannière. Is sont une gloire lirangase el ils jonissent de leur vivant d'une réputation universelie. 


\section{MÉDAILLES DOR.}

\section{Dufreste de Shixt-Léon (Ilenri), à Paris.}

Ce'ni-ci est un artiste aussi dans tonte l'acception du mol, artiste convaincu, enthousiaste, passionné, ayant gardé d'autrefois une conviction que n'ont plus nos confrères d'aujourd'lui, car II. Dufresne n'est plus jeme, c'est un vieillard; mais, en dépit de ses clreveux blancs, il a des ardeur's de jeune lıomme et sa main conduit avec une fermeté juvénile l'ébauchoir et le ciselet. Ce n'est ni un orfevre, ni un ourrier : c'est un homme dn monde qui reste artiste et se fail ourrier par passion; il aime l'orfêvirrie et a voulu réaliser de ses propres mains ses rêves de mélal; il ne vend aucune de ses auvres; il a consacré une partie de sa fortume à exéculer les pièces qu'il avait dessinées et modelíes et si parfois il a consenti à faire sur commande quelques objets d'art, c’était à la condition que le prix qu'on lui en offrait serait consacré à une fondation piense ou à une ouvre de hienfaisance.

11. Dulresne de Saint-Léon est l'inventenr d'un procédé de damasquinage qui ne ressemble ni à celui de Gauvin, ni à celni de Znloaga, et, bien (fu'il ait pour base un nnoyen chimique, il n'est pas comparable non plus au procédé de Christolle. Mons avons expérinenté nous-même la solidité de ses damasquines; les nielles d'or et d'argent adhèrent à l'acier aussi solidement que les damasquines allabes, el c'est peut-ètre dans l'exposition considérable de N. Dufresne ce qui nous charme le plus, car certains modèles ont pu vieillir au gré d'une clientèle jeune, mais les ornementations dont l'arliste couvre les arnues qu'il a forgées lui-même sont d'une invention si charmante que nous en aimons quelques-unes à l'rígal des armes qui sont à l'Armeriu de Nadrid ou an Nusée d'artillerie de Paris.

On pourrait établir un rapport intime entre certains ourrages de M. Dufresne el les compositions de Vechte, de Klagynanu et de Jules Peygre. Ils ont été ì même école ct celui-ci, leur ayant survécu, reste seul ì nous apporter le souvenir d’un art un peu démodé, mais encore puissant el très vivant; il ı’est pas une coupe, un vase, un poignard où quelque intention ne soit écrite. Its empriuntent à la nuytholog̣ic ou à l'lisistoire les figures qu’ils mêlent à l'ornement el traduisent un poème out une idéc; on sent que l'artiste a commencé au temps du romantisme, il a voulu être :

................. Le fameux ciseleur,

Calui qui le mieur creuse, an gré des belles filtes,

Dans un pommeau d'épée, une boile à pastilles.

Mais j’ai vu sourire les orfèvres d'aujourd'lui, qui ne pensent plus comme leurs pères. Le grand vase des couronnes est une œuvre colossale, plus importante encore par ses proportions que le rase d'argent de Froment-Heurice.

Nous avous dit cependant que celui-ci n'avait pas d'équivalent et c'est vrai, car il est entièrement d'argent, tandis que le vase de M. Dufresne de Saint-Léon est en fer' modelé par l'artiste, il a été fondu clez Cail. L'argent n'y joue qu'un rôle accessoire; il vient, arec des damasquines d'or, illustrer les surfaces de fonte; c'est une auvre un peu fouguense, qui étonne plus qu'elle ne sédnit et qu'il anrait fallu voir dans un milieu plus farorable; trop grande pour sa vitrine de glace, elle restait inexplicable pour le vulgaire. Les trois cavaliers qui soutiemnent la vasque symbolisent un rêve de peruseur, de philosophe et de poc̀te; l'artiste a traduit la pensée, mais le passant a besoin qu'on la lui explicpue.

Outre les armes orientales, les masses et les haches damasquinées, les canons de fusil niellés, les coupes et les huires taillíes dans les genmes et ornées de figurines d'argent; outre les inventions ì la 
Cellini, qui mèlent des réminiscences de l'art italien anx caprices orientaux, il y a des brorteries d'argent sur acier, car je ne sais pas de nouts plus exacts à donner aux nielles dont je parle, qui sont bien le plus joli décor ' fu'on puisse imaginer.

M. Duliresue de Saint-Léon n'a, comme collaborateurs, que quelrues onvrier's indispensables, orlères et ciselenrs : IIM. Gillain, Buhot, Muleret, Dionède et quelques autres encore qu'il nous a nommés; mais il est l'auteur, l'inventeur, le dessinateur, le sculpteur et l'ouvrier tont ensemble, et nul phus que lui n’avait droit à une récompense pour des aures qui sont véritablentent siemes.

\section{Brateiu (Jules-P.), ì Paris.}

Comme les Fannière, celui-ci est bien plus un ciseleur qu'un orlèvere, mais il a conquis par so's arlunirables travaux en étain le droit de figurer parmi les orfêvirs parisiens. Élève de Honoré, il est depuis sa jeunesse le collaborateur assidu de tous les maitres, mais il ne se contente pas de retoucher en cisclure le modèle créé par des sculpteurs, il modèle aussi lui-mème; toutes les compositions quilil expose sont ses œurres.

Si nous cherchions bien, nous trouverions dans les classes ․ 1 et 37 lheancoup d'ourrages auxquels .l. Brateau a contribur pour une large part.

Au milien de sa vitrine est un plateau de forme reclangulaire en argent repoussé et en fer dą̧nasquiné, avant pour sujel: Le Relour du Printemps; e'est une composition aimable; la figure de femme. est un peu Jongue el svelte, conme toutes celles quaine à modeler Brateau; elle est dans le gout de la Renaissance, mais avec des cofuelteries ın peu maniérées, qui sont bien françaises; ce n’est pas savant, e'est incorrect, nrais c'est d'un art sincère, naif et précienx, qui rappelle en son afféterie les petits maîtres du xvm1 siècle. Brateau prenait déjà une place importante quand il a exécuté, en 1880 , ce plateau pour l'Exposition des Arts décoratifs, mais il a depuis fait de sérieux progrès et sa manière est si bien ì lui qu'elle le rend reconnaissable entre tous et constitue une originalité. Qu'il fasse en or repoussé une bonlonuière, comme celle qui appartient à M. Corroyer; qüil décore un gobelet d'argent, comme celui quenroyaient ì M. Danger ses anis, quand il était pensionnaire à la villa Mélicis, son ciselet rérit les ornenents et les figures dlim style personuel qui dispense Brateau de les

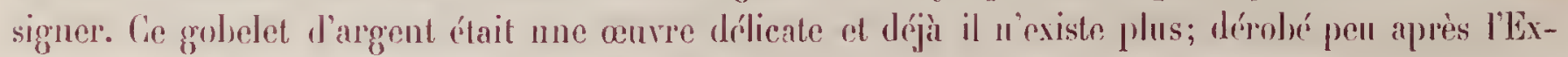
position, il a été détruit et fondu, m'a-t-on dit.

Je cite pour mémoire deux plaquettes en lironze: un portrait d'homme el un portiait d'enfant. l'enfant du maitre, une délicieuse fillette de deux ans.

Tout à l'henre, nous royions la lyre d'or qui offraient à Victor Hugo ses fidèles; voici une palune: en arģent ciselé que les élèves du peintre Cormon lui ont donnée en souvenir de son salon de 1887. II. Mcissonnier possìde une merreillense plarquette d'or repoussée et ciselée qui lui a été offerte dans une circonstance analogue. Je preffère la palme modelée par Brateau au verron de fer repoussí qu’a cependant choisi le musée du South-Kensington.

Oit Brateau devient alssolument un maîtee et représente à lui seul un art quion croyait perdu, éest dans les travaux d'étain. L'orfêrrere d'étain a tenu une place intéressante dans les usageses domesliques; l’étain a des qualités de couleur, de fusibilité et surtout de sanité, qui rendaient son emploi nécessaire avant l'invention du plaqué et du cuivre argenté. Les potiers d'élain formaicnt une corporation importante; mais, ì côté de ceux qui faisaient des vases d'mn usage courant, il y eut de grands artistes, comme Francois Briot, en France, el comme Gaspard Euderlen, en Allemagne; ceux-li out été, pour l'orfêrrerie d'étain, ce qu'avait été Benvenuto pour l'orfèrreric d'or et d'argont; les échantillons qui subsistent de leur's traraux sont conservés arec anour dans les collections publiques 
ou privées. C'est de Briot surtout que s’est inspiré notre ami Brateau; il a sagement évité tout ce qui aurait pu le ramener aux faciles imitations des ćtains d'Allemagne et de Suisse; ce ne sont là, pour la plupart, que des curres d'ordre secondaire, qu'on ne peut pas comparer à celles du maittre bizontin (1). En 1880 , lor's de l'Exposition du métal par la Société des arts décoralifs, M. Brateau présenta ses jremiers essais : ćétait nne petite assiette dont le marli portait les douze signes du zodiaque; nous la retrouvons ici et ce n'est pas la moins bonne de ses ouvres; il fit, à peu près vers le mème temps, une autre assiette plus grande, imitée de Virgilius Solis; it apprit ainsi la technique d'un art qui il ne faut pas confondre arec celui du bronze et moins encore avec celui de l'orfèrrerie d'argent. On a cru longtemps que l'aiguière el le plat d'étain de François Briot étaient la répétition ééonomique d'une aiguière et d'un plateau d'argent faits préalablement; ce sont an contraire des curres originales conçues pour l'étain et qui ne convienment qu’à ce métal; il faut que l'artiste apporte toute son attention à la confection du moule de cuivre, dans lequel il coulera le métal fusible; c'est comne une intaille délicate, il faut la faire aussi parfaite que la gravure sur pierre dure destinéc ì apposer un sceau dans la cire.

II. Brateau a étonné ceur des membres du jury qui n’avaient pas encore étudiél'orfèrrerie d'étain quand il leur a expliqué les phases si délicates de cette fabrication el qu’il leur a présenté les moules de sa huire et de son bassin; s'il n’a pas encore égalé Briot, son maittre, il s'en est approché el c'est un coup d'audaco d'avoir osé faire après lui deux pièces qui rappellent par la destination et par la forme, sinon par le dessin, le ehef-d'ouvre du grand potier d'étain : des sujets symbolisant les arts décorent la pause du vase el s'inscrivent dans l'ombilic et dans le fond du plateau; l'anse de la buire elle-même est laite d'mue élégante figurine ronde-Josse, représentant la V'érité. Quel est le style 1 . ces ligrures el des ornements. demandera-t-on? C'est un composé de choses vues, de formmles alpprises, de sensations éprourées, mais qui appartiennent à l'arliste et se retrourent dans plusieurs de ses ceurres. Ce qui est absolunent parfait, c'est l'exécution des détails, e'est la saillie räisomnée tes relicfs, c'est te conlraste de ces reliefs entre enx, c’est l'harmonie générale et c'est pourquoi celle pièee pent ètre citée comme l'une des meilleures qu'on ait rues à l'Exposition de 1889 . Une maïre consécration lui a été donnée par un orfèvre suisse, qui déjà l'a contrefaite et vendue à des annateurs non moins nail's, comme ancienne et authentique.

J'aimais moins la chope d'étain où sont représentées Les trois Parques, el l'assietle marquée des l. royales dont le marli est orné de sujets empruntés à Glodion; mais la cafetière et son plateau de style jersan sont du meilleur goût, l'arliste s'est sagenent enfermé dans une ormementation d'où la figure est exclue et nous préférons cet oljet à tous les autres.

II. Brateau n'a pas d'autres eollaborateurs que sa femme qui est aussi son éléve el que quelques ouvriers latcommés à sa manière; mais il reste lui-même, l'artiste qui crée et l'ouvcier qui exécute; il est jeune, on peut attendre de lui beacoup encore.

\section{Vernaz $(C h$.$) et Mne V_{\text {ernaz-V }}$ Echte, à Dieppe.}

Ceur-ci encore sont des ciseleurs, elle est la fille, et lui, le gendre du grand Vechte; ils ont gardé quelque chose de la tradition paternelle, sinon l'emportement, la verve et le génic, du moins une habileté d'outil, un sceret légué de cet ar' du repoussé si délicat en ses bas-reliefs. De même que Brateau a fail son élève de sa femme, de même Vechte arait enseigné son méticr à sa fille et celle-ci

(1) Voir les recherches de II. Castan, bihliothécaire à Besançon, sur François Briot, graveur, ainsi que les notes recueillies par M. Germain Bapst. 
a fóminisé tout naturellement les compositions de son père; elle les a traduites aree son temprínunut de lemunce et les ourres qu'clle nous montre, hien qu'elles soient menées en collaboration arec son mar', ne rappellent en rien La gouerre des Titans; ce sont au contraire, des fiğrnes très douces, rondes, estompées, où, par une commune erreur, les deux artistes exagèrent ì plaisir les mollesses de l'ontil el du dessin.

Ils vivent loin de Paris, à Dieppe, n'y royant pas les maîtres qu’il faudrait ćludier de près, se continant dans le souvenir des closes qu'on aimait el qu'on naine plus, encouragés mais mal conseillés par des clients qui ont plus de goût que de science et c'est grand dommage, carr lorsqu'on

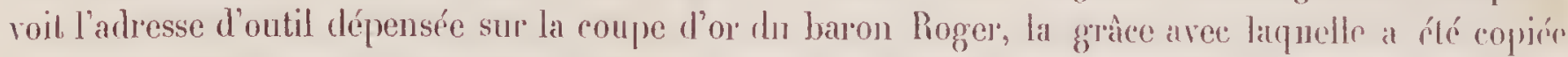
sur' une rondelle d'or la Vierge de Saint-Sixte, on songe à tout ce que ces habiles repoussent's pourraient faire de merveilles, si, moins näls et moins confituls en eux, ils se résignaient ì demander it un maître un modèle meilleur et le copiaient docilement.

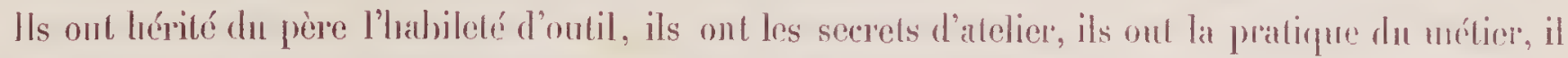
leur manque ce qui ne se lègrne pats, l'imaginalion, le goût, le gónie.

\section{MÉD MILLES D'ARGENT.}

\section{1/. Boucherox (Frédéric). à Paris.}

Ce n'est plus l'orfèron s'essayant aux services l'argenterie, que nous arons jugé lout ì l'heure, ce u’est pas nou plus le joaillier faneur à qui le jury de la classe 37 arcordera la plus haute véroutpense; c'est l'orferre que nous allons voir, l'orfère rni s'ontoure des meilleurs artistes, des preniers

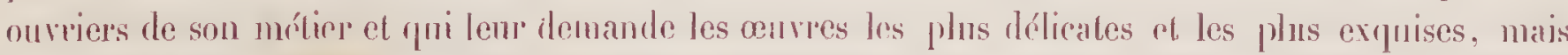
qui, apportant à l'orfèverie la façon orighinale, parisionne et mondaine qui contient à la joaillerie,

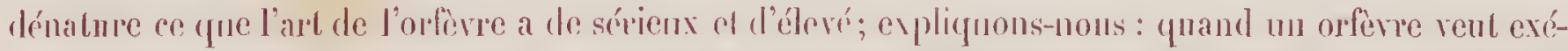
culer une crosse d'érî́gue, il doil se rappeler d'abord que le baton pastoral est un soutien pour la marche, quon doit en pouvoir lieurler les dalles de pierre sans danger el que les ciselures el les émaur ne doivent pas souffrir du voyage. M. Boucheron a fait une crosse d’érèque aussi fine, aussi élégante

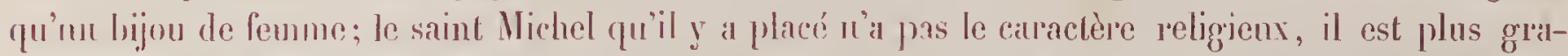
cieux que fort, plus joli que saint, il s'encadle dans une couronue de fleurs émaillées trop fragiles, al ce serait phutòt la houlette du berger qui conduit son troupeau à Cyllière que le bâton du pasteur qui guide des chrétiens vers Dieu. Il ne faut donc pas trop s'étonner si les plus élégantes parmi nos dévoles n'out pas encore offer't cette crosse merveilleuse à un érèque; elle est toin de ressembler an tripe sinple, pur et si charmant qu'on voyait au musée rétrospectif du Trocadéro, elle est plus voisine des crosses d'Armand-Calliat, mais l'orfêrre lyonnais a la tradition religieuse et chrétienue qu ïgnore absolmment le bijontier du Palais-Royal; l'art chrétien exige une initiation laborieuse.

'Tont antre est le vase de cristal orné d'un dragon d'or émaillé. Honoré l'a composé el modelé; c'est, je crois, la seule ourre que nous retrourions, en 1889, du ciseleur estimé dont Bratean est le nueilleur éleve. C'est mne composition hardie, rappolant par la forme du vase le style de J'Extrème Orient. mais gardant dans le dessin et le modelé dn dragon des réminiscences françaises de nos vienx styles. Hoi qui ai vn cet onvrage en cour's d'exécntion, je déclare ne pas connailre nn travail plus achevé; c'est un clref-d'oarre dans toute l'arception dn mol et, qu'il soil bijoutier ou cu'il soit orfève, l'ourrier

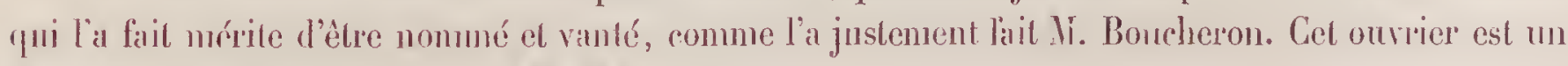
de nos meilleurs liabricunts, c'est M. Menu père.

Je regrette que l'émail ail caché l'ounre d'ol'; cet émail constitue certainement un autre clinf- 
d'œurre en son genre, urais il y manque des repos el, an risque d'être arcusé de vandalisme, jr voudrais que des accidents, des éclats viussent réréler que sous cette conche d'émaux. rouge, vert, jaune, nrangé, violet, il y a de f'or modelé, limé, riselé. Tel qu'il est, ce dragon ressemble plus à un travail de céraniste qu’à une œuvre d'orfèrre et ce qui la compromet encore, e'est que le vase est en verre fondu; il eut été mieux de le tailler diuns un liloc de cristal de roche, Várangoz l'ent entrepris et réussi.

Antonin Nercié a modelé un jeune enfant qui tient en unain un coqfuillagge; il n'est pas, comme Ie célèbre Pécheur de Rude, occupé à écouler la voix de la mer çui chante dans la valve sonore, mais il regande ta lumière qui joue à travers le coquillage. C'est en effet pour tronver une application de ces émaux transparents que N. Boucheron a demandé ce modèle au sculpteur; la staluette a été fondue en irgent, elle est de grandeur naturelle, le coguillage est un thavail de bijonterie d'or d'une extrène délicatesse, ses alvéoles sont remplies d'émaux transparents, la lumière les traver'se et s'y joue, c'est l'application des émaux à jour, dont parle Benvenuto Cellini dans un chapitre du Truité d'orfêorerie et c'en est une des plus curieuses. II appartenait à M. Boncheron de nous montrer ce nourel essai, parce que c'est chez lui qu'on a vu les premières tentalives en ce gemre, à l'É position de 1867 , dans un cadre de uniroir (qu'avait fait Riffaux. Ver's le mène tenups, M. Chardes Lepec fit une coupe d'énuil transparent pour M. Morisson ef nous verrons tout à l'henre le parti que les orfêvres russes ont tiré de ce procédé.

Nous ue trouvons plus à citer dins la vitrine de Xl. Boucheron qu'une série de mignounes figgul'nes d'argent ciselé qui sont directement inspin'ées de celles qui appartiennent au czar; elles tiennent daus un surtout de table le rôle décoratif que les statuettes de Sévies et de vieux Save ont sur nos étagères et nos cheminées, ce sont de délicieux joujoux dont la mode s'éprendra, les gens de gooùt et d'imagination domeront au sculpteur, à l'orferve et au ciselenr un prétexte aur conprositions les plus diverses, les plus originales, les plus spirituelles et les plus amusantes.

\section{Phllippi, ì Paris.}

II. Philippi est un des doyens parmi les orfêrres-hijoutier's; lidbricant estimé, il n'exerce plus sou unétier que par déscurrement, il s'en fait pas le conmerce comme autrefois, it compose lui-même, modèle et exécute presqne tout do ses mains. Il est rai que ce n'est pas aussi bien que s'il employait des artistes, il y mot plus de conviction que de véritable science, inais ces uaîvetís ont du charme pour quelques amateurs, qui trouvent, dans un graud coffret de cristal décoré d'émanx et de ciselure, un ressourenir des anciens coffres italiens et dans le miroir an cadre de lapidairerie ot de ciselure une imitation des uniroirs florentins, que Marie de Médicis arait introduits en France. II n'y a pas : faire de comparaison entre ces ourres-là et celles que nous apporte M. Philippi; cependant celles-ci vaient, comme leurs années, trouré ì se loger au chàteau de Chenonceax.

\section{MÉDAILLES DE BRO\ZE.}

\section{M. le docteur Camus (M.-G.-Émile), ì Paris.}

Le docteur Camus a près des amateurs de bronzes, de menbles et de porcelaines montées, une grande réputation, ef il l'a bieu iuprudemment compromise en se mêlant aux orfèvres. Nons croyous qu'il aurait minux lait de rester parmi les bronziers qui décoreut de cuivres cisalés liss potiches et les 


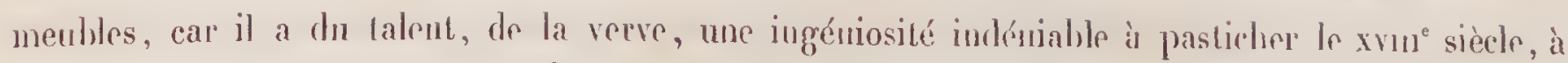
monter les gemmes el toute sorte de poreelaines dout il tire un très heureux parti; Ir pretit bronze est son aflaire, mais il n'entend rien à l'orfêvrerie.

Sur la haute réputation que lui a faite la coterie des gens à la mode, le grand-duc Alexis lui avait commandé un vase d'argent de grande proportion. Le docteur-orfèvere y a fait tontes les fautes fu'on pouvait commettre; il a fondu ce vase qui aurait dù être fait au martean et n'a su, ni par la cisclıre ni par ancun travail accessoire, pallier les imperfections de cettr pièce qui est trop lourde de poids et mastoque de forme.

J'aimerais mienx les candélabres d'irgenent dn duc de Gramunont, ils sont presque bien; le pied pèclıe cependant par le dessin, et la masse manque d'équiliłre. Mr. Camus s'était donné ì peu près le même thème que M. Ancoc; il aura en la bonue foi de reconnaîlre fure les candélabres d'Ancoe étaient très supérieur's aux siens.

On nous a raconté par quelle suite de circonstances le doctenr' Camus, qui a heaucoup d'esprit, une certaine fucilité à tripoter la cire et à tirer parti des bronzes anciens el des modèles cfu'il a rarlietés avec le fonds de feu Cornu, on nous a raconté, dis-je, comment il a quitté la médeciue pour devenir une manière d'orfèvre-hronzier dn xvin siècle, ressuscité d'entre les morts. Nous avons trop de confiance dans le goût de la société parisiemne pour blâmer ceux qui se sont pris d'afiection pour ces aimables pastiches; nous y voyons qu'avec de l'audace et du savoir faire, un fabricant peut convaincre l'acheteur' et lui prouver que les wuvres modermes égalent les anciennes; il est vrai que celni qui a démontré cela n'est ni un artisle ni un orfèvere, mais il est doctour et c'est assez.

\section{Useldingen (Georges), ¿i Paris.}

Encore un ciseleur qui montre son adresse à repousser le métal; la pièce principale de son exposition est une brancle de lilas, dont les flenrettes rélicates sont esorties n d'une plaque d'argent avee lieancoup de dextérité. C'est, en effet, un tour d'adresse rnil montre tont ce que, sous les coups répétés du ciselet frappé par le martean, la duclilité dn mélal permet d'olutenir de saillies, de crenx et de modelés.

Un portrait, également en repoussé, donne une note très différente; c'est encore la nature, mais copiére à l'aide du mod̀̀te plıotographié; c'est d'un réalisune ruiexagère la patiente recherche de l'onvrier qui ne veut rien oublier; il y a là plus de science et d'aulresse qu'il n'y a d'art el de goût. Pour le visiteur qui ne connaît pas les phases progressives du travail, il était intéressant d'examiner la cafetière encore inachevée, où le ciseleur avait repoussé à la ressingue toutes les bosses de la panse pour trouver les saillies dı modelé; remplissant alors d'un ciment à demi résistant son vase, il avait commencé à ciseler des rinceaux, des rocailles, des fignrnes, el jusqu'an paysage que l'on commait par une estampe célèhre nommée l'Escarpolette. Le travail achevé sur une partie de la pièce, ébauché sur l'antre, s'expliquait de lui-même; ce qui nous snrprend, nous qui connaissons les difficultés du métier', c'est que M. Useldinger ait pu, pour 200 francs, faire un tel travail ; il fant qu'il soil prodigirnsement habile. Il est le collaborateur de beancoup d'orfèvres.

\section{JoRET (Eugène) fils, ì Paris.}

Nous blâmerons plus loin, che\% les orfèvres viennois, la disposition à initer les libislots anciens,

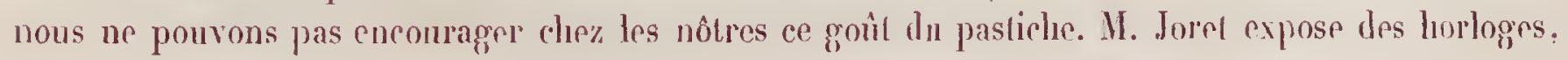


des vases el toutes sortes de bibelols d'argent ciselé el émaillé qui sont la copie plus ou moins exacte des choses qu'on trouve mn nos musées. C'est une fabrication liyhride qui n’a pas même pour excuse la science archéologique; mal copiées, sans aucun style, ces pièces ne sont pas faites pour tromper de naïfs acheteurs, puisque M. Jorel a la bonne foi de les exposer sons son nom; mais elles contribueut à fausser le goût el désolent les grens qui ont la passion des helles orfêvreries et des émaur anciens. Ponrequi donc II. Jorel qui a copié les assieltes émaillées dn Louvre écrit-il, sous les figures peintes, deux lettres d'or, un I et un C? Qnand je le lui ai demandé, il m’a répondu que cela signifiait Premier chrpitre; or toutes les pièces qui forment la suite de l'Histoire de Joseph, d'après Jacas de Leyde, portent ces deux initiales dui, dans les originanx du Louvre, sont de Jehan Courtoys, I'I et le C sont sa signature. II. Joret est-il aussi naî' qu'il le veut paraître? Se lait-il to conplice des truqueur's el des revendeur's de faux émaux? Seuls les ignorants s'y laisseront prendre. J'aime mieux croire à la sincécité de cet exposant. Il est très jenne el trop osé, il se live avec une ahondance regrellable à la copie de toutes sortes de choses connues. Quand Legros composail son carle do miroir et le repoussail en fer, il le faisail très naïvement aussi, ne se doutant pras que le liasard des ventes et l'habileté des marchands le feraient passer pour vieux el aullientique et le coteraient tun jour à 100,000 francs; mais il se doutait moins encore qu'il serait à son tour copié comme ancien; c'est ponrtant ce qu'a fail M. Joret, il a tout nä̈vement reproduit le fameux miroir qu'a gravé Jacquemard, qu’a décrit Paul Mant\% ef qu'a acheté le baron Gust. de Rothischild. Ce joli pastiche innocent a trompé toul le monde, et le pauvre Legros est mort à l'hôpital (").

Lá pièce capitale de cetle exposition, celle que l'auteur nous a montrée a rec complaisance, est mne grande nef, représentant le Bucentaure. C'est mn énorme jouet d'argent destiné à un milieu de lable; on en ferait autant en bois peint on verni, tes naïvetés, les fautes de proportion et d'échelle y seraient plus excusables.

On trouve, dans les musées d'.llemaģne, des orférreries analogues, conınosêes par des ouviers adroits, mais accisant loutes les fantes de goút, d'arrangement el de proportion qu'on regrette de inir ici; le temps, la patine el certains accidents heurenx ont domé, à ces oljjets anciens, ine apparence meilleure; il s'y altache surtout l'admiration complaisante qu'on donne à toutes les choses du passé. Le Bucentaure de M. Joret n'a pas la nène excuse et nous ne croyous pas aux naïretés des orlèrres d'aujourd'luiv.

\section{Maisor (Léon), à Paris.}

Celui-ci est bien réellement un orfève et un onvrier travaillant de ses mains; c'est un naïl' anssi, mais d'une nä̈reté qu'on excuse plıs voloutier's; il s'est trompé, et, pour lni, le jury a été sévère.

M. Maison a, je ne sais pourquoi!, une grande admiration pour le phus lairl des ćdifices parisiens, il a copié en or et en argent le paluis de la Bourse, avec son jardin carré, sa grille et ses candés fabres ¿ui s’allument par l'́lectricité. Quelle idée bizarre! II y a eu des gens patients qui ont fait en liège la copie réduite de nos édifices, nous ne supposions pas que cette innocente manie pourait atteindre les orfères. A-t-il espéré séduire quelque heurenx joueur reconnaissant à Plutus et épris de son iemple? En ce cas, c'est une pièce rotive faite pour un conlissier, prour un financier on pour quelque agent de change retiré des affaires après fortune faite; ce qui le ferait croire, c'est que le socle qui supporle ce curieux oljet est très joliment composé d'une grande rone de la Fortune el d'une corne d'abondance. Nous anrions préféré que M. Maison n'exposât pas cet onragge, bien quil soil très adroitenent exéeuté; il étomnait, amnsait ou scandalisail les visiten's, sa place est daus la chapelle
qu'ourriront à la Fortune cenx qu'elle comble de ses dons.

(1) Coir i propos de ce miroir, parmi les fottres de II. Josse, la lettre à II. Antonin Proust (Monitour universel). 
Ici s'arrête la liste des orfèvres que le jury avail à juger et à récompenser, mais il y a plusieurs exposants qui ont sollicité sa visite; ceux-lì appartiennent, pour la plupari, a la classe 37 et concourent, dans cette classe, pour les bijoux et la joaillerie; ils ont cependant quelques pièces d'orfèvrerie quils ont voulu soumettre ì notre appréciation et nous sommes tenus d'en rendre compte ainsi que des curres de quel ques artistes. Parmi ceux-ci, citons d'ibord:

\section{Colliot (Jules-F.), à Paris.}

11 expose dans la classe 25 ; c'est un ciscleur de lalent qui prête sa collahoration ì II. PoussielogueRusand; il nous a présenté un joli cadre de style limnaissance, reponssé sur argônt; la manière en est souple, le toucher gras, l'aspect plaisant, et d'aillen's celte pièce arait remporté celle méme année le prix Crozatier. Un bouquet de fleurs et de frnits, f́galement en repoussé, pourrait dre compraé aux fleurs que nous avons vues cliez Useldinger, mais l'exécution en est lien supérieure, ot M. Colliot d'ailleurs a obtenu une médaille d'argent dans la classe 25 prour ces travaux-lì et pour tes fleurs quili a ciselées sur métal fordu.

\section{MÉDAILLE D'OR DE COHLABOR ITEUR.}

\section{DIonÉDe, ì Paris.}

C'est comme collaborateur de M. Odiot, chez qui étaient exposés ses travaux, que M. Dionède a obtenu une médaille d'or. Il n'est pas d'orfèvre qui ne comnaisse l'atelier de Diomède, c'est te plus ancien, c'est encore l'un des plus considérables. Tous ceux qui décorent l'argent ont passé par là et Diomède était l'ami et l'émule des vieux maitres du ciselet : de Vechte, de Morel, de Poux et de Désiré.

Il exposait un cofle en fer et en argent où sont représentés Les sept péchés capitaux, et il nous a déclaré que le modèle était rle sa composition; nous aimerions mieux voir des ciseleurs habiles comme Diomède demander leurs modèles ì des maitres comme Rodin, comme Dalou, qui pourraiont leur donner des cuvres impeccables. Ce coffret est ingénieusement arrangé et d'un grand effet décoratif, la luxure fournit nécessarrement le molif le plus en vue, et l'artiste n'a pas eu de peine à trourer dans l'histoire des épisodes célèbres pour raconter les vices des hommes. Je ne sais pas pourquni ce sujet tente nos artistes : on trouvail exposé dans la classe 11 un autre coffret en fer damasquiné par Gauvin. sur les mêmes données; mais si les vices sont réellement un prétexte à de helles ciselures, il y a dans l'atelier de Rodin la plus admirable collection des péchés d'amour', c’est la série ricébanches et de marquettes qu'il a modelées pour sa grande porte de bronze : voilà des merveilles dont s'éprendraient nos ciselenrs et des vices dont s'ébaurliraient les blasés.

Dans un grand plateau d'argent reponssé est représenté le Piéveil de l'aurore; cela me rappelle heaucoup la manière gracieuse de mon regretté ami Morel Ladeuil; mais toules les ourres de ce dernier sont restées à Londres, tandis que Diomède n’a jamais quitté Paris : il fant lni en savoir gré, car les orfèvres anglais et américains ont fait les offres les plus brillantes à Diomède, à Honoré. ì Brateau, el c'est par un sentiment de patriotique indépendance ru’ils sont restés ici. 11 y a encore de Diomède, outre les travaux de son atelier, une jolie hoìte à gants faite, je crois, entièrement de sa main : toute l'habileté dı vieux praticien y apparaît, comme elle apparaìt dans une autre boîte 
d'argent comparable à celle-ci pour la forme, et que nous arons retrouvée dans l'exposition de Bartiedienne : c'est Désiré Attarge qui l'avait ciselée jadis, el nous associons volontiers son nom ¿ relui de Diomède, its comptent parmi les gloires de l'orfèvrerie.

MM. VéVEn frères, ì Paris.

Les frères Véver exposent avec les joailliers, ils ont obtenn, pour des travaux que nous n’arons pas à juger, un graud prix; mais parmi les pierres merveilleuses, les perles et les parnres d'art, il y a quelques essais d'orfèverie qui dénotent beaucoup) de goût et de sérieuses reclierches. Tous n'avons pas ŕté les voir quand nous avons parlé de l'argenterie, cependant nous aurions trouvé là mne cafetière et un sucrier dont linvention n'emprunte rien aux types de la Renaissance ni du xvin siècle. Tout au plns, y pourrait-on signaler une analogic arec l'idée japonaise, car c'est directentent it la nature que l'artiste a pris les piroines, les liserons, les mimosas, la vigne-vierge qui forment l'ornementation de ces pièces; nous ne voulons pas demander à MM. Véver le nom du sculpteur qui a fait le modèle; ils nous ont nommé seulement les ciseleur's Gauthier et Desprez.

II. Bottée et M. Steiner avaient fait les modètes et les statuettes d'argent fondu qri'exposaient III. Véver. Lá plus réussie, celle dont le succès s'est affrrmé dès le premier jour, est celle du petit dieu Anour s'apprêttant ì lancer une flèche d'or; éternellement il servira de thème aux artistes, et enmme sons la statue de Pigalle, on a put tracer ici les vers célèbres de Voltaire :

Qui que tu sois, voici ton maitren,

Il l'est, le ful ou le doit ètre.

C'est une étrange et intéressatule fantaisie qu'a cue l'orlèvre de surmouler en argent une terre cuite de: T'anagra : il doit être convaincu maintenant que les wurres modelées en terre cuite ne gagnent pas à être traitées en métal; ce n'est pas ta première fois que cela aura cété clémontré, et Barbedienne aussi s'est trompé quand il a reproduit en bronze les statues antiques qui avaient été faites en marbre; nos artistes ne savent pas assez qu'il faut modeler pour le bronze très différemment de la facon dont on modèle pour la pierre; les effets c'tangent selon la nnatière employée.

Comme M. Christofle, comme M. Froment-Meurice, conme nous encore, MM. Véver ont essayédle la sculpture clryséléphiantine : c'est encore Bottée qui a composé la figure de Pandore et c'est Scailliet qui a sculpté livoire, taudis que Mariotton ciselait le métal; la curiense Pandore est assise sur une colonne de lapis et de jaspe, elle a refermé la boìte fatale d'où sont sortis tous les maux, une flenr y reste attachée : c’est l'espérance. La lacen de cet ivoire est un peu lourde, plus lourde assurément que l'Amphitrite de Mercié, et les arrangements de pierres sont un pen trop compliqués; c'est néanmoins une fort agréable pièce de vitrine.

La préoccupation de la polychromie se nanileste encore dans un coffret orné de camées anciens: les ciselures, les ors de couleur et les rinceaux d'émail blanc y produisent avec les gemmes une halrmonie que j'ai for't admirée.

Une veilleuse orientale, de forme octogonale, présente une lieureuse application des émaux à jonr, car elle enferme la lunière et la laisse transparaitre dans la mit, comme à traver's des vitraux de couleur.

La pendule Renaissance à quatre faces est une réminiscence de deux autres pendules de même style précédemment faites par un autre orfêvre, mais il convenait à MM. Véver de montrer tonte lent lıabileté à traiter un sujet, qu'avait déjà traité en 1867 Beaugrand, le prédécesseur de lenr père.

Nous nous apercevons à ce propos que nous n'avons rien dit des origines de la maison Véver : 
elle n'est pas parisienne de longue date, mais les Messins la connaissaient bien et ils ont vu son clief faire vaillamment son devoir de citoyen et de soldat dans la ville assiégée. Après la guerre Vérer a quillé Metz, emportant tout ce qu’il possédait, vendant ce qu'il ne pouvait pas prendre; c'est quil lenait ponr tui el ses fils à rester Français; il vint à Paris, racheta la maison de Beaugrand qui venait, lui, de mourir des misères de la guerre; il maria ainsi sa vieille fabrique de province is ta maison bien counue qui, avant d'appartenir is Beangrand, avait porté successivement le nom de Varret el celui de Gloria.

Ainsi, malgré les changements d'enseignes, c'est une vieille et célèbre maison qui est anx mains le res deux jeunes gens, ils ont assez de volonté el de talent pour l'agrandir encore. Ils savent oser, el si, dans la pendule dont nous parlions, ils ont, avec la collaboration de Joindy et celle d'Émile Olive, fait une ourre $n$ pen complexe, ils ont apporté une recherche intéressante dans la facon des émaux en relief; nous préférons ces émaux aux fiğures d'or ciselé (pui garnissent les angles; ces prannearr sont d'or fin reppoussé et émaillé : ils représentent les Saisons, mais combien loin sont-ils des émaux italiens et français qu'on faisait encore au xvie siècle, et dont le plus merveilleux modèle est conservé à la Bibliohlèque nationale; ce petit émail rejrésente des guerriers et des caraliers combatlants; il devrait être étudié de près par nos faloricants, ánsi que le bijou du musée de Dijon, qui vient de la collection Trinolet. WII. Véver aiment, comme nous, passionnément l'émail, et voici qu’̀ leur tour ils s'essayent aux émaux de basse-taille: ils ont fait la reliure d'um missel et ont mis au centre de la couverture une plaque d'émail que Vernier a gravée et qu’a émaillée Tourrette. Sans donte, ils ont compris en traitant le sujet combien difficile est cet art dont la définition paraît aisíe; il y a des lois d'harmonie pour les couleurs, il faut accorder avec les profondeurs des tailles le jeu du burin, el ce n’est que par une longue pratique, une expérience clièrement acquise et l'instinct que rien ne domne, qu'on parvient ì faire un clief-d'œuvre : c'est comme le secret des tapis d'Orient et des laques de Chine, on les déerit, on les explique, on ne les imite pas.

La petite grlace ronde émaillée est d'une jolie invention; il est drôle d'avoir appliçué le décor précieux du xve siècle et le style des figures qu'on trouve sculptées sur les hoîtes à miroir de ce temprslì ì la forme et à la façon du miroir rond fu'on rend cinc sous dans les bazars. J'aimais un antre miroir à main de style grrec dont $\mathrm{Ol}$. Bratean a fait la cisehure; le manche en était formé par me très jolie fignre de fenme ailée, dont le corpss se terminait en gaine; les ornements d'argent niellé avaient un eflet charmant, est-ce un hijou, est-ce encore de l'orfêvirerie? Nous nous arrêterons ì cette limite extrême des deux arts jumeaux, en regrettant de ne pouvoir pas la franchir.

\section{Bounder (Th.), ì Paris.}

II. Bourdier est surtont el avant tout nu joaillier, il a vouln cependant faire ouvre d'orfềre et nous a présenté la maquette d'un gyrand vase que nous ne jugerons pas, puisquil ne l'a pas exécuté eı métal; nous ne croyons pas non plus devoir apprécier l'œuvre de son collaboratenr M. Laliqne, mais nous signalons un travail précieux et pralient fait à l'atelier : c'est une veilleuse d'or, nons montrant encore lapplication des émaux à joul. Il nous souvient d'avoir dit nous-même en 1876 à M. Clarles Blane, (qui nous denrandait comment on fabriquail ces émaux, il nous souvient de lui avoir dit que l'application la phs logique en serait une lampe de nuit. L'éminent critique l'a écrit dans un de ses livres, et son conseil a été trop suivi, car nons retrouvons dans l'exposition française et dans l'exposition l'usse six ou Imit veilleuses à émaux transparents: M. Boucheron, du moins, a vait eu l'esprit de faire la première. 


\section{Lefebratefils ainé, à Paris.}

II n'y a clicz. II. Lefelvre qu'um petit nombre de pièces que puisse réclamer l'orfève, entre autres une corbeille à fleurs dont M. Brateau a fait le modèle et la ciselure el Glachant la montme. II. Lefelovre nous a très loyalement donné les noms de ses collalorateurs; c'est ainsi encore qu’il a díclaré que le joli panneau, exposé chez lui, qui représente lu Salutation angélique, est l'œurre de If. Vichaut, dont nous arons vu l'exposition el dont cette pièce-ci démontre le joli talent de ciseleur.

Mais l'oljet capilal qu'expose M. Lefebre, c'est une grace à double face, formant cadre, et dont l'exécution difficile est due à son ourrier, M. Poileux. Ce n'est pas la faute de celui-ci si le dessinateur n’a pas enfermé d'une liggne assez ferme, d'une mouluration assez énergique, Ies jolis détails dn radre, l'ourrier n’avait quà̀ obéir: il a fait en or et en argent ce qu'aurait fait en grand un serrurier halite, car 'e cadre est comme une réduction de quelque belle ferronnerie. Brateau, que nous refrourons partout, en a cisclé les ornements, et Grandhomme, en collaboration avec son ami Garnier, a encadré sons la glace un de ses phus beanx émaux; il a pour sujet, je crois : La Fable et la Véritr'.

\section{Debut (J.) et Covlov (L.), à Paris.}

Il y a beancoup de goût chez ces deux associés, ils l'ont pronvé de toutes les manières, dans lenrs bijonx, dans la monture des diamants, et si les pièces d'orfêrrerie proprement dite sont rares, la recherectie de la forme, du dessin, le gount très moderne des arrangements, exigent que nous tes cilions; il serait injuste de les onblier. Eux aussi ont une veilleuse on plutôt une lampe de nuit, malis l'arrangement dn pied, la façon des ornements, l’̈ngénieuse disposition de la lumière, en font une pièce originale el ce n'est pas à travers des émanx à jour que se tamise la lomière, c'est à traver's un petil vitcail, vilrail en miniature, peint à la manière des vitraux de Linarrl Gonthier (1), ce merveilleux artiste français, qui fit an $\mathrm{xrn}^{\circ}$ siècle des peintures sur verre bien supérieures à celles Ires Suisses. Le petit vilrail dont il s’agit ici a été fait par M. Janin, un ancien bijoutier.

Nais la pièce la plus élonnante par l'exécution est un double cadre à portraits, exécuté en or par II. Eme sur les dessins de Debut; ici encore, quelques orfèvies prétendront que nous sortous de l'orfèrrerie pour toucher aux lijoux: Eme est un bijoutier, c'est vrai, mais c'est aussi mn orfêrre, car il a fait tout entière une chapelle d'or, que j'aurais roulı voir exposée, et il a prouvé ainsi cuül n'y arait pas de démarcation entre deux méliẹ's qui ont la même technique, les mêmes outils, les mênes éléments. Le double cadre à portraits est une gorille, une dentelle d'or, non pras de filigrane comme nous en verrons chez les étrangers et qu'on nous impose comme ouvres d'orfèvres; ce sont iei des ornements très citudiés, pris sur pièce, tournés à la tenaille, façonnés à la lime et au burin, montés, soudés et terminés par le ciseleur. Je signale ce joli travail comme un des plus intéressants et des plus difficiles.

MII. Debut et Conton ont appartenu longhtemps à la maison Boucheron; its n'ont pas déchu en s'atallissant sous tenr's noms.

\section{Gaillard fils (Ernest), ì Paris.}

S'il y a ici des bijoux, ils sont tous d'argent comme les petites pièces d'orfèverie que nous venons ! vir el. plus que certains antres. M. Gaillard est voisin de loutèvrerie, telle que la comprennent

(1) Voir les vitraux qui sont ì la bibliothèque de Troyes (Aube). 
nos confrères; c’est lui qui fait ces articles de bureau, ces ornements d'étagères et lous ces menus bihelots d’argent que la mode la plus nouvelle a répandus dans un monde ćlófgant. Il a modifié arec un gront très personnel les formes que nous improsaient les Anglais; admiralenr passionné de l'art japonais il a marché longtemps à la remorque de Chrristofle, se servant de ses procédés ef dépendant de lui. mais, depuis peu, it a conquis une originalité plus grande, il a cessé de copier les dessins japonais; il a iuventé des formes et des décor's où l'argent trouve un charme qui souvent lui manque dans des pièces d'orfèvrerie, plus importantes. Je conseillerais à plusieur's orfèrres de mes annis, qui font de la grrande orfèvrerie, de regarder avec altention les fantaisies et les bihelots de M. Gaillard. Il se sert de rouleaux gravés au laminoir ou de matrices ì estauper, de façon à imprimer l'arghent de la même. manière qu'on imprine mu tissu; ef comme ces dessins sont fails arec goût, comme il découple de jollies formes dans ces plaques gravées, — qu’il les nielle, rn’il les émaille, qưil les dore. qu'il les flatiun ou quìil les polisse, - il obtient des effets noureaur, il impose une morle, il charme et colte séduction est tellement évidente qu'il a remporté un des grands succès de l'année.

Nous n'allons pas essayer de décrire les plateaux, les petits vases, les cadres, les ustensiles de fumeur, les garnitures de bureau, les nécessaires, les trousses et les fantaisies de lout genre quiexpose II. Gaillard; mais il est mn mode de décor qu'il faut signaler chez lui, parce qu’il constitue toule une révolution dont les effels sont considérables. On se sonvient de ce que nous avons dit des décors Gratués sur l'argenterie de M. Boucheron, décor's obtenus par la gravure en taille-douce et par la giravure à l'ean-forte, ce sont tous procédés à la main. N1. Gaillard nons montre des gravures au moins aussi parfaites, dessinant d'un trait noir tous les détails du burin, sur le fond de l'argent. blanchi : c'est comme une estampe où le métal remplace le papier hlanc.

Pendant que les memhres de notre jury visitaient l'exposition de M. Gaillard et que je regardais avec eux ces essais de gravure, le souvenir me revint de la visite que m'avait faite en $1878 \mathrm{ll}$. Gillot, l'habile héliograplıe : il renail me proposer de chercher pour l'orfèvrerie et les hijour le moyen de graver chimiquement le métal, par des reports photograpliqques, et il se disait certain d'y réussir. Pourquoi cette conversation n'eut-elle pas de suile? II. Gillot a fait pour le livre et pour l'image des travaux tellement importants quilil a pu oublier l'orfèvrerie, et moi, entran̂né vers d’autres recherches. je n’ai plus songé à cette tentante proposition; le souvenir m’en est revenu nel et précis, en regardant les estampes reportées au fond des plateaux de M. Gaillard. - N'obtenez-vous pras cela par des reports photographiques, cher Monsieur? - «Viment? Cependant, si on meltait à côté de votre plateau lá gravure-type qu'a publiée la maison Goupil, je suis persuadé que les tailles seraient identiquement les mêmes; royons, mon cher confrère, songez qu'il est aussi lonorable et avantageux pour vous d'avoir inventé un nouveau procádś de gravinre que d'avoir employé un très habile graveur el que vous anriez tort de cacher an jury une découverte qui constitue un véritable progrès». - M. Gaillard est un esprit très droit, mu curactère très franc, un hornme fort intelligent: il noŭs avoua aussilôt que sa gravure était obtenue en effet par des reports photographiques et, sans vouloir entrer dans la démonstration complète des procédrís quili emploie, il nous fit entendre que si Gillot les avait soupçonnés en 1878 , Niepce et Daguerre les avaient indiqués bien auparavant par le daguerréotype et que, depuis, Vidal ef Dujardin avaient poussé plus loin leurs découverles; mais M. Gaillard réclame pour son fils le mérite d'avoir appliqué ces clécouvertes aux travaux d'orfèrrerie. Son fils en effet est un élève de Dujardin et de Salmon, il a ćtudié l'héliogravure et la glyptolypie. Je regrette de ne pouvoir m'étendre ici sur l'application au métal des procédés de report qu'on emploie déjà pour l’impression sur papier et sur étoffe; mais le temps rst proclie où l'on gravera f'argent et l'or, où l'on guravera même les matrices d'acier, par le simple. report d'un cliché photograplique, en sorle que la froideur du métal s'animera de tons les caprices rqu'y voudra metlre le crayon de l'artiste. 


\section{Gallerand (Jules), à Paris.}

Quelques rases décoralils, des ustensiles de fumeur, des boîtes, des bonbonnières d'argent ciseIńes, dorées, nieliées, où linspiration japonaise le dispute aux réminiscences du xvrü siècle, voilà le fonds de cette exposition qui dónote un certain goùt et gui satisfait aux liesoins dn commerce de Paris et de la provinee.

$$
M^{m e} \text { Favier }(E .) \text {, à Tours. }
$$

Dans mue tonte pretite vilriue, perdue dans l'ombre, on tronve quelogues bijonx d'argent aree des fantaisies ciselées, qui sont encore du domaine de l'orfèvrerie. Ce qui est intéressant, e'est que cet art soil venu de la province. M Me Favier a commencé à 'lour's et nous nous rappetons qu'clle était avee son mari à l'Exposition de 1878 ; comment s'en est-elle séparée? Ceci n'est point notre affaire, mais depuis dix ans heaucoup de jolis onvrages d'argent ont aids a rópandre le gont des honnes eiselures el ces essais étaient dus à l'initiative de M. Couquanx.

\section{DAUBRÉE, à Nancy.}

Comme Couquanx vient de Tours, Daubrée vient de Nancy; il y a de même à Bourg. (Ain) et à Blois des orfevres qui gardent une personnalité qu'il faudrait craindre de lenr voir perdre. Je ne dirai donc jas à M. Daubréc que ses cisehres sont trop rudes et ses ornements incorrects; ces défauts, si ce sont des défants, ont un charme qui plaît par sa nouveanté et par ses incorrections mémes.

\section{Graxduonme et Garnien, peintres-émailleurs, à Paris. \\ (Classe so.)}

Voilà deux arlistes, deux amis, qu'me même passion pour l'émail unit dans un commun labeur; nous les avons nommés sourent, nons avons trouvé leurs ouvres diez Ponssielgne-Rusand, chez. Wollard, chez Vever, chez Lefèvre, chez nous-méme et chez d'antres encore. Nons n'avons pas à rendre comple de lenr exposition parce qu'elle appartient ì la classe so oi ils exposent, et nous u'irons pas davantage voir celle d'Alfred Heyer et celles d'antres peintres sur émail dont le concours est cependant précienx pour l'orfère; mais nons espérons que les expositions futures rendront à l'orfẻverie ces fins artistes qui lni appartiennent bien plus cqu’ils appartiennent ì la eéramique. On classe au Lonve les émanx limousius ì côté des gemmes et des orfêvreries; re sont trois formes d'un art complet qui s'aident et (gu'il faut qu'un même artiste dirige. Le preintre procède de l'orfèrre. C'est l'orfèvre qui a fait les premiers émaux; el nous avons autrefois sontem cette thèse avec quelque avantage.

\section{Vanakgoz (Charles), lapidaire, ì Paris.}

(Classe 18.)

It ne nous appartient pas plus que MM. Grandhomme et Garnier, et rependant it est ce lapidaire halile dout nous venons de parler, et dont la collaboration nous est charque jour nécessaire; c’est lui qui taille le jaspe, le lapis, les agates, les sardoines, le cristal de roche, loutes les gemmes les plus 
dures, dont la forme el ta couleur s'alliaient si hien, dans les orfèrreries du passé, à l'or et ì l'émail.

On a clissé $\mathrm{H}$. Vanangoz avec tes décorateurs et les Lapissicrs, et je ne comprends pas eucore quelle analogrie il y a entre le carton-pâte, les bois peints, les sièges el les tentures et fout ce que cette classe 18 renfermait, arec ces pierres dures, ces matières précieuses que Varangoz taille et polit el qui seraient si úcessaires à l'orfèvererie reliģieuse et ì l'orfèvrerie d'art.

Nous arrêterons là l'examen des produits de l'orfèvrerie française, mais, avant de visiter les produits étrangers, nous allons domner un rapide conp d'œil aux objets qui nous sout venus des colonies ef des pays de protectorat; pour cela, nous suivrons l'ordre du catalogue.

\section{COLONIES.}

\section{ALGERIE.}

\section{IIENTION HONORABLE.}

\section{U. OEuancur fils, ì Saint-Eugène (Alger).}

Fu arrivant sur l'esplantade des Invalides, dans les jolis palais qu'on y arail si piltoresquement édifiés, nous espérions trouver une orfèrrerie indigène originale aussi, rappelant par la forme et lc Iravail les ouvrages des Maures ou les ornements kabyles. Le premier orlère que nous ayous vu, II. Demarchi, est mu ancien ouvrier parisien qui s'est établi à Alger et qui débite, sur des types néobarlsaresques, des orfèvreries à l'usage des voyagenr's; ce sont des ornements d'argent, marqués d'unc hâte filigranée qui dessine des lignes blanclıes sur des fonds vernis en noir; des fausses turrquoises et des coraux grossiers jettent leur note brutale, bleue et rouge, sur ces plaques découpées, et ceprudant il y a une certaine harmonic dans ce procédé de décor dont on a fail tontes sortes d'oljets étranges : des tasses, des lampes, des armes, juscułà des meubles el surtout des bijoux. Si notre rôle de rapporteur nous oblige ì domer des conseils el que nous ayons quelque chance d'être entendu ì Alger, nous dirons à M. Denarchi de se souvenir darantage qu il a travaillé à Paris, pour travailler nieux, ou de l'oullier tout a fait sil veut devenir africain, mais d'emprunter alors aux vieux types kabyles leurs admirables ornements, si décoratifs dans leur naïveté. Ce serait une mine riche of féconde et pent-ètre lat source d'une fortune pour qui saurait imiter et reprendre la tratlition perduc.

\section{Molnaned SAId NatT Oukebolbéche, à Fort-National.}

Celui-ci doit être un orfêrre indigène, son nom l'indique, mais sa fabrication ressentble tellement ¿ celle du précédent, qu'il est difficile pour nous d'en rechercher le véritable auteur. Nous sommes trop loin et trop peu aidé dans notre enquête pour obtenir des renseignements séricux, et d'ailleurss le sujel en vant-il la peine? Il faut regretter (fủune grande colonie comme l'M Igérie n'ait rien à nous offrir' quand il s'argit d'une industrie aussi importante que celle de l'orfèrerie. Certainement. la métropole expédie en . Itgérie ses produits manufacturés, clle y introduil ses nodèles et ses usages; les colons emportent de fiance largenterie et tous les ustensiles de lable aurruets ils sont accontumés: 
mais nous croyons quil a dù rester pour les choses de l'orfèrerie comme pour les tissus, pour les meubles el pour les armes, mn style propre à ce payss amexé, un style quilil faudrait réveiller, cultiver ct qui, encouragé par mne société intelligente, pratiqué par des ouvrier's indigènes, sous la conduite d'ortères firancais, deviendrait un art plein de saveur et serail gouté en France.

INDE FRANÇAISE.

\section{MÉDAILLE DE BRONZE.}

\section{Conité DE L'EAPOSITION DE L'TNDE.}

Il serait plus aisé de réveiller aux Indes qu'en Aggŕrie l'orfèrrerie indigène; c’est la contréc où cet art a eu le plus admirable développentent; tout y semble eréé par l'orlèrese : le sol lui offrait l'or. l'argent, les pierres précieuses et les perles; de ces matières rares il a fait les plus admirables bijoux, Jes vases les plus larmonien de forme et les plus gracienx d'ormements, mais en outre, il semble qu'il ait été l'architecte de tous tes monmments. Il n’est pas un temple de Bourlha, un monastère souterrain, une pagode, une mosquér, une tour. un pilier. un portique qui ne ressemble à une wurte d'orfèrerie inposante et gracieuse, gigrantescute et légère. Les flancs des montagnes sont ('iselés comme s̈ils étaient d'argent; les cavernes mystérieuses sont sontenues par des colonnes plus décorées de gravures qu'une genune de nunsée, et le soleil a doré les marbres, a patiné la pierre. a ínaillé de ses feux celte scuppture qui joue, plus éclatante sons la lumière qu'nn amas de rublis et de diamants. Jusqu'à l'arrivée des Européens, J'Indien est resté l'artiste incomparahle, le décorateur le mieux inspiré; il semble que nous ayous rompu le clarme, nous, hommes de l'Occident, en pénétraut dans cette contrée magirque. L'Inde s’est repliée sur elle-mème, blessée, elle a cessé de produire. sà civilisation s'est étiolée et la nôtre ne prend pas racine chez elle. Les nations d'Europe se sont disputé sa possession : Angglais et Français. Portuggais et Hollandais ont convoité cette riche proie: tes Angrgais en sont restés les maìtres, ils n’ont pu réveiller l'lnde endormie, ils règnent sur une contrée ì demi morte. De Jaggernauth on de Myrzapore, d'Eillora ou de Siringan, rien ne germe, parmi les rnines imposantes, qu'une imitation maladroile, qu'entretient un commerce ćgoïste et dominaleur.

Inrions-nous fait mieux si Dupleix et Labourdonuais avaient pu conserver les Indes à la France? Ce que nous y possédons encore est si peu de chose! Pondichéry et Chandernagor ne sont pas les foyers d'ou jaillissait l'art hindou, el le comité qui a préparé l'exposition actuclle n'y pouvait pas trouver d'éléments bien remarquables à nous montrer.

Ce sont des boîtes à bétel, des plateaux d'argent, des objets divers dont la forme est empruntúe à nos vases et à nos ustensiles d'Europe, mais sur lesquels l'artiste indigène a brodé avec l'outil des cisclures imitées de celles qu'il a sous les yeux, saus les comprendre, sans les modifier; représentaur Boutha sans y croire, Siva sans le craindre, Krichna sans l'aimer. Ces copies de dieux, de lleurs, d'animaux sacrés, cxécutées an reponssé, mais mal finies, constituent, toute une falırication cur'on inporte. Combien cela nous fail regretter la seule exposition sincère et fertile en enseignements que nous avons ene en 1873 à Vienne l Là abondaient les documents authentiques, les rases, les armes, les harnais el tout te molilier d'argent, si riche par la ciselure, l'éntail et les pierres. Rien de semblable cette amnée, pas plns, du reste, dans le palais des Indes anglaises pue dans la section des Indes firançaises. Pour qui veut étudier l'art indien et en retrouver les types originaux, il faut aller à Londres visiter la goalerie indienne du South Kensinguton Musenun : c'est là que goisent les dépouilles de l'orfêrrerie indiẹne en sa splendeur éteinte. 


\section{PAYS DE PROTECTORAT.}

\section{ANNAM-TONKIN.}

\section{MÉDAILLES DE BRONZE.}

Protectorat de l'Anam et do Tonkxin, vice-résidence de Hung-Yen.

Lat différence est sensible entre les produits que nous trourons ici et ceux que nous venons do décrire aux ludes. Si les orfèvreries indiennes sont grossières, faites sans conviction, si elles ne rívident plus que le souvenir lointain d'un art dégénécé, les quelques pièces apportées de nos colonies d"lndiChine dénotent an contraire l'adresse de l'ouvrier et des dispositions singulières pour le travail dess métaux. Le style est un composé de motils chinois el hindous; ce sont des tasses, des boîtes, de petits vases à couvercle, des brùle-parfums.

J'ai remincqué surtout un de ces brûle-parfuns; il était copié avec une grande fidélité d'aprè̀s une zousse de januier aree ses feuilles et ses tiges; la ciselure en était morléée arec beaucoup l'esprit. Mais le chef-d'aurre de cette exposition était une grtaude vasque avec sa buice, dont la forme élégrgante el lière était un modèle de pureté; sur la surface de bronze patiné courait une fine damasquinure de lils d'argent. J'aurais roulu qu'un musće achetât cette pièce pour sá beauté, mais elle est la propriété du résident.

\section{Province de HaNoÏ.}

La collection d'objets exposés ici est moins importante; on y troure quelques boites it tabac, des porte-chaur en argent, mais il y faut encore constater l'habileté de l'ouvrier tonkinois. Si donc quelque orferve allait chercher fortune en ce pays lointain, il y tronverait des ouviers plus propres a l'aider qu'on Algécie el qu'aux Indes; c'est lit du moins ce qui ressort de la eomparaison des produils qu'on nous a présentés.

Nous nengageons personuc à comir l'aventure sur notre seule aftirmation.

\section{CAMBODGE.}

\section{MENTIOYS HOYORABLES.}

M. Planté, à Phnom-Penh.

Dans le magnifique palais du Cambodge, il n'y avait que fort peu d'orfèverie : des petits Boudlats d'argent repoussé et doré, des boîtes rectangulaires décorées des mêmes ornements que les palais de 
pierre, des sceau gravés, des étuis d’argent. Du moins ici, cette fabrication ressemble-t-elle moins aux produits d'une pacotille destinée à l'exportation; le travail n'en est pas meilleur que celui que nous Irouvons dans le bazar indien, mais ce sont bien des objets indigènes; ils inspirent nute confiance que uous n’avious pas quand nous visitions les boutiques algrériennes.

\section{JEANDOT.}

Les oljets d'argent exposés par celui-ci ressemblent beancoup ì ceux que nons arons rns chez to précédent; il est regretlable qüils soient inférieurs ì tout ce qui est seulpté sur le hois et sur l’ivoire. Ilais, pour quii voudrait tronver les types parfaits du style cambodgien, il faut visiter l'exposition installée an Trocadéro, dans l'aile qui s'élend du côté de Passy : l'ornementation s̀y allie puissanto aux caprices de la llore et aux grandes figures des dieux.

\section{TUNISIE.}

\section{MÉI) MILLLS DE BRONZE.}

\section{Comité tuxisiex (Président: Mohamed Dsellouli), à T'unis.}

L'orferreric tunisienne n'a pas la finesse des ciselures arabes; elle est, si nous derons en jugror par les échantillons qui nous ont été sommis, naĩve et d'mn travail flou; mais elle dénote une tradition ancienne el garde en sa forme des réminiscences d'un art dégénéré. Ce sont des conpes reponssées au marteau el décorćes d'un ornement brutal.

Cependant, l'amour des Tunisiens pour les bijoux, pour les pierres, pour les riches orlèvreries, nurait dù entretenir dans les atelicrs indigènes une labrication plus soignée. Avant l'occupation frangaise, le Bey et ses ministres achetaient des pièces d'un grand prix, el nous avons vin revenir de lit, comme des pays d'Extrème Orient, des curres d'orfèvrerie de toutes les épocques, qui pronvent qu'autrefois les Orientaux avaient collectionné avec passion les chefs-d'œure de l'orfêrrerie liancaise. Comment done alor's n'exigeaient-ils pas de leur's ouvriers des aurres plus achevées? Faut-il croire qu'ou nous traite en barbares et que le Connité tunisien lui-mème ne trouve à enroyer dans une exposition comme celle-ci que des objets de liabrication courante? Bien qu'ordinaires, ils sont cepenlant de beaucoup supérienr's à tout ce que nous avons rec̣u d'IIgérie.

\section{Sä̈don Catrax, à T'unis.}

Il a des britle-parfums et de lourds flambeaux d'argent, ressemblant en leur lacon brutale aux chandeliers qu'on trouve an fond de nos camparnes. Ce que je préfere, ce sont les coffrets de bois planués de fenilles d'argent bossuées et repoussées : l'effet en est joli; ils doivent constituer dans le mobilier du payss un des objets les plus estimés, car le nombre en est considérable. 


\section{MENTION HONORABLE.}

\section{ACHEM ZiRRoLK.}

Ce sont smtout des coupes d’argent ciselées que nous trouvons dans le lot de cet exposant; elles ont la forme de certaines patères romaines; est-ce 1 m reste des temps antiques, nne tratilion qui s'est perpétuée de Carrdhage à Tumis ou n’y a-t-il là ru'une logique application des formes les plus simples ou les plins commoles?

\section{TAÏEB-EL-MESTAOLt, ì Tunis.}

Les coffres de bois présentés par cehti-ci ont un décor particulier : les minces fenilles d'argent, où courent des ormements relevés en bosses, sont découpées à jour, puis ces feuilles sont clonées sur des paillons rouges, blens ou verts.

Certainement, ce rni nous parait brutal et imparfait prendrait un charme puissant sous le soleil d'Afrurue; dans le fonillis des tapis et des étoffes, j’imagine que ces coffrels, qui servent à renfermer les bijoux des femmes, auraient fait une jolie tache lumineuse dans un tablean de Guillanmet.

Il sarait imprudent de jugrer de toutes les orfèrreries exoliques arec notre tempérament d'orfèrre parisien : ce que nous estimous à Paris n'a pas raison d'átre pour ens nomarles du désert. Mais nous aurons d'autres surprises et de plus grandes désillusions en visitant les nations d'Enrope; il en est qui, jarlis, brillaient les premières à la tète de la civilisalion ct des arts et qui maintenant sont de beaucoup an-dessous des peuplades de l'Afrinue el des onvriers dígénérés de l'Inde.

\section{PAYS ÉTRANGERS.}

Il est bien diflicile, cette année, de faire une comparaison entre l'orfèverie francaise el l'orfévrerie ćtrangère, ol cela pour des raisons que nous n’ivons pas à discuter : les nations étrangères n’ont pas répondu ì notre appel. Nons devons nous borner à examiner individnellement les exposants qui se sont présentés, en expliquant pour eux, comme nous l'arons fail pour nos nalionaux, les jugrements de notre Commission; nous tronverons ì faire des observations d'un ordre spécial, mais nous renoncons dès à présent à toute comparaison entre la production commerciale de ces pays el la nôtre; nous n’aurions aucune base pour un tel travail. Mais si dans uno aulre cxposition on avait à faire une telle recherche, il faudrait munir le jury et son rapporleur de pièces séricuses et probantes, que nous avons en vain demandées à l'AdminisIration el aux commissaires étrangers.

Nous allons suive pour cette revue géographique l’ordre du catalogue, mais lorsque dans une mème nalion nous tronverons plusieurs exposants, nous tes présenterons dans l'ordie dos récompenses que leur a altribnées le jury de notre classe. 


\section{AUTRICHE-HONGRIE.}

\section{MÉDAILLE D'ARGENT.}

\section{Böнм (Hermamm), ì Vienne.}

C'est un très liahile fabricant que NI. Bölım, on doit lui savoil goré d'être venu it Paris avec mn stock aussi considćrable. Il y étail attiré sans doute par l'espoir d'importantes affaires, mais les raisons qui empêchaient M. Klinkosch et M. Watschmam 'de venir en $188_{9}$, comme ils l'avaient fait en 1878 , auraient pu le retenir aussi; il faut done le louer, lui et cenx qui ont osé affronter le public de Paris, el plaindre ceux qui n’ont pas su comprendre ce que leur réservait ce magnifique concours. Cela dit, nous nous étonnous dn goitt apporté par M. Böhnu dans le choix de ses orfêvereries; nons surtout, qui croyons avoir gardé un souvenir exact des choses quil vendait jadis, nous nous demandons comment, il est devenu l'émule de Diglinguer et comment à la fin da suxe siècle. il en est aux orfèvreries qui faisaient les délices de la cour de Saxe, il y a deux cents ans.

Nons ne ponvons pas être plus indulgent pour l'orfève viemnois que nous l'étions tout à l'heure pour M. Joret, d'autant plus qu'il nons vient constamment d'Autriche et de Hongrie des pièces d'or et d’argent émailkées, qui prêtent à des mép̣rises; l'art dn pastiche a rtrí poussé très loin par les onvriers viemois et c'est grand dommage; nons, qui les avons vus à l'œuvre en $\mathbf{1 8 7 3}$, lors de lenr magrnifique exposition, nous, qni savons de quoi sont capables lenrs artistes, nous nous étonnons qu'ils s'atlardent à de misérables copies et qu'ils contrefassent les hibelots de la Voûte-Verte.

Il y a chez M. Böhm des cornes à boire, des coffrets, des cabinets ornés de pierres el d'émanx, des cristanx de roche montés; il y a des masses de hérauts à manclies de lapis avec des garnitures d'argent et d'or; il y a même de ces grosses perles haroques où la fantaisie de l'orfềre a trouvé prétexte ì des arrangements, qui en font des sirènes ou des nains habillés, des dragons aux ailes d'émail ou des oiseaux fantastiques. Mais tout cela, c'est la répétition exacte de ce que l'on voit dans les musées d'Allemagne, c'est bien fait, mais c'est un genre bâtard cqui ne plâ̂l pas ici.

Quand nous voyageons, nous nous prenons de curibsité pour ces spécimens de l'art allemand à son déclin; revenus en France, nous n'éprouverons plus aucune sympathie pour ces ććlantillons d'un goût qni n'est pas le nôtre. Nous sommes donc mal placé pour jnger ici d'me mode qui doit avoir ses prartisans à Vienne, mais nous nous étonnons qu'un orfèvre de talent, s'il renonce ì composer et à créer des auvres originales, ne preme pas de meilleur's modèles, quand il en il de si parfaits an trésor impérial el royal de Vienne el dans quelques musées d'Allemagne.

\section{MÉDAILLES DE BRONZE.}

\section{Livk (P. Étienne), à Buda-Pesth.}

Quelpues pièces d'orfêtrerie religieuse se mêlent aux initations d'orfèvrerie ancienne, car M. Liuk fait à Buda-J'estlı ce que M. Bölım fail à Vienne, et nous devons croire qne le gônt rétrospectif l'emporte de heaucoup le long du Danube sur l'amour des clioses nouvelles.

La fahrication de M. Link nous parât moins soignée que celle de son confirère, mais elle dénote 


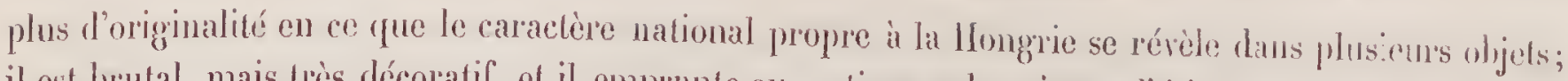
il est brutal, mais très décoratif, et il emprunte au sertissagge des pierres l'ćclat des orfèreries orientales.

Ce qui fait absolument délaut daus l'exposition austro-hongroise, éest l'argenterie, le service de table, la fonte el la ciselure, tout ce cui, aux expositions précédentes, faisait homneur aux orfêrres viemnois; mais, nous le répétons, on ue peut pas cousidérer comme la représentation d'une industrie nationale le maigre apport des exposants autrichiens, et nous qui nous souvenous d'avoir vu it Nuremberg en 1885 l'apport considérable de l'industrie allemande pour les objets d'or et d'argent, nous préférous nous abstenir de tout jugement ici, et attendre que l'oecasion d'une revanche soit offerte ì nos coufrères d'Autriche.

\section{École industrielle de Gilḱdina, à Cortina (Tyrol).}

Il ent été plus juste de classer parmi les écoles industrielles cetle ćcole qui ne présente à juger qu'une pièce. C'est un vase d'argent en filiggrane avec une lougue hampe garnie de feuilles et de fleurs: les détails en sont fins et habilencut traités. Cette ouvre de patience et de dextérité rappelle un peu le travail du maitre allemand Jannitzer, dans la célèbre pièce qui appartieut au baron Karl de Rothschild.

Il est élrauge que l'industrie si spéciale du filiggrane d'argent se soit implantée partout : à Gênes comme en Norvège, dans le Tyrol conme en Syrie, en Espagne comme an Gabou. Tout en reconnaissant leur adresse ì tourner et ì souder de minces fils d'argent, uous ne croyons pas devoir encourager les jeunes élèves de Cortina à un travail sans intérêt.

\section{BELGIQUE.}

\section{MÉDAILLE D'ARGENT.}

\section{WiLMotte fils (J.), ì Liège.}

On s'étail accoutumé à trouver parmi les exposants belges la maisou Bourdon de Bruynes, de Gaud; c'était même le seul représentant de l'orfèvrerie belge à l'Exposition de 1878 . 11 n'a pas paru cette fois, mais on pouvail atteudre quelque effort d'un pays qui, jadis, a tenu une si graude place dans l'art de travailler l'or' et l'argent et qui possède encore les ćchantillons les plus maģuifiçues te lorferrerie religieuse. Ceux qui, en 1888 , ont va à Bruxelles l'exposition rétrospective de l'orfévrerie comprendront que c'est à l'mitation des Belges qu'on a fait à Paris, cette fois-ci, l'exposition des trésor's de nos églises : toute proportion gardée, avouons que l'exposition bruxelloise l'emportait sur la nôtre.

M. Wilmotte travaille à Liège, dans l'ancienno ville des princesuévèques, non loin de la place où s'élevait avant la Révolution la magnifique cathédrale de Saint-Lambert, qui passait pour une des merveilles de la chrétienté; son trésor était riche entre lous les trésor's des couvents et des églises. Saint-Lambert n'existe plus, mais M. Wilnotle a, dans les églises de Tongores, de Maëstricht, de Namur et de Liège même, des modèles excellents. On a fait à Liège, en 1881 , une exposition rétrospective de l'art ì laquelle M. Wilmotte a pris part, et nous croyons qu'il est appelé à hériter 
de: Ir réputation de M. Bourdon de Bronyues. La maison quil dirige a déjà soixante ans d'exisleuce, elle a été crére par son père et cmploie, s'il en faut croire les renseignements qui uons ont été donnés, soixante-quinze ouvriers; on y lait non pas seulement l'orlèvrrerie d'argent, mais les grands travaux de bronze, et M. Wifmotte a quelquefois réussi ì l'emporter sur nos ortèvres parisiens, pour des commandes firangaises.

Il a fait naturellenent pour les égrlises de Liège les travaux décoratifs qui relevaient de son art; il a cxéculé la clàisse de Saint-Wandru, ¿̀ Mons; la chàsse de saint Wivine pour l'église des Sahlons, à Bruxelles; le relinguaire émaillé de l'église d'Hooggstraten; la grande courome de lunière en cuive ćmaillé, qui est daus la cathédrale de Tournai; le lutrin cu'ont offert les danes de Tournni am pape Pie IX; le y̧rand osteısoir nielté et émaillé de la cathédrale d'Anvers; et en ce monent mème, il fait f:our le couvent de Sainte-Julienıe, à Bruxetles, un grand autel avec ciborium en brouze doré, avec des décor's de fifigrane et d'émail; l'égylise de Saint-Servais, ì Maëstricht, lui a commandé la rejproduclion extele des quatre reliquaires, qui appartenzient jadis ì cette église, el qui sont maintenant Ix propriété du musée de la porte de Hall, ì Bruxelles; enfin, M. Wilmotte étudie le projet d'une chisse en argent repoussée, destincée à conserver les reliques de saint Lambert, patron de la ville de liège.

Si, comme nous le croyons, la première condition du succès pour un industriel est d'avoir des traraur; si les progrvès en art sont toujours en raison directe de l'inlérêt que comportent ces comurandes, on peut ètre assuré que II. Wilnotte, qui vit dans un monde savant, à qui les conseils ne feront pas c.éliut, el qui lui-mêne est un artiste véritable, deviendra parmi les orlèves religieux l'un des plus remarquables. Ce ru'il faut loner particulièrement chè hui, e'est l'entente de l'énail, il a réussi nienx que beaucoup dorferres lrançais à se servir de la couleur. Est-ce parce qu'il est roisin d'Aix-litC'iapelle et de Cologne, et qu’il est allé voir dans les trésor's de ces deux villes les ćchantillons d'únaillerie assurénent plus fins que ceux de l'orfèvrerie limousine? Nais nous-mèmes, n'avous-nous jas au Louvre et au musée de Clung les plus admirahles types de l'émaillerie rhénane ct linousine? N'os orfêvres sont impardonuables sils ne les étudient pas mieux.

La châsse qu'avait exposée M. Wilmotte est destimée ì l'église Saint-Jacques de Liègege, elle est de styl ogival : sous un édicule aux gables ornés de sculptures fleuries et porté par quatre colonnes, un urc'.ent des figurines näves, (pui portent un reliquaire de cristal. La façon de celte pièce est brutale, sa dorure clinquante et trop neuve lui fait du tort; les émaux valent mieux que la ciselure, mais ce que nous lni préférons de beanconp, c'est la croix émaillée, ce sont des placues champlevées aux tons fondus, que MI. Wilmotte nous a montrées avec un très légitime orgunif. Il a mème commencé les essais d'énıail de basse-taille, en copiant le célèbre tryptirne d'or émaillé, qui appartient au baron de Selys, à Liège, el qui est de facon italienne.

Deux médailles de brouze ont été accordées à M. Lasseav, ciseleur, et ì M. Mouffard, dessinateur, tous deux collaborateurs de M. Wilmotle.

\section{RÉPUBLIQUE DE BOLIVIE.}

Nous arous vainement sollicité de la Commission bolivienne des renseignements sur la production des mines d'argent en Bolivie. Le pavillon de la Bolivie contenait des échantillons très riches de minerai, et l'une des portes de ce parvillon figurail, d'une facon assez pittoresque, l'eutrée d'une mine. Il nous aurait paru très intéressant, à propos de l'orfèrerio, de fomrnir des chilties exacts sur la production d'argent du 
pays, mais nous u'avous pu les obtenir el nous devons nous borner il ciler les quelques pièces d'orfévrerie exposées par le Conté ne ha Botrue (médaille de lronze): ce sónl des plats d'argent très pesauts, dont quelques-uns ont gardé un caractère primitif, des noix de coco garnies d'ornements et montées sur des pieds tournés; ce sont surtout des filigranes très adroitement travaillés, et ce qui est la marque distinctive de celte orféverie nationale, c’est l'imitation souvent répétée du lama; on a fait de ce yuadrupède un prélexte ì orfèvrerie, mais sans jantis en changer l'attitude; l'animal, debout sur ses quatre pieds, est assez grossièrement représenté; il est fait d'argent battu et plus souvent de filigrame: e'est une tradition conservée dans les ateliers boliviens, et de tous temps les ourriers indigènes ont dì faire la représentation de l'animal qui constitue l'une des grandes richesses du pays.

\section{MEXTION HOYORABLE.}

$$
M^{\text {me }} \text { Vve ARToLA. }
$$

la maison Litola avail exposé déjì en 1878 ; ses filigranes et ses vases en forme de lama ne présentent pas un caractère différent de ccux gun’exposait le comité do Bolivie.

\section{CHINE.}

\section{MENTION HONORABLE.}

\section{YoxG-HEXG.}

La Chine avait envoyé un grand nombre d'objets de pacotille dont elle avait rempli les compt jirs d'un hazar, agissant à cet égard comme linde, et dédaignant de nous montrer ce que ses artistes sont encore susceptibles de faire. Comment cet empire si riche, oì l'art décoratif a trouvé des manifestations si merveilleusement belles dans l'industrie du bronze, de l'argent, de l'émail et de la lapidairerie en est-il réduit à nous montrer des boites du plus unanvais travail; des vases d'argent mince hórissés de figures, de fenilles piquantes et pointues, de vilains émaux et tous les produits d'ordre inférienr?

Quand on songe aux adurirables chefs-d'ouvre d'orfèverie que contenail le palais d'Été, ruand on roit mène ce que rapportent encore ceux de nos compatriotes qui ont résidé à Canton ou à Pŕkin, on hísite à jugrer de l'ortèvrerie chinoise sur les très médiocres échantillons quion nous a soumis celle fois.

Nous ne faisons une réserve qu'en ce qui concerne quelques plats émaillés, non pas tant ì canse dn dessin el dn travail lni-même que par la nuance cliarmante des émaux bleus qni jonent avec largrent et font un décor d'une puissance et d'un charme remar(quahles. 


\section{DANEMARK.}

\section{MÉDAIILE D'OR.}

\section{Chnistesex $(V)$, il Copenhague.}

Cente maison d'orfèrerie jouit d'une réputation méritée, elle a temu sa place dans tonles les expositions miverselles depuis $186_{2}$, et c'est son chef actuel qui l'a créce, il y a près de cincuante ans, d:ans tune pretite ville de l'île de Sécland où il travaillait seul avec un aide; sa persévérance et son gont ont attiré l'attention de ses compatriotes; il a, pour une large part, ressuscité le caractère national, et c'est en 1856 qu'il a transporté son établissement à Copenhagrue; il a, depuis, mulliplié ses curres d'orférrerie et de hijonterie à ce point, ru'elles sont recherchées par les amatenrs de tous les pays. Chrrislesen tient ì Copenlaģue mu rôle comparable à celui de Castellani ì Rome.

Naris l'un des éléments de fortune de la maison Christesen réside dans l'orfèvrerie d'usage; l'atelier marche à la vapeur, on y fait des cuiller's d'argent et la maison, qui a des dépóts ì londres et ì Dresde, exporte en Russie, anx Ĺtats-Unis, en Allemagne el en Anghleterre.

A côté de ces produits de consommation comrante, il faut citer des essais intéressants de services à thé el à café, d'ustensiles de table, dont l'exécution a paru correcte aux orfèves qui formaient l'élément technique du jury; malliemreusement, les types de cette vaisselle sont pris anx styles gree et renaissance el sont trop souvent imités des motèles dénodés de Paris et de Lontres. Dè même, apparaît, daus les fiğures décoratives, l'influence du grand maître Thorwalstein. Ce n'est pas pour ces imitations-là que le jury a récompensé M. Cluristesen, c'est pour un retome plus franc aux procéclés de décoration de l'art danois; les antiđgnités scandinaves que les savants archrónloģues ont remises au jour ont été d'abord imitées par. M. Cluristesen dans sa bijouterie d'or, puis il a progressivement élendu à l'orfèrrerie d'argent ce styte mâle et, de ses ligunes robustes, de ses entrelacs, de ses spires, de ses méandres, il a fait une broderie qui s'enlève comme un cordonnet d'argent blane sur les surfares sombres de l'argent bruni. Le filigrane dont nous parlions tout à l'hemre el qui u'est chez quelques peuples qu'un remplissage minutieusentent compliqué de fils, de cordes et de grains d'apgent, est chez les Danois un dessin ferme, presque une écriture qui ressemble aux dŕcor's grarés des anciens peuples scandinaves et aux calligraphies enluminées dont les scribes tonsurés enrichissaient les manuscrits; des ćcoles admirablement dirigćes et donnant des résult its surprenants nous montraient, dans la même salle d'orfèrrerie, les compositions et les copries d'apprentis qui promettent de devenie de très habiles ouvriers. Déjì des artistes comme M. Péters, conme M. Obrik, dessinent ponr la naison Christesen, les modèles d'orfêverie qu'on y exécute. De ce dernier, est la complnsition d'un grand bouclier d'argent dédié aux gloires nationales; au centre, la hataille de Volner où les anges du Ciel apportèrent au roi Waldemar II le drapean victorieux de Dannebrog. La mort de la reine Dagmar, la captivité dn roi et de son fils, te serment de la loi, forment, avec des fignres symboliques d'mn grant effet, les déments d'une décoralion savante. Ce bonelier a me loiutaine ressemblance avec ceux qu'on admire an musée du Louvre et au musée d'artillerie; il n'alteint pas ì la perfection de ces modèles célèbres, mais il est très supérieur aux essais (fui avaient fiģuré dans de précédentes expositions. Le ciselenr' à yui est dû ce hean travail, M. Scumatreld, méritait bich la médaille d'argent que le jury lui a décernée et l'orfêvre, M. Haxsen, qui a obtenu me médaille de Ironze, nous a dété présenté par son patron comme un de ses meillenrs ouvriers. Notons que c'est à si personnel et rui ont attiré l'attention du jury. 


\section{MÉDAILLE D'ARGENT.}

\section{Hertz (Peter), à Copenhague.}

Celte maison-ci est plrts ancienne que la précédente, mais les éléments de comparaison nous manquent pour prononcer entre elles snr leur importance commerciale et nous ne pouvons les juger que d'après le nombre et le mérite des objets qu'elles soumeltaient à notre appréciation. M. Mertz n'occupe done pas antant de place ì l'Exposition que M. Churistesen, el ses essais sont moins variés, mais il a, lui anssi, cherché à ressusciter les types nationaux.

Ses cornes à boire, ses pots à vin, ses cuillers émaillées, largées, profondes, oì sont gravées des frgures de saiuts et dont les mancies sont brutalement taillés avec une robustesse qui rappelle le travail du bois et de l'ivoire, tont cela a une saveur qui est pour nous plaire, mienx que les imitations néo-renaissance des orfevreries allemandes. Nous n'aimons pas les hanaps el ees vases i convercles, que les Allemands noument politls el rue M. Hertz n'a pas copiés simplement d'après les admirables modèles de Nurmberg et d'Augshomrgo mais qu'il a modernisés en y ajoutant des tropliées de canons ol de fusils, en y ciselant des petits hateaux, en rmplaçant les figures do la fable par des bonshommes d'argent costnmés en matelols. Ces faules de govit, si fréquentes eliez les orfêvres anglais, méritent d'être signalées; ce n'est pas de la sorte que l'idée moderne doit se formuler et nons essairrons en terminant cetle éturle de préciser la façon dont l'évolution nourelle se pourait produire.

M. Hertz a d'halbites ciseleurs el sa fabrication est assez. recommandahle pour qu'on ait altribué des médailles de bronze à MIM. Gl. Boss et K. G. Jansev, contremaitres; le professeur V. Dallierup est le grnile et le conseiller de M. Ifertz. N'oublions pas qu'en 1888 les Franęais ont recu ì l'Exposition de Copenhague un accueil des plus ģracieux et que nos artistes ont trouvé an Danmmark une admiration entlonsiaste. Le pays qui possède un Mécène intelliggnt et généreux comme M. Car] Jacobsen est assnré de faire de rapides progrès dans tontes les industries.

\section{ÉGYPTE.}

\section{MÉDAILLE DE BRONZE.}

\section{Kater, Syrie.}

Tont cenx yni ont visité l'Exposition do 1889 se souviennent de la rue du Caire, Ja foule y faisait nn perpétucl mourement et si, prar ses costumes, elle en gâtait la conleur et le décor, on pourait réchapper à cefle promiscuité en pénétrant dans quelques-unes des échoppes ouverles sur eelle rue; lì, on retronvail l'illusion. C'est ainsi que des ouvriers venus de la Syrie avaient formé un véritable atclier d'orfêvie, où, avec les outils les plus rndimentaires, ils avaient entrepris cependant l'exécution de pièces importantes : vases, coffrets, flambeanx, grands plateaux, tous couverts de ciselures on formés de filigranes plus fins qu'élégants, mais faits avec une hardicsse ot une sûreté remarquables. Leur patron, Kateb, était un grand garçon à la mine intelligente et qui travaillait au milieu de ses 


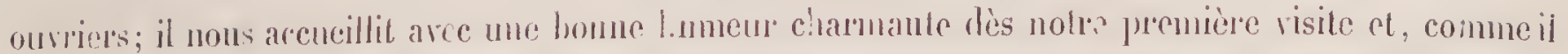
parlait assez couranment le francais, il nous fit entrer chez lui et nous donna tous les explications que nous sonhaitions aroir; it nous prit ensuite en telle amitié qu'il vonlait nous suivre et, après l'lixposition, transporter c'lez nous son éruiqe d'ouvriers et toute la ferraille qui lui servait d'outils; lui ct ses liommes, disait-il, voulaient nous apporter leur aide. Très lẩbleur, douŕ d'une faconde anusante, ce garcon, tout en forgeant ou en soudant ses fins cordelés d'argent, nous racontail combion

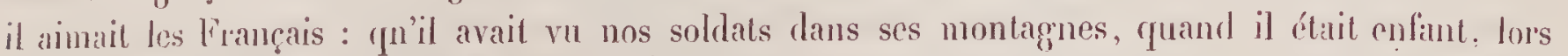
te lat lutte des Druses et des Maronites. Était-ce une rouerie de marchand on bien étail-il sincère? l.e fail est qüil nous plùt et que nons nous anusûmes longtemps ì lui voir repousser les fiğnres uärves el barbares oi se reflète l'art de l'ancienne Syrie : dans cet orfève en plein vent, nous nous Wrisions ì faire revivre un descendant de ces ouvriers de Tyr et de Sidon, qui furent les premiers warni tes marchands et tes fabricants d'orfevererie du monde ancien.

\section{MENTION HONORABLE.}

\section{SARIDIS.}

Très infúrieur an précédent, celui-ci nous a paru faire te commerce des lijoux et des orfêreries, plutôt que de les falbriquer lui-mème; du moins n'avait-il pas joint à son échoppe une forge commue son confrère. Près de la porte il avait disposé son étalage conme il aurait pu le faire dans un bazalr du Caire : colliers de sequius, lracelets faits d'un lingol tordu, pendants d'oreilles aux menus filigranes, narghilés ì la panse ventrue, buires de Brousse, plateaux de cuivre grralés, chargés de :astilles du sérail; armes incrustées d’argent et tons autres oljets dont la provenance incpuiète; où ont-iks été laits? En Égypte on dans quelque atelier parisien? M. le haron Delort de Gléon nons aỹant répoudu de ta bomne foi de Saridis, nous avons accepté comme vrais et autlientiques ses énaux. ses damastuines et ses gravures.

\section{ÉQUATEUR.}

\section{La Coumassox coopéthitrete, à Quito.}

C'est un long royage d'aller, sur la carte, de R'Égype à la République de l'Équatenr'; il uous a paru loin, à nous aussi, d'aller par un jonr de soleil de la rue du Caire aux pieds de la tour lïffèc; nous avions à chercher, dans le pavillon que s'étail construit la commission de la Répulliqque érpartoriale, ce qui pouvait bien y représenter forfèvrerie. Nous arons fouillé fongtemps et nous avons enfin trouvé un dé en or', décoré de filigrane; le dernier dé peut-être du travail a l'aiguille, el sous Ponbre de la tour Eiffel, an milieu des appareils électriques, non loin des gaderies annéricaines où triomphe la machine à coudre. il nous a paru curienx de découvir ce ligjou mignon, lait pour un doight de femme et quiune pelite République américaine renail apporter comme offrande à Jenny l'onvrière, la dernière coulurière des faubourgs de Paris. 


\section{ESPAGNE.}

\section{MENTION HONORABLE.}

\section{M. et $M^{\text {ne }}$ Garcia (veure el fils), it Salimanque.}

Pourcunoi la dimasquine est-elle comprise parmi les linonzes? Si, comme en $1855 \mathrm{do} \mathrm{all} 867$. on arait mis a catalogie le nom de Zuloaga parni les nons d'orfères, nous aurious lo joie de faire du travail espagnol un très intéressant ́́loge. Nais Znloaga appartient à la classe a.5. quoiqui il travaille l'or et l'argent et fasse par ses damasquines et ses incrustations des vases qui sout lien phlus du domaine de l'orfêve que de celui du fondeur et du bronzier.

Du temps des Maures et depuis, pendaut de longs siècles, les orféres de la Péninsule out pratífué la damasquine; les arabesques qui courent sur les pierres, sur Ie bois, sur l'iroire, sur l'acier des armes sont dérivées des nielles de ces orfèvres, qui, venus du fond de ithalie arec les liordes musulmanes, ne quittèrent plus l'ispagne et y laissèrent leur gont expuis.

11 nons aurait paru intéressant de pouvoir étudier ici mn art du'on néglige trop en France, qui a en cependant des manifestations très remaryuables au xve siècle et nous aurions en ì opposer ì Zuloaga notre damaśfuinenr parision Gauvin, mais aux jurés de l'orfevrerie on n’a pas montré d'autres produits de l'industrie espagnole que des filigranes d'argent, dont l'applieation la plus nourelle consistait en des pelits batenux, jouets d'étaģère, mal copiés et ridicules d’aspect.

linsi ces grands orfêres d'Espagne, à qui le baron Charles Davillier a consacré un beau bivie, ces maîlres qui ont illustré notre art et dont l'auteur a donné la généalogie conplètr, qui ont disputé à la France et à l'ltolie la suprématic du goute, qui puisaient l'or dans les galions du noureau monde, qui receraient les pierres précieuses de l'Inde, qui ont rempli de merveilles les c'anubres des mosquées et les trésors des convents; ces maîtres n'ont eu pour successeur à l'Texposition universelle yu'une venve de Salamanque qui apportait quelques dentelles d'argent, pareilles ì celles des ouvriers syriens ou des nègres du Gabon.

Nous n'osons pas juģer de l'orfèrerie espagnole sur de tels échantillons.

\section{ÉTATS-UNIS.}

Toici heureusement un sujet d'éturde plus intéressint pour l'orfèvre et ce n'est pas le rapprochement le moins étrange en cet ordre alphabútique que de trouver immédiatement à côté de l'Espagne, d'oì partit Cihristophe Colomb, l'un des F́tats de cette Amérique qưil raltachait ì notre monde et de comparer au puissant royaume qui s'enrichissait de l'or des Indes les terres ignorées, presque désertes, que couvraient les forèts, les lacs et les montagnes. Quatre siècles ont passé, l'Amérique a, par la force du travail, reconquis tout ce qu'a perdu l'Espagne, elle est plus riche, plus prospère, et les orfèvres de New-York l'emportent sur ceur de Madrid, de Grenade et de Cordone. 


\section{GRAND PRIX.}

\section{TIFFANY and $C_{i}$, ì New-York.}

Cette maison est grande comme un Louvre, j’entends un magasin du Louvre, car elle ocenpe à New-York, dans Union-Square, un immeuble colossal dont les comptoirs vendent l'orfèvrerie, le plaqué, la bijouterie, les diamants, la labletterie, l'article de burean, l'hordogerie el la coutellerie fine.

Créée depnis cinquante ans à peine, par M. Ch. L. Tiffany, la maison n'était à l'origine qu'un comptoir d'importation, qui tirait de la Chine ses principanx articles; c'est en 1848 que te commerce des pierres précieuses devint le prenier élément de fortune de Tỉffany el c'est en 1851 (frï commença ì vendre de l'orfêvrerie. Mais, pendant longtemps, il se borna à acheter en Anghleterre el en France les articles qu'il revendait ensuite dans son pays. Nous l'avons connu ì Paris, ou sinon lui-nème, nous y connaissions depuis trente ans son associé, M. Reed.

It y liasait un commerce considérable, alimentant les ateliers de bijonterie, de joaillerie, d'orfèrrerie el de bronzes, par des commandes dont l'importance allait toujour's en angmentant. C'est ì l'Exposition de 1867 que Tiffiny apparaìt pour la première fois, c'est à celle de Philadelphie, en

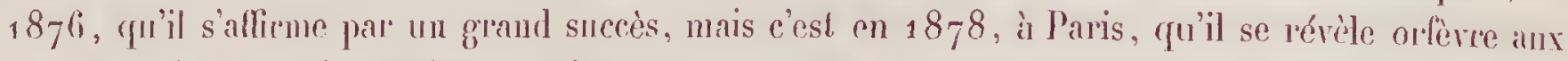
grens de gonit, qui lui font fête et qui accneillent comme une mode aimable les créations nouvelles apportérs d'Amériçue.

II y aurait beancoup à dịe sur la facon dont est né ce style américain qui menaçait de prentre ici la vogure; ce n'est pas senlement paree que pendant trente ans Paris et Londres ont exporté leurs produits à New-York qne le goût a gormé lì-bas comme une graine dans une terre neuve; pout cultiver ce germe, Tiffany avait pris des jardiniers français; nous ne les nommerons pas tous, mais nons rappellerons qu'Heller le graveur. ami et protégé d'Ehmond About, avait ćté jusqu'en 1878 le collahoraleur de la maison Tiffany, et nous allons tout à l'heure le retronver dans la maison Gorhan.

Il y aurait quelque injustice ì prétendre (que c'est à la France seulement (pue Tiffany et ses confrères d'Amérique ont emprunté des maîtres, ils en ont pris à Londres, ils en ont pris en Allemagne surtout, car beauconp d'evcellents ouvriers allemands qui travaillaient à Paris avant la guerre et qui, après, ont vu se fermer pour eux tes ateliers où ils avaient tout appris, s'en sont allés en Anérique. En oulre, Tiffany, instruit par l'éclatant succès des Japonais aux Expositions de Vienne el de Philadelphie, a pris à Kioto et à Nogaga des leçons plus directes que celles qu'avail recues Christofle. On voit dès lors, comment s'est composée celte orfèvreric américaine faite d'étéments divers pris à l'Europe et àl Lxtrême Orient; l'Américain qui n'a pas d'bistoire, qui n'éprouve pas eomme nous l'attrait des choses du passé et qui plus ignorant encore que dédaigneux des belles formes classicques, préfere ne les pas mềler à ses compositions, l'Américain, dis-je, a d'mn senl eoup tronvé ce style composite, analgame te toules sortes de choses prises aux ornements connms; la saveur en a paru neuve à nos palais blasés, et cette adaptation nourelle a eu quelıues années de succès en Fránce. Nous, (pui en 1878 , nous sommes fait le partisan convaincu de cette orfèvrerie-là, nous devons bien expliıner pourquoi; ce n'est pas ì canse des enchevêtrements compliqurús des fleur's, des feuilles et de toute mue régétation tonffue qui trérissait de bosses et de pointes les surfaces d'une vaisselle sans forme.

C'étail lì le très mauvais còté de l'orfèvrerie de Tiffany, mais je suppose tur'elle plaisait à des clients dont la fortune s'est faite pluts rapidement que ne s'est formé te groût.

Ce que nous aimions, c'était l'adaptation des formes et surtout des procédés décoratits des Japo- 
nais; ce que j’avais vonlu faire moi-même en 1868 , prendre an Japon ses ouvriers et ses moyens, Tiffany l'avait fait qnelques années plus tard, et je me souviens d'avoil vu en $18 \overline{7} 8$, dans sa maison et dans la section japonaise, des travanx identiques. J'art des Japonais à travailler l'argent, ì thi garder les douceurs de pean, les contrastes, les repos et les colorations dont le secret nons écliappe, cet art, les Américains se le sont approprié en partie déjì. On se souvient des martelés qui ont fait depuis dix ans la fortune de la liante et de la basse orfèvrerie, on les a vus parâtre d'alord en 1878 cliez Tiffany, et je me rappelle la naïre résistance d'un de mes collègyes du jury d'alor's, qui s'étonnait de nons voir admirer une prèce sur laquelle l'ouvrier e avait négligé d'offacer les conps de marrteaur. Ce sont là des faveurs de la fortune; l'invention la plus simple, le décor le phus solse, sont pour sédluire la masse du public, plus que les dessins corrects et les modelures les plus savantes. 11 fillait aux Tiffany cetle année une expression nouvelle et M. Monre, le directeur artistique des travaux de la maison, a donné le nom de style suracenique au dessin qu'il nons montre.

J. Noore est un homme d'un grand goût, qui a heaucoup va; il a rapplorté de ses courses it trarer's le monde les échantillons les plus variés en dessins, en plotographies, en moulages, en oljegets authentiques; il vil daus la sociélé la plus riche qui soit au moncle, en continuelle relation arec des millionuaires et les milliardaires dont la fortme rapide nous étonne; nvec leurs femmes élíformtes et capricienses, dont l'lumeur changeante et volontaire stimule son invention. Il a fallu, pour ohécir à celte clientète autoritaire qui commande et qui paye, trouver, et le somecenique style n'pst plus emprunté au Japon, il est pris à l'Inde, mais les ornements indous sont accommodés à la mode yankee.

C'est en s'affranchissant des liggnes d'architecture, des moulnres et ales profils dont notre mémoire it nons autres est encomhrrée, (que N. Moore a fait des pièces d'argent dont la sillonetle n'a pas l'ap)parence des nôtres; il est indépendant en cela de la routine anglaise et française, ses formes sont tries souples, très rondes, n'ont pas de pointes; elles ressemblent beancoup plus ì des fruts et it des fleur's qu' ì des morceaux d'architecture et de scnlpture. Un chandronnier lrahile serait plus voisin qu'un orfère français des tour's de main des ouvriers d'Amérigue, mais quand il a fait au martean a vec une perfection que j’adnire le large tankard des hanquets ou le locing-cop des fiançailles, on même te nutional-tenpot, il le couvre d'ornements bossués, gravés, clamplevés, ciselés, niellés et ŕmaillés, car tous les modes de drécor sont bons aux Américains el c’est précisément quand Christofle, yni les a pratiqués arec succès, les abandonne pour revenir à des surfaces unies que Tiffany et Gorltan s'muparent des moyens quiemployait Christofle an temps où les Américains importaient cl:er enx ses prorluits; mais l'émail n'est plus la coulenr clande des Orientaux, c'est une pâte à tons rompus, où les jaunes, les gris, les bruns, les mauves, les violets et les ver's ont des tons sourds, qui se mêlent et se fondent en des larmonies voisines des pâleurs de l'argent. Du reste, ces couleur's et ces or'nements sont pris à la flenr à la mode; les orchidées à la pean tigrée prêtent le contour de leur's pétales et la nuance de leur robe à celte orfêvreric nouvelle qui incquiète l'ail autant qu'elle le charme et qui, pour nos yeux parisiens, excite plus de curiosité que de sympathie. Euntre ce décor dit saracenique el les belles ornementations dont les Manres d'Espagone et les Arabes lirnlaient le métal, nous n’leésiterions pas, et eu dépit de la nouveanté, du charme, notre préférence irait ì l'art aralıe si pontlévé dlans sa grâce et sa fantaisie.

II y a toule une série de cafetières à l'apparence semi-orientale, dont quelrues-mues resteront comme le lype d'un effort d'invention réellement origginal et puissant, mais dont leaucoup dénolent déji. par l'exagération des formes el la redondance des ornements, le défaut d'un style composite. qui ne survivra pas à la mode du jour. parce qu’il manque de simplicité et se décompose en des étéments trop divers.

Si des oljegts d'usagge qui composent le service à thé, nons passons à ces énormes coupes à denx anses que les Américains nomment loving-cups, les formes pleines et largement assises de ces vases 
offrent à l'artiste plus d'aisance pour dessiner son déeor. It ne le lait pas seulenent en ciselure ou en émail, il g met les incrustations de cuire on d"or'; il y emploie le nielle, c'est-ì-tire l'alliage du plomb, du soufre el de l'argent. Comme on le roil, tous les moyens sont bons it nos confrères d'Amérique; ils usent de toules les ressources, ils osent être coloristes, comme n’osent pas encore les orfèrres de Parris; mais leur audace se heurte à de grosses difficultés toutes les fois qu’ils emploient la figure lumaine; l'inexpérience de leurs artistes est nanifeste. Deux pièces remarquablement helles sout le grand vase d'argent émaillé el ciselé, dit le vase à orchidées, et le rase en mokoumé. Le purenier est une pièce de grande proportion, car il mesure 27 pouces en hauteur el 16 en dianètre; il a śté rétreint au marteau sur une plaque d'argent, et c'est un travail intéressant déjà pour le bou ouvrier; la forme, plus large an sonmel qu ì la base, se nodèle dans sa partie laute en côtes de melon, alternativement plus larges ou plus donces, et ce n'est qu'ì la hase que se profilent quelques monlures solres. Un mélange d'ornements orientanx et de fleurs d'orchidées couvre la panse du vase, faisant joner l'ćmail avec la ciselure et la grravure ì l'eau-forte.

C'est évidemment le travail le plus extraordinaire en ce genre qui ait été fail par un orfèvre américain. Le prix qu'on en demande est de 20,000 liancs. L'autre vase, plus grand encore et plus élancé, était formé d'une feuille de mokoumé (c'est, on le sait, le nonn que donnent les Japonais à une combinaison de métanx forgés et laminés ensemble, où l'or, le cuivre et l'argent entrent dans des proportions déterminées). Nous avions en 1878 trouvé cliez les Japonais des spécimens de ce travail ¿ni nous avait vivement intéressé. Chrnistofle a ficit un travail irlentique et nous avons vu en 1880 , cliez lui, plusieurs applications du mokouné, très réussies, mais jamais aux climensions extraortinaires du vase cui nous occupe.

Lieffet de ces métaux mélangés est assez semblable à celui de certains granits, ou nieux encore, des lames damassées des Orientaux. Ce n’est en réalité pas autre chose que ce damassé même, si ce n'est que le cuivre remplace l'acier el que l'argent remplace le fer' des patines chiminiques et des cuissons successives amènent le cuivre à des tons l'ouges d'une grande puissance, dans lespuels l'argent noir et l'or forment des dessins marlurés. Le col et le pied de ce vase étaient d'un gouit parfait.

La fantaisic ancéricaine va de ces pièces de grande décoration aux objets d'nsagge courant. Tout derient prétexte à orfèvrerie et ì ciselure : des lampes de travail, des encrier's, des ustensiles de fumeur, des ustensiles de toilette et jusqu’à des revolvers dont la crosse est d'argent, et qui sont assez jolis, pour faire croire qu'au nouvean monde on pousse la corquetterie jusqu'au suicide.

Tiffany aime aussi les gemmes, il a taillé des vases dans des crislaux de roche, et nous admirons l'adresse des lapidaires à décorer de helles grrarures les formes pleines de ces cristaux, où s ajustent des montures d'argent; la corne, livoire et l'éc aille se mêlent aux argenteries niellées. On y incruste des turquoises, et c'est toute une larmonie de tonalité donce qui nous plaìt à nous, mais dont la surprenante nouveauté déroute le public routinier.

Il y a entre le gout français et les andaces de la mode amóricaine des nuances que franc'iriront difficilement nos plins osés chercheurs de nouveautés. Ainsi, l'argenterie de table et les couverts sultout ne trouveront pas à Paris, ni mêmé ì Loudres, de débouchés dans la consommation; la forme, le poids, l'éfuilibre des parties, tont diffère, et comme les cuillers et les fourchettes sont les outils du repas et, pour beaucoup de gens, les outils les plus indispensables, la main et la bouclie ne se déshahitueront pas de ceux que nous aimons. En 1878 . Tiffuny avait ficit graver par Heller tous les dieux de l'Olympe sur les spatules de ses courerts. Il y a cette fois représenté les ludiens des Montagnes liocheuses et des prairies; on dirait que Fenimore Cooper a inspiré l'orfèvre et c'est, en effet, le seul style national qui soit permis aux États-Unis; ce n'est qu'une fantaisie. Il appartiendra au rapporteur d'une autre classe de décrire les pierres précienses et les bijoux merveilleur de Tiffruy, mais nous pouvons signaler la riche collection de gemmes brutes et taillées qu il avait exposée, parce que ces gemmes sont toutes tirées du sol américain el qu'elles constituent pour l'orfèvere les ćléments 
utites de décoration. Sil est juste de nommer les collahorateurs d'une paissa:Ite maison. celui quil fant meltre liors ligne, éest M. Moons, il est rimitialeur, le chef, le gonile véritable de loute la faluricalion; mais immédiatement après lui viennent M. Dıms, le contremaître, of M. Cunnax, le dessi-

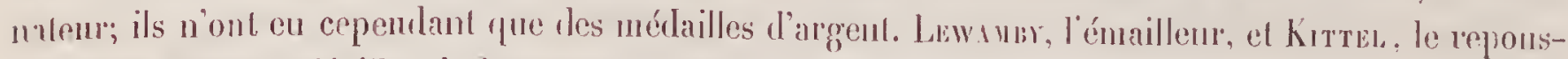
semr, ont en des médailles de lronze.

\section{MÉDIILLE D’OR.}

\section{Gormal Manufacturing $C^{o}$, ì New-York.}

Chez 'liffany nous avons trouvé l'orfèrrerie mélée aux bijons et anx diamants, mais une orfèrrerje on la lautaisie avait plus de part que l'oljet utile; l'argent n'y figure pas comme un mélal de prix, mais conme une matière propre ì receroir une décoration nonvelle et à satisfaire anx caprices d'une clientèle riehe et hasće. La Gorhan Manufacture, au contraire, n’a ni bijoux ni pierreries, elle firit nne exposition d'orferrerie, à l'exelusion de toute autre marehandise. Elle se présente comme Cirriswhle, comme Odiot, conme mu argentier.

Crécée en 1831, celle société a sa fabrirque à Providence, dans l'État de Rhode-Island, et sa maison de vente it New-York, daus Broadway. Elle occupe, tant dans ses magrasius que dans ses ateliers, Whis de 1,000 enployés et ses machines représentent 300 cheraux de force. Les affarres contmerciales varient entre deux et trois millions de dollars annellement et c'est des provinces de l'Ouest fue la maison lire l'argent gui elle transforme en vaisselle et en couverts de table.

Qui sont les agents de cette falmrication? Oi se recrutent les ouvriers? En Amérique, nous dira-t-on: " tous nos ourrier's sont dméricains r. C'est lá réponse qui est de mode chez tous les exposants et il serail oiseux de la provorquer. Nous ne dontons pas qu’il y ait des Américains dans les usines américaines et nous supposons même qu'ils y sont en majorité; nons savons notamment que les rejrésentants à Paris de la Gorham Manufacture, M. Geo Hougton et M. Ed. Holbrook sont Américains tons deux, mais ce que nous avons dit de Tiffany, nons pourrions le répéter de la Gorlan $\mathrm{C}^{\circ}$, en expliquant que c'est d'Angleterre, de France et d'Allemagne que sont venus les premiers ouvricrs qui ont organisé cette superbe usine et qu’ils sont nombreux encore les étrangers qui travai lent lì, comme Heller, l'artiste fiançais the nous y retronvons.

Heller est revenu sourent en France, mais il retourne volontiers vers l'autre bord de l'Itlantique, il consacre son talent aux Américains qui l'accueillent, l'estiment et le payent mieux que nous.

P'our Gorham, il a fait en ces dernières années un très grrand nombre de modèles el nous en avons sous les yeux les dessins exacts, l'artiste les a désignés sous des noms lien franęais; c'est le service dit de Verscailles, le style Louis XIV y a des allnres qui scandaliseraient Saint-Simon, mais il s'y unêle des déesses el iles enfants modelés en bas-relief, dont la garâce sonple rérèle bien un maitre lirancris.

Le service da Fontainebleru est moins conpliqué, les formes sont phus simples; sur chaqne pièce un personnage, en costume renaissance, semble un scrvitenr de nos plaisirs; ce sont des pages, des écnyer's et des servantes qui s'empressent, portaut des fruits, des vins et des mets.

l'uis vient le service de Saint-Cloud où la figure humaine n'a pas de place, mais que décorent des fenillages or'nés aux reliefs très doux; c'est enfin le service Coloniul, qui n'a d'autre eflet que los jeux de lunière, prodnits par le métal alternativement côtelé et camelé.

Nous ne croyous pas utile de nommer tous les. modèles de la Gorham $C^{\circ}$, nous nituns pas entre-

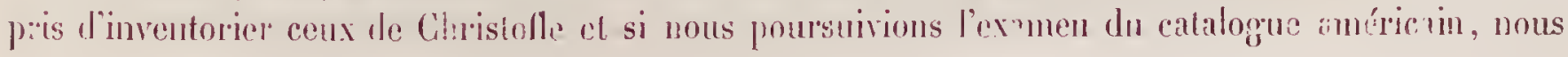


finirions par y découvrir les modèles de l'orfèrrerie française, car on ne se fait aucun serupule, là-Jsas, de prendre son bien où on le tronve. Aucune loi ne nons défend ulilement. Toujour's on retrouve it J'origine de la maison américaine l'idée française et liidée anglaise. C'est de fuoi se défend la Conpagnie Gorhan, dans la préface du joli catalogue qu'elle a fait imprimer ponr l'Exposition; quoi qu'il en soit, ce qui nous étonne, c'est de trouver díjà chrez Gorhan le mêne slyje que chez Tiffany, le même mode d'onementation à certains oljjets. Si M. Moore est bien réellement le créateur du genenre quiil appelle saracenique, comment ce genre a-t-il péuétué chez un concurrent, est-ce une imitation déjà ou l'inventeur est-il rquelque artiste qui se partage entre les deux maisons? Les services à thé, les plateaux, les garnitures de nécessaires mêmes, rappellent d'assez près ce que nous arons vu dans la maison voisine, non pas senlement par le dessin, mais par les ciseln res en repoussé, exaģérées de détails, qui couvrent de fleurs les surfaces d'argent; ce sont d'habiles ciscleur's ceux qui font ces repoussés et nous sommes surpris d'avoir à consta ter de si grands progrès dans un pays relativement si neuf. Le goût des arrangements est bon, pour peu que l'artiste se modère et qu'il fasse des contrastes aux fines ciselures par des repos et des clramps unis. Contrairement à ce que nons avons vu en France, Gorlan et Tiffany ne s'alandonnent pas à l'imitation des styles Lonis XV et Louis XVI; si l'on trouve quelques rénuiniscences du Queen-Anne-Taste, des imitations des ciselnres de Morel-Ladeuil et des orfêrreries d'Elkingon, la préoccupation est visible de créer une orfèvrerie anéricane originale. La Compagnie Gorlan prodnit surtout l'orfèvrerie d’argent à un titre élevé (sterling silver), mais clle fait aussi le métal blane, l'argenté et certains oljjels de cuivre et de hronze fu'on ponrrait classer à là fois dans l'imitation et dans l'orfèvrerie d'art. Ce pgui trahil l'inexpérience et ce qui marque mue faute de gontt chez ces orfèvres, c'est l'importance qu'ils allaclaient à la grande pièce cutils avaient mise en évidence et qu’ils appellent le Century vase. Ce n'est pas pon' la fète du Centenaire français rüil a été fait, rassurons-nous, mais ponr commémorer l'achèvement du premier siècle de la répul,lique des États-Unis d'Amérique; c'est donc nue sorte de testimonial où s'étagent en pyranide des figures allégoriugues mal modelées, maladroilenınt groupées et qui révèlent toute linexpérience du sculpteur et de l'ornemaniste.

Les Américains ont cependant des arlistes de valeur, soyez certains qu’ils les sauront trouver et qu'ils mettront moins de temps à se les associer que nous n'en avous mis en France : nous sommes passés par les mênes fautes. Gorlıam a plus que Tiffany la tendance à employer la figure hrunaine; ce n'est qu'avec Heller qu'il y a réussi, mais chez lui et son confière, l'argenterie subit une modification qui rappelle ce qui, en France, s'est passé pour la céramique : quand, par exemple, je vois à la Gorham and $\mathrm{C}^{\circ}$ qu'on ne craint pas de faire un pot à thé cn cuivre, hronzé au feu, c'est-à-dire que de préférence à la valcur de l'argent on vent une note rouge éclatante, la couleur que le cuivre seul peut donner, je constate une idéc décorative plus virtuellement per'sonnelle que cliez nos petits falmicants orfèvres de Paris.

Le jury a décerné une médaille d'or de collahorateur ì M. HELLEk, l'habile graveur sur acier; une médaille d'argent à M. Georges Wuknsson, suriutendant des ateliers; une médaille de bronze à M. Jordix, ciseleur, et une autre à M. Hugues, ottèvre; une mention honorable, cnfin, à M. Shaner, orfevre.

\section{Meriden Britannia and Cò à New-York et à Meriden (Connecticut).}

Cette médaille d'or n'a pas été votée par le jury de l'orfêrrerie. Elle n'a été obtenue du jury supéricur qu'à la suite de démarclies répétées et gràce à de puissantes intercessions : ces influences sé̉taient exercées déjà vis-à-vis du jury de groupe, qui avait unaintenu avec impartialité les conclusions du jury de classe. qui attribnait à la Meriden Britannia and $C^{\circ}$ une mérlaille d'argent. 
P'our nous, rapporteur, qui n’avons pas à connailre les raisons qui ont déterminć le jury supéricur à modifier notre jugrement, nous persistons à croire qu'il fant d'autre mérite qưune grande prospérité commerciale pour obtenir des récompenses, el que les médailles sont à ceux qui falmrijuent le mieux et non pas à ceux qui font les phus grosses affaires. Cela dit, nous recomaissons ine la Ncriden Brilannia and $\mathrm{C}^{\circ}$ est une manufacture considérable, elle emploie 2,000 personnes et le chiffre annuel de ses ventes monte a 5 millions de dollars on 25 millions de francs. La quantité de métal employé chaque année dépasse 10 millions de livres, l'or y entre pour 5,000 onces. Finfin, clle traite avec toules les parties de l'Amérique, car la Compagnie n’a pas seulement des átablissements à New-York, à Boston, à Ghicago et à San-Franciseo; elle en a à Rio-de-Janciro et à Buenoslyres, elle en a à Melhourne, elle en a à Londres, elle en ouvre maintenant à Paris. Ciest lì qui est le danger de ces complaisances : un jury aide par des récompenses exagérées une maison puissante el riclıe à s'implanter chez nous anx dépens do commerce national, en s'attribuant des mérites qui un jury spécial n’avail pas recommus.

II ne doil pas suffire de jeter (quelques millions dans le plateau de la balance. It fiut dire la vérité, et la comparaison est impossible entre les produits de la Meriden Britannia and Co el cens des deux autres orfèves amćricains. Ni par le gooût, ni par la cqualité du travail, il n'y a de rapprochement à élablir : les formes sont généralement nauvaises et la partie artistique tout ì fait négligrée, on, pour être plus exact, il n'y a rien d'artistique dans cetle fahrication; c'est à tort qu'on use de ce mol art ì tont propos, it le faut réserver pour les choses qui le méritent : or nons n'arons pas déconvert une forme pure, une imilation correcte de quelque type consacré, un dlécor nonvean; encore moins parterons-nous de ciselure, de grarure ou d'émail, ce sont des procédés qu'on ignore à Neriden, oì tout est fail mécaniquenent. Là ne serait pas l'objection, nous aurions au contraire voulu découvir une fabrication courante, pourant satisfaire aux besoins des classes moins aisćes, mais donnant arec le luxe à bon marelé la notion des belles formes et des élérances simples. La compagnic américaine dont il s'aģit devrail avoir cet oljectif; elle obéira peut-être $1 n$ jour à des conseils comme celui-ci, parce que c'est son intérềt de le faire, mais elle ne l'a pas compris encore el notre devoir est de lui dire que ses modèles sont défectueux, que nous les voyons avec chagrin se répandre à Paris, dans les boutiques, parce que ce sont de mauvais exemples et qu'ici comme ailleurs il y a des ignorants que le bon marché tente el qui ne savent pas discerner le beau du laiıl.

Ces orfêres ne travaillent pas l'argent, ils ne produisent que l'imitation et encore te métal blane $n$ y entre-t-il que pour une faible part; la société fabrique presque tout en un alliage fusible qu'on nomme ici métal anglais, et mieux, le Britannia; on le recouvre d'argent par des dépôts chimniques.

L'ụsine de Neriden prépare surtout le plargué d'argent sur étain; ce métal donblé obéit docilement a la pression et on falırique par l'estampage, le tournagge et les emboutissages, des pièces qui ont l'apparence de l'argent, mais qui ne supportent pas le feu.

II fant, anx États-Unis, à l'immense population qui va croissant, se multipliant et se civilisant, des ustensiles de table appropriés à ses besoins; la nnanufacture de Clnistofle, que nous trouvons puissante et prospère, paraitrait bien petite, si elte était comparée à la Mleriden Britanuia and $\mathrm{C}^{\circ}$, qui produit 10 millions de couverts par an.

Nous adnirons sincèrement cette puissance industrielle, mais, en protestant contre la complaisance qu'on a eue pour elle, nous lui rendons service; faites de homne foi, nos critiques hni seront profitables, plus qu'une banale lonange. C'est M. John Jepson qui a la direction des travaux à Meriden, il élait précédemment employé à Birmingham dans la maison Elkinğon; c'est M. Hirschffeld qui dirigge les travaux de gravure dans les ateliers ılepuis trente-scpt ans; il est venn d'Allemagne. 


\section{ANGLETERRE.}

S'il est un pays duquel nous attendions arec confinte une helle exposition d'orféverie, c'est l'Angleterre; nous espérions trouver chez nos confrères de Londres une bonne volonté réclle à nous soumettre leurs ouvrages d'argent ef ì concourir courtoisement avec nous. C'est avec eus que nous sommes en lutte, ils sont nos concurrents les plus sérieux, ils passent pour des orfèvres émérites, on leur accorde depuis cent ans un gont si parfait, une entente si exacte des conditions où l'orfèvrerie devrait être faite, fue nous attendions leur venue comme une lecon. Et ils ne sont pas venus. Il n'est pas dans le caractère anglais de reculer, ce sont des gens braves, hardis, résolus; ils aiment la lutte, ils ont l'énergie d'un grand peuple et les qualités de persévérance des travailleurs.

Mors pourquoi celte absence? Ce n'est pas comme en d'autres pays le fait d'une réserve imposée, puisque certaines industries anglaises sont représentées avec le luxe de li qualité el du nombre, c'est une abstention des orféres, une réserve craintive, presque l'aren d'une infériorité, car on pent difficilement juger autrement celui qui refuse le concours loyal qu'on lui offre.

C'e qui rend cette absence plus fácheuse encore, c’est le souvenir du passé.

C'e sont les Anglais qui les premiers ont inauguré ce système d'exposition internalionale; ils nous ont invités les premiers à porter chez eux nos produits et nous y sommes allés, nous y sommes retournés chaque fois quils ont voulu; ils ne se sont pas contentés de prendre nos idées, nos modèles, notre goût; ils nous ont emprunté nos ouvriers et nos artistes : très réservés cur-mèmes en leur's usages commerciaux, ils ont opposé à notre entreprise une barrière défensive quils ne trouvaient pas chez nous, carr ils ont envahi notre marché en même temps qu’ils défendaient le leur, par des lois prohibitives spéciales à l'orfèvrerie.

Enfin, pour activer le gont, pour aider ì répandre la bonne doctrine dans le public el dans l'atelier, ils ont fait le musée de Kensington, ils ont créé des écoles dans les trois royaumes, ils ont provoqué un mourement d'éducation et de curiosité qui prend l'enfant dès son apprentissage et qui excite chez l'homme l'admiration pour les curres anciennes et nouvelles de l'art et de l'industric. On nous parle de ce musée, de ces écoles, de ce progrès, de la poussée de sève que cola a déterminé en Angleterre; des délégués sont envoyés par le Ministre de l'instruction publique, qui reviennent arec de volumineur rapports et qui nous alarment en nous disant : e Travaillez, organisez votre enseignement artistique et industriel, c'est une ourre de défense nationale au même degré que l'organisation de notre armée (1). "Et quand nous attendons curiensement le résultat que cela a produil, nous ne voyons rien venir; cela rappelle l'épisode des bitons

\footnotetext{
(1. Marius Vachon. Liapport au Ministere de l'instructeon publigue.
} 
flotumts, car si nous jugions de l'orfèvreric anglaise sur ce qu'on nous en a montré, nous pourrions dire avec le fabuliste :

De Join c'est quelque cliose el de près ce n'est rien!

Nous n’irons pas jusque-là, ce serail fort injuste, mais nous nous étonnons de n'avoir vu ni Garrard, ni Haucock, ni Phillips, ni Hunt et Roskell, ni Elkington, ce champion fidèle de toules les expositions passées. Eux, qui nous connaissent, qui sont nos amis, qui usent librement de nos idées et de nos artistes, qui vivent dans notre intimité, qui ont des racines en France, dans nos itcliers, dans nos musées, daus notre clientìle, et qui nous prennent beaucoup de ce que nous leur offrous si libéralement, pourquoi ne sont-ils pas venus, pourquoi ont-ils boudé? Nous pardonnerions à d'autres la crainte ou l'indifférence : d'eux, cela nous surprend et nous offense.

\section{MÉDAILLES DE BRONZE.}

\section{DIXON (James) and sons, à Shellield.}

Il n'y a pas à cliercher ici de pièces d'art et de ciselures fines. Tout y est d'un usage pratique, on ne copie aucun style, on s'applique uniquement à rendre utile et commode l'ustensile qu'on fabrique. Ces pièces sont rarement en argent, on les fait en métal argenté, en ruolz, en plaqué, en étain. Ce sont des formes rondes, bien assises; elles manquent de grî̀ce, mais elles sont inversables et la facon correcte des pièces en constitue la senle beauté. Nous sommes hahitués à voir ces boîtes à coins arrondis, ces théières à côtes dans quelques boutiques anglaises de la lue de la Paix ou des environs de l'Opéra. On les désiģne généralement sous celle rubrique : genre anglais; elles jouissent d'une certaine faveur parce qu'elles sont d'un facile entretien. Tout cela constitue une des forntes du goût, unais n'a aucune prétention à l'art, el c'est uniquement pour les qualités confortables de cette fabrication que MII. Dixon ont été classés avant leur's confrères de Iondres.

\section{Goldsmitus Alliakce, ì Tondres.}

Sous cette raison commerciale se présente une vieille el importante maison de la Cité, qui n’a pas la réputation de goût des grands orfêrres que nons nommions tout à l'lenre, mais qui tient cependant un rang très lıonorable dans son conmerce. Pour qui connaît Londres, la différence est sensible entre un orfêrre de Cornhill ou de Cheapside et un orfêrre de New-Bond-Street; l'un fournit à la cité, obéil aux vieilles traditions, garde les formes anciennes, fail, de la routine et de l'usage, les vertus essentielles de sa maison pour ıe pas déplaire à sa clientèle de marchands; l'autre, au contraire, est à l'affùt de toutes les nouveautés, adopte toutes les fantaisies les plus étranges et cherche à amuser, à séduire ses clients du West-End. Nous aurions eu plaisir par conséquent à examiner dans les viluines de la Goldsmiths Alliance l'orfèrrerie anglaise telle qu'on la retrouve en certaines familles, telle fuion la fabrique encore et qu'on la fabriquera longtemps daus ce pays de traditions et de coutumes. C'est tme argenterie d'usage, bourgeoise, cossne, faite pour un peuple de frarchands et nou pour une aristocratie dirigeante. A l'époque où notre orfèrrerie française subissait, sous la direction de grands artistes, les formes et les modifieations successives de la Régence, du Louis XV el du Louis XV1, l'orfèvrerie anglaise s'écartait insensiblement de ces types qu'elle arait copiés d'ubord assez fidè- 
Jennent. Une maladresse naire el qni n’est pas sans charmes apparaît dans toutes les œurres de celle époque : coupes, brocs, fontaines, flambeaux d'argent, pots à thé et ì café, vases à anses, buires, chocolatières, sont bien plus la composition d'artisans que d'artistes; l'outil de l'ouvrier se trahil plus que le crayon du maitre. Ce qui fail le charme de nos pièces françaises, c’est le slyle, c'est l'esprit, c'est linvention ‘c'est le goût d'un détail, la cisehinre d'un ornement, le profil d'une forme; la composition anglaise est brutale, la pièce solide, elle tient debout, elle répond à l'usage qu'on veut d'elle, mais elle est sans grâce; la gravure est d'un ouvrier', la ciselure d'un manœuvre, la forme est estropiée; l'anse remplit la main, mais est sans élégance. Le décor manque d'espril, n'évoque aucune idée et n'it de raison d'être que s'il est emprunté aux armoiries du propriétaire ou aux marques de la corporation.

Les musées de Londres, les collèges d'Oxford et de Cambridge, les corporations et les compagnies de la cité et des principales villes des trois royammes gardent les échantillons précieux de cet art national; il eut été bien de nous en apporter la représentation comme on a fait il y a quelques années dans une exposition d'orfèvreric au musée de Kensington.

Au lieu de cela, la Goldsmiths Alliance a ouvert une véritable boutiqne de vente où sont étatés des olyjets clinquants, légers, sans style; ils semblent faits pour l'exportation; ils ont des dorures criardes, des lrunissages trop nenfs, des bossuages exagérés, des gravnres cógratignées; les fignres y sout si maladroitement composées quielles en deviennent drôles; ce n'est plus le retard d'mu siècle qui nons lamènerait à tont ce (qu'a d'ainable une tradition et de respectable l'attachement à de vieilles contumes. C'est l'ankylose d'une maison rui n'a pas fail un pas depuis cincquante ans, qui n'a rien vu, rien compris, rien essayé dans son indnstrie, autour de largnelle s'est faite l'évolution des autres arts sans rqu'elle ait voulu modifier rien ì son métier. L'Exposition de 185 I, qui a elhangé l'orientation de l'esprit anglais, n'a rien changé pour ceux-ci; ils n'ont pas visité le musée de Kensington; ils doivent obéir à quelque parti pris bien arrêté, à quelque mot d'ordre antoritaire fail d'entêtement, de rancune, de mauvaise volonté contre l'esprit nouveau. Et pour cqu'ils agissent ainsi, il doit y aroir une cause pratique, une raison d'argent et d'affaire. Un négociant de la cité ne fait rien sans oljectif et sans résultat. Donc l'Angleterre et ses colonies possèdent une clientèle qui boude à l'ilée moderne, qui se confine en son maurais goût, qui s'enferme dans la mode ćtrange de la première moitié de ce siècle et qui y mourra; cette clientèle suffil à la fortune de la Goldsmithıs Alliance et nous n'arons pas mission de la convertir à notre gon̂t.

\section{Goldshitus and Silvershitiss $C_{i}^{\circ}$, ì Londres.}

Il y a entre cette maison et celle que nous venons de quitter la différence que nous signalions entre le quartier de la Cité et celni du West-End, mais on aurait tort d'espérer que nons y allous trouver les élégances et les richesses de ce monde vivant, brillant, cqui fait de Londres une ville si animée et si vivante pendant les mois que dure la saison.

II aurait fallu pour nous en domner l'illusion et le reflet qu'une grande fabrique d'orfêrererie comme celle de Garrard ou celle de Hunt et Roskell consentît à exposer. Ceux cui sont renus ont ouvert une boulique de vente plutôt qu'ils n'ont fait une exposition el lenr orfèvrerie, comme les bijoux rqu'ils étalaient, présente une réduction de ce cqu'on trouverait en leur's magasins de Regent Street; ce n'est pas tout à fait ce qu'il faut faire dans me exposition; je sais bien qu'on y vient aussi pour faire des affaires, mais il ne faut pas transformer en foure el en marché les galeries d'un Champ de Mar's; on n'agissait pas ainsi dans la section française.

La Compagnie des orfèves et des argentiers, pour traduire en frangais son titre, a été fondée en 1880 , par l'association de M. Dixon, orfèvre, avec M. Langmann, bijoutier' les chiffres d'inventaire que nous communiquent ces Nessieur's accusent une prospérité croissante; mais ce n'est pas ce genre 
de succès que noas avons à constater; noas jugeons sor les pièces frion nous moutre, et pas plus ici que dans la boulique roisine nous ne lroavous d'ourres dignes de lonanges. C'est cependant une exposition relativement sincère, qui est cmpruntée d̀ la fabrication courante de vingrt ateliers de Londres, sincère en ce qn'elle ne présente que des objels de consonmation journatière, sans aucun de ces tour's de force (pron fait exceptionnellement poor' les concours. La vaisselle de style anglais est celle qu'on voit dans les hoótels et dans les maisons aisées d'Angleterre. Les inventions les plus agréables sont dans le style Queen Anne; c'est solide, confortable, d'un entretien facile; le décor est brillant, soit cqu'il procède par surfaces polies et bronies, soit ru’il tire ses effets de contrastes avee les ormements d'un bilanc mat. Nos amis du jury se sont arrètés longtemps à examiner, entre autres clioses, un service ì thé d'un bon marché réel, oǹ étaient représentées des scènes épisodiques des romans de Walter-Scott; le procédé d'estampage élait asse\% hien fait pour donner à croire que ces bas-reliefs avaient été repoussés et la façon élait meilleure en ces pièces mécaniquement produiles qu'en d'autres que nous avons critiqnées. Les articles de nécessaires et de toilette : brocs, curelles, flacons, boîtes en tous genres, sont d'une moyenne fabrication; tous ces articles sont faits poar une clientèle qui emplit le monde, pour des colonies qui sont acax quatre coins du grobe, et si le public londomnien reste par habitude fidèle à ces traditions sans goût, c'est parce que la clientèle d'exportation suffit à entretenir des fabrirgnes que ne stimule ancune concurrence étrangère. Si les orfères de Paris, de New-York, de Vienne et de Berlin pouvaient introduire à Londres lenr's marchandises sans payer des droits énormes (1), on verrait promptement disparaître ces produits démodés, car ils semblent dater d'avant les Expositions de $1851 \mathrm{el} 1862$, et il serait bien nécessaire, pour l'orfêvrerie anglaise, qu'on recommençât à son profit la leçon qu'avait prise l'indastrie d'art de la GrandeBrelagne. Nous vocudrions racheter ce que notre critigae a de désobligeant pour ceux que nons jugeons en loaant la perfection de la main-d'œunve; la vérilé noas force à dire que la fabrication de cetle orfèvierie est médiocre el qu'il cút mieux vala, pour la répulation des orferres anglais, n'ètre pas représentés du tout que de f'être anssi imparfaitement; ceux de nos collègues du jury, qui apportaient le plus de soin à vérifier la façon des pièces, étaient étonnés, comme l'avaient été en 1878 les jurrós de la même classe, car on s'imaginait que l'orfèvrerie anģaise était correctement faite; il ne faut pas la voir de près, les fautes y apparaissent presque grossières.

\section{MENTIONS HONORABLES.}

\section{Ardesino et Byramu, à Bombay (Indes).}

Pas plus que dans les colonies françaises, l'orfèvrerie n'a été représentée convenablement par les exposants indiens venus sous pavillon hritannicque. La Commission anglaise arait élevé un palais pitloresque, imité de l'arehiteclure bouddhiqae; des Hindous en costmues blanes et coiffés du turban ajoutaient à l'illusion du décor, et dans l'intérieur des galeries s'ounait un bazar rqa'encombraient les productions de l'Inde; malheureusement, l'orfèvrerie ne consistait qu'en des objets de pacotille et d'exportation, comme on en trouve à Londres dans les boutiques d'Oxford-Street; nous avons vainement cherché quelque chose (nui rappelât ce que nous avions vu en 1878 , ce qu'avait rapporté de son voyage aux Indes Son Altesse le prince de Galles. Nous croyons donc absolument inutile d'eutrer ici dans une étude fuelconque ou de faire la description d'objets sans intérêts, non pas qune le style

(1) Ces droits onl été abolis depuis que celte partie du Rapport a été écrite el l'espérience peut ètre tentéc dès à présent. 
indien ne persiste encore dans la forme et l'ormementation des vases de cuivre et d'argent qu'on fabrique à Bombay ou à Madras, mais la sincérité manque à cetle falbrication autant qu’à celle que nous avons critiquée dans notre colonie d'Ilgérie, el je soupçonne les Anglais d'aroir établi quelque part une usine à quincaillerie indienne qui soit comparable aux ateliers parisiens où sont faits les bijoux kabvles el algériens.

IIV. Ardeshic el Byramji avaient un comptoir dans le palais indien des Anglais; ils en avaient un autre daus le palais de l'Inde française et présentaient ainsi sous deux pavillons les mêmes marchandises; le jury n'a pas voulu mettre en doute leur bonne foi, il leur a accordé une ntention.

\section{Rillugara Frinjee Pestonjee, à Madras (Indes).}

Mêlés à des tapis, à des étoffes imprimées, à des meubles de bois de santal, à des coffrets aux paillons découpés, à toute une papillotante industrie décorative, sont là aussi quelques pièces de cuive adroilentent martelées, des cafetières d'argent ciselé et des vases gravés d'un dessin brutal copié sur les vieux types. C'est à Londres, dans les galeries indiennes de Kensingóton qu'il faut étudier l'orfêvrerie indienne; elle a, par l'élégance des for'mes et la dílicieuse ornementation des surfaces, des modèles dignes de charmer les artistes, mais ce serait compromettre celte merveilleuse école que de nous arrêter plus lonģtemps à ce qui n'en est qu'une copie amoindrie et pleine des fautes les plus grrossières. Déjà l'exposition spéciale des colonies faite à Londres, en 1887 , a vait accusé la ruine de l'orferreric.

\section{GrìGE.}

\section{MÉDAILLE DE BRONZE.}

\section{Coussourelis (Nicolas), à Athènès.}

Si la Grèce a été le bercean de lorferrerie antique, si les types les plus parfaits y ont été créés par les artistes les plus famenx, si, nous orfèveses, nous vivons encore sur le fonds de cet art rafliné dont les formes exquises n'ont élé ŕgalées dans aucuı temps el chez ancun peuple, comment reste-t-il si peu de chose en Grèce de ce glorieux passé el comment cette terre, qui recèle encore des inerveilles en ses entrailles, ne produit-elle plus la moindre aure nouvelle, est-elle épuisée à ce point? N'a-t-elle plus de sève?

L'orfêre Coussourelis expose des veliqnaires filiģranés, des vases veligieux qui n'ont pas plus le caractère byzantin que le caractère antique; ce sont des ouvres banales, très inférieures à tout ce qu'on voit en liussic, mais qui ressemblent aux images l'usses plus qu'à toute autre close; les qualités de main-d'œuvre ne rachètent même pas la pauvreté du dessin.

\section{MENTION IIONORABLE.}

\section{Liacopoulos, ì Lamie.}

Un tableau d'argent ı'epoussé, décoré de filigrane el de gravure, est la seule pièce digne de quelıne altention; ce qui la rend intétessante c'est l'extrème nä̈veté de la composition; si celte naïveté était 
celle d'un peuple jeune, bégayant les premiers mots d'un art, ce scrait digne d'intérêt et diencouragement; si ce n'est que la maladresse d'un ouvrier sans éducation, cela ne vaut pas la peine qu'on s'y arrête; si c'est, au contraire, l'indice d'une civilisation qui fmit, d'un art qui s'est éteint el qui, en plein $x_{x}$ siècle, retombe dans la barbarie, mieux vaut ne pas insister plus et ne garder de la Grèce et des orfèvres de Corinthe que le magnifique souvenir du passé.

\section{ITALIE.}

Encore un nom gloricux. L'Italic avait hérité de la Grèce ou du moins l'avait dépouillée, lui prenant ses statues, ses marbres, ses orfèverics el transportant à liome sur des chars de triomphe tous ses trésors, en même temps qu'elle emmenait ses ouvriers et ses artistes, les réduisant à une sorte de demi-esclavage, payant leur génie, les couronnant et les enrichissant pour leur faire oublier leur patric, leur histoire et leur ruine.

L'Italie avait acquis tout ce que l'orfèvrerie anlique a produit de plus précienx par le travail el la matière; l'invasion des Barbares détruisit et éparpilla ces merveilles amoncelées, mais une renaissance superbe devait éclairer une fois encore l'Italie, et l'orfèvrerie a joué dans cette histoire un rôle supéricur à tous les autres arts. C'est des atcliers d'orfèvres qu'étaient sortis les grands artistes, architectes, peintres ou sculpteurs; le $\mathrm{xv}^{\mathrm{e}}$ et le $\mathrm{xv}^{\mathrm{e}}$ siècle ont connu ces maîtres illustres, mais depuis s'en est allée, s'amoindrissant sans cesse, la grande école qui à Pise, à Florence, à Sienne, ì Arezzo comme ì Milan, à Venise et à Rome arait eu des ateliers célèbres.

De nos jours il y a eu cependant un homme, un savant, un artiste, un maittre qui a ressuscité l'orfèvrerie italienne, qui a enrichi par ses découvertes les musées de Rome, de Naples, de Paris, de Londres, de Saint-Pétersbourg et de Berlin : c'est Cástellani; il est mort et nous devons à sa mémoire un éclatant hommage; il a aidé ì la renaissance dı goût étıusque et plus encore de l'art exquis, qui florissait dans la grande Grèce, dans cette partie de l’ltalie méridionale où les colonies grecques avaient apporté de bonne heure le génic de la patrie-mère.

Castellani a réveillé cette ûme antique, il a pris une étincelle à ce feu sacré pour animer en lui la faculté créatrice; il a fait à son tour des ouvres belles et presque aussi précieuses que celles qu’il dérobait à la terre, par des fouilles heureuses. L'Exposition de 1862 , à Londres, a marqué la phase la plus gloricuse de l'orfèvre romain; depuis il s'est livré avec passion aux recherches archéologiques, abandonnant à son frère la conduite d'un atelier qui recoit encore à Rome la visite de tous les étrangers, mais qui reste stationnaire; nous y avons vu les essais du neveu de Castellani, ils font présager hien de l'arenir pour ce jeune orfèvre.

Comme il arrive toujours, Castellani a provoqué des imitations, il a fait des élèves, formé des ouvriers, et à Rome comme à Naples, à Florence comme à Milan, à Turin 
comme à Venise se sont ouvertes et ont prospéré d'importantes maisons d'orfèvrerie et de hijouterie.

L'Italien est naturellement adroit et propre aux meilleurs ouvrages d'orfèvrerie; il garde en ses veines un peu du sang de cos Étrusques qui furent les premiers ourriers du métal; si nous arons éliminé de nos ateliers, depuis la guerre, les ouvriers allemands, nous y employons encore des ouvriers italiens; ils ne sont pas les moins habiles. Nous nous attendions à un intéressant concours de l'orfèvreric italienne, nous n'avons trouvé à examiner parmi ceux qui se disent orfèvres que l'exposition de II. Accarisi.

\section{MÉDAILLE D'ARGENT.}

\section{Accarisi (Joseph) et neveu, à Florence.}

Nous n'avons pas à parler de leurs bijoux d'or, ils sont une imitation de ceux de Castellani, mais une imitation diminuée, amoindrie, comme il y en a dans toutes les villes d'Italic. Quant à l'orfèrrerie ce n'est pras l'argenterie solide, on y clicrcherait vainement quelque chose de comparable ì ce que nons a vons vu en France, en Amérique, en Angigterre même ou encore en Danemark; ce sont des pièces de dimensions réduiles qui auraient place entre l'orfèrrerie proprement dite et les bijonx, clles sont adroitement faites, mais ce sont des bibelots inventés surtout pour séduire le voyageur el dans lesqucls on a copié les modèles fameux qui captivent sa curiosité; je n'explique : le commerce noderne de l'Italie consiste dans l'exploitation de son passé; ses arts décoratifs sont une mise en action des restes de l'art antique et de la Renaissance. De même que les hôteliers el les ciceroni vivent sur ta population flottante d'Anglais, d'Anéricains, de Russes, d'Allemands et de Français qui passent, de même les ouvriers du bois, du marbre, du métal et de la terre exploitent ces visiteurs cosmopolites, en reproduisant par des copies sans cesse répétées les chefs-d'œuvre qui peuplent les musées et les églises; de paurres peintres rééditent prar centaines les maîtres qu’ils comprometlent inconsciemment; les photographes, du moins, ne gâtent rien, mais l'orfèvie fait une œuvre assez voisine de celle du méchant peintre et du photographe vulgarisateur, quand il accommode le Persée de Cellini ì l'ornementation d'une salière, quand il traduit en bijoux d'argent les bronzes du Bargello, ou qu'il enprunte aux portes de Brunelleschi ou à l'aulel d'argent du Dôme les admirables modèles d'un art, qu'on n'a pas surpassé, pour en faire de médiocres ciselures que des acheleurs ignorants emportent en passant comme des échantillons de l'art italien.

Ainsi vivent des mietles du passé des ouvriers cependant habiles, qu'un maître pourrait commander ef rendre dignes d'une grande nation par_un travail plus personnel. M. Accarisi mérite par son adresse, son ingéniosilé, la qualité de ccrtains ouvrages qu’il expose, un éloge que nous ne lni marchandons pas; à ses emprunts aux chefs-d'œuvre de l'art florentin, il mêle des réminiscences de renaissance italienne et de cette fausse renaissance française qui florissait il y a trente ans. Mais le travail à la main, la ciselure prise sur pièce, la conscience apportée dans la copie des détriits, la connaissance des fins travaux d'atelier font de MM. Accarisi et neveu des orfêvres véritables; s'ils n'avaient pas à salisfaire à la fois aux voyageur's qui traversent Florence et aux baigneurs qui vont à Wiesbaden, où ils ont un dépôt; s’ils avaient une clientèle plus fixe et les amateurs plus sérieux, ils feraient aussi des pièces plus dignes des grandes traditions italiennes. 


\section{JAPON.}

Le Japon arait exposé, en 1878 , une' quantité considérable d'ouvrages d'argent lont la beauté avait excité l'attention des orfères el l'admiration des amateurs. C'est, qu'en effet, les Japonais déploient, dans le travail des métaux, rme adresse comparable à celle des artistes anciens dont les wurres sont recherchées maintenant avec autant de curiosité et de passion que le seraient des orfèvreries italiennes du $\mathrm{xr}^{r^{\mathrm{e}}}$ sièce ou des pièces françaises du siècle dernier.

Pourquoi les Japonais, qui ont tiré un si grand honneur et un si réel profit de la précédente exposition, n’ont-ils pas renouvelé cette fois-ci lenr effort de production? Ils n'étaient pas prévenıs, nous a-t-on dit, its n'ont pas eu le temps de préparer leur exposition, clle a été faite avec des éléments recueillis à la hâte. Cela est probable; nous avons, en effet, admiré dans la section japonaise des étoffes, des paravents et divers produits de l'industrie indigène; mais il en est d'autres que nous avons inutilement cherché à retrouver et notamment les ouvrages d'argent; c'est grand dommage, car l'art japonais exerce depuis vingrt ans une telle influence sur nos arts d'Europe que l'étude s'en impose, en un rapport complet.

Il n'y a cependant aucun rapprochement à faire entre l'orfèvrerie telle que nous la pratiquons et le traviail du métal, tel que le font les Japonais, du moins dans la forme et la destination des pièces. Chez nous, l'orfèveric est presque exclusivement faite d'argent; au Japon, l'argent n’est pas, pour sa valcur, accepté comme l'unique métal consacré aux ouvrages d'art, il n'est qu'une des couleur's métalliques dont l'artiste dispose; le cuivre, le fer, l'or et tous les allinges sont, pour le Japonais, la facon de peindre, d'animer une orfèrerie qui, chez nous, est monochrome et froide Depuis vingt ans, nous avons, sous l’influence de ces leçons, modifié quelque peu nos goûts; avant que les Américains eussent apporté leurs essais excentriques, nous avions vu cliez Christofle d'abord, chez quelques-uns de ses confrères ensuite, des tentatives hardies faites à l'imitation des pièces du Japon. La collection des vases rapportés par II. Cernuschi de ses voyages avait montré le parti décoratif à tirer des vieux types coréens et la suite des livres de métiers empruntés à l'art japonais avait inspiré à II. Reiber des créations, où le goût curopéen se mariait aux idées de l'Extrême Orient; depuis, se sont créées des collections fameuses sous la direction de M. Burty, de II. Haviland, de M. Taigny, de M. Gonse, de M. Montefiore et surtout de M. Bing, et ce goût japonais qui enrichissait nos arts, notre molilier, nos étagères, notre bibliothèque el jusqu’ì notre costume, šintroduisait aussi dans les atcliers d'orfèvres; il est difficile de dire jusqu'où s'étendra cette influence. Elle pénètre tous les pays d’Europe, elle n’a pas seulement métamorphosé la céramique française, elle gagne jusqu'aux pays du Nord, car la manufacture royale de Copenlagne est plus qu'aucune autre pénétrée de la formule nouvelle. Les lois d'équilibre sont renversées, l'artiste trouve une 
liberté dans le décor que n’avaient jamais eue ses prédécesseurs; on a fait ce grand détour, il a fallu passer par les îles du Nipon pour revenir aux choses de la nalure, l'artiste japonais nous a montré à copier la plante, l'oiscau et l'insecte sur le vif et non plus ì les arranger en des symétries voulues, comme nous avions toujours fait; cependant, ces admirables maîtres ont souflert du contact de notre civilisation; subissant les effets d'un mutuel échange, ils nous imitent et perdent l'originalité charmante quils avaient gardée jusque-là. Ils ont voulu travailler pour nous et se sont mis à fabriquer, suivant nos besoins; ils créent ainsi une industric de convention, moitié européenne et moitié japonaise, et ces inventions bàtardes n'ont plus déjà la saveur des clioses exquises qu’ils ont su faire. Ce qui reste à l'orfère japonais c'est la tradition des moyens d'atelier, c'est le secret des alliages, l'habileté prestigieuse des doigts, c'est la fantaisie dans le décor; c'est enfin l'indépendance que nous n’arons pas ici; mais ces qualités se perdent ou se traduisent par des maladresses si, prétendant se substituer à nous pour exploiler ici son commerce, le Japonais mal conscillé fait à notre usage des cafetières, des plats on des couverts destinés à remplacer les nôtres. Les exposants japonais de 1878 avirient évité cet écueil, mais nous trouverons cette fois des sucriers, des tasses et des plateaux fabriqués pour nos besoins, d'après des types inventés à Paris et à Londres.

\section{MÉDAILLES D'ARGENT.}

\section{Kirivkosio-Kaisia, à Tokio.}

Celte société figurail en 1878 avec un nombre considérable d'oljets d'argenent, de brouze, de ciselure et d'émail; elle n'a exposé cette fois cur'un très petit nombre d’ohjets, entre autres un service à llıé, de ceux que nons critiquons; la forme diffère peu de celle des nótres et le décor fait au repoussé représente des dragons; la seule coloration est obtenue par des oxydations violette el grise qui accentuent les modelés et mettent en lumière les saillies claires de l'argent. Très supérienr de rualité est un grand vase d'argent, sorte de brûle-parfuns, à la panse arrondie, qui est orné de personnages: bonzes, dienx ef prophètes, modelés en demi-relief et faits de métaux rapportés el soudés; les patines variées produisent une harmonie métallique très agréable, le modelé est simple, les cisc-

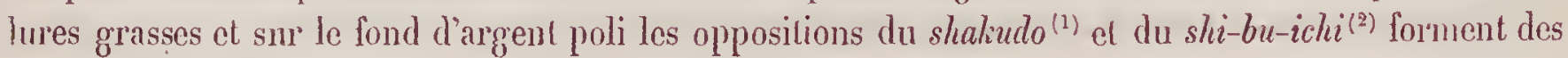
contrastes violents.

Un échantillon très précieux du travail japonais consistail en une boîte plate liexagonale dont les parties s'ajustaient d'une façon rigoureusement exacte et dénotaient l'adresse et la précision de l'ouvrier; la décoration en était faite de fleurs, d'ornements et d'un fin casse-têle anx lighes enlacées, le tout plaqué d'or, d'argent el de bronze; il n'y avait pas, dans l'Exposition, un seul objet qui füt comparable à celui-ci pour la précision de l'ajusté et la délicatesse des ornements, si ce n'est peut-être un pelit vase à parfum en argent, tout filigrané de délicicux ornements; élagés à des plans différents, anxquels des émaux transparents et oparques ajoutaient la vibration de leurs couleurs; cétait un d'or.

(1) Le shakudo est un alliage de cuivre el d'un pen

(2) Le shi-bu-ichi se compose de 6 parties de cuivre et de 4 parties d'argent. Pour polir ces alliages, on les cuit avec du soufre on bien on emploie du sulfate de fer et du vinaigre de prune. 
modèle parfait, il serait inimitable par d'antres outriers. Je ne parle que ponr mémoire des plateanx, des brocs à eau, des conpes el des bols unis ou estampés qui, faits d'argent ou de cuivre argenté, constituaint le stock courant de cette exposition; la façon de toutes ces pièces est tellement irréproclable que s'il y avait à prononcer entre les ouvriers japonais et les nòtres, ceux-ci n'auraient pas l'avantage.

\section{Sн̈̈то (Masakichi), à Tokio.}

Il smble que celui-ci soil plutôt un laqueur qu'un orfère ou, du moins, il a pris ses modèles à des dessins composés nour le laque; ses hoîtes el ses plateanx ressemblent, par la forme et le dlécor, aux oljets de bois léger qu'on couvre du vernis résineux, mais au lieu du bois, c'est sur l'argent que s'incrustent en d'autres métaux variés des fleurs et des combinaisons de lignes empruntées aux allums des métiers. Un très léger relief accuse les incrustations, mais l'effet en est aussi doux à l'œil et à la main que celui des bois laqués. Bien qu’à Paris on ait essayé de procédés analogues, on n’a jamais égalé la perfection de cet ouvrage.

Il ny a pas, affirnons-le hien, d'ouvrier supécieur à l'ouvrier du Japon. Queleues netzké, une conpe à saki, des pipes, des boites à couvereles et des fermoirs de hagues, forment à peu près tout l'apport des orfêvres japonais; nous trouverons, pour les observer, des occasions meilleures que l'Exposition de 1889 .

\section{NORVÈGE.}

\section{IIORS CONCOURS.}

\section{Tostnup (Jacob), à Christiana.}

M. Tostrup faisait partie d'un jury, il était donc exclu par ce fait des conditions du concours, mais nous avons visité son exprosition avéc beaucoup d'intérêt. Elle ne diffère pas par le caraclère des vitrines que nous verrous ensuite, unais c'est par la netteté de l'exécution et la pureté des liggnes qu'elle était surtont recommandable. Ses filigranes d'argent étaient faits avec un soin infini; ce sont les plus parfaits que nous ayons trouvés. Ils sout généralement d'argent blanc mat, appliqués et unontés ì froid sur des fonds d'argent bruni; quelquefois on les marie à des parties d'émail. Clicz M. Tostrup se voyait un essai d'émail à jour particulièrement réussi à la façon des émaux dont nous avons dit quelques mots, mais ressemblant surtout à ceux que nous rencontrerons en nombre considérable chez les orfêrres russes. Il était mieux fait, le dessin en était plus'correct, il révélait une main plus lıalile, une fahrication moins courante. Au milien de la vitrine était une grande coupe de cristal bleu montée dans une bordure d'argent ajourée composée de fils unis el de cordeletles du dessin le plus joli; cet oljet gracieux en sa forme, solsre d'arrangement et admirablement exécuté, a emporté tous les suffrages.

\section{MÉDAILLE D'ARGENT.}

\section{Otsen (Theodor), à Bergen.}

Ce qui paraît être la pièce préférée des orfêvres norvégiens, c'est le grand bol monté sur son plateau et entouré de petites coupes à pied; ce vase est-il destiné à servir le punch ou comme en Allemagne y verse-t-on le vin de mai? Peu nous importe, il suffic qu'il soit un motif propre aux décors 
de la cisclure, du filigrane et de l'émail. N1. Olsen fait tourner sur le sien une ronde d'enfants, repousséc en relief, et c'est son fils Thorwald Olsen, îgé de 19 ans, qui l'a entièrenent exécnté de sa main, c'est pourguoi il a eu, lui aussi, une médaille d'argent de collahorateur; en effet, c'est un excellent travail d'orfèrére, sohrement traité el qui pourrait à hon droil satisfinire des ouviers de plus grande expérience. La maison Olsen est honorablement connue, elle emploie me trentaine d'ouvriers et fait environ 240,000 francs d'affaires; ses filigranes anx dessins scandinaves ne se consomment pas senlenent dans le pays, l'Amérique en alssorbe une grande partie, soit directement, soit par les comptoirs suisses; nous n'avons pas à décrire les bijoux, unais, nous signalons une grande corne à boire montée en argent el une massive reliure de livre, composée dans le vieux style national.

\section{MÉDAILLES DE BRONZE.}

\section{HAner (Marius), à Bergen.}

Encore des pots à vin, des lroes à bière et des ourrages en filiģrane. Nais Il. Hammer joint à sa fabrication d'orfèvrerie le connmerce des antiqunités et son exposition contenait plus d'argenterie ancienre fue de nouvelle; ce n'en élait pas d'aillenrs la partie la moins inléressante el les larges cnillers anx spatules gravées, aux manches ciselés, rudes parfois, comme des seulptures de bois, miis si franches de dessin et si jolies de forme, nous tentaient pour nos muscées; ees types se rapprochent assez de cenx que nous avons trouvés au Danemark; mais $\mathrm{Ul}$. Hammer Jes a mieux copiés qu'aucun autre; il profite de l'étude des curiosités anciennes pour modifier el ramener son dessin à des types nationaux, de même qu'en ses bijoux il conserve l'usage des rondelles hrillantes el moliles qui reflètent la lumière comme des miroirs, et lintent comme de Jointaines sonnailles; il expose rueldues émaux proprement faits et des cornes d'argent ciselées.

\section{ANDERSEN (David).}

La ciselure n'est pas ici d'une qualité égale à celle qu'on tronve chez Ul. Theodor Olsen, mais les filigranes sont très bien réussis, nets, purs, corrects et l'on commence ì essayer des émaux.

\section{PORTUGAL.}

\section{MENTION IIONORABLE.}

\section{Bitetos.}

Au xwme siècle, la cour de Portugal laisait aux orlèvres parisiens des commandes importantes el les ourres de Germain sont encore conservées daus le trésor roval. Il y a à lishomne des collectionneurs du plus grand goùt qui possèdent des pièces d'argenterie ancienne, comme on en trouverait diflicilement en France; il est done surprenant que les orfèves portugais, qui ont près d'eux de tels exemples, n’en aient pas profité. M. Bitetos expose un grand bassin en argent repoussé avec des ornements sortis en bosse it grands rantages; il n'y a pas à signaler plus particulièrement ce travail runi rappelle les plats de cuive hollandais et allemands d'antrefois. 


\section{MÉDAITLE DE BRONZE.}

$M^{\text {me }}$ Vue Monerit et fils, à Porto.

Ceux-ci exposent beancoup d'oljets (qui apparticnnent à la classe 37 et en outre quelques pièces de petite orfèrrerie, dont nous hésitons à parler, car elles sont de médiocre intérút.

Nous ne dirons rien de Fraxcisko (Henriquez) qui a été assez mal inspiré pour copier en argónt un petit jonjou suisse en forme de chalet, comme on en donne aux enfants : ce n'est pas lì de lonfévrerie.

\section{ROUMANIE.}

\section{MLNTION IIONORIBLE.}

\section{Ropala (Georges), à Jassy.}

la relinre en argent doré qui forme la converture d'un évangéliaire semble avoir été copiée sur un modèle italien du xvm! siècle; cela est mal interprété, banal, et les personnages saints, peints sur émail, ressemblent à des images enluminées el font tache dans les ornenents d'argent très rudimentairement repoussés en bosse. Les flambeaux d'autel n'ont aucun style et la coupe d'argent repoussé est une imitation des mauvais décors de la décadence italienne; il y a cependant plus d'adresse chez les ourrier's roumains que chez ceux d'Athènes.

\section{RUSSIE.}

\section{MÉDAILLES D'OR.}

\section{Ovtscinnimofic (P.) fils.}

Les orferves russes avaient exposé il y a onze ans des pièces l'argenterie colossales appartenant au Czar et dénotant nne fabrication trìs perfectionnée; ils u'ont apporté cette fois ancune curve ayant un caractère officiel, l'Empereur n'ayant pas consenti à prèter les jièces appartenant à la couromue. C'est done rédnits ì leurs senles ressources, avec les marchandises courantes qu’ils araient en magasin. qưils ont fignré ì l'Exposition de 1889 ; nous leur sommes d'autant plus reconnaissants d'ütre venus ainsi, qu’ils pouvaient craindre de paraître inférieur's à eux-mêmes; tous nous ont apporté des émaux, et en telle abondance, que leurs vitrines ćtaient papillotantes de taches multicolores.

Déjì nous avions vu les Russes s'adonner à l'émail cloisonné, mais sans imiter les cloisonnés ổrece. Il semblait qu’ìs auraient dù emprinter à l'art byzantin ses dessins et ses procédés d'émaillagoe; an lieu de cela, ils ont fait des dessins en fils cordelés, soudés sur des fonds d'argent et ils en ont rempli les interstices, d'émaux opaques fondus, en partie concaves; nous retrouvons quantité de ens émaux et notamment des plateaux, des játtes, des gobelets el surtout des tasses, de celles que l'on nomme czarlia. Ces dermières sont décorées dans le style russe et portent souvent des inscriptions; le trésor 
de Moscon possède plusicurs types ancieus de ces czarkas. La nouveauté en émail pour les Russes, c'est l'émail à jour, ce mêne procédé d'émaillage que nous avons remarqué chez M. Boucheron; l'exposition russe en est inondée, au point de rendre presque vułgaire un travail précieux et difficile; nous royons par lì que les émailleurs russes ont acquis une grande dextérité, mais leurs dessinatenrs manquent d'imagination, leurs dessins sont d'une banalité regrettable; au lieu de conserver le style semi-oriental qui doune tant d'originalité et de charme aux vieilles ouvres russes, ils vont jusqu'ì copier l'imagerie japronaise et à la peindre des couleurs les plus dures et les plus henrtées; quelques nielles de Toula, des clopes d'argent à couvercles, des gravures soignées complètent l'exposition de M. Ovtschimnikoff fils, mais la pièce la plus importante est une figure en argent représentant Ermak, le conquérant de la Sibérie, dont la statue en marbre faite par Kafta était exposée dans la section des beaux arts; celle-ci est fondue et ciselée avec une grande perfection et dénote chez les ciselenr's russes, une adresse de main qu'on avait déjà signalée. Ml. Ovtschimnikoff fils a ohtenu pour ses collaborateurs : une médaille d'argent pour M. Kousrorr, dessinateur, et deux médailles de bronze, l'une à M. Micuaïloff, ciseleur, l'autre à M. T'atakine, émailleur.

\section{KHLEBNIKOFF (J.-P.) fils el $C^{\text {ie }}$, ì Moscou.}

Leur exposition ressemble beaucoup à celle de leur confrère, les sujets nationaux y sont peut-être plus nombrenx, les images saintes donnent un caractère vieux russe à leur vitrine, mais cependant le dessin archäque se perd et l'abus du filigrane et des émaux se manifeste partout; si quelques pièces d'argenterie proprement dite se mêtent à ces fantaisies, clles affectent des formes allemandes, mais la monture en est assez correcte; les tasses sacrées sont copiées d'après celles qui sont au musée d'artilleric de Moscon, entre autres plusieurs kovsch ou petits vases à manche qui servent à puiser le vin. M. Khlebnikoff avait exposé un grand tableau d'argent repoussé représentant tous les monuments célèbres de Moscou; cette grande plaque, encadrée dans une bordure de la plus grande richesse, a été offerte au directeur d'une compagnie d'assurance de la ville; le sujet en est peu intéressant, mais l'exéculion, comme celle du groupe de M. Ovtschinuikofr, prouve la grande habileté du ciseleur. Les portraits en émail peint de l'emperenr et de l'impératrice sont arrivés trop tard pour que le jury pût les voir. Une médaille de bronze a été accordée à M. Bacascherf.

\section{M. $F_{R A G E T}(J$.$) , à Varsovie.$}

Ce sont deux Français, Joseph et Alexandre Fraget, qui, en 1824 , ont fondé à Varsovie la maison dont nous allons examiner les produits; on n'y faisait à l'origine que des articles de plaqué et ce sont eux qui avaient introduil cette industrie en Russie. Leurs progrès ont été assez rapides pour leur permetlre d'avoir des dépòts à Saint-Pétershourgò à Moscou et dans diverses autres villes, el surtoul d'avoir un comptoir daus chacune des grandes foires qui se tiennent chaque antée dans l'Empire; depuis $\mathbf{1} 847$, on a joint à la fabrication du doublé celle de l'orfêrrerie argentée sur métal blanc et la production des couverts de table; en 1867 , nous trouvons a l'Exposition universelle la maison Fraget occupant 200 ouvriers et accusant un chiffre d'aff:ires de 250,000 roubles; c'est cette année-lì que meurt son ancien chef, Joseph Fragel. La fabrique, que dirige aujourd'lui son fils Jules, a triplé le chiffre de ses affaires et presque doublé le nombre de ses ouvriers, qui tous sont Polonais et sujets r'usses à l'exception de deur, l'un orfèvre, l'autre doreur', qui sont Français. Aussi l'intérêt de celte exposition réside-t-il dans le caractère de ses produits; ils diffèrent essentiellement de ceux qu'exposent les orfèvres de Pétersbourg el de Moscou; la maison Fraget donne ì ses compositions une allure patriotique, le sentiment polonais y est exalté; parmi les pièces capilates contenues dans la vitrine est 
un coffret d'argent modelé par Intoine Kurzawa, les bas-1’eliefs représentent des scènes nilitaires enpruntées à la vie du prince Poniatowski, des revues. des combals, le passage de la Bérésina; la statuetle équestre du prince surmonte la cassette. Il y a beaucoup d'art el de goùt dans la facon dont sont composés ces petits bas-reliefs, et c'est l'une des meillenres parmi les pièces modelées et ciselées que présentaient les orfêvres russes. lls ont une grande adresse dans la composition de ces petites scènes et leurs ciseleurs justifient les espérances que nours avions conçues à l'Lixposition dernière en visitant leurs travaux.

C'est à un liéros polonais, encore, à Solieski, qu'est dédié le grrand surtout de table pour l'exécution duquel se sont associés plusieurs artistes polonais, tels que Jean Krynski le sculpteur, Jules Kossac le peintre et Antoine Kurzawa le modeleur. Jaime médiocrement l'arrangement de cette pièce, elle est trop compliquée, sa silhouette manque de franchise, c'est un composé d'épisorles, de figures détacliées et d'ornements sans style où apparaissent tous les défauts qu'avail notre orfêrerie à la fin du règne de Louis-Pliilippe; la façon en est honne et la ciselure exécutée par Lopienski, par Guaranowski el par Chodanowski est digne d'éloges. Plus original est le vase en forme de tour inspiré de la légende des Piasts ${ }^{(1)}$; on sait que Piasts était un simple paysan de la Cujarie qui vivail au $\mathrm{x}^{\mathrm{e}}$ siècle et d'où sortil la dynastie des rois qui régnèrent cinq cents ans sur la Pologgne; on voil par là que les maîtresses pièces de l'exposition de M. Fraget empruntent à toules les époques de l'histoire nationale leurs sujets héroïques.

Quant aur produits de consommation courante, ils sont d'un goût qui participe à la fois des formes allemandes et des modèles français, cela nous reporte de trente aus en arrière; les oruements en semblent empruntés aux dessins publiés par Hanser et par quelques éditeurs de ce temps-là; mais l'exécution en est correcte, les montures à froid très adroitement faites; il y avait notamment un grand plateau très lonrd de forme et de poids, mais présentant des difficultés d'exécution qui auraient embarrassé heancoup d'ouvriers et dont s'étaient tirés à leur lonneur cenx de 11 . Fraget.

Le jury a accordé une médaille d'argent au sculpteur Kunzawa et des médaille de bronze aux ciseleurs Lopienshi et Gilodanowski que nous avons déjà cités, ainsi qu à l'orfêvre Miécislas Plewicki.

Des caisses d'épargne, des caisses de prévoyance, des crèches-écoles pour les enfants et une société d'assurance la Rossia, créée au capital de 100,000 roubles, sont fondées chez M. Fraget ponr venir en aide à ses ouvriers. Le rapporteur de la classe 2.4 avait déjà siģnalé en 1878 la sollicitude des orfêvres rnsses pour leur personnel; il avait, à propos des maisons Ovtschimnikoff et Khlebnikoft, parlé de l'école et de l'hôpital existant dans clacune de ces maisons, et il disait equ'en soiguant ainsi le corps, en développant l'intelligence de leurs ouvrier's, les patrons récolteraient dans l'avenir les plus heureux résultats $\%$. Je me souviens en effet que ces orfêvres nous avaient envoyé des étals sur leur personnel et sur lenr prodnction, ainsi que de belles photographies montrant les ateliers, les dortoirs, les salles d'étude où semblaient vivre une quantité d'hommes el d'enfants. Nous n'avons eu celte année ancune indication semblable de la part des deux orfevrres moscovites, mais nous supposons que ces institutions philanthropiques n'ont pas périclité : les clıefs sont morts, mais leur curre doit avoir été continuée par leurs fils.

\section{MÉDAILLES DE BRONZE.}

\section{Klingert (Gustave), ì Moscou.}

C'est une fahrique d'orfêvrerie émaillée qui existe à Moscou depuis 1866 ; elle n’a pas de magasin, mais elle alimente la plupart des boutiques de Pétersbonrg, de Moscon, de Varsovie et des prin-

(1) Une particularité du vase des Piasts, c'est qu'il est fait complètement en nickel fondu. 
cipales villes russes, elle exporte en Allemagne, en Angleterre, en Amérique et même en France; nous avous, dans plusieur's magasins de Par'is, vu des objets absolument semblables à ceux que nous avions trouvés dans la vitrine de M. Klingert, c'est de la petite orfèvrerie niellée et plus généralement émaillée, des boîtes, de pletits vases et plus p̣articulièrentent encore l'arlicle de funeur et l'arlicle de lureau; quelques-mnes de ces pièces sont gravées, mais la plupart sont faites de plaques estampées ou laninces à laide de rouleaux d'acier gravés eux-mêmes; les plaques ainsi obtenues servent à la confection des articles de fantaisie et sont eusuite émaillées. Ces dispositions d'émail forment des jeux de fond de plusieur's nuances et dénotent un groût très fin. On nous affirme que M. Klingert occupe une centaine d'ouvriers et qu'il a treize four's allumés pour la cuisson de l'émail. Nous n'arons pas pu vérifier ces chiffres; cette maison serait alor's l'une des plus considérables parmi les fahriques d'émaux.

C'est en Russie d'ailleurs que l'orfêvrerie émaillée prarait avoir' rencontré le plus de faveur.

Tous avions fini nos travaux, le jury était près de déposer ses listes quand le commissaire russe a sollicité notre attention pour des orfères qui ne figuraient pas au catalogue et qui faisaicut partic d'une association d'arlisans fondéc ì Moscou. Nous avons dì chercher dans le bazar russe leurs marchandises qui y étaient confondues avec d'autres; c'est d'abord:

\section{Aschmarine (B.-M.), ì Moscou.}

C'est une maison jeune, elle produit des pièces d'argenterie de consommation courante dans le style russe et quelques tableaux ì images, comme on en voit chez tous les Grecs orthodoxes.

\section{MENTION HONORABLE.}

\section{Milliovkoff (P. P.), ì Moscou.}

Un tableau gravé rejrésentant une vue de Moscou, des gohelets, un alhum décoré d'émail, un encrier, voila les pièces exécutées en argent par cet exposant, qui déclare faire à la main tonte son orfèverie et en produire environ pour 40,000 roubles par an.

\section{SAN SALVADOR.}

\section{MENTION HONORABLE.}

\section{Daniel AviLi, à San Miguel.}

C'est dans un des pavillons si pittoresques du parc, parmi les éclrantillons des productions nalurelles d'un pays neuf encore, que nous avons fini par déconvirir quelıues oljuets d'orfêvrerie mêlés à des momaies espagnoles et à de vieilles médailles d'argent. Nous n"aurions rien à en dire si, prarmi ces oljets de provenances diverses, nous n'avions remarqué un porte-bouquet d'argent dont l'originalité nous a surpris. C'est que rien n'est plus rare qu'une idée neuve. Il étail laid, ce vase, prétentieux 
et naif, fait par quclque onvrier sans maitre, mais du moins il n'avait pas été copié d'après une forme apportée d'Europe; l'orfève avail orné sa pièce d'une longue tige sonple quill avait faite ì l'image de la plante vivante, y soudaut des fenilles découpées dans l'argent, y perchant un petit oiseau sommairement cofuillé dans une plaquette mince, arrangeant cela conme il avait vu s'arranger senles les lierhes d'un champ : c'étail sauvage et simple, brutal et nenf. Ce n'était pas beau; il n'y a lieu de vanter ni le modèle, ni la ciselure, ni rien absolument; mais cétait sincère, et cette facon barbare nous reprortail aux orfêvreries primitives, qu'apprécient tant les chercheurs d'antiquilés.

\section{SERBIE.}

\section{MENTIONS HONORABLES.}

\section{Payı O. MuLochevitch, à Mionitza.}

Daus leurs anciens costumnes, les Serbes, comme les Bulgares et les Roumains, out gardé des ornements d'argent dont l'effet est charmant et réjouit l'artiste : agrafes, plaques de ceintures, cartonchières, décorations d'armes; ces closes ont une fière allure, un dessin seni-oriental, el nous espérions décourrir dans l'orfêvrerie serbe des objets équivalents, conservant la tradition des formıes et la grâtec des ornements.

Nous n'avons trouvé parmi de paurres bijonx que deux on trois pièces en argent, telles qu'une sorte de compotier ou de plat à convercle dont la destination ne nous a pas semblé clairement indiquée; juis des armes dont les fourreaux et les garnitures d'argent ciselées et filigrancées ne sout pas sams quelque mérite.

\section{Yovan MLADÉnoritch, à Négotine.}

Des forte-cigareltes, des plateaux, des coffrels d'argent découpé ou fails de filigrane sont les senles pièces que nous ayons à signaler. Là encore se manifeste le goût du peuple pour ce travail de dentelle d'argent qui a l'avantage de peser pen, de briller beauconp et de séduire par sa délicatesse.

\section{ROYAUME DE SIAM.}

\section{MÉDAILLE D’OR.}

\section{COMTTÉ DE SIAM.}

Le roi de Siam avait ordonné qu'on envoyât à l'Exposition quelquies-uns des lypes de l'orférrerie nationale. Il est regrettahle que chaque pays d'Europe n'ait pas fait comme ce roi d'Asie.

La collection des vases d'argent aux formes simples, amples, telles que la tradition la phus ancienue les a consacrées, étail la meilleure leçon d'orfèvrerie qui pût être donnée. Sans comparer ces vases anx vases grecs, comme le voulait quelqu'mn, nous constatons qu'ils élaient de beaucoup supérieurs à tout ce que l'Inde nous avait expédié; ils étaient si jusles de proportions, si ingénienx de forme, que beancoup d'artistes les voulaient acquérir, et la commission se refusait à les vendre; 
il fallait altendre la permission du roi. Celle autorisation est venue el maintenant les phas belles de ces pièces décorent les dressoirs et les étagères de quelques gens de goît : je crains leur voisinage pour plusieur's inventions parisiennes. La forme de ces vases et de ces coupes est dérivée de la flenr du lotus; ils ont les belles lignes cu'on trouve dans les bronzes anciens de la Chine et l'artiste siamois at repoussé, avec une liherté d'outil extraordinaire, toute mne broderie de flenrs et de feuilles qui accrochent la lumière et papillotent richement comme les fleur's d'un bouquet, comme les sculptures d'un chapiteau hindou; les façons en sont homnes, elles révèlent chez l'ouvrier beancoup d'adresse à se servir du marteau.

Nous avons remar'fué un ingénieux système de fermeture sur le couvercle d'une bouilloire; il est fait d'une plaque triangulaire à charnière, s'abaltant.

Le jury a reconnu l'excellence des produits de l'orfèvrerie siamoise el lui a décerné une médaille d'or' ${ }^{\text {(1). }}$.

\section{SUISSE.}

\section{MÉDAILLE D'OR.}

\section{Jerm Bossand, à Lucerne.}

Tous les étranger's qui traversent Lucerne connaissent la maison Bossard, non pas senlement parce qu'on y voit de helles orfèvreries, mais parce qu'on y vend des curiosités el des pièces anciennes de styles suisse et allemand.

Fondée en $177^{5}$ par l'aienl de son propriétaire actuel, la maison Bossard est une des plus anciennes de la Suisse; elte emploie une vingtaine d'ouvriers et fait pour plus de soo, 000 francs d'aflaires.

En 1885, nous avions remarqué déjà quelques-unes des pièces de M. Bossard à l'exposition d'orfèrerie de Nuremberg; il n'en a pas exposé beancoup plus ici, mais ses qualités de goût, de dessin et d'exécution font de la sienne une des meilleures parmi les expositions étrangères.

J'aime la coupe d'argent à bossages relevés an marteau, qui est inspirée d'un drageoir du xve siècle; les feuilles délicatement contournérs qui en ornent le pied rappellent Jes orfèvreries si préciensentent conservées dans les tableanx flamands el dans les peintnres des maîtres de Cologne. Pourquoi avoir mis, an milieu de cette pièce d'allure allemande, la reproduction du David, de Verocchio? C'est faire mn mélange de deux styles qui n'ont aucune analogie.

Très supérieur comme milé de composition est un autre drageoir copié sur un dessin d'Holheiu qu'on garde au musée de Bâle; ce u'est pas dans celte vitrine la seule copie d'après le maitre bâlois, et nous félicitons NI. Bossard d'aroir repris cette belle tradition, car Holbein est un des plus merveilleux clrefs d'école qu'on puisse ciler' : il n'était pas seulement le grand peintre dont les aurres sout la gloire du musée; il était dessinateur, ingénieux à composer des bijoux, à iuventer des coupes, des horloges, des vases. Le British Museum de Londre; conserve nne importante série de dessins origoinaux qu'il a faits pour les orfêvres de Londres; on sail qu'il y resta longtempss sous le règne de Henri VIII, et c'est lui qui détermina en Angleterre la renaissance de l'orfèvrerie.

Pourquoi les orfères anglais n'ont-ils pas, comme l'orfèrre suisse, essayé de reconstituer quelques belles pièces d'Holbein? Cela eût mieux valu, mais je donte fu’ils y aient pu réussir aussi bien que

(1) C'est ici l'occasion de rappeler le zèle et la compétence de notre collègue M. Léon Dnu, qui représentait le royaume de Siam, dans notre jury, mais qui a dû résigner ses fonclions pour obéir au rèğlement et garder ses droits à la haute récompense que lui méritaient dans une autre classe ses travaux scientificues. 


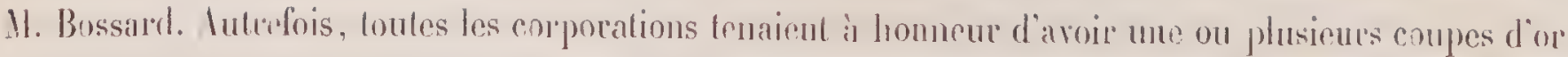

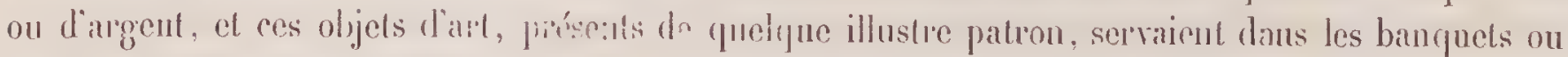
paraicut les dressoirs. Le muscée de Kensiugton a exposé nute collection de ces vases à convergles. On en trouve dans tous les musérs d'Allemağır; c'est en Franer quon en voil le moius, uon pas que l'usage en ail été moins géuéral, mais parce que les corporations ont disparu et que des édits réprótés ont envoyé au creuset ces pièces d'un girand luxe.

Les boucher's de Zurich conservent les uaurs anciennes : ils ont commandé à II. Bossard une belle coupe ou mieux un pocall d'argent; les cisclures au repoussé de ces pièces méritent furou s'arrète à les bien voir, mais l'une des mieux faites est celle que dérore une statuette en ronde-bosse de saint Christophe; charmant aussi, te joli petit flacon, entièrement ciselé arec des olmenents et des snjets copiés d'aprè̀s les petits maîlres allemands.

J'aine moins les couvertures de lives de prières, cisclies en argent dans le strle de Louis XII rt de Louis $X V$, et le service ì thre en argent du Xru⿰ siècle; on y roit plusieurs des fautes commises a Paris, par nos orfèvres; y a-t-il lieu de s'étonner aujourd'luni qu'un orfère étranger s'égare, alor's quia siècle dernier ces fautes ctaient commises couramment en Allemagne, en Angleterre, en IJollande, en Itali: et en Espaģne, partout où le style français élait copié, exaggéré et travesti. Cest, je crois, sciemment que II. Bossard a traduit ainsi le Louis XV; il a dù copier fidèlement gnelene pièce étrangère très authentique, mais il fera mieux de revenir aux beaux types allemands et suisses du $x^{e} 1^{e}$ et du xvı siècle : il les aime, il les comprend et nul ue sait les interpréter aussi bien que lui.

\section{MÉDAILLES DE BRONZE.}

\section{Bechen (Andreas), ì Genève.}

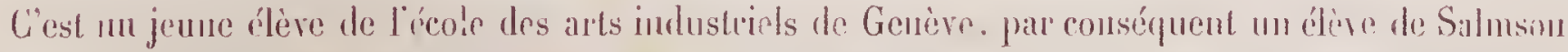
le scupteur of de Jerdelet le ciseleur; ces deur maîtres fiancais ont consenti à s'eypatrier depuis: plusieurs années pour aller ì Genève créer une école oi les bïjoutiers el les orférres principalement s'enercent au dessin, à la composition, à la ciselure, à la gravure et ì tous les arts du décor. M. Bucher expose plusieurs pièces, toutes faites par lui, mais à dillérentes époques; elles marquent un progrè̀s continu el la plus récente est une gr'ande couverture d'allum divisée en compartiments où des ornements et des figures se marient d'heurense facon. M. Bucher est digne d'áloges, mais nous croyons dangereux pour lui de se risquer ì des aeures si complexes; il est ciseleur et non pas orlève, il lerait mieux d'erécuter les commandes de quelques maitres el de perfectionner la façon de son outil que de se risquer à des ourrages de longue haleine; nons arons ru dans l'exposition suisse des ornementalious si compliquées et d'un gonit si douteur, que nous eraignons pour lui qu'elles airnt une maturaise influence.

\section{MHI. PmLnpe et $C^{c}$ (Ferdinand), ì Riesbach (Zurich).}

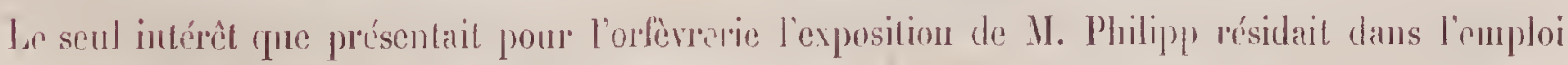
dune sorte d'émail mat, rui ressemble à une peinture, mais qui, sommise au fru, acquiert la soli-

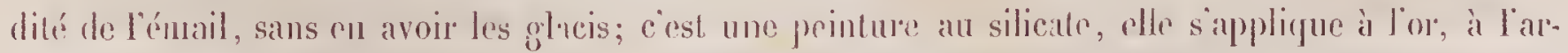
yent el au cuive, et nous ue pourons mieux la comparer qu'aux dícors fue l'on láit sur la porcelaine et la fäence. Il y a la peut-ídre un procédé décoratif nouveau, dont l'appliestion deviendra préciense

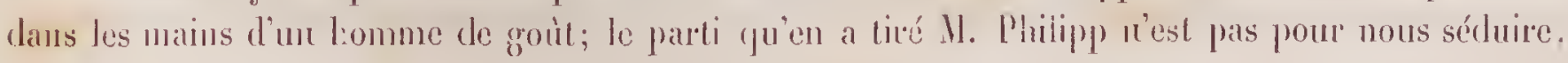


l'effet est triste et, à notre sentiment, c’est par l'éclat el la richesse des couleurs que l'émail peut plaire, tandis qu'ici l'aspect est froid el ressemble plus ì une peinture sur bois quä un une peinture sur métal. Nous nous sonvenons quïl y a près de dix ans, Ml. Mollard a fait ì Paris des essais de peinture directe sur métal, qui ont donné de loons résultals el que nous préférons aux émaux de II. l'hilipp.

Nous avons terminé l'exanen minutieur et altentif de l'orfèverie, nous l'avous fait arec une fidélité dont on nous saura gré, obéissant en cela aux désirs exprimés par les exposants, par le jury et par le rapporteur général.

Peut-être cependant s'étonnera-t-on de la complaisance que nous avons mise ì pholographier li physionomie des expositions les plus humbles; il nous a pirru nécessiure de leur prêter autant d'altention qu'iur premiers et aux plus en vue, car c'est aur lumbles surtout qu'on doit des conseils; ce sont leurs fiutes qu'il fiut reprendre, c'est pour cur que sont frits ces grands concours, ces grindes lecons.

Il fiut que le professeur s'occupe du dernier de ses élèves, qu’il corrige le devoir du plus petit d'entre eur. C'est lì sa tàche, elle est fastidiense et monotone, mais elle est honnête el profitible. de ne l'avais jamais comprise autant qu'en accomplissant la mienne.

Et maintenant que j’ai fini cet exanen je vais, reprenant ma liberté et royaunt de plus hiaut les choses fue nous avons examinées par le détail, essayer de dégrager les enseignements qui en découlent pour le bien de l'orfèrrerie française.

Comme je l'ai annoncé dès le commencement de ce clappitre et pour répondre au désir exprimé par tous mes collègues du jury je donne ci-iprès la liste des récompenses diuns l'ordre exact où elles ont été votées, rétablissant ainsi la valeur relative des mídailles. C'est ce qui aviut été fait au expositions précédentes par les rapporteurs de l'orfevrerie et c'est une tradition qu'il convient de garder. 


\section{LISTE PAR ORDRE DE MÉRITE \\ DES RÉGOMPENSES PROPOSÉES PAR LE JURY.}

\section{HORS CONGOURS.}

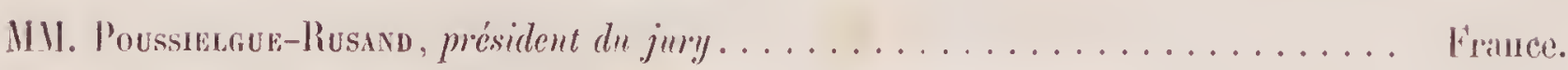

Bapst el Falize, membres du jury....................... France.

Оргт, membre du jury........................ France.

Sundoz (Gustare), membre dn jury................... France.

\section{GRINDS PRIX.}

1. Cumistofle et $\mathrm{Cic}^{\mathrm{ic}}$. - France.

2. Anmavd-Gahist. - France.

3. Fronext-Meurice. - France.
4. Tifrany and $\mathrm{C}^{\circ}$. - Élats-Uhis.

5. Fanvibe frères. - France.

\section{MEODALTES DOOR.}

1. Bon-Tавuret. - France.

2. Gorhan Manufacturivg $C^{\circ}$. - Élats-Uhis.

3. Tŕturd. - France.

4. Frar. - France.

5. Ortscminnikofr (P.) fils. - Russie.

6. Debar (A.). - France.

7. Cinnistesen. - Danemark.

8. Dufreste de Sant-Léox. - France.

9. Brateau. - France.
10. Fraglat. - Russic.

11. Bossand. - Suisse.

12. Comité de Sunr. - Siam.

13. Vertaz el Ime Vervaz-Vecite. - France.

14. Bicheiet. - France.

15. Aucoc. - France.

16. KnLebsikoff fils el $\mathrm{Ci}^{\mathrm{ie}}$. - Russie.

17. Meridex Britaynia $C^{\circ}{ }^{(1)}$. L Lalas-Unis.

\section{MÉD IILLES D'ARGENT.}

1. Bouchenox. - France.

2. Ciridilunac. - France.

3. Mighaut. - France.

4. Leroy el $\mathrm{C}^{\mathrm{io}}$ - France.

5. Trovulien frères. - France.

6. Bovlevalin. - France.

7. Wiциотте fils. - Belgique.

8. Gamiar, Bayard el Cie. - France.

9. Bruxet (P.). - France.

10. Kinuvkosho-Kä̈sh. - Japon.

11. Thloos et Mayesce. - France.

(1) La Meriden Britannia $C^{o}$ a élé haussée à la médaille d'or par le jury supéricur; le jury de classe el le jury de groupe ne lui avaient accorlé que la huitime médaille d'argent.

(2) Le jury n'a pas vu les produits de M. Fonn=
12. Olsex. - Norwège.

13. Pinlippr. - France.

14. Mérits. - France.

15. Hertz (P.). - Dancmark.

16. Bönn (Hermanu). - Autriche-Hougrrie.

17. Sіїто. - Јароп.

18. KELLEn frères. - France.

19. Accinisi. - Italie.

20. Foxsequa (Henri(guez) ${ }^{(2)}$ - Portugal.

21. Germitsex (I. A. A. $)^{(2)}$. Pays-lias.

sequa (Portugal), non plus que ceux de M. Gerritsen (Pays-Bas); c'est pourquoi le rapporl qui précide n'en fiit pas mention. Ces deux noms onl élé ajoulés par le jury supérienr ì la lisle des médailles d'argent. 


\section{MÉD WLLLS DE BRONZE.}

1. Merle. - Fiance.

2. Borrs. - Francs.

3. Ganus (le docleur). - lirance.

4. Bucuer (А.). - Suisse.

5. Hamer. - Norvège.

6. Freviss - France.

7. Dixox and Sons. - Grande-Bretagne.

8. Useldinger. - France.

9. Goldsmis Lluaxce. - Gande-Brelagne.

10. Gavard. - France.

11. Gufrchet. - France.

12. Goldsmeths and Sicversultirs Ca - GrandeBrelaģne.

13. Kunghit. - Russie.

14. Moreau (Felipe) (1). - Uruguay.

15. P'nulpe et Cir. - Suisse.
16. Testevunde. - France.

17. Anerhasen. - Norvège.

18. Liкk. - Aubrichellongrie.

19. Jon:t. - France.

20. Coussolnglis. - Grèce.

21. Masox. - Fance.

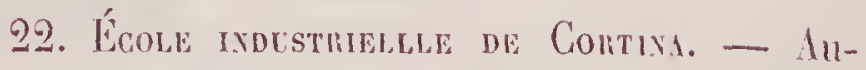
Irichre-Hongrie.

23. Ascmintse. - Russie.

2\%. Kateb. - Égyple.

25. Comté dexposition ae l'Troe. - Colonies.

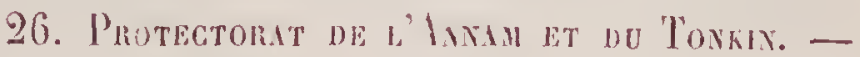
Colonies.

27. Provinge de Hinoö. - Colonics.

28. Comité tuxisher. - Thunisic.

29. Counté de Bounve. - Bolivic.

\section{MENTIONS IIONORABLES.}

1. Limbert. - France.

2. Lifonge. - France.

3. Arovsur et Brnusi. - Grande-Bretague.

4. Demancm fils. - Agrérie.

5. Graticin (reuve). - Espagne.

6. Antola (venve). - Bolivie.

7. Biteros (J.) - Portugal.

8. Pinto-Gouvea. - Brésil.

9. Lacopoulos. - Grècr.

10. Monema (veuve el fils). - Portugal.

11. Ropola. - Roumanic.

12. Avisi. - Salvalor.

(1) Le rapport ne fait pas mention des travaur de II. E. Moreau dont le nom ne figurail pas an calalogne. Le commissaire de l'Uruguny a cependant montré aux membres du jury, avant le dépoot de sis listes, quelques-échantillons du travail de cet exposant qui lui ont mérité la mélaille de bronze.

(2) Le rapport qui précede ne fait pas mention de;
13. Muochevitcu. - Serbie.

14. Puaté. - Colonies (Cambolige).

15. Іспем Znrouk. - Tunisic.

16. Sünov-Catras. - Tunisic.

17. Jarvot. - Colonies (Camboilge).

18. Tä̈b-el--Ifestaovi - Thuisio.

19. Yovg-Hexg. - Chine.

20. S.ribis. - Eigle.

21. Miloukore. - Riussic.

22. Festratets (P.) (2). Belginue.

23. Parker ${ }^{(2)}$ - Elats-Unis ${ }^{(3)}$.

prohuits de M. Fustrets, ni de M. Parker. Cinlle deruière récompense a élé dommée par le jury supérieur.

(3) Les récompenses aux collaboraleurs sont inp:imées an Calalogrue officiel; il en est fait mention dans lo présent rapport, à la suite du chapilte consacré à l'exposant qui l's a employés el présentés an jury. 


\section{III \\ GOVSIDERATIONS GENERALES STR LORFETRERIE.}

\section{ART. - INDUSTRHE.- COMMERCE.}

Les Expositions n'ont pas seulement pour objet de comparer la valeur des produits qui y figurẹnt et de récompenser ceus quii les ont inventés on fabriqués. Au-dessus des mériles privés de l'artiste et de l'ouvrier se placent des intérêts généraux dont il est temps de parler. Le jury des récompenses a terminé sa tiche et dans chaque groupe, daus charque classe, des questions surgissent de l'examen des choses rnes.

C'est peut-ètre la partie essentielle d'un rapport, c’en est certainement la plus délicate.

En eflet, si charne rapport avait sur l'avenir d'une industric l'action logique et effeclive qu'exerce sur la direclion d'mne usine l'inventaire qu'on dresse après chaque exercice, il faudrait $y$ apporter une prudence excessive, et la responsabilité du rapporteur serait telle, qu'il hésiterail à poser ses conclusions.

Mais les rapports qu’on a faits, après chacune des Expositions précédentes, ont dormi dans une obscuritési profonde, qu’il ne faut pas prendre la peur d'écrire et que nous oserons dire, pour quelques rares lecteurs, ce qui résulte de nos observations el des documents recueillis par nous et nos amis. Il ne s'agit plus de parler des orfèves ed de leurs travanx individuels, mais de l'orfèvreric; c'est elle seule qui est en jen et nous devons l'examiner sous ses grands aspects; elle est un art noble, une industrie riche et puissante, un commerce florissant enfin qui, malgré la diffusion des fortunes, s'étend et grandit, apportant les jouissances du luxe dans toutes les classes de la so. ciété el constilnant à la fois un bien-être et une épargne.

Avant d'aborder celte étude et d'analyser les forces de notre industrie nationale, j'iurais voulu faire une revue rapide des conditions où se meuvent les fabriques étrangères el déterminer la situation de l'orfèvrerie chez les autres peuples, opposer leurs goûts, leurs besoins, leurs procédés, leur production aux nôtres. Nais je me crois dispensé de celte recherche par l’indifférence même des orfèvres étrangers. La plupart ont manqué à l'appel. Qne ce soit par un sentiment de crainte exagéréc ou par une modeste défiance d'enx-mèrnes, ils en ont été punis par le succès de l'Exposition, et beaucoup regreltent leur abstention.

Je n’ajouterai done rien ì ce qui a été dit au chapitre précédent sur l'orfèvrerie étrangère : je me borne à constater la supériorité que conserve l'orfèverie française.

Cetle supériorité n’a pas besoin d'être démontrée, elle ne résulte pas seulement 
dans l'histoire du passé de la comparanison des arurres qu'on voit en nos musées ef dans les grandes collections d'Europe, elle réside dans la tradition d'un art qui, depuis ses origines gauloises jusqu’à la fin du xvm siecle, s’est transmis sans lacune.

Les orfèvres d'Italic et d'Allemagne ont fait des chefs-d'ourre et leurs ateliers ont brillé du phus vif éclat : Pise et Florence, Rome et Milan, Augsbourg el Nürembergr ont eu des maitres fameux, unais ces écoles étaient d'importation étrangère; saint Bermward avait, au $x^{e}$ siècle, créé dans le monastère d'Hildesheim un atelier d'ouvriers grees el c'est à Constantinople que l'abbé Didier, qui fut élu pape en 1086 sous le nom de Victor III, avait été prendre des modèles pour refaire me école d'orfèrerie à l'Italie ruinée.

Ce n'étaient donc pas des industries nationales, elles ne tenaient pas au sol, elles y avaient été importées comme des plantes étrangères, elles y avaient fleuri, nlais jantais floraison n’avait été plus belle que celles du $x v^{\mathrm{e}}$ et $\mathrm{du} x \mathrm{v}^{\mathrm{e}}$ siècle en Italie, du $x \mathrm{r}^{\mathrm{e}}$ et du xwi siècle en Allemagne. Puis, comme il arrive aux plantes exoliques qui dégénèrent et s'étiolent, ces belles écoles d’orférerie ont été s’appaurrissant; la décadence est venne et rien n'est reslé du passé qu’un glorieux souvenir.

11 en a été de même en Espagne où les Arabes avaient apporté leurs formules, mêlant leur génie à celui des ateliers créés par les Visigoths; mais l'orfèvrerie espagnole est morte de l'abus des richesses : les galions du nouveau monde ont tuć le gonil, l'abondance de la matière précieuse a étouffé l'art et le métier, comme en Angleterre le génie commercial a détruit l'esprit inventif de l'artisan. Holbein avait cependant introduit à la cour de Henri VIII les modèles les plus parfaits et donné aux orfévres de Londres une technique admirable.

L'histoire de l'orfèvrerie française n'a aucune analogie avec colle de l'orfèvrerie étrangère; elle commence avec la race, elle a ses origines en Gaule, la science archéologique l’a démontré; ni la conquête romaine, ni les invasions barbares n’ont détruit ses ateliers; ils prenaient aux artistes grees ou romains, comme aux rudes onvriers venus arec les perples de l'Orient et du Nord, les formules nouvelles, les transformaient pour se les assimiler, et quand vinrent ì leur tour de Byzance des ouvriers tonsurés, ils trouverent aux bords de la Meuse, de la Seine et de la Vienne, des orferres aunquels ils n'avaient rien à apprendre. Ainsi le vaniteux Cellini, arrivant ì la cour des Valois, s'étonnail aussi plus tard de trouver à Paris des maîtres non moins habiles que lui.

Liorfèvrerie française se poursuit à travers notre histoire, si intimement soudéc à l'art national, qu'elle le traduit en toutes ses variantes : romane ou gothique, c'est-it-dire absolument francaise, elle suit les modifications de l'édifice et du mobilier, calquant de trop près quelquefois l'œuvre de pierre, mais gardant cependant les règles du métier el se parlageant entre sa clientèle de rois et d'évêques, de princes et d'abbés.

Givile et religieuse, somptueuse et sacrée, elle rayonne pendant plusieurs siècles, pénètre de France en Italie, en Allemagne, en Angleterre, olle constitue le fond de tous les trésors. ILes rois la protègent, lui donnent des lois; e'est une listoire orlorieuse 
qui fail de l'orlèrerie une caste fermér, privilégiée, où la lradition se Iransmet lente, mais eontinue. Fin rain essaie-t-on dr faire adopler, an xve siecle, par une conr avide de noureautés, les modes d’Ttalie: les vieus orféves parisiens résistent, ils s'obstinent à rejeter les types inposés, ferment leurs ateliers aur ouvriers du delor's et ne prennent aux idres nouvelles que de quoi inspirer les maitres. Ce que Jean Goujon a fait pour la sculphure française, Élienne Delauhe l'a fait pour l'orféverie. C'est de ce orrand artiste qu'est venue une nodification importante de l'ornementation qui s'est étendue aux arts voisins, s'est propagéc chez tous les petits maitres de l'Allemagne ef des Flandres. C"est de là que date l'expression si personnelle el si puissante de l'orféverie francaise

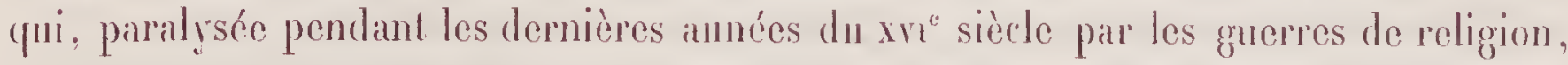
se développe sous Louis XIII, a sou complel ápanouissement sous louis XIV, toul son esprit sous Louis XV, sa gràce sous lauis XVI ef qui s'est imposćc à l'admiration de tous les peuples, au point qu'aujourd'luni encore ses ouves seules ont une valeur, ses poincons, un cours, et que les commaisseurs les estiment el les pilyent à l'égall des auves d'arl peintes ou seulptées do nos plus grands mailtres.

C"est done bien une tradition ininterrompue qui va des premiers temps de notre histoire jusqu’à nos jours, car la crise rérolutionmanire n’a pas détruit cette suite, elle en a retardé la marclic peut-étre, mais nous arons vu que, délirrée de quelques entraves, rendue accessible ì tous, l'orfèrerie ar gagné en force, en science, en confiance et qu'elle a garrdé ses fidèles, se perpétuant dans les mèmes familles, s'attacliant ì des dynasties de maitres.

En quel pays trouverait-on une aussi longue el aussi ferme tradition? Si c'est un gage de sécurité el d'estime, n’ivons-nous pas toute risison d'allribuer à l'orfévrerie francaise, dans le passé comme dans le présent, une supériorité que d’ailleurs personne n’a jamais contestéc?

Il nous reste à l'étudier daus ses éléments constitutifs qui sont l'art, l’industrie et le commerce. Et c'est en trois parlies que nous diviserons ee dernier chapitre du rapport, afin de traiter successivement des choses relatives an goût, des choses relatives au métier el de celles relatives aux règlements, à la consommation et à la prospérité commerciales.

\section{\$1. LE GOÛT.}

Le xaxe siècle a fait la récapitulation des siècles quil l'ont précédé. Il l'a faite en pliilosophie, en listoire, en littérature, en arl, il l'a faile par la critique el par l'outil, éludiant et copiant à la fois le passé sous toutes ses formes, et c'est à la veille de s'éteindre lui-même que ce siècle, qui a tout imité, clıcrche quelle sera la marque dont il pourra frapper ses curres, il vent aroir un style. Tel l'oiseau que décrit Buffon imile le chant des autres oiscaux et pousse après un rri moqueur.

Ce que nous avons fait en at décoratif, depuis rent ans, n’a élé que la récapilulation de tous les styles, la science critique y a gagné. nuais l'art y a perdu; l'éclectisme, qui 
ust un systeme en philosophie, est une faule dans le domaine de l'art et de l'industrie, carr il inporte moins de choisir que de prodnire, moins de sivoir que de croire.

Ni le maître, ni l'omrier, ui le client ne comprennent rien ì ces styles qui ont amené la confusion des formes et des lignes el qui font de nos méliers de petites Babels.

C'est une science dangereuse ì laquelle cependant l'arliste peut échapper, car il sisole, alors mème que l'école se parlage en phusicurs fractions. Nous avons vu des seulpteurs et des peintres se rendre indépendants el libres, et, sans aucun souci des tendinces publiques, imposer leur penséc el l'écrire fortement arec l'ébauchoir of le pinceau. Ce sont ces maîtres-lì qui donneront an siècle la caractéristique qüil réclame, mais ils n'ont pas su l’imprimer an choses de l'industrie paree que, par une anomalie

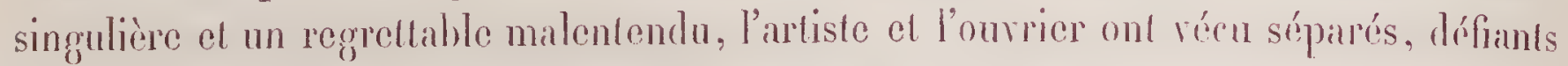
l'un de l'autre et non plus unis comme aux grandes époques.

Liondustriel n’a pas la frère indépendance de l’artiste; il ne crée pas la mode, il la suit, il cède au caprice de l'acheleur el, pour lui plaire, pour alimenter son commerce, il accomplit en sa fabricalion de perpélucls clangements.

Ces changements, l'orfère n’y est point obligrá; il est le seul peut-être dans l'industrie qui ne subisse pas cet esclivige et éest à lui d'oser s'affranchir le premier des tyrannies de la mode. Pourquoi? C'est que l'orférerie tient dams la forlune publiqur un rôle économigue, qu’elle n’est pas assujellic comme les étofies el les meubles ì des rariations périodiques, qu’elle ne s’use pas, qu’elle ne dépend pas du rostume, qu’il n'est point d'usage qu'un homme renowelle soment son argenterie el qu'une église remelte au creuset les vases sacrés, pour en changrger la forme.

rest le voisinage des joailliers el des bijoutiers qui a parfois entrainé l'orfère ì

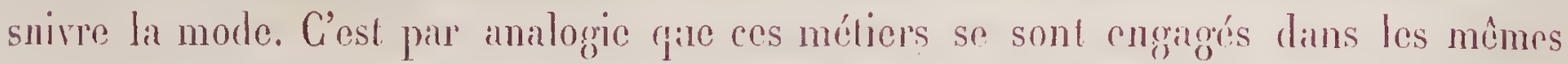
chemins, les tendances d'un atelier se commmiquant ì an autre, pir des dessinateurs, par des ciseleurs, par des collaborateurs communs.

La mode clangeante s'est transmise par ces fréquentalions comme mo maladie contagicuse et la complaisance des aclıetenr's y a aidé.

Il en était autrement quand l'orérre, attaché à des tradilions, voyait en son métier un art entier, dont l'unité ne soufrait auncum partage et dont les règles absolues étaient écrites, transmises, enseignées, examinées à l'aide d'une móllocle et de régglements étroits. En ce temps-lì, maitres, compugnons et apprentis vivilient sous la garde de leur maison commune et ne rêvaient d'aucune indépendance; la liberté quiils ont recue s'est traduite en inventions de toule nature, elle est derenue licence dans les choses du dessin, non pas parce qu'on a micur su, mais parce qu'on n'a plus le temps d'apprendre.

Beaucoup de patrons dont le sourenir est lié à l'industrie de ce temps-ci nont été orfères que de nom; bien peu ont su manier l'outil et tenir le crayon. Nous craindrions d'être indiscret en insistant d'arantage sur un fait malheureusement rrai, mais il est regrettable que celle vieille el si logique condition qui imposail au maittre d'aroir 
conquis son grade en passant parr l'atelier n'eviste phus. On n'anrail pats vu des orféveres acheter el condune une fiblipue comme une boutique, el cela explique bien des errenrs de gout, bien des faules de filbrication; cest la liberté du commerece

Nons aurons l'occasion plus loin de parler de l'atelier el de l'école et par conséquent de voir comment se doit faire l'éducalion rle l'orfévre. Cie quili importe de préciser d'abord, cest l’influence du goût public sur l'orférrerie.

Le gont pulblie, il le faut définir et ne pas le confondre arec la node; la mode est une manière d'être essentiellement rarbable el de peu de durée que l'orférre doit craindre, lui qui fait des ouves durables; olle est tonte de convention, sourent déraisonnable, el nous apparait ridienle dès quólle a cessé d'ètre; elle est défmie, tout Ir monde la connaît et la copie, on la suit, tandis fue le goût est difficile à noter', quil

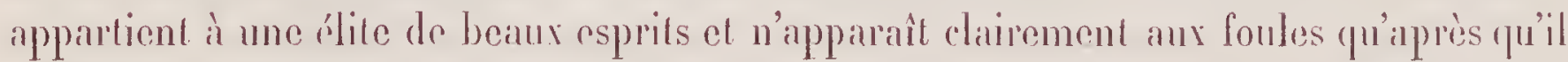
est adopté el classé.

Le gont public résulte d'un comrant d'opinion qui marque l'esprit d'une société; il est en parfait accord arec la manière de penser et d'agir d'me éporque, il reflète les besoins, les aspirations of les émotions d'mn perple, se modifie selon les érénements et reud arec la plus alosolue logique l’image d'mue période d'histoire. Il fant beancoup de disceruement pour saisir les caractères dı gont public, et les antistes senls ont le génie de les fixer.

Cie n’est donc pas la foule qu’il fant suivre, car elle ne s'ittache qu’à la mode, éest uncélite qui a le sens du goût. Voltaire l’a dit, et son jugement est le méme sur les choses de la littérature et des beaur-arts : e Le goût est comme la philosoptrie, il appartient ì un très petit nombre d’imes privilégrées. Les counaisseurs seuls ramèuent

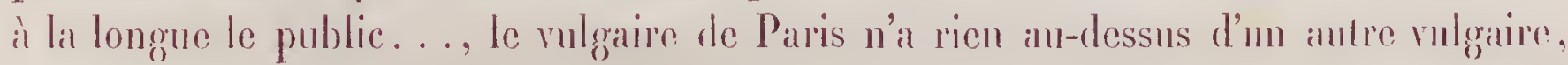
mais il y a dans Paris un nombre considérable d'esprits cultivés pour meuer la foule. Cette foule se conduit presque en un moment dims les mourements populaires, mais il faut plusicurs années pour fixer son goût dans les arts."

C'est aussi vrai maintenant qu'au temps de Voltaire, et nous n'y insisterions pas si nous avions ì parler d'une iudustrie de mode, mais l'orfévrerie est faite pour durer, elle doit subir le jugement du lendemain, et c'est pourquoi celui qui lä compose et en modile la forme doit s’inspirer de sages conseils, fréfuenter les meilleurs artistes, s'orienter vers ce goût particulier de la nation dont parle Voltaire, afin de laisser des curres digues d'ètre conservées, comme celles des Balin et des Germain où se reflètent si bien l'art et le caractère de leur temps.

Voilia le premier point: donc l'orférre ne doit pas suivre la mode, it commet une faute s’il flatte le caprice de la foule et s̈̈l cherche l'actualité. Ses curres doireut être, comme les eurres supérieures de morale et de philosophie, nie expression yui survive il leur teups, mais qui en garde, aree le reflet, linspiration directe.

Comment l'orfère peut-il rencontrer cette inspiration? Quelques-uns y ont-ils rénssi? 
Oui, quelques orfirres l'ont compris, el il ! a de ce temps-ci des ceurres qui sont déji des documents pour l'histoire.

Biennais a, sur les dessius de Prudlion, fait le bereau du roi de Rome, el Napoléon lont puissant revit dans ce meuble sompluens.

Fanconier a ciselé arec Nuleret et Vechte le grand rase d'argent qu'arail modelé Chapouniere, ot la France libérale, qui l'offrit par souscriplion ì Lafingette, sest peinte en ce présent symbolique.

Barye a fait les modeles d'in surtout de chasse que possèdent les prines d'Ortéans et qui marque les débuts du grand artiste.

Feuchères, Kligmamn et Geoffroy Dechiume ont composé pour Froment-Meurien les belles pièces qui ont assis la réputation de cet orfére : elles ont le caractiore de leur époque, mais elles marquent dans la seulpture du né́tal l'évolution de l'art que des noms fameux illustreut dans la peinture. 11 y a des aures modernes d'orférerie qui méritent d'être classées conme des Delacroix, des Ary Schoffer et des Decimps.

Tels le vase de jaspe el d'or que Morel a fait pour M. Hope; la Minerve de Simart, que II. Duponcliel a vêtue d'or et d'argenl; te Louis XIII de Rude, qui est au rlâteau de Dampierre. Ces cemres-lì sout l'houneur de notre nétier, elles mirquent les efforts et les progrès de nos aleliers.

La jolie trirème d'argent que l'impératrice arail commindéc aun Fimuière pour II. de Lesseps restera comme l'éteruel témoin d'une conception ograndiose, la date du percement de l'istlme de Suez, une relique nationale.

Viollet-le-Duc a éroqué de son crayon la r'enaissance de l'orférerie religieuse, el ses dessins ont une importance capitale dans l'étude de notre art. Peu apress sal mort, on a payé 100,000 franes la collection de ces modeles.

Ciluristofle, aidé de deux dessinateur's, Rossigneux et Reiber, a fail aussi une érolulion considérable, en survant; arec le premier, le conrant du style néo-grec qui apparlient à la fin du second empire, et arec le second l'influence du goht japonais, qui s'est, depnis viugr ans, étendue à toutes les manifestations décoratives.

Les pièces créées par ces divers artistes marquent les étapes du gonit, eu ce qu’il a de mieux défuni elles ont leurs places aussi nettement désignées dans les collections de l'arenir que les chefs-d'œure de Cellini el de Jannitzer. On ne saurail pars faire de différence, il n'y manque que la cousécration du temps el dejà cependaut ces pièces nées d'lier sont entrées dans l'histoire.

Les anciennes ne sont pas plus exemptes de défults que les nouvelles : ce sont ces défauts qui souvent constituent le caractère, el cela nous amène à parler de la curiosité. Ce n'est pas sortir de la questiou, lant de gens croient que l'amour du passé résume le gont de notre époque et que du bibelot peut naitre un style.

Mais la curiosité n'est pas non plus une maladie nouvelle, elle existait dans la Rome des Césars et dans la Rome des Papes, à la cour des Valois el dans la société du xrme siède. Il y a toujours en des savants et des maniarnes, des érudits et des naifs. 
On payait, an temps de Pline, l'irronenterie à raison de 5, 000 sesterces la livre (près de 1,40o franes de notre monnaie), quind elle portail te nom de quelque illustre maitre de lil Grèce antique, mais en même temps on fibriquait, pour les grogos de l'empire, de la fausse orféverie de Corinthe.

Si Rome avait accaparé les trésor's d'art de l'ancien monde, si elle élait devenue le musée incomparahle et le marché unique, Paris est aujourd'tui le centre de l'art el de la curiosité; par une réaction naturelle, c’est ce Parris révolutionnaire, qui dispersait ses trésors il y a cent ans, qui s'est pris d'amour pour tous les arts et qui en fiit pieusement l'histoire. La curiosité n'y est plus senlement une manie, une patssion, c’est une science : l'atrehéologie s'est étendue aux moindres closes dı passé, il n’est pas un nom d'artiste, un détail de métier qu'on ne cherche el qu’on n’imprines.

Et tous les archéologues, grands et petits, sivinuts et gens du monde, collectionneurs et marchands, critiques et amateurs ont pris sous leur protection Ins ouvriers el les artistes, les conseillent, les guident, écrivent pour eux, leur apportent des doenments, des dessins et des notes, en sorte qu'ils parlent souvent des closes quils ne savent pas avec plus d'autorité que ceux qui les ont apprises et qui les pratiquent.

Trop de documents, trop de science, trop de modèles, le moindre brin de naturel vaut mieux que cette connaissance démodée de tout un passé mort.

L'archéologie est une admirable science qui éclaire l'histoire d'un jour nouveau et qui apporte des preures indéniables, mais il ne faut pas que des bibliothèques et des musées elle envilusse l'atelier. C'est à l'école seulement qu’il en faut donner aux jeunes une teinture suffisante, et l'artiste ne doit pas plus s'inquiréter de ce qu'on a fait avant lui que l'écrivain ne doit s’inspirer à l'excès des auteurs classiques.

Je pense en cela comme le marquis de Laborde, qui écrivait :

Je voudrais que les élèves prissent de cette science ce qu'elle a de fécond et qu'une fois liors de l'école ils ne fussent plus tentés de l'étudier. Comme ces passions dont on est facilement désabusée it lägre où on ne doil plus les éprouver, quand on les a ressentics dauss sa jennesse, et qui, an contraire, deviennent des entrainements irrésistibles quand on en est atteint alors pour la première hois, ainsi,

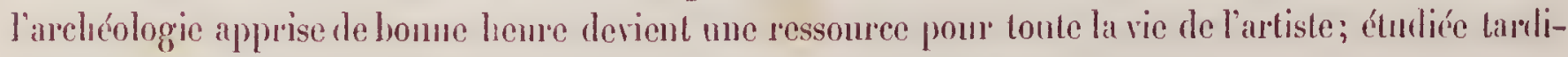
vement, c'est une mer sans fond et sans rivage où il se noic corps et biens ${ }^{(1)}$.

Voilì quarante ans bientòt que cela est écrit, nélait-ce pas une prédiction? Si, par un instinct de hon sens, l'artiste se défend de lis science archéologrique qui le vide ou qui l'égare, l'industriel n'y vient que tardivement et s'y abandonne pirce que ni l'école ni le lycée n'ont su la lui enseigner en temps utile.

Et c'est sollicités par les curieux, les sarants et les gens du monde que les filbricants se sont mis à pasticher les arts anciens, salls y rien mettre de leur grénie propre, do leur intelligence et de leur goût.

Je préfère l'originalité primesautière et mal réglée d'un arliste ì cette obéissance

(1) De Laborde. Union des arts el de l'industrie (lome XI, p. 37.3). 
servile d'un copiste qui s'acharne ì quelque besogne rétrospective. Il exécule des choses quil ne comprend pas. C"est comme si l'on écrivalil sous la dictéc d'un mort.

les musées, à mon sens, sont des trésors où il ne fant pas puiser à l'excés. On n’y allarit pals assez autrefois, on n'en sait phlus sortir.

Ils sout bons pour éveiller le goût, pour faire l'éducation, pour enseigner el pour aider anx comparaisons, mais il faul se garder dy fare des copies, aubul pour les choses de métier yue pour les coures peintes : ou ne souffrirail pas qu'un peintre calcutut Lesuen on Watteau, doit-on admelle darantage qu'un orfére recomnence Germain ou Veissomnicr?

C'est lì pourtant ce qu'on farit, et la faute en est moins à l'orférre qu'à celui qui

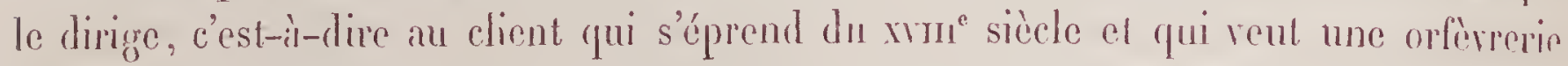
en harmonie arec ses lambris et ses meubles. C'est la mode qui réagit en cela sur le gô̂t, c'est la science archéologique qui régente le métier, el qui le compromet au lieu de l'aider.

L'orférerie en est ausi revenue par d’étringes dótours au point oil elle avait perdu sa route, ì ce xrme siècle où elle élait tant labile, oì ses maìtres élaient les premiers, où l'Europe átait tribulaire de ses ateliers, où de Versailles à la Mounaie ses reures éphrimères avaient lem triomphe et leur tombeau. En sorte que nos modernes orfères ont une occasion propice de renouer la tradition et de reprendre leur art au point précis oì cette tradition s'est rompue. Puisque la bonne volonté des collectionneurs nous est acquise, voici comment je roudrais qu'elle se manifestât.

Que les Pichon, les Eudel, les Mannheim, les Stein; les Spitzer nous apportent un jour leurs merveilles, tout ce gui reste de l'irgenterie de la Régence, de lonis IV et de Inuis XVI, qu’ils y joignent les prèces de faïence et de porcelaine qui ont étó calquées sur l'orfieverie, car la cérimique a pris tous les modèles ì l'argenterie quand les édits royan envoyaient la vaisselle an creuset. Qu'on fasse ainsi pendant un mois une exposition spéciale pour l’instruction des orfères, qu’ils y viennent ćtudicer, maîtres et ouvriers, dessinateurs, modelenrs, commis, apprentis, tous, pour se bien pénétrer de ce quétait leur métier au temps oì il y avait encore un enseignement el une méthode. Et pour que la lecon profite, quoon fasse installer un établi, un étau, des las, des bigornes dans la salle du musée, quion apporte des marteaux et des limes et qu'on choisisse le plus habile ouvrier.

Ce sera Glachant, je suppose; on convoquera avec lui Cameré qui dessine, Joindy qui modele, en priera M. Paul Gasnault, l'aimable conservaleur du Muséc des arls décoratifs, de cloisir parmi les pièces qu’il connail si bien l’une de celles où il apparaît de facon évidente que la céramique a pris modèle sur l'orfévrerie. Glachant devra s'appliquer à refirire en irgent, au mogen du marteau, la pièce telle qu'elle avait dì ètre primitivement. Cameré et Joindy suivront l'opération, lecoustilueront l'ornementation par comparaison avec les pièces d'argenterie d'époque correspondante, et un ciselenr comme Brateau, Diomède ou Richan’r, exéculera le décor. 
Celte expérience plusiemes fois répétéc d'après des lypes Louis XIV et hígence, aux planes énergiques, ann moulures savanles, d'après des vases louis XV am contonts glas et pleins, mais point lrop surchallyés de rocailles, d'après d'élégantes el sobres pièces louis XVI un peu grèles, mais sohres, point trop sèches de ciselure ni trop avancées d'époque, celle expérience, dis-je, applendra aur patrons el iur curiem, aux ouvrjers el aur artistes, que c'est l'outil seul qui donne la forme el que éest à l'itelier qu’on invente en traraillant le métal; qu’il y a des rèogles dont on ne se départit pas, qui sont basées sur la logingue of l'usage, et que les inventions ingrabenses du dessinateur el du modeleur ne sont acceplables que si l'outil peul les traduire sans superelicrie.

Les moyens nouveans dont nous parlerons en lemp place, le tour, la gravure ef l'estampage, la gialvanoplastie, ele., ont rendu d'incontestables services, mais souvent ils ont produit en orféverie des contresens et ont détruit l'honnéte simplicité du modrile. C'est ainsi qu'une vulgaire houillotle fait ì voir plus de plaisir qu'une sonpière d'argent surchargée de ciselure. Le chaudrounier reste en cela plus orfévre que l'orfève lui-même, parce quiil est fidèle au marteau et qu'il a gardé la tradition du métier.

Qu'est-ce que l'orféverie? C'est l'art d'embonlir et de rétreindre an marteau une fenille de mótal, pour en firire un vase capable de contenir un liquide.

Tous les ornements que lit fonte, la lime, te ciselet et le burin y peurent ajouter ue viennent quensuite. Mars la forme générale doit expliquer le but du vaisseau ou du plat d'une facon logigue. Cefle règhe est anssi absolue pour l'orfieve qu'olfe l'est pour le céramiste qui fait un pot de tere.

Cependant nos orferres l'ont somvent oublié el c'est en cela quil ferait hou leur rendre une lecon publique ave les types d'argent, de porcelaine ou de faïence qu'on emprunterail aur musées et aux collections.

On en ferait une grammaire pour les apprentis, mais lì derrait s'arrêter la copie : il est temps de créer.

Copier est un dinger pour tout le monde, et si l'industrie en souffie, les curieu risfuent de se rumer à ce jeu. Ils ne savent pas à quel degré d'habileté sont parvenus quelques ouvriers qui u'exposent jamais, qui n'ont pas d'enseignes sur la rue el qui font en chambre le travail cactó dont is vivent asse\% mal, mais dont profitent des spéculaleurs malhonnìtes.

On a dit el écrit hien des histoires curieuses sur l'art du lrurpuge, el moi-même jai dévoilé quelques manoures que javais hésité longtemps à dire; mais ce qu’on sait n’est rien près de ce qu’on igrnore, ef les plus habiles ont été trompés par les faiseurs d'orfivrerie incienoe. Tout y est, la forme et le décor, la qualité de l'argent, la paliue, les poincons et les marques, la grinure des armoiries, le vieil écrin; et l'histoire, et la provenance, et les preures, et la famille qui témoignera que, de père en fils, on s'est trausmis celte argenterie comme une relique. Je ne puis de ce rapport faire une chronique scindaleuse de l'orlevverie, mais je raconterai si l'on n'y obliger 
comment de paures diables d'artistes sont engagés, exploités, volés mème. par des gens qui font ce vilain coumerce et dont on serait étonné de savoir les noms.

Qu’ils ne craignent pas, je ne veux pas les dénoucer, mais qu’ils sachent que c'est un trafic honteux et aussi indigne que de faire un faux billet, de biseater une carte et de voler un ami.

Car ce truquage s'est pratiqué jusque dans le monde des curieux, et on n'a pas toujour's pu exécuter les joueurs masqués comme on le fait dans un cercle.

La loi s'est montrée plus sévère pour les faussaires de has étage qui, d'Allemagne, de Hollande et de Suisse, avaient envalii les boutiques de Paris avec des pièces d'argenterie de mauraise fabrication. Les ignorants seuls peuvent être trompés par ces marchandises de rebul, tandis quil y a dans les plus fameuses collections beaucoup de pièces réputées anciennes et payées à des prix considérables qui sont l'ouvre d'ouvriers et d'artistes dont on a chichement acheté le silence, et qui ont pourlant la vertu de se taire.

Le jour où ils parleraient, il y aurait un krach formidable à la bourse du bibelot ef de la curiosité.

Pour ces roisons et pour d'iutres qui sont de goût et de hon sens, je crois quil faut se garder de suivre le penchant qu'a pour les choses anciennes un groupe d'amateurs et de gens du monde. C"est une fausse piste dont il faut détourner les orféres comme d'un danger. Trop d'imitations ont été failes, honnes et mauvaises, coupahles ou naïres, pour qu'il n'en subsiste pas après nous, mais ces ouvres seront mal classíes et sévèrement jugées, car l'histoire ne se recommence pas plus en art qu'en fait.

Le faux Louis XV sera toujours du faux, comme seront jugés faux et sans valeur les meubles, les étoffes et les bronzes que l'on callque sur ceur de Cluny, du gardemeuble et de Versiilles.

Les acheteurs aujourd'hui peuvent s'en contenter; ceux de demain seront plus difficiles, ef malgré le goût, le soin, l'adresse qu'on y dépense, ces accessoires du mobilier resteront le prokluit bâtard d'une époque de tàtonnement, le résultat d'une erreur, un compromis entre les curieux ef les artistes, en attendant que survienne un acrord de bonne foi qui va se préparant ef qui aura sur l'industrie d'art une gloriense et féconde influence.

Du reste, les esprits les mieux nourris de la science archéologigue, les curienx passionnés pour leurs merveilles et les gens de goût ne s'y trompent pas; il n'en est pas un parmi ceux-là qui soit venu dire à un ébéniste, à un bronzier, à un brodeur ou ì un orfèvre: e'Tenez, voilì un modèle, copiez-le fidèlement". Non, les rapports qui se sont établis entre les collectionneurs ef l'atelier soni tout autres; ils sont venus chercher des renseignements techniques et nous ont foumi des documents curieux; ils désiraient apprendre ce qu'ils ignoraient du métier, et nous donnaient en retour des recettes perdues, des formules retrouvées en leurs livres. ("est un intéressant rechange (pui 
s'ost fait entre ces silvauts ef nos fabrifpues, el quand j'inrai dit, pour le pronver, que je dois personnellement beaucoup il IIIT. Barbet de Jony, Darcel, Silglio, Bertrand, Francks, C. Owen, Eissenwein, Ad. de Rothschild, Comrajod, Müntz, Duplessis, Lavoir, Molinier, Foulc, Héron de Villefosse, je n’anrai pas payé ma dette et ue les aurai pas nommés tons; mais presfue tous sont venus avec une boune gratce el une simplicité charmante me consulter chaque fois qu'une expression se rapportant à un détail de fabricalion leur paraissait obscure, el tous m’ont renseigné fuand je suis allé leur demander conseil.

Cies rais savants veulent que nous nous servions du muséc pour apprendre à mieux faire et non pas pour copier. Ils s'étonuent de voir des fabricants orférres imiter saus raison ce qu’il y a de mauvais ef d'evulécraut dans les plus médiocres orfèrreries allomandes et hollandaises du xrmi siècle, el néggliger ce qu'ivait d'élégant le slylo frangais de la Régence. Il fallul phus d'un demi-siècle pour inventer les fantaisies d'un art quii, de 1715 à 177 / passa par toutes les modificalions de la forme; mais en trois ans on anra épuisé ce style Louis XV en ontassant chicorées sur rocailles, ct on n'aura pas su dégager ce qu’offraient de pur et de savant les dessins tracés par des maítres.

Cela vient de l’ignoranee des dessinateurs el de la hâte des fabricants. On doit en cela regretter la sage lentenr ancienne et les routines prudentes de la tradition.

Les conservateurs de nos mustés ont done raison de montrer quelque dédain pour ceus qui vienneut saus s'être fait initier, qui voient trop vite, qui calquent saus intelligence : ils les comparent avec chagrin aux maitres dont ils gardent les omures.

Il y a des riggles cependant pour l'orfevrerie, comme il y en a dans tous les arts; les premières sont la clarté, la simplicité el la loginue.

Un pot à eau chaude, qu’il soit destiné à contenir du café, du thé ou tout antre liquide, doil aroir une assiette solide, c'est-ì-dire une base proportionnée à sa hauteur, une anse facilement saisissable, permeltant de porter le vase en équilibre saus se brûler ou se salir, et un bec on un exuloire par où le liquide puisse ôtre versé sans accident.

Tout appareil qui ne remplit pas ces conditions prévues, quelle que soit sal beauté ou sa richesse, est maurais parce qu’il est mal construit et illogique.

Il faut que sa forme explique clairement sa destinatiou. Il y a des vases italiens du $m 1^{\circ}$ siècle clargés de sculptures et d'ornements qui restent inexplicables, car on ne sait pas s’ils sont faits pour contenir de l'eau ou des fleurs, pour être posés ou suspendus; ils inquiètent l'espril comne des problemes.

Il faut être simple dans la composition d'une forme; cela ne veut pas dire qu'il faille s'ilsstenir d'orner celte forme, mais il convient de l'écrire sobrement; on doit s'atlacher à ce que le dessin initial reste transparent el lisible malgré l'addition de ces ornements.

La gràce, la beauté, le style résultent de ces trois conditions.

Ge que je dis d'mu vase, je le dirais d'un plat, d'une corbeille, d'une cuiller, d'un 
cadre, d'un flambeau. La destination doit être nettement indiquée el les lois d'équilibre, de pondération, respectées.

On doit comprendre mo pièce d'orfèvrerie comme on comprend un édifice, comme ou lit un live; si l'ait reste inquict et la pensée surprise, l'objet est mauvais.

Qu’est-ce que la vaissclle d’argent, sinon une súrie d’ustensiles destinés à contenir les aliments, à servir aux convives ou it parer la table?

Cielle vaisselle doit être solide et confortable; on veut aussi qu'elle soil décorative, on peut exigrer qu'clle soit luvueuse.

Fant-il done quand on a trouré en qui convient ì ces usages, l'assietle la mieus assise, la forme du plateau la plus appropriće au service, la proportion exacte du légrumier, la juste contenance de la sonpière, la longuenr, le poids et l'épuitibre de la cuiller, la disposition des dents de la fourehelte, fant-il recommencer sans cesse ef défaire tout cela pour trouver autre chose?

Non, car ens proportions constituent des règles, elles sout les canons de l'orferrerie. On les doit enseigner à l'atelier comme la grammaire du métier, et les maîtres s'eu doirent faire les gardiens. C'est pour cela (qu’un orfère doit garder une autorité absolue dans lia création de ses modèles et n’abdiqner jamais, mème en présence d'un grimd artiste.

Dès lors on conçit que les modifications aux formes soient lentes et que le décor ne soit pas aussi changeant en orfèrerie qu'en d'autres métiers d'art.

C'est bien phus ì se débarrasser des maurais types introduits chez enx qu’ì créer des formes nourolles que doivent tendre les bons orférres. Ils ont à procéder par élimination.

Trop d'emprunts ont été faits aux arts voisins, et si la porcelaine el la fiäence ont pris à l'argenterie beancoup de types dont il est facile de recommaitre l'origime, ce n'est pas une raison pour emprunter ì la céramique des profils qui ne conviennent pas à l'orfèrreric.

On ne compose pas pour la terre, pour le verre, pour le bois, pour le fer, pour le bronze mềme, comme pour l'irrgent.

Une assielte de porcelaine, quelque fine et légère qu’elle soit, ne peut pas être copiée en orfèvrerie. Le verre de Tenise le plus gorarieur ou le cristal taillé de Bohuème domera en argent un vase ridicnle. On ne doit pas faire une corbeille de métal, deslinće à contenir des fleurs, comme on ferait nne corbeille de jonc ou de paille.

Un coffret de bois précieux finement mouluré par l'ébéniste produira en argent une masse lourde et sans gràce. Les serruriers el les armuriers sont loabiles à manier la lime et le marteau, et cependant leurs plus fins onvrages de fer et d'acier perdraieut à ritre faits en argent d'après les mêmes méthodes. Enfin quelque voisins que soient le métier de l'orférre et celui du bronzier qui, jadis, n’en faisaicout qu’un, il y al des règles absolues qui veulent qu'un chandelier d'argent soit différent d'un chatuidelier de cuive. 
La matière donc régit le dessin et il faut se garder de changer celui-ci quand il s'explique et ne prête à aucuue équiroque. Le bon goût consisterait à rechercher dans toutes les créations antérieures les types les plus parfaits et les plus logiques de l'orfévrerie. Il en est qu'on reprendrait à l'art romain et à l'art du moyen âge, et on s'étonnerait, je crois, de trouver qu’ils s'adaptent encore ì nos besoins et à nos goûts.

Nous n'avons pas dessein de faire ici un cours d'orfèvrerie, et les quelques réflexions qui précèdent ne sont pas présentées dans l'ordre qu'il faudrait y mettre. Ceur qui seraient curieux de les compléter liraient avec fruit les pages qua écrites sur l'orfèvrerie Charles Blanc, à l'époque où il faisait patiemment visite à tous les orfèvres de Paris, recueillant des notes et prenant à l'atelier des leçons qu’il éditait ensuite en un beau style ${ }^{(1)}$.

Il a même pris pour titre d'un de ses chapitres la pensée que jexprimais tout à l'heure et voici ce titre: e L'orfévre, même quand il appelle un artiste à son aide, doit rester maître chez lui $\%$, et il fait plus loin cette remarque :

"Quand on passe en revue les travaux les plus fameux de nos orfèvres, ceux qu'on a le plus admirés, sans même remonter plus haut que 1800 , on est frappé d'une chose, c'est que la figure humaine, - j’entends la figure en ronde bosse, - y est employée avec une telle profusion que le sculpteur tient dans l'orfèvrerie la première place et l'orfève la seconde."

La critique de Charles Blanc était fondée et il la justifie an cours de ce chapitre, mais elle uous amène à constater qu'en $188 \mathrm{~g}$ la figure humaine a tenu dans les æuvres de l'orfèvre un rôle bien moins absorbant qu’aux expositions précédentes.

Ce n'est pas que la bonne volonté des artistes ne reste acquise à l'industrie de l'argent; nous avons vu que les meilleurs de nos sculpteurs lui ont prêté leur concours. Mais on n'a pas retrouvé cette fois la profusion de dieux, de déesses, d'amours, de sphinx et de sirènes qui peuplaient autrefois les tables et les vitrines; pour ceux qui se souviennent encore des Expositions de 1855 et de 1862 , le changement est considérable.

Est-ce à la mode Louis XV qu'il faut attribuer cetle modification dans l'invention? Peut-être, mais c'est aussi certainement à l'influence de l'art japonais.

L'orfèvre a presque autant que le céramiste accueilli l'idée venue de l'Extrême Orient, et bien que les modèles soient moins nombreux et moins variés pour les ouvrages d'argent que pour ceux de terre et même de bronze, il s'est pénétré d'une esthétique étrange et nouvelle qui le ramenait à des idées simples et à une construction logique.

L'erreur a été longtemps de copier exactement sans y rien changer les formes et les décors japonais. Mais l'évolution s'est faite peu à peu dans l'esprit des orfèvres comme dans celui de tous les artistes et, à travers le Japon, ils ont enfin aperçu la na-

(1) Ch. Blanc. Grammaire des arls décoralifs. Paris, Renouard, 1 vol. gr. in-8, 1886. 
ture; ils ont compris qu'il ne fallait pas copier le vase de Kioto, mais bien le modèle qui avait servi à faire ce vase, une gourde, un fruit quelconque et comme ils ont vu quels rapports existaient entre ce fruit, ce vase et d'autres vases encore dont les modulations successives constituaient une gamme de profils variés, ils se sont mis à chercher, ils ont trouvé d'étranges analogies entre les vases chinois ou japonais et les vases grecs eux-mêmes.

Ils ont constaté que ces formes suffisaient à flatter les yeux, qu'il n'était pas utile d'y joindre la figure humaine, que le décor des parties modelées gagnait à ne pas prendre de hauts-reliefs, quill y avait d'autres procédés d'ornementation qui remplacaient par la couleur et les patines les ressources de la fonte et de la ciselure.

C'est sur ces règles récemment retrouvées qu’ont été faits de nombreux essais qui ont eu Paris comme point de déparl et qu'ont imités surtout les orfèvres d'Amérique.

Aussi ne trouve-t-on cliez ces derniers aucune figure modelée. Les très rares exceptions à cette règle constituent des auvres de dernier ordre, et il est à peu près démontré que nos confrères américains n’ont pas de sculpteurs, tandis que dans les derniers ouvrages d'orfèvrerie cxécutés en Allemagne et en Autriche, la figure modelée occupe encore le premier rôle.

Sans juger à fond le procès qui se plaide entre la sculpture et l'arl japonais, remarquons bien les tendances opposées des deux systèmes. La figure humaine ne joue dans les bronzes et les compositions japonaises dessinées et sculptées qu'un rôle humoristique ou terrible qui ne séduit pas par la grâce, mais qui effraye ou qui amuse.

L'artiste japonais n’a pas compris la beaulé de la femme, l'harmonie du corps humain, l'équilibre des attitudes, le charme et l'altrait qu'exerce à nos yeux celte nudité chaste qui faisait déjà les délices du peuple grec.

Et nous qui sommes sensibles à cette beauté sensuclle, qui aimons encore les dieus et la fable pour la jouissance qu'ils donnent aux yeux, nous les avons cependant caclus non seulement de l'orfèvrerie, mais du bronze. On ne voit plus sur nos cheminées des pendules avec des sujets, des candélabres avec des statuettes, des groupes fondus et ciselés, mais des vases en bronze japonais, des cloisonnés de la Chine, des porcelaines anciennes. Les sculpteurs ne trouvent plus à faire. éditer en bronze que quelques figures médaillées au Salon. Il y a toute une famille d'artistes qui vivaient des modèles que leur demandaient les bronziers et les orfèvres, ils n'ont plus de travail.

C'est lì un changement profond el très caractéristique sur lequel il faut insister; il dépend bien de ce gout public que nous cherchions tout à l'heure à définir. C'est même la preuve indéniable du progrès de ce goût. On s'est lassé des mauvais bronzes. On a rebuté toutes ces choses naives, ridicules et baroques dont s'étaient contentés nos pères, et le commerce d'exportation n'accepte plus même les garnitures de cheminées et les surtouts de table qui s'imposaient à la mode à la fin du second empire.

Pour qu'un bronze moderne soit apprécié, il faut qu'il soit signé d'un maître, il 
faut que la fonte et la ciselure n’en aient pas altéré le modelé; les noms de Mercié, de Dubois, de Chapu, de Barrias, de Dalou, de Falgnières gardent, aux bronzes français d’à présent, une valeur de grand art, mais notre admirable école de sculpture ne trouve pas dans l’industrie de la fonte les profits qu'elle en pouvait espérer et plusieurs de ces maitres sont venus s'offrir à l'orfèvre, en avouant qu'ils auraient autant de joie à faire des figures d'argent qu’à les faire de marbre.

C'est ainsi qu'on a vu naitre une expression nouvelle, plus réaliste, plus vivante, plus intime et que, laissant dormir les mythes anciens, nos sculpteurs ont modelé des scènes prises sur le vif.

Les concours ouverts pour des prix d'agriculture et des prix de courses ont provoqué des inventions nouvelles. Ce que Millet avait fait en peinture, les sculpteur's l'ont essayé plus volontiers dans cet art intime et familier qui n'a pas la majesté du marbre; ils ont fait, pour la fonte et la cisclure, des scènes empruntécs à la vie des champs, et Coutan, Mathurin Moreau, Delaplanche, Barrias, Roty, etc., ont trouvé le chemin de la nature avec la figure humaine, comme les Japonais l'avaient montré avec la plante.

C'est par là que s'ouvre la voie, et comme il faut que nous la montrions à ceux qui la cherchent, c'est cette forme-là que nous déclarons la seule véritable et bonne.

Le goût public tend à revenir en toutes choses à la nature; les brutalités en art et en littérature ne sont que les exagérations d'une force qui s'exaspère et qui se conformera peu à peu aux exigences du plus grand nombre.

On veut une forme simple, dont le décor soit compréhensible. L'expression n'a pas besoin d'en être exagérée, on ne cherche plus ni hérö̈sme, ni fable. La logique et la vérité sont les conditions fondamentales d'un art qui demande à la nature son inspiration et son modele.

L'orférre comprendra-t-il l'avantage que lui offre cette formule renouvelée? Il peut éclapper par elle à la tyrannie des maîtres quil s'était donnés.

L'architecte, en effet, se partageait avec le sculpteur la direction de l'atelier, et l'orfèvre n'était plus pour eux qu'un entrepreneur.

Combien d'œuvres en métal semblent aroir été conçues pour le bois ou la pierre! Et sans remonter à l'époque gothique où l'on faisait l'autel et le tabernacle de bronze doré à l'image de l'église elle-même, n’a-t-on pas fait au xvIl et au xrul siècle des vases d'argent qui ressemblaient exactement aux vases de pierre dont on décorait alor's les jardins et les péristyles des palais.

Il faut donc rédnire la part de ces deux éminents collaborateurs, faire d'eux des conseillers et des amis, mais ne pas leur abandonner la direction absolue du métier!

Que l'architecte règle les proportions, dessine les profils, corrige les moulures, c'est fort bien, mais si vous le laissez pénétrer chez rous, il y voudra commander, et comme il ne sait pas le métier d'argent comme le métier de pierre, et qu'il ignore vos besoins, il commettra des fautes dont vous seul serez responsable.

Donnez-lui vos épures à revoir et confiez au sculpteur le róle décoratif, apprenez à 
modeler vous-même, faites grossièrement votre maquette, n’ạcz pas de crainte. Tournez la forme en plitre ou en bois. Nassez en terre ou en cire les figures et ilors seulement appelez l'artiste en lui disant : r Voilà ce que je veux \%. C'est lì que son rôle commence, il est et doit rester dépendant et vous devez être le maitre absolu de l'œuvre.

Cependant, il est un cas où l'architecte doit être le seul inspirateur, c'est pour l'orfèvrerie religieuse. Il va de soi que le mobilier de l'autel tient à l'édifice et que l'unité ne saurait être rompue sans dommage. Encore faut-il que l'architecle s'entende avec l'orfère et qu'il prenne de lui certains conscils que plusieurs semblent n'aroir jamais reçus.

Il y a des églises où les stalles de bois ont le même dessin que les murs et les piliers, où les grilles de fer ressemblent ì du bois et où l'orfèvrerie semble construite avec de la pierre et du ciment.

Nous avons trouvé ces fautes plusieurs fois répétées dans les ouvres récemment exposées, et l'architecte devrait savoir que le bronze et l'argent ont pour l'exécution d'un autel, d'une grille, d'uir candélabre ou d'un ostensoir, des complaisances que n'auront jamais la pierre, le bois et le fer. On y peut réaliser les plus admirables conceptions de la couleur et de la forme; la fonte, la sculpture, la ciselure et l'émail sont pour l'orfèvre religieux des moyens admirables et précieux, et quelques rares essais de maîtres ont prouvé que l'art chrétien était l'inspiration la plus liaute de l'orfèrerie.

Viollet-le-Duc et avant lui quelques savants auteurs que leur caractère religieux n'empêchait pas de dessiner et d'écrire sur les choses d'industrie, comme le père Calier et l'abbé Texier, ont fixé les règles de cet art chrétien. Mais Armand-Calliat, tout orfèvre d'église qu'il soit, a osé rompre avec la tradition, s'affranchir des entraves de l'archéologrie religicuse et provoquer l'éclosion d'un style nouveau où, sans refuser la tutelle du prêtre, l'artiste aspire à plus de liberté(1). On a vu qu'il avait réussi daus ses œuvres autant que le faisaient espérer ses paroles, et nos archilectes peuvent tenter avec des maitres comme celui-là, comme les Poussielgue-Rusand et les Trioullier, d'entreprendre une orfèvrerie digne de la vieille et superbe école française.

L'invention cependant doit être plus prudente en cette voie que dans celle de l'orfèvrerie civile; il y a des types consacrés et des formes que le culte impose. Mais en échange, quels magnifiqnes sujets! quel cliamp merveilleux ouvert à l'imagination de l'artiste! Tout, depuis la croix jusqu’à la reliure des livres saints, depuis l'autel jusqu’à la burette, depuis la châsse jusqu’à la crosse épiscopale, tout est matière à orfévrerie. C'est la magnificence antique, la magie des couleurs et des pierres comme à Byzance; les émaux, conme à Cologne et à Limogres; les mosaïques, comme à Ravenne; les ciselures, comme à Florence et à Pise. C'est l'admirable histoire du Ciel et de la Terre

11) L'orfêrerie (discours de réception à l'Académie des arts de Lyon), par Armand-Calliat. Lyon, 1888. 
à modeler et à peindre avec ses cortèges d'anges et de saints, ses vierges, ses martyrs, son Dieu, ses symboles: cet infini de l'histoire et de la foi qui a fait les grands artistes. C'est, de plus, l'immuabilité promise, car l'égrlise garde ses trésors et n'a pas les caprices d'une société changeante.

La piété des fidèles alimente encore l'atelier des orfèvres, et quand la clrétienté célècre le jubilé d'un pape, elle surpasse en faste et en magnificence tout ce que ferait un roi, tout ce qu'oserait un peuple.

L'orfève religieux est donc encore le premier dans notre art; il fond en bronze comme celui qui a fait les grands candélabres de Milan, repousse l'argent comme le Verrochio, qui cisela une partie de l'autel de Saint-Jean à Florence, émaille et grave comme Ugolino de Sienne à qui l'on doit le tabernacle d'Orvieto, il nielle comme Finiguera.

Il n'y a pas, pour ses confrères, de joies aussi complètes, car l'orfèvrerie d'art ne trouve pas dans le mobilier civil à prendre un grand développement. II n'y a plus chez nous de cour et dans les monarchies voisines les rois se sont embourgeoisés; le luxe ne réside plus que chez quelques parvenus du commerce et de la finance qui n'osent pas encore ou ne savent pas se servir de leurs grandes fortunes pour créer des œurres d'art. La jouissance de l'argent exige un apprentissage difficile; il est plus aisé de ramasser dans les ventes des objets tout faits et déjà cotés que d'en faire produire aux artistes. Mais on n'est réellement quelqu'un qu'alors qu'on a attaché son nom à une .uure durable. Il y a des clients de Cellini qui doirent à l'artiste de vivre encore dans l'histoire et ce n'est pas la collection de M. P. . . ou du marquis de V. . . qui sauvera leurs noms de l'oubli; elle se dispersera après eux sans laisser de traces.

Les seules applications luxueuses de l'orfèrerie civile se résument dans le faste de la table, et sans égaler encore les somptueuses pièces d'argenterie dont on ornait les buffets et les dressoirs, on revient à la mode des surtouts. Il faut, sous l'éclat des bougies, parmi les cristaux, les fruits et les fleurs, l'accompagnement de l'argent et des dorures.

C'est à cela que la collaboration du sculpteur se prête, et j'hésite à fixer des règles à cette décoration, car elle tire du caprice et de la liberté tout son charme et sa raison d'être.

On a fait des surtouts de chasse, on a raconté en argent les Fables de La Fontaine, on a pris à la mythologic les dieux qui président aux repas, Cérès, Bacchus, Pomone, Vertumne et Flore elle-même. On a raconté les Mćtamorphoses d'Ovide, on a imité les nefs du moyen îge, on a copié les somptueuses vaisselles de Versailles, on a tout refait jusqu'aux vases et aux candélahres de l'Empire dessinés par Percier et Fontaine. Il reste à nos artistes une expression à trouver, qu'ils cherchent el qui sera la caractéristique de notre temps; peut-être cet art naturaliste et simple, qui déjà s'est manifesté dans quelques prix de course et d'agriculture, créera-t-il demain quelque chefd'euvre. 
Un programme avait été donné par l'Union centrale des arts décoratifs qui n’a pas eu tout le résultat qu'on en pouvait attendre. Il s'agissait précisément de composer une grande pièce de surtout.

Les sculpteurs qui sont venus à ce concours n'ont pas assez osé, la plupart ont gardé les vieux symboles; les plus hardis avaient représenté l'un les vins de France; l'autre, la moisson avec un char attelé de bœufs et portant les produits de la terre. Si ces idées simples avaient été mieux étudiées, on aurait pu en faire des œuvres de premier ordre. Le monument colossal que Dalou élève en bronze sur la place de la Nation a d'abord été présenté dans un concours à la dimension réduite d'une maquette d'orfèvre, et ce Triomphe de la République formait ainsi le plus beau surtout de table que j'aie vu jamais.

Rodin serait capable de donner une vie intense à des groupes qui animeraient une table peut-être au delì des conventions acceptées; s'il y faisait courir la fièvre qui enflamme sa porte de l'enfer, le repas se changerait en orgie.

J'imagine cependant qu'il est aisé d'illustrer un banquet aussi bien qu'un livre, qu'on peut faire descendre sur la table, en des attitudes pittoresques et libres, des dieur ou des hommes qui, comme des génies familiers et aimables, vivraient parmi les fruits et les fleurs, les lumières et les mets. On a créé, jadis, d'aimables figurines de porcelaine de Saxe ou de hiscuit de Sèvres qui font encore les délices de quelques collectionneurs. La mode veut qu'on les dispose sur la table entre les candélabres d'argent, les réchauds et les corbeilles. C'est empiéter sur le rôle qui appartient à l'orfévrerie.

Si les sujets font défaut, la figure décorative mêlée à l'ornement, s'engaînant dans les feuilles, soutenant comme des cariatides les bouquets de lumières, toute cette classique et jolie convention de formes humaines conviendrait aussi. Mais il faut oser, il faut provoquer l'éclosion de ces petits chefs-d'œuvre. Il n'y a pas au monde d'ateliers mieux préparés pour cela que ceux de Paris.

Cependant il faut que quelqu'un patronne ces ateliers, qu'on leur donne l'occasion de produire, qu'on leur apporte des commandes.

Cette initiative devrait venir de l'État. C'est le rôle du Gouvernement d'encourager' les industries d'art et c'est une faute grave de croire que c'est aux seuls peintres, sculpteurs et architectes que le Ministère de l'instruction publique et des beaux-arts doit sa protection. Le Garde-Meuble va s'appauvrissant, il paraît uniquement roué à la glorification du xvirr siècle et ne présentera rien d'autre à l'admiration de la postérité, car on n'y a fait entrer aucune œuvre de notre temps.

Ne conviendrait-il pas que la République commandât quelque magnifique service d'argenterie?

En parlant ainsi, je joue absolument le rôle que Molière prête à M. Josse, mais je ne crains pas qu'on m'en fasse reproche. On dîne beaucoup sous la République, et jamais la table de l'Élysée n'a été plus hospitalière; toutes les notabilités de l'art, de l'intelligence, de la science, y sont conviées; on y recoit, avec nos hommes politiques, 
les diplomates de tous les pays. Or ne conviendrait-il pas que le goût français figurât sur cette table d'une manière somplueuse?

Ne serait-ce pas un bon emploi du budget des beaux-arts?

On n’a pas encore remplacé les deux surtouts détruits sous la Commune par l'incendie des Tuileries et de l'Hôtel de Ville, encore étaient-ils de cuivre argenté, et la France n'a plus dans ses palais une seule œuvre d'orfèvrerie passable, tandis qu’à Windsor l'Angrteterre montre d'antiques vaisselles d'or et qu'elle garde à Mansion-House une massive argenterie dont le faste insolent étonne chargue année les convives. Après la guerre, on a vu la nation allemande offrir à l'Empereur un service d'argent ciselé où s'illient an luxe de la matière de beaux spécimens d'art moderne. J'en ai vu les copies fidèles et cela dénote un réel progrès, mais je voudrais qu'on pût voir de combien l'emporterait l'union d'un orfèvre et d'un sculpteur français à qui ce bel effort de gónie serait demandé.

Cela aurait dû être une conséquence de notre Exposition, et jimagine que la chose eût été facile à obtenir de ceux qui y ont pris part; ils auraient, dans un généreux élan, souscrit à ce présent national; c’eût été un monument commémoratif de la grande fête de la paix et du travail.

l'occasion est perdue et les orfèvres s'en consolent, mais ils doivent espérer que les artistes leur ouvriront bientôt les portes de leur exposition annuelle, qu’ils n'auront pas plus longtemps pour l'industrie un dédain que rien ne justifie. Oui, il faut que le Salon recoive les betles créations de l'industrie moderne. Au Louvre, c'est par la galerie d'Apollon qu'on pénètre dans le salon carré.

Les auvres de Cellini sont voisines de celles de Véronèse, et les meubles de Boulle sont logés dans le même musée que les tableaux de Poussin el de Lebrun et que les marbres de Puget.

Le sentiment public exige que les artistes accueillent aussi l'art dans toutes ses formes; ils peuvent exiger du jury d'admission plus de sévérité dans le choix des œuvres d'art décoratif que dans les œurres de peinture et de sculpture pour lesquelles on a tant d'indulgence, mais ils ont tout à gagner en prenant cette mesure libérale, eux qui sont nos collaborateurs et nos associés.

Cette réforme est demandée depuis vingt ans; Davioud s'en était fait le partisan convaincu dans un mémoire qu'a couronné l'Académie des beaux-arts ${ }^{(1)}$. Meissonier avait aceueilli ce projet peu de temps avant sa mort et nous pourrions nommer plusieurs artistes, les meilleurs et les plus illustres, qui ont donné à la proposition déposée par la chambre des bronzes une complète approbation ${ }^{(2)}$.

L'art et l'industrie ne sont pas de principe opposé; ils n'ont rien d'incompatible; ils

(1) L'Art et l'industrie, par Davioud. Paris, Morel, ${ }_{1874}$ (voir p. 97 et suiv.).

(2) Voir la pétition adressée à l'Union centrale des arts décoralifs, par M. Gagneau, président de la Chambre syndicale des fabricants de bronze (Revue des arts décoratifs, 1890). - Les artistes ont donné satisfaction à ce vou en ouvrant, potir la première fois, le Salon de 1891 aux œurres d'art industriel présentées par l'artiste qui on a liait le modele. 
se fondent au contraire et s'unissent par de nombreux contacts. Le dessin, la couleur, la forme sont communs à tous deux. L'architecte fait de l'industrie du haut en bas de l'édifice; le dessinateur et le peintre s'associent à l'éditeur du livre; le sculpteur travaille avec le fondeur et compte avec le bronzier. Il n'est pas un des grands maîtres du passé qui n’ait consacré son pinceau ou son ébauchoir à quelque œuvre purement décorative et Raphaël a composé des dessins d'orfèvreric.

A côté de l'ouvrier qui tient la lime et le marteau, il y a des ouvriers qui sont des artistes et des artistes qui sont des ouvriers. La ciselure, la gravure et l'émail sont des parties inséparables de l'orfèvrerie, et ceux qui pratiquent ces arts délicats sont estimés encore autant qu'ils l'étaient.

Pour rendre à ces arts exquis la juste consécration qui leur est due, il faut non pas seulement les encourager, mais les enseigner, et l'École des beaux-arts devra faire entrer dans ses programmes ces chapitres oubliés.

Pourquoi n'enseigne-t-on pas la ciselure comme on enseigne la gravure? Est-ce que le rapport n'est pas le même; le ciseleur traduit l'œurre du sculpteur comme le graveur traduit celle du peintre, et si l'on se préoccupait de faire une classe de ciseleurs, nos sculpteurs ne se plaindraient plus d'être trahis par eux.

Tout sculpteur sait terminer un marbre, aucun n'est capable d'achever un bronze.

L'émail est une couleur que rien ne détruit. L'émail a des nuances chasdes qu'aucune autre palette ne pourrait produire, et nous avons des peintres dont le génie a rêvé des magies de lumière que seul l'émail peut réaliser. Si Gustave Moreau avait su peindre en émail, il aurait surpassé tous les limousins du $\mathrm{xI}^{\mathrm{e}}$ et du $\mathrm{xvl}^{\mathrm{e}}$ siècle.

Et nous n'avons plus de graveurs en orfèvrerie parce que la mode les avait laissés sans travail, et qu'il n'y a pas un conservatoire où se transmettent les enseignements comme se conservait le feu de l'autel.

Pourtant l'art se ranime alors qu'on le croit éteint; il suffit d'un peu de foi, de conviction, d'audace. N'a-t-ou pas vu dans un art absolument voisin de l'orfèvrerie, la gravure en médaille, un inconnu de la veille grandir en peu de temps et prendre la première place? Roty est un maître qui donne la main aur grands médaillistes du passé, aux Pisans et à Dupré; son ami Chaplain partagge avec lui la gloire d'avoir ressuscité cette forme délicate et spirituelle de l'art du métal, et combien simple a été le moyen qu'ils ont pris!

Faire vrai, abandonner les types convenus, inscrire un portrait dans un rectangle quand la circonférence de la médaille ne leur convenait pas. Modeler un bas-relief comme on fait un tableau, illustrer par une spirituelle allégorie la verte vieillesse de Chevreul, glorifier un épisode militaire, raconter le dévouement d'un médecin, exprimer avec moins d'emphase qu'au grand siècle, mais avec plus de persuasion el d'esprit, toutes les idées nobles qu'on frappe en bronze et qu'on lègue à l'histoire comme des exemples de vertu, d'héroïsme et de foi.

Roty et Chaplain sont deux grands artistes que nous aimons tous et que nous récla- 
mons comme orfèvres, parce qu’ils sont déjà et seront plus encore demain nos collaborateurs et qu'il leur appartiendra d'entrainer, s’ils veulent, l'orf'evrerie dans leur roie.

Un autre artiste de valeur, Levillain, l'a compris, et, dans une traduction du basrelief non moins curieuse, il a marqué profondément la voie que doit suivre l'orfére et que suit déjà le bronzier. Heller, un graveur en médailles encore, qui manie le burin, coupe l'acier, grave le poinçon et pratique encore le vieux métier des maitres, Heller, avant ceux-là, a collaboré à l'orfèvrerie, et, sachant qu'on n'est pas prophète en son pays, il est allé chez les Américains. C'est lui qui a enseigné à New-York, à Boston, à Philadelphie. Les orfèvres d'Amérique lui doivent ce qu’ils sont; il a fait école, et maintenant qu'il est revenu en France, on l'oublie; il demande qu'on créc un prix de ciselure et que la section des beaux-arts à l'Institut songe ì cette forme de l'art qu'on semble ignorer. Sa proposition est approuvée, mais elle n'a pas encore reçu de consécration.

Combien on est lent en France à donner une forme aux idées les meilleures!. . . . .

Ce n'est pas ici la place de développer ces idées cependant, mais j’insiste pour que l'orfèvrerie demande aux graveurs en médailles des modèles. Nous verrons tout à l'heure les admirables procédés qu’on possède pour les éditer.

Il y a quelque chose à faire de plus urgent si l'on veut s'associer ces maîtres, si l'on veut mettre à profit toutes les ressources d'art, de goût et d'invention qui s'offrent, c'est d'enseigner ì l'atelier, c'est de mettre l'ouvrier en état de comprendre en lui donnant l'intelligence en même temps que l'adresse de la main. Le dessin est indispensable. Tous ceux qui ont été des maîtres orfèvres ont été de grands dessinateurs, et Thomas Germain avait pris très jeune les lecons du peintre Boulongne. «Frappé de ses heureuses dispositions, Louvois le fit conduire à Rome par le sous-directeur de l'Académie que le roi y avait établie ${ }^{(1)}$." Et le jeune orfèvre resta treize ans en Italie, à dessiner d'après les maîtres tout en exerçant son métier.

C'est du reste ce qu'ont bien compris nos orfèvres quand ils ont créć, en 1866, une école de dessin qui est commune à leur industrie et à celle des bijoutiers et des joaillier's.

On trouvera dans le très excellent rapport de la classe 5 bis des renseignements sur cette école. M. Paul Colin, rapporteur de ce jury, et dont l'autorité en matière d'art et d'enseignement est connue, a formulé, dans ce remarquable travail, des préceptes que voudront suivre tous ceux qui sont soucieux d'apprendre. Nous faisions nous-mêmes partie de ce jury, et c'est sous la haute direction de M. F. Guillaume et avec des collìgues éminents que nous avons étudié les envois de toutes nos écoles françaises de dessin. Ces écoles préparent une éclosion nouvelle; la jeunesse des ateliers apprend ce que nous n'avons pas appris; le dessin sera pour la génération de demain une écriture cou-

(1) G. Bapst. Les Germain, Études sur l'orfètrerie francaise. Paris, 1887 , un vol in- $8^{\circ}$. 
raute; si tous ne sont pas hiabiles à tracer, tous auront compris, tous liront avec intelligence le modèle dessiné; il n'y aura plus d'obscurité entre l'artiste qui crée et l'ouvirer qui exécute.

Le dessin obligatoire est un progrès décisif vers une nouvelle renaissance de l'art; c'est pour la France une évolution comme en ont dû faire la Grèce antique et le Japon moderne.

Malheureusement cette évolution s'arrête aux classes laborieuses; ce que fait l'école communale, le lycée se refuse à le faire. L'ouvrier saura dessiner, le patron ne le saura pas; l'artiste se recrutera à l'école primaire, car le bachelier n'aura pas eu te temps de liacher la plume pour prendre le crayon; l'entêtement de l'Université est en cela déplorable; elle persiste à ne voir dans le dessin qu'un art d'agrément pour ses élèves, tandis que, pour d'autres enfants, on le regarde comme un art indispensable. On doute, en présence de cette anomalie d'opinions, que la direction des beaux-arts dépende encore du Ministère de l'instruction publique.

Le mal qui en résultera, si le dessin est le véhicule du goût, s’il fait l'éducation de l'œil et complète le sens du jugement, c'est qu'il y aura une disproportion flagrante entre la classe des travailleurs et celle des consommateurs.

Au lieu de venir d'en haut, c'est-ì-dire d'une société riche, privilégiée et qui devrait être dirigeante, la conception viendra d'en bas, et si elle n'est pas comprise, elle amènera des déreptions, des colères.

Il serait temps que le dessin devint obligatoire pour tous et qu'un artiste osât dire qu'il est indispensable autant que l'écriture, quili faut savoir écrire une forme comme on trace une phrase et que le goût est une richesse de l'esprit qu'il faut cultiver comme l'intelligence et la mémoire.

On a commencé la réforme par l'instruction primaire et, pour que la connaissance pratique du dessin pénètre dans chaque école de hameau, on a voulu mettre nos futurs instituteurs à même d'apprendre ce qülls auraient ensuite à enseigner.

Des écoles normales de dessin ont été créées par toute la France, et 174 de ces établissements figuraient avec leurs travaus à l'Exposition de $1889^{(1)}$.

Il est donc permis d'espérer que ce progrès commençant avec les plus jeunes montera peu à peu comme d'une racine, dans la génération nouvelle, et la fúcondera de sa sève.

Notre école professionnelle n'a pas donné tous les résultats qu’on en pouvait attendre. Nous ninsisterons pas sur les défiauts et ne montrerons pas plus de sévérité que n'en a montrée M. Colin dans son rapport. Mais, en ce qui touche cette école, les critiques formulées par le jury ont porté leurs fruits; une importante réforme a été tentée et e'est avec le concours de M. Paul Colin lui-même que la chambre syndicale des orfèvres et des bijoutiers vient de créer un nouveau programme d'enseignement

(1) P. Colin. Journal officiel du 5 novembre 1889 . 
qui est déjà mis en vigueur et que suivent avec une attention soutenue les apprentis de nos ateliers ${ }^{(1)}$.

Cet enseignement est collectif; il fait de la géométrie la base du dessin; on apprend à l'enfant à tracer des figures planes, à comprendre les figures régulières, à aimer la précision, puis à exprimer, par le seul moyen des lignes, la forme de tous les solides, à concevoir les idées de symétrie et de proportion. Ces leçons progressives amèneront l'enfant aux principes de perspective et lui donneront une grande rectitude de jugement pour l'exécution rigoureusement exacte des modèles qui suivront.

Mais ce n'est là que le programme élémentaire, l'exercice de la première année; it faudra trouver ensuite le maitre capable de mener plus loin ses élèves et de parler comme il faut à des enfants du métier, car si l'art est un, s’il n'y a pas deux facons de dessiner, il ne fant pas cependant montrer ì de futurs orfèvres de la mème facon qu'à des brodeurs ou à des ébénistes.

M. Galland, qui est un maître aussi, un des plus autorisés, déplore la création de ces écoles professionnelles et roudrait que l'apprenti dessinât, comme au vieux temps, dans l'atelier, au milicu des choses de son état, qui lui entreraient ainsi dans l'esprit. Davioud, qui a fait sur ce sujet un livre, avait rêvé qu'on apportât l'atelier dans l'école et qu'on apprìt à tous ceux qui dessinent les qualités de la matière et le maniement de l'outil.

Il est done indispensable que le maitre de dessin qui a des apprentis orfévres saclie lui-même ce que c'est que l'orfèvrerie, quil leur enseigne par exemple la théorie des vases et leur apprenne à en tracer la forme comme on apprend aux architectes toutes les choses de l'architecture. Cela est si évident qu'on s'étonne qu'on ne le fasse pas et pourtant il n'y a pas une seule école où on ait jamais enseigné le dessin d'orfèvrerie, même et surtout dans la nôtre.

Je me reprends : il y a une école privéc où ces règles sont données, où on essaie de démontrer au crayon et au compas ce qu'on fait à l'atelier. C'est dans la maison Christofle et cet exemple doit être cité pour être suivi par l'école syndicale.

II faudra chercher des modèles, pen nombreux, mais les choisir avec un soin extrême : les fautes sont plus vite copiées que les beautés, elles attaquent l'esprit comme les maladies attaquent le corps.

C'est dans les vases grees et orientaux, dans les ornements antiques, dans les travaux de métal que gardent nos musées qu’il faudra puiser les meilleurs types.

Puis, au lieu de fatiguer les enfants par la copie des ornementations de tous styles, il les faudra ramener promptement à l'étude de la nature, leur donner à copier des plantes vivantes, leur en expliquer le rôle décoratif, leur en faire comprendre le caractère, les engager à faire des croquis rapides des choses entrevues et à dessiner de mémoire.

(1) Voir Recueil des procès-verbaux de la Chambre syndicale de la bijouterie, de la joaillerie et de l'orfèvrerif. Janvier 1891 . 
Dans la plante, ils ne s'allacheront pas uniquement à dessiner la fleur en ses petits aspects, mais la feuille, la tigre, les racines, le fruit et ils iront aux légumes, aux plantes potagères, à des modèles admirables qu'ils n'ont jamais vus et que les maîtres soupconnent ì peine. On pourra commencer par mouler en plâtre sur nature quelques feuilles et quelques grands fruits afin de démontrer sur le plâtre les qualités de forme. do morlelé que possèdent ces beaux échantillons.

L'histoire de l'orfèverie sera enseignée en des cours oraux, rapidement, sans insister plus quil ne faut sur les documents archéologiques; il ne faut pas que les jeunes s'attachent de passion aux choses anciennes et se prennent ì les vouloir refaire.

Ce vice i déja trop profondément atteint nos ateliers et nous avons des plagiaires ì tous les degrés du métier. Les plus intelligents et les plus habiles pourront cependant visiter les musées, y prendre des croquis, compléter les leçons reçues à l'école par une recherche des types de style. Il vaut mieux faire celte étude à 15 ans que de la commencer ì 30 .

L'action qu'un maitre comme Lehrun imprimait aux ateliers des Gobelins et communiquait à l'art décoratif de son temps, un artiste plus modeste, mais aussi convinincu la donnerait à une industrie comme la nôtre s'il prenait les apprentis ì l'école et pénétrait avec eux dans tous nos ateliers. Le rôle semble modeste, il serait grand par le résultat, il peut tenter un homme de talent, si cet homme de talent existe, s’il en est ún qui puisse dire, en toute sincérité : «e suis orfèrre et dessinateur, je sais, et ce que j’ai appris, je veux l'enseigner aux jeunes pour qu'après moi le progrès continue." Mais cet homme-là, je ne le connais pas; il faut le chercher et au besoin le faire.

Une idée généreuse qui aurait pu dans tous les métiers amener un tel progrès, c'est l'enquête ordonnée en 1881 par le Ninistre de l'instruction publique et des beaux-arts, sur la situation des ouvriers et des industries d'art.

On n’a pas tiré des réponses recueillies au cours de cette enquête le fruit quoon en pouvait attendre; l'entreprise a tourné court, mais les procès-verbaux sont conservés et il appartiendrait à un Ministre de s'en servir, ou, à défaut d'une direction officielle, on peut espérer que l'initiative privée fera ce généreux effort.

Nos voisins y travaillent avec intelligence. Les Anglais, les Allemands, les Italiens, les Belges, tous les peuples qui nous envient et qui savent que la fortune industrielle a pour élément de progrès et du succès le goût, tous s'adonnent au dessin, créent des écoles et des musées, et, par un instinct prodigieux de simplicité et de raison, tous se gardent des imitations multiples et de la complicalion archéologique; ils remontent ì leurs origines, cherchent ì ressaisir les fils perdus de leur art nalional; les Danois restent Danois, les Suisses se rattachent aux traditions de leurs cantons, ce en quoi ils ont ilutant de raison que de goût.

Il y aurait danger à ne pas faire comme cux. Les Anglais ont créé pour cela le musée de Kensington en appliquant immédiatement une idée française, et ce musée n'est pas seulement une collection d'objets d'art, c'est un musée roulant qui va de ville en ville, 
rayonne dans les trois royaumes, correspond avec des écoles, prête des modèles, choisit des maitres, patronne des livres, enseigne, propage, agite les idées, instruit te public, stimule les arlistes, soutient les fabricants et aide aux ourriers.

L'évolution remarquable dı goût en Angleterre vient de là.

Nous avons en France quelque chose de comparable: c’est le Musée des arts décoratifs. Il n'a pas la même autorité, le même prestige, puisqu’il n’a pas le même budgoget, le unême rôle officiel et qu'il ne résume pas tout comme le Kensiugton Museum. Irais, cependant son effet a été considérable depuis vingt-cing ans et de grands progrès ont. été amenés par les expositions et les enseignements de cette société.

En ce qui touche le dessin, c'est lì qu'est née la méthode dont M. Louvrier de Lajolais s'est fait le promoteur, qu’a patronnée M. E. Guillaume et qui est aujourd'hui l'enseigrnement approuvé par la direction des beaux-arts.

En ce qui concerne l'orférreric, on se souvient de l'exposition du métal onverte an palais des Champs-Élysées en 1880 : le travail des métaux précieux y tenait la premic̀re place.

L'Union centrale annonce comme prochaine une exposition de la plante qui sera le corollaire des expositions divisionnaires qui l'ont précédée.

Elle doit, dans l'esprit de son promoteur, résumer l'histoire de tous les styles et de toutes les industries décoratives.

C'est, nous l'avons dit plusicurs fois an cours de ce chapitre, à la fleur, à la plante, autant qu'à la géométric et à la figure humaine, qu’il faut emprunter, nou pour copier ce qui est, mais pour éveiller la faculté créatrice qui gìt en l'artiste comme dans le poète et qui ne se développe qu'en face de la nature.

Le défaut de l'orfévre est de vivre enfermé dans l'atelier, d’ignorer les cliamps, de ne pas sortir de la ville, de ne savoir ni la forme des feuilles, ni le port des tiges, ni rien de ce qui constitue la grâce et la vérité des clıoses végétales.

Le peintre va chercher ses études à la campagne, le sculpteur fait poser son modèle, le romancier de la nouvelle école va prendre des documents sur le vif; il écrit ce quil a vu, ce qu'il a vécu; il écrit d'après nature, il n’y a que l’industric qui vive encore sur les vicux clichés, qui réédite les vicilles formes, les dessins démodés et qui, rat de bibliotlı̀que et de muscé, fasse un rapiécage plein de fautes chronologiques en recousant les lambeaux des styles épuisés.

Une clientèle ennuyéc, maussade et mal instruite pousse à cette maluraise besogne les orfèvres, comme les bronziers, les ébénistes et les tisseurs d'étoffes. Échapponsnous et donnons à tous ceux qui travaillent un peu de liberté; allons aux champs, nous en reviendrons reposés, rajeunis avec des idées qu'on fêtera et qui seront jugées bounes quand nous les auront múries.

Nous sentons une brise de jeunesse et de liberté qui déjà a caressé notre littérature et nos arts, clle éveille nos atclicrs et nous grise d'espérance. 


\section{\$2. LE MÉTIER.}

Après l'Exposition, M. le colonel Laussedat a transporté aux arts et métiers la curieuse boutique d'orfèvre quil avait arrangée avec tant de goût dans la section de l'histoire du travail. Est-ce bien, comme on l'a dit, la boutique des Germain? Peu importe. C'est la reconstitution de la modeste installation d'un orfèvre au siècle dernier et il en̂t été plus facile encore de copier exactement d'après Jost Amman ou d'après Stephanus l'atelier d'un orfèvre du xvi siècle.

Les choses depuis n'ont pas varié beaucoup et il suffit, pour s'en convaincre, d'aller chez quelque fabricant resté fidèle au vieux quartier, place Dauphine ou quai des Orfèvres, on y trouvera son atelier à peu près semblable à celui d'autrefois; les outits n'ont pas sensiblement changé.

Ce n'est pas que notre industrie n'ait pas, elle aussi, profité des progrès dont ont bénéficié tous les arts. Si notre siècle cherche encore l'expression originale de sa pensée et de son goût, il a du moins fait dans le domaine de lá science et des découvertes mécaniques un pas immense.

L'orfère a des moyens de fabrication dont on ne soupconnait pas l'existence il $y$ a cent ans; l'outillage s'est modifié, la machine a pris la place de l'homme, les forces de la vapeur et de l'électricité se sont substituées aux siennes et la précision automatique a, dans bien des cas, remplacé l'intelligence de la main.

Cependant il a suffi d'emprunter à nos confrères leurs marteaux, leurs tas, leurs bigornes, leurs limes, leurs pinces, leurs ressingues, leurs étaux, leurs billes et leur banc à tirer, pour reconstituer le mobilier de l'ancien atelier; ni la forme ni l'usage de ces outils n'a changé, mais on a quelque peu désappris à s'en servir.

Ce qui a changé, c'est la façon de travailler, c'est la manière d'apprendre, c'est la division du travail.

La division du travail est-elle un bien ou un mal? Le problème se pose de lui-même et je ne sais s'il est bon de le discuter, car il ne faut pas espérer le résoudre.

C'est par la division du travail qu'on est parvenu à produire dans des conditions de bon marché et d'abondance qu'on n'avait jamais connues; mais c'est à cause de la division du travail que se sont perdues les qualités de main-d'œuvre et les perfections d'autrefois.

Dans l'enquête ouverte sur « la situation des ouvriers et des industries d'art", lorsque le 21 janvier 1882 , la commission que présidait ce jour-là M. le sénateur Tolain eût à étudier les conditions relatives à l'orfèvrerie, c'est M. P. Christofle qui fut appelé devant elle et sa déposition est une des plus intéressantes parmi les meilleures.

Mais par une pente naturelle et fatale le dialogue entre lui et le président en arriva bien vite à cette proposition dangereuse : 
M. Christofle. Si la division dn travail était supprimée, je crois qu'on aurait grand'peine à faire face aux besoins actuels; l'industrie qui arlopterait cette mesure serait complètement livrée à l'étranger.

M. ue Put́sident. Ni l'artministration, ni persomne dans la commission ne songe à porter atteinte à la division du travail; e’est un phénomène industriel contre lequel personne ne peut réagir. On s'est demandé si le niveau du savoir professiounel ne baissait pas dans beaucoup d'industries d'art et si, par l'enseignement méthodique, on ne pourrait pas le relever.

Or l'atelier d'orfèvrerie le mieux outillé, celui où la machine fait la plus grande part de travail, ò̀ l'homme n'est plus un ouvrier, mais un surveillant, un manouvre donnant à l'outil qui marche sa pitance, et lui obéissant au lieu de le diriger, l'usine où le travail est divisé à l'excès, c'est précisément l'usine Christofle, dont le chef répondait ce jour-là à la commission d'enquête.

Mais s’il se rendait compte des nécessités commerciales et industrielles de sa maison qui exigent une telle division, il savait bien aussi qu'elles perdent l'ouvrier et nuisent à la qualité de l'œurre; c'est pourquoi il répondait à M. Tolain, en lui expliquant comment il avait essayé de porter remède à ce mal, en formant à une autre école ses jeunes ouvriers, e en modifiant les conditions de l'apprentissage, en rendant cet apprentissage métliodique, raisonné, en faisant passer l'enfant par toutes les plaases de la fabrication d'un objet."

Et c'est à l'expliquer en détail que se dépense toute la séance de ce jour; M. Christofle ne raconte pas à la commission les merveilleux résultats de sa grande usine, les chiffres de sa production, l’importance de ses affaires, il parle de ses apprentis, il explique, comme un maître d'autrefois, qu'il faut cinq ans pour faire un orfèvre et qu'avant de devenir ouvrier, chacun de ses élèves a fait six mois de planage, un an de ciselure, trois ans de montage et six mois de moulage et de travail au tour.

Il m’a paru bon de rappeler cette déclaration pour la donner en exemple à d'inutres patrons; je la crois instructive parce qu'elle vient précisément de celui de nos confrères qui représente par son usine la division la plus absolue du travail, mais qui alfirme qu'on ne fait un ouvrier véritable qu’en lui apprenant, par la méthode et la pralique, toutes les parties d'un art quil ne devra pas exercer comme un manœurre.

Eh hien! il n'en est malheureusement pas ainsi cliez tous les maitres, car nos ouviers ne savent qu'une spécialité; il n'y en a plus guère qui soient capables, non pas de finir une pièce, ce serait demander l'impossible, mais de l'amener au point où le ciseleur l'achève. Ce rapport n'est pas un traité d'orfèvrerie, je n'aí pas à expliquer à mes lecteurs ce qu'ils savent du reste, comment on fabrique un plat ou un couvert d'argent, comment on rétreint une cafetière, comment on estampe et comment on soude.

Mais sils le savent, ils savent aussi que le tour a remplacé dans bien des cas le marteau, mais que cette admirable machine, qui rend la matière obéissante, a le grave inconvénient de ne se prêter qu’à des formes régulières. Cette nécessité a écarté tous les types d'orfèvrerie à pans, à bosses, à saillies, et ce serait un travail difficile de refaire les pièces allemandes du $x_{v 1}^{\mathrm{e}}$ siècle et les vaisselles Louis XIV à pans carrés. 
Les tourneurs ont pris dans l'atelier la place des maitres du marteau. On entend chanter le tour, mais on n'entend plus le son rythmé du marteau frappant à coups comptés sur l'enclume; le métal n’est plus le même, il se distend, il ouvre ses pores sous l'action du brunissoir, tandis que le marteau les resserrait, qu'il e nourrissait "l'argent et que la forme emboutic était nette, que la forme rétreinte était forte et que ce joli métal sonnait clair comme une cloche, qu’il réjonissait le bon orfère et quil arait des qualités de tenue, de perfeclion, d'honnêté égales à celles qu'on exige d'une gravure de prix et d'une médaille fleur de coin.

Tourner, estamper, fondre, roilà les trois termes de l'orfévrerie moderne. Les formes rondes et ovales se font au tour, on estampe au balancier le reste. Ce qu'on ne peut ni tourner ni estamper on le fond. On ajuste, on soude, on répare et tout est dit.

La lime ne sert pas beaucoup à l'orfève, il n'est plus que monteur et c'est à préparer les parties de la pièce pour les raccorder avec peu de façon qu'un bon contremaître s'ipplique.

Le dernier mot de la perfection pour les orfèvres aujourd'hui, ce serait de pouvoir estamper d'un coup de balancier une plaque d'argent et d'aroir une matrice assez parfaile pour que la pièce en sortit achevée. Ils y sont arrivés presque.

Le sculpteur fait un modèle dout les saillies ont une dépouille calculée pour les creux du moule; on le fond en acier, le ciscleur retonche le poincon; on l'enfonce dans un bloc d'acier doux chauffé au rouge que l'on corrige et puis qu'on trempe et c'est sous la pression formidable d'une puissante machine qu'on y estampe ensuite les coquilles d'argent. Quelques-uns se contentent de fondre en acier les bons creux du modèle. Enfin les Américains ont le secret d'assouplir l'acier, de le rendre obéissant comme une cire et d'y creuser l'empreinte du modèle qu'ils ont fait ou qu'ils ont pris, sans passer par la coûleuse opération du poincon gravé et ciselé.

Heller m’a raconté des expériences que j’ai peine à comprendre et auxquelles jo n'aurais pas ajouté foi s'il n'était un homme de métier en qui on peut aroir loute coufiance.

Cette orfèvrerie-là, c'est la vulgarisation du luxe comme l'imprimerie est la vulgarisation du livre.

Il ne faut pas en médire, le balancier est à notre état ce que la presse est à la librairic.

Les cuillers et les fourchettes se font ainsi, et c'est presque une ouvre de civilisation car les missionnaires anglais ont entrepris la grande croisade en portant aux derniers sauvages d'Afrique et d'Océanie des bibles quils leur donnent et des couverts qu'ils leur vendent.

Multiplier le produit, dépenser sur le modèle et l'outil autant qu'il le faut pour les rendre parfaits, puis en tirer un nombre considérable d'épreuves à un prix de facon très minime, vulgariser, répandre, éditer l'orfèvrerie comme les feuilles d'un journal, 
demander à peine un peu plus que le prix de la matière, rendre le luxe de l'argent accessible à tous, car ce ne sera bientôt plus qu'une question d'échange, profiter de l'énorme stock du précieux mélal qui va s'accroissant claque année et que l'adoption du système monométallique de l'or augmentera considérablement un jour, tel semble être le but rêvé par quelques orfèrres ici et surtout par les orfères américains qui ont, à cet effet, monté des usines colossales.

Nous avons déjà parlé de l'usine métallurgique de Christofle et Cie et des ateliers de la rue de Bondy.

C'est la plus importante fabrique d'orfèrerie qu'il $y$ ait en France, mais on y fait peu de pièces d'argent. C'est en métal blanc argenté que sont exécutées les ourres de celte maison. On traite directement le minerai de nickel, on l'allie au cuive, on le lamine. C'est à Saint-Denis que se font les travaux de découpage, d'emboutissage et de préparation. On y estampe aussi les couverts et l'outillage est monté de façon à pouvoir en produire 400 douzaines par jour.

L'Autriche a des ateliers qui dépassent comme production celui de Christofle, mais on trouve aux États-Unis des usines à couverts qui laissent loin derrière elles les fabriques autrichiennes.

Voilà qui donne idée du nombre de bouches qu'il faut encore nourrir.

A Paris, les orfèvres cuilleristes ont créé, rue des Trois-Bornes, un atelier où ils fabriquent à frais communs les couverts d'argent. Cette Société fondée depuis 1843 est dirigée par un des sociétaires qui exploite pour son compte et celui de ses co-associés et répartit les charges et les bénéfices au prorata des travaux apportés par chacun. Tous les modèles de couverts numérotés avec ordre sont en garde dans les magasins, on y recoit l'argent préparé, mais on y fond et l'on y lamine les rognures découpées, en sorte que, sur une mise en train de 100 kilogrammes en moyenne, on livre environ chaque jour 40 kilogrammes de couverts achevés.

Il ne faudrait pas baser sur ces chiffres la production totale, car il y a vingt cuilleristes à Paris et l’atelier de la rue des Trois-Bornes ne compte pas plus de sept sociétaires. Nous verrons plus loin comment se chiffre la production annuelle de l'orfèvrerie et dans quelle proportion y entrent les couverts.

Quand j’ai visité l'usine, j’y ai été conduit par mon très sympathique et très regretté confrère, M. Puyforcat, que la mort enleviait subitement bien peu de temps après. II. Hénin lui a succédé dans la górance de la Société et il expliquerait mieux que moi, s’il $y$ avait lieu de le faire, le fonctionnement de ses machines. Mais je ne crois pas nécessaire d'entrer ici dans ces détails. Il suffit d'indiquer qu'on fait les couverts, à la Société des orfévres, par les trois procédés : au marteau comme autrefois, au balancier et au laninoir. Ce dernier procédé, qui est le seul en usage chez MN. Christofle comme chez les Américains, est relativement peu usité par les cuilleristes de Paris qui trouvent avantage à se servir du balancier à cause de la multiplicité des modèles el des frais de mise en marclie. 
C'est un rare exemple de sagesse, de confiance et de bonne entente que donnent ces orfèvres réunis, ils sont arrivés à réduire leurs frais et à produire avec le plús grand ordre et les meilleurs procédés pour le bien de tous et de chacun.

$\mathrm{Si}$, par le poids de l'argent, Jes couverts représentent une part considérable de l'orfèvrerie, ils ne figurent comme façon que pour une très petite proportion dans l'industrie. C'est à peine de l'orfèvrerie, c'est un métier spécial, où la machine fait tout et où le rôle de l'ouvrier est spécialisé ì quelques opérations très définies et très rudimentaires. C'est à l'invention des modèles et à la gravure des poinçons que s'altache tout l'intérểt de cette branche de l'orfèvrerie. Le besoin de nouveauté ohligọe à renouveler constamment les types, mais les plus anciens modèles et les plus simples restent les meilleurs, chaque pays a ses habitudes et nos couverts français ne sont pas plus acceptés à l'étranger que nous ne pourrions adopter les formes anglaises et américaines. Ces dernières cependant ont fait de grands progrès, grràce au concours d'artistes français comme Heller.

Les graveurs en matrices trouvent dans cette industrie une source importante de travail et ils ont bénéficié des progrès de fabrication de l'acier; ils emploient généralcment les marques françaises, quelque effort que fassent les Angliais et les Autrichiens pour y substituer les leurs.

Mais si les cuilleristes libres ou syndiqués apportent à leur travail une précision mécanique, il n'en est pas de même des autres orfèrres; tous ne mènent pas la fabrication avec une monotonie désespérante comme les tourneurs de coulants de serviettes et de timbales. Il y a plus de variété dans les autres fabriques et la division même du travail exige une étude, une surveillance, une intelligence qui font comparer le maitre à un chef d'orehestre attentif à accorder tous les instruments quil dirige.

Un modèle étant accepté, il faut, pour l'exécuter en argent, que l'orfèvre préparc sa matière, détermine l'épaisseur de la plaque d'argent et, suivant que la pièce sera ronde, plate ou diversement moulurée, qu'il la monte sur le tour, l'emboutisse, la plane, la fonde ou la découpe. De là divers métiers qui ne sont pas ordinairement réunis dans le même atelier.

Il y a des faconniers au dehors pour toutes les opérations. On va chez le fondeur, chez le planeur, chez le tourneur, chez l'emboulisseur, chez l'estampeur, et ce n'est encore là qu'une mise en train après laquelle la pièce présente un commencement do forme. L'orfèvre la reprend à l'atelier, en ajuste les parties, assemble, soude ct s'adresse ensuite au ciseleur, pour faire les raccords ou pour entreprendre le décor complet de l'objet.

Le ciseleur, sans être orfèvre lui-même, joue dans l'orfèvrerie un rôle très important, soit qu'il vienne corriger les imperfections de la fonte, soit quill fasse au repoussé la décoration des surfaces. Aussi a-t-il quelque prétention à se dire artiste parmi les ouvriers et il serait à souhaiter qu'il le fût réellement, car il donne le mouvement, le charme, l'esprit de l'œuvre. 
Il y a trois façons de décorer l'orfèvreric par la ciselure :

Prendre sur pièce, repousser et réparer.

Prendre sur pièce, c'est faire à peu près ce que fait un sculpteur qui tire du bois ou de la pierre une forme qu'il taille en se servant du ciseau (d'où est venu le mot ciseler). Mais si le ciseleur procède ainsi quand il fait pour l'arquebusier ou le ferronnier un travail en plein fer, il use rarement de ce moyen pour l'or et l'argent: ce sont matières précieuses où les déchets doivent être évités; nous n'avons trouvé d'exemple d'un tel travail à l'Exposition dernière que chez M. Boucheron qui possède les petits chefs-d'œuvre de M. Rault.

Plus aisée est la reprise des figures et des ornements fondus; encore faut-il que le ciseleur ait un grand respect du modèle, qu’il en comprenne le caractère, ne cherche pas à se substituer au maître qui a fait le modìle et que surtout l'outil ne perde pas la forme en soignant le détail.

Les ciseleurs susceptibles de faire ces ouvrages de facon courante sont les plus nombreux, ils se partagent entre l'industrie du bronze et l'industrie des orfèvres. Nous en avons nommé quelques-uns qui sont de véritables artistes, mais il en est beaucoup qui ne sont que des ouvriers très ordinaires. C'est à leur défaut de goût et d'éducation qu'il faut attribuer la mauvaise qualité de beaucoup d'objets. Ils sont mal dirigés souvent, insuffisamment payés, ont des pièces mal fondues, des modèles usés.

La Société des bronziers décerne chaque année des prix aux ciseleurs qui se présentent aux concours institués par Crozatier ${ }^{(1)}$ et par Willemsens ${ }^{(2)}$. et les orfévres profitent dans une certaine proportion des progrès qui en résultent; comment se fait-il qu'aucun orfèvre n'ait cu la même initiative généreuse et n'ait créé des prix analogues ${ }^{(3)}$ ?

Le comte de Laborde, empiétant sur les attributions de son collègue du jury, le duc de Luynes, écrivait en 1851 , à propos de l'orfévrerie et de la ciselure :

En orfèverie, la foute et la ciselure sont des procédés bornés; le repoussé est l'art sans limite.

Et quelques pages après, revenant au même sujet, il dit en se défendant :

Ma prédileclion pour le repoussé ne me porte pas à conseitler à l'orfèvie d'abandonner la fonte et l'estanpage et de renoncer aux excellentes facilités offertes par la pile....

Enfin, plus loin, il conclut :

On ne doit conseiller qu'une chose : c'est de lutter contre la banalité des idées et coutre la correcte précision de la machine.

Oui, certes, mais le repoussé est pour le ciseleur et pour l'orfèvre le moyen par excellence, et l'éminent critique avait raison; ses préférences étaient justifiées; elles

(1) Prix annuel de 500 francs institué par Louis Crozatier, le 27 janvicr 1855 .

(2) Prix annuel de 300 francs créé le $1^{\text {ex }}$ juin 1863 par II. Willemsens.
(3) Lat Société d'encouragement des bijoutiers-orfèvres offre cependant des prix aux jeunes ouvriers el aux apprentis, dans des concours de travail, mais les programmes sont plus étroits. 
étaient dictées par l'expérieuce quilil avait acquise à la conservation du Lourre et par l'étude des merveilles d'orfèvrerie de tous les temps et de tous les pays. Il parlait en savant, comme me parlait un artiste, le grand peintre qui vient de mourir, Meissonier, quaud tout récemment il m'expliquait conment il voulait que je copiasse en or le modèle qu'il avait lui-même modelé en cire.

Et c'est un de mes bons souvenirs que cet entretien avec le maître illustre, pour qui tous les arts n'en faisaient qu'un et qui, par un sens prodiggieux, devinait ceux-lì même qu’il n’avait jamais essayés; il me disait : «Mais je ferais du repoussé, moi; mais ça n'est pas dilficile du tout et il suffit de vouloir. Tenez, voulez-rous que je vous montre comment je m'y prendrais? Il me faudrait un métal mou. Voilà mon affaire. n Et, déreloppant un tube à couleur vide qu'll avait pris sur la table, il l'unissait avec l'ongle et continuait : esupposez que ceci soit de l'argent, ou de l'or plutôt, du bel or fin, bien malléable, avec une couleur riche et chaude, comme les anciens avaient l'esprit de s'en servir, tandis que vous employez maintenant un vilain or sec, pauvre et résistant. Je dessinerais mon sujet comme cela avec une pointe fine, vous voyez, puis par-dessous j'appuyerais comme je le fais avec cet ébauchoir de buis. Regardez comme c'est facile. Je u'ai rien de ce quili faut, ni ciment, ni mastic, ni ciselet, ni marteau, et je sors des bosses; voilà un corps, des bras, des jambes, une tête. Voyez le bonhomme qui se modèle dans la feuille de plomb! Il est inutile de ciseler : l'artiste peut faire, en r'epoussant une feuille de métal, un bas-relief plus spirituel et plus beau qu'une cire. Les Grees ont laissé des types admirables de cet art que vous devriez étudier et qui sont bien plus beaux en leurs modelés gras et fins que vos modernes ciselures. Quand vous voudrez, j"irai chez vous. Je prendrai vos outils et je vous montrerai que je puis aussi faire du repoussé. Ce n'est pas difficile du tout; c'est du dessin et du moḍclage en métal comme on en fait avec un crayon, de la terre ou toute autre chose."

J'essaye de rendre exactement les paroles de Meissonier; elles me revienuent fidèlement et j’ai uue éruotion à me le rappeler, à le revoir, conme je le voyais ce jour-lì, comme je l'ai revu sourent au cours du travail que jai exécuté sous sa direction, car je me faisais soumis, obéissant, silencicux, ne voulant ni l'interroupre ni même l'aider dans ses explications, comme si j'avais eu le pressentiment que je ne le verrais pas longtemps et que peu après il se tairait pour toujours.

Oui, le repoussé est bien l'expression la plus complète de l'orfèvrerie. C'est lì que se marient le métier et l'art. Le métal se prête avec obéissance à tout ce qu'on veut lui faire dire; il se modèle, sort, rentre; on en met, on en ôte; on exagère, on efface. Il faut avoir senti la molle résistance de l'or et de l'argent pour juger de la jouissance de l'artiste qui a tâté du marteau.

C'est Morel-Ladeuil et Désiré Attarge qui m’out initié à leur joie et il appartiendrait aux Fannière de dire ici toute la puissance d'un art où ils restent les premier's aujourd'lıui.

Le grand mojen de décoration en orfèvrerie, c'est douc la ciseluie en repoussé. 
Voyez les travaux des Grees, des Égyptiens, des Romains, des Barbares, des artistos du moyen âge, des maìtres de la renaissance ou des orfères français du siècle derniè' ils repoussaient l'or et l'aront. Tout ce qu'il y a de meilleur est fait an repoussé. C'est l’imprévu, c'est l'œurre directe du bon ouvrier. C'est original comme une esquisse au crayon ou un trait de plume. Ce sont bien les autographes d'un arliste, tandis que les fontes et les estampages ressemblent à des imprimés et donnent la banale sensation des choses refaites.

Il ne faut pas, dans ce chapitre tout consacré à l’industrie et aux choses techniques, que je revienne sur les théories d'ar't et de goût que j’ai essayé d'indiquer sommairement plus haut.

Cependant je puis, sans me répéter, engager les orfèvres à regarder sourent les pièces du trésor de Bernay, qui sont au Cabinet des antiques, et, quoique de basse époque, elles serviront de modèles et d'enseignement à beaucoup d'ourriers et de maitres qui ne les ont pas assez vues.

La ciselure ne doit donc pas être considérée comme un métier annexe de l'orfèverie, mais comme une part essentielle de cet art; elle fait corps avec lui. L'orî̀re qui repousse au marteau la panse d'un vase fait œuvre de ciseleur; il modèle les grandes formes avant qu'un autre en finisse les plans, les nervures et les délicatesses avec uи marteau moins lourd et des ciselets plus fins.

Le défaut du ciseleur, e'est de se perdre en des minuties, de ne pas voir d'assez loin les éléments décoratifs d'un ensemble ou de faire de son art un prétexte à une virtuosité d'outils. Il y a, dans la plupart des œurres modernes de ciselure, un défaut d'harmonic, un manque d'ensemble, un désaccord entre la forme et le détail. Quand Vechte faisait son grand vase de La lutte des dieux et des Titans, il couvrait d'un bas-relief inspiré, plein de fougue et de talent, une pièce dont la construction était mauvaise. Morel-Ladeuil a fait, pour la satisfaction des Anglais, un bouclier qui est l'ceuvre de ciselure la plus populaire de notre temps, mais qui aurait été infiniment plus belle s’il n'y arait pas sacrifié à la précision mignarde des détails. Les Fannière ont dépensé des années de labeur patient sur un autre bouclier que leur avait commandé le duc de Luynes et qui est plus mâle d'allure; mais combien tout cela reste au-dessons de l’admirable armure de Henri II, parce que là tout s'accorde, la forme générale et l'ornementation, et que tout est dans un même caractère!

Aussi Duponchel, qui comprenait son art et qui avait le sens des ensembles décoratifs, s'était-il rendu compte de la nécessité qu'il y a pour l'orfèvre de savoir ciseler. Il avait voulu faire apprendre à son fils ce qu’il ignorait lui-même et l'avait mis dans les mains d'Honoré. C'est ainsi que Ludovic Duponchel et Brateau sont camarades d'apprentissage et sont restés amis; mais le fils de l'orfèvre-architecte n’a pas succédé à son père: il continue à faire à l'écart de la ciselure d'amateur.

Il a vu comme moi le groupe de ces artistes de verve et d'imagination qui ciselaient avec un entrain qu'on ne connaît plus : les Muleret, les Vechte, les Dallergue, les 
Cauchoir, les Jerdelet, les Lavigne, les Désiré, les Morel, les Huot, les Vernant, les Hubert et tous les descendants des Thomire, des Kierstein et des Fauconnicr.

Les uns sont morts, les autres se reposent, comme Honoré, ou sont passés à l'étranger, comme Jerdelet; Brateau s'est adonné à l'orfèvrerie d'étain; Mariotton préfère modeler la glaise et tailler le marbre; mais il y a toute une école jeune dont nous avons eu ì citer quelques noms en examinant les curres exposées. Les Fannière en restent les chefs respectés : ils n'y ont pas de rivaur.

Ce n'est pas par des ourres magistrales de ciselure que l'orfèrrerie s'impose, ct c'est pourquoi nous réclamons comme indispensable une école où soil enscigné cet art comme il convient.

Les Suisses l'ont déjà créée à Genève, cette école, et pour la diriger ils nous ont pris Salmson et Jerdelel, deux Français.

Il faut qu'on fasse à l'École des beaux-arts un cours de ciselure el que l'État enconrage, par des achats et par des commandes, une forme de l'art qui n'est pas moins recommandable que la gravure en camées.

Il y a cependant, pour suppléer à la ciselıre, un procédé d'une perfection rare et que l'orfèvre n'a pas encore employé comme le bronzier : c'est le tour à réduire.

On sait comment procèdent aujourd'hui les graveurs en médailles : ils font en grand leur modèle, cxécutent le bas-relief à des dimensions proportionnelles déterminées, el la machine fait ensuite avec une fidélité absolue la réduction du plàtre, en creusant au moyen d'une fraise le poinçon d'acier qui servira ì enfoncer la matrice. Ce moyen a été récemment employé avec un grand succès pour obtenir directement un l)as-relief d'argent.

Prenez un des panneaux délicieur de Clodion ou même quelque antique bas-relief de l'école grecque, et suivez-en tous les détails avec le stylet d'ivoire du pantographe; si vous mettez à l'autre extrémité une plaque d'argent, la molette reproduira au 1/4, au $1 / 5$, au $1 / 10$, à la proportion que vous voudrez, une sculplure d'mne adorable finesse qui aura les perfections d'une réduction photographique, mais avec tous les reliefs, tous les modelés. Il n'y a pas d'outil plus fidèle, plus naif.

Roty, Chaplain, Alphée Dubois et tous les graveurs en médailles ont usé de ces moyens, mais M. Tasset et M. Janvicr sont les réducteurs les plus liabiles et ils ont fait en or et en argent de petites merveilles qui sont en réalité de la ciselure ou de la gravure prise sur pièce.

Levillain et Heller ont, mieux encore qu'aucun autre, mis à profit ce procédé, et, comme il est applicable aux poinçons d'acier pour l'orfèvreric comme pour la médaille, il ouvre la voie à des expériences sans nombre. A défaut d'habiles ciseleurs, on peut recourir directement aux sculpteurs et se passer de l'intermédiaire qui traduisait mal et trahissait sourent le maître.

Ce que ne donnera pas cependant le tour à réduire, c'est la touche de l'outil; nos ciseleurs sont devenus fort adroits dans cette façon de décorer l'argent, et Cellini lui- 
même, qui, dans son 'Traité d'orfévrerie, donne le moyen de varier par la ciselure l'aspect du travail, s'étonnerait des progrès qu'on a faits en cette manière; il s'étonnerait plus encore de voir les œurres japonaises, qui sont supérienres à toutes.

Il importe, en effet, que l'orfèvre sache décorer la peau de l'argent d'effets variés. Sans parler encore des couleurs de l'émail, de la niellure, des damasquines et des dorures, il convient d'insister sur l'aspect que peut donner à l'argent blanc l'outil qui s'y imprime sons le choc du marteau.

Pour en citer un exemple qu'avait répandu partout la mode, après l'Exposition de ${ }_{18} 8$, rappelons ces martelés qui couvraient les pièces du jeu régrulier de la plane du marteau. On a fait ensuite une décoration qui ressemblait aux craquelures d'une peau de serpent. Ce sont lì des types simples et larges d'un travail d'outil qui peut être varió à l'infini : le bois, le cuir, le tissu de l'étoffe, les pores de la peau, les mailles d'un tulle, les rugosités de la pierre, les stries des coquillagges, les plumes de l'oiseau, les craquelures de l'écorce, les nervures des feuilles, les maculatures des pétales de fleurs, les ondulations de l'eau, les écailles de poissons, les grains de sable, les trainées de poussière, tout l'infini des duvets, des semis, des jeux d'ombre et de lumières, mêlés aur polis, aux usés, aux grenus, aux brunis, donnent à peine une idée des moyens qu'on a de varier l'aspect du métal.

A ces délicatesses de doigté, à cette virtuosité du marteau, quelques ciseleurs sont devenus si merveilleusement habiles que c'est une musique amusante à écouter autant qu'un plaisir de voir ce petit marteau qui bat d'un coup sec et d'un bruit clair et vibrant la tige d'acier, et qui chante comme un cri strident d'insecte.

C'est un moyen de décor, mais, je viens de le dire, il y en a d'autres : la gravure, d'abord, trop oubliée, trop dédaignnée, presque morte et qui pourtant accentuait d'un dessin si ferme et si expressif les belles orfèvreries aux pans droits et aux grands champs de l'époque Louis XIV.

Qu'elle soit faite à l'échoppe ou au marteau, c'est-à-dire coupée ou frappée, la gravure est un mode excellent d'illustrer l'argent, car c'est comme une arabesque, un dessin, une écriture sur les surfaces qui, sans cela, resteraient froides. On s'en servait pour décorer les boîtes grandes et petites et surtout pour orner les fonds de plateau. On le fait encore, mais moins bien, car les bonnes mains sont rares et presque introuvables.

Les gravures actuelles sont tremblées, écorchées, sautillantes; elles sont maladroites et timides, ou brutales et dures. Les graveurs en vaisselle ne font que la lettre et les armoiries, mais ils ne dessinent plus.

S'ils sont incapables de faire un bon tracé, ils sont plus malhabiles encore à exécuter un champlevé, et c'est chose impardonnable en ce pays de France où les émaux champlevés florissaient au temps jadis.

Qui fera maintenant ces moulures ornées d'oves, de rais de cœur, de feuilles d'acanthe, de perles, d'écus comptés et de toute la classique variété des ornementations 
qui, en orfèvrerie comme en architecture, sont la parure obligée des belles formes et des profils corrects?

Les pièces d'art et les vaisselles anciennes sont décorées de ces grarures qui, naïres ou savantes, ont toutes une honnêteté d'outil, un charme de facture qui rejouit les yeux.

On a supplée à cette pénurie des gravures par un moyen d'exécution plus rapide et plıs économique : la gravure à l'ean-forte. On procède par épargne. On peint arec un vernis gras toutes les parties d'argent qu'on veut épargner et on ronge ì l'acide les fonds qu'on veut descendre. Cette gravure à l'eau-forte domne des effets agréables, elle est d'un emploi utile dans bien des cas, mais elle ne peut pas toujour's remplacer la gravure au burin; les bords sont bavocheux, les fonds se rongent uniformément, il n'y a ni modelé, ni finesses. On a même abusé de ce rapide moven pour faire les champlevés d'émail dans les travaux d'orfèvrerie religicuse, ct les résultats sont mauvais.

Encore aurait-on pu espérer qu'usant des mêmes moyens que le graveur à l'eauforte, qui enduit de vernis une planche de cuivre et $y$ dessine à la pointe, nos graveurs trouveraient à faire des travaux d'un accent plus personnel. Il n'en est rien, c'est avec le pinceau que nos graveurs industriels font directement l'épargne, et si quelques-uns ont un véritable talent d'exécution, ils n'ont pas eu souvent à l'exercer d'après de bons dessins. C'est dans l'exposition de M. Dufresne de Saint-Léon que nous avons trouvé le meilleur emploi de la gravure à l'ean-forte.

Christofle avait essayé de quelques décors larges et d'un grrand caractère autrefois; pourquoi n'a-t-il pas conservé cette expression qui tenait de la manière de Reiber? Mais nous signalons lingénieux procédé automatique de gravure qui marque un progrès industriel, sinon un progrès d'art, et dont on use dans l'usine des Christofle.

Le dessin type est peint sur un cylindre de cuivre avec un vernis isolant. Un doigt métallique suit toute la surface du cylindre et établit ou interrompt un courant électrique selon quil touche la surface de métal ou la couche isolante. Ce courant se con:munique à un burin tranchant qui descend ou se relève et qui creuse ou interrompt le dessin sur un plateau de cuivre.

Ainsi se grave seul un dessin comme s’imprime à distance une dépêche télégraphique. Et ce n'est pas assez, on a fait encore un nouveau progrès. Les miracles de reports photographiques, les procédés de gillotage, les merveilles de photoglyptie dont on use pour l'imprimerie et qui ont métamorphosé le livre et l'image, voici qu’on les applique au métal.

C'est précisément à l'heure où les graveurs font défaut que la science y va suppléer et qu'on pourra faire au crayon ou à la plume le dessin dont on veut graver une pièce d'argent ou de cuivre (je n'ose par encore dire une pièce d'or); au moyen de la photographie, avec un cliché sur gélatine dont la fine pellicule se fixe à la surface du métal, on parvient à reporter le dessin et à le graver dans ses tailles, ses hachures, ses pointillés et ses grenus. 
Remplacez le dessin par li nature, photographiez une feuille arec ses nervures, ses pores, ses détails admirables et vous graverez en quelques instants sur l'argent cette feuille qu'un artiste n'anrait su copier qu’imparfaitenınt.

Déjà nous avons vu des fleurs, des feuilles, des tiges séchées comme dans un herbier s'imprimer en creux dans le métal sous une pression directe et y laisser la trace délicate de leur passage.

Des applications décoratives ont été faites au lendemain de l'Exposition et ont, par co procédé, donné des résultats surprenants. On peut prévoir un rôle très nouveau et très direct de la plante dans le décor de l'orfèvrerie; l'instinct de l'arrangement suffira presque à l'orfèvre, car la nature fera tous les frais de ce décor; on composera un dessin comme on fait un bouquet, en choisissant des fleurs et des feuilles et en les groupant sur les surfaces ì orner.

Si ce n'est pas de l'art, c'est du goût, mais il faut oser faire plus et mieux, en interprétant la nature sans la copier, en accentuant les traits et en les colorant.

Les graveurs italiens niellaient leurs gravures, c’est-ì-dire que dans les creux taillés au burin ils coulaient un alliage de plomb, de soufre, de cuivre et d'argent très fusible qui prenait une belle teinte sombre contrastant avec les blanes de l'argent.

Ce procédé, connu des anciens, pratiqué par les Byzantins et que le moine Théophile explique minutieusement en son livre, a été porté à sa plus haute perfection par Finiguerra et Pollä̈olo. Il n'est plus guère usité que par les Russes, et c'est grand dommage. C'est un des plus jolis décors de l'argent et il suffirait de bons dessins pour le remettre en faveur. On remplaçait quelquefois la nielle métallique par un émail d'un bleu noirâtre, et nous avons signalé dans l'exposition de M. Armand-Calliat une série d'objets absolument remarquables faits de cette façon.

Mais le décor de l'orfèvreric par excellence, le plus difficile à bien faire et, par conséquent, le plus négligé, c’est l'émail.

C'est à regret que nous le constatons et cela vient assurément de l'ignorance, où sont encore la plupart des orfèvres, de l'art et du métier de l'émail. Ils n'attendent pas de moi que je fasse ici un cour's d'émaillerie; il suffira que jindique l'excellent résumé que vient de publier chez. Hachette le jeune et savant conservateur adjoint du Louvre, M. E. Molinier ${ }^{(1)}$. Ils trouveront dans ce petit livre l'histoire très succincte de l'orfèvrerie émaillée et comprendront pourquoi je m’étonne qu'un art qui était en si grand honneur soit aujourd'lui tant oublié.

Il n'y a pas fort longtemps encore, l'ignorance des orfèvres était telle que bien peu auraient su expliquer la diflérence quil y a entre l'émail champlevé et l'émail cloisonné, dire ce qu'est un émail de basse-taille et distinguer entre les émaux peints des maitres.

C'est en 1867 , qu'à la suite du rapport de mon honorable prédécesseur en ce jury,

(1) E. Molinier. L'Émaillerie, 1 vol. in-16. Paris, Hachelle, 1891 . 
M. Paul Christofle, il y eut une annexe, signée de M. Philippe Delaroche, qui était spécialement consacrée aux émaux et à la damasquine, et le rapporteur croyait utile précisément d'expliquer ce qu'étaient: $1^{\circ}$ les émaux cloisonnés; $2^{\circ}$ les émaux de basse-taille; $3^{\circ}$ les émaux champlevés; $4^{\circ}$ les émaux de Limoges; $5^{\circ}$ les émaux de Toutin et de Petitot.

Nous n'arons pas pu, dans le présent rapport, donner à l'émail toute l'importance que nous lui reconnaissons et qu’on lui donnait déjà en 3867 , parce que, par un caprice de classification contre lequel nous avons protesté déjà, l'émaillerie a été rangée cette fois-ci dans la classe 20 avec la céramique, comme la lapidairerie a été mise dans la classe 18 avec les ouvrages du tapissier et du décorateur. C'est done M. Lobnitz qui rendra compte de l'émaillerie.

Mais, si je n'empiète pas sur son domaine, il m'est permis d'affirmer que l'émail est à l'orfèvre et qu'avec le mode de champlevé ou de cloisonnage il a une double facon d'opérer qui, dans les grands travaux d'église autant et plus que dans l'orfèvrerie d'art, appelle les applications les plus variées, les plus belles, les plus utiles.

C'est, je le répète, dût le mot fâcher quelques-uns et cenx-là seulement à qui il s'applique, c'est par ignorance que les orfèvres ont négligé l'émail. Ils ont laissé sans travail les mains d'artistes que d'autres avaient formées; its n’ont su employer ni Tard, ni Gagneré, ni Routhier, ni Houillon, ni Dotin, ni Tourette, ni surtout Thesmar, Ch. Lepec, Diflotte et Pye, qui étaient de véritables arlistes. Il y avait avec eux à faire dans l'orfèvrerie religieuse une rénovation complète. Comment les architectes, les archéologues, les prêtres et les orfèvres, qui voient et qui admirent les trésors d'émaillerie ancienne, nont-ils pas eu l'idée de recommencer cet art quand les moyens de le faire s'offraient à eux? On collectionne les cloisonnés et les champlevés anciens; on recherche les cloisonnés de la Chine et du Japon, mais on sait à peine qu’il s'en fait en France. Ce sont les étrangers qui ont acheté presque tout ce qui s'est produit ici par ce mode de décoration.

La routine d'atelier n'a pas été changée, il aurait fallu que quelqu'un osât, et le seul qui ait fait pour l'orfèrrerie religieuse une sérieuse tentative, c'est l'artiste lyonnais Armand-Calliat.

Christofle avait essayé dans une autre voie, il a produit des pièces de grande dimension qui, pour la plupart, sont sorties de France. On les a copiées à Londres fort mal, mais les Américains les ont imitées avec plus d'esprit, modifiant avec un goût très original et très personnel ce que nous avions fait et nous apportant un décor plein de saveur, d'harmonie et d'étrangeté. Les Russes surtout ont profité de la lecon, et si la théorie de l'émail pouvait être soutenue et démontrée comme certains problèmes, je ne dis pas par l'absurde, mais par l'exagération, c'est à l'orfèvrerie r'usse qu'il faudrait recourir.

Les procédés simples n'ont pas suffi. Beaucoup d'orfèvres qui n’ont jamais essayé de cloisonner un dessin et de le remplir d'émail ont voulu faire des émaux à jour, et 
nous avons compté à l'Fiposilion plus de cent pièces, généralement très nédiocres de forme, de dessin et d'exécution, qui ressemblaient plus ou moins ì des émaux à jour. Les meilleures n’y figuraient pas, car Thesmar n'avait pas exposé, et c'est au Muséo des arts décoratifs qu'on peut voir les échantillons parfaits de son art.

J'émail translucide sur basse-taille est un procédé d'une difficulté plus grande encore et qui marque à présent comme au $\mathrm{xv}^{\mathrm{e}}$ siècle la supériorité de l'orfèvrerie. Il fant, en effet, que l'orfèvre soit un artiste véritable, qu’il ait un sentiment du dessin aussi irréprochable qu'une habileté d'outil consommée. C'est à des œuvres de prix seulement que ces émaux peuvent être attachés; ce serait une erreur d'y vouloir amener la mode, car la mode n'a rien à faire avec ces émaux d'art. Il y a assez de gens de haut goût, d'un jugement au-dessus du vulgaire pour le très petit nombre d'œurres qu'on produira.

Mais c'est la couleur joyeuse de l'émail qu'il faut savoir employer. L'exemple que nous avaient apporté les Japonais en 1878 n'a pas été compris, encore moins suivi. On sait que les rouges ne viennent pas sur l’argent, mais que les émaux bleus, violets et verts y gagnent en puissance. C'est en vertu de ces lois chimiques, quils avaient vérifiées par la pratique, que les Japonais avaient fait de gracieux décors d'une harmonie de tons tout à fait inconnue avant eux. La lecon n'a porté qu'en Amérique, probablement parce que presque tous les modèles dont je parle y sont allés après 1878 . Ici on ne veut pas comprendre, les orfèvres se refusent à accepter cette facon qui les déroute; je n'ai trouvé de mon avis que des artistes et des gens du monde tout à fait indépendants. Je n’ignore pas par conséquent que je vais contre une opinion professionnelle et que je ne serai pas approuvé. Mais je n'en persiste pas moins à prédire que le gon̂t s'attachera tôt ou tard à des décorations analogues, où les bleus, les verts et les violets d'émail seront employés. Les évolutions sont très lentes en France dans les choses de métier.

Il y aurait indiscrétion par cela même à parler davantage de l'émail, je n’ai indiqué que les procédés que l'on a, dans les catalogues, rangés sous la rubrique : émail des orféres, et j’ai gardé le silence sur l'émail des peintres; je pense cependant que les peintres, qui pratiquent l'émail, auraient tout avantage ì s'associer aux orfèvres.

Damasquiner est un autre moyen de décorer le métal. Il a surtout été pratiqué par les arquebusiers et les armuriers, et c'est sur le fer et l'acier que les or's font un meilleur effet. On trouve cependant en orfèvrerie de bonnes applications de damasquine, les vieux chefs-d'œuvres de nos musées en offent de beaux exemples et récemment on a vu les Vechte, les Morel-Ladeuil s'en servir pour faire de franches oppositions avec les blancheurs de l'argent. Zuloaga en Espagne, Tiffany aux États-Unis, Dufresne de Saint-Léon, les Fannières, Boucheron, Christofle et Brateau en France, ont démontré que cet art n'était pas délaissé encore.

Ai-je analysé tous les modes de travail dont peut user l'orfèvre et les richesses dont il doit disposer? Non, et ce n'est pas alors dans l'exposition de la classe a 4 que je 
prendrais mes exemples, ce serait au Louvre, dans les vitrines de la galerie d'Apollon. Là, je prouverais que l'orfèvrerie est l'art le plus riche, le plus indépendant, le plus varié; quil a toutes les ressources de la forme et de la couleur, quil use de la sculpture et de la ciselure, de la peinture et des émaux, qu'il a l'or, l'argent, le bronze, que la fonte amollit; les gemmes lui appartiennent, les cristaux de roche, les agates, les sardoines, les camées, les pierres précieuses, les nacres diaprées, lui offrent le jeu de leur transparence.

On s'étonne que cet artiste soit si riche et qu'il reste si timide, qu'ayant toutes ces lumières chaudes il ne fasse que des æurres froides et ternes, que, descendant de maitres si puissants et si variés, il s"immobilise en de banales répétitions et se fasse l'esclave de quelques préjugés.

Mais il lui manque quelqu'un qui lui dise d'oser, qui le soutienne, qui commande et encourage. Nous l'avons dit déjà et nous le répétons encore, il faut une impulsion d'en haut.

Les seuls Mécènes qui parfois rendent à l'orfèrre un peu de confiance et d'ardeur sont des étrangers. Il n'y a personne en France qui, pour cet art, sache faire ce rqu'on a fait en d'autres temps, et cela est si vrai que je crains de m'étendre en ce chapitre sur les arts annexes de l'orfèvrerie. Mes confrères attendent de moi que je parle plutôt des ressources commerciales, des applications usuelles, des moyens économiques, des outillages simplifiés, de la vulgarisation de l'argenterie courante et de la vaisselle de table. J'y viens done, et c'est de l'orfèvrerie d'imitation que nous allons nous occuper; elle a pris toute la place qu'a perdue l'orfèvreric d'art. La science a créé une industrie nouvelle.

Autrefois c'était le plaqué qui remplaçait l'argent dans la fabrication économique et ce mode d'exécution avait constitué un progrès véritable et un commerce florissant jusqu'à l'invention de la dorure et de l'argenture galvaniques. C'est à l'Exposition nationale de 1839 qu'apparut pour la première fois la méthode nouvelle; nous retrouvons au livret des exposants sous le $n^{\circ} 752$ : « Elkingron, 34, rue du Temple, à Paris. Dorure sur bijoux et sur bronze, sans mercure."

Aujourd'hui nous aurions peine à trouver un doreur au mercure. C'est par l'électricité que se fait tout le travail de dorure et d'argenture et le plaqué qui avait des lois spéciales, qui occupait à Paris plus d'ouvriers que l'orfèvrerie d'argent, ne subsiste que dans la fabrication des lanternes de voitures et de quelques menus articles de détail. Il n'y a plus qu'en Angleterre qu'on fasse encore de l'orfèvrerie de plaqué, car nos voisins sont plus que nous fidèles à leurs vieux usages. Cependant Elkington avait commencé l'exploitation de ses brevets de dorure et d'argenture un an avant que Ch. Christofle ne lui en achetât le monopole pour la France comme il avait acheté les brevets de Ruolz, en sorte que ces deux puissantes maisons se partagèrent le monde et concoururent en même temps à répandre l'orfèvrerie nouvelle.

La découverte de Jacobi date à peu près du même temps (1839), la galvanoplastie 
est le complément de cette science industrielle qui a fait une révolution si profonde. On trouvera dans le rapport de M. P'otier (classe 62, électricité) tout ee qui est relatif à la galvanoplastic, car la classification nous a pris lí encore un des éléments de l'orférrerie. Il est juste que nous ne disions rien des choses purement scientifiques, mais nous croyons avoir le droit d'en indiquer sommairement les résultats industriels, en ce qui touche notre art.

La gralvanoplastie, en effet, s'est substituée dans bien des cas à la fonte; elle a ce précieux avantage d'épouser les moindres détails du moule. L’emploi de la gulta-percha a depuis longtemps rendu te moulage absolument parfait. En même temps que Gonon et Bingen retrouvaient les procédés de fonte à cire perdue, M. Bouillıet, secondé par IIII amateur de Rouen, M. Pellecat, inventait un moyen facile de mouler, arec la grutta fondue, sur des modèles de terre glaise, en sorte que nos artistes peuvent à leur choix user du feu ou de l'électricité, pour reproduire directement en métal les ourres modelées à l'ébauchoir, sans qu’il soit besoin d'y venir faire après des retoucles de ciselure.

On avait vu aux expositions précédentes les figures colossales moulées et reproduites en cuivre par l'électricilé, mais si l'architecte avait mis à profit ces méthodes nouvelles pour certaines décorations comme avait fait M. Garnier à l'Opéra, l'orfève se montrait plus défiant; il ne voulait pas reconnaître au métal déposé par la pile l'homogénéité de la matière fondue et forgée; les bronziers, les ébénistes ne se servaient qu'avec défiance des appliques et des moulures ornées que la galvanoplastic reproduit avec tant de perfection.

Un changement d'opinion s'est fait. Il y a des pièces d'argent entièrement obtenues au bain et qui semblent achevées au ciselet; on a reproduit par la galranoplastie les chefs-d'œurre de l'orfévrerie ancienne sans les délériorer aucunement, et de la sorte on a dans les musées de province multiplié les exemples. Enfin les coquilles galvaniques de cuirre ont été renforcées intéricurement d'un alliage, qui leur donne la fermeté, l'apparence d'une fonte et par un artifice ingénieux et fort simple, le dépòt d'une couche de zinc et d'étain à la surface, on obtient par une recuite un bronze véritable.

Il serait superflu d'expliquer ici les procédés d'incrustation et de damasquine par voie galvanique. Les premiers essais datent de l'Exposition de $186_{7}$, et, s'ils ont été perfectionnés, il ne paraît pas qu’on ait continué chez nous à s'en servir; les Américains, eur, s'en sont emparés et s'en servent si bien que quelques critiques, en rendant compte de l'Exposition, leur ont attribué complaisamment le mérite de cette invention toute française.

Les brevets d'argenture et de dorure électro-chimiques sont depuis de nombreuses années dans le domaine public, ce n'est plus le monopole d'une seule maison, mais l'avance considérable qu'avait prise en France la Société Christofle, comme la maison Elkington en Angyleterre, explique lis supériorité de ces deux formes sur toutes leurs rivales. 
Le jury a visité les ateliers de M. Christofle et $C_{6}^{\text {ie }}$, et tous mes collègues ont admiré la facon intelligente dont s'étaient combinés el complétés les moyens chimiques, les moyens mécaniques et les procédés purement manuels. Tous les perfectionnements industriels qu'il faudrait expliquer ici sont réunis dans cette usine, depuis le gigantesque balancier jusqu'à la machine à sabler, dont M. Bachelet a vanté dans son rapport les curieux effets, depuis les découpoirs automatiques et les grands laminoirs jusqu'au tour à guillocher que l'électricité conduit, depuis le procédé de moulage de Pellecat jusqu'aux tours à polir en feutre et en papier. Cela commence au marteau-pilon pour finir à la graminée qui s’incruste dans une surface de cuirre polie.

Le produit par excellence de cette immense fabrication, c'est le couvert; la raison de cette grande industrie, c'est la vulgarisation de l'ustensile de table; on y fait l'orfèvrerie pour tous, c'est de là que se répand le luxe à bon marché, le confortable, le bien-être, l'outil de civilisation qui remplace la cuiller d'étain, la fourclıette de fer. C'est une révolution économique comparable à celle qui a eu lieu quand l'assiette de faience a succédé à l'écuelle de bois.

Le philosophe applaudira à ce progrès qui a péuétré dans nos campagnes el qui s'étend aux colonies.

Tout est relatif : dans le ménage ouvrier comme dans la famille bourgeoise, l'orfívrerie a fait entrer un semblant de luxe, d'un luxe désirable et permis qui engrendre des idées saines d'économie et de travail. Il resterait à trouver des types plus simples, des formes absolument correctes et pures pour douner ì cette orfèverie d'usage une façon moins changeante. Cela est d'autant plus à souhaiter que du dehors nous vieunent des fabrications rivales d'un bon marché excessif qui s’imposent. L'Autriche importe chez nous des pièces d'orfèvrerie courantes faites de nickel pur, (jui, même sans argenture, restent inoffensives et d'un emploi facile, et l'Amérique inonde déjà certaines boutiques des échantillons clinquants de sa fabrication d'étain argenté. Ce faux luxe trompera longtemps les acheteurs et il faut regretter qu'on ait accordé une haute récompense à la maison qui fait cette orfèvrerie condamnable. Si le métal anglais est acceptable quand il garde son apparence véritable, il devrait être interdit dès qu'il est recouvert d'argent. Les services à thé en étain qui sont passés d'Anglcterre en France et sont très généralement employés ne sont en réalité qu'une suite à notre vieille poterie d'étain trop oubliée et qui était saine, propre et économique. L'unique danger de cette fabrication réside en son extrême fusibilité : on ne peut pas placer sur te feu les vases et les plats d'étain. Or ce que fait la Meriden Britamia $C_{1}^{\circ}$, c'est de recouvrir d'une couche d'argent ses ustensiles d'étain; elle enveloppe sa fabrication d'un mensonge, non pas avec l'excuse d'une précaution hygiénique comme lorsqu'on argente le cuivre, mais uniquement par une raison de faux luxe et de tromperie.

Les pièces ainsi fabriquées présentent au feu les mèmes inconvénients que les objets d'étain, et si la faveur devait revenir à ce métal, nous voudrions que ce fût pour encourager une industric française que Brateau a le premier remise en honneur et conti- 
nuée avec autant de persévérance que de goùt. On a fait pendant six cents ans des pots et des plats d'étain qui, des plus simples aux plus ornés, suffisaient aux besoins de nos pères; ce sont ces jolies formes qu'il faudrait reprendre, et, dans l'élain comme dans la faience, on retrouverait les saines traditions de l'orfèvrerie ancienne.

Nais le vulgaire ne goûterait pas cette simplicité, il faut à la masse des acheteurs des formes bizarres et des ornementations compliquées. C'est ce qui explique le succès de certaines fabrications que le bon gout condamme et dont il faut pourtant dire ici quelques mots parce qu'elles s'imposent par le nombre.

Tous les orfèvres ne font pas leurs modèles et n'en restent pas les uniques propriétaires; il y a un stock considérable de types mis en commun, qui appartiennent ì des estampeurs et dont se servent les façonniers et les fabricants de petite orfèverie. Aucune ville n'a autant d'ateliers d'estampage que Paris: on en comptait déjà 60 en 1847 et si le nombre n'en a pas augrmenté, leur production s'est accrue de tous les perfectionnements de l'outillage, en sorte qu'aux modèles anciens se sont joints d'innombrables modèles nouveaux, que la fantaisie des ouvriers mêle et complique.

C'est avec ces ornements d'argent mince ou de cuivre estampé que des orfèrres en chambre composent ces pièces si légères de poids, si bizarres d'arrangement, dont le dessin étonne tant les gens de goût et qui trouvent cependant des débouchés par les boutiques de province, les magasins de nouveautés et les comptoirs des commissionnaires; on garnit ainsi les cristaux, on monte des nécessaires, on soude ces coquilles sur des fonds unis, on emploie de la même façon des ornements déposés à la pile el ce n'est que par l'adresse des ouvriers et le bon marché des façons qu'on peut lutter contre la concurrence des fabriques viennoises qui excellent en ce mode d'orfèverie courante.

Nous n’avons pas à faire la critique de cette orfèvrerie, elle est nécessaire puisqu'elle répond à des besoins, et elle ne cessera d'être que quand on cessera de la demander. Nous avons essayé, dans un précédent chapitre, de définir quelques-unes des r’ègles du goût, ici nous n'arons qu'à enregistrer les moyens dont l'industrie dispose. Cependant si nous signalons ceur dont elle fait un usage mauvais, selon nous, qu'il nous soit permis de dire ceux qu'elle néglige ou dont elle ne sail pas assez bien se servir.

Le décor de l'orfèvrerie ne consiste pas seulement dans la ciselure et la gravure, dans le guillochage et l'émail, il réside aussi dans la coloration de l'argent, dans le poli, le bruni, le poncé, le gratte-boëssé, la dorure ou la patine. Il y a maintes façons de modifier l'aspect du métal.

Or, quelque progrès qu'on ait fait en cette voie, nous sommes très routiniers et restons fort en retard sur les Japonais qui sont passés maitres. L'argent est un métal terne, froid, dont les blancheurs et les oxydations trahissent les formes en s'éclairant ou en s'ombrant à contresens; des lèpres sulfureuses marbrent de vilaines taches les surfaces unies et si, par de fréquents nettoyages, on essaie d'enlever ces taches, on arrondit les saillies, on use les ciselures; c'est pourquoi beaucoup de gens préfèrent les 
types absolument simples, unis, d'un entretien facile, qui gardent pour la vaisselle de table le beau poli et le bruni.

L'oxydation naturelle de l'argent a produit cependant dans quelques pièces anciennes de superbes effets et nous en avons cité plusieurs en pirlint du Cabinet des antiques, du musée de Cluny et des collections du Louvre. C'est un art de savoir prévoir le jeu de ces oxydations, de comprendre que les creur resteront noirs ou gris et les surfaces polies, et que cette ombre devra venir à point aider au dessin et ne pas le contrarier.

Ce devrait être pour le modeleur el l'orfère le premier souci; mais la plupart ont fait à cet égard une très regreltable erreur. De même qu’il était de mode il y a vingr ans de blanchir au mat les figures et les ornements, de méme on s'est pris à aimer avec exagération l'argent oxydé et à l'oxyder trop, non plus au ton naturel de l'argent, mais en employant l'eau de Barrèges, le sulfhydrate d'ammoniaque ou simplement le noir d'imprimerie. Ce procédé sommaire et très insuffisant avait été adopté par la généralité des orfères et donnait à l'ensemble des pièces exposées un aspect sale, triste qui en faisait une orférrerie de deuil. Ce n'est pas ainsi que l'argent doit apparaitre aux yeux, il faut lui garder un éclat métallique et, même en l'oxydant, il faut éviter de le salir et de l'encrasser comme on fait. Les Japonais attachent un soin extrềne à leurs patines, ils dépensent autant de temps et de peine à colorer le métal qu'ils en ont mis à le façonner et à l'orner. Un vase d'argent, suivant eux, peut prendre des colorations aussi variées et aussi solides qu'un vase de terre; peut-être ne sont-ils pas aussi arancés en chimic que nous le sommes, mais ils ont appris par une curieuse pratique et ont gardé la tradition des méthodes que nous ignorons. Ils ensevelissent leurs pièces d'argent dans des terres composées de certaines façons, les y laissent de longs mois, les arrosent avec des préparations acides, les chauffent à des températures prérues; ils font ainsi pénétrer dans l'argent ou le cuivre des oxydations profondes qu'ils accentuent par des opérations nouvelles; ils les polissent avec des terres fines mêlées à des vinaigres de fruits. Tout le lent et minutieur travail que le Japonais dépense à corriger, à polir et à faconner ses laques, il le répète avec une altention égale pour ses orfèveries et ses bronzes. Il y fait des taches, des marbrures, des pluies d'or ou de sang, il les enrichit comme des gemmes de vibrations profondes et il arrive ainsi qu'un vase d'argent poli, sans un trait de dessin, sams un accident de cisclure, devient un pur objet d'art si sa forme est parfaite et si sa couleur violette a le velouté d'une prune ou d'une aubergine. Qui done se soucie de cliercher cela parmi nos orfères? Aucun. Si fait, Gautruche, le doreur, et Guignard, le fidele et adroit collaborateur de la maison Christofle, se sont passionnés tous deux pour cet art des patines; ils jouent de l'or, de l'argent et du bronze avec une réelle habileté; mais sils sont parvenus à de curieux effets, leurs couleurs n'ont pas la profondeur, la solidité, la transparence et l'éclat des patines japonaises, ils vont trop vite, ils ne comptent pas avec ce facteur puissant, le temps. Is fout de la chimic d'atelier, s'aident des biins de cuivre et d'or. 
Il faut cependant citer leurs noms, ne pas permettre qu'on les onblie, pare que les fremiers ils se sont intéressés à cotte harmonie jusqualors ignorée de l'orfère.

Peindre l'argent ou plutôt le teindre de muances d'or, de bronze ou d'oyydes noureaux pour en changer l'aspect froid, pour l'animer, l'embellir, à l'exemple des gemnes, c'est un art nomvau.

Nos argentiers ne veulent pas se rendre à celte nouvelle exigence qui demain soimposera absolue, parce que le goût des choses d'Orient pénètre le public. qu'on adore la couleur, quion reut des harmonies de tons, des chaleurs de métal, el que nos peintres et nos décorateurs en font une condition absolue de beanté.

On aide à ces effets par des morsures d'acide, par des accidents de surface, on mate l'argent comme le verre, on le soumet daus des ejlindres clos a l'action du sable ou de limailles d'acier qu'une souflerie précipite en pluie, on grèle, en aralandse; le vase sort de cette douche marqué, pointillé d'une microscopique irruption, morda de millions de dards, et 'qu'il soit doré, argenté ou loronzé, il change aninsi d'aspect. Il y a d'autres mojens encore qui sont des secrets d'ateliers que nous ne pourons dire et pier lesquels l'argent se modifie comme si des veines de nielles couraient sous sa peaur. Nons avons parlé du mokoumé et du sibouitchi; mais il faudrail preut-être ponr égraler en perfection les Jiponais, nos maîtres, pouvoir s'affranchir des règhles qu’impose la loi en délerminant aux alliages des proportions qu'on ne peut pas changrer.

Arons-nous tout dit? Non, mais on n'attend pas de nous qu'en quelques parges nous analysions toute la technologie d'une industric qui touche à l'art, ì la science, à la mécanique et à la prestigieuse adresse des mains. Il suffit que nous donnions confance ¿̀ nos confrères qui parfois doutent, comme nous arons douté nous-mème, et aux jeunes gens, qui ne savent pas encore tout ce qu'ils peuvent oser.

Qu'ils sachent done que l'orfère est tout, peut tont. Croit-on que jexagère? Artiste et ourrier, il est sculpteur et peintre, il a la libre disposition de toutes les matières dures ou dociles, précieuses et riares. Il est fondeur, ciseleur, graveur, émailleur, lapidarire, il sculpte l’ivoire, incruste le fer, damasquine l'acier, grave les camées on creuse les intailles, il sertit les gemmes, il a tous les ontils, depuis le tour et le balancier jusqu’à la lime, le burin, lo ciselet. Il n’a rien à envier au céramiste, rien à demander au lailleur d'images, sa clientèle est faite do rois, de papes, de femmes et de nababs. C'est lui qui enrichit l'or, qui donne aux pierres leur éclat, il a décuplé la valeur des trísors par son art.

Peut-être le rôle de l'orfère était-il plus considérable dans le passé, mais il lui appartient ì force de groût, de passion, d'étude et de conviction de reprende dans le présent la place qui lui est due à la tète des métiers pour servir de trail d'union entre l'art pur et l’industrie patiente.

On peut évaluer à 200 environ le nombre d’orfères établis à Paris, mais ce rhiffre n'est pas régulièrement ronstaté, il résulte de nos renseignements particuliers of ne saurail ètre donné avec la garantie d'eractitude que présenterait une enquête officielle 
comme celles que fit en 18/17-18/8, 1860 et 1872 lia Chambre de commerce de Paris. Dans ce chiffre de 200 orfères, nous comprenons cenx qui traviallent le cuirer. lo nickel et l'étain mème, comme ceux qui ne font que l'orfèrrerie d'argent, ceux qui font l'article d'église, ceux qui font la grosserie ou la gianiture. tous les orfères enfin. i la senle exclusion des joailliers et des bijouliers.

Mais nous ne comprenons pas dans ce nombre les orféves de province; notre chiffer n'en serait pas sensiblement modifié, car si chague grande ville de France possède au moins un orfère, celui qui prend ce titre n’est généralement qu’un marchand revendeur, lirant ses articles des fabriques de Paris et ne produisant lui-mème aucune pièce d'argenteric.

Il n’y a guère qu’ì Lyon, ì Marseille, à Anniens, à Ercuis (Somme), à Lille, à Bordeaur, à Courtalin (Seine-cl-Marne) et à Long"ry (Meurthe-et-Moselle), quon puisse compler des fahriques d'orfèvrerie, encore plusieurs sont-elles des usines créces pill des maisons parisiennes ponr les appréts métallurgiques.

Il n'en était pas ainsi jadis; toutes les grandes villes de france avaient des communautés d’orfèrres mélées ruelquefois, il est rrai, de bijoutiers, d'horlogrers, de potiers d'étain, roire même de chaudronniers, mais conservant de véribbles maitres orfères a yant marque et poincon.

Paris a tout cenlralisé el c'est aujourd'uni par excellence la ville des orfévres; Londres, Vienne, Berlin, Rome, New-York el Bruselles ont de grands aleliers, mais ces villes n'absorbent pas toute la fabrication d'un pays. Birmingham et Sheffield ont des fabriques d'orfèrrerie; Budapest et Prague produisent des pièces estimées; l'Allemagne a des villes réputées pour leurs articles d'orfèrerie riche on courante comme Munich, Karlsruhe, Stutgard, Francfort, Cologne, ete.; l'flalie oppose Florence à Rome et Turin ì Vilan, et nous arons vu enfin que les Américains avaient créé de véritables usines d'orfèrrerie, à Philadelphie; à Providence, à Boston et jusqu'à Hamilton, dans l'Ontario.

Ce qui fait la supériorité absolue de Paris sur tous les centres d'orfèrerie du monde, c'est la diversité des moyens d'invention et de travail. La division du travail, qui est une gêne pour l'artiste, devient pour l'industriel un secours précieus. Ce n'est plus comme. dans l'usine de Birmingham ou de Saint-Denis, Ja division par l'oulil, Ja spécialisation des facons dans un mème atclier. C'est la variété des moyens offerts par toule une collection d'ouvriers libres, de facomniers intelligents, de collaborateurs, qui pensent, cherchent, inventent, rivalisent d'ardenr pour créer à bon marclée el trouver des moyens nouveaur. C"est ansi qu'en 18 / 7 déjà, l'enquête de la Chanbre de commerce de Paris relevinit pour l’industrie des orfères : 162 ciseleurs, graveurs el guillocheurs qui cmployaient 5 , 3) ouvriers; 92 doreurs el argenteurs qui avaient 64 4 ouvriers; 69 émailleurs qui occupaient 415 ouvriers; jo estampeurs et grareurs en matrices chez qui travaillaient 277 ouvriers; 11 lamineurs avec 53 ouvriers; 96 lapidaires emplojant un nombre double d'ouvriers; 3 affineurs, 5essiyeurs of 16 lavem's de cendres occupaul 
ensemble 15.3 onvriers; 10 apprèteurs, 11 lamineurs et 21 planeurs ajant sous leurs ordres 1 zo ouvriers. Quant anx orfévres eux-mêmes, ils étaient plus nombreux qu'anjourd'lui; les grandes maisons ont absorbé les petites, les labriques de plaqué, qui ćtaient au nombre de 55 el qui occupaient près de 800 ouvriers, ont disparu; mais si les orfèvres sont moins nombreur, nous ne croyous pas qu’il faille évaluer à un cliffre inféricur le nombre des ourriers (qui était alors pour ces maisons réunies de $3,318, \mathrm{y}$ compris les femmes, et qui doil s'ètre aceru dans la même proportion que les chiffres de, fabrication, c'est-ì-dire de près d'un sixième(i).

Il y a lieu de louer les ouvriers orfères; soit quails aient plus que d'autres le senliment de leurs intérêts et de leurs devoirs, soit qu’ils aiment leur métier arec plus de patriolique intelligence, ils ne se sont prêtés à ancune des manceures qui ont troublé si profondément d'autres industries, car il ne faut pas allribuer plus d’importance qu’elle n'en eût à une grève partielle des onvriers en métal blane, qui, au nombre de 150 , demandèrent et obtinrent une augmentation de 15 p. 100 sur le travail an pieces ${ }^{(2)}$. Celte sagesse tient aux rapports étroits de l'ouvrier et du patron, à l'entente fui règne entre eus, par la nature méme du travail.

Le patron orfère vit près de l'atelier, il y entre constamment, il est en contact perpéluel avec ses contremaitres et tous les ouvriers qui sont ses collaborateurs. Il s'établit ainsi une confiance réciproque, une solidarité d'intérêts el la chose du maître devient la chose de tous ceux qui y participent. On comprend que c'est une fortune qu'on exploite en commun et qu'une atteinte à l'industrie ne profiterait qu'aux marcliés étringers.

D'ailleurs l'ouvrier vit bien de son travail, il est payé suivant son savoir el son habileté et peut débattre de gré à gré le prix de sa journée. Aucun contrat ne l'attache ì l'atelier, les heures supplémentaires lui sont payées à part; aussi voit-on souvent l'enfint suivre le mème état que son père, et si le travail de ces apprentis ne présente ancun des dangers que la loi sur ce te travail des enfants dans les manufactures" a justement essayé d'écarter, ils n’en ont pas moins profité des bénéfices de cette loi. La condition de l'ouvrier est donc particulièrement heureuse et suivant ses aptitudes il peut prétendre à gagner de 5 francs à 10 francs par jour (3). Nous ne parlons pas des ouvriers exceptionnels qui alleignent à des journées de beaucoup supérieures ì celles-ci.

(1) Aucune statistique n’a élé ofliciellement puhliée sur l'industric de l'orfèvrerie depuis de lonģues années, wais nous pouvons espérer d'avoir prochainement de II. J. Barberet, clief de bureau des sociélós professionnelles au Ministère de l'intérieur, des renseignements aussi complets sur l'orfèveric que ceux qu'il a domnés sur la bijouterie dans le prenier volume du Travail en France, monographies profissionnelles, Paris, 1866 , chez Berger-Levrault el Cie.
(2) Voir l'enquète pardementaire sur l'industrie et l'agriculture faite en 188 h sous la présidence de II. Spuller (p. 333, résultat des grèves de 1879 . à 1883).

(3) D’après les Lablraux de slalislique de la France la moyenne du salaire des ouvriers bijoutiers-orfèves varie entre $6 \mathrm{fr}$. 5o of 1 i francs pour Paris et 3 fiumes à g francs pour la proviuce. 
Nous arons dit qu'on s'occupait d'instruire ces enfants, que des écoles de dessin leur ádaient ouvertes, soit dans lears quartiers, soil dans le local installé par la clambre syndicate; quelques orfères ont créé chez eur des cours spéciaur et on peut espérer qu’il résultera de celte éducalion très récente une élite d'ourriers meilleurs. comprenant mieur, travaillant arec plus d'intelligence et de soin.

Un bénéfice immédiat que peuvent trourer au débul de leur carrière les bons sujels de l'atelier et de l'école est lans l'arlicle $23, \$ 3$, de la loi militaire dn 15 juillet $188 \mathrm{~g}$. On sait que quelques catégories d'ouvriers d'art jouissent d'une dispense spéciale et peurent n’être gardés qu'un an sous les drapeaux sils ont satisfait aur. épreures que jugent des experts choisis. Les orfères sont en bon rang parmi ces calégrories privilégiées et déjà l'émulation des candidats a produit d'assez bons résullats(i).

Lal chambre syndicale de la bijouterie, de la joaillerie et de l'orfèverie, créée en 1861, représente les intérèts communs de ces trois industries socurs. L'horlogeric ef la bijouterie d'imitation s'en sont détachées autrefois, mais l'orfévrerie reste absolument liée à l'industrie des bijoux et des diamants.

Nous arons dit au début de ce ripport les grandes analogies qu'ont ensemble ces trois parties d'un art qui jadis n'en formaient qu'un seul. I es orféres, en outre, ont des intérêts communs à ceur des bijouliers, its sont régis par la même loi de contróle, soumis aur mèmes règlements, leurs clients sont les mèmes el, par l'association, ils acquièrent une force qu’ils perdraient sims aucune compensation, s’ils étaient divisés.

C'est en vertu de celte force d'union qu’ils ont créé en commun, outre la Chantbre syndicale dont nous parlous :

$1^{\circ}$ La Société des joailliers, bijoutiers et orfèves, dite Société des cendres, qui a son immeuble, à Paris, rue des Franes-Bourgeois, 39 , et où sont traités les déchels, rendres et limailles, résullant des travaux d’atelier. Cette Société a déjà trente ans d'existence;

$2^{\circ}$ L'école professionnelle de dessin, dont nous arons parlé, et qui date de 1866 . Elle a commencé au Conservatoire des arts et métiers sous le patronage du général Ilorin;

$3{ }^{\circ}$ L'orphelinat général de la bijouterie, de la joaillerie, de l'orférerie et de l'horlogerie, qui date de 1869 et qui recueille les enfants des sociétaires décídés, les élére, les instruit, les place et les surveille jusqu'à leur majorité;

1 ${ }^{\circ}$ La Société d'encouragement aux apprentis ouvriers et employés de la bijouterie. de la joaillerie et de l'orférerie, reconnue d'utilité publique en 1875 , el qui chaque aunée recherche les vieux serviteurs et les plus dignes ouvriers de l'industrie pour les récompenser publiquement, et les meilleurs parmi les jeunes pour les encourager pir des prix;

$5^{\circ}$ La liraternelle, cirisse de retraite pour la vicillesse, fondée en 1875 pour les ouvriers orfères. joalliers et bijouliers, el qui contribue, avec lia Société Benvenuto

(1) Voir las dispositions du chapitre V (décret du 2.3 novembre 1889 ) : dos dispanses an tilue des induslries dart. 
Cellini qui est beaucoup plus ancienne, ì défendre les camarades éprourés el ì les aider dans les jours d'épreuve.

Nous nous bornous à nommer ces institutions sins douner de chiffres ni de renseignements sur leur fortune et leur fonctionnement. Maris il est permis d'espérer que, sans changer rien à ces sociétés yni s'administrent chacune séparúment, l'orférrerie, la bijonterie et la joaillerie parviendront un jour.par l'association ì avoir une maison commune, d'où partira l'action bienfaisante fue récliment des intŕrêts si divers.

Ce ne sera pas revenir ì d'anciens errements et refaire la corporation d'autrefois, avec ses règlements exclusifs et ses privilèges. Mais jai toujours été jaloux, quand jallais à Londres, de voir que les orfères anglais possédarient un palinis magnifique qui est une des curiositís de la ville, qui a ses salles de séances, son musée, ses tableaur, ses portraits de gardes et de syndies, son ancienne vaisselle d'argent. qui a surtout ses bureaux, son administration, ses archires ef enfin son directeur dévoné aux intérîts de lil corporation.

Ne sommes-nons pas assez riches pour acheter un terrain, y bitir un immenble, $y$ rémir tout ce grui est d'intérêt commun et en ficire la maison des orfères, des joailliers, des bijoutiers et de tous les métiers et de tous les arts voisins?

Ce que conterait une telle création ne demanderail it chacun de nous qu'un sacrifice relativement faible, mais il serait digne des riches industries que nous représentons d'avorr un lieu de réunion fixe. Les imprimeurs et les éditeurs ont eu celte ambition, ils ont formé le cercle de la librairie et l'union est devenne plus grande, la confiance plus profonde entre eux depuis qu'ils s'y rencontrent et s'y fréquentent. Il en serinit ainsi de nos confrères sils avaient la maison des orfères, leurs intérêts y seraient défendus et c'est de lì peut-être que sortirait la loi de protection des modèles que rérlament non pas seulement l'orfèrerie, mais tontes les industries et dont il faudrait firire mo toi intermationale. Nous examinerons dans le chapitre suivant les questions d'ordre purement commercial.

\section{$\$ 3$. Le conyence.}

La question qui s'impose an début de ca dernier chapilre est relative à l'argant et it sil valent.

L’orfère, en dépit de l'élynuologie de son nom, n'use de l'or que rarement, tandis que l'argent est l'élément de son travail. Alors mème qu’il fail des ceuvres de cuirs: on de nickel, il les dore ou plus sonvent les argente; l'orferrerie d'innilation consomme chargue année une part importante de l'argent lirré ì l'industrie.

Je me souviens à ce sujet, que causant avec M. Bonillet, l'intelligent associé de Christofle, je lui faisais certaines questions relatives à la production industrielle de sal maison et lui demandais des renseignements sur les procédés galvaniques. C'étail en 1889 et nous nous promenions dans les jardins de l'Exposition: vo:ci la réponse quiil 
me lit : Yous royez, mon dere Falize, ces parterres, ces allées, ces palais, res gat leries, ces dômes! Eh bien, arec l'argent que nous avons déposé sur uos courerts. nous pourrions argenter tout cela d'une munce pellicule blanche; ce serait comme sil avait neigé sur le Champ de Vars el sur les édifices de l'Exposilion."

Vous représentez-vous ente neige d'argent, cette couche de métal sortie des bains gatvaniques. Elle péserait ì peu près .30o millions de grammes, cest un joli exemple de divisibilité el c'est environ la moitié de ce qu'emploient amnuellement les fítials d'Europe el d'Amérique (1).

L'argent est done pour l'orfère le métal indispensable. C'est sa matière premic̀re à lui el les questions qui surgissent pour d'antres industries du cours de la soie, du coton, du fer, ete., se posent iri avec lis même autorité, elles constituent même un singulier problème que nous aurons à préciser, sinon à résoudre.

Il y ivait à l'byposition, au centre de la grande galerie Rapp, un gigantesque lingot d'argent de forme circuliaire, qu'avait foudu la maison G. Dumont el frères, de liègre A ce lingot élail fivé un tableau qui représentait les varialions du pris de l'argent dopuis un siècle, c'est-ì-dire de 1789 à 1889 , l'mité de poids átant de 1 lilogramme. Voici comment on avait établi celte échelle par périodes de dic ans:

$$
\text { PIIX DE LARGEXT PEADANT UN SIliche }(1789 \text { i } 1889) \text {. }
$$

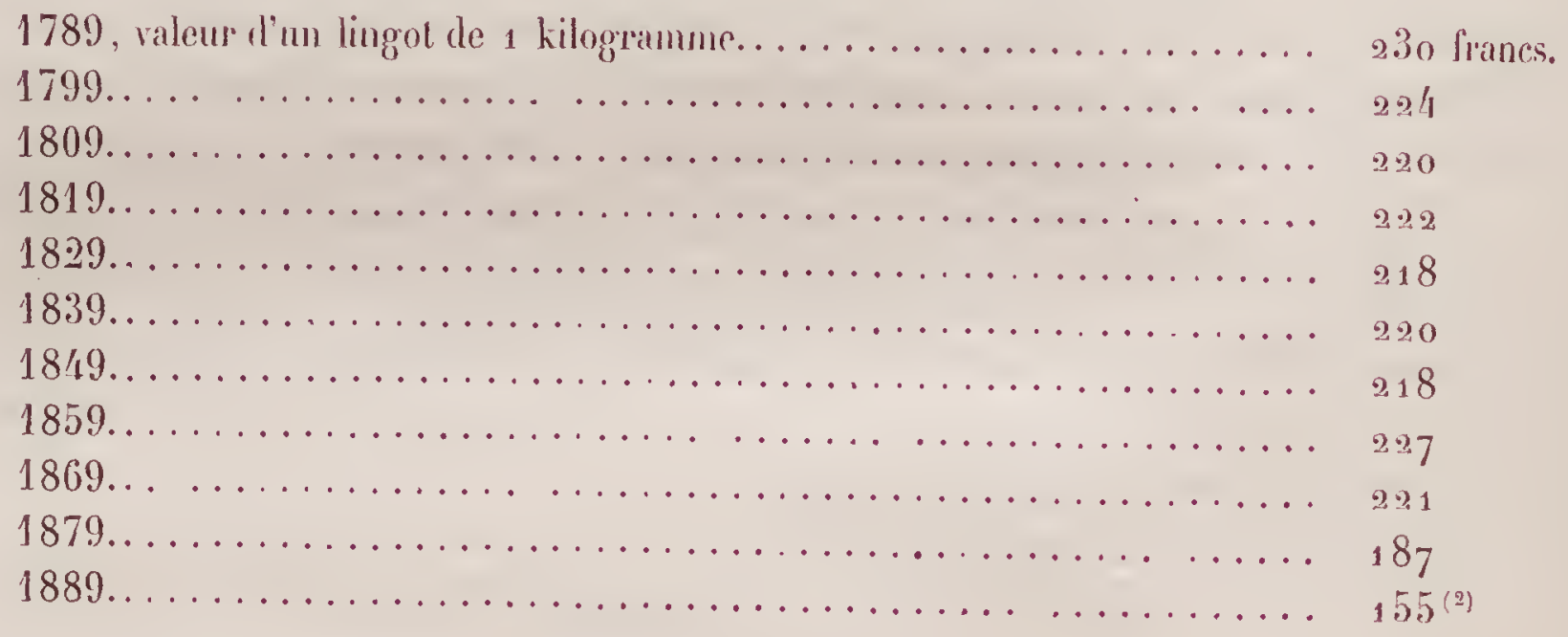

Pen de gens s'arrétaient ì lire, la foule passint sans se douter que cette énorme meule, qui semblait être en étain, représentait un capital immobilisé de $309,000 \mathrm{fr}$. Maris quelques-uns s'en allaient pensifs, inquiets de cette rapide déprécialion d'un

(1) M. Soëlbeer.

(2) Pendant celte mème amnée 1889 les cours de l'irgent ont varié sensiblement; ils se relevaient à la fin, de façon à présagrer déjà une reprise sensible; les voici mois par mois :

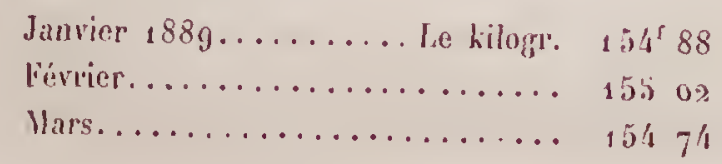

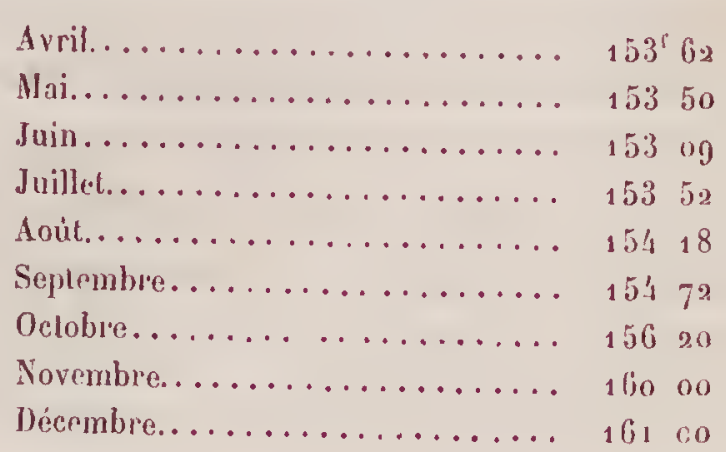


mébal qui conslitue mu des áléments de la fortune pulblique el qui, depuis cent ans, a perdu im tiers de sa valeur.

L'orfère s'en préoceupe plus que persomne: la question se pose pour lui el pour son client à un double point de vue.

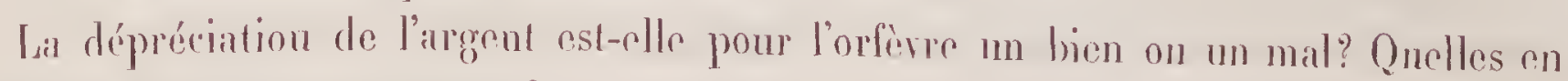
peuvent être los conséquences?

Il semble, á priori, que le bon marché el l'abondaner de lat malliepe ourrable soient loujours pour une industrie une condition de progrès et que les bénéfiees du productenr en doivent être augmentés en même temps que seront salisfaits les besoins de l'achicteur.

Arant d'accepter pour juste cetle conclusion, il convient d'eviminer si l'orférerie se comporte comme d'iulres méticrs, si elle a les mèmes lois et les mèmes raisons d'ètre.

Lia production des mines s'est accrue dims des proportions tout ì fait impréves. Tandis que de 1851 ì 1855 les pays argentifieres ne livraient ì la consommation qu'une moyenne aunuelle de 887,000 kilogrammes, le rendement est monté lant pirr la drécouverte des gisements de l'État de Nevada que par les perfectionmements apportés dans les procédés d'ovlraction, el al alteint 3,400,000 kilogrammes. C'est une angmentation de 283 p. 100.

II en résulte que la production annuelle s'est élevée pour l'argent jusqu'ì priss de 550 millions de francs; or la consonmation industrielle n'absorbant pas plus de 100 millions de francs, il est resté on fin d'année un stock à employer de 450 millions do francs.

Autrefois, il y avait une concurrence active entre l'industrie de l'orferre ef l'indusIrie monétaire. Les Étals s'emparaient des métaux précieux pour les frapper et les transformer en monnaio et la richesse des nations s'augmentait de ces trésors noureaus.

les conditions économiques ont clangé, le papier et les valeurs de banque ont pris une large place daus les opérations d'échange; l'or est devenu l'unique étalon de quelques États, en sorte que l'argent, rejeté de ces pays, a aflué chez les peuples qui étaient, comme le nôtre, restés fidèles au système himétallique, et la valeur de la pièce de 5 francs, qui était à jeu près réelle, est tombée à 3 fr. $5 g^{(1)}$.

Le Gouvernement francais a dî, pour ces causes, suspendre la fabrication des monnaies d'argent, mais il n'a pris aucune mesure pour absorber le surplus du mótal, Landis que le Gourernement des États-Unis a tenté d'atteindre ì ce but el d'arrêter la dépréciation de l'irgent en achetant, au cours du marché, les lingots d'argont contre un papier monnaie qu'il recoil au pair pour l'acquit des droils de donane ef d'impoits. Cetle loi (le bland-bill), qui date de 1878 , est un système de bimétallisme restriclif 
asantageus, mais qui deviendrat rumeur si la dépréciation de l'argent continuat(i); il a divisé les Iméricans en dem partis : les Silermen of les Goldmen.

On roit le dinger économique que conrent tous les pays ef en particulier ceus qui n'ont pas arloptrí le monométallisme; cela constitue, outre la dépréciation de l'argent, l'augmentation d'un stock inemployé de métal.

l'orferre doit-il se planindre de cette ahondance de l'argent? Ses affaires n'en ont pas diminué ef ses clients n'en ont pas pris penr; an contraire, la prospérité des ateliers d'orferres coüncile ì peu près arec cette modification du rôle de l'argent ef tout fail présager une conlinuation hemreuse.

L'arhetenr semble n'aroir va dans ce changement qu'm avantage réol qui est. cehui-ci: avoir pour une somme égale une quantité d'argent plus grande, ou pronr exprimer par des chiffres le rapport, le prix qu'auraient conté au poids douze coureds d'aryont en 1879 permettrait, en 1889 , d'en acquérir dix-sept. C'est done un bénélice réel.

Iris ce bénéfien comparé aux conrs anciens deviendra-t-il une perte si on le comjance aux cours fulurs? L'acheteur ne s'en préoccupe pas encore. Il exprime moins d'inquićtude en ce qui regarde l'argenterie qu'en ce qui touche à la joaillerie : il y a quelque anilogie entre le rôle du diamant et celui de l'argent. Il semble que nos manufactures et nos comptoirs attendent arec confinnce des débouchés pour lesquels ces stocks ne seront jamais trop considérables. La civilisation qui pénètre en des contrées nouvelles, la diplomatie qui ourre paticnment aus Europécns les pays jusqu'alors fermés de l'Estrême Orient, y font pénétrer avec les objets de consommation indispensable le goût du luxe el du bien-être; nos besoins deviendrout ceux de ces sociólés dont la trinfocmalion s'opérera plus vite quon n’imagine el le trop-plein de l'Europe ira ì ces peuples neufs ou jajeunis.

Done, en dépit du ròle économique de l'argent dans l'orférerie, la dépréciation du mótal n'est pas um dangar. On n'achète pas un plat ou des couverts dans le seul but d'épargner, puisque éest une valeur morte, quelle cesse de porter intérêt. La prensér d'économie n'est que rolative puisqu'on sait qu'en cas d'urgence on ne retrouvera qu'une part réelle du prix d'achat. Mais cet avantage, que l'orférerie partige arec Jes bijoux et les diamants, est une supériorité sur tous les antres objets de luxe qui riont aurun cours fixe et réalisable. La légère différence que peut subir le cours de l'argent est en tous cas moindre que les variations de prix des pierres; quant aus facons, elles n'atteignent jamais pour l'argenterie celles que comportent les bijoux.

Il s'ensuit que le laxe de l'argenterie est de tous les luxes celni qui présente les

(i) Le blend-bill a ceté modifié par une loi nonvile yu'ont volés les Chambres amciricaines le 11 juillet 18900 . Cette loi, qui rélablit la frappe de l'argent, feut avoir de graves conséquences i'ans le régime monetinire el apportera d's porturbations tians les rapio:ts commercianx ef financiers des nations. (Lire it ca sujel, Le nourean silier-lill aux Liluts-Uwis, par M. Émile de Laveleye, Revue des Deux-Mmdes, $\mathrm{n}^{\circ}$ du 1.) mar; 189 s.) 
meilleures conditions et que tolèrent la préroyance el la sagesse. Laes éloffes s'usent, les meubles sont exposés au feu et ì des accidents de tous genres, l'argenterie ne redoute ancun danger, elle est indestructible et c'est pourequoi elle a joué arec l'or et quelfues picrres un si grand rỏle dins l'histoire des sociétés anciennes; l'argent constitue encore, sous forme de lingols, d'objets d'art el de bijous le lrésor et l'épirrgne des peuples indieus.

La fortune publique augomentant clez nous avec le goût du lnxe, du bien-èlre, du confortable, il $y$ a de grandes probabilités pour que l'orfèverie prenne un très grand développement; les cours de l'argent n’en seront pas relevés peut-être, mais ils seront fermenent maintenus; ce qui s'est passé depuis 1889 , nous est un indice de la sol:dité du marché(1).

Il n’est pas d'industrie plus loyale, l'honnêteté dos orfévres est proverbiale et c'est pour nous une joie de pouvoir dire qu'en tous pays l'orférrerie francaise est particulierement estimée, ponr sa qualité intrinsègne aussi bien que pour sa vieille répulation d'art el de goût.

C'est par lì, du reste, qu'elle acquiert et qu'elle conserve sa valemr. Trois condilions concourent à farre d'une pièce d'orfèrerie un objet de prix : la matière première, la facon el la marque.

Un vase d'argent ne vaut à fondre que le produit réel du poids multiplié par le taux du mélal; mais si l’orfère a donné à ce vase une forme élégante, s’il y a dépensé un peu d'arl, qui done songera ì détruire la pièce pour n’en tirer que la valeur vénale? Les ouvres admirables, fondues en des jours de crise, vaudraient ì présent dix fois le prix qu'on en a tiré; ce qui. aux yeux des connaisseurs, donne un ciractire d'authenticité aux objets échippés à la fonte, c’est la marque de l'État, c'est le poinçon du maitre, qui se complètent l'un par l'autre el qui sont, pour la pièce d'orférrerie, ce qu'est la signalure du peintre ou lir marque de l'imprimeur.

Il ne s'agit pas là seulement d'oures d'art rendues précieuses par de fines ciselures : toutes les pièces du siècle dernier qui portent te poincon francais et qui sont l'ocure d'un maître ont un cours absolu, supérieur de beaucoup au prix du métal.

Il y a lieu de croire qu'il en sera de même des ourrages modernes, mais il faul, it cet effet, ne choisir que des produits parfaits, de bons modìles, des travaur de maitres. Le soin qu'on met ì acheter un livre, un tableau, un bronze, il faut l'ipporter dans le clooi d'une pièce d'argenterie. Le service à thé que signe Froment-Ileurice, le

(1) L’argent, qui étail tombé en 1889 à 153 fr. og, s'est relevé depuis; voici, d'apmìs les rensoiguncmints que nous fournit le comptoir Lyon-Allemand, les cours de l'annéa 18 go :
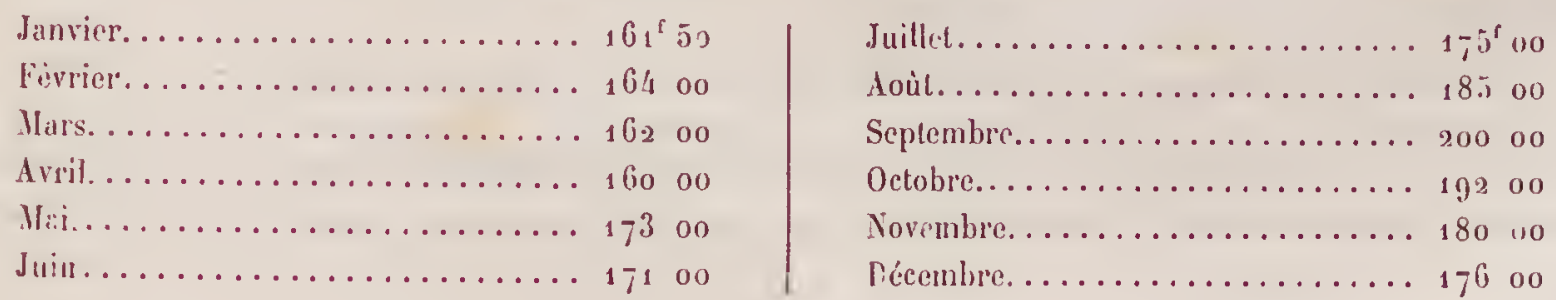
Lígnmier qu’al ciselé Famnière. Le surtont qu’exposait Boin, seront des raretés dans vingt ans; il ne sera pas plus question de la valeur de l'argent quand on estimera ces pièces quil n'en est question quand on prise un bel ourrage de Biennais, d'Auguste on de Finconnier, et c'est le cas de répéter avec le poìte des Métamorphoses :

Materiam superabat opus.

L'industrie n’a done pas à souffrir un préjudice appréciable de l'abaissement des cour's de l'argent, même en ce qui touche le cilcul de l'épirrgne: mais, aur contraire, l'orfirve doit lirer profit de l'abondance de la matière; c'est lit conséquence ordinaire et logique qui, dans tous les métiers, résulte de circonstances analogues et nous ne royons pas ce qui causerail chez nons un cas particulier. Cependint l'orfère ne tirera le profit quili attend d'me telle siluation qu'en msant de toutes les ressources pour éveiller le goùt de sa clientète riche, en lui offrant des cenves d'une qualité supéricure et en répandint l'usage de l'argent dins la masse du public par des modètes simples ef appropriés aur besoins nouveaus.

Il s'aggit, en effet. de persuader à chacun qu’il est de son intérêt d'acquérir ce luve suivant son étal et sa fortnne; l'argent répond ì un besoin de bien-être of d'aisince ot, s'il est proggressirement démonétisé palr les títats d'Europe, il n’anra bientôt plus d'antre emploi que l'orfèvrerie. Or ne semble-t-il pas que l'argent ait été providentiellement créé pour cette fin? Seul il a la solidité, la ductilité, l'éclat, le charme et surtout la sanité, qui est tant désirable pour le service de la table. Il ne répond pas seulement ì des goùts de luxe, mais à des conditions d'hygiène et à des satisfactions intimes. L'homme vit de soupe et de viande, il lui faut, à chaque repas, s'irmer d'une fourchette et d'une cuiller, car tont pour hir se rédnit prosaïguement à l'acte de nutrition.

On pent, à ce propos, rappeler la bontade d'mo ourrier cuilleriste qui prétendivit tu’Henri IV, s'il arait réellement roulu que chaque paysan pût mettre la poule au pol, aurait dî lui donner un couvert d'argent pour lia manger.

Fonrnir ì chaque Français ce convert ce serait employer déjà 5 millions de kilogrammes d'argent; en étendant ce luxe à toutes les nations civilisées on absorberait le stock entier de métal disponible et on résoudrait, dn même conp, le problème de l'estinction du paupérisme. C'est peut-être ce que rèvait le vieil ourrier philosophe en forgeant ses lingots. Il faisait de l'économie sociale à coups de marteau; nous arons, ì l'atelier, beancoup d'utopistes générenx comme lui, mais le courert de rnolz suflit iu besoin de luxe des campagnes; il succède ì la cuiller d'étain comme celle-ci atail remplacé la cuiller de bois ou de corne.

Cie quili faut, c'est que l'exemple parte d'en hant; qu'on ne voie plus à l'Élysée ou ¿ l'Hôtel de Ville des surtouts de cuivre argenté; pas de faux luxe, pas de flambeaus de pliqué, pas de vaisselle en ruolz. Laissez aux restaurints, aux hôtels et aur paquehots ce luse trompeur. 
Notre bonrgeoisie est assez liche pour se donner le luxe honnete de l'argenterie, ce serait assurément faire un placement meilleur que celui qu'ont fait lant de grens ŕronomes et crédules en achetant des valeurs qui ne leur ont laissé aux doiggts que des papiers ì vignettes roses ou blenes. Le métal ne ment pas, il demenre fidèle et solide; on donnait jadis, aux époux, une argenterie pesante : six comverts anx plus modestes, un service complet aux plus fortunés, el c'était un fond qu'on augmentail dharpue année; la vieille noblesse avait sa vaisselle armoriée, belle en ses formes, massive, réflétant le style des grands jours. Ils en sont fiers ceur qui l'ont gardée; on s'est repris d'affection pour ce luse sérieus qui dénote la maison riche, la fimille heureuse, la fortune assise. On juge l'ampleytrion par l'orfévrerie dont il orne sa lable.

La France, à cet égard, avait subi le goût clinquant d'une époque de transition; elle se reprend ì amer ce mode décoratif et cela vient à point pour entamer le bloc inemployé d'argent. L'exemple parti de la France fera le tour du monde.

Nous avons vu que la production annuelle de l'argent avait atteint le chillre considérable de 3,400,000 kilogrammes, mais c'est la un maximum exceptionnel, tandis que la moyenne de production observée par le docteur Soütbeer, de Götlingone, pendant une période de trente années, avait été de 1,300,000 kilogrammes. Lal consommation totale des nations civilisées serait, au dire du mème sarant, de 521,000 kilogrammes ou, plus exactement, de 515,000 kilogrammes par an, en déduisant les malières d'argent provenint de pièces remises à la fonte.

Voici au surplus les chiffres quil donne pour la consommation industrielle des pays civilisés :

\begin{tabular}{|c|c|c|c|}
\hline \multirow{2}{*}{ PAYS. } & \multicolumn{3}{|c|}{ ARGENT. } \\
\hline & EMPLOI BRLT. & $\begin{array}{l}\text { DÉDECTION } \\
\text { pour } \\
\text { vieux malérians } \\
\text { refondus. }\end{array}$ & EMPLOI \ЕT. \\
\hline 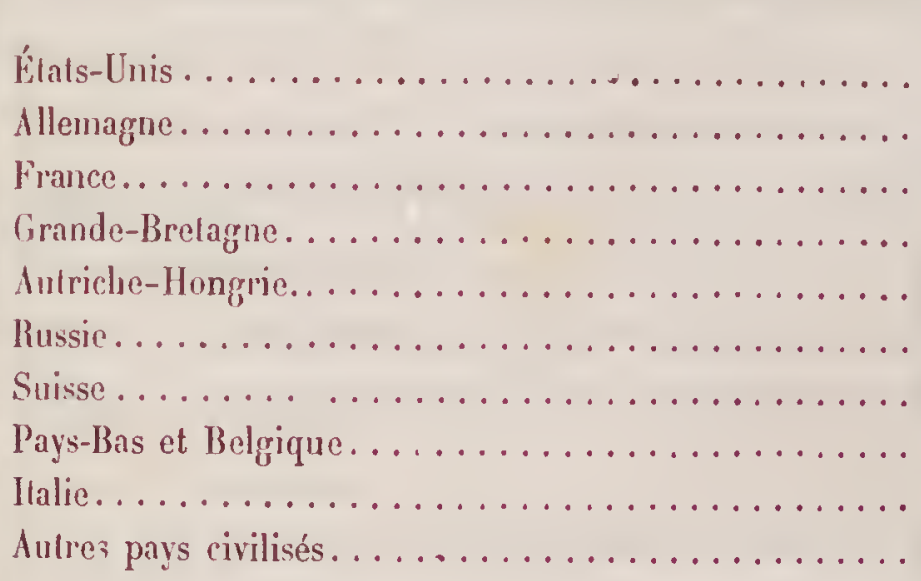 & $\begin{array}{r}\text { hilogrammes. } \\
135,000 \\
110,000 \\
100,000 \\
90,000 \\
40,000 \\
40,000 \\
32,000 \\
30,000 \\
25,000 \\
50,000\end{array}$ & $\begin{array}{l}\text { pour cent. } \\
15 \\
25 \\
25 \\
20 \\
20 \\
20 \\
25 \\
20 \\
25 \\
20\end{array}$ & $\begin{array}{r}\text { kilogrammes. } \\
115,000 \\
82,000 \\
75,000 \\
72,000 \\
32,000 \\
32,000 \\
24,000 \\
34,000 \\
19,000 \\
10,000\end{array}$ \\
\hline 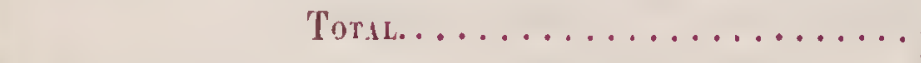 & $65_{2,000}$ & & 515,000 \\
\hline
\end{tabular}

D’autre part, II. Riche rappelle dans son livre qu’è la conférence monétaire inter- 
nationale de 188 , les délégués des divers pays avident élé invités à élablir la quantité de métaux précieux employés aux usiges industriels; voici quelles étaient pour la France les quintités d'argent consommées:

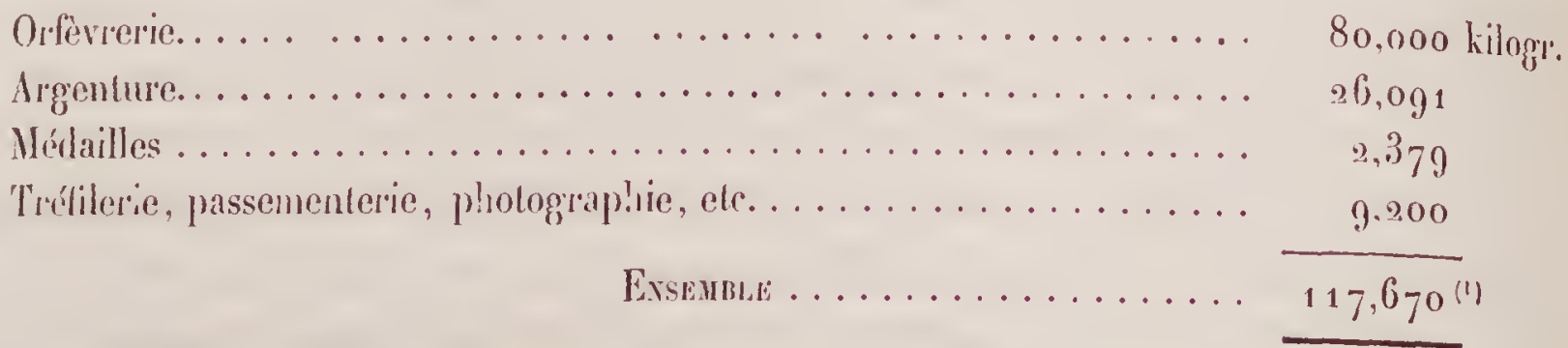

ce qui représentait une valeur de 24 millions de franes.

Nos reuseignements personnels, puisés aux meilleures sourees et contrôtés par le président de la Chambre syndicale, nous permettent d’indiquer comme mise en curre de l'argent pour l'année 1888 les quantités suivantes : argent fourni ì l'industrie par le comptoir Lyon-lllemand, les maisons Caplain, la maison Hesse et $C_{i}^{\text {ie }}$ et diverses se décomposant en :

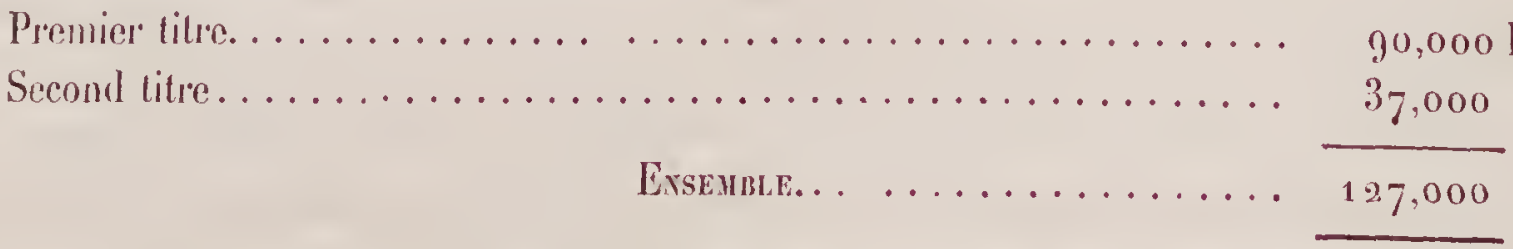

L'orfèverie française absorbe la presque totalité du premier titre : soit 80,000 hilogrammes, el peu du second, environ 6,000 kilogrammes; le reste est employé par les argentenrs, les hijouliers, les lorlogrers de Besancon et les orféves belges et suisses qui tirent de Paris teurs matières apprètées.

Il est ì remarquer par conséquent que la presque totalité de l'argent au second litre est consommée en dehors de l'orférrerie française; encore la faible partic quelle retient est-elte presque entièrement destinéc à l'esportation.

Quand tout récemment on a consulté l'industrie à propos de la revision de la loi du 19 brumaire an $\mathrm{vl}$, la grande majorité des orfères s'est prononcée pour la suppression du second litre. C'est pour satisfaire aux veux de la minorité el ne pas nuire à des intérêts respectables, non phus qu’à certaines exigences spéciales de fabrication, qu'on a maintenu les dispositions de l'article \& du chapitre $I^{\text {rr }}$, en ce qui touche les titres légraux de l'argrent; encore la commission, en conscrvant le premier titre à găo millièmes, a-t-elle demandé qu’on relevât le second litre ${ }^{(2)}$ de 800 millièmes à 825 nuillièmes.

Cette motion est tout à l'honnenr des orfèves, et il fant constater que jamais les réclamations qui se sont produites contre la loi ne sont venues d'eux. On sait les discussions engagées à propos de la garantic el du contrôle de l'or et de l'argent, el nous

(1) Riche. Monnaies, médculles et bijoux, Y. 302. - (2) Voir le rupport de la commicsion de la revision de ls loi de brumaire, par S!. Vinent Carce, P. 9, $10 \mathrm{el} 11$. 
n’avons pas à jurger ici des raisons qui ont amené les plainles des bijouliers, mais re que nous voulons noter, c'est l'allitude gardéc par les orféres : ils n'ont pas rérlamé la liberté, ils aceptent la tutelle de l'État, il trowent bonne et profitable celte proanction qui rassuce l'acheteur el qui donne à leurs owres me garantie ollicielle.

Il y a pour eux un avantage réel à conserver celte garantie, mème en la payant d'un droit élevó, mais il faudrait que le poinçon d’ístat cü un caractère plus spécial.

Outre la nécessité de changer les poingons en usage et de remplacer les symboles qui ont été contrefaits à l'étranger(1), it y aurait lieu de revenir an anciens modes de marquer l'argent. Ies poinçons étaient d'un effet plus décoratif, ils ne déparrient pas la pièce sur laquelle on les frappait. ils étaient mis arec plus de goùt et de précaurlion, enfin ils avaient le prócieux avantage de donner mo date certaine à la pièce qui les porlicit.

Le baron J. P'ichon, qui est un juge autorisé, cxplique diuns le Calulogrue de lingonterie ancienne $^{(2)}$ que Louris XII, par une ordonnance du 12 décembre 1506 , prescrit l'emploi d’un econtre-poincon dont les maîtres jurés contre-marqueront les omragges des orferres, et qui sera chaque année enregistré à lil Chambre des monnaies et empreint sur une tilble de cuivre $\%$.

Ce contre-poingon n'était pas alors d'usage nouveau, ce n'étail que la réglemenLalion obligatoire d'une coulume ancienne qui consistait à marquer d'une lettre de l'alphabel la pièce d'argent, mais à changer cette lettre chaque annéc et à recommencer ì l'd après une période de vingt-trois années.

Ce fut le 5 février 1506 que fut insculpé le premier A a la Cour des monnaies, le B lui succédr le 10 dícembre 1507 , et cel usage dura jusqu'en 1783 , où le $\mathrm{V}$, ou plutòt l'U, fut insculpé le 12 juillet.

De 178 à 1789 , un poinçon de maison commune prétendu invariable fut donné à l'orf'verie de P'aris; cítait un P' ciangeant de formes tous les ans et portant les denx dernières lettres du millísine gravées en creux entre la couronme el le P.

Le P' de 1789 fut le dernier. Cel orilre si juste, si simple, si respectable, ne devail pas survive à la glorieuse monarchie qui l'avail fondé (3).

C'e n'est, ajonterons-nous, que depuis l'ébablissement du droit de marque en 1672 qu'ou peut reconnatite d'une facon absolument certaine la date de fabricalion d'une pirece d'orfévere par la comparaison du poinçon des fermiers généraux à la lettre du poincon de la maison commune el an poincon particulier ou marque de l'orfívere. On trouvera des renseignements très complets à ce sujet auprès du haron Pichon, de II. Eudel et de VI. G. Bapst, lequel a relevé lous les poinçons de maitres mème au delà de 1 jo6. C'est la connaissance approfondie des marques qui a permis aux experts de confondre certains truqueurs et de démontrer la fausseté des pièces imitées quils vendaient avec des poincons mal accordés entre eux. Depuis, ces faussaires sont de-

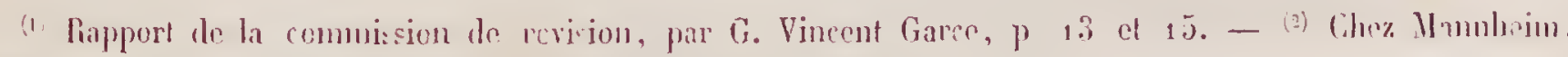

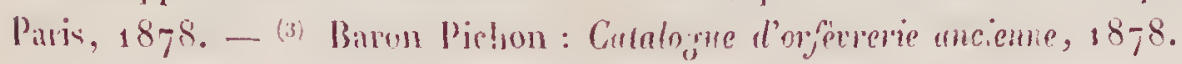


venus assez savants pour ne plus faire les mémes fautes, et leur adresse rend plus dangereuse encore la recherche de l'orfèreric ancienne.

Nous souhaitons que l'administration revienne à l'usage d'un signe qui permelte de dater les onvages d'orferrerie comme on date un live et me peinture; la raison qui avait fait adopter cet usage et l'avait fait conserver pendant des siècles n'a pas cessé d'ëtre bonne; nous estimons sans valeur l'objection des marchands qui craignent d'accuser l'ìge de leurs modèles et de les déprécier ainsi.

Du reste, nous le répétons arec joie, la bonne foi des orfèrres est absolue, it y a des corporations aussi lionnêtes et aussi respectables que la leur, il n'y en a pas de plus loyale : l'orfèvre a toujours eu cette belle réputation de droiture, c'est un honneur d'appartenir à un métier qui n’a jamais démérité dans sal longue histoire et qui a conquis le respect du monde entier.

Aussi la loi qui régit l'orfèrrerie n'est pas une loi de surveillance ef de suspicion, mais une loi de confance et de garantie : loin de redouter la tutelle de l'État, l'orfére la réclane et s'en prévaut. Du rapport de la commission de revision de la loi de brumaire, nous ne voulons pas extraire toutes les parties qui ont trait à l'orfévreric; nous renverrons ceux qui s'y intéressent particulièrement, au travail très complet de M. Vincent Garce.

Mais il convient de rappeler que c'est dans le courant de l'année 1889 que fut nommée, par le Ninistre de funances, une commission extra-parlementaire pour la revision de la loi qui réglemente la fabrication et la vente des objets d'or et d'argent.

Cette commission, présidéc par le Ministre des finances, n’a pas encore terminé ses travaux; elle a été composée de :

MiM. Dautresme, député, vice-président.

Dietz-Monix, sénaleur.

ToLanx, sénateur.

Jules Rocus, député.

Bunueav, député.

Prevet, député.

Ruau, direcleur général des monnaies et médailles.

Catrsse, conseiller d'État, directeur gónéral des contributions indirectes.

Marre, directeur du commerce intérieur au Ministère du commerce et des colonies.

Funant fils, vice-président de la Chambre syndicale des bijoutiers, joailliers el orfères.

Ganldand fils, vice-président de la Chambre syndicale des brjouliers, joaillier's et offérres.

LaBie, membre de la Chambre syndicale des bijoulier's, joaillier's et orférres.

Labocrua , membre de la Chranlore syndicale des lijoutiers, joaillier's et orfèves.

Y ont été adjoints avec voix consultative :

MII. Ricue, directeur' des essais à l'Administration des monnaties.

GaL, essayeur au bureau des garanties.

Les délégués de l'industrie ont voulu, pour se mieux éclairer sur les intérêts quils 
représentaient et pour acquárir phus d'antorité dans lis commission, se faire assister par leurs confrères, et, le $/ 1$ juillet 1889 , tous les intŕressés ont étri comvoqués en ansemblée et ont nommé quatorze représentants, lijouliers, joaillicers, horlogerers ef orféres; parmi ces derniers nous relevons les noms de M. Hénin el de II. Puiforcat. Cir sont enx que sadjoignit II. Flamant, membre de la commission extra-parlenentaire,

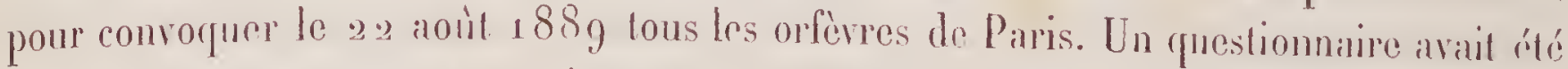
préparé el enrojé par avance ì tous les intéressés, les points relatifs à l'éfude de la loi araient élé précisés, ef nous ne croyons pas indispensable de les reprodure ici. Maris il nous semble nécessaire de donner comme document le résultal sucrinct de cette encuète sous la forme de rous; ces vour ont été transmis par la chambre srudicale à la commission d'enquète, et il en a été tenu comple dins le rappont de Vi. Vincent Girrce. C'est un document quil importe de conserver aussi dims le rapport du jury de la classe 24 , car il correspond exactement comme date, il est l'expression fidide de l'opinion des orferres, il reflète les tendances commerciales el les besoins industriels; c'est en un mot le résumé le plus concis el le plus sincère de l'opinion des onfèreses parisiens en $188 \mathrm{~g}$.

\section{REVISION DE LA LOI DU 19 BRUMAIRE AN VI.}

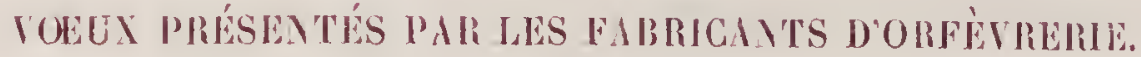

\section{EABRICATION}

Interliction de fabriquner sans déclaration légale.

Ol,ligation du poincenon du maître.

Interdiction d'apposition de poinçons ou marques de fantaisie.

Factures de vente mentionnant le titre des ouvrages et la nature des poincons apposés.

COMMERCE.

Ohligation de déclaration légale pour les négociants.

liactures de vente mentionnimt le titre des ouvrages, la nature el lorigine des poincons apposés.

Interdiction de rentes publiques de marchandises neures frauçaises ou étrangères.

$$
\text { OHFĖVHERTE D'IMITATION. }
$$

Obligation pour les falnricanls de unarques indicatrices de la nature, ue pouraut anener de confusiou arec les poinçons de l'État.

\section{CONSOUHATION IATÉRIEURE.}

Ilaiulien du $1^{\text {er }}$ litre à 950 milliènes.

Riclèvement du $2^{e}$ titre à 825 millièntes.

Liberté d'allier l'argent à tous tnétaux, la quantité de lin l'égłennentaire restant observée.

Extension de la lolérance pour les objets creux et soudés portée à 20 millièntes.

Interdiction en France de tonie rente à litres inférients. 
ESS $1:$ S.

Service des essais confié à l'Étal.

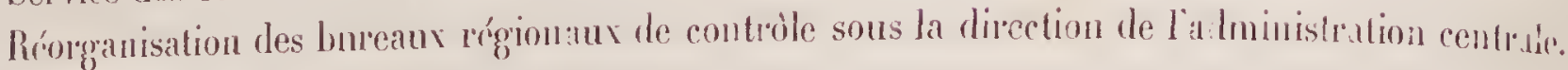
Sippression de l'essai au touchau.

CONTRôLe.

Contròle olliggatoire.

Création de nouveaux poinçons.

Simplification dans leur nombere ef daus lenr emploi.

Protection des poincons d'ítat ì l'ŕltanger.

'Taxes d'essais et de contrö̀.e réduites antant que possible.

INPORTATION.

Conformité de traitement pour les articles d'importation.

Sounission des nóģyocianls inportateurs anx cilligations imposćes au comnerce national.

\section{EXPORTATION.}

Liberté de falmricalion ì tons titres saus entraves administratives.

Suppression des visites dans les atelicrs.

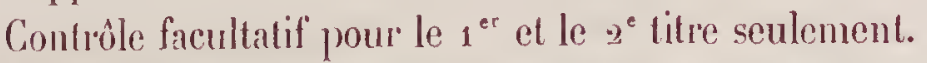

Ifrranchissement complet des droils réservé exclusivement aux produits nationaux exportés.

Suppression de cette faveur pour les articles étrangers importés el réenportés.

Lir cas de retour, simplification des formalités en donane par la présence d’inspecteurs de la gatrantic.

$$
\text { pÉxALITÉS. }
$$

Édiction de pénalités proportionnelles aux délits.

Comparution arant poursuites au correctionnel devant le juge d'inst'uction.

Constitution diune commission arbitrale de fabricants et marchands appelće à consultation par les maigistrals.

Cette pièce me dispense d'entrer dans de plus Jongunes explications relativement ì la loi de garantic et aux rapports de l'orfévre avec le burean du conlròle. Il ne faut rien préjuger de ce qui sortira de l'enquête en cours, et il appartiendra aux Chambres de faire la loi nouvelle ${ }^{(i)}$.

Mais ce qu’il importe de faire ressortir, c’est la volonté expriméc par tous les orfères français de conserver le contrôle obligatoire de l'État, de maintenir, pour la consommation intéricure, le titre de 950 millièmes de fin el de relever le deunième litre; de ne réclamer la liberté de fabriquer à un titre inférieur que pour l'exportation sculrment, sans apposition de poincon de garantic, et suivant les seules règles des pars aniquels seraient destinés les produits exportés.

L'obligation découle pour les orfères étrangers de se conformer aux lois françaises

1) Pour tout ce qui est relatif a la loi de hrumaire, aux usarres de la franonlie, aux marques, poincons,

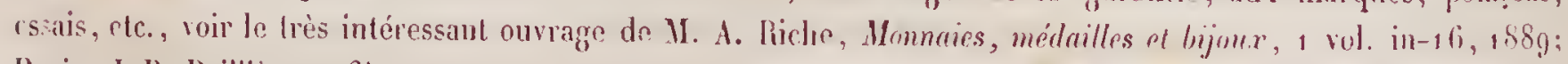
Paris, J.-I3. Baillière et fi's. 
sils reulent introduire leurs produits en France; ils y seront soumis comme les orfères français aur droits et regglements de la garantie, sans aucune des immunités dont ils jouissaient autrefois aux dépens de nos nationaux.

Il est une question cependant que nous croyons utile de dégager du rapport de la commission d'enquête puisqu'elle touclıe ì la valeur de l'argent, ef fu'clle grrève le prix du métal fahriqué.

En 1797, quand la loi de brumaire fut édictée, l’article 2 a fixail le droit de garantic à 1 franc par hectogramme d'argent, non compris le droit d'essai (1).

Par application des lois du 30 mars 1872 et du 30 décembre 1873 , ce droit a été élevé pour l'or el pour l'argent, soit pour l'orfèverie d'argent :

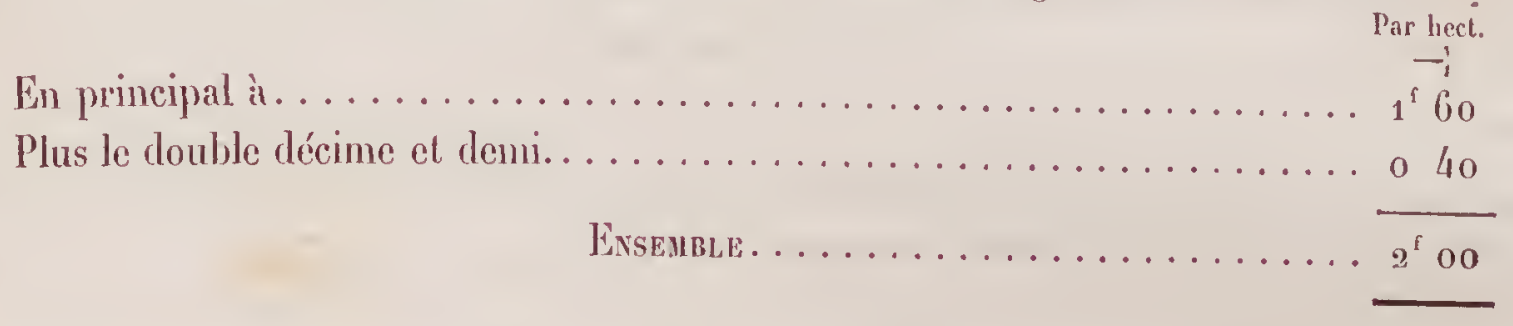

En conséquence, en l'an vi, c'est-ì-dire quand l'argent valait 230 francs le kilogramme, il payait un droit de 10 francs ou de 4.34 p. 100 ; en 1889 quand il ne raut plus que 155 franes le kilogramme, il paye 20 francs $0 u 12.9^{0}$ p. 100 de la valeur.

Il y a certainement là un abus, car les droits sont en raison inverse de la valeur du métal, et, suivant ce rapport, n’ont pas été doublés mais triplés.

La commission demande que le droit de garantic ne puisse pas excéder 10 p. 100 de la valeur de l'argent.

Le prodhit de ces droits aurait pu être donné ici, et nous avons trouvé près de II. Castan, directeur du hureau de la garantie de Paris, l'accueil le plus obligeant. Il nous a permis de prendre tous les renseignements qui nous étaicut utiles dans son service, et nous lui devons l'état des droits de garantie depuis 1852. Mais cet état comprend les droits perçus sur l'or et sur l'argent, sur la bijouterie et sur l'orfévrerie. 11. n'est done pas absolument utile à notre démonstration de copier cet état tout entier. Tous en eatrayons seulement les chiffres des années comprises entre l'Exposition de 878 et l'Exposition de 1889 :

\begin{tabular}{|c|c|c|}
\hline & Droits. & Droits. \\
\hline 1878. & $4,308,615^{r} 82$ & $3,477,482^{f} 68$ \\
\hline 1879. & $4,139,011 \quad 06$ & $3,083,15966$ \\
\hline 1880. & $4,887,00230$ & $2,997,17140$ \\
\hline 1881. & $4,77^{6,663 \quad 42}$ & $1887 \ldots \ldots \ldots \ldots 2,982,403$ o9 \\
\hline 1882. & $4,601,696 \quad 11$ & $1888 \ldots \ldots \ldots \ldots 3,029,09730$ \\
\hline 1883. & $4,136,591 \quad 08$ & $1889 \ldots \ldots \ldots \ldots 33_{241,431} 24$ \\
\hline
\end{tabular}

(1) Pour les droils d'essai sur largent, voir le livre de M. Riche, p. 267.

Cunse 24. 
La décroissance de ces chiffres jusqu’i l’année 1887 n'élait pas faite pour disposer l'administration des contributions indirectes à faire droit ì notre requète, mais depuis trois ans les inventaires se relèvent. D'ailleurs c'est au remboursement des droits ì l'exporlation quil faut attribuer cetle dimimulion des recettes, ainsi qu’à l'abaissment des affaires de bijouterie, tandis que l'orfèrerie d'argent est en pleine prospérité.

Nous avons pu relever tous les chiffres des quantités d'or el d'argent présentées au bureau de la garantie de Pirris depuis l’année 1818 , el c’est encore aux persévérantes recherches de MI. Castan que nous devons d'avoir pu compléter cet état : il nous parait assez curieux pour que nous l'annexions ì ce rapport, c'est une pièce présentant un caractère officiel et documentaire ${ }^{(1)}$.

Mais ici nous ne donnons que le résumé des amnées 1878 i 1889 avec les quantités d'argent soumises à la marque dans tous les bureau de garanlie de la Rípublique.

Nous jugeons inutile d'y joindre les relevés d'imporlation et d'exportation. Ce serait fairc double emploi arec les états que nous emprunterons aux services des douanes.

\begin{tabular}{|c|c|c|c|}
\hline & $\begin{array}{l}\text { Poids d'argent } \\
\text { soumis aux droits } \\
\text { de garantie. }\end{array}$ & & $\begin{array}{l}\text { Poids d'argent } \\
\text { soumis aus droits } \\
\text { de garantie. }\end{array}$ \\
\hline $1878 \ldots$ & $7^{6,384^{k} 800^{(2)}}$ & 1884. & $75,282^{k}{ }^{k} 48$ \\
\hline 1879 & $7^{3} .79^{4} \quad 555$ & 1885. & $74.465 \quad 734$ \\
\hline $1880 \ldots$ & $7^{5} .499850$ & 1886. & $7^{3,649} \quad 69^{2}$ \\
\hline $1881 \ldots$ & $82,09^{\circ} \quad 600$ & 1887. & 75,142539 \\
\hline 1882 & 82,201000 & 1888. & $78,7^{6} 9356$ \\
\hline 1883. & $82,235 \quad 217$ & 1889. & 84,121483 \\
\hline
\end{tabular}

L'année $\mathbf{1} 889$ marque le chiffre le plus élevé qu'on ait jamais conslaté aur bureaux de la girantie.

Le lotal des matières d'argent poinçonnées en 1818 au bureau de Paris avail été de 28,584 kilogrammes. Il n’a jamais dépassé 54,33 a kilogrammes pendant la Restauration. Sous le gouvermement de Juillet, nous observons de curieuses variations : le minimum est de 27.240 kilogrammes d'argent en 183 , et le maximum de 64,674 kilogrammes en 1845 . La révolution de 1848 fait tomber le poids de l'orférerie contrôlée à 18,807 kilogrammes, mais clle se relève immédiatement après cette année de panique où on avait détruit plus d'argenterie qu'on en avait produit.

Nous n'avons pu trouver dans les comptes de la garantie pour l'année 1851 que le résultat des six premiers mois tant pour l'or que pour l'argent, soit, pour l'orfèvrerie, 21,715 kilogrammes pour la moitié de l'année; les feuillets relatifs au denxième semestre ont été arrachés du registre de l'administration ${ }^{(3)}$.

(1) Voir tableau $A$ à la fin du rapport.

(a) Quoique l'usage au bureau de la garantie soil de chiffrer les quantités par heclogrammes, nous avons cru mieux laire en les présentant ici par unité de kilogramme.

(3) Pour remédier' à ce qu'aurait eu d'anormal ce 
Sous le second Empire, en farisanl abstraction de l'amnée 1870 , le chilliere minimum est de 47,46g hilogrammes en 1854 el le chiflie maximum de $58.995 \mathrm{ki}$ logrammes pour 1869 ; lit gruerre fait fléchir les quantités d'argent contrôlé ì 32,210 kilogrammes en 1870 et à $35,00 /$ kilogrammes en 1871 , mins, aussilot. après, l’undustrie des métaux précienx se relève el après quelques fluclualions elle parvient à une prospérité jusqu'alors ignorée.

Nous attirons l'attention d'une facon toute spéciale sur notre graphlique ${ }^{(1)}$. On y verra que la bijouterie d'or a suivi de $187^{2}$ à 1881 une progression sensible; mais depuis elle a diminué de moitié.

L’orférrerie est restée plus longtemps stationnaire, marquant mème des oscillattions curicuses à observer; mais, dis 1872 , elle remontait à 56,780 hitogrammes pour Parris et, depuis, n’a pas cessé de croìtre. Les chiffres du contröle pour 1889 accusent 71,537 kilogrammes pour Paris el 84,421 kilogrammes pour la France entière.

Arant d'abandonner ce tableau de la garantie, nous croyons intéressant de mettre en regard les chiffres correspondant aux années des grandes Expositions internationales, depuis et y compris 1851 , et à cet effet nous rébablissons la moyenne probub)le de celte annéc-lì.

COMPARAISON DES QUANTITÉS D'OR ET D'ARGENT MARQUÉES AU BUREAU DE PARIS PENDANT LES ANNÉES D’EXPOSITIONS UMIVERSELLES.

\begin{tabular}{|c|c|c|c|}
\hline A TXÉES. & EYPOSITIONS. & $\begin{array}{l}\text { BHJOUX DOR } \\
\text { COstrólés. }\end{array}$ & $\begin{array}{c}\text { ORFEYRERIE } \\
\text { D'ARGEXT } \\
\text { controlée. }\end{array}$ \\
\hline 1851 & 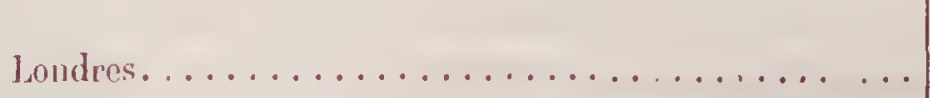 & $\begin{array}{l}\text { hilogrr. } \\
3,91 \text { ? }\end{array}$ & $\begin{array}{l}\text { kilogr. } \\
\text { /อั,330 }\end{array}$ \\
\hline 1855 & 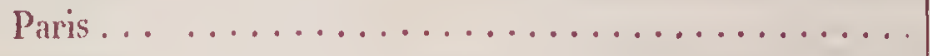 & 5,188 & 55,701 \\
\hline 1862 & 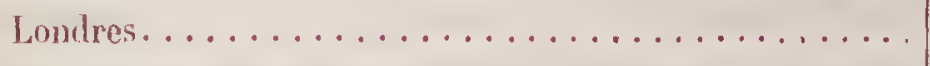 & 6,641 & $53,79^{h}$ \\
\hline 1867 & 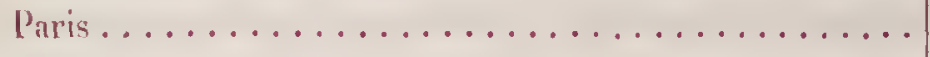 & 6,979 & 55,036 \\
\hline 1873 & 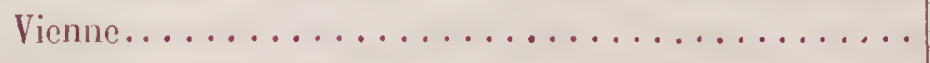 & $7,9.5 \%$ & 53,438 \\
\hline 1878 & 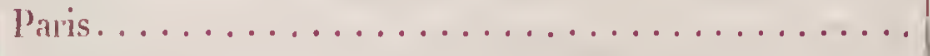 & 8,307 & 60,908 \\
\hline 1889 & Paris ............................ & 4,767 & 71,537 \\
\hline
\end{tabular}

Cet cramen rétrospectif est de nature à donner confiance, il démontse les progrès constiunts de l'orfèrrerie; s'ils sont plus lents que ne l'élaient d'abord cenx de la bijouterie, ils sont plus róguliers et tout présage une suite prospère. Nous allons essajer de démontrer par quels moyens on y doit tendre.

chiffre dans notre diagramme, nous avons, d'accord avec le directeur de la garantic, rétabli la moyenne probable de l'année 1851 , jair le rappont des six mois connus aux unois correspondants des années $1850 \mathrm{el} 18.5 .3$.

(1) Voir lableau $A$ à la suile du rapport. Il ne contient que le: chitfres du bureau de Paris. 11 serait diflicite de reconstiluer la production entiere de la province, les documents relatits aux autres hureaux ayaut ćlé délruits en 1871 . Cependant une partie de ces ćtals a ćté rélablie et on les trouverait dans le Bulletin de stılistique ot de légrislation comparée, publié pal le Minislère des finances (1mprimerie Vatio:tale, 1.88 ' , p. 39?) 
L'orfèrrerie est bien organisée. Elle a Parris pour centre de production, elle possède le marché français en totalité et rayonne par un sysstème des plus simples dans toutes les villes de province.

Nous arons ru combien rares sont les fabricants d'orfèvrerie dans nos départements, mais, par contre, nous pourrions chiffrer par milliers les marchands qui vendent des articles de vaisselle en argent on en ruolz; il n'y a pas une petite ville qui n'ait son orfèvre, jentends par là un horloger, un bijoutier, un opticien faisant en grand ou en petit le coumerce de l'orfèvrerie; ce sont les intermédiaires entre les consommateurs et le fabricant. L'orfèvrerie est un luxe tellement nécessaire que le rôle du marchand d'orfèvrerie vraie ou imitée s'impose partout comme un hesoin, il y a des tarifs connus et acceptés qui laissent un écart suffisant pour faire vivre l'intermédiaire; les cours de l'argent, les taux de la façon sont réguliers et les manufactures d'orfèrrerie ont la sazesse de se ménager entre elles; les fabriques ne sont pas assez nombreuses pour se fiire une concurrence ruineuse, la diversité des modèles aide à cette entente loyale et, de la sorte, il se fait un perpétuel écoulement de Paris, centre de fabrication, à toutes les villes grandes ou petites et jusqu'aux moindres communes, où l'on consomme des articles de qualités diverses. La loyauté, que nous nous plaisions à constater tout à l'heure, préside ì tous ces rapports et je n'écris pas ceci par complaisance; jail fait moi-mème mon enquête à ce sujet auprès des principaus orfèrres parisiens: tous m'ont dit que les relations étaient faciles, courtoises, réģulières, entre eux et leurs correspondants des départentents. Des voyageur's aident à ces relations, stimulent les affaires, proposent les modèles nouveaux, rapportcut aux patrons les observations des clients.

Il faut comprendre combien ce commerce est privilégié, les marchandises se démodent noins que d'autres, elles ne sont pas sujettes à des araries et à des pertes: s’it s'agit d'argent la matière garde sa valeur entière. S'il s'agit de cuivre on de nickel, il suflit d'un simple brunissage ou d'un bain, à la rigueur, pour rendre au métal son éclat et plusieurs grandes maisons de Paris, qui ont des dépôts en province, renouvellent leurs stocks et remplacent les marchandises démodées ou défraichies. De cette façon d'opérer, il résulte que le commerce de l'orfèvrerie est resté plus qu'un autre en possession de ses débouchés. Il n’a pas été accaparé comme le commerce des tissus, de la confection et de l'alimentation mème. Il n'a pas eu non plus à souffrir de la concurrence étraugè̀re. Il est dífendu par son titre, par ses lois de garantie, par ses modèles, par la bonne foi réciproque, par l'habitude et l'usage et c'est ainsi que l'orfèrrerie française jouit du marché français sans partage et pour le bien de tous.

En veut-on lia preuve?

Lal production annuelle moyenne pour l'intérieur de la France étant de 62,506 kilogrammes, l'importation moyenne annuelle n'est que de h,112 kilogrammes ${ }^{(1)}$. Done, les étrangers, hien quilils trouvent notre mirrché ouvert, et quilis puissent y faire entrer

(1) Extrait du Bulletin de la Chambre syndicale de la bijonterie, de la joaillevie et de l'orférrerie, rapport de M. Flamant, séance dı 16 décrmbre 18 go. 
lenrs produits d'argent au $1^{\text {er }}$ et au $2^{\circ}$ titre, en se sommellant au controble el en paryant un droit minime, n'ont pu nous enlever que $6 \frac{1}{2}$ p. 1 oo de la consommation.

Encore exportons-nous plus quils n’imporlent en France.

On paralyserait sensiblement cette concurrence, en faisant droit à la demande des orfèves, c'est-à-dire en élevant à 825 millièmes de fin le $2^{\mathrm{e}}$ titre et en refusant aux produits de provenance étrangère le remboursement des droits de contròle à la sortie. Car presque toules les affaires d'orfèrerie étrangère se traitent arec des articles d'argent bas à 800 millièmes, qui entrent en France et qui profitent de la faculté de remboursement des droits, s’ils restent invendus.

Il est hien permis d'imposer à nos concurrents étrangers les conditions qui nous sout faites à nous-mêmes.

Dans une récente étude sur la situation de l'orférreric à l'Exposition de 1889 notre confrère II. Hénin a donné des chiffres que nous relevons avec beaucoup d'intérêt, surtout en ce qui toucle la fabricalion des couverts : par sa situation et sa grande cspérience de ce genre d'affaires M. Hénin est mieux renseigné qu'aucun autre.

La consommation industrielle de l'argent, qui n'était en 1867 que de 66,000 kilogrammes environ, est en moyenne depuis dix ans de 80,000 kilogrammes répartis comme suit :

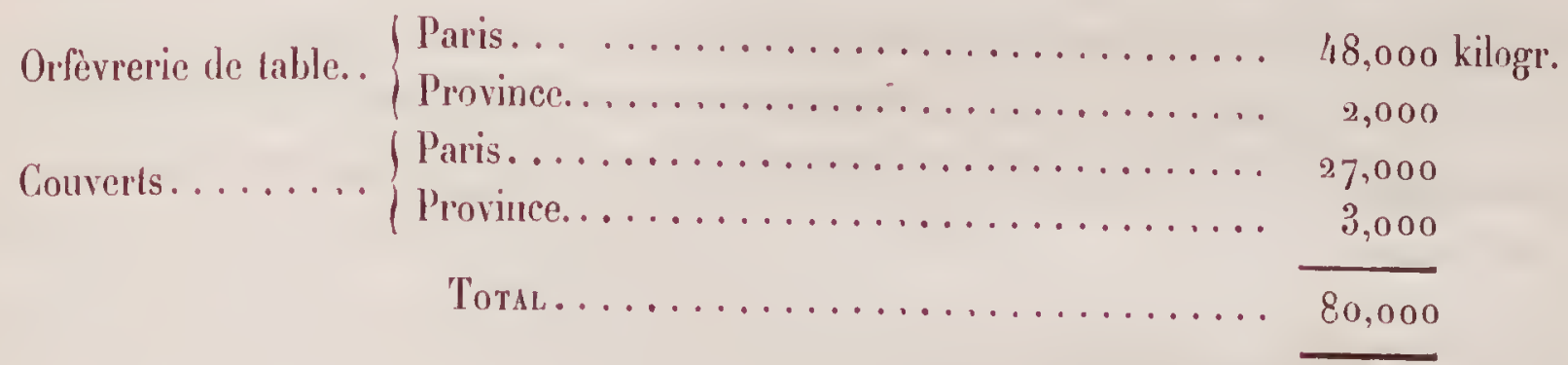

Qu'on ne dise pas qu'il y a une contradiction entre ces chiffres et ceur que nous iudiquons plus haut, ce ne sont ni les relevés de consommation intérieure, ni les états de la garantie; c'est la consommation des fabriques d'orfèrrerie et nous reproduisons ces chiffres pour indiquer :

$1^{\circ}$ Que les atcliers de Paris absorbent 75,000 kilogrammes et ceus de la province 5,000 kilogrammes seulement;

$2^{n}$ Que sur ces 80,000 kilogrammes on en transforme:

Pour l'orfèvreric proprement dite................. 50,000 kiloggr.

Pour les couverts spécialement................. 30,000

Total................ $\overline{80,000}$

Nous aurions voulu indiquer la force de la production de l'orfèvreric d'imitation arec autant d'exactitude que nous l'avons fait pour l'orfèrerie d'argent, nous ne sommes pas en mesure de le faire. Si de quelques maisons nous arons obtenu des domnées, elles nous manquent pour d'autres fabriques; il n'y a d'ailleurs aucun contròle pour ces 
rrticles; jadis on ponvait faire arec précision ces calculs pour le plaqué, parce qüil tait soumis à la marque.

Le senl document que nous ayons est une slatistique dressée par la réunion des faBricauts de bronze de Paris el donnant pour l'année 188 a les chiffres d’importilion ot d'exportation de l'orfèvrerie argentée.

\begin{tabular}{|c|c|c|}
\hline - & IMPDTTTIOX. & expontation. \\
\hline Allemaggie. . . . . . . . & $201,34 o^{\mathrm{r}}$ & $131,580^{f}$ \\
\hline$\ldots \ldots \ldots \ldots \ldots \ldots \ldots$ & 344,940 & 81.080 \\
\hline 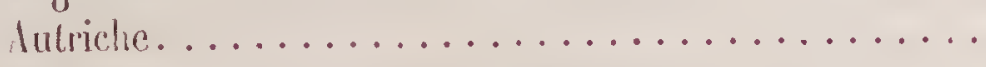 & $2 \cdot, 8 \cdots 0$ & " \\
\hline 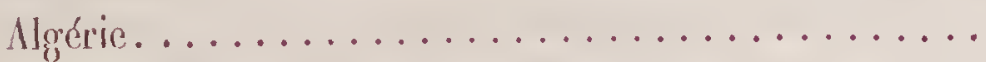 & " & 197,620 \\
\hline Belgique. . . . . . . . . . . . . . . . . . . . & 28,900 & " \\
\hline 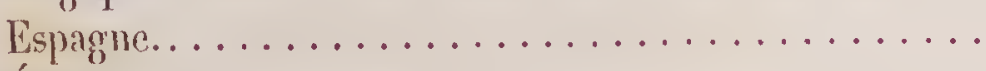 & " & 163.460 \\
\hline Etats-Unis $\ldots \ldots \ldots \ldots \ldots \ldots \ldots \ldots \ldots \ldots$ & " & 109.960 \\
\hline Japon . . . . . . . . . . . . . . . . . & $96.9 / 40$ & " \\
\hline 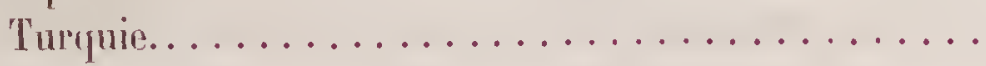 & $"$ & 87.160 \\
\hline Suisse $\ldots \ldots \ldots \ldots \ldots \ldots \ldots \ldots \ldots \ldots \ldots$ & 7,600 & " \\
\hline Autres pays.... $\ldots \ldots \ldots \ldots \ldots \ldots \ldots \ldots \ldots$ & 24,420 & 512,580 \\
\hline Totaix. . & 656,960 & $1,283,440$ \\
\hline
\end{tabular}

Nos exportalions dépassaient donc de 626,180 francs les importations, c'est-it-dire que nous fournissions à peu près le double de ce que nous recerions du dehors(1).

C'était un bon résultat, mais il pourrait ètre cependant meilleur. J'Angletrre nous fomrnit quare fois plus qu'elle ne reçoil de nous: si les modèles anglilis conviennent à nos goûts el si les nôtres ne conviennent pas aux mours anglaises, pourquoi nos fabricants n̈imitent-ils pas les types confortables de l'orférrerie d'outre-mer; ils reprendraient ainsi ce quils perdent sur notre marché et ils auraiont chance de s’introdnire sur le leur.

L'Allemagne nous a enlevé la Belgique, elle inonde les colonies, mais elle recoit de nous plus d'orfirrerie que n'accusent les chiflres cités : nous cxpédions à l'Allentagne des produits bruts avant l'argenture, afin d'éviter les droits considérables (que payent les produits argentés. On les argente et on les brunit de l'autre coité de la frontiòre.

lidutriche fabrique en abondance, elle ne nous achète plus et nous envoie au contraire des articles vojants et légers.

L'Fspagne el le Porlugal restent avec l'Amérique du Sud nos meilleurs clients. Les affaires ont baissé arec l'Ltalie el l'élévation des droits a rédnit notre exportation aux ÉtalsUnis. Mais la consommation intérieure dépasse dans d'énormes proportions nos chiffres d'exportation; il en est ainsi de l'orfévrerie d'argent et de l'orférerie argentín. On a calculé que si la France produit annuellement 14,000 ì 15,000 donzinines de converls d’argent, clle n’en fait pas moins de 250,000 donzaines en métal blane. lue reste à l'avenant.

(1) Il conviendrait cepeudant d'ajouter à ces chiffres d'exportation les articles d'orferrerie qui sortent de lrance à l'élat brut et sunt argentés à l'étranger; la scule usine de Pforzheim en reçoil ponr un somme de 1,800,000 fiancs que consomment les pays allomands. 
On trouvera plus loin le lablean de notre commerce extéricur et le relevé des donanes. Avant d'examiner ces chiffres et d'aborder lis questions des tarifs, nous voulons dire quelques mots de nos relations extéricures; nos exportations dépassent aussi pour l'argenterie les importations et nous trouvons pour la moyenne des années deruières ${ }^{(1)}$ :

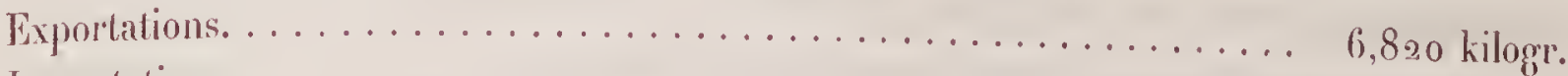

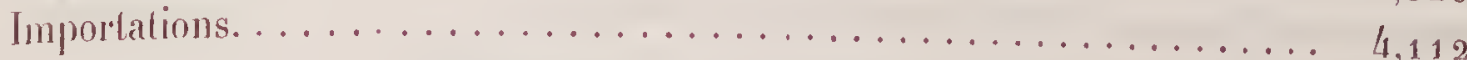

Différence en notre faveur............ $\overline{2.708}$

Nais là encore c'est un résultat très insuffisant; l'Allemagne et l'Angleterre se dispulent à parts ágales notre importation ${ }^{(2)}$ et il sulfirait d'un pen de tenacité pour augmenter nos relations exléricures. Examinons notre situation avec l'étranger pour les articles d'orfèrerie. J'ai questionné un grand nombre de mes confrères et voici le résumé des observations que j’ai recueillies.

\section{GRANDE-BRETAGNE ET COLONIES ANGLAISES.}

Les droits élevés que frappait sur l'argenterie la douane anglaise fermaient absolument ì notre commerce le marché britannique. L'abolition récente de ces droits permeltrait d'espérer d'importantes affaires si le peuple anglais n'était attaché d'une facon si particulière à ses usages. II y a pour l'orfévrerie des formes et des traditions consacrées, nos modiles n’ont pas clance d'ètre acceptés par la grande masse du public qui consomme. Les négociants anglais sont aussi peu disposés que leurs clients à accepter nos produits; on ne pourra vaincre cette résistance qu'avec des oljets d'art d'une qualité supéricure ou des produits d'un extrême bon marché. Il est à remarquer que les orferres anglais nous empruntent nos artistes scnlpteurs, dessinateurs et cise. leurs; leurs meilleures fabriques ont des collaborateurs francais. Cette manière d'agir

(1) Voici les chiffres fournis par M. Castan, sous-directeur de la garantie, à la Clıambre syndicale (séance de la Chambre sundicale du 16 décembre 1890$)$ :

\begin{tabular}{|c|c|c|c|c|c|c|}
\hline \multicolumn{3}{|c|}{ EXPORTATIONS. } & \multicolumn{3}{|c|}{ INPORTATIONS. } & \multirow{2}{*}{ DIFFÉR ENCE. } \\
\hline ANXÉFS. & poids. & MOYEXYE. & ANXÉES. & POIDS. & MOYENNE. & \\
\hline $\begin{array}{l}1887 \ldots \ldots \ldots \ldots \\
1888 \ldots \ldots \ldots \ldots \\
1889 \ldots \ldots \ldots \ldots\end{array}$ & $\begin{array}{c}\text { kilogrammes. } \\
7,, 160 \\
5,883 \\
7,4_{17}\end{array}$ & $\begin{array}{c}\text { kilogrammes. } \\
6.820\end{array}$ & $\begin{array}{l}1887 \ldots \ldots \ldots \ldots \\
1888 . . \ldots \ldots \ldots \ldots \\
1889 \ldots \ldots \ldots \ldots\end{array}$ & $\begin{array}{c}\text { kilogrammes. } \\
3,665 \\
3,824 \\
4,857\end{array}$ & $\begin{array}{c}\text { kilogrammes. } \\
4,112\end{array}$ & $\begin{array}{l}\text { kilogrammes. } \\
\qquad \begin{array}{l}3,495 \\
2,059 \\
2,560\end{array}\end{array}$ \\
\hline
\end{tabular}

(2) Importations par pays, anuée 1880 . (Renseignements fournis par M. Castan.)

\begin{tabular}{|c|c|c|c|}
\hline Allemagne................... & $1.660^{k}$ & Russie .................... & $146^{k}$ \\
\hline Autriche...................... & $33_{2}$ & Étals-Unis. . . . . . . . . . . . . . . . . & 323 \\
\hline 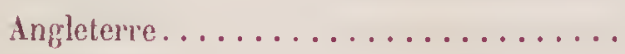 & 1,505 & Autres pays.................... & $4 \overline{1} 7$ \\
\hline Brlgique..................... & 109 & \multirow{3}{*}{ T'oraL.............. } & 4.857 \\
\hline ollande. ................. & 123 & & 1,807 \\
\hline lie. & 202 & & \\
\hline
\end{tabular}


se poursuit depuis 185 . Nous arons dit prócédemment notre opinion sur l'orférerio anglaise; nous n'y revenons pas; mais nous crofyons quil y a en Angleterre asse\% de grens de goût, de grandes fortunes, d'artistes éclairés pour ne pas aider à l'introduction de nos meilleures orfèvreries, si nous agissions avec intelligence, avec persévérance, maintenant surtout que les droits protecteurs ont été abaissés. C'est ì nous de ne pas provoquer leur relèvement par des mesures maladroites.

Nous devons à l'obligeance du directeur dı Coldsmiths' Hall de Londres la statistique suivante ${ }^{(1)}$.

POIDS TOTAL DE L'ORFĖTERIF D'ARGENT MANUEACTURÉ Á LONDRES

PENDANT LES DIX DERNILRES ANNÉES.

\begin{tabular}{|c|c|c|c|}
\hline & Livres troy. & & Lirres Iroy. \\
\hline $1881 \ldots \ldots \ldots \ldots \ldots$ & $68,959^{(2)}$ & $1886 \ldots \ldots \ldots \ldots$ & $7^{0,6} 7_{7}$ \\
\hline $\begin{array}{l}1882 \ldots \ldots \ldots \ldots \ldots \ldots \\
1883 \ldots \ldots \ldots \ldots \ldots \ldots\end{array}$ & $7^{4,4,400}$ & $1887 \ldots \ldots$ & $7^{2,148}$ \\
\hline $1884 \ldots \ldots \ldots \ldots \ldots$ & $\begin{array}{l}78,179 \\
81,198\end{array}$ & $1888 \ldots \ldots$ & $7^{0,1 / 7}$ \\
\hline $1885 \ldots \ldots \ldots \ldots \ldots$ & 74,436 & $1890 \ldots \ldots \ldots \ldots \ldots \ldots$ & $\begin{array}{l}77,176 \\
86,757\end{array}$ \\
\hline
\end{tabular}

On voit que la progression est à peu près la même que celle que nous signalions en France; le rapport avec les chiffres de notre bureau de garantie est très curieur à noter.

Voici maintenant les renseignements très complets que j’ai obtenus du Custom-Ilouse de Londres; je me plais à reconnaitre la courtoisie et l'empressement que jail trourés dans tous les services en Angleterre et je regrette de n'avoir pu rencontrer la même bonne volonté près des représentants des autres nations.

ORPÈVRERE D'ARgeNT IUPORTÉE DATS LE ROYAUME-UNI DE 1880 A 1889 .

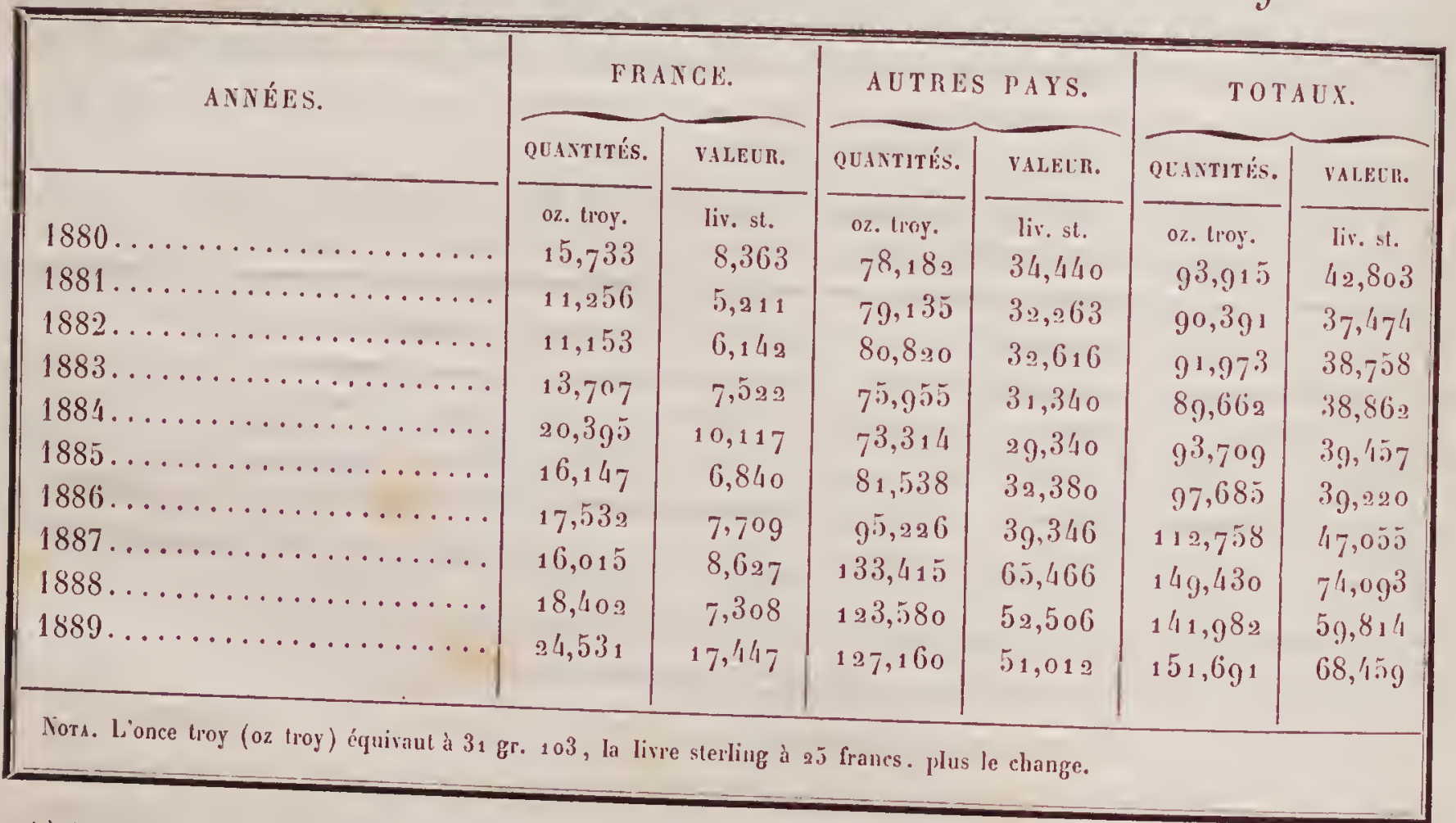

(1) Exlrail d'une lettre de B. Waller S. Pridram. - ${ }^{(2)}$ La livre troy usitée pour les mélaux précieux équivaut
373 gr. 24 . 
Nous signatons la progression croissante des chiffres d'importation, surtout en ce quii regarde la France. Il y avait eu me baisse sensible en 1881, 1882 et 1883 ; le mouvement a repris depuis ef l’importation française a dépassé de 60 p. o/ o ce qu'elle était il y a dix ans. Le marché anglais avec ses colonies est en réalité le plus liurge, le plus riche, le mieux achalandé qui soit, et les résistances sont bien plus apparentes que réelles. Les acheteurs y sont aussi avides de nouveautés qu'en d'autres palys et l'occision fourne par l'abolition des droits prohibitifs sur la vaisselle d'irgent ne doit pas étre manquée. Voici l'état de réexportation de l'orfèvrerie étrangère, c'est-ì-dire ce que les donanes renvoient au dehors de ce qu'elles avaient reçu. La différence constitue ce qu'en Firince nous nommons le commerce spécial.

Nous recommandons anx intéressés l'examen minutienx de ces chiffres; ils y verront par exemple qu'en 1888 il élait resté pen de chose en Angleterre des produits français, tandis quils ont été presque totalement absorbés par la consommation intérieure en $188 \mathrm{~g}$. Si c'est un résultat de l'abolition des droits et du prestige de l'wiposition franearse, il est plein d'encouragement.

ÉTAT MONTRANT LES QUANTITÉS ET VALEURS DE L'ORFÈVRERE D'ARGEYT ǴTRANGíRE

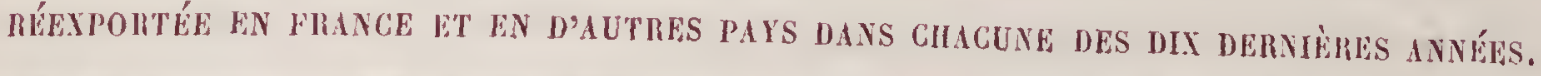

\begin{tabular}{|c|c|c|c|c|c|c|}
\hline \multirow{2}{*}{ ANNGE. } & \multicolumn{2}{|c|}{ F R A N CE. } & \multicolumn{2}{|c|}{ AUTRES PAYS. } & \multicolumn{2}{|c|}{ TOTAUY. } \\
\hline & Quintitís. & VALEUR. & QQUANTITÉS. & VALEUR. & QUANTITÉS. & VALEUR. \\
\hline $1880 \ldots \ldots \ldots \ldots \ldots \ldots$ & $\begin{array}{l}\text { oz. troy. } \\
2,421\end{array}$ & $\begin{array}{l}\text { liv. st. } \\
1,764\end{array}$ & $\begin{array}{l}\text { oz. troy. } \\
5,685\end{array}$ & $\begin{array}{l}\text { liv. st. } \\
2,372\end{array}$ & $\begin{array}{l}\text { oz. troy. } \\
8,106\end{array}$ & $\begin{array}{l}\text { lir. st. } \\
4,136\end{array}$ \\
\hline $1881 \ldots \ldots \ldots \ldots \ldots \ldots$ & 2,339 & 1,267 & 7,878 & 3,434 & 10,217 & 4,701 \\
\hline $1882 \ldots$ & 2,579 & 1,620 & 8,133 & 3,357 & 10,712 & 4,977 \\
\hline $1883 \ldots \ldots \ldots \ldots \ldots \ldots$ & 3,269 & 1,797 & 6,131 & 2,850 & 9,400 & 1,647 \\
\hline $1884 \ldots \ldots \ldots \ldots \ldots \ldots$ & $1,1,45$ & 610 & 8,105 & $3,2,5$ & 9,550 & $3,88$. \\
\hline $1885 \ldots \ldots \ldots \ldots \ldots \ldots$ & 546 & 313 & 10,279 & 5,040 & 10,8 a 5 & 5,353 \\
\hline $1886 \ldots \ldots \ldots \ldots \ldots \ldots$ & 2,665 & 1,293 & 9,569 & 4,024 & 12,234 & 5,317 \\
\hline $1887 \ldots \ldots \ldots \ldots \ldots$ & $3, \bar{\jmath} 28$ & 3,376 & 11,502 & 5,022 & 15,030 & 8,398 \\
\hline $1888 \ldots \ldots \ldots \ldots \ldots$ & 15,128 & 4,937 & 8,308 & 4,321 & 23,436 & 9,258 \\
\hline $1889 \ldots \ldots \ldots \ldots \ldots \ldots$ & 1,169 & 375 & 10, 彳11 & ధ,, 323 & 11,580 & 4,698 \\
\hline
\end{tabular}

On aurait tort cependant de considérer les chiffres de réimportation sur la France comme le retour absolu des marchandises qui en avaient été exportées, car ces chiffres contiennent une notable proportion d'articles allemands et américains qui premnent, pour entrer sur notre marclié, la voie anglaise.

Enfin, il reste à compléter ces documents par la statistique de l'exportation anglaise, c'est-à-dire de l'orfèvrerie d'argent que la Grande-Bretagne filbrique réellement et exporte. L'importance en est beaucoup moins grande qu'on ne l'imagine, mais il faut noter que cela ne comprend pas le commerce des colonies. 
GETT MONTRANT PAR POIDS ET VALEUR L'EXPORTATIOY DE VASSELLE D'ARGENT 1'ORIGINE ANGLASE PENDANT LES DIX DERNL̀̉ES ANNÉES.

\begin{tabular}{|c|c|c|c|c|c|c|}
\hline \multirow{2}{*}{ AXYGES. } & \multicolumn{2}{|c|}{ F RANCE. } & \multicolumn{2}{|c|}{ AUTRES PAYS. } & \multicolumn{2}{|c|}{ TOTAUX. } \\
\hline & QVHITITÉs. & PALEUR. & QLANTITÉs. & VALEUn. & QLATTITÉS. & VALEER. \\
\hline 1880 . & $\begin{array}{l}\text { oz. troy. } \\
22,040\end{array}$ & $\begin{array}{l}\text { liv. st. } \\
1 \mathrm{2}, 662\end{array}$ & $\begin{array}{l}\text { oz. troy. } \\
8 \Omega, 605\end{array}$ & $\begin{array}{l}\text { liv. st. } \\
46,748\end{array}$ & $\begin{array}{l}\text { oz. troy. } \\
10 / 1,6 / 15\end{array}$ & lir. st. \\
\hline $1881 \ldots$ & $3 a, 175$ & 20,778 & 109,317 & 50,639 & $141, / 992$ & 80,117 \\
\hline $1882 \ldots$ & 24,613 & 16,435 & 123,505 & 67,522 & 148,118 & 83,957 \\
\hline $1883 \ldots$ & 23,169 & 14,811 & 117,527 & 60,979 & 140,696 & 75,790 \\
\hline $1884 \ldots \ldots \ldots \ldots$ & $17,79^{4}$ & 11,271 & $87,27^{5}$ & 47,809 & 105,069 & 59,080 \\
\hline $1885 \ldots \ldots \ldots \ldots$ & 15,511 & 9,088 & 97,692 & 55,293 & 113,903 & $64,38_{1}$ \\
\hline $1886 \ldots$ & $20,49^{\circ}$ & 12,887 & 130,966 & $7^{1,379}$ & 151,156 & 84,366 \\
\hline $1887 \ldots$ & 19,984 & 11,918 & 101,322 & 58,799 & $121,3 \circ 6$ & 70,717 \\
\hline $1888 \ldots$ & 25,1183 & 14,899 & 140,503 & 78,908 & $166,07^{6}$ & 93,807 \\
\hline $1889 \ldots \ldots$ & 59,079 & $34,1,99$ & 172,123 & 97,067 & 231,502 & 131,266 \\
\hline
\end{tabular}

Nous tenons tous ces renseignements de source officielle. Nous avons en mains les lettres el les états signés du Statistical office, Custom-IIouse de Londres, et, si nous nous sommes borné à donner ici les chiffres de vaisselle d'argent ${ }^{(1)}$, c'est que l'orférerie d'or ne joue, chez les Anglais comme chez nous, qu'un rôle très effacé.

La plus forte quantité de vaisselle d'or qu'ait anmullement exportée l'Angleterre est de 814 oz. troy, ayint une valeur de 7,182 lives sterling.

Nous croyons inutile d'insister plus sur ces statistiques, dont le caractère apparaitra imx plus clairvojants el quiils devront comparer ì nos états de donanes, qu'on trourera plus Join.

Ce qu'il faut signaler, c'est l'intelligence des négociants angrtais à suive le mouvement commercial du monde, à noter les besoins de charpue pays, à profiter des oceasions qui s'offrent à eux. Ils n'ont pas seulement les oflices des ministères et les chambres de commerce; ils se tiennent dans chaque industrie au courant de la situation commerciale étrangère, et c'est ainsi qu'aux bureaux des Goldsmith's Hall, de Londres, nous avons obtenu immédiatement, avec les marques de la plus grande courtoisie, les renseignements les plus exacts sur la siluation de l'orfévrerie à Londres, el qu'on nous a introduit au Somerset House auprès du secrétaire de l'Inland Revenue et auprès du directeur des donanes ${ }^{(2)}$.

(1) Daus une lettre datée du 22 avril 1890, M. John Courroux m'avise, au nom des commissionnaires aux donanes de Sa Majesté, que les chiffres d'exportation qui m'ont été fouruis ne sont relatifs qu'à la vaisselle d'or et d'argent (gold el silver plate) sounise aux droits et ne comprenment aucun des articles de lijouterie qui entrent en Angleterre sans ètre cxaminés sous une rubrique spéciale.

(2) Dans cette mime lestre, le directeur de la maison des orfèvres ne répond que la baisse dı prix de l'argent n'a en sur la production de l'orfévrerie aucune influence appréciable. 
Il serait sonharibable que la chambre syndicale de Paris réunît chaque année les ćléments de stalistique commerciale qui intéressent ses clients.

L'orferercric d'imitation a d'importantes usines en Angleterre. C"est par mn accord lacite el depuis l'origne des brevets de dorme et d'argenture électro-chimique que la plus considérible des fibriques françaises s'est abstenue de faire concurrence, sur le marché angolais, ì la maison Elkington.

On ne peut qu'appliundir ì cette délicate facon d'agir; elle est tout à l'lonneur de maisons plus amies que rivales. Cependant il est regrettable que l'immense marché britannique reste ainsi perdu pour nos affaires et que les consommateurs anglais soient privés de jouir d'articles, dont la grande supériorité a été si bien constatée en 1878 que la fabrirque anglaise n’a pas osé, en 1889 , affronter une comparaison uouvelle.

l'orférrerie religieuse a pris un certain développement en Angleterre, gràce aux progrès de la religion catholique. Nos orfèvres ont là des sources d'affaires que n'accusent pis cependant les états de douane, car ce sont presque tous articles de bronze doré.

\section{PAYS SCANDINAVES.}

Le Danemark, la Suède et la Norvège peuvent-ils fournir à uns fabriques d'orfèvrerie des clances sérieuses d'iffaires? Nos confrères ne le croient pas; le titre de l'argent est en ces pay's de 825 millièmes et le contrôle est obligatoire. Nais nous arons vil arec intérét l'exposition des orfères de Copenhague, de Stockholm et de Christiania.

L'originalité de leur fabrication, le caractère national repris aux traditions antiques, ont escité la curiosité en 1889 comme en 1878 el ils ont réussi, dans une certaine mesure, à écouler ici quelques-unes de leurs marchandises, tandis que nous n’avons pas pu introduire chez eux l'usige de nos produits.

L'Exposition de Copenhague en 1887 a démontré la supériorité de l'industrie fran!aise. Plusicurs de nos confrères y ont joué un rôle important. MII. Christolle, FromentMeurice et Boin ont étŕ particulièrement remarqués en cette circonstance, mais il ne parait pas cependant que le commerce de luse ait en un succès comparable à celui qu'ont remporté nos artistes en Danemark. Les sympathies sont assez étroites entre les deux pays pour' 'qu'on essaie d'en profiter.

\section{BEIGIQUE.}

La loi du 5 juin 1888 , qui a supprimé le contrôle obligatoire de l'État et rendı libre la fabrication à tous titres des objets d'or et d'argent dans le royaume de Belgique, a cu pour conséquence de paralyser les affaires françases au profil des fabriques allemandes et sans qu’il en soil résulté aucun bien pour les Belges.

Aı contraire, les fibriques nationales ont été arrêtées. Les bijoux d'Allemagne, 
l'orfèrerie à bas titre des pays voisins ont envahi le marché et nous arons cessé de fournir aur Belges les produits plus honnétes el meilleurs, qu'ils appréciaient avant celte loi malheureuse. Ce n’est pas que, dans la haute société belge, si riche et si pleine de goût, les articles d'Allemagne l’aient emporlé sur les nôtres; non, mais on ne trouverait pas dans les états de douane des deux pays la trace des affaires particulières qui se négocient. La Belgique est si roisine que de tels achats se font directement à Paris; ils ne figurent pas an commerce d'exportation. Nous connaissons nombre de riches industriels et de représentants de l'aristocratie belge qui viennent en France fréquemment el y achìtent leur orfèvrerie et leurs diamants.

Bruxelles a de bons orfères qui cherchent à réagir contre l'influence néfaste des Allemands, et l'un d'eux a déjà réussi ì introduire ses travaux de ciselure à Cologne et à Francforl.

\section{HOLLANDE.}

Nous avons signalé l'abstention regrettable de MM. Van Kempen et fils qui araient eu en 1878 un succès très lonorable, à l'Exposition de Paris; mais l'Liposition d'Amsterdam n'a pas ouvert à l'orfèreric française le chemin des Pays-Bas. Il est sur. prenant que ce pays si riche, si commerçant, si intelligent des bienfaits de la forlune n’ait pas le goût du beau luxe de l'argent.

La fabrication et le commerce sont libres en Hollinde; le contröle des onrages d'or et d'argent est régi par la loi de $\mathbf{1} 852$, modifiée le 7 mai $185 \mathrm{~g}$, laquelle n'oblige à faire marquer du poinçon d'État que les articles d'un titre élevé.

Ces titres sont pour l'argent de 934 et de 833 millièmes de fin.

La conséquence n'a pas été un relèvement de l'orfèvrerie, mais, au contraire, In abaissement notable. La Hollande fabrique des pièces très minces, à bas titre; elle litte péniblement contre la concurrence étrangère, et nous n’avons pas, malogré la liberté que nous donne à l'exportation la loi modifiée, tenté de disputer ce marché aur
fiabriques de Vienne et de Birmingham.

L'importance de ses colonies mérite cependant qu'on étudie avec attention les besoins de la Hollande et qu'on s'efforce de nouer des relations qui seraient aussi profitables à l'argenterie, qu'à l'orfèvrerie d'imitation.

\section{RUSSIE.}

La Russie serait pour les orfèvres un pays d'élection si les tarifs de douane ${ }^{(1)}$ et les variations de change ne rendaient très difficile l'introduction de nos marchandises sur ce marché. Les traditions de luxe de la Cour, le gout de l'aristocratie pour les choses d'origine française, les affinités des deux peuples, le faste déployé dans les cérémonies (1) $3,1 / 4$ francs les 100 kilogrammes. Droit, a roubles $9^{0}$ copccks; poincon, $9^{6}$ copecks; soit, par livre
russe, 3 roubles 86 copecks. 
religieuses, tout marrque une tendance évidente vers l'emploi des matières précicuses luxuensement ornées de ciselures, le pierres el d'émaux.

b'ailleurs les orfèves russes sont fort liabiles, ils ont de bons ourriers et lenr commerce est en pleine prospérité. Nais il est protégé à l'excès par des lois de prohibition réelle, et nos fabricants ne se hasardent pas à tenter des affaires qui ne donneraient aucun résultat.

Les plus sérienx achats se traitent ici sur place et il appartient aux clients qui les font d'introduire en Russie les choses qu’ils ont acquises. L'Exposition française qui va s'ouvrir à Moscou, au printemps de 1891 , fournira l'occasion de faire une espérience dont profiteront plusieurs orfèvres parisiens. Ils jouiront des bénéfices que la douane accorde en semblable circonstance, et peut-être réussiront-ils à nouer des relations, à introduire le goût français, non plus dans l'aristocratic de Saint-Pétershourgr où il rògne déjà, mais dims la riche clientèle des négociants moscovites.

Si une telle tentative réussissait, il faudrait souhaiter qu’elle füt puissamment aidéc par les gouvernements des deux pays et qu'un accord des tarifs permît à la liussie el il la krance de passer des promesses plitoniques à des satisfictions plus réelles.

L’orferreric est soumise en Russie ì l'essai et au contrôle pour toute pièce supérieure en poids à un demi-zolotnik (le zolotnik égale 44 gr. 26 ). Il y a pour l'argent trois titres reconnus, dont le moindre égale 875 millièmes de fin.

Les droits qui frappent l'argent frappent aussi l'orfèrerie d'imitation; l'Allemagne cherche par tous les moyens à pénétrer le marché russe; il serait d’une sage politipue d'étudier une question d'où dépend notre influence et qui pent se modifier sensiblement dans un arenir très prochain.

\section{EMPIRE D'ALLEMAGNE.}

L'Allemagne n’est pas dans les mèmes conditions, bien au contraire; elle ne se défend ni par des tarifs cxagérés de douanes, ni par des lois de contrôle; le commerce ! est libre, mais l’industrie s'est déreloppée à un tel point que la lutte y devient diffirile, et la fabrication à bon marché, qui domine dans l'empire, rend impossible la concurrence.

Cependant, on l'al ru, nous continuons à vendre en Allemagne et notre orfèreric argentée, principalement, y jouit d'une grande faveur ${ }^{(1)}$.

Ce qui pourrait aider au succès de l'orférerie française d'argent, c'est la loi promulguéc le 16 juillet 1884 qui, tout en permettant de fahriquer librement à tous les titres, établit un contrôle d'Étal pour les earticles" égaux ou supéricurs ì 800 millièmes (et par erarticles" la loi désigne l'argenterie de table : cuillers, fourchelles, cou-

(1) L'article 11 dı fameux traité de Francfort n'a rien qui nusse aux intérits de l'orferrerie : c'est le régine du taitement réciproque de la natioa la plus favorisée; les droits sur l'orfèvreric à l'entrée en Allemagne sont de 750 franes les 100 kilogrammes; ils sont de joo francs en France. 
teaux, assietles, plats, service de lable, ete.). Il est probable que par une réaction naturelle of à la suite des inconvénients nombereux qu'entraînent à l'usago les ustensiles de table alliés à ume forte production de cuivre, la classe aisée de la nation allemande reviendra ì l'emploi d'une arcrenterie d'un litre supérieur, et comme les formes el les modèles français sont aimés, recherchés et imités en Allemagne, il ne dépend que de nos confrères de profiter d'une revanche industrielle très légilime et très tentante. Ceur d'entre eux que nous arons questionnés croient ì un succès. Les afficires sont ficiles el déjà les centres principaux comme Berlin, Nunich, Francfort, Dresde accueillent arec une grande faveur les articles d'argent premier titre qui ont un caraclère de goût, de simplicité et de nouveauté.

L'Alsace et la Lorraine restent fidèlement allachées ì l'orfèrerie francaise. On u'y veut pas d'autres modìles que les nòtres; les usagges n’ont pas varié daus la famille, et c’est une satisfaction intime, pour ces résignés, de vive à la française el de ne se. servir à table que de ce bon argent honnête et sain qui vient de la mère-patrie (1).

\section{SUISSE.}

La Suisse se partage comme les cantons entre deux influences. Française le long de notre frontière, clle est toule allemande de coulumes depuis Bile jusqu'au lac de Constance; mais la Suisse est hien plus un comptoil qu'un pays de consommation. Les Suisses ne se horment pas à exporter dans les pays voisins, ils rendent ì tous les étrangers qui visitent chaque année leurs lacs et leurs monlagnes. C’est une boulique onverte d'échange; on y tronve, outre les marchandises indigènes, tous les arlicles d'Italie, d'Allemagne, d'Angleterre el d'Autriche el c'est une faute aux grands négociants français de ne pas entretenir à Genc̀ve, à Lucerne, à Berne, à Neufchaltel ef même en des villes moins grrandes el très fréquentées pendant les mois d'été, de grands ef luxueux magasins où seraient exposés les meilleurs échantillons du goût français. La supériorité de nos produnts aurait facilement raison dı hon marché très relatif des

(1) Nous aurions voulu donner sur la production de l'orfèverie allemande des renseignenienls officiels. Ils nous sont promis, inais nous ne les avons pas encore au jour où nous meltons sous presse. Nous nous bornons à reproduire la slatistique des douanes allemandes de 1883 accusant pour tous les produits manulacturés ell argent :

Exportation (vileur)...... 19,425,000 marcks。 Inportation (valeur). . . . . 5, 5161,000

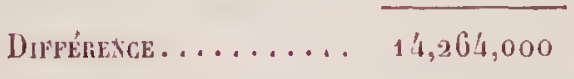

Mais dans ce chiffre sonl compris les hijoux d'angent qu'on fait à Ṕforzlıcim, qui consomme 7,000 kilo- rrammes; à Inanan, qui entploie 1,80o kilogrammez; à Gmïnd et à Sctuorndorf, qui traitent 6, 500 kilogranmes. Heilbron a mis en oenre pour la bijouterie d'argent senle 12,300 kilogrammes, en 1884. Nüremberg, qui ne fabrique plus ni orfererie ni bijoux, est le centre d'une importante indusirie dior el d'al'gent en Ccuilles, de fils el de poudl'es unćtalliques pour le lissaye, l'inpression, l'argenture et la dorure, el ses fabriques emploient annuellement 12,000 kilogrammes d'argent.

La défalcation de ces quanlités, qui n’ont rien de commun aves l'orféverie, réduirail de beauconp l'iuporlance des chiflies d'exportation. (Voir Soülber, Broch et le live de M. Riche.) 
artictes qu'on y roit el il en résulterait un profit pour tontes nos aflaires, car il rient en Suisse lout 111 monde d'étrangers riches, oisifs, avides de luxe qui feraient la comparaison à notre profit et au lemr.

La Suisse a d'importantes maisons de bijonterie et surtout d'horlogerie, elle est pour la commission un grand comptoir où tous les pays s'approvisionnent. Ellr fait arec l'Italie des affaires considérables et elle voit chaque année les plus riches familles d'Amérique. Elle n'il pas d'antres orfères que ceux que nous avons vius. LiNlemagne s'est emparée de ses burearx, il ne serail pas très diflicile à nos orfères de prendre li place; ils tronveraient dans te commerce suisse, qui est intelligent et honmete, une grande complaisance à l'aider, car ce serait un stock nouveau et considérable qui amónerait une grande prospérité commerciale. Il n'existe à cela aucune entrave : deur inportantes maisons ont commencé et ont réussi au delà de leurs prévisions.

\section{AUTRIGHE-HONGRIE.}

L'orfèrrerie d'argent est soumise an contrôle obligatoire pour tout le territoire de l'kmpire et il $y$ a quatre titres légaux : $1^{\circ} 9^{50}$ millièmes; $2^{\circ} 900$ millièmes; $3^{\circ}$ Soo millièmes; $4^{\circ} 700$ millièmes.

La fabrication est libre pour l'exportation, mais les pièces non revêtues de poinçon sont présentées au bureau de l'admimistration qui en surveille la sortie. Les orfèrres autrichiens profitent largement de cette faculté pour envoyer des articles de bas titre, d'un bon marché qui défre toute concurrence, aux contrées qui ne sont pas sonmises à une loi du contrôle ${ }^{(1)}$.

Il n'est pas diflicile de farre pénétrer en Autriche nos articles d'orfèvrerie, mais il

(1) Jous devons à l'obligeant concours de notre honoré confrère de Vienne, M. J. (.. Klinkosch, la conmunication de renseignements officiels et nous cxlrayons d'une lellre émanant de l'administration centrale du coulróle impérial et royal de Vienuc, datée du 26 juillet 1890 , les parties qui concernent plus particulièrement l'orfèvrerie d'argent :

¿.....Les renseignements concernant la produclion et limporlation de marchandises d'or et d'argent sont du reste régulieremnnt pulliés dans les rapports aunuels des chantres de contmerce el d'industrie de la Basse-Autriche. Ils ne se rapportent qu'àl'. Jutriche cisteithanienne en en cxcluant la Hongrie.....

«....Dans l'année 1889 la production indigène d'objets d'argent a ćlé de 35,704 kilogrammes, valeur d'environ $2,500,000$ florins.

C'importation d'oljel d'argent, de 11,657 kilogrammes; valcur, 800,000 florins (parmi lesquels 230,967 montres du poirls de .5,984 kilogrammes).
«En ce qui regarde l'exporlation par les nćrociants intigènes tlobjets narqués du contróle autriclien, il nous manque des renseignements positils : cerlains négociants exportent à l'étranger nou soulement dés oljejes de production indligène, mais aussi des produits tirés l'Allrmagne.

«.... les voyageurs de commerce viennois parcourent les Principantés dauubiennes, la Gréce el l'Mllemagne. On expédie par Trieste des marchandises d'or et d'argent.

"Pour ce qui regarde la Hongrie, l'indinstrie d'or et d'argent, qui représente 10 d 1 ? p. 100 do ta nòtre, y est pen importante.

«Dans l'année 1889 . le contròle a prorluit pour 1"Autriclıe cisleithanienne environ 2, 0,000 florius (fui pour 1890 pourront alteindre 270,000 florins. La valeur réelle di mélal peut c̀tre évaluée en moyenuc à 600 millièmes pour l'or et 800 millièmes pour l'argunt.

"Signé : A. Shader." 
est moins aisé de lutter contre le bon marché de la main-d'œurre. Les ateliers viennois ont de bons ouviers et d'habiles ciseleurs; on $y$ a introduit tous tes perfectionnements de l'ontillage. Le goût brillant, clinquant mềme, de la population s'accommoderait peu de nos meilleur's modèles, ils sont trop simples; on trouverait à P'esth de meilleurs débouchés qu’à Vienne.

\section{ITALIE.}

Matgré les difficultés de douane créées depuis quelques années et les entraves que cette situation metlait anx aflaires, l'Italie reste un des pays arec lesquels l'orfére traite volontiers. Il y a des relations établies, suivies. Nos modèles sont aimés, recherchés, mais l'Allemagne et l'Autriche font de grands efforts pour nous enlever ce marché el les progrès qu'elles ont faits à notre détriment sont sensibles. Le contrôle a cessé d’être obligatoire depuis 1872 ; il est facultatif et il y a trois titres pour l'argent. 950,900 et 800 millièmes. Il se pourrait qu'avant pen on rétablît la loi ancienne el qu'on relevât le titre de l'or' et de l'argent; c'est une des lois de finances que réclame la situation ef jai vu récemment un des négociants qui ont été consultés à ce sujet. Beaucoup d'lonnêtes orfèves réclament ce changement, car l'Italie est devenue comme la Belgique la proie des bijoutiers et des orfèvres allemands, au détriment de l’industric locale. Les acheteurs sont trompés el la confiance est perdue. Sans donte la France profite moralement de cette situation, on n'a confiance que dans ses poincons, mais il n'est pas aisé de lutter de prix contre des objets bourrés, doublés el fails à tous titres. Une grande prudence est désirable dans nos rapports avec l'Italie, antant ì cause de la situation rendue délicate par la revision des traités qu’à cause dı goùt bizarre et si peu clıâlié d'un peuple qui jadis était si bien doué.

\section{TURQUIE, SERBIE, ROUMANIE, GRÈCE.}

Il n'y a pas à espérer beaucoup encore des petits royaumes qui oceupent la presqu'île des Balkans. Les affaires considérables qu'on traitait jadis aree la Turquie ont bien dimimué et les États qui sont sortis de l'ancien Empire ottoman n'ont encore ni la solidité, ni les besoins, ni les usages qui rendent prospères les opérations de l'orfère. Le roi Milan avait, après son avènement, commandé à Odiot son argenterie, et les églises de Sophia et de Bukarest ont acheté à Paris leurs ornements dorés.

C'est l'article d'usage, le couvert d'argent et l'orfèvrerie de métal argenté qui pénètrent d'abord en ces contrées; on y fait des opérations, mais non pas sans se troutver en concurrence avec les Allemands, les Autrichiens et les Anglais.

La Grèce ne fournit qu'un chiffre très minime ì nos exportations. 


\section{ESPAGNE, PORTUGAI.}

C'est l'Espargne qui ofle à l'orfèrerie les meilleures relations d'affaires, le contrôle n'y est pas obligatoire, mais on y recherche les marques qui donnent une garantic sérieuse el il n’y en a piss de plus estimée que la nôtre. Le titre de l'argent est de 916 milliemes pour lout objet pesant plus d'une once quand on le sommet ì l'approbation du feel contraste.

Les droits de douane ì l'entrée sont de 35 franes par kilogramme, ce qui est cons:dérable, surtout pour les articles d'Allemagne; nous avons moins qu'eux à nous plaindre de cette législation qui n’obère pas à l'excès notre orfèrerie et qui écarte les maurais produits de bas lilre.

Li Havane est de toutes les possessions espagnoles celle où se font les plus grands achats d'argenteric.

Au Portugal, on a récemment relevé le titre légal de l'argent qui était de 830 millièmes. Mais on a aussi tròs sensiblement augmenté les droits d'entrée; nos affaires ne pariassent pas trop en souffrir.

Les Portugais n'estiment rien ant-dessus de l'orfèverie parisienne, ils sont restés fudeles ì nos atelier's comme au temps de Th. Germain; les chefs-d'œurre qu'ils araient acquis au xrrí siècle ne sont pas sortis du royaume; ils étaient la propriété du feu roi et uous complons quelques amateurs d’un goût éclairé qui sont en continuelle relation arec Paris. Nous pourons profiter de ce qu'a lout récemment perdu le commerce anglais au Porlugal.

Voilà succinctement, mais aussi exactement que possible, les renseignements que nous arons obtenus sur les pays d'Europe; il serail bien long de passer eu revue tous les pays lointains; nous n'en cilerons que quelques-uns.

\section{ÉTATS-UNIS D'AMÉRIQUE (1).}

II u’y a pas de contrôle des ouvrages d'or et d'argent, par conséquent pas de droits intérieurs sur la falbricatiou, mais les droils d'entrée déjii si considérables ${ }^{(2)}$ vienuent cncore d'être surélevés par le bill Mac-Kinley, el dís lors il est presque impossible de tenter des affaires d'orfévrerie sur le marché américain ${ }^{(3)}$.

(1) Nous arons tardé autant qu'il a été possible de déposer notre rapport pour y joindre les renseignements qui nous étaient promis. Mais notre conlière de New-York, M. T'iflany, à qui nous nous éfions adressé, nous communique la réponse du Census uffice depariment of the interion de Washington, cleclarant que "les stalistiques sur le commerce de l'or et de l'arfrent aux Élals-Unis ne sont pas en étal d'ètre commn- niquées ». Nous n'insistons pas. Nous remercions JI. Tiffany l'avoir bien voulı nous offrir son aide et nous renvoyons les curicux à des élats qui paraitront tardivement.

(2) 45 p. 100.

(3) L'orfèvrerie religicuse fait d'importantes allaires anx Fitats-Lnis, elle n'est pas soumise anx mimes larifs. 
('’est une interdiction complìte el la mesure a été aussi sévèrement jugrée dans notre métier que dans toutes les industries d'art et de luse. Combien durera cette mesure? Peu de temps, crojons-nous; clle est le fait d'un parti politique et cause de grands préjudices dans le pays même. L’industric américaine est assez développée, assez maítresse de ses mojens et de sa clientèle pour n'avoir pas besoin d'une protection si intense; n'étant plus stimuléc par la concurrence étrangère, elle pourrait perdre en peu d'années ce qu'elle arait acquis.

Ce qui serait désirable, ce serait de voir une convention internationale s'établir entre les États-Unis d'Amérique et les États d'Europe pour la propriété des modèles. On réclame depuis longtemps cette loi de bonne foi, d'honnêteté, qui rassurerait sur lia suite de nos rapports avec cette grande et puissante nation. Il y a quelque chose d'immoral et de coupable à tolérer la contrefaçon, telle qu'olle se pratique aux États-Unis : ce n'est plus de la protection, c'est de la complicité dans le dol.

Les orfèvres américains ont commencé en 1878 à importer en France leurs travaux d'argent. Tiffiny est renu le premier, d'autres ont suivi et nous assistons à l'invasion de notre place par une médiocre fabrication du métal «Britannia argenté».

Par contre, le consommateur américain vient à Paris et à Londres chercher ce quil ne trouve plus chez lui. Les familles si puissamment riches qui chaque année arrivent des États-Unis et qui parcourent l'Europe y prennent nos mours, nos goûts, s'attachent à nos arts. L’Américaine est l'aggent le plus actif de nos intérêts commerciaux; arec un sens très fin des choses belles, une intelligence très remarquable, un goût qui se développe plus rapidement que celui d'autres femmes, l'Américaine s'est éprise de l'art français, des modes françaises, elle a pris une place déjà considérable dans notre société parisienne; clle scra l'alliéc de notre fortune intellectuelle et réelle quand elle rentrera à New-York, ì Philadelplice ou à Boston.

C'est à elle qu'il faut s'adresser. Elle a le subtil instinct du luxe; on a créé pour clle, chez elle, en peu d'années, une facon d'orfèvrerie nouvelle dont nous avons longuement parlé. Hais elle n'en est point satisfaite, elle vient demander ici des closes plus rares, plus savantes, plus précieuses. Quand il n'y aura plus ì acheter d'orferrerie ancienne, quand tout ce qui porle un vieus poincon de maître aura franchi l'Océan, l'Américaine exigera enfin que l'artiste s'associc à l'orfèrere. Ce que n'ont pas su faire nos clients d'Europe, elle le fera el c'est elle qui relèveria notre art, en exigeant de lui tout ce qüil peut donner de richesse, de goût et de perfection.

Le bill Ilac-Kinley n'empêchera pas cela d'arriver; alors même qu’on engagerait nos dessinateurs el nos ouvriers à prix d'argent, on n'acelimaterait pas ì New-York la faģon française : nos artistes perdent en Amérique comme ils perdent en Anģlelerre la faculté d'invention et le goût quils ont à Paris; il y a des influences de milieu qui s'excrcent en vertu de certaines lois et qui ont leur action sur le créaleur el sur l'acheteur. C'est pourquoi l'Amérique continuera à venir à Paris chercher les produits d'un art aux formes diverses et changeantes qui ne fleurit nulle autre part. 


\section{AMERIQUE DU SUD.}

Le tempérament n’est pas le même, le goût est moins fin, mais les besoins de luxe sont aussi impéricur. Les républiques espagnoles qui ont grandi dans l’Amérique du Sud el jusqu'aux frontières des États-Unis ont tout à la fois du sang des conquérants el du sang des indigènes. L'amour de l'or est resté dans leurs cours. C'est pour la possession de trésor's convoités et dléfendus qu'on s'est battu pendant des siècles au Mexique et an Pérou. L'or, l'argent qu'on extrait, qu’on transporte, les diamants qu'on trouve dans les rivières du Brésil, on veut les ravoir taillés et montés. On a pour les lijous, les vaisselles, les ornements brillants, une passion un peu sauvage, une adoration d'enfant. La fortune trop rapide de ces pays vierges, où toutes les forces de la nalure se combinent pour produire la richesse, a des soubresauts dangereux; l'équilibre n'est pas fait encore. Mais on a confiance dans un lendemain où l’industrie el le travail établiront un échange entre le vieur monde et le nouveau. Une crise a frappé la Confédération argentine en sa prospérité trop rapide; elle aura bientòt une fin, car les causes de richesses subsistent. La rérolution du Brésil s'est faile sans passer par les secousses qu'arait amenées celle du Mexique et les guerres qu'avaient eues le Chili et le Pérou. Le calme renait, le commerce altend patiemment l'heure propice pour refleurir, et nos orlévres ont, en ces contrées, un marclié de premier ordre, que ne troublent aucuuc des lois qui gênent les pays européens.

Il appartient à l'État d'y farre protéger nos intérêts par nos consuls, et de choisir ces consuls avec plus de discernement.

Le commerce anglais et l'industrie allemande sont, à cet égard, beaucoup mieur serris que les nôtres.

\section{ASIE.}

L'Asie ne réalise ancune des promesses qu'elle faisait au siècle dernier. Le luxe s'y éteint; l'Inde s'endort sur ses riclıesses, les Anglais la tiennent, l'épuisent; les Russes sétendent au Norrd; la Chine s'ouvre lentement, défiante, inquiète, rebelle aux offres qu'on lui fait, paresseuse et malhabile à employer l’intelligence et les forces de ses 400 millions d'labitants et nous attendons que l'évolution se fasse, nous sarons qu'un jour viendra où ces peuples absorberont le trop-plein de nos usines, à moins qu'ils ne nous envahissent eux-mêmes, quand ils auront appris de nous tout ce que nous sarons.

Le Japon, peuple d'irlistes et d'artisans, nous a plus étonnés qu’il n'a été surpris par nolre civilisation. La science seule le séduit: il se l'assimile par ses jeunes ingénieurs arec une prompritude merveilleuse. Les Japonais auront fait en un demi-sièrle l'évolution que nous avons accomplie en cinq cents ans.

Quant à ce qui touche l'orféreric, les Japonais n'ont rien à nous envier et j’ai dit. arec quelle attention nous devons au contraire étudier leurs procédés; c'est à nous 
d'apprendre; il serait dommage de lear envoyer les produits de nos fabriques. Ne gatons pas leur originalité, respectons ces admirable artistes. Leur's iles devraient ètre sacrées.

\section{AFRIQUE.}

C'est la contrée convoitée par la vicille Europe: depuis l'antique Égyple, que gardent les Anglais, et les côtes barbaresques, qui sont à nous en partie et que jalousent nos voisins d'Espagne et d’Italic, jusqu'à l'extrémité du Cap, toute la côte est envahie. C"est une prise de possession hâtive. Les petits drapeaux européens flotlent sur tous les ports naturels, à l'embouchure de tous les fleures, ef de hardis royageur's se lancent à l'aventure dans les ténèbres de l'Afrique.

Science, dévouement, foi, curiosité, ambition, patriotisme, tous ces sentiments réels ou feints cachent la soif des richesses, la fièrre commereiale qui reut imposer à des nègres, à des sauvages, ses produits et les formes d'une civilisation qüils ne comprendront peut-être jamais, parce qu'elle n'est pas faite pour eux.

Et l'Égypte qu'on a percée, à travers laquelle passent tous les navires du monde, l'Égypte que devait enrichir ce canal comme un Pactole nouveau, l'Égypie appaurie n'a pas de quoi payer ses gardiens. Le vice-roi n'est plus ce somptueux monarque qui commandait à tous les orfèrres, qui avait des meubles d'or constellés de pierreries et qui, à l'Exposition de $\mathbf{1} 867$, éblouissait de son luxe les souverains de l'Europe. Vingt ans ont ruiné le pays auquel on avait annoncé le retour de sa splendeur antique.

Et l'Algéric, notre grande et belle colonie, qui est à nos portes, qu'en arons-nous fait? Nous ne parlons qu'en orfèvre. Cette nouvelle France n'a plus mềme le charme du luxe dont s'argentait jadis le palais du dey et de ses pirates. Nos chiffires d'affaires en Algérie sont misérables; ce commerce est aux mains des juifs. Pas un orfère français n'a cu l'idée généreuse d'aller au pays des Maures ressusciter un art qui aurait fail sa fortune et sa gloire. On y travaille moins bien qu'avant la conquête et nous sommes aussi malhabiles que les Anglais, qui ont tué aux Indes le vieil art hindou et qui essaient trop tard de le relever; quel est l'artiste ou l'ourrier français qui ira chez les Kabyles ou chez les Nauresques chercher la graine endormie et la faire germer? Il y a une fortune à faire, une industrie à créer.

Les chances de succès sont très inégales et les conditions d'échange bien diverses entre nous et les pays d'exportation; mais il ne faudrait pas user de rigueur pour les étrangers ni adopter des lois de protection qui amèneraient des représailles. La loi du contrôle sulfit à nous protéger, et les étranger's n'auront pas lien de se plaindre, ils sont traités chez nous à l'égal de nos nationaux.

A notre avis, il n'y a pas lieu d'augmenter les tarifs de douane. 
Les ourrages en or, cn argent, en platine, comme les ourruges dorés ou argentés, soit au fou, soit par les procédés électro-chimiques, les ouvrages plaqués et doublés (1) payen l'entrée en France, suivont le tarif général de 1881, 50 o francs pour les 100 kilogrammes. Le laux cst le méme pour le tarif conventionnel. La commission chargée d'éludier la revision des tarifs de douanes propose de porter le tarif général à 600 francs les 100 kilogrammes, et le tarif minimum à 500 franes pour l'orférerie d'argent.

l'augrgmentation de 20 p. o/o an tarif général n’est pas tellement considérable sur l'orfèrerie qu'elle puisse moliver contre nous une surélévalion de droits de la part des aulres pays. D'ailleurs le tarif minimum sera seul en vigueur avec les nations qu’il importe de ménager.

On peut donc envisager sans inquiétude pour l'industrie des orfèvres les conséquences de la loi qu'on va discuter; la chambre syndicale a été consultée; elle a conclu dans le même sens, estimant que l'obstacle le plus efficace à l'invasion du marché résidait dans notre système de garantic.

"Le droit de contrôle qu’il faut acquitter, les essais à subir gênent évidemment l'entrée de prorluits dont l'écoulement est aléatoire.

* Nous demandons la liberté complète de fabrication pour l'exportation seulement.

"Notre opinion changerait toutefois par le fait de la revision de la loi de brumaire an rr, dans le sens de la liberté à l'intérieur comme à l'extérieur.

"C'est alors qu'il faudrait réclamer un tarif de protection pour laquelle les taux indiqués seraient insulfisants ${ }^{(2)}$."

Yous avons donné cet extrait pour montrer l'accord complet des orfèvres. Ils estiment que la loi de garantie suffit à les protéger.

De plus, ils demandent le relèvement à 825 millièmes du second titre d'argent, ce qui fermera le marché français aux produits d'un alliage inférieur; enfin ils insistent pour que les articles étrangers qui auront été soumis à la marque ne puissent pas oblenir en ressortant le remboursement des droits de garantic.

L'examen comparé de l'importation et de l'exportation depuis 1878 n'est pas très satisfaisant. La différence reste à notre avantage encore en ce sens que nous exportons plus que nous ne recerons, mais cette proportion diminue; on en va juger par le tableau suivant :

(1) Il y a lieu de remarquer cependant que les arlicles d'urfivrerie de cuivire et de nickel argentés ne payent jas suivant celte taxe; ils sont compris au tarif do 1881 sous la rubrique erouvrages autress entre la bijouteric fausse et l'horlogerie et sont taxés à $100 \mathrm{fr}$. les 100 kilogrammes.

(2) Bulletin de la Chambre symdicale de dérembre 18 g. 0 . 


\section{DOUANES FRANGAISES.}

ORFÉVRERIE D'ARGEN'T.

tablead de l'expontation ft de L'mpontation par Valeurs de 1878 i $188 \mathrm{~g}$.

\begin{tabular}{|c|c|c|c|c|}
\hline \multirow{2}{*}{ ANNÉES. } & \multicolumn{2}{|c|}{ EXPORTATIONS. } & \multicolumn{2}{|c|}{ IMPORTATIONS. } \\
\hline & $\begin{array}{l}\text { ComuERce } \\
\text { gíníral. }\end{array}$ & $\begin{array}{l}\text { Couvinge } \\
\text { spépial. }\end{array}$ & $\begin{array}{c}\text { comserce } \\
\text { fróneral. }\end{array}$ & $\begin{array}{c}\text { Comperce } \\
\text { spicial. }\end{array}$ \\
\hline 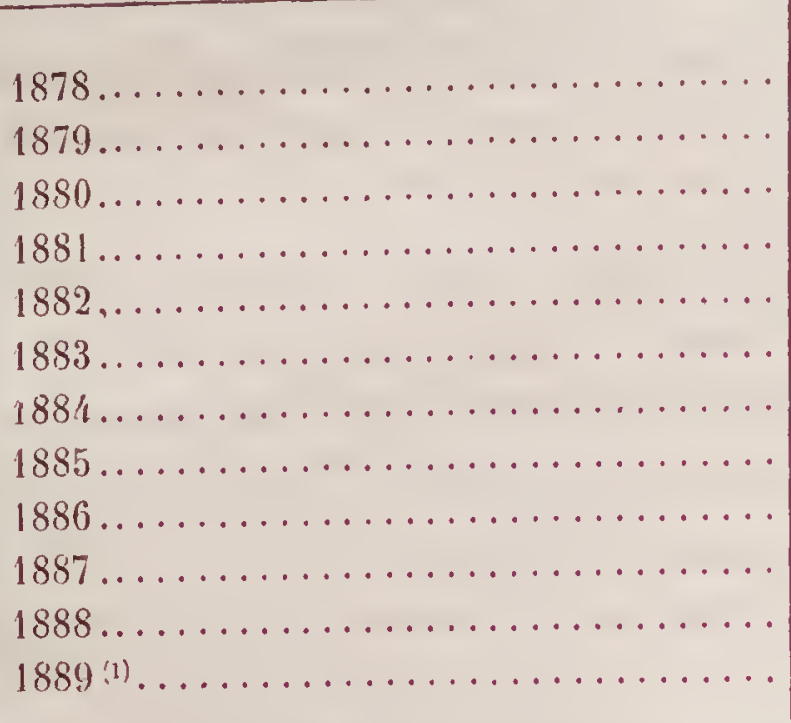 & $\begin{array}{l}\text { franes. } \\
3,904,928 \\
3,020,510 \\
3,113,402 \\
3,234,238 \\
3,655,152 \\
2,832,739 \\
2,404,810 \\
2,938,950 \\
3,406,110 \\
3,217,452 \\
2,627,306 \\
4,048,338\end{array}$ & $\begin{array}{l}\text { franes. } \\
2,718,832 \\
2,037,820 \\
2,101,192 \\
1,892,337 \\
1,99^{1}, 921 \\
1,952,849 \\
1,415,326 \\
1,689,715 \\
1,753,459 \\
1,8160,072 \\
865,489 \\
2,750,155\end{array}$ & $\begin{array}{l}\text { franes. } \\
1,537,048 \\
1,802,806 \\
1,723,278 \\
2,000,332 \\
2,339,099 \\
2,775,647 \\
1,602,878 \\
1,791,648 \\
2,426,589 \\
2,556,200 \\
2,143,237 \\
2,627,306\end{array}$ & $\begin{array}{r}\text { fraurs. } \\
663,608 \\
647,600 \\
630,700 \\
9 / 4,713 \\
1,030,956 \\
1,067,614 \\
757,119 \\
766,119 \\
1,191,469 \\
1,195,596 \\
787,716 \\
865,489\end{array}$ \\
\hline
\end{tabular}

Ainsi done, en dix ans, notre chiffre d'exportation an commerce spécial n'a pas progressé et ce n'est qu’à la faveur de l'Exposition de 1889 qu'il est remonté au point de départ, sans quoi nous aurions subi jusqu'au bout une décroissance à peu près continue.

L'importation au contraire est en progrès et le commerce spécial, qui indique les quantités restant en France, a presque doublé. Nous ne consommions, en 1878 , que 663,608 franes d'orfèvrerie étrangère. Nous en arons gardé pour près de 1,200,000 fr. en 1887 .

La progression est plus sensible et plus régulière encore au commerce général et cela démontre que la France est une voie de trausit et que nos douanes servent d'entrepòt, pour des affitires qui s'y traitent avec des articles de provenance étrangère.

Nous arons voulu pousser la démonstration el nous avons, ì cet effet, dressé des graphiques qui expliquent, d'une façon saisissante, les mourements du commerce d'importation et d'exportation de l'orfèrerie. Nous sommes remontés aussi loin que nous le permettaient les états de douanes conservés au Hinistère du commerce el au Ministère des nfinaces. Nous devons ces renseignements à l'obligeance de notre ami, 
1I. Vannacque, chef de division de la stitistique au llinisicre da commerce, de lindustric et des colonies. (Voir, à la suite, les tableaux B, C, D et E.)

Antérieurement ì 1825 , les tableaux publiés par l'administration des douanes ne donnent pas les valeurs pour le commerce spécial. Les valeurs officietles ont été établies par l'ordonnance du 27 mars 1827 et remplacées, on 1847 , par les valcurs dites uctuelles et fixées chaque année par la Commission de valeurs de douanes ${ }^{(1)}$.

Ces graphiques parlent aux yeux et n'exigent aucun commentaire.

On y verra la progression constante de notre exportation depuis 1820 jusqu'en 1878 ; les oscillations qui ont suivi et la comparison à pen près proportionnelle qu’il y a entre les quantités en poids et les valeurs en francs; les variations entre le commerce général et le commerce spécial.

Limportation est plus curieuse ì observer. Nous avons des notes à cet égard depuis 18,6 et on voit la résistance du pays à accepter l'orfèvrerie étrangère. Longtemps encore après le traité de commerce de 1860 la ligne du commerce spécial reste horizontale. Eille ne s'élève progressivement qu'après $187_{1}$ et $187_{2}$. Quant au commerce général d'importation, il accuse des fluctuations nombreuses, des soubresauts très brusques surtout dans le graphique des quantités en poids. Le tableau des valeurs en douanes démontre combien le marché français est devenu favorable aux affaires des orféres étrangers par la complaisance de nos commissionnaires.

C'est à ces derniers que nous dédions surtout ces tableaux; ils pourront les méditer et nous espérons qu’ils travailleront, d'accord avec nos fabricants, à reformer les tracés ct ì farre à l'arenir monter la ligne de nos exportations.

II n'y a pourtant pas lieu de se plaindre outre mesure et je ne crois pas qu'il $y$ ait en France d'industrie mieux partagée et moins menacée que la nôtre.

Tous arons vu par les chiffres relevés au Bureau de la garantie depuis 1818 (tableau A) que l'orfévrerie d'argent a augmenté sans cesse de production. Elle a atteint, en 1889, 84,121 kilogrammes et a donné pendant les dix dernières anmées une mojenne de $78,3,75$ kilogrammes.

Or, dans la même période de dix ans, le chiffre le plus considérable que nous relevions ì l’importation a été au commerce général de 6,933 g kilogrammes sur lesquels il est resté seulement dans la consommation (commerce spécial) 2,669 kilogrammes.

Cela revient à dire que la proportion la plus élevée qu'on ail notée à l'importation ne représente pas plus de 3.33 p. 100 de la production nationale. Dans le même temps, l'exportation était de 5,691 kilogrammes, c'est-il-dire que nous fournissions au dehors le double de ce que nous recevions.

Dans ces conditions, l'orfèvre peut travailler en toute sécurité.

Son industric est centralisée à Paris. Nous l'arons dit, elle y est excercéc par un groupe de patrons qui vivent en bonne intelligence et qui travaillent librement arec

(1) M. A. Liegard, sous-chef de bureau au Vinistère du commerce, de l'indıstrie el des colonies, nous a fourni ì cel égard de précieux renseignements. 
des ouvriers libres aussi, mais assez sages pour ne jamais céder aur sollicitations mauvaises du dehol's.

Cette entente du maitre et de l'ourrier s'élend à tous les collaborateurs de l'orfíre, à une élite d'artistes, à des spécialistes de l'outil comme il n’y en a nulle autre part; en sorte que, sans plus avoir ses réglements et ses statuts d'autrefois, l'orfévrerie francaise reste aussi unie que jamais ol loujours fidele aux traditions de goût et du métier, - fière, honnête et forte.

Aussi a-t-elle, avec l'estime du monde entier, le prestige d'un passé plein de gloire. L'État lui donne sa protection la plus large et la plus efficace et cette dépendance, que d'autres estimeraient gênante, est devenue pour l'orfévrerie une garantie profitable, un titro de noblesse, une marque qui fait prime. ("est une mesure égale pour lous, qui suffit à défendre l'industrie contre les envahissements du dehors et qui, en empêthant l'avilissement de la matière, la garde au dedans contre elle-même. Cette situalion, rien ne doit la modifier, le producteur et le consommateur s'en trouvent également bien l'un et l'autre.

L'orferrerie française a la clientèle la plus étendue et la plus belle. Coest d'abord la nation libre et économe, mais cependant éprise d'un luxe qui la pénètre à des degrés divers, et qui inspire, dans toutes les classes, le besoin intime du bien-être avec le sentiment de l'épargne; c'est ensuite l'étranger, cet étranger qui traverse Paris, y revient et s'y fixe, en faisant la capitale des capitales, y prenant lecon de goût, acherant de s'y policer en se modelant à notre inrage.

Pour tout ce qui tient aux industries décoratives, Paris est un centre d'où émanent l'invention, la mode et le charme, mais où s'exerce pourlant la critique la plus sévère; pour l'orfèvre, c'est done, en mêne temps que le foyer de production, l'école où il s'instruit. Il y a son atelier et son comploir de vente, mais il y trouve ses maìtres, des musées grand ouverts, des bibliothèques riches en documents spéciaux. Il y a des amis qui le conseillent, les plus fins connaisseurs visitent l'orfèvre, les gens du monde recommencent la collaboration spirituelle du siécle dernier; ils entrent dans l'atelier de l'orférre comme dans celui du peintre, provoquant ainsi l'évolution de l'art.

Car c'est un art enticr, c'est de tous les métiers celui qui est le plus intimement lié à la sculpture, au dessin, aux règles de l'esthétique. Cette dépendance du bean empêche l'orfèrre de s'abandonner à de fantasques inventions, il est tenu ì plus de sagesse, il ne peut pas comme d'autres maitres en industrie, céramistes, tapissiers, décorateurs du mobilier el du costume céder à des cntraînements qui ont leurs fièvres et qui amínent de funestes réactions. Ses progrès sont lents mais continus el sa force s'accroit; elle a toute la puissance des actions raisonnées, patientes et c'est ainsi que, depuis le commencement du siècle, l'orfévrerie a reconquis l’immense supériorité qu'elle arait eue dans l'histoire de l'art français. Ce nous est une grande joie de le constater et nous regardons comme un honneur d'avoir été choisi pour dire, en cette étude, le succès de l'orfèvrerie ì l'Exposition universelle de 1889 . 


\title{
TABLE ALPIIABETIQUE DES NOMS
}

\author{
CONTENUS
}

DNNS LE RAPPOR'T SUR L'OREEVRERIE.

ABente, cisclentr, 65.

Anolit (Edmond), 106.

Ácosrisi (Jos.), bijoutier-nrfive, $118,131$.

Acuen Zarrouk, orfévie, 97, 132.

diguer, sculpteur, 56 .

Alexayure III, empereur de Rinssie, $7^{0}, 123$, 124 .

Alexis (Grand-dluc), de Russie, 85.

(li,ARo, graveur-estampeur, 13,1 l.

Amuix (Josl), graveur, 158.

Avoersex (David), orlève, $122,132$.

Arunieu, chef d'atelier, 52.

Anvan el dir 'Tonkin (Protecloral de l') , 95,132 .

Arcura (Le prolesseur), d'lidimbourg, 19.

Ardesiur el Brranj, marchands orlèves, 115 , 132.

Anuavo-Caldiat (T.-J.), olfèvie, $15,17,32$, $33,34,35,53,7^{8}, 83,131,1 / 8,169$, 170.

Armand-Cinluat fils, 34.

Artola (IIne veluve), orlèvre, $101,132$.

Arits uéconatros (voir Union centrale des urts décoritifs).

Arvisevet, ciseleur, 50,53 .

Ascimarine (B.-M.), orfévre, $126,132$.

Atrarge (Désiré), ciseleul', 19, 79.87,88, 16 \%, 166.

Ac зе́, sculpleur, 48.

Avoot, orfève, 14.

Aucoc père, orfèvre, $10,14,53$.

Arcoc (André), orfévre, 53, 54, 55, 85, 131 .

Iucoc el Giver, orfèvres, 9 .

Arguste, orfèvie, 7,8, 9, 26, 40, 186.

Arrulac, ouvier orfève, 11.

Avrus (Daniel), orfèvre, 126, 132.
Baris, gravenr-ornemaniste, 43.

Buchelet (Georges) fils, orferre, 53, 54, 131 .

Bıсицат père, orlève, $13,14,15,16,17$. $19,29,53,174$.

Bus.aY, ouvrier orfèrre, 52.

ВАко, ciseleur, 52,57 .

Balaine, orfèvre, 9, 14 .

BalaschefF, contremaîlre, 12 l.

Balun (Les) [Claude et Jacques], orferres, 5 , $26,28,137$.

Ballue, archilecle, 29,36 .

Bapst (Les), joailliers de la Gouronne de France, $40,68$.

BAPst (Germain), joaillier-archólogue, 46,68 , $82,153,18 \%$.

Bapst el Falize, orlèvres-bijoutiers, 27, 68, 69 , $70,71,72.73,7^{4}, 88,131$.

Banbedenne, bronzier el orfèvre, $19,76,88$.

B.trberet (J.), statisticien, 179 .

Barbet de Jour, ancien directenr des musées liationaux, 73,143 .

Barrias (E.), sculpteur, $69,70,71,1 / 7$.

Barte (A.-L.), sculpteur', 8, 9, 138.

Basset, ciseleur, 63.

Bıstıé, contremaître, 31 .

Bastien-Lepage, peintre, $7^{6}$.

Baudry (Paul), peintre, 71.

Badgrand, joaillier, $16,17.88$.

Bayard, orfève, 64.

Beaulieu, ciselenr, 55.

Becouerel, physicien, 14.

Bellog, peintre, 35.

Beraix, architecte-rlessinateur, 20.

Bermard (Saint), 13/.

Bertiet, orfève, 1 4. 
Bertiolle, graveur sur acier, 50 .

Bertrayd, orfèvre, 35.

Bertrand (Alexandre), archéologue, 143.

Besvier, orfevre, 46.

Bidault, contremaître, 38 .

Bıexsais, orfèvre, $8,9,29,138,186$.

Bixg, importateur, 119 .

Brsgex, fondleur, 70, $17^{3}$.

Bitetos, orfevre, 122,132 .

Busc (Charles), critique d'art, $72,89,145$.

$\operatorname{Blaxc}\left(M^{\mathrm{me}}\right), 45,79$.

Boss (Ch.), contremaître, 103 .

Botswilwald, architecle, $19,30,36$.

Bonм (llermann), orfèvre, 98, 131 .

Bonner et Bossavge, joailliers du roi, 68 .

Bon-Tabunet, orfève, $46,47,48,51,54,55$, $131,186,203$,

BolRer, monteur, 63.

Bonvx (Viclor), orfèvre, $59,132$.

Bolıve (Comité de la). 101,1 ร̃.

Boxat, sculpteur-ornemaniste, 47, 48.

Boxmard, ouvrier orfèrte, כ34.

Boxyalet, dessinateur, 56 .

Bossax (Pierre), architecle, 32 .

Bossard (Jean), orfèrre, $128,129,131$.

Boтtée (L.--1.), sculpleur, 88.

Bolcuer (Anthelme), éditeur, 9 .

Bougnerox $\left(F_{r}\right.$.), joaillier-orfève , 1 7, 18, 55, $56,58,83,84,89,91,124,131,163$, 171 .

Botcnox, contremaitle, 73 .

Bovnhet (Henri), ingénienp-orfèvre, 43, 61. $62,63,7^{5}, 7^{6}, 77,173,181$.

Boulıt, ouvrier orfèvre, 3 द.

Botlexger et $\mathrm{C}^{\text {ie }}(1$.$) , orfève, 63, 64, 131$.

Bovlle, ćbéniste, 151.

Boulongke, peintre, 153.

Bourdier (Th.), joaillier, 89 .

Borrdon-Debrune, orfève, 17, 99 .

Bourlet-Aubertot $\left(\mathrm{M}^{\mathrm{me}}\right), 54$.

Borssard, sculpteur-ornemaniste, $50,51$.

Bouvilin, fondeur, 8.

Bragange (Le duc et la duchesse de), 44, 79 .

Brard, ciseleur, 55, 70 .

Brateau (J-P.), ciseleur-modeleur, 70, 81, 82, $83,87,89,90,131140,165,166,171$, 174.
Bréguet (Jouis-Abraham), horlogel-mécanicien, 7 .

Bвиот (François), graveur el polier d'élain, 26, 81,82 .

Broескx, chef d'atelier', orfèvre, 63.

Brosse (Jacqnes DF), architecte, 51 .

Brunellescm, sculpteur, 118.

Brunet (Paul), orfève, 37, 38, 131 .

Brcuen (Audreas), ciseleur', $129,132$.

BufFet, ministre, 10.

Büuns, orfèvre, 11.

Bunot, ciseleur, 81 .

Busseret (Le comte R. de), 34.

Burdeac, député, 190.

Burty (Plı.), critique d'art, 119.

Cabadès, roi de Perse, 73.

Camer ([úon), orfèvre, 8, 9, 29.

Gahier (Le R. P.), archéologue, 28, 148.

Carl, fondeur, 80 .

Cancar (Noël), négociant, 64.

Callar el Bayard, orfèrres, 17, 6h, 65, 131 .

Gallzot, bijoutier, 46.

Ganeré (Henri), dessinateur el sculpteur, 5o,

$55,78,79,140$.

Gavos (Le docteur E.), 84, 85, 132 .

Gaplatx, marchand d'or el d'argent, 188 .

Cardeilhac, coutelier-orfère, $14,56,57,131$.

Carluer (Émile), sculpteur, 23.

Carrot (Sadi), Président de la République, 71.

Carox, fondeur, 63.

Ciarrier-Belleuse, sculpteur, $23,44,61,72,7^{6}$.

Ciastax, bibliothécaire, 82 .

Ciastan, sous-directeur du burean de garantie de Paris, $193,194,199$.

Castellati, bijoutier-dessinateur, 10.

Gastellant (Alessandri), orfèvre-archéologue, $15,117118$.

Gatusse, conseiller d'Ĺtat, 190.

Gaucuorx, ciseleur, 166.

Gavelier, scilpteur, $10,11$.

Cencisi (Benvenuto), 45, 74, 81, 84, 118 , $134,138,149,151,166$.

Cerruschi, publiciste, 119 .

Chambaud, ouvrier-orfèvre, 3 々.

Cilambre syndichee des bijoutiers, des joallulirs Et des onfèvres, $24,180,188,213$.

Gilambrox (Ie comte df $), 35$. 
Champagne (De), duc de Cadore, 9 .

Culapt.in (J.-Cl.), graveur en médailles, 63, 71, $152,166$.

Gunposvìne, sculpteur, 138.

Cuaptus. (Jean-Antoine), chimiste, 8.

Culipu, senlpteur, 147 .

Giarles X (Le toi), 29.

Cunnoot, orfèvere, $1 /$.

Cinstoer (A.-D.), scnlpleur, 8.

Cinalixes (Le duc de), 45, 79 .

Cinavicourt, contremaitre, 65.

Cuedevilue, sculpteur, 69 .

Cunvihilier, orfèvre, 3 ,

Cumpavard (Antoine), archilecle, 21.

Cueser, ciselenr, 31.

Cuńret, sculpteur, 43, 44.

Cuertier, orfèvre, 38.

Cunctreul (M.-E.), chimisle, 152.

Choparowski, ciseleur, 125 .

Cuopıs, président du jurry de l'nrfevrerie en 1878,3 .

Cunosroès le Graxd, roi des Perses, 73.

Cunistesean ( $\mathrm{V}$.) , orfèvre, $102,103,131$.

Curistopine Coloub, 105.

Curistofle (Charles), orlèvre, 10, $13,14,15$, $16,43,60,17^{2}$.

Curristor le et $C^{\text {ie, }}$ orfèvre, $18,42,43,44,50$, $51,60,61,62,63,64,7^{5}, 7^{6}, 77,80$, $88,91,106,107,108,109,111,119$, $131,155,161,168,17^{1}, 173,17^{4}, 17^{6}$, 203.

Cunistofle (Paul), orfèvre, 16, 17, 43, 62, ${ }_{7} 5,77,138,158,159,170$.

ClefF, ciseleur', 11 .

Cherrc, dessinaleur, 37 .

Chobion, sculpteur, 82, 166.

Cocurs (Clı.-Nicolas), ressinateur et graveur (xrmi siècle), 55 .

Colbert (J.-B.), 22.

Cole (Sir Henry), 15.

Coux (Paul), inspecleur principal de l'enseignement du dessin, 153,154 .

Coциот, ciseleur, 31,87 .

Cosué (Le grand), 71 .

Costé (Nicolas Jacques), industricl, 7 .

Condoximer, arclitecte, 36 .

Cordosvier (A.), semlpteur, 60. 70.
Consos, peintre, 81 .

Consu, lronzier, 85.

Cornorer (Édouard), architecte, $30,31,70$, 81.

Cortiva (voir Ghédina).

Cosson-Conby, orfèvre, $14,17,53$.

Costaz (Le baron Louis), ingénieur, 8, 9 .

Coulox, joaillier', go.

Couguaux , bijoulier-orfèvre, 92 .

Corrajon, conservateur au Musée du Lonvre, 143.

Courret (Liamiral), 79 .

Courcy (Charles de), peintre-ćmailleur, 74 .

Courrers (Les) ou les Courtois, peintres-émailleur's, $7^{4}, 86$.

Counquix, graveur sur pierres, $7^{3}$.

Courroux (Joln), 202.

Coussourelus (Nicolas), orfêvre, 116,132 .

Covtax, sculpteur, 61, 62, 76, 147 .

Coyserox (Antoine), sculpteur, $6 \mathrm{~g}$.

Croville, orfère, i1.

Crozatier, fondeulr en bronze, 163.

Corran, dessinatenr, 109.

Dafnique, bijoutier-orfèvre, 10.

Diguerre, peintre-phlolographe, 62,91 .

Dalierop (Le professeur V.), 103.

Dalov, sculpteur, $87,147,150$.

Disov, ébéuiste, 44.

Danger, peintre, 81 .

Darcki (Alfred), directeur du Mnsée des Thermes et de l'Hồtel Cluny, 7, 143.

Darcy, arclitecte, 30 .

Dardatre, gravenr, 31 .

D.uBnéE, orfêvre-bijoutier, $9^{2}$.

Dautresne, député, 190.

David (Louis), peintre, 8, 20.

David (d'Angers), sculpteur, 8.

Daviluier (Le baron), 105.

Davroud, archilecte, 151,155 .

Debiux (Hphonse-E.) fils, orfèrre, $52,55,131$. Debals père, orfère, 14 .

Debass, onvrier orfèvre, 63.

Debut el Courox, joailliers, go.

Decasles, peintre, 138 .

Degazbs (Le comte), 9 .

Degras, contremaittre, 64.

Désardix, orfètré, 26. 
I) Eracroux (Eugienr), peinlre, 8, 138.

Deilaplatche, sculplemr, 31, 61, 69, $7^{0}, 7^{1}$. $75,77,147$.

Delarocue (Plilippe), rapporteur, 16,170 .

Delaucke (Étienne), maître graveur, $135,158$.

Delort de Gléox (Le baron), 10 亿.

J) E,oYe, sculpteur; 70 .

Deмsicı, b̈joutier-orfève, 93, 132 .

Dexière, industriel, 10.

Depertines, architecte, 36 .

Desinosse, chef d'atelier, 52.

Drscamps, peintre, 8.

Désıé ( voir Attrigoce).

1) Esprezz, ciseleur, 52,88 .

1) Estignes, ciseleur, 56.

Deveris, conservateur ì la Bibliothèque impériale, rapporteur, 13.

Didier (L'abbé), 134.

Dipor (François-Ambroise), imprimeur-éditeur, $7 \cdot$

Dipnox (d.-X.), archéologue, 28.

Didrox (El.), peintre-verrier, 19.

Dietz-Monnın, sénateur, $75,7^{6}, 190$.

Dirlotte, ćmaillemr, 170.

Digiomger, orfève, g8.

DIns, industriel, 7 .

Dises, contremaître, 109 .

D10àide, ciselenr, ${ }_{17}, 4_{2}, 57,81,87,88$, 140.

Dixox, orfèvre, 114 .

Dixor (Janes) et fils, orfèvres, $113,132$.

Dolbergue, ciseleur, 11, 165 .

Dotın, émailleur en orfèvrerie, 14, 170.

Dour, ciseleur, 11.

Dreox, ouvrier orfètre, 48.

Dru (Léon), ingénieur, 128 .

Durois (Alphée), graveur en médailles, 63, 71, 166.

Durors (Paul), sculpteur el peintre, 147.

Ducuesse (Jean) aîné, iconographe, 21.

DufÊtre, contremaître, 34 .

Durour, tourneur, 63.

Dufouryoux, ciseleur, 34.

Dufresne de Sant-Léon (Henri), sculpteurciscleur et damasquineur, $80,81,131,168$, 171.

Duиаме, bijontier-joaillier, 46 .
Dusandx, héliograveur, 91.

Dunoxr (G.) el frères, fondeurs, 182.

Dupin (Le baron Charles), 9, $14,41$.

Duplessis (Georges), conservateur du Calinet des estampes, 143 .

Dupoxcuel, archilecte et orlèvere, 8, 10, 11,12, $14,17,73,138,165$.

Duporanel (Ludovic) fils, 165 .

Dupré, orfève, 51.

Dupus, giraveur en unédailles, 71 .

Dupors, ouvrier orfève, 52 .

Duraxd, orlèvre. $10,14$.

Durox, hijouticr-orfèvre, $8,16,17,73$.

Dusomenaro (Mexandre) père, antiqnaire, 2. 28.

Desommerarn (Edmond) fils, 18.

Disseldorf (Académie de), 14.

DUteIL, orfèvie, 78 .

Dutrour, architecte, 30,31 .

Eisex (Charles), peintre el graveur [ 'vur' siècle]. 55.

Eissexwers, directeur du musée germanique de Nuremberg, 1 /13.

Eı.кingtox el $\mathrm{C}^{\text {ie }}$, orfèrre, 10,1 /4, $15,17,60$, $110,113,17^{2}, 17^{3}$.

lílor (Sainl), érêque, orfèvre ut ministre, 5, 26.

Emaveer. (Harry), joaillier-orfèvre, 17.

Eve, bijouticr-orfèvre, 90.

Exofrlex (Gaspard), graveur el polier d'élain, 81.

Fxcel-Gros, manufacturier, 70.

Epilrussi (Maurice), 70.

Ermak, chef cosique, 124 .

Eudel (Paul), collectionneur, 7, 110, 189 .

Eugéxae (Limpératrice), 22.

Fanne, orfèvre, 9.

Fabvre, graveur, 31.

Fatguìre, sculpteur, $7^{6,14} 7$.

Falize (Alexis) père, bijoulier-orfère, 68,75 .

Falize (Lucien), bijoulier-orfèvie, 3, 68, 18..

Faxmiere (Auguste et Josepli) frères, sculpteni'sciseleurs-orfèvres, $9,11,1$ h, 15, 16, 17, $23, \underline{15}, 64,72,131,138,16 /, 165,166$, 171,186 .

Fauconvier, orfève, $8,9,45,79,138,166$. Fauves, contremaître, 37 . 
Favier $\left(\mathrm{N}^{\mathrm{me}}\right)$, bijoulière, 92 .

Festruest (l'.), orfévire, 132.

Feucuìris (Jean), sculpteur-ciseleur, 8, 10, 11 , $12,21,138$.

Finiguera, graveur-nielleur, 149, 169 .

Fizhase, orfêvre, 17.

Flamast, orfève, 3, $188,190,191,196$.

Flonave, repoussenr au marleau, $50,51$.

lioxsequa (Henriquez), orfevre, 131 .

Foxtexar (Eugène), bijoutier-joaillier, 18.

l'onugé, architecte, 36 .

Fossix, joaillier, $13,15,16$.

Fovı, libliophile-archéologue, 143.

Fraget, nifèvie, 17, 124, 125, 131.

Finacisco (Henrigue\%), orfevre, 123.

Fraxcks, du British Museum, 143.

Fraxcous II, roi de Naples, 33.

Fiangols ne Neufchateau (voir Neufcheleriu).

Frar père, orlevire, 10, 14, 51 .

Fral (Ph.), orfevre, 51, 52,131 .

Finimovtenlab, orfèvre, 11.

Fiśxus (Armand), orlère, 65, 132 .

Fromext-Mlema: (Émile), orfêve, 17, 44, 45 , $49,77,78,79,80,88,131,185,203$.

Fromevt-Meunice (François), père, orfèvre, 8 , $10,11,14,22,44,79,138$.

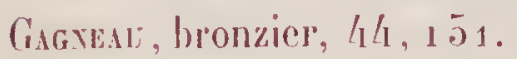

Gagerét, émailleur, 170.

Gauland (Ernest), fils, orfèvie, go, 91, 190.

Ga, essayeur de la garantie, 190.

Guldixp, peintre, 71, 155.

Gulué, maitre-verrier, 78 .

Galiknaxd (Jules), orfère, 92.

Gidues (S. A. R. le prince de), 115.

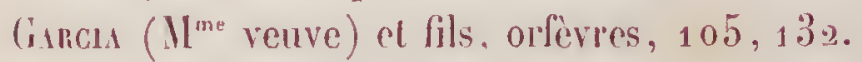

Girnver, archilecte, $17^{3}$.

Girmen (Jean), ciseleur-énuailleur, 73 .

Ganver, peintre-émailleur, 31, 74, 90, 94.

Garrard, orfère, 14, 113,11 h.

Gusvicut (Paul), conservaleur du Musée des arts décoralifs, 140.

Gudir, ciselenr, 47.

Gatrierix, sculpteur, 76 .

Gactuen (Charles), sculpleur, 3o.

Galther, ciseleur, 88.

Gictier (Théophile), 67 .

Gietnche, doreur, $57,58,176$.
Gucve, damasquineur, $80,87,105$.

Gianad (lierre), orferre, 59,132

Geoffroy de Chacues, sculpleur, 11. 138.

Gírard, dessinateur, 31.

Genmax (Les) [Pieme Ier, Thlomas, Francois-

Tliomas, l'ierre II, dil le Romain], orfèvres, $5,26,28,39,43,44,46,52,54,55$,

$79,122,137,140,153,158,209$.

Gerritsex (I. A. A.), orferre, 131.

Gú́bra (École industriclle de), 99, 1 ว̈..

Glubert, sculpleur, 17.

Gillain, ciseleur, 81 .

Gıьoт, typograveur el héliograveur, 91 .

Gıвсfы, gyrareur, 63.

Gravex, bronzipp-orferre, 1 h.

Glacinart, orfère, 72, 73, 90, 140 .

Groni, joaillier, 89 .

Gomin, archilecte et dessinateur, 63.

Goloscumidt (I'me Léopoli), 40.

Golosmitus' Aluhace, 113,11 / , 132.

Gordsuitus and Silversutus $\mathrm{C}^{\circ}, 11$ / $, 115,132$.

Gombaclt, orfèvre, 17.

Govox, fondeur, 173 .

Gonss, Gazelte des beaur-arls, 119.

Gonnan and $\mathrm{C}^{\circ}$, orfèvres, $106,107,108,109$, 110,131 .

Govsox (Jean), sculpteur, 135.

Goupru, éditeur, 91.

Gourdon, ouvrier orfevre, 63.

Godtue-Socland $\left(1 \mathrm{~g}^{\mathrm{gr}}\right)$, archerêque di lix, 33 .

Gramioxd (Le duc de), 85.

Gruxdoune, peintre-émailleur. 31, 71, $7^{4}, 9^{\circ}$, $9^{2}$.

Gravger, bijoutier-ollèvre, 10,1 l.

Grucurous, orfèvie, 14.

Gurayowski, ciseleur, 125.

Gunchet (M"me venve Gustave), orfère, 59 , 132.

Guérix, ciseleur, 56.

Gueytox, orfève, $10,14,16$.

Guichard, architecte-décorateur, 16.

Gugrard, doreur-galvanoplaste, 176 .

Guldanme (E.), ancien directeur des beaux-arts. 153,157 .

Gunlacmet, peinlre, 97 .

Guxsbolra, 12.

Halimis, cuilleriste, 14. 
Hamen (Marius), orfève, $122,132$.

Hanos, peintre, $7^{\circ}$

Ilaxcock, orfèvre, $14,15,17,113$.

Haxoï (Province de), 95,132 .

Ifaxsex, ouvricr orferre. 102.

Harlegux, orfèvere, 17, 51.

HaLSER, ćdileur, 125.

Havilaxi, céramiste, 119 .

Haret (Henry), sculpteur, 14.

HEINT\%, ourier orfèvre, 63.

Heilier, graveur en médailles, 71, 106, 108, $109,153,160,162,166$.

llécix, orfèrre, $161,191,197$.

Нехณ, graveur, 56.

Hexny (1.-H.), faconnier, 66.

Hexry VIII, d'Ingletelre, 72, 128, 134.

Hérucart de Tulny (Le vicomle), 9, 10, 11 .

Hérox de Viliefosse, conservateur des antiquités grec(ues et romaines au Lourre, 143.

Hertford (Le marquis d') , 13.

IInntz (Peler), orfère, $103,131$.

Hesse el Cie, marchands d'or el d'argent, 188.

HIOLLe, sculpleU', 76 .

Ilinscinreto, chel graveur, 111.

Hınт, dessinateur, 73 .

Hol.seix, peintre-graveur, 128,134 .

Holв oок (Elm.), orfèrre, $10 \mathrm{~g}$.

Hovoné, ciscleur, $17,56,81,83,87,165$, 166.

Hore, financier anglais, $\mathbf{1 3}, 138$.

Hoctox, sculpleur, 8.

Holgtox (Georges), orlèrre, 109.

Hocillox, émailleur, $74,17^{\circ}$.

Ilı веRт, ciseleur, 70, 166 .

Hegurs, ourier orfère, 110.

Hugo, orfère, 17,49 .

Hugo (Le moine), oifèrre, 33.

Hego (Viclor), 79, 81 .

Hoxt ct Roskell, orfèvires, 14, $15,17,113$, 114.

Hıot (Les frères), ciseleurs, 166.

have (Comilé de l'exposition de l'), 94, 132.

Ingres, peintre, 8.

JACOB, orfévre, 35.

$\mathrm{J}_{A C O B 1}$, chimiste, 172 .

Jicobsen (CarI), lurassenr, 103.

Jacromilakd, graveur, 86.
Jacquemart, sculpteur, 76 .

Jimitzen, orlève, 99, 138.

Jaxix, bijoutier el verrier, $9^{\circ}$.

JASsex, contremaître, 103.

JAxver, graveur-réducteur, 63, 166.

JARRY, ainé, orfèrre, 14.

Jear de Bologne, sculpleur, 72.

Jеахрот, lijontier-orfèvre, $96,132$.

Jepsox (John), contremaître, 111.

Jerdelet, ciseleur, $129,166$.

Јоскв-СLе13, 47, 70, 71, 76.

Jowny, sculpteur-ornemaniste, $43,51,73,89$, 140.

Jondr, ciseleur, 110 .

Jone't (Engène), orfère, 85, 86, 98, 132.

Jules II, pape, 72.

Julumexre, des inateur, 23.

Justux, sculpieur, 11, 23.

Kafta, sculpteur, 124.

КАтев, orfève, $103,132$.

Keluer frères, orfèvies, 58, 59, 66, 131 .

Kensivgton (Musée du Soltu), 81, 94, 112, $114,116,129,156$.

Killebikofr, orlère, $124,125,131$.

Kinnster, ciseleup, 166.

Kiritrosho-Kaisha, 120,131 .

Kittli, repousseur, 109 .

Klagman, sculpteur, 8, 23, 80, 138.

Kungert (Gustave), orfêvre-ćmailleur, 125 , 126,132 .

Kuixnoscu, orfève, $98,207$.

Koumus, plancur, 37 .

Konarofr, dessinateur, 122.

Kossac (Jules), peintre, 125.

Krog (A.), archilecte peintre, 3, 119.

Kryiski (Jean), sculpteur, 125.

Kunzawa, modeleur, 125 .

LABiche, tourneur, 31.

Labie, bijoutier-ingénieur, 190.

Laborde (Le comle léon de), archéologne, 7 , $12,13,14,16,22,139,163$.

Labodrlad, commissionnaire-exportatenr, 190.

JaFAуeтte (Le général marquis be), 138.

la Foxtaine (Jean de), 149.

Laforge (Paul), orfère-monteur, 66, 132.

Lafraves, sculpteur, 61,76 .

Lanbert (Léon), orfèra. 59, 132. 
Laneme, peinlie-archilecte, $33,34,78$.

Lanuxìne, bijoutier, 3.

Lancosue, ouvrier bijoulier-orfèvre, $7^{3}$.

Janguan, bijoutier, 114.

Lantosi, ouvrice orfève, 31.

Lasseau, ciseleur, 100.

Litovi, planeur, 63.

Laussevat (Le colonel), directeur du Conservatoire des arts el métiers, 46, 158 .

Lavaliée, orlève, 57.

Lavigina (Le cardinal), archevếrgue d'Alger et de Carthage, 33.

Lavigne, ciseleur, 166.

Lavorx, conservateur à la Bibliothèrque nationale (Cabinet des antiques), 143.

Lebrux, orfève, $9,10,14$.

Leniux, peintre, 20,157 .

Licuive, ciseleur, 57 .

Leghevalier-Cuevigrard, peintre, 44.

Jeconte du Noüy, architecte, 36 .

L.econder, contremaitre, 59 .

Lacot (Adolplie el Charles), ouvrier's orfèvres, 31 .

LEDAGRe, narchaud orfèvre, 13,15 .

Llefebve fils, joaillier, 90, 92 .

Lemaxe, orfevre, 10.

Lfanos (Alphonse), graveur ell médailles el peintre, 71 .

Legros, ciseleur, 86.

Jk:our, ingénénieur, 7 .

L.ér XIII (Sa Sainteté), pape, 33, 37, 79.

Líoxard-Linousin, peintre-émailleur, 74.

Lapautre, archilecte, $20,151$.

Lepec (Charles), émailleur, 17, 24, 84, 170 .

LE PLir, économiste, 16.

Lenor (Louis et $\mathrm{C}^{\mathrm{ic}}$ ), orfère, 57,131 .

J.esseps (Ferdiuand DE), 138.

Lesteur, peintre, 140 .

Levasseur, sculpteur, 69,70 .

Levildain, sculpteur, 44, 61, 63, 71, 76,77, $153,166$.

Lетинв, émailleur, 109.

Liacopollos, orfèvie, 116,132 .

LuÉGEaro (A.), sous-chef de la statistique adninistrative, 215 .

Láxaro, dessinatemi, $11,23.56$.

Lì̀ve (Édouard et Justin), dessinateurs, 23.
Ligieredx, contremailtre, $5 \mathrm{~g}$.

Lisarn-Gostuler, peintre-verrier, go.

Livirès (Le marquis de), 50.

Lixk (P.-Eslieme), orfevre, 98, 99, 132.

Liscir, architecte, $36^{\circ}$.

LCEBsitz, céramiste, rapporteur de la classe 18 , 170.

LoEtitua (S. A. I. Ja princesse), duchesse d'Aostr, 69.

Lolr (.lexis), orfèvre, 5,78 .

Losgepied, sculpteur, 76 .

l.opiexski, ciseleur, 125 .

Lonsax (Paul), archilecle, $25,26$.

Lodantier, ouvier orfèvre, 65.

Lous IX (Saint), roi de France, 33.

Louis XII, 72.

Lours X1V, 78 .

Louvols, 153 .

Louvrier de Lajolais, directeur de l'école des arts décoratifs, 157 .

Lucas de Leyde, graveur, 86.

Lurves (Le duc DE), 7, 11, 12, $13,17,20$. $22,23,37,40,41,45,73,163,165$.

Iyox-Illemaxd (Conlptoir), 185.

Lroxrus, galvanoplaste, 14 .

Nac-KineEX (Bill), $209,210$.

Magnus, onvricr orfèrre, 11.

Maire, orfèvre, $9,53$.

Maisov (Léoul), orfèvire, 86, 132.

MaLLet, sculpleur, $61,63,76$.

Naximein (Chartes), expert, 7, 140.

Maxtz (Paul), crilique d'art, 86 .

Mappix, orfèvre, 17.

Marces (Cl.), orfève, 26.

Marcunnd dessiuateur, 38.

Marie, directeur du commerce intérieur, 190.

Mariotros, sculpteur-ciseleur, 70, 88, 166.

Млгот, architecle-graveur, 20.

Marnel frères, bijoutiers-orfères, $10,13,14$.

Mlareet et Beaggrayd, joailliers, 89 .

Martix (Le Père), archéoloğue, 28, 29.

Marvie-Mhartis, dessinateur-graveur, 55.

Mason el El.kington, orfèrtes, 14 .

Mitudux-Moreau, sculpteur, 50, 61, 62, $7^{6}$, 77,147 .

Mayen (Maurice), orfèvre, 10.

M.Y.er, nodeleur, 56. 
Meissonier, peintee, $71,81,151,164$.

Meissomier, orfèvie, $6,42,43,46,47,55$, 140.

Mellerı, joaillier-orfèvre, 17,18 .

Méxarn, chef d'atelier, 48.

Mextiox, orfèvre, $9,10$.

Mexc, bijoutier-orfère, $55,56,83$.

Mercis (Antonin), sculpteur, 61, $75,7^{6}, 7^{8}$, $84,88,147$.

Meridex Butamia $C^{0}, 110,111,131,17$ h.

Mérmée (Prosper), 15, 16.

Mérite (Charles), orfèvre, 58, 131 .

Merte (Charles) et fils, orfèvres, $65,132$.

Merice (Fr.-Paul), auteur dramatique, 79 .

Merer (Alfred), peintre-émaillour, 74,92 .

Mıcinaïlofr, ciseleur, 124 .

Mrcuatr (Eugène), ciscleur-otfèvre, 1 7, 56, 9o, 131.

Michel-Gilevalier, économisle, 14,15 .

Migxerox, 9 .

Migrox, sculpleur, $7^{6}$.

Mhlan (Le roi), de Serbie, 208.

Miliket ( Aimé), sculpteur, $69,7^{\circ}$.

Miliet (Jean-Francois), peintre, 8, 6h, 76 .

Mulovkoff (P. P.), orfèvre, 126, 132 .

Mılocievitcu (P. 0.), orfêvre, 127,132 .

Ministre de l'ixstruction publique at bes beauxAliTs, $150,154,156$.

Mladéxovitcu (Yovan), 127.

Monımed Djellock, orlèv'e, 96 .

Monamed Sä̈́ Natt Ockebolbèche, bijoulier-orlèvre, 93 .

Morsset, ciseleur, 47, 48, 50 .

Molıère, 150.

Molivier (E.), archéologrue, 7, 143,169 .

Molchard, bijouticr, 92, 130 .

Moxcer (Le maréchal), duc de Conegliano, 40.

Moxsrate (Ch.), littérateur, 77.

Moxtefiore, collectionneur, 119 .

Hoxtr, sculpteur, 15 .

Ноore, dir. orfêvre, $107,109,110$.

Moreau (Augusic), sculpteur, 6/s

Moneau (Felipe), orfèvre, 132.

Moreau (Gustave), peintre, 7h, 153.

Moriac-Vauthier, sculpteur, 44, 72, 75 .

Morel, orfëvre, $10,11,12,13,14,17,73$, 138.
Morel-Ladeuit, ciscleur, $14.15,79,87,110$, $164,165,166,171$.

Morera ( $\mathrm{I}^{\text {me }}$ veuve), orfèvie, $123,{ }_{1} 3$.

Monıx (Le général), mathénaticien, 15.

Morix (Paul), orferre en aluminiun, 65.

Morrisson (Afred), $73,8 /$ s.

Noccur (Lá duchesse de), 69 .

Nourrari, dessinateur, 100.

Muleret, ciseleur, 11, 81, 138,165 .

Mïstz, conservateur-bibliolhécaire des beauxarts, 143 .

NApolÉox I I $, 9,20,138$,

Napolḱox III, $10,13,16,22$.

Négnier (Le général), 79 .

Nedfchìtean (François ne), 7, 8, 11 .

Nevilé, dessinateur, $11,23$.

Nicord, orfère, 57 .

Niepce, inveuleur de l'héliographie, 9).

Oввік, sculpleur el dessinaleur, $10 \%$.

Oрioт (Cl.) père, orfèvre, 8, 9, 10, 40, 41.

Ovгот (G-Gustave), orfèvre, $3,14,16,17,27$, $40,41,42,44,49,57,109,131,208$.

Oргот (Frnest), 40 .

Oprot (Mme reuve), 7, 40.

OrNe (Émile), bijoutier-joaillier. 8().

Olsen ('Theodor), orfêre, $121,131$.

OLser (Thornwald), orlèvre, 121.

OVIDE, 149 .

Ovtscunvikoff, orlevie, $17,123,124,125$, 131.

Owex (Sir Phil, Gunliff), 143.

Orenne, ancien directeur de lagriculture et du commerce, 18.

PARAXd, orfèrre, 35.

Pariser, orfèvre, 35.

Parker, orfevre, 132.

Pascal, sculptcur, 11.

Patollet, Acbry el Lebeat, plafueurs sur mítal, 7 .

Paren, bijoutier-orfèvre, 10.

Реск, bijouticr, 46.

Pellegat, de Rouen, 173.

Péxicacd, maître peintre-énaaillenr, 7 亿.

Percier el Foytane, architectes-dessinateurs, $20,40,44,149$.

Pereire (Gustave), 69 .

Perrire (Isaac), 71 . 
Perlutat, onvricl ollèvere, 31.

Peliratior (Charles), lilléralcur, 78.

Péters, dessinateur, 102.

PEtrte clief d'alclier, 56.

Pistot, peinlre sur énail。 170.

Prixot, sculpteur, 47, 50.

Perre (Jules), dessinateu, 2.3, 80.

Pluturs (Ferdiuand) el Cie ćmailleurs, $129,132$.

Puntape (Eunile), orfève, 18.

Puntape, bijontier-orlevre, 75, 84, 131 .

Pmulass, bijontier-orlevre, 113.

Pissts (Les), dues de Pologue, 125.

Pricur (Jules), contelien-onfevie, 57.

Picuor (Le baron), bibliopliele, 46, 74, 140 , $18 ?$.

Pie IX, pape, 100.

Pinrrit, onvier orlèvre, 48.

Pigille, sculpleur, 88.

Pixto-Gourka, orfevre, 132.

l'isms (les), múlaillistes, 152.

Punté, bijoulicr-orlè̀re, , $5,132$.

Puewcki (Miécislas), ouvrier orferre, 125.

Puxe, 139 .

l'sour (les), onvricrs orfères, 11.

Pouncx, ouvrier bijoutier, go.

P'olä́lolo, graveur-niclleur, 169.

Polse, ouvrier orfèrle, $\$ 4$.

l'ONLTOWSKI : 125.

Poxecarue, sculptemi, 71.

Popeux (Claudius), peintre-ŕmailleur, 7 h.

lotin, rapporteur de la classe $62,173$.

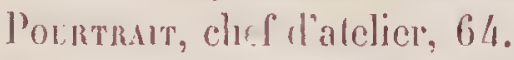

Poissielaue-Risivin (Placile), orfevie, 3, 13 , $14,15,16,17,18,26,29,30,5.3,131$, 148.

Potsielgul-lilsixd al fils, orfeveres, $27,29,30$, $31,32,35,36,78,87,92,148$.

Polssix (Nicolas), 151 .

Pocx, ciseleur, 11,87 .

Prívet, député, 1 go.

Prévost, ciscleul, 47, $50,51,63$.

Pridray (B. Walter S.), 200.

Prediox, peinlre, 8, эo, 138.

Puger (Pierre), sculpteur, 151.

Purfoncat, orlère, $161,191$.

Pye (Émiln), graveur-cloisonneur, 73, $7^{4}, 17^{0 .}$

Questel, architecle, 3 o.
Quntor, sculpteur, 50, 71.

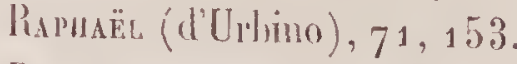

Rauı, graveur, 55, 163.

Récupox, dessinalenr-modeleur, 42, 57.

ReEd, joaillier-orfère, 106.

Rejler, architede-dessinatent', $119,138,168$.

Rumgara Fiane Pestonee, 116.

Ricusnd (Paul), ciselene, 140.

lícue, directeur des essais ì la Monnaic, 183 , $187,188,190,192,193,206$.

líchisieu (lac cardinal de), 28.

Rirfucx, lijoutier-émaillenr, 84.

Procne (Jules), dépulé, 1 go.

Ronis, sculptenr, 70, 87, 150.

liö̈rtiers, orlèvie, $43,46,55$.

Riogkr (Ie baron), 8:3.

Ropala (Geo), orlevre, $123,132$.

liossrgneux, architecle-dessinaleur, $14,23,138$.

Rotnscund (Le Jainon Idolphe oe), 74, 143.

Rotuscirlo (Le haron Alplionse os), 76 .

liotusculd (Le baron Call ne), 99.

liotuscmud (Ic baron Guslave de), 71, 86.

Roty (0.), grareur en médailles, 63, 71, 77 . $147,152,166$.

Roviliard, schlplenl', 11.

Rousser, orlevere, 17.

Roussea el Jinet, orfevres, 59 .

Routuer, ćmaillem, $73,74,170$.

Rocvexat, bijoulier-orfève, $10,16,18$.

Rooven, orlève, 9.

Pioyer, graveur, 57 .

Ruau, directeur général des monnaies at médailles, 190.

Rude, sculpteri, 8, 12, 84, 138 .

liuner, fondenr, 50.

Recolpur, orfève, $10,11,14,16$.

Ricolz (Ie comle Fr. ne), chimiste, 60, 63, 172 .

Rupricu-liobert, arclitecle, 30.

Saglier (E.-Viclor), orfèric, 66.

Sigluo, conservateur des monments du moyen îge et de la renaissance au Louve, 143.

Saïnou Cartax, orlèrre, $96,132$.

Stïro (Masakichi), 121, 131 .

SAlmox, gravent, 91 .

S.lluson, sculpleur, $129^{-166 .}$

Sixnoz (Gustave), loijoulier-tiolloger, 3, 27, $7^{5}$, 131. 
Saridis, olfèvre, 104, 132 .

Suriazix (Jacquues), sculpteur, 28.

Sisinofr, orfevre, 17.

Siuvagrot, archéologue, 21.

Salvagiot, architrcte, 30,36 .

Scalleft, sculpleur sur ivoire, 75,88 .

Scilickler (Le laaron de), 71, 76 .

Scurer (Jacques), vice-président du jury de la

classe 24,3 .

SchMLfELl, ciscleur, 102.

Schofferer (dry), peintre, 138.

ScotT (Lady), 72 .

Stibllue, architecte, $36,7^{8}$.

SéLys (Le baron DE), 100.

Slineflidoeli (1loïs), lithographe, 62.

SÉvix (Constant), dessinateur-sculpteur, 23.

Shaker, ouvrier orfête, 110.

Silaw el Fisura, orfères, 17.

Sian (Le roi de), 127, 128,131 .

Siadx, ouvrier orferve, 34.

Simart, sculpteur, $8,11,12,73,138$.

Sinox, ciseleur, 63.

Sinox (Jules), 19.

SoвiEski, 125.

SoётréR, économisle, $182,187,206$.

Soldr, sculpteur, 71.

Sous (Virgilius), gravenr, 82.

Soluen, émailleur, 11.

Solor, sculpteur-dessinatrur, 23.

Spitzer, collectionneur, 74, 140.

Sprturir, Ministre de l'agriculture et du com-

merce, 179 .

Stefille-cilasfes (Société des), 71.

STEn, collectionneur, 140.

SteINFR, sculpteur, 88.

Stepianus (Haîlıe) [voir Delaulue Étienne].

Strass, joaillier, 68 .

Sr, orfèvre, 17.

TAbunet, bijoutier-antiquaire, 46 .

Tä̈b-el-Mestaoti, orfève, 97, 132.

TALLE, contremaître, 42.

Tallois el Mayexee, orfevies, 57, 58, 131 .

Tanisier, sculpteur, g.

Tard, émailleur, 170.

'TAsset, graveur et réducteur en médailles, 71, 166.

Tatakine, émailleur, 124.
Teisserexc de Bort, ancien Ministre de l'agriculture et du commerce, $7^{1}$.

Tistevune ( V. ), orfévie ell alumininm, 65,132 . Tútard, ordère, 47. 49, 50, 51, 54, 131 .

Texiln (L'abléé) 148.

Teyssien, 45,64 .

Théophule (Le moine), $16 \mathrm{~g}$.

Thйв: lapidaire, 10.

Thesuar, émailleur, $170,171$.

Theurat ( $M^{\mathrm{gr}}$ ): évépue de Monaco, 34.

Thisrny, orfèvre, 14,17 .

Thuers (Louis-Adolple), 9 .

Thouas ( $\left.\mathrm{II}^{8}\right)$, archeveque de Rouen, 37 .

Thomrn, ciseleur-bronzier, 9, 26, 40, 166.

Thouket (Antony), publiciste el représentant dir peuple, 11.

Thouret, orfevte, $14,64$.

Thorwalster, schlpteur, 102.

TrFaty et $C^{\text {ie }}$, orfères-joailliers, 1 7, 106, 107 , $108,109,110,131,171,209,210$.

ToLıN, séllatemr, $158,159,190$.

'Toximluer, orfère, 59 .

Tostrup (Jacol), orfevre, 121.

Tounhette, émailleur, $7^{3}, 7^{4}, 89,170$.

Toutan, orfèvre-émailleur, 26.

Toctin, peintıe sur ćmail. 170.

Trémoille (Le duc de la), 42.

Trmolet $\left(\mathrm{M}^{\mathrm{n}}\right)$, 34, $8 \mathrm{~g}$.

Triouldien fières, orfevies, $17,35,36,37,78$, $131,148$.

Trioulaer père, orfèvre, $10,14$.

Trotté, ciseleur, 63.

Trovox, peintre, 76 .

Trufraut, sculpteur, 64.

Tunisiex (Comité), 96, 132.

Turgot, 6.

Turquet, orfève, 17,57 .

Ugoliyo de Siennls, 149 .

Union centrile des arts décolatifs, 33,45 , $52,53,69,74,82,140,157,171$.

Useldinger (Georges), ciselcul', 85, 87, 132 .

VAx KFupex, orfètre, 1 7, 58, 204.

Vaxiacque, économiste, 215.

Varaxgoz (Ch.), lapidaire, $73,84,9^{2}$.

VAudreuer, architecle, 35.

Vechte, ciseleur, 8, 10, 12, 14, 15, 21, 79, $80,82,83: 87,138,165,171$. 
Veriatt, ciscleui, 166.

Verraz (Ch. ), cisclcur, 8:, 13.

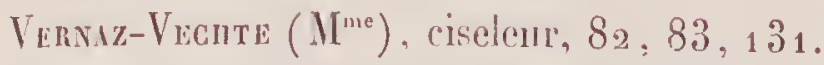

Vervifr (E.), modeleur-ciseleur, 89.

Veroccuiro, peintre-sculptenr, $128,149$.

Veroxèse (Panl Calliari dil), 151.

Verrade, ourpicr orfèvre, 11.

$V_{\text {ever frères, }} 88,89,92$.

Vesrat, orfévre, 9, 10, 1/1, 17, 19 .

Victon III, pape, 134.

VIDal, pholographe, 91.

Vili:MnNot, sculpteur, 19.

Vhaceyt-Garce, commissiomanire, 188,189 , $190,191$.

Vindr, seulpleur, 34.

Violdet-t.e-DuG, arclialcele, $1 / 4,29,30,53$, $138,158$.

VІот, ciseleur, 56.

Voltaire, 88,137 .

Wagxen (de Berlin), orfèvre, 17.
W Waldeara II, roi de Danemark, 102.

Whalace (Sir Richard), 7 tr.

W

Watscimist, orferre, 98 .

Watteau, peintre, 140.

Wattieaux, émaillcur, 31.

IVEBR, orfèrte, 17.

Whatuerson, orfèvre, 17.

Wiese, orfève, 1 /t.

Wilkissox (Geo), contremailtre, 110.

Willemsexs, hronzier, 163.

Whinotte (J.) fils, orferre, 99, 100, 131.

WiLis, senlpleur-orferre, 17 .

VIsser, orfèvre, 11.

Wolgotd, orfère, $1 /$.

Wolowsky, ćconomiste, 7, 10, 11, 41 .

Yacitr-Cluub (Sociélé du), 71.

Yoxg-Hexg, orfère, $101,132$.

Zuloaga (Placido), damascuineur, 80, $105,171$. 


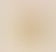


Tableau A

BUREAU DE LA GARANTIE

QUANTITES DOOR ET D'ARGENT GONTRÒLÉES AU BUREAU DE PARIS DE 1818 ì 1889 

Tableau B

\section{ORFÈVRERIE}

\section{DOUANES FRANÇAISES - EXPORTATION \\ 1820 À 1889}

QUANTITES EN POIDS 
Grover III, Chasse gh

Tameau B

EXPORTATIO

COMNERCE GÉNÉRAL E'T GOMMERGES

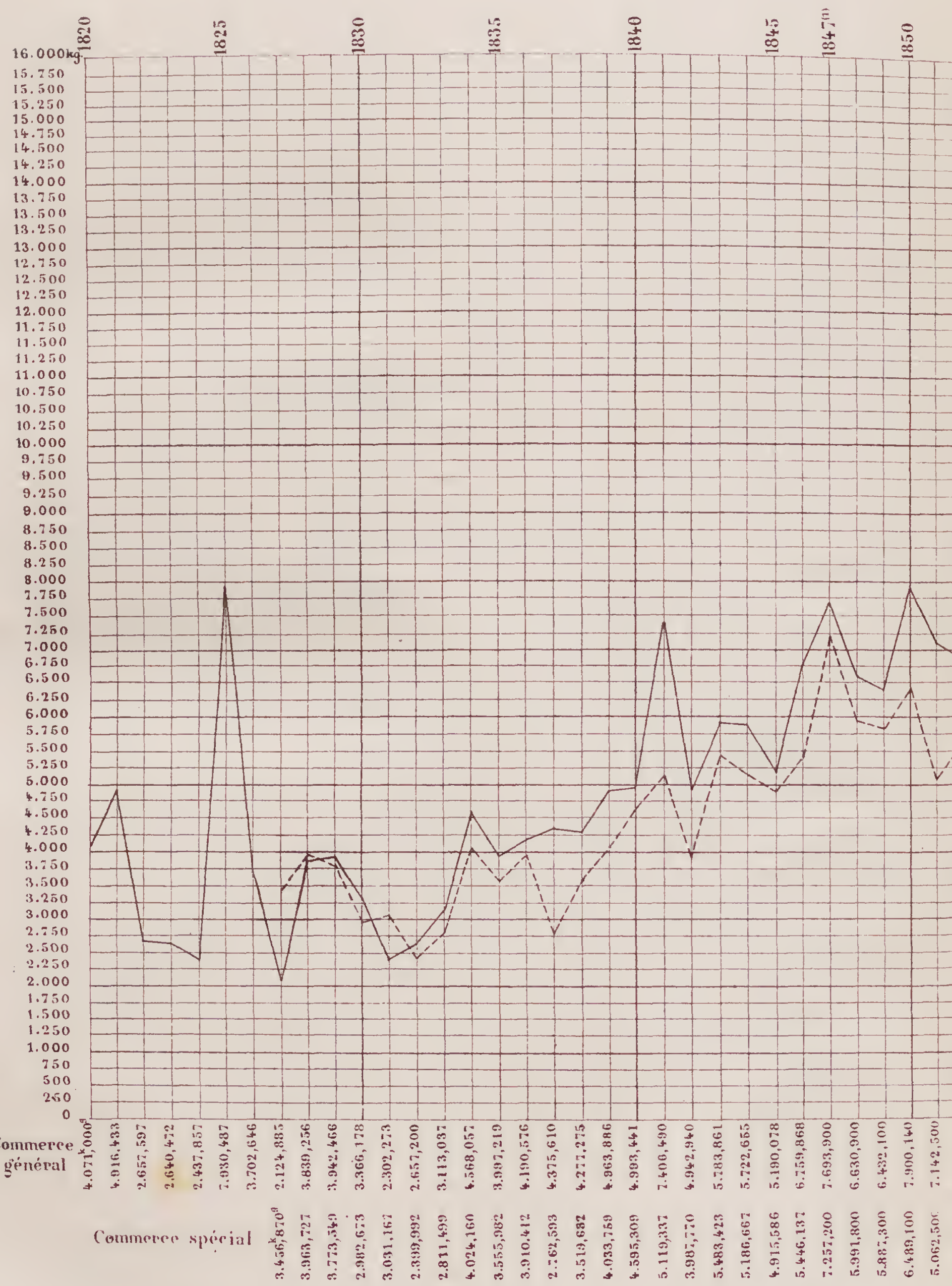

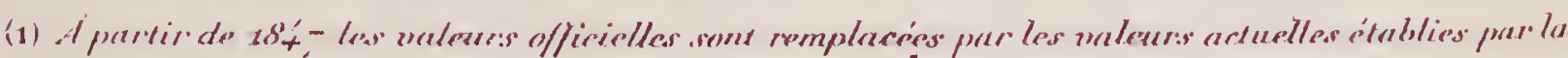



Jableau C

\section{ORFEVRERIE}

\section{DOUINES FRANGAISES - EXPORTATION}

1820 ¿े 1889

VAEUR EN FRANGS 


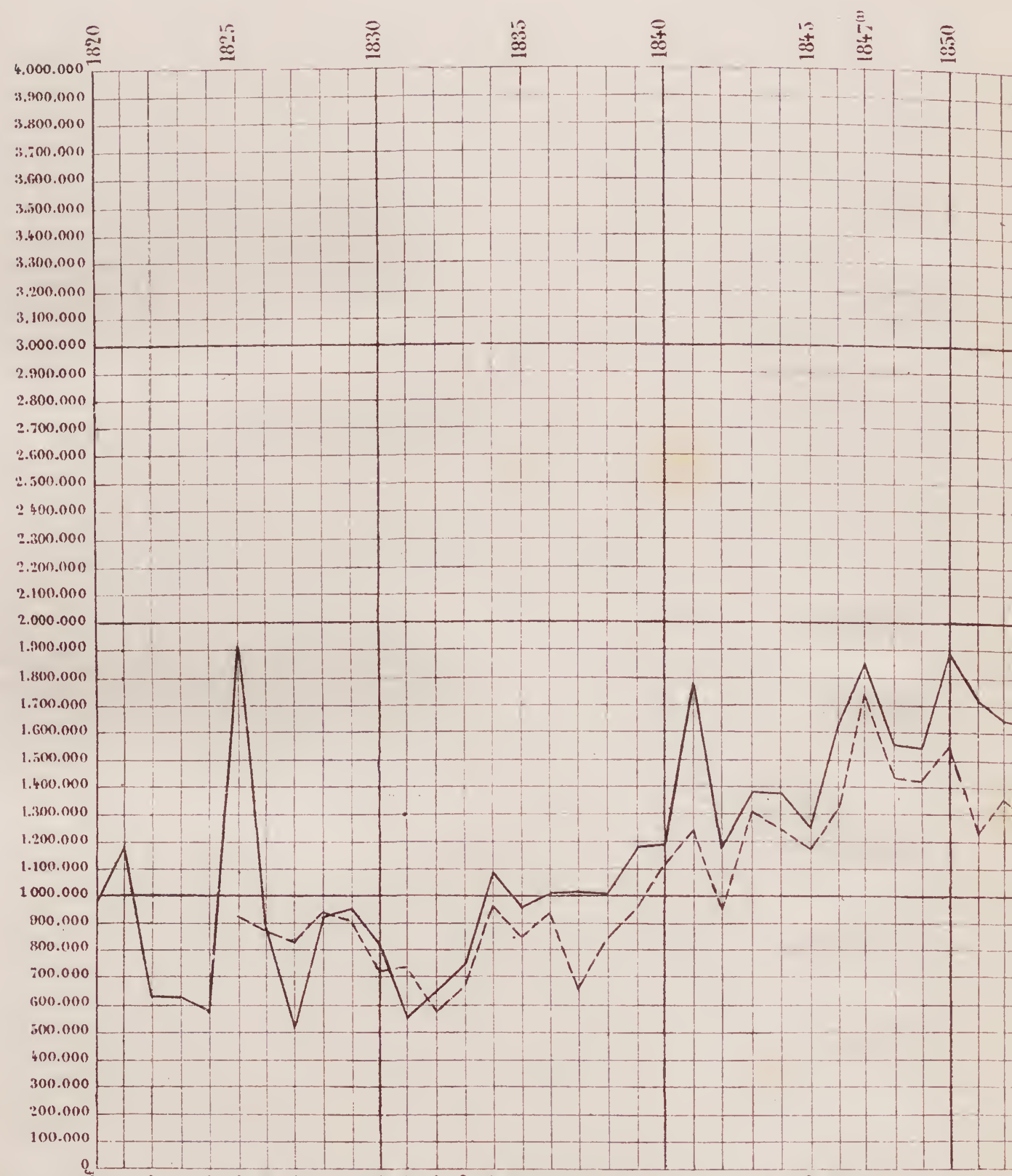

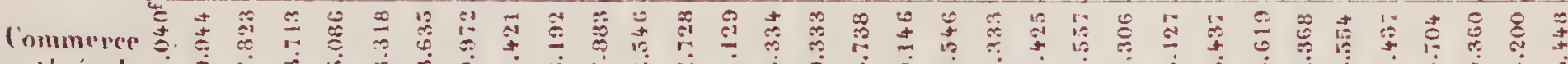
général

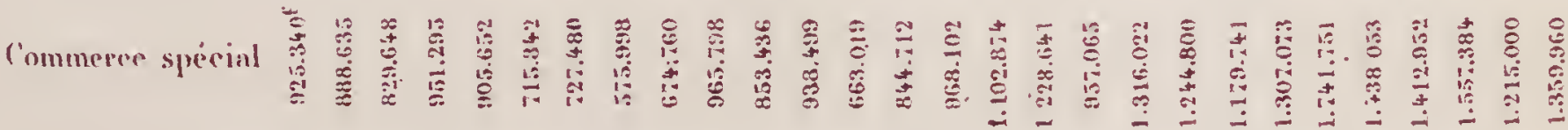

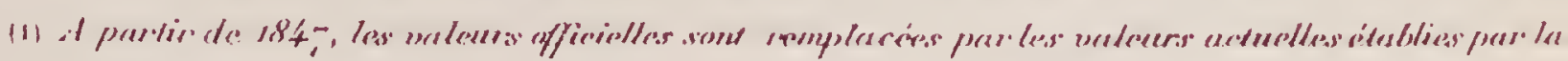




\section{S DE FRANCE}

F SPECIIL. - VALEUR EN FBANCS

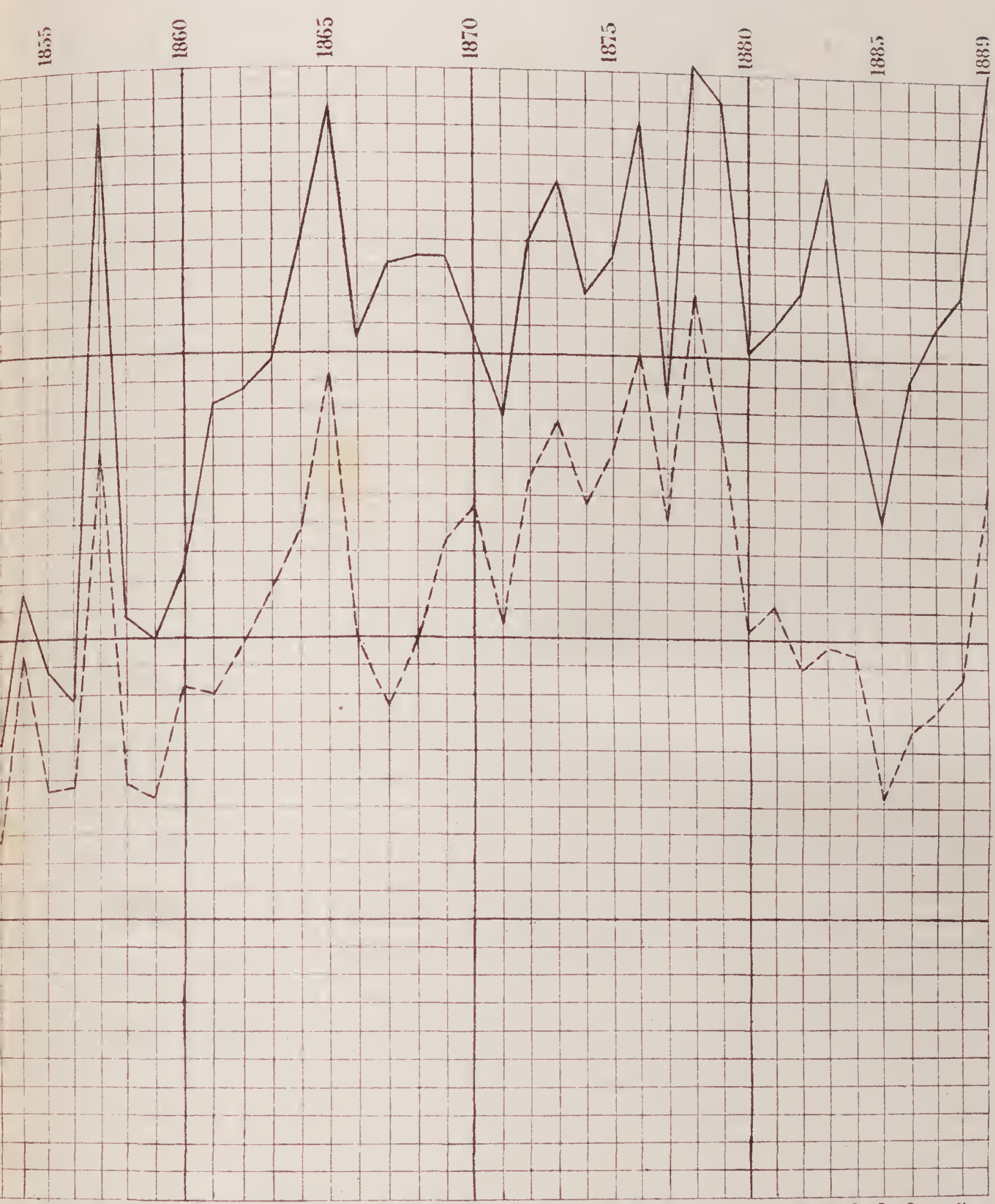

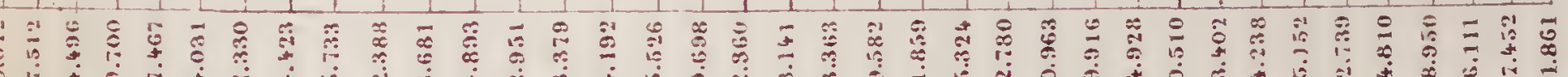

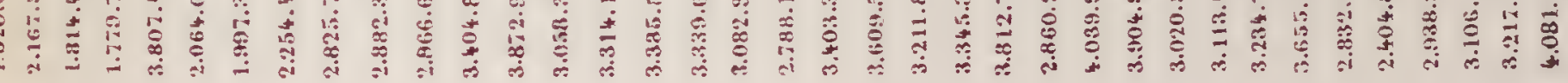

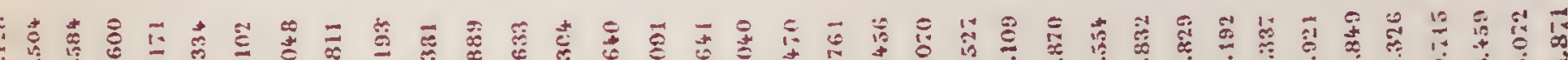

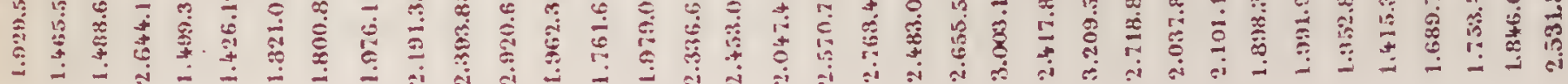
munission des uoloners. 

TABLeaU D

\section{ORFEVRERIE}

\section{DOUANES FRANGAISES - IMPORTATION}

1816 À 1889

QUANTITES EN POIDS 
liapport sur l'Orfevrerie

Grotpl: III, Chasse :

Tableate D

IMPORTATIO

COMMERCE GÉNÉRIL E'T GOMNERCES

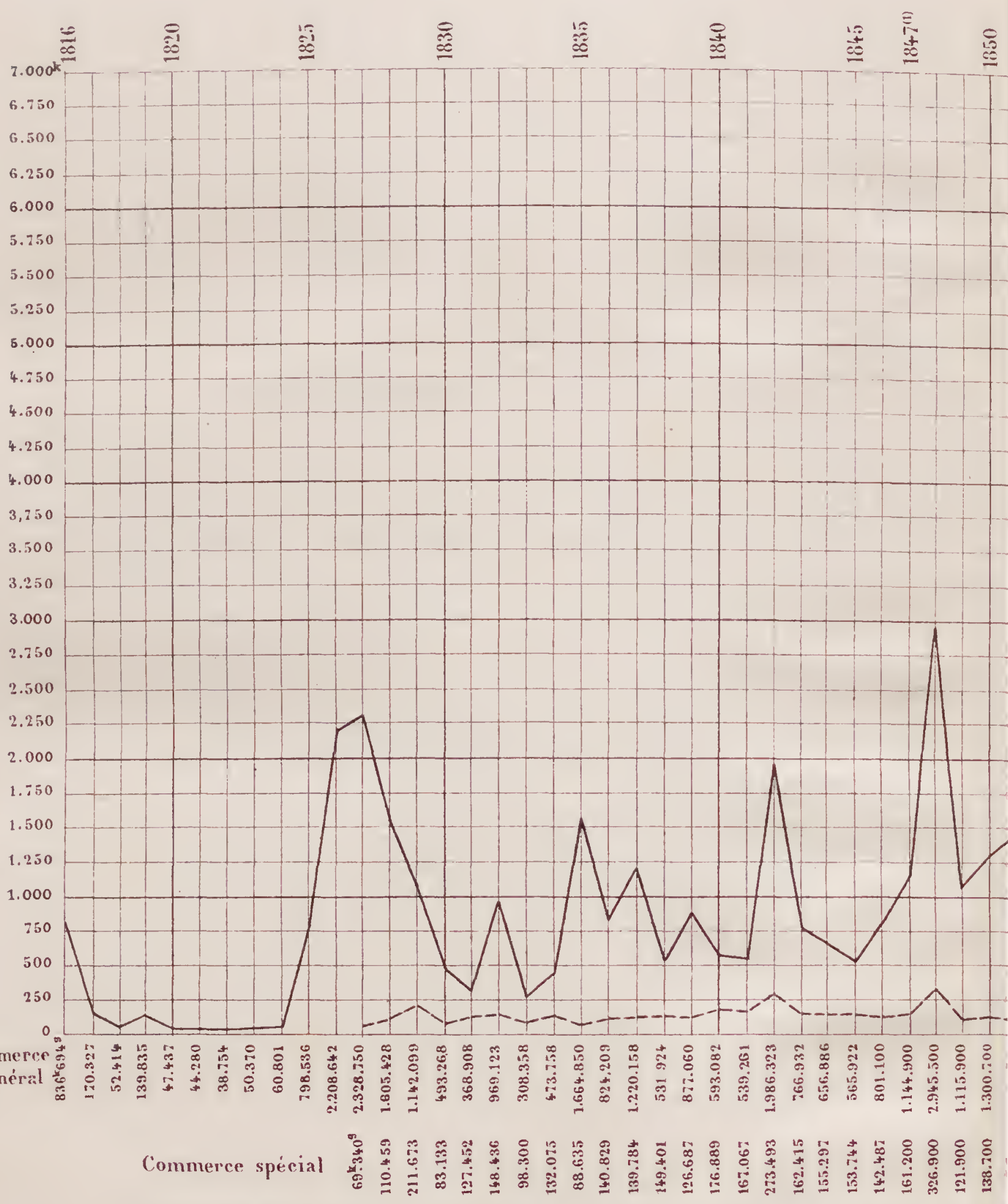

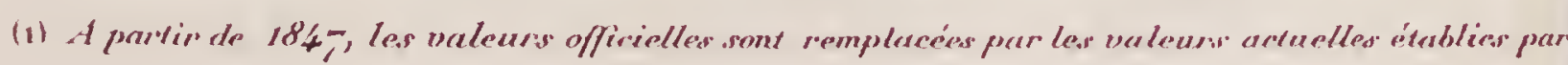



Tableate E

\section{ORFËVRERIE}

\section{DOUANES FRANGAISES -- IMPORTATTON 1816 ̀̀ 1889}

VALEUR EN FRANGS 
Gionpr III, Gisser a/

Tablean E

I MPORTATIO

CONMERCE GENERAL ET CONHE

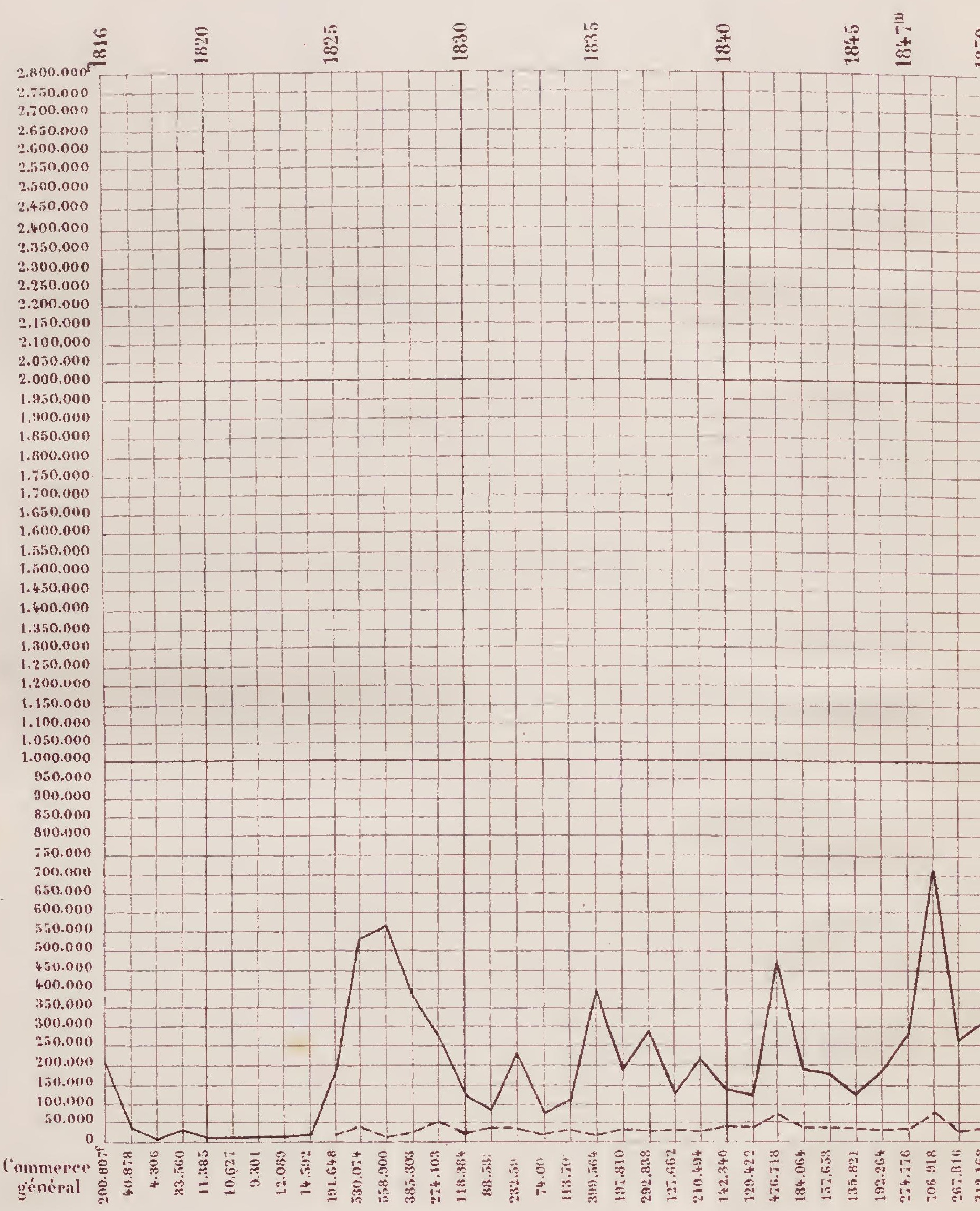

Commerer special $\begin{gathered}0 \\ 0\end{gathered}$

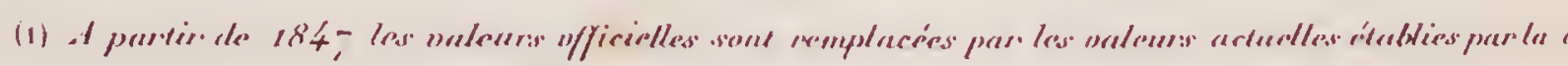




\section{S EN FRANCE}

E SPÉCHL. - VALEUR EN FRAMCS
遂
$\stackrel{8}{\stackrel{0}{0}}$
产
总
$\stackrel{10}{2}$

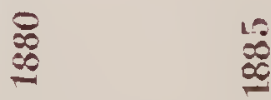


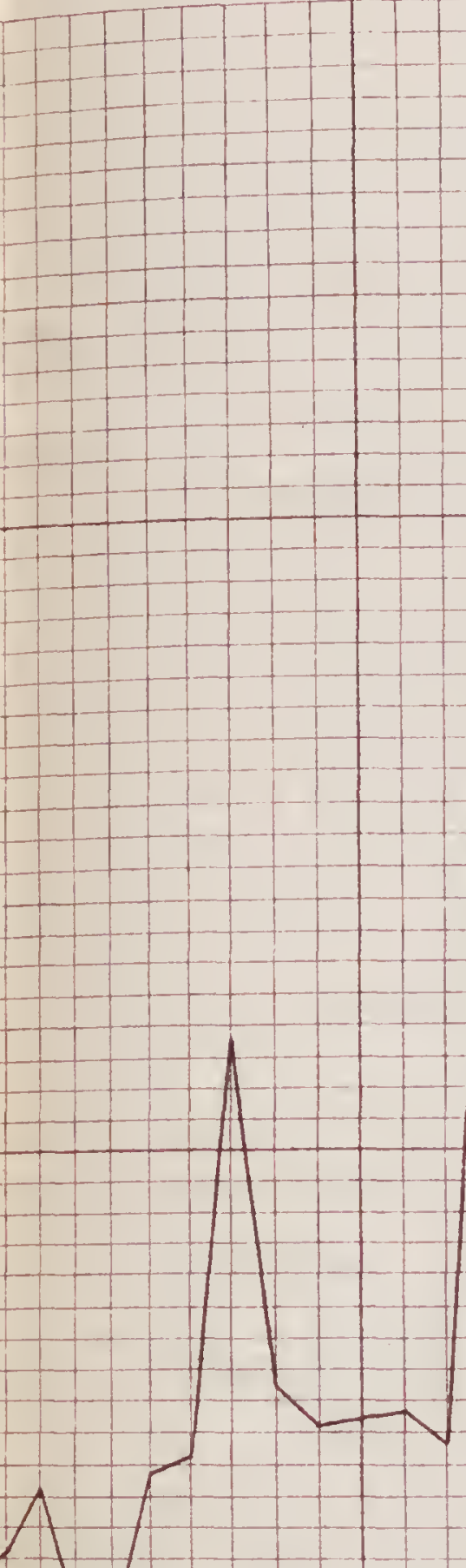

A
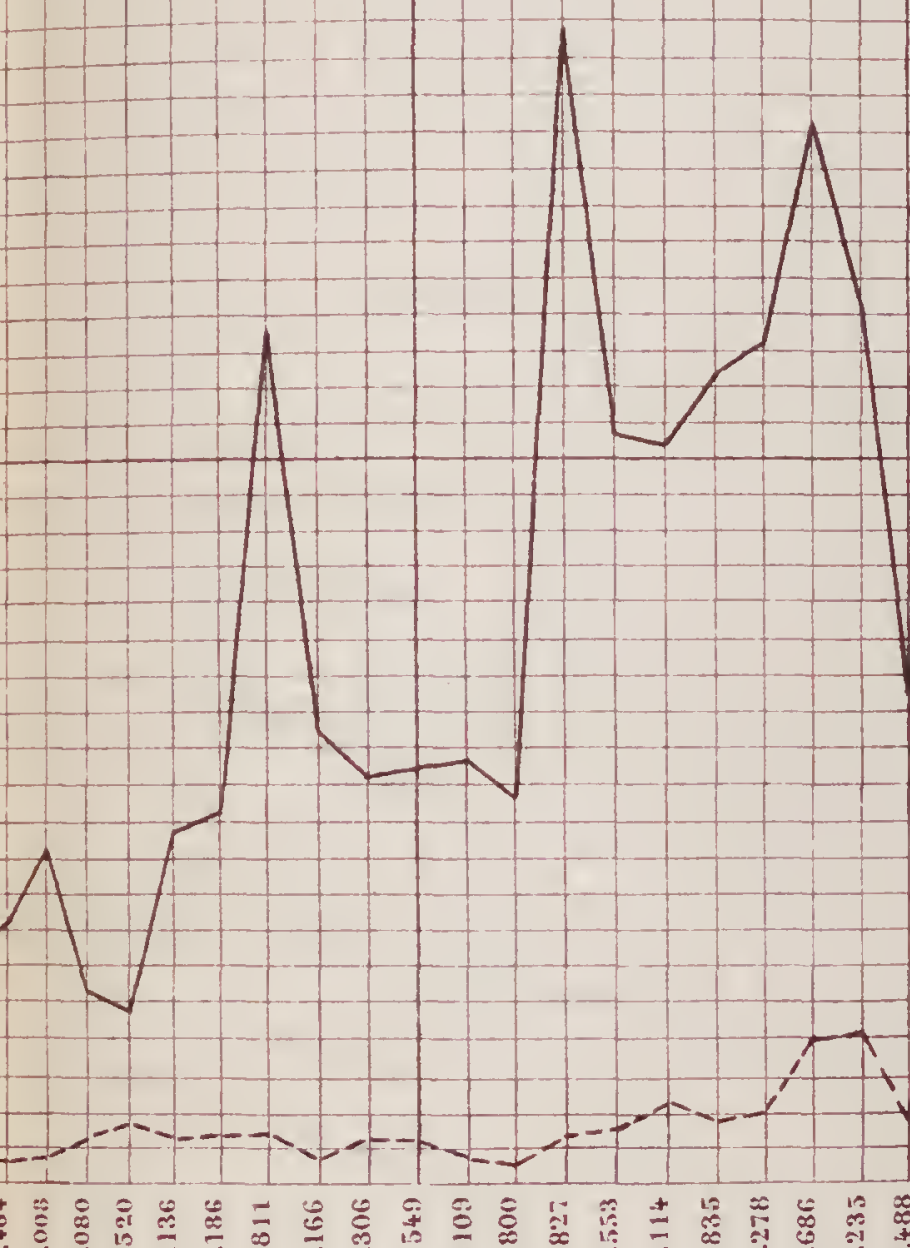

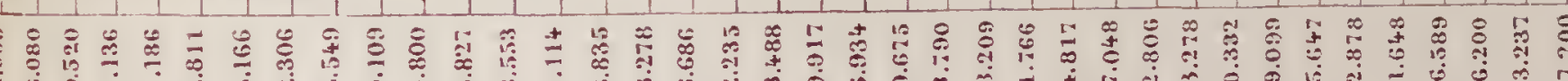

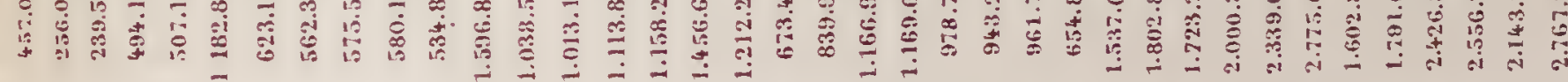

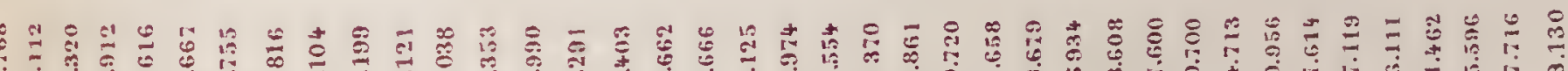

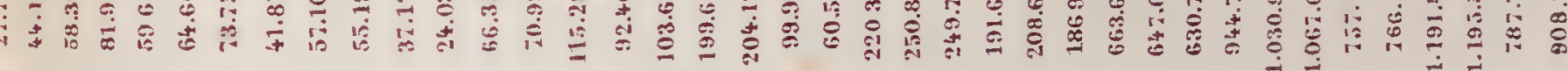





\section{TABLE DES MATIERES.}

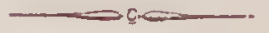

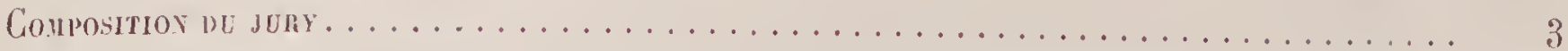

Chaptre phener. - Lorfevrerie française aux exposilions depuis l'an vi . . . . . . . . . 5

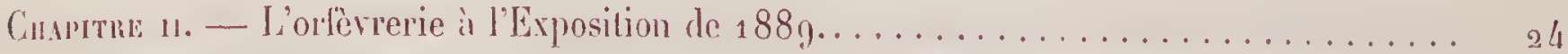

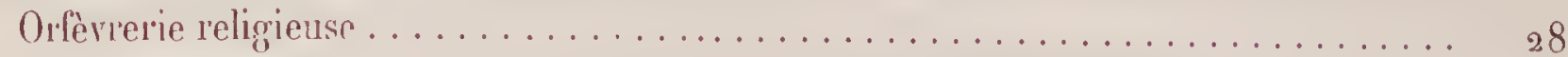

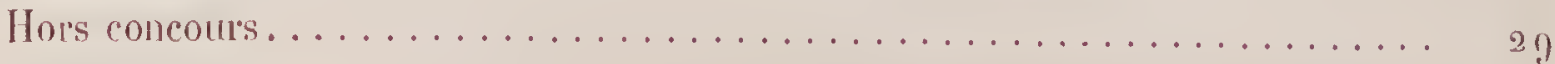

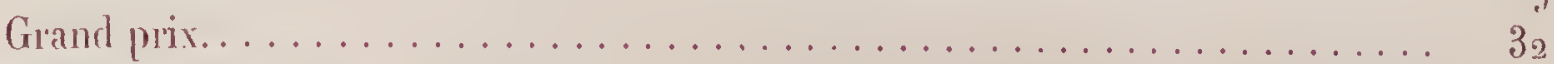

Médailles d'argent ........................... 35

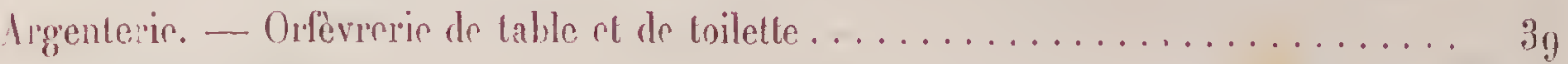

Hor's concours. . . . . . . . . . . . . . . . . . . . . . . 40

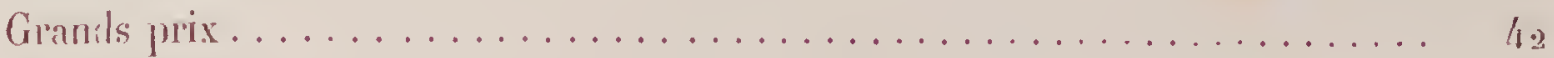

Médailles d'or ............................. 4q

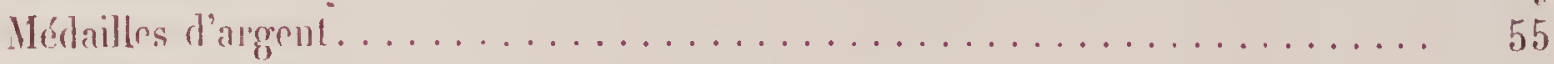

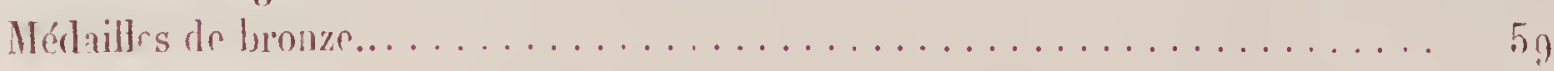

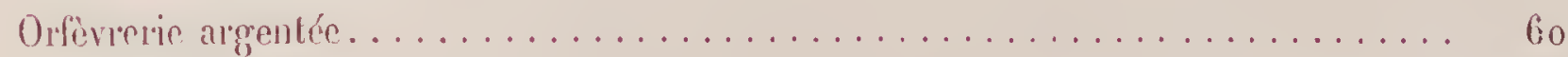

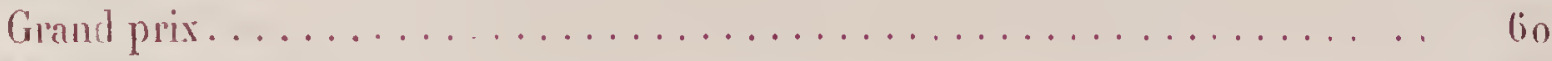

Médailles d'argont . . . . . . . . . . . . . . . . . . . . . 63,

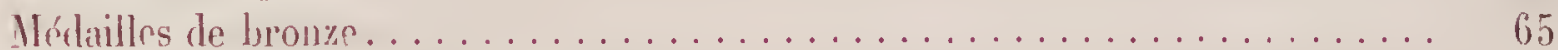

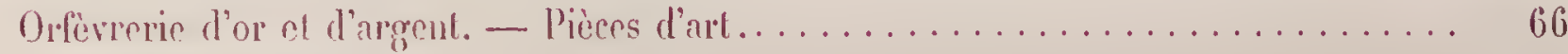

IIors concours. . . . . . . . . . . . . . . . . . . . . 68

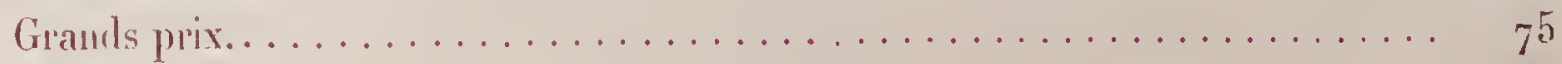

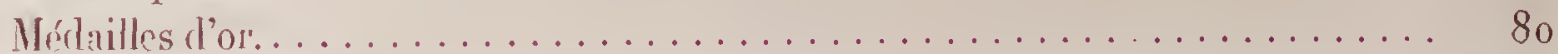

Médailles d'argent. ............................ 83

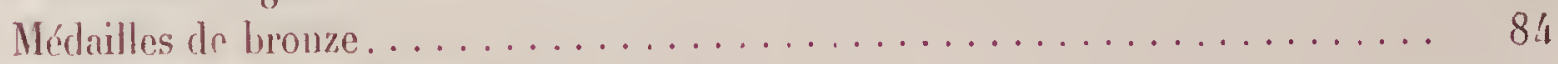

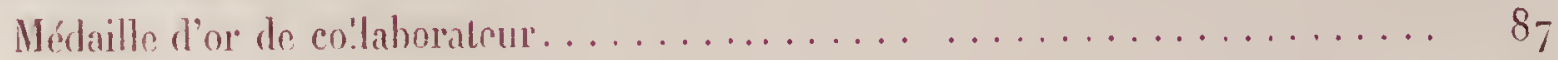

Colonies................................... $9^{3}$

Pavs étrangels. . . . . . . . . . . . . . . . . . . . . . . . . 97

Aulriche-llongrie.................. . . . . . . . . . $9^{8}$

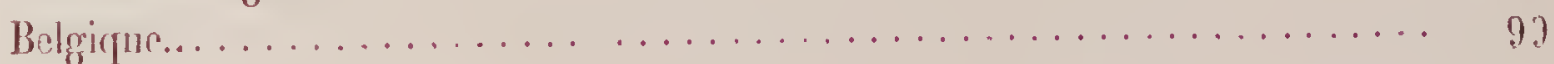

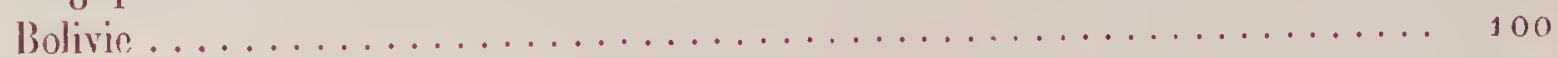

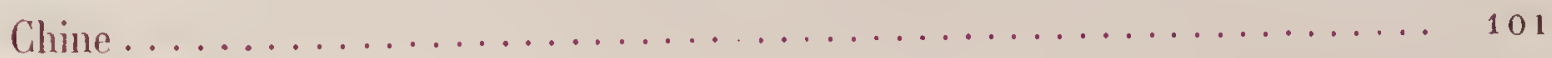

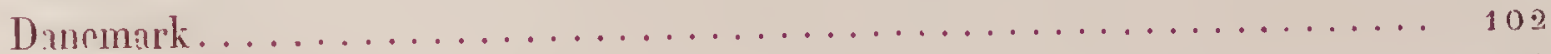

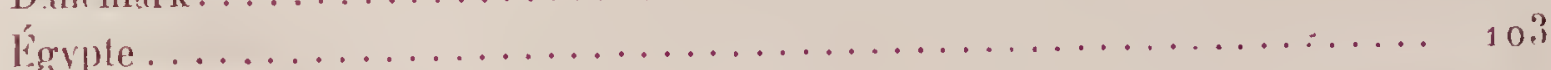

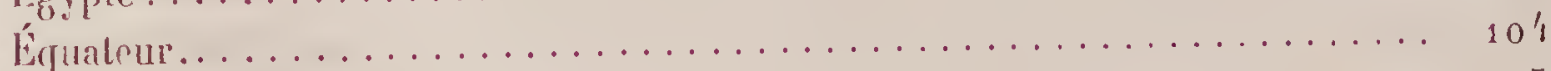

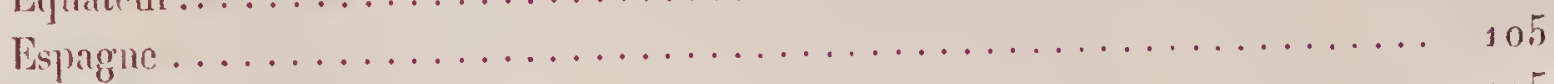

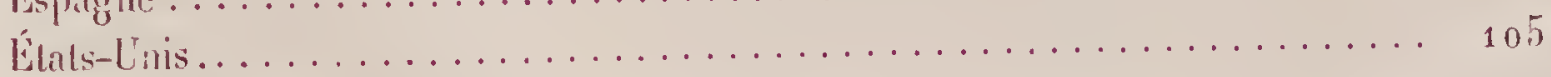

Grande-Bretagne............................. 11 s 


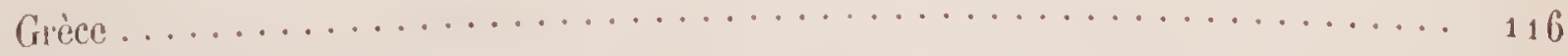

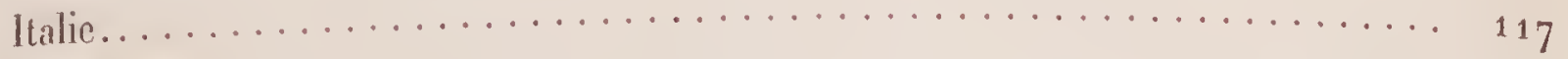

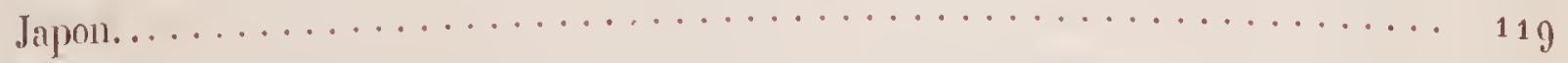

Volvège. . . . . . . . . . . . . . . . . . . . . . . . . . . 121

Portugal . . . . . . . . . . . . . . . . . . . . . . . . . . . . . 122

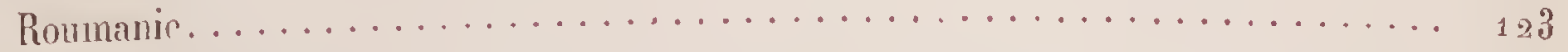

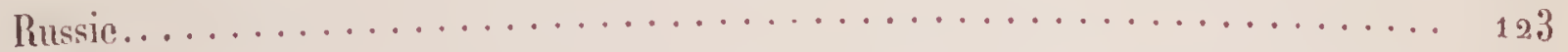

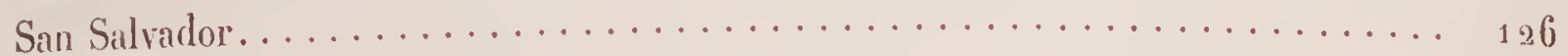

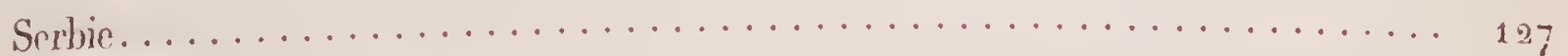

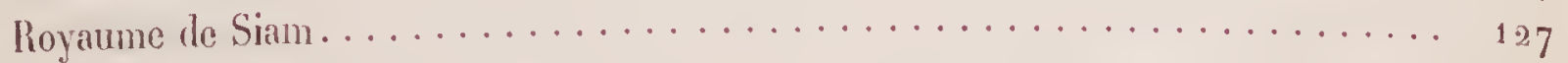

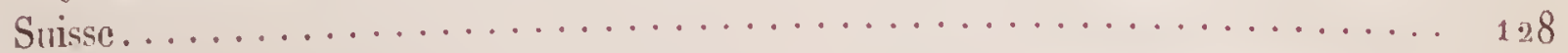

Liste par ordere de mérite des récompenses proposées par le jury. . . . . . . . . . . 131

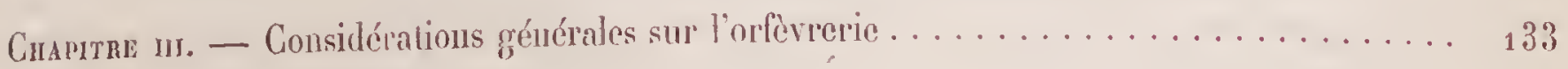

Le goût. . . . . . . . . . . . . . . . . . . . . . . . . . 135

Le $\operatorname{métier} \ldots \ldots \ldots \ldots \ldots \ldots \ldots \ldots \ldots \ldots \ldots \ldots \ldots \ldots \ldots \ldots \ldots \ldots \ldots \ldots$

Le commerce................................ 181

Revision de la loi du 1 g brumaire an vi. - Voux présentés par les fabricants d'orférerie. . 191

Table alphabétigue des noms conienus dans le rapport . . . . . . . . . . . . . . 217

Importations ef exportations de lorfèrerie d'argent de 1878 à 1889 . (Tableaux 1, B, C, D, E.) 









